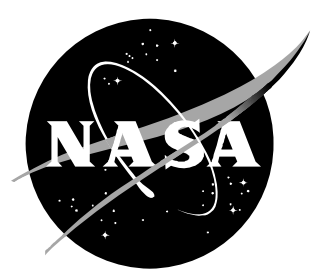

\title{
The Apollo Medical Operations Project: Recommendations to Improve Crew Health and Performance for Future Exploration Missions and Lunar Surface Operations
}

Richard A. Scheuring, DO, MS, NASA

Jeffrey A. Jones, MD, MS, NASA

James. D. Polk, DO, MS, NASA

David B. Gillis, MD, Ph.D., UTMB/NASA

Josef Schmid, MD, MPH, NASA

James M. Duncan, MD, NASA

Jeffrey R. Davis, MD, NASA

Johnson Space Center, Houston, Texas

Joseph D. Novak, MEng

University of Chicago Pritzker School of Medicine, Chicago, Illinois

National Aeronautics and

Space Administration

Lyndon B. Johnson Space Center

Houston, Texas 77058

August 2007 


\section{THE NASA STI PROGRAM OFFICE . . . IN PROFILE}

Since its founding, NASA has been dedicated to the advancement of aeronautics and space science. The NASA Scientific and Technical Information (STI) Program Office plays a key part in helping NASA maintain this important role.

The NASA STI Program Office is operated by Langley Research Center, the lead center for NASA's scientific and technical information. The NASA STI Program Office provides access to the NASA STI Database, the largest collection of aeronautical and space science STI in the world. The Program Office is also NASA's institutional mechanism for disseminating the results of its research and development activities. These results are published by NASA in the NASA STI Report Series, which includes the following report types:

- TECHNICAL PUBLICATION. Reports of completed research or a major significant phase of research that present the results of NASA programs and include extensive data or theoretical analysis. Includes compilations of significant scientific and technical data and information deemed to be of continuing reference value. NASA's counterpart of peer-reviewed formal professional papers but has less stringent limitations on manuscript length and extent of graphic presentations.

- TECHNICAL MEMORANDUM. Scientific and technical findings that are preliminary or of specialized interest, e.g., quick release reports, working papers, and bibliographies that contain minimal annotation. Does not contain extensive analysis.

- CONTRACTOR REPORT. Scientific and technical findings by NASA-sponsored contractors and grantees.
- CONFERENCE PUBLICATION. Collected papers from scientific and technical conferences, symposia, seminars, or other meetings sponsored or cosponsored by NASA.

- SPECIAL PUBLICATION. Scientific, technical, or historical information from NASA programs, projects, and mission, often concerned with subjects having substantial public interest.

- TECHNICAL TRANSLATION. Englishlanguage translations of foreign scientific and technical material pertinent to NASA's mission.

Specialized services that complement the STI Program Office's diverse offerings include creating custom thesauri, building customized databases, organizing and publishing research results ... even providing videos.

For more information about the NASA STI Program Office, see the following:

- Access the NASA STI Program Home Page at http://www.sti.nasa.gov

- E-mail your question via the internet to help@sti.nasa.gov

- Fax your question to the NASA Access Help Desk at (301) 621-0134

- Telephone the NASA Access Help Desk at (301) 621-0390

- Write to:

NASA Access Help Desk

NASA Center for AeroSpace Information 7115 Standard Drive Hanover, MD 21076-1320 


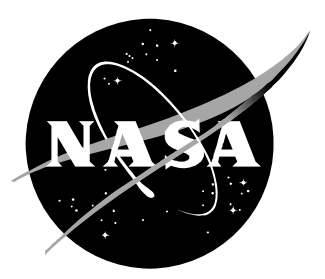

\section{The Apollo Medical Operations Project: Recommendations to Improve Crew Health and Performance for Future Exploration Missions and Lunar Surface Operations}

Richard A. Scheuring, DO, MS, NASA

Jeffrey A. Jones, MD, MS, NASA

James. D. Polk, DO, MS, NASA

David B. Gillis, MD, Ph.D., UTMB/NASA

Josef Schmid, MD, MPH, NASA

James M. Duncan, MD, NASA

Jeffrey R. Davis, MD, NASA

Johnson Space Center, Houston, Texas

Joseph D. Novak, MEng

University of Chicago Pritzker School of Medicine, Chicago, Illinois

National Aeronautics and

Space Administration

Lyndon B. Johnson Space Center

Houston, Texas 77058

August 2007 


\section{Acknowledgments}

The Apollo Medical Operations Project was a team effort. Members of this team included the core Summit group at Wyle Labs: Kae Parker, Phyllis McCulley, Mary McFarther, Luisa Rivera, Christopher Stokes, Marilyn Sylvester, Karen Mathis and Sandy Ballesteros. The facility hosting the Summit, Space Center Houston, provided excellent accommodations and service led by Sheri Armstrong. The JSC Center Director, Michael Coats, provided opening remarks to the group and set the tone for the meeting. A tremendous thank you is offered to Dr. Joe Kerwin who provided insight and encouragement throughout the development process and for the face-to-face meeting. Of course, thank you to all the NASA-JSC flight surgeons and astronaut physicians: Ellen Baker, Lee Morin, Scott Parazynski, Michael Barratt, Thomas Marshburn, Bob Satcher, David Wolfe and Anna Fischer offered their time in preparing for the meeting which could not have happened without them. Other individuals contributed to the writing of the manuscript and deserve heartfelt thanks: Barabara Tomaro, Donna Baumer, Jennifer Fogarty, Nancy House and Malinda Moller. Lastly, the future generation of lunar explorers will benefit greatly from the servant spirit offered during the few days in June 2006 by the Apollo astronauts and flight surgeons. Their effort will improve the new vehicles and protect crew health and performance for years to come.

Available from:

NASA Center for AeroSpace Information 7115 Standard Drive Hanover, MD 21076-1320

301-621-0390
National Technical Information Service 5285 Port Royal Road Springfield, VA 22161

703-605-6000

This report is also available in electronic form at http://ston.jsc.nasa.gov/collections/TRS/ 


\section{Table of Contents}

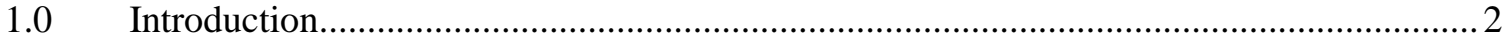

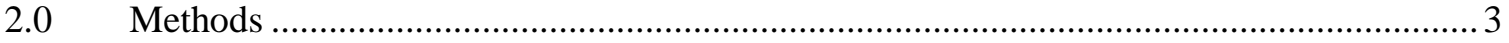

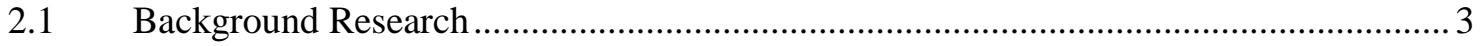

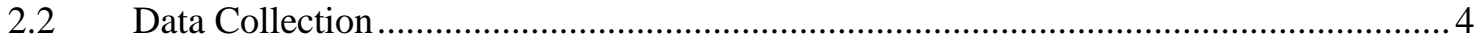

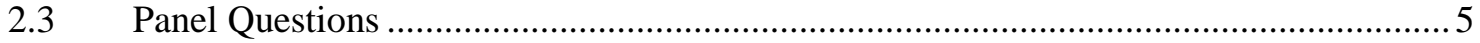

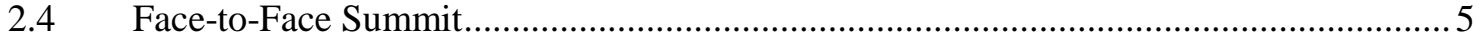

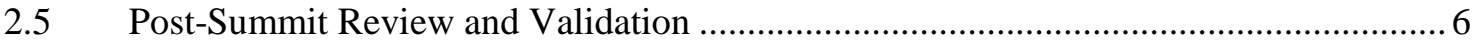

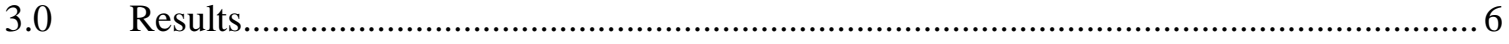

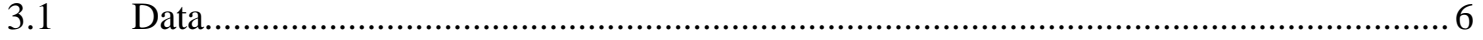

4.0 Operational and Research Recommendations by Category …......................................... 8

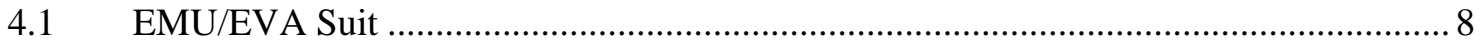

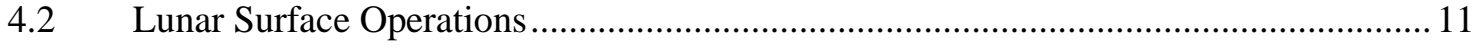

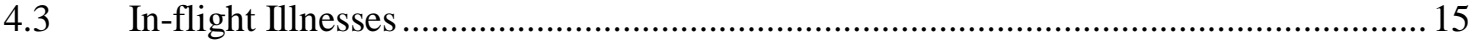

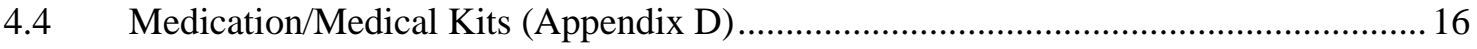

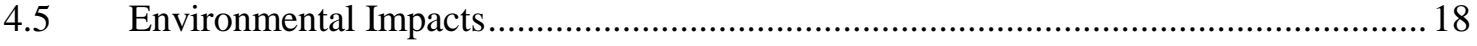

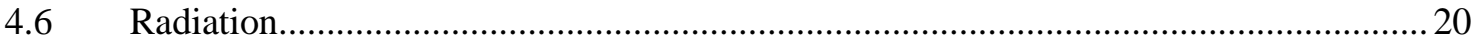

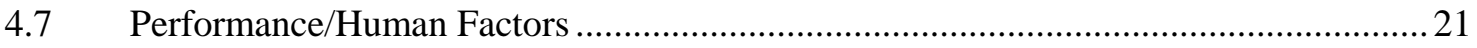

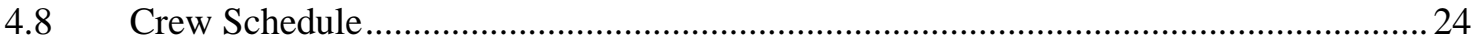

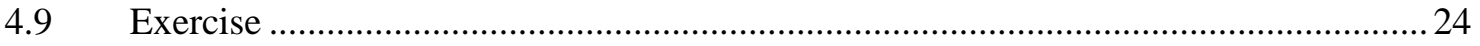

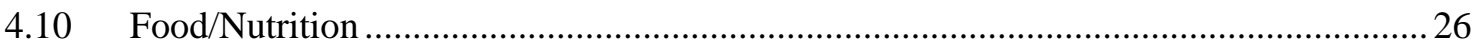

4.11 Launch/Landing/Recovery Operations................................................................. 27

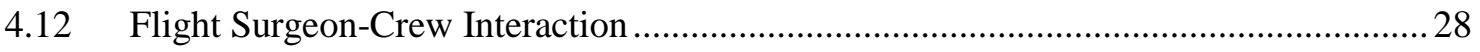

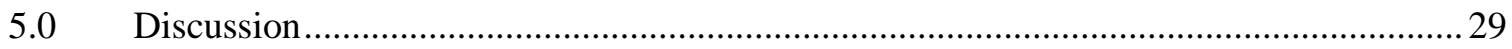

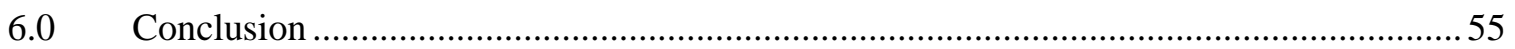

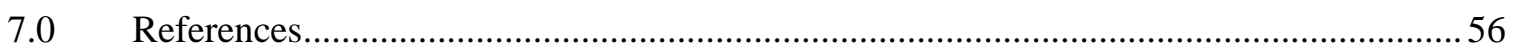

Appendix A Non Attributable Access Data Records.................................................................5

Appendix B Non-Attributable Panel Discussion \& Post-Panel Responses .................................. 321

Appendix C Apollo Medical Operations Project recommendations Excel Spreadsheet .............. 419

Appendix D Apollo Medical Kits from Biomedical Results of Apollo ${ }^{5}$....................................... 427

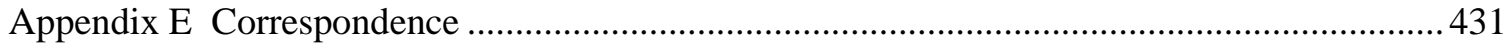

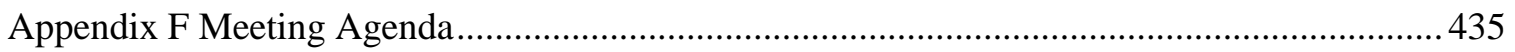

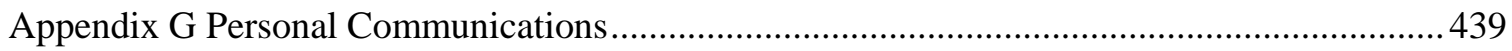




\section{Figures}

Figure 1. Sample Access data record from the Apollo Medical Operations Project .......... 5

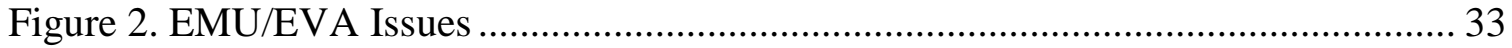

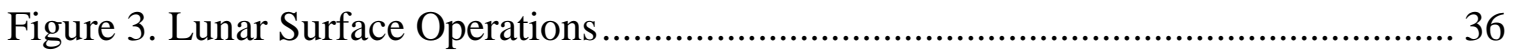

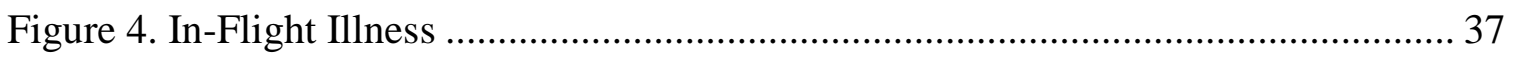

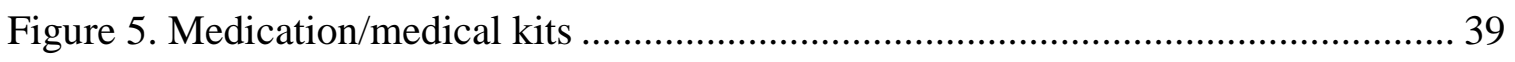

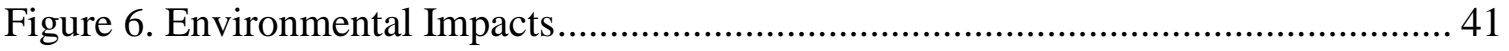

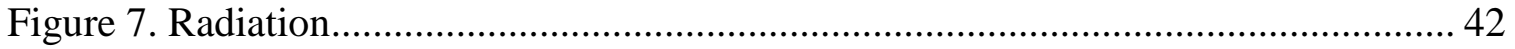

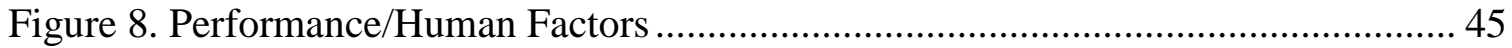

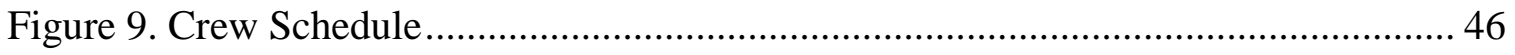

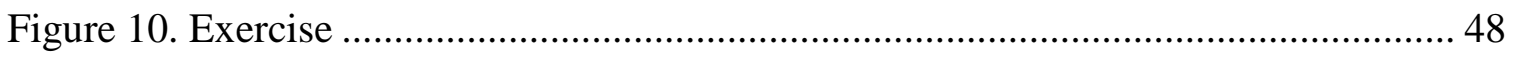

Figure 12. Launch, Landing, and Recovery Operations ............................................. 51

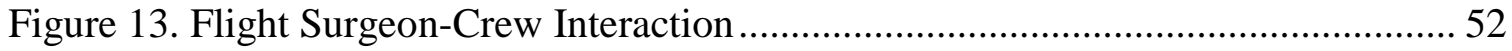

Figure 14. Overall Status of the Apollo Suggestions................................................... 54

\section{Tables}

Table 1. Astronaut Attendance and Participation at the Apollo Summit.......................... 7

Table 2. Post-Summit Questions, Answers and Recommendations. ............................... 7

Table 3: EMU/EVA Issues Recommendation Implementation ..................................... 32

Table 4: Lunar Surface Operations Recommendation Implementation ......................... 35

Table 5: In-Flight Illness Recommendation Implementation ...................................... 37

Table 7: Environmental Impacts Recommendation Implementation ............................. 40

Table 8: Radiation Recommendation Implementation .............................................. 42

Table 9: Performance/Human Factors Recommendation Implementation....................... 44

Table 10: Crew Schedule Recommendation Implementation .................................... 46

Table 11: Exercise Recommendation Implementation ............................................... 47

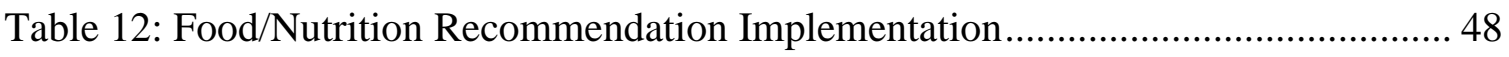

Table 13: Launch, Landing, and Recovery Operations

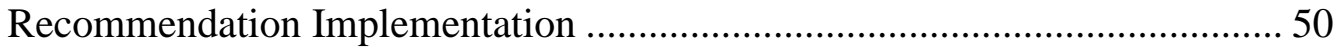

Table 14: Flight Surgeon-Crew Interaction Recommendation Implementation............... 51

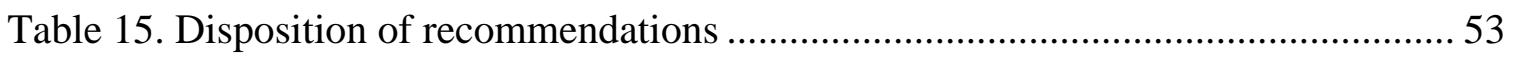




\section{Acronyms}

$\begin{array}{ll}\text { ARDIG } & \text { Advanced Requirement Development Integration Group } \\ \text { BM } & \text { Bowel Movement } \\ \text { CA\#\#\# } & \text { CARD Requirement number } \\ \text { CAD } & \text { Coronary Artery Disease } \\ \text { CARD } & \text { Constellation Architecture Requirements Document } \\ \text { CDR } & \text { Commander } \\ \text { CEV } & \text { Crew Exploration Vehicle } \\ \text { CM } & \text { Command Module } \\ \text { CMP } & \text { Command Module Pilot } \\ \text { CSM } & \text { Command Service Module } \\ \text { CXCB } & \text { Constellation Control Board } \\ \text { EARD } & \text { Exploration Architecture Requirements Document } \\ \text { ECP } & \text { Exercise Countermeasures Program } \\ \text { EMU } & \text { EVA Mobility Unit } \\ \text { EPSP } & \text { EVA Physiology Systems and Performance } \\ \text { ESP } & \text { EVA Systems Project } \\ \text { EVA } & \text { Extravehicular Activity } \\ \text { ExMC } & \text { Exploration Medical Capability } \\ \text { GI } & \text { Gastro-Intestinal } \\ \text { HRP } & \text { Human Research Program } \\ \text { HS\#\#\#\# } & \text { HSIR Requirement number } \\ \text { IR } & \text { Infrared } \\ \text { ISS } & \text { International Space Station } \\ \text { JSC } & \text { Johnson Space Center } \\ \text { LAT2 } & \text { Lunar Architecture Team 2 } \\ \text { LADTAG } & \text { Lunar Airborne Dust Toxicity Analysis Group } \\ \text { LBP } & \text { Low Back Pain } \\ \text { LEVA } & \text { Lunar EVA } \\ \text { LM } & \text { Lunar Module } \\ \text { LMP } & \text { Lunar Module Pilot } \\ \text { LSAM } & \text { Lunar Surface Access Module } \\ \text { MAG } & \text { Maximum Absorbant Garment } \\ \text { MCC } & \text { Mission Control Center } \\ \text { MORD } & \text { Missions Operations Requirements Document } \\ \text { PMC } & \text { Private mMedical Conference } \\ \text { POGO } & \text { Partial Gravity Simulator } \\ \text { PRD } & \text { Personal Radiation Dosimeter } \\ \text { R\&R } & \text { Rest and Relaxation } \\ \text { RFID } & \text { Radio-Frequency Identification } \\ \text { SRD } & \text { Systems Requirements Document } \\ \text { STS } & \text { Space Transportation System } \\ \text { TEC } & \text { Trans Earth Coast } \\ \text { TLC } & \text { Trans Lunar Coast } \\ \text { WBC } & \text { White Blood Count } \\ & \end{array}$




\begin{abstract}
Introduction. Medical requirements for the future Crew Exploration Vehicle (CEV), Lunar Surface Access Module (LSAM), advanced Extravehicular Activity (EVA) suits and Lunar habitat are currently being developed. Crews returning to the lunar surface will construct the lunar habitat and conduct scientific research. Inherent in aggressive surface activities is the potential risk of injury to crewmembers. Physiological responses to and the operational environment of short forays during the Apollo lunar missions were studied and documented. Little is known about the operational environment in which crews will live and work and the hardware that will be used for long-duration lunar surface operations. Additional information is needed regarding productivity and the events that affect crew function, such as a compressed timeline. The Space Medicine Division at the NASA Johnson Space Center (JSC) requested a study in December 2005 to identify Apollo mission issues relevant to medical operations that had impact to crew health and/or performance. The operationally oriented goals of this project were to develop or modify medical requirements for new exploration vehicles and habitats, create a centralized database for future access, and share relevant Apollo information with the multiple entities at NASA and abroad participating in the exploration effort.
\end{abstract}

Methods. A review of medical operations during Apollo missions 7 through 17 was conducted. Ten categories of hardware, systems, or crew factors were identified during preliminary data review generating 625 data records, which were captured in an Access database. The preliminary review resulted in 285 questions which were posed to surviving Apollo crewmembers using mail, face-to-face meetings, phone communications, or online interactions. Crewmember responses to these questions formed the basis for recommendations to items in each of the categories.

Results. Fourteen of 22 surviving Apollo astronauts (64\%) participated in the project. Approximately 236 pages of responses to the questions were generated based on the Apollo experiences, with 107 recommendations garnered for future vehicles, habitats, EVA suits, and lunar surface operations.

Discussion. The Apollo medical operations recommendations are being incorporated into the exploration mission architecture at various levels: 21 recommendations either validated, revised or created new requirements, 4 are currently in practice, 34 are being evaluated, and 54 are being considered. A centralized database has been developed, and the recommendations have been presented to the different organizations involved with building the new vehicles, habitats, suits, or systems that may impact crew health and performance.

Conclusions. The Apollo crewmembers' input has proved to be an invaluable resource to a multitude of departments beyond space medicine. We will continue soliciting input from this group as we evolve and refine requirements for future exploration missions. 


\subsection{INTRODUCTION}

The Apollo program, which began in January of 1966, was comprised of 18 missions: 12 crewed missions (including the Apollo 204 mission with Virgil "Gus" Grissom, Ed White, and Roger Chaffee) and six crewless missions which tested the capabilities of the Saturn rocket components ${ }^{6}$. The Apollo 7 mission heralded the first successful crewed mission, and in July of 1969, Apollo 11 fulfilled John F. Kennedy's mandate to send a man to the moon and return him safely home ${ }^{7}$. Twenty-six men flew Apollo missions, including four repeat flyers. Of the manned missions, six flights conducted between July 1969 and December 1972 successfully landed 12 humans on the lunar surface and returned them to the Earth.

In January 2004, President George W. Bush committed the United States to the further exploration of space $^{8}$. This new vision for space exploration has the benefit of the cumulative knowledge and experience gained from the Apollo program. The exploration effort will require the development of new vehicles to transport crews from Earth to the lunar surface and for transportation while on the moon. In addition, crew will need (EVA) suits and extended duration habitation elements for the lunar surface operations ${ }^{10}$. The Crew Exploration Vehicle (CEV) and Lunar Surface Access Module (LSAM) though slightly larger, will bear many similarities to the Apollo Command Module (CM) and Lunar Module (LM). The EVA suits may serve the dual function of a launch and entry suit as well as the lunar surface suit. Lunar habitation is a new frontier, enabling humans to live on the moon for extended periods in order to conduct science experiments and use the lunar environment for in-situ resource utilization.

During previous studies, Apollo astronauts provided input into the engineering and mechanical aspects of EVA suit system designs ${ }^{2}$. However, no study has specifically addressed the impact of the Apollo vehicles, hardware, and systems on crew health or performance throughout all mission phases, including lunar surface operations and the influence of that impact on the new exploration vehicles and mission architectures.

To identify Apollo mission issues that had impact to crew health and/or performance and were relevant to medical operations, the Space Medicine Division requested a study in December of 2005. The goals of this project were to develop or modify medical requirements for new vehicles and habitats, create a centralized medical operations database for future access, and provide this knowledge to the multiple directorates at NASA-JSC participating in the exploration effort. Secondary objectives included using this information to validate current requirements and refresh knowledge regarding lunar operations in an effort to reduce programmatic risks and risks to crew health, productivity, and safety. The Space Medicine Division study and this paper are not intended to be a review of information contained in previous publications, such as Biomedical Results of Apollo.

Due to the multidisciplinary operational focus of this study, the target audience is diverse. This audience includes flight surgeons, engineers, and scientists developing the medical requirements for exploration vehicles, habitats, and suits, the mission planners developing crew timelines, and experts supporting behavioral health and performance. 
Various aspects of this report will be of interest to a broader readership outside the medical operations community. Therefore, the report is written in a medically nonattributable format accessible to anyone with an interest in the Apollo program.

The Apollo Medical Operations Project was headed by Rick Scheuring, DO, MS, UTMB/Wyle Labs flight surgeon, James D. Polk, DO, MS, Manager of Medical Operations at JSC and Josef Schmid, MD, also with Medical Operations at JSC. The team included other flight surgeons from the Medical Operations office at JSC and University of Texas Medical Branch, Galveston, as well as project scientists and engineers within the Space Life Sciences Directorate (SLSD) and the Mission Operations Directorate (MOD) at JSC. Participation of the Apollo astronauts was solicited through the Space Medicine Division.The team would like to acknowledge of the enormity of the task and express an appreciation to the Apollo crews for discussing their missions which occurred at a time when most of the team members were still children.

\subsection{METHODS}

This section addresses the spectrum of approaches taken to assimilate, categorize, and assess the data.

\subsection{Background Research}

Background research was undertaken by the Apollo Medical Operations Project team to maximize the benefits from the study. The approach taken consisted of the following:

- Identify specific medical-related problems, if any, in each area associated with the operational environment during all mission phases

- Define the impact on crew health and/or performance

- Identify problems that recurred or were fixed on subsequent missions

- Develop an integrated, comprehensive set of questions that could be used in a face-to-face meetings with the Apollo astronauts

The impetus to "do our homework" before meeting with the astronauts came from the Apollo crewmembers themselves ${ }^{11}$. The crews voiced annoyance at discussing subjects or responding to questions that had previously been published. Therefore, it was incumbent upon the team to research areas and develop questions not previously documented.

Review of Apollo resources pertaining to Medical Operations and the sources of data included: Apollo medical mission debriefs (7-17); Apollo flight surgeon logs (7-17); Apollo biomedical engineer logs (7-17); Apollo mission commentaries (7-17); Apollo mission reports $(11-17)^{13}$; Apollo lunar surface journals $(11-17)^{3}$; preliminary science reports $(11-17)^{12}$; the Apollo lecture series ${ }^{11}$; Apollo videos; NASA technical 
memorandums, related papers ${ }^{2,14,15,16,17,18}$; and personal communications with the crewmembers through email, phone or direct contact. These materials were reviewed by the team to understand the Apollo astronauts' experiences and the issues impacting their health and/or performance as previously reported. It is important to note that the medical debriefs and flight surgeon/biomedical engineer logs are considered medically confidential material and subject to the Medical Privacy Act of 1974. All other resources are available to the public. It is equally important to note that some issues identified in the debriefs were detailed in the crew logs, crew questionnaires, or air-to-ground communications but were unavailable. Every attempt was made to fill in the missing information from available resources for this study.

After reviewing historical data, the team identified eleven categories within the operational environment occurring during Apollo 7-17 that had impacts to crew health and/or performance. The data assembled into these categories formed the basis of the questions used to interview the Apollo astronauts. The categories included EVA mobility unit (EMU) and EVA suit issues; lunar surface operations; inflight illnesses; medical kit, medications, or bioinstrumentation; environmental (vehicle); radiation; exercise; food and nutrition; performance and human factors; crew schedule; launch, re-entry, and recovery; and flight surgeon-crew interactions. Certain well-documented areas relating to crew health or performance, such as lunar dust, were identified but not covered in detail

during this study. Likewise, areas that affected the Apollo crews but were not relevant to the new vehicle design, such as the Apollo water chlorination system, were identified in the data collection but were not addressed during the face-to-face meetings.

\subsection{Data Collection}

The historical data collected was organized and compiled into an Access database (Appendix A). This database facilitated the search capabilities of the team in identifying areas that had health and/or performance impacts. The data was organized by mission, source of information, topic (category), medical/hardware issue, crewmember involved (if applicable), description of the problem, general comments about the issue, and resolution/reoccurrence. Questions related to the issue were generated from this body of data. The team used this method, to create 625 data records. An example of one record is provided in Figure 1. Note that any attributable medical information contained in Appendix A has been removed for the purpose of this paper and exists as a separate document. 


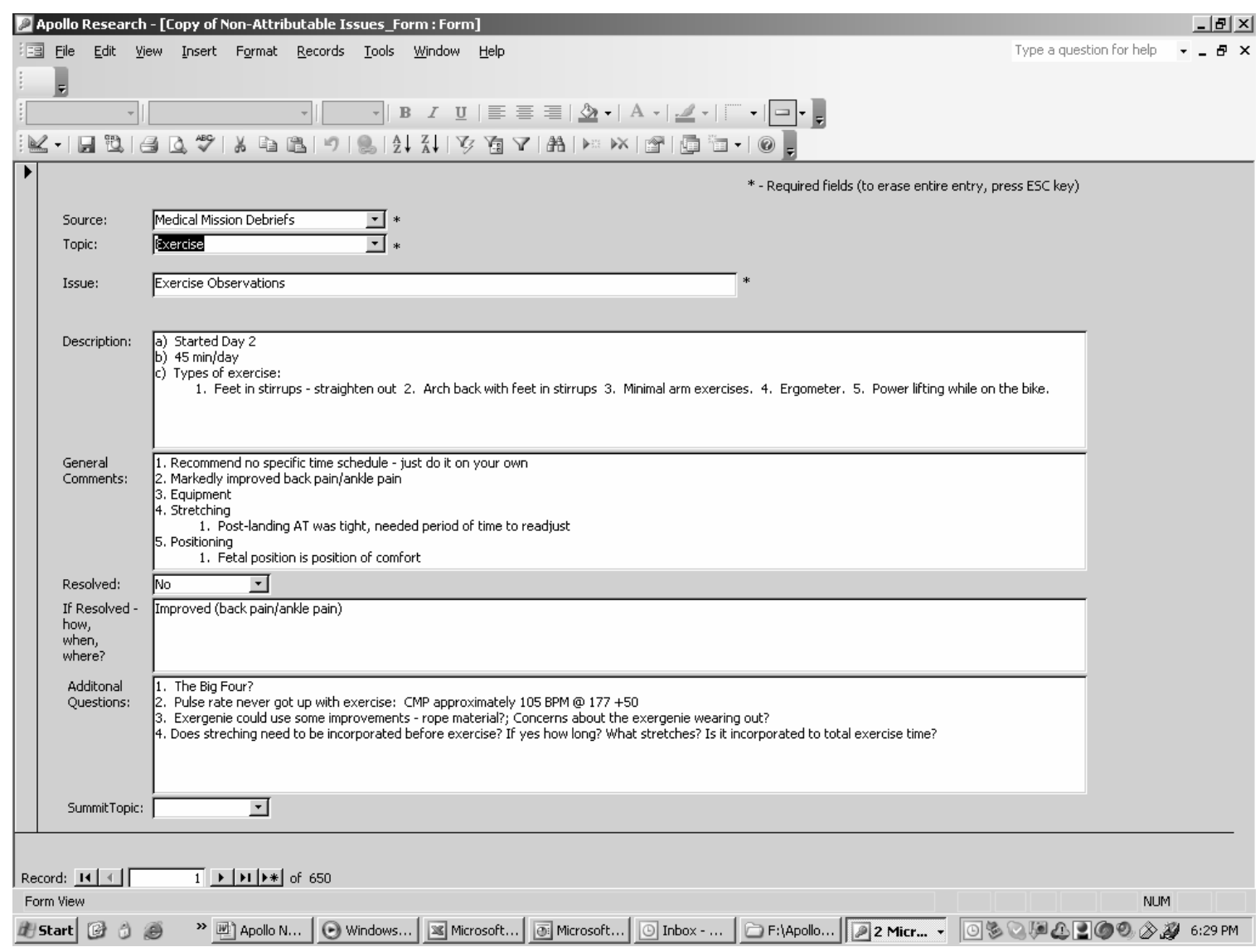

Figure 1. Sample Access data record from the Apollo Medical Operations Project

\subsection{Panel Questions}

Questions were generated from the historical data search effort and from operational and research disciplines associated with each category (Appendix B). These questions were augmented with others solicited from discipline leads in each category. The categorized questions were reviewed by flight surgeons and current astronaut physicians at JSC for relevance and operational applicability to the exploration effort. This resulted in a final list of 285 questions used during the face-to-face meeting with the Apollo astronauts.

\subsection{Face-to-Face Summit}

The face-to-face summit with the Apollo astronauts was held in June of 2006 in Houston, Texas. Per the crewmembers' request, Days 1 and 2 were closed sessions limited to Apollo crew, the current flight surgeon cadre and astronaut physicians. Day 3 was limited to invited guests and the Apollo flight surgeons. Of the original 29 Apollo astronauts, 22 survive today and were invited to participate in the face-to-face summit (Appendix E). Dr. Joseph Kerwin, who served as CAPCOM for Apollo 13 and astronaut physician on Skylab I, was a project team member and invited to participate as an astronaut. The invited guests for Day 3 submitted questions to the Apollo Medical 
Operations Project team prior to the meeting to insure the appropriateness of the question and to facilitate interaction with the crewmembers during the session.

Prior to the panel question discussion on Days 1 and 2, the project team presented informational briefings to achieve the intended outcome of the meeting. The two-fold purpose of the meetings was to capture the experiences of the Apollo astronauts to validate findings from the historical data search and to project applicable aspects of Apollo operational experience to the exploration initiative. The project team presented the issues that faced the crews during their missions from the historical data research to increase their awareness of the current knowledge base. It also served to stimulate memories garnered three and a half decades ago. The presentation concluded with a discussion of the exploration architecture to familiarize the participants with the new strategies and mission plans.

The panel discussions were held with the astronauts and project team members meeting in one room. A professional transcriptionist recorded all comments from the astronauts and later organized the responses with the corresponding questions. The Day 3 session was conducted in a similar manner by the team and transcriptionist. This document was then reviewed by the project team for accuracy and clarification. Notes taken by the panel team during the question sessions were added to the document as necessary.

\subsection{Post-Summit Review and Validation}

The purpose of the post-summit phase was to compile the accumulated responses to the panel questions and then organize the responses into a comprehensive report (Appendix B). Apollo astronauts who participated in the face-to-face summit reviewed and validated the report. They also submitted additional input and points of clarification. After review by the project team, the updated version including recommendations was then submitted to all the Apollo astronauts providing an opportunity for an additional six crewmembers not attending the face-to-face meetings to participate. These responses can be found in Appendix G.

\subsection{RESULTS}

\subsection{Data}

Sixty-four percent (14 of 22) of the surviving Apollo astronauts participated in the project. The combined crewmember responses to the 285 questions generated from the background research resulted in 236 pages of data. A comprehensive review of all the responses from the astronaut sources revealed 107 recommendations that was subsequently broken down into 113 recommendations for easier data analysis (Appendix C). The input shown in Table 1 formed the basis of the Apollo Medical Operations

Project recommendations. Note that the total number of astronauts participating includes 
the eight attendees plus the responses to the post-summit report and questionnaire which included both attendees (4) and non-attendees (3).

Table 1. Astronaut Attendance and Participation at the Apollo Summit

\begin{tabular}{|l|l|}
\hline Number of attendees & 8 \\
\hline Post-summit full responses & 7 \\
\hline Total number of Apollo astronauts input & 14 \\
\hline Number of Apollo astronauts available & 22 \\
\hline
\end{tabular}

The panel discussion questions and answers document is broken down into the number of questions per category, the responses from the post-summit participants, and recommendations per category in Table 2 . Note that this section is only post-summit responses and does not include the eight summit attendees' responses, which could not be individualized. Note that the "Post-Summit \# of Responses" column refers to the number of responses given within that particular category to the document that was sent to all astronauts following the face-to-face meeting.

Table 2. Post-Summit Questions, Answers and Recommendations. Listed below is the number of questions in each of the categories with number of post-summit participant responses and validated recommendations. Note that the number of categories is further broken down into subsections of the main category where bolded.

\begin{tabular}{|l|r|r|c|}
\hline \multicolumn{1}{|c|}{ Category } & $\begin{array}{l}\text { \# of } \\
\text { Questions }\end{array}$ & $\begin{array}{l}\text { Post-Summit } \\
\text { \# of Responses }\end{array}$ & Recommendations \\
\hline EMU/EVA Suit & 63 & 30 & 13 \\
\hline Lunar Surface Operations (ops) & 36 & 20 & 16 \\
\hline In-flight IIInesses/Medications & 16 & 24 & 9 \\
\hline Medical Kit & 3 & 4 & 4 \\
\hline Bioinstrumentation & 3 & 5 & 0 \\
\hline Environmental Impacts & 35 & 75 & 16 \\
\hline Radiation & 5 & 4 & 5 \\
\hline Exercise & 20 & 33 & 8 \\
\hline Food Nutrition & 28 & 76 & 8 \\
\hline Performance/Human Factors & 16 & 48 & 11 \\
\hline Crew Work-Rest Schedules & 10 & 30 & 5 \\
\hline Launch/Landing/Recovery Operations & 34 & 121 & 10 \\
\hline Flight Surgeon Crew Interaction & 2 & 7 & 2 \\
\hline General Questions & 14 & 31 & 0 \\
\hline Totals & $\mathbf{2 8 5}$ & $\mathbf{5 0 8}$ & $\mathbf{1 0 7}$ \\
\hline
\end{tabular}




\subsection{OPERATIONAL AND RESEARCH RECOMMENDATIONS BY CATEGORY}

\subsection{EMU/EVA Suit}

1. Improve glove flexibility, dexterity, fit. According to the Apollo lunar crews, the most fatiguing part of surface EVA tasks was repetitive gripping. Regarding the glove, one crewmember stated, "Efficiency was no more than $10 \%$ of the use of the hand." The fingernails generally tended to be pulled back resulting in separation of the nail from the bed, or onycholysis. Additionally, the skin frequently was abraded from the top of the knuckles. This event took on operational and potentially mission significance as several lunar walkers stated that they would not be able to work in the glove beyond the two to three EVA's they completed due to the swelling and pain over the bony prominences of the metacarpal phalangeal (MCP) and proximal interphalangeal (PIP) joints (knuckles), although had they been asked, it is probably that at least one more EVA would have been possible. It is also interesting to note that the lunar crews stated that they did not experience hand or forearm trauma in training, though muscle fatigue occurred. However, these training sessions typically lasted only two to three hours whereas the lunar EVA's plus pressurized prep time were seven to nine hours in duration. [Note: Recent experience with ISS-related EVA's suggests that better conditioning can solve most of the forearm fatigue problems; however, lack of dexterity and hand trauma remain as critical issues. (For perspective, you may wish to expand on the ISS experience as it relates to future lunar work.)] In terms of flexibility and fit, the glove should come as close to Earthnormal use of the hands as possible. Lowering the pressure [in the suit] was suggested, i.e., the less strength it takes to manipulate the glove, the less physically tasking to the hand and forearm musculature. This can also be accomplished by reducing the glove bulk and making the bladder thinner. Other glove recommendations included:

- Gloves should be custom designed for each crewmember and should incorporate mechanical closure for gripping

- Designers should consider a wrist seal and depressurized glove

- Robotic power-assisted glove should be used for repetitive tasks

- Special inner bladder surfaces should be developed and glove liners should be worn to prevent skin chaffing and abrasions

A consensus statement made by the Apollo astronauts who participated in the project on the EVA suit issue was that given a fixed budget for suit development and improvement, the funding for the new suit would be best spent in improving the glove. If money is left over for other components, then address those issues, but fix the glove first.

2. Reduce the mass of the suit by a factor of two. Once the glove issues have been addressed, reducing the suit mass would help. Availability of recharge of consumables during EVA should be strongly considered. Despite suit bulkiness, the astronauts cautioned that suit mass was an asset to some extent in the partial gravity environment. It provided an inertial point of reference that allowed them to adapt to $1 / 6 \mathrm{~g}$. (But that point is always going to be there as long as some significant mass is present - i.e., body, suit, 
and backpack.) Reducing the suit mass too much would remove the familiarity the crewmembers relied on and may predispose one to falls.

3. Increase general mobility by a factor of four. EVA suit mobility was more of an issue in terms of surface locomotion and energy expenditure. The crews often felt they were fighting the resistance in the suit (including in the glove as mentioned above). This was fatiguing, especially in the thighs. The astronauts pointed out that the lunar surface is more similar to an ocean than to a desert. The undulating surface posed a number of challenges, including ambulating against a suit that did not allow mobility at the hip. Normal human locomotion includes flexion at the hip and the Apollo A7LB had limited ability to bend the suit at the hip and to rotate within the suit. The crewmember had to bend forward from the knee joint, which demanded considerably more work load on the quadriceps muscles. Therefore, the mobility recommendations centered on adding hip mobility and improved knee flexibility. One comment summed this point well, "Bending the knee was difficult in the suit. We need a better [more flexible] knee joint."

Reducing suit pressure to $\sim 3.0$ psia (sea-level oxygen partial pressure) with a pure oxygen system would accomplish this to some extent. However the crews understood the limitations with using this approach to improving suit mobility. Namely, the risk of decompression sickness would be increased and the margin of safety with a suit puncture would be decreased (This risk could be mitigated by an emergency regulation of oxygen flow to maintain 3.0 psia). It was also pointed out that lowering suit pressure may remove some of the suit extremity splinting effect and could predispose to limb injury, which was generally not a concern at the Apollo suit pressure of 3.75 psia.

4. Lower suit Center of Gravity (CG). Although this area has garnered considerable attention recently with new suit design, the crews felt it was not a main issue, compared to the glove issues or suit mobility. They reported adapting to the suit CG quickly on the lunar surface, which was described as "aft and slightly high." A number of crewmembers stated "Don't make moving the CG your primary priority. Move the CG only if it becomes convenient to do so while taking care of other issues like reducing the mass of the suit, fixing the glove, etc."

5. Develop a system that prevents helmet fogging during heavy exertion. Although the lunar walkers did not experience fogging of their visor while on the moon and used an anti-fogging wipe to prevent it, its possible occurrence could be catastrophic. An example for potential adverse effects due to visor fogging was the Apollo 11 mission.

Crewmembers remained in their suits during recovery operations for quarantine concerns. The visor fogged once the CM was opened to the humid, warm South Pacific air, completely obscuring their vision. One crewmember became very concerned during transfer from the CM to the rescue basket, as he was unable to clear the visor to see where he was going. Whether it was due to exterior fogging due to the cooler visor causing consdensation to occur on the visor or that there was no anti-fog wipe available or used is unclear. The implications on the lunar surface are obvious. Visor fogging needs to be eliminated as a concern, especially if a contingency situation occurs where the crewmember is physically exerting him or herself for extended periods of time. 
6. Improve peripheral vision by adding neck ring (movable joint). The surface crewmembers stated, "You would always have to turn your body [and the suit] to see to the side." The astronauts' inability to see their feet during lunar operations, partially due to the large camera mounted on their chests, made working close to the suit difficult at times. Helmet design should allow the astronauts to see their feet while working and traversing the surface of the moon. Another participant concern was the inability to see their arm during a fall to the side, which occurred with some frequency. A movable neck ring, such as the Navy deep sea diving helmet with rotating neck ring, is a good option and should be considered in the new suit design. One lunar crewmember added a slightly different experience: "I never found walking and running difficult for the same reason it is not difficult on Earth, i.e., your brain integrates location of the potential obstacles with where your foot will land in order to avoid those obstacles."

\section{Develop a reliable Heads-up Display (HUD) displaying consumables information,} limited biomedical (BIOMED) data, navigation and position data on demand. The crews felt the HUD should primarily present the operational information that you need in an instant, e.g., if you want to see oxygen consumption, you say "oxygen" and it appears on the display. Crew did not feel a pressing need to know their heart rate, metabolic rate, or other physiological information during an EVA as in a continuous display. However, a heads-up display would be acceptable with limited physiological information on demand. Certain flexibility in reprogramming should be possible in anticipation of greater demand for information with longer and more complex EVA sequences. A concern expressed by one participant was to avoid increasing the complexity of the system to the point of reducing its reliability; however, the other crewman and telemetry and communication links provide a clear backups to the HUD information if needed.

8. The lunar boot functioned well and does not need to be improved. The boot was very comfortable; however, it was slippery on rocks or boulders that had some regolith covering that reduced friction. Generally this was not regarded as a problem during the surface operations. Concerns regarding "slipping" in the moon regolith were unfounded. The lunar regolith has a high, gross coefficient of friction and is well packed beneath the upper one $\mathrm{cm}$ or so of loose material. This property helped maintain the crewmembers footing despite its "slippery" or "loose" appearance. There was not concern about ankle sprains or injuries with falls due to the lunar soil although one crewman strained a shoulder with extreme exertion and another noted some slight discomfort at the site of an old knee tendon sprain with extended side-hill traversing.

9. Use a self-sealing pressure garment within the suit in case of puncture. EVA suit puncture hazard was a primary concern of the lunar astronauts, although the risk was considered low. Astronauts suggested that protecting suit occupants from a break in suit integrity was appropriate for future research and development activities. However the trade-offs for this need to be considered carefully relative to mission rules if there is a puncture and emergency regulation of suit pressure and the availability of rover consumables, etc.

10. A drink bag should have capability to contain a high-energy liquid in addition to having a bag with plain water. The A7LB suit had a 15-ounce drink bag, an amount 
considered insufficient for the crews on the surface. Typical lunar surface activities may last up to 7.5 hours, but the total time in-suit from don-to-doff could be up to 10 hours. The astronauts strongly agreed the amount of liquid beverage contained in the suit needed to be increased for future crewmembers, including separate capabilities for plain water and a non-caffeinated high-energy drink. In addition, pre-donning checklists should include a standard procedure to load up on water, plus and adequate urine collection device (see below).

11. Develop a better in-suit Urine Collection Device (UCD) that will work in $1 / 6 \mathrm{~g}$. The UCD provided to the crewmembers for use in the suit was a device requiring proper fitting of an elastic connector that worked for some and did not work for others. Urine leaks sometimes resulted in skin irritation. In one case, the elastic connector was too tight on the first EVA, resulting in some injury during forced urination. This problem was solved for subsequent EVAs by stretching the remaining connectors on the LM hand-controller between EVAs.

12. The suit should be a low pressure (3.50 psia), single gas system. Referring to recommendation \#3, the crews stated that testing a lower pressure suit should be considered but suggested a lower pressure of 3.50 psia at $100 \%$ oxygen. Reducing suit pressure to $\sim 3.0$ psia (sea-level oxygen partial pressure) might be considered with a pure oxygen system. The risk of a suit leak could be mitigated by an emergency regulation of oxygen flow to maintain 3.0 psia .

13. Protect the suit zipper function. The Apollo A7LB suit was a single zipper system, unlike the Gemini suit which was a double-zipper system. The lunar dust was difficult to clear from the zipper and impaired normal function on each subsequent lunar EVA for some missions. Other missions had no problems with adequately cleaning the zipper. The abrasive nature of the dust scored the metal connections, primarily circumferencially on the bearing surfaces. The lunar dust exposure did not result in a breach of the sealing capability of the suit however repeated exposures may increase this risk.

\subsection{Lunar Surface Operations}

Among the lunar surface operations recommendations, crew scheduling, feasibility of surface activity commencement, and airlock/hatch design was given particular importance for the exploration architecture. The key recommendation is that because EVA efficiency is extremely valuable with respect to freeing the crew to due what humans do best, i.e., we must use crew experience and training to react instantaneously to new and unexpected situations and to use their brains, eyes and hands to take advantage of that experience and training. Routine and repetitive tasks should be as automated as possible, particularly those tasks related to the determination of position and to sample and other science and operational documentation.

14. Schedule crews for two Lunar EVA (LEVA) days on and one day for maintenance, alternating crews throughout the week. The surface walkers were adamant that surgeons protect the future lunar crews from overwork. Multiple factors allowed the Apollo lunar crews to work and stay awake for long periods of time during 
their relatively short stay: disruption of normal circadian rhythm influencing wake-sleep cycles; loud ambient noise levels in the lunar module (LM) (the exact background noise level was not measured according to Jerry Goodman, Apollo vehicle engineer); and crew psychological state, i.e., the lunar astronauts were excited considering their current circumstances. The ability to sleep varied significantly. For some sleep was described as very restful, but for others it was described as a couple of hours of "nodding off" on the lunar surface. The astronauts stated that to optimize crew performance for extended stays on the moon, the schedule should never allow for more than two days of LEVA consecutively without a day of rest or for the alternation of EVA teams, with one acting as support on the day of rest. On extended stays, one day per week would be considered an intravehicular activity (IVA) day spent performing suit maintenance or planning and preparation for future field activity. A crew of four could alternate this schedule thereby protecting the crewmembers from overwork.

\section{The hatch and ingress corridor should be sized appropriately for an inflated 1/6 $\mathrm{g}$} pressure suit. A curious finding during the background research involved reviewing the individual crewmembers metabolic activity during their lunar surface activity. All the crewmembers had notable increases in their metabolic rate during the last 30 minutes of their 3.5 to 7.5 hour LEVA. The initial assumption was that the crews were deconditioned from their micro- and partial-gravity exposure thereby reducing their exercise capacity. However, the crews' stated sudden increase in energy expenditure had to do with the hatch design on the LM: the pressurized suits were too big and bulky to get into the hatch without bending and twisting their bodies. The position of the display keyboard above the hatch also prevented the crews from placing their hands in this area to gain leverage to pull themselves into the LM. This activity usually took several tries to ingress the LM and was quite a fatiguing process. Jerry Goodman, an Apollo vehicle engineer who helped with the LM hatch design, identified that the problem occurred before the vehicle arrived on the moon. Apparently the hatch design and pressurized suit design, although dependent and initially corroborated, later changed without being communicated to the other. The LM hatch size was decreased and the suit size increased and this went unrecognized until the crews attempted ingress to the vehicle on the moon.

16. An airlock may make ingress/egress easier and will also be a good idea from a dust control standpoint. Designing an airlock to separate the vehicle hatch from the habitation area could decrease the risk of tracking lunar dust into the lunar module.

\section{Surface activities can begin once operationally feasible after landing. Crews} generally felt a little "wobbly" upon stepping on the moon, but this was attributed to adapting to the EVA suit CG and the partial gravity rather than the neurovestibular dysfunction experienced by crews upon return to the $1 \mathrm{~g}$ environment. This statement had been reported in the literature ${ }^{20}$ and needed to be explained by the Apollo crewmembers to determine if this would be a problem for lunar crews in the future. Coordination seemed to improve steadily during first couple of hours on the surface. The crews did not experience recognizable problems with spatial orientation on lunar landing. This was a concern operationally as experience with rotary wing pilots suggests spatial disorientation and conditions known as "brown out" have contributed to mishaps. The commander and 
lunar module pilots reported similar conditions during landing operations on several missions ${ }^{14}$ but did not experience recognizable spatial disorientation.

18. There is no special training needed for 1/6 $\mathrm{g}$ EVA's other than a familiarization session. The astronauts stated the limited training they received using the Partial Gravity Simulator (POGO) and parabolic flight aircraft was sufficient for preparing them for lunar EVAs. Future lunar crews would do well to use this as lunar familiarization training but should not engage in elaborate partial gravity training devices or environments as the human body quickly adapts to the $1 / 6 \mathrm{~g}$ environment of the moon.

19. Limit navigation into craters with a slope $<20-26^{\circ}$ slope. Aside from the risk for injury on slopes greater than $20-26^{\circ}$, the crews reported that they had to use a sidestepping approach going up and down sloped terrain because of the limitations in suit mobility. This motion often placed the inertial mass of the suit and crewmember on one leg, which would tire after repetitive loading, either uphill or downhill. The slope of the terrain affected the ability to perform this motion and the crews estimated that $20-26^{\circ}$ was the safe limit unassisted.

20. Crews requested that an automatic position determination device be available to aid navigation on the lunar surface. All sorts of ambiguities exist on the moon, e.g., slopes, terrains, sun shadows, and bland environments. With the undulating terrain, it was very easy to lose known points of reference and geographic orientation despite being well versed in the two-dimensional topography. One lunar crewmember admitted to spending twenty minutes trying to re-orientate during the surface traverse. A navigation system available on the suit HUD and/or rover would be very helpful and save time during surface operations.

\section{Ladder rung height and width on the LM were good but the glove did not allow} adequate grip for safety. Crews were able to ascend and descend the LM ladder without difficulty and felt the rung height and width were easy to use. Their only concern was related to the inability to adequately grip the rung or side rails due to the limitations in the glove (see EVA suit section). Ladder height could be a concern if the glove issues are not addressed, especially if the crewmember is carrying equipment or an individual up the ladder.

22. Ensure adequate water and food are available before and during lunar EVA. Lunar EVA ranged from 3.5 to 7.5 hours. Total in-suit time for surface operations averaged 10 hours. The LM atmosphere was similar to the CM at 5.0 psia and $100 \% \mathrm{O}_{2}$ therefore no EVA pre-breathe period was required. It is generally recommended that humans should drink 4-6 ounces of fluid for every 30 minutes of moderate exercise to maintain adequate hydration status ${ }^{21}$. The Apollo crews stated that they became thirsty and hungry during their LEVA and suggested making available adequate amounts of high-energy food and plain water.

23. Lunar EVA should be performed as one continuous event. The question was raised regarding LEVA and whether it should be broken down into two shorter duration events allowing the crew time to hydrate and replenish energy stores, etc., or as one continuous 
event. The astronauts' inputs overwhelmingly supported the later choice as the suit and vehicle prep time for LEVA take up an unreasonable amount of crew time.

24. Risk factors for injuries identified. The Apollo astronauts were queried about risky behaviors on the lunar surface or conditions that could predispose them to injuries. Overall, the crews felt the injury risk was low due to the partial gravity providing considerable time to react to a fall and the relatively short distance to fall considering their lunar weight was 1/6 their Earth weight. They were quick to mention that the videos of their falls on the moon were misleading, and that it did not hurt to fall. However, the crews pointed out that their inertial mass did not change on the moon. Given the EVA suit/PLSS ( 194 lbs. on Earth) and crewmember mass and right set of circumstances listed below, sufficient energy could be applied to a joint or extremity to cause injury.

a) Navigation into terrain or craters with slopes $>20-26^{\circ}$. A fall on sloped terrain may be well tolerated unless the crew was moving or carrying an external load, such as equipment or rock samples. Although the exact angle of the slope was an estimate, the crews remarked that stable footing was limited and leg fatigue would become more pronounced in terrain steeper than approximately $26^{\circ}$. Lack of suit mobility, primarily at the hips, made getting in and out of steep terrain difficult. Another concern was the lack of peripheral vision in the suit and the inability to see where an outstretched hand might land. Hand or wrist injuries were more of a concern for some of the crewmembers than lower extremity injuries. The ability to estimate crater dimensions was compromised as mentioned by one crewmember in the following statement: "Reflective light in the shadows isn't as evident as on Earth. Craters did appear steeper visually. But we knew we had to go down into that crater, so it gave us concern."

b) Rover activities. The safety harness took roughly three minutes to fasten and some crews opted not to engage the buckle. The astronauts stated that the lunar module pilot in the right seat was at particular risk of falling out due to the undulating terrain and often being tilted downward and out the vehicle.

c) Falling from a height. Falling from the rim of a steep crater was a concern in some instances. Ladder height on the LM was less that six feet, but it became a concern with the poor glove grip mechanics. Mention of the proposed LSAM ladder height ranging from 20-28 feet drew sighs and obvious concern for injury.

\section{To ensure operational success and optimize performance of the crews, allow adequate time to practice mission activities in a variety of environments including analogs that allow preparation for off-nominal events. The Apollo astronauts used at least five different $1 \mathrm{~g}$ analog environments for training and testing equipment. The crewmembers stated that training in a lunar analog environment prepared them for actual lunar surface operations. They also indicated that this training gave them confidence under nominal circumstances that they would be well prepared for off-nominal events.}


26. Plan the operations on the surface so that you protect the crews from themselves. This recommendation relates to the earlier recommendation about protecting the crews from overwork and burnout. Adequate time is required for the lunar crews to have mental and physical rest during and between LEVA to prevent mistakes and reduce the risk of injury.

27. With extended operations on the moon, establish all the experiments in the first week. Related to the previous recommendation, the Apollo crewmembers were sensitive to the fact that lunar surface operations are difficult and demanding. Astronauts with longer surface-stay time would be more likely to make mistakes in procedures or handling equipment. Therefore, it would be good practice to deploy all the experiments and heavy load activity within the first week of a lunar stay to minimize error and injury risk.

28. A robot should perform routine, systematic, repetitive, menial tasks (may help prevent repetitive use injuries). Physical tasks, such as surface drilling, moving equipment, and setting up experiments should be performed by automated systems where possible to minimize repetitive use injuries and free up crewmember time on the surface. Examples of overuse injuries include medial or lateral epicondylitis in the elbow (tennis or golfer's elbow), DeQuervain's tenosynovitis at the wrist, and shoulder rotator cuff injuries. These overuse injuries have been reported in astronaut training ${ }^{22}$. Other overuse injuries seen in microgravity EVA include fingertip and fingernail trauma. Repetitive use also poses a risk of associated space suit wear and tear.

29. The Rover should have the ability to recharge your suit. The crews felt they could have performed longer LEVA but were limited to the consumables in the suit. A remote recharge station in the field or placed on the rover could potentially extend surface activity duration or be used in the event of a suit incident, such as a leak.

\subsection{In-flight Illnesses}

30. Low back pain should be treated with aggressive pre-mission and in-flight core strengthening program. Some crewmembers complained of significant low back pain (LBP). LBP was noticed early on in space flight by $>70 \%$ of crewmembers. Symptoms were relieved by curving back into the fetal position. Aspirin and other analgesics provided little to no relief. This has been a consistent finding throughout the space program ${ }^{23}$. Etiology is unclear but probably related to stretching of the fibers of the intervertebral disc's annulus fibrosis. Interestingly, the crewmembers denied exacerbations of LBP on lunar surface or return to $1 \mathrm{~g}$. The astronauts suggested developing a preflight exercise protocol to strengthen abdominal muscles. This recommendation is consistent with musculoskeletal expert recommendation that abdominal or "core" strengthening pre- and in-flight helps improve lumbar spine strength and stability and may prevent or lessen in-flight low back pain ${ }^{24}$.

31. Therapy to relieve muscle soreness, primarily in the forearms, must be available (improved glove design may assist this). All the lunar astronauts suffered from some 
degree of forearm soreness during their surface activities. This soreness was related to repetitive grasping-releasing against resistance in the pressurized glove. Although the soreness improved overnight, this could result in overuse injury if the crew was subjected to consecutive LEVA. Therapy, such as non-steroidal anti-inflammatory medication, heat packs, and massage were offered as solutions by the crewmembers. The overall solution in their mind, however, was improving the glove design and adding mechanical assist with repetitive grasping-releasing motions.

32. Constipation: improve the waste management collection system. Constipation was related to diet (low residue), low fluid intake, and waste management problems.

Individual crewmembers intentionally "constipated" themselves with Lomotil in order to reduce the frequency or prevent bowel movements (BMs). One Command Module Pilot (CMP) went an entire 6-day mission without a BM.

33. Screen for CAD prior to selection for lunar missions. The arrhythmia experienced during LEVA in one Apollo lunar crewmember was presumed to be related to hypokalemia (low serum potassium level) and dehydration on the lunar surface. This forced subsequent crews to take potassium supplements, which caused loose stools. Underlying coronary artery disease (CAD) was found years later as the cause of arrhythmia in this crewmember. Current CAD screening for ISS crewmembers is much more sensitive than the screening technology in the 1960s and should detect this condition in astronauts.

\section{A physician crewmember would increase the comfort level among the} crewmembers and can be cross-trained to do other activities. This was a consensus statement among the crewmembers regarding extended duration lunar operations. The Apollo crews had limited medical training and relied on input from the ground flight surgeon for medical issues (if they even acknowledged that a medical issue occurred). A physician astronaut could be cross-trained to carry out mission related activities, as demonstrated by Skylab, Space Transportation System (STS), and NASA-Mir programs. One Apollo astronaut remarked, "Hell, if they can take a naval aviator and train him to do geology [on the moon] they sure as hell can train a doctor to do useful things."

\section{Adequate preventive measures and treatment for diarrhea must be available.}

Another consensus statement by the crews was related to the bad experience using the Apollo waste management system. Unless this system is improved, loose or liquid stool contaminants in the cabin is very difficult to manage and clean. Fecal-oral contamination and infection also becomes an issue. Therefore, medications and/or dietary measures must be available to prevent its occurrence.

\subsection{Medication/Medical Kits (Appendix D)}

36. A card is needed in the med kit to inform the crew of the medication duration, indication, and interaction with other meds. Confusion regarding use of medication, and more importantly, the duration of action occurred on several missions. This prevented crewmembers from using medications properly. One Commander (CDR) remarked that 
he had forgotten how long Dexedrine lasted and suggested putting a card in the med kit to inform the crew of the medication duration, indication, and interaction with other meds. Crew felt they did not want to report any medication usage or other problems because of privacy concerns (a private medical conference (PMC) was not available on the early Apollo missions). In addition to this recommendation, crew education by the flight surgeon was requested to clarify drug duration of action and potential interaction with other medication. It is important to note that current STS and ISS medical kits have this information readily available to the crews.

37. Add non-sedating antihistamines for allergy symptoms due to lunar dust exposure. Symptoms related to lunar dust were described like as "allergies" with runny nose, nasal congestion, and itchy, watery eyes. These symptoms gradually subsided with subsequent exposure during the short lunar stays for most crewmembers and CMPs upon return of the lunar walkers to the CM. One Apollo astronaut recommended, "Adding a nonsedating antihistamine like Claritin ${ }^{\circledR}$ to the med kit might help." One of the Apollo flight surgeons related a story of moderately severe upper respiratory symptoms due to lunar dust exposure when he unstowed the suits after landing. These symptoms worsened with each subsequent exposure. He noted moderate elevations of his total WBC count, primarily the eosinophil levels which are commonly associated with allergic reactions. It is important to note that he did not have pre-exposure baseline WBC counts done to document if the elevation was in fact due to the lunar dust exposure. Lunar dust, however, is not an allergen but a toxic irritant, so it is unlikely that a anti-histamine would work to ameliorate the upper respiratory symptoms. This area is currently under investigation by the Lunar Airborne Dust Toxicity Analysis Group (LADTAG).

38. Saline eye drops need to be available in large quantities (however, an eyewash will be available as part of the environmental health kit). The lunar dust was ubiquitous in the vehicle cabin, and was very difficult to clear from the hands. Cabin fiberglass was also a problem on some of the missions. In each case ocular irritation occurred that required copious saline irrigation to treat. The crews felt that plenty of saline eye drops should be available in the medical kit for both ocular and nasal irrigation.

39. Provide items that are needed in daily life, e.g., nail clippers, lotions, Band-Aids, etc. (Individual hygiene kit will be available). During medical debriefs, several crewmembers noted frustration at not having items used during the course of normal daily hygiene available in the on-board kits.

40. Sufficient analgesia to treat headaches. Headaches were frequently reported during the missions. Crews were concerned that they may be due to elevated cabin $\mathrm{CO}_{2}$ levels since the monitoring devices were unreliable. Headaches are one of the symptoms of Space Adaptation Syndrome ${ }^{20}$ and noted as one of the most frequently occurring symptom throughout the space program. Crews used acetaminophen or ibuprofen with improvement in symptoms. The recommendation was for a sufficient quantity to supply all astronauts for the duration of their mission.

41. Sleep medication must promote restful sleep but not be too sedating. The sleep medication used during Apollo, Seconal, was a barbiturate. Side effects included 
excessive sedation and "hangover" effect, essentially drowsiness the day after a dose. Some lunar crews described sleep on the moon as "two hours of nodding off" but were reluctant to take the sleep medication because of the sedation effect. The sleep medications, currently used by U.S. astronauts on STS and ISS, are of a different drug class and generally much less sedating while promoting restful sleep.

\section{An adequate delivery system for nasal decongestants must be available for the} crewmembers. Nasal congestion was experienced by most crewmembers, and was attributed to the $100 \% \mathrm{O}_{2}$ environment, dust, and viral exposures preflight. Actifed was used and provided moderate relief. Oxymetazoline (Afrin ${ }^{\circledR}$ ), a topical decongestant, was unavailable for Apollo 7-13 due to packaging problems. Lunar crews stated that symptoms resolved on lunar surface after initial exposure to dust only to return when reentering the $\mathrm{CM}$ as the particulates floated throughout the cabin in microgravity.

\subsection{Environmental Impacts}

43. Consider adapting the Skylab waste management system into the new vehicles. In general, the Apollo waste management system worked satisfactorily from an engineering standpoint. However, throughout the medical debriefs the crews reported that the system required $\sim 45$ minutes from start to finish for defecation. Crewmembers had to strip off underwear requiring BIOMED sensor removal, a time consuming process. Application of the Apollo bag was often difficult. One Apollo astronaut described the process as "a complete mess" and "the only part of the whole mission that made me feel uncivilized." Crews strongly recommended creating a device that would allow them to assume a squatting position to have a BM. The Skylab charcoal system was good for waste management as it provided both the ability for the crew to strap down to the toilet and assume the squatting position and a ventilation system that controlled odor.

However, off-nominal "output" such as loose stool or diarrhea is an issue not adequately addressed by either Apollo or Skylab systems. The urine collection system was "lousy" as the UCD frequently leaked. The crew was very concerned about voiding difficulties during critical operations. The urine bag, if used, created backpressure in the system, which contributed to one occurrence of in-flight urinary tract infection.

\section{The sleep restraint system on the Apollo CM worked well and should be} incorporated into the new vehicle design. The straps used on the couches allowed the crewmembers to fasten securely within the sleeping bag. Some crewmembers found wedging themselves under the couches to be comfortable. The sleep system used in the LM was adequate for later Apollo missions, with a few members commenting that the hammock was very comfortable in $1 / 6 \mathrm{~g}$. However, other factors impaired restful sleep (See Appendix G). A few crewmembers suggested that alternatives to the hammock system would have to be created for extended duration missions. One crewmember chose to sleep on the LM floor but found it very cold and dirty with lunar dust. 
45. Sleeping bag needs to be large enough for crewmembers to get both knees to their chest. The crewmembers often assumed a "fetal position" to treat low back pain and found it difficult, if not impossible, to bring both knees to their chest during sleep.

46. Thermal protective clothing or equipment should be available on board. The Apollo 13 crews suffered hypothermia in the $39^{\circ} \mathrm{F}$ LM they used as a "lifeboat" during the contingency return. The EVA suits were available but they chose not wear them because of the difficulty stowing and unstowing items from storage compartments. The A13 CDR and LMP offered the recommendation that a simple, light, and effective thermal blanket should be available in contingency situations.

47. Drinking water should be available during sleep periods. The CM and LM cabin was very dry prompting a frequent need to drink water, interrupting sleep. The astronauts suggested having a water bottle available next to the couch or in the sleeping bag.

48. Hot water capability for hygiene, beverage, and food preparation is essential. The astronauts felt very strongly that having the capability to heat water for routine daily dietary and hygiene use was a necessity. Cold water would be nice to have, but hot water was required. This was a position they felt was not negotiable.

49. Apollo bag aperture and capacity needs to be larger and easier to apply in microgravity. The Apollo bag was a bag that crewmembers passed stool into. Crews unanimously stated that the Apollo bag aperture was too small and the application was very difficult in microgravity. A better system has to be developed for future crews.

50. Create a device that would allow crewmembers to assume a squatting position in microgravity. The crews summed it up well with this statement: "Try pooping standing up with a bag stuck to your butt and see how you like it. Engineers will have to do a better job in the waste management design on future vehicles."

51. Do not design the galley and waste management areas together. The reason for this recommendation should be obvious but the Apollo galley and waste management area were designed within a foot of each other. The crews frequently had diminished appetites for other reasons and did not need the added effect of odor and mess to further compromise their nutritional intake.

52. Minimize noise but do not eliminate it (earplugs are an adequate countermeasure for noise). Noise was an issue for sleep, especially on the LM, but was comforting to the crew. Non-essential communications from the Mission Control Center (MCC) were annoying and need to be eliminated during the sleep period. Simple ear plugs work well and more elaborate systems are not necessary. As an aside, in the LM sunlight was blocked with shades to aid in restful sleep.

53. Carbon dioxide $\left(\mathrm{CO}_{2}\right)$ monitoring device needs to be robust and reliable. The $\mathrm{CO}_{2}$ monitor was frequently malfunctioning with resultant unreliable sensor readings. Crews often remarked they had headaches during the missions, one of the initial symptoms associated with elevated $\mathrm{CO}_{2}$ levels. The faulty sensor system made it difficult to attribute 
the crew's symptoms to elevated $\mathrm{CO}_{2}$ levels in the cabin. This problem persists today on the STS and ISS with crews frequently reporting headaches.

\section{A food warmer is desirable.}

55. Astronaut participation in the design and development phases of the new vehicles is essential. The Apollo astronauts were intimately involved with the requirement development phase through vehicle assembly. Many attributed their mission success to their knowledge of the vehicle systems and hardware. Astronauts associated with the new vehicles should be involved with all phases of its development.

56. RFID tags should be considered for stowage items. Radio-frequency identification (RFID) systems are well established in organizing stowage and retrieval of equipment and other mission gear. This system would provide a reliable tool to locate items within the stowage compartments of the new vehicles and track consumables usage.

57. LSAM windows should be designed to see only what is necessary for landing and/or rendezvous with IR protection. Windows are heavy components of the vehicle and should be designed with these requirements to minimize their mass. Crews will require adequate protection from IR radiation exposure.

58. Design an efficient method for clearing the lunar dust from the vehicle cabin. Lunar dust particles floated everywhere in the LM upon return to microgravity. Dust particles floated into crewmembers eyes, nose, and lungs, which prompted the Apollo 12 crew to keep their helmets on prior to docking with CSM. The dust did not appear to be filtered from the environment through ventilation/LiOH system although the vacuum cleaner that was used beginning with Apollo 14 seemed to help clear the larger particles.

\subsection{Radiation}

59. The lunar excursion vehicle should have an active radiation detector with an automated audible alarm that sounds when the dose rate exceeds a predetermined level. The Apollo mission plan for a radiation event on the lunar surface was based on incorrect assumptions. The assumption was that after Earth-orbiting satellites detected the initial x-rays, the crews had between 15-20 hours before the solar protons arrived at the moon $^{25}$. During this time the crews would be directed to make the traverse back across the lunar terrain from the worksite to the LM, prepare the vehicle and launch off the surface, successfully rendezvous with the CM, dock and secure the hatch, transfer to the $\mathrm{CM}$, and rotate the vehicle so that the thicker side of the vehicle faced the sun thereby absorbing the radiation. Apollo crews did not have an active radiation detection and alarm system on the lunar surface. Recently (2005), a solar event occurred where energetic protons arrived at Earth within 5-20 minutes of the original x-ray detection. (Note: We also have more information about the directionality of solar protons which suggests crews should not launch from the lunar surface during a solar particle event.) Obviously, the Apollo response requires reconsideration. The crews were adamant that the lunar return crews have the capability to detect hazardous radiation levels. The EVA 
suit, rover, and habitat should have the capability to provide autonomous detection and immediate response countermeasures should be embedded in these systems.

60. A personal radiation dosimeter (PRD) is a requirement for all crewmembers. Although this was a requirement for all crewmembers, some of the Apollo crewmembers neglected to wear the device in the suit during lunar surface operations. They recommended designing it into the suit garments thereby eliminating the possibility that it would be left behind.

61. The rover should be equipped with a radiation shield. A durable and effective shield for solar protons should be available for crews on the lunar vehicle for a solar particle event.

62. Radiation protectants should be made available to the crewmembers. Recent developments in radioprotectants suggest that they may be useful to mitigate the risk of developing radiation sickness in crews exposed to solar radiation. The Apollo astronauts stated that they would consider using such compounds if exposed to radiation while on the lunar surface.

63. Create a trench with shovels or explosives to protect the crew short term in the event of a solar particle event. For radiation protection on the surface, creating a trench with shovels or explosives would be adequate to protect the crew short term. It is important to cover the trench quickly with regolith. A real-time active PRD in the suit will let you know how well you have done with regards to exposure and when it would be safe to leave the site. In-suit consumable recharge capability would have to be available also.

\subsection{Performance/Human Factors}

64. Recreational activities need to be made available for crews during trans lunar coast (TLC) and trans Earth coast (TEC). Trans-lunar and Trans-Earth coast were relatively "boring," however, this was an individual experience. Crew wish they had brought recreation materials. Apollo CMPs remarked that the CDR/LMP could relax but he was always on task during this [TLC/TEC] mission phase. Crewmembers reported that they liked having the non-work related time during TLC and TEC, but wanted recreational activities available during this time. Exercise was one of the most desirable activities during this mission phase. This was also important for the CMP during lunar surface operations. Apollo crews recommended for long-duration missions within the constraints of the vehicle "make the space vehicle environment as normal as it is down on Earth." The CEV should be as autonomous as possible. Several of the CMP's stated that it was difficult at times to stay focused during lunar surface operations. Air-to-ground communications helped tremendously. MSFN relay was the best thing CMP had during this time. Other activities included watching the local news to make the day more similar to Earth. Delegation of routine operational "chores" and flight plan maintenance to the MCC would free the CMP to do non-work related activities, such as lunar or deep space 
photography. The A15 CMP stated he used this time to explore deep space while on the far side of the moon.

65. Mental and physical rest plans should be introduced into extended moon stays to allow adequate rest between lunar EVA. Apollo astronauts stated, "Consider mental and physical fatigue here separately. Although there was not a lot of physical fatigue [during the lunar activity], the mind was being used quite a bit. You can sometimes wear your brain out before your body is fatigued."

66. Mission focus should be project-oriented and not timelined. The Apollo lunar surface crews lamented that the timeline on the moon was very ambitious leaving little room for completing tasks in the event things did not go as planned. Future timelines should not be rushed and should allow crews to complete projects thereby minimizing error and potential injuries. A non-EVA suit related injury did occur during one mission that was a result of the astronaut trying to complete a timelined activity with a malfunctioning piece of equipment. The injury required the crewmember to use an excessive amount of analgesics for pain.

67. Use of sleeping medication should be encouraged where appropriate. The crews were generally reluctant to use sleep medication because of the side effects previously described. "There was always the fear of not being alert if an emergency came up. This can't work for long duration stays." A number of astronauts also felt that use of sleep medication would be perceived among their peers and ground controllers as a sign of "weakness" and chose not to use the medication despite suffering insomnia (refer to \# 41).

68. Countermeasures to combat mental fatigue are necessary throughout the mission. Mental fatigue pre-launch was due to the amount of non-essential training [that was not operationally oriented]. There was too much last minute emergency procedure training just prior to launch. They suggested more "normal procedure" training and less emergency procedures training during this time period. Additionally, they suggested slowing the pace of training within 1-2 weeks prior to launch. They all launched fatigued. Preflight quarantine is very valuable as it allows time for simulation training, exercise, and rest. The crew schedule should have "slack early in the mission to allow time for learning/training."

69. Education and psychological services should be available to the crewmembers' families. The crews commented that NASA should be more sensitive to the families needs than they were during Apollo. Family counseling was rejected by NASA when the crewmembers requested it. The crews were relieved to hear that the policy toward family psychological services within NASA has changed since their missions took place and that these services are provided.

70. Allow adequate time in the schedule for all activities. In designing future mission scenarios, the following are recommendations for optimizing operational success and crew health: allow adequate time to practice mission activities in a variety of environments where tasks are defined and duplicated just like on the moon; allow time for all 
activities such as eating, resting, exercise, experiments, etc. This will take coordination with the mission planners, and is especially important to allow enough time for meals. However, the astronauts were quick to point out that during certain mission phases, such as rendezvous and docking, adequate time may not be available for these activities.

71. Provide adequate capabilities for sleeping on the lunar surface. Refer to the environmental section. The lunar crewmembers cited three environmental factors that impaired their ability to get restful sleep: light penetration into the vehicle, loud ambient noise level, and cool cabin temperature (particularly near the floor of the LM). Planners for the LSAM and future lunar habitat will have to correct these factors in addition to the aforementioned requirement for short-acting, well-tolerated sleep medication that does not cause excessive sedation or hangover effect. In addition, the sleep facilities will have to take into account the factors mentioned in the environmental section. In addition, the EVA suit did not provide comfortable sleep on the lunar surface. The inability to get restful sleep on the moon [because of the suit] "could have jeopardized the mission."

72. If a crewmember dies during the mission "cut him loose." Death of a crewmember during a mission is straightforward: "If a crewmember dies, you cut him loose. You can depressurize the hatch and dump him." "Yes, if it happens, it happens...No psycho babble here." The crews emphasized that trying to retain or recover a deceased astronaut could put the other crewmembers at risk. This plan would require working out the details far in advance of the mission so that all individuals involved, including the astronaut family members, would be prepared in the event this happened during a mission.

\section{In planning crew size/makeup, the authority structure is much more significant} than crew size. This recommendation arose out of questions pertaining to the makeup of future exploration crews with regard to number of crewmembers, male/female ratios, etc. The Apollo astronauts were unified in their recommendation to emphasize that crew make-up requirements are secondary to the crew authority structure, i.e., the commander is in charge under all circumstances. Nearly all of the Apollo astronauts were military trained and understood authority structure. This was never more evident than during Apollo 13. The crew supported their commander and insured that he was given whatever was necessary to make the correct decisions during the mission rather than trying to usurp his authority over concerns he might be succumbing to fatigue or stress. Bottom line with crew size/makeup is to make sure they understand who is in charge. The other issues are of less importance.

74. Consider the impact on the mission control flight teams and take actions to ensure that they are rested and provided for during the lunar missions. The crewmembers were sensitive to the demands made on the flight control teams and their families that resulted from planning and carrying out a lunar mission. They urge that NASA take necessary steps to support these individuals and their families during all phases of the mission. This included allowing enough time for sleep, family time, and training prior to and during the mission. The impact of the workload on mission control support personnel is a factor. In addition, they need defined sleep periods and time off to keep the mission functioning. 


\subsection{Crew Schedule}

75. Preflight quarantine is very valuable for providing time for mission simulation, exercise, and rest. From an operational point of view, it removed a large number of distractions from the last three weeks of preparations and the crews were much more rested for launch.

76. The preflight training schedule should allow crews to concentrate on issues that will be used for the nominal mission. The crews wanted only mission related activities, such as simulator training and safety briefings, to occupy their time during the month prior to launch. Activities outside of training, such as exercise and rest, were often compromised during this time and should be as high a priority as any other training issue.

77. Lunar crews should have one day per week for "rest" (freedom to select their activity). During the lunar surface stay, crews should have a scheduled day of rest during each seven-day period. This day would not have timelined activities but could be used at the crew's discretion. The Apollo astronauts emphasized that for extended duration operations, the crew will burn out if they do not have protected rest time during the week.

78. An eight hour per day sleep period must be protected in the daily schedule and must not be compromised. Crew rest time was often the subject of compromise in the daily timeline, as it is today. However, the crew strongly encouraged the flight surgeons to protect the sleep period regardless of whether the crew actually slept. Circadian rhythm was considered not to have been an issue on lunar expeditions. Regarding sleep shifting, it was not optimum to have large shifts in short periods of time. Also, the Schumann Resonance Frequency must be considered. Crews suggested discussions with experts to evaluate the risk factor influencing sleep cycles once the crew is out of the Earth's geomagnetosphere.

79. Crews should be scheduled for simultaneous sleep periods. The initial Apollo missions had staggered crew sleep periods but were later changed to accommodate all crewmembers. This practice should be continued with the lunar return missions.

\subsection{Exercise}

80. Loosen the pre-mission timeline to allow adequate time for preflight conditioning program. The astronauts recognized the importance of maintaining musculoskeletal strength and stamina prior to their mission and felt that time should be set aside during the pre-flight phase to exercise. This was noted to be particularly important to some of the lunar crewmembers who attributed their ability to operate the surface drilling equipment to an aggressive pre-flight upper body strength training program.

81. A more robust (and lightweight) piece of in-flight exercise equipment is needed than the Apollo Exer-Genie. This device was the only exercise equipment available during the Apollo missions and was used by all crewmembers with varying amounts and intensities. A major limitation of the Exer-Genie was the friability of the ropes that connected to the cylinder that provided resistance and the heat that was generated with its 
use. The Apollo CM atmosphere was $100 \% \mathrm{O}_{2}$ and there was a real concern that the heat generated represented a fire hazard. The crews used the device at sub-maximal levels to reduce heat generation. One crewmember stated that the rope and material "frays and kinda smells" after prolonged use.

82. The flight surgeon/mission planners should not plan specific exercise prescriptions for short duration (< 14 days) mission. The crews performed exercise for rest and relaxation purposes as much as for the physical benefit. They cautioned the flight surgeons against trying to timeline specific exercises. They felt the crews should be instructed on what exercise would be beneficial and applicable for the device available, choosing what they wanted to do during short duration missions.

\section{Exercise is not necessary on short trips (14 days or less) [from a fitness} standpoint], however, crews demanded that the capability be available and varied as much as possible for crew "rest and relaxation" in all phases of the mission. The crews did not feel that they suffered noticeable deconditioning during their relatively short missions. However, they do not dispute the science that shows muscle and bone strength decrements with longer microgravity exposures. In the context of their short missions and lunar EVAs, they were able to perform all mission related activities without concern from loss of strength or stamina. The astronauts demanded exercise capability for the $\mathrm{CM}$ for rest and relaxation purposes. A couple of crewmembers also experienced minor Achilles tendonitis after return to Earth and suggested that a more aggressive lower extremity stretching program enroute to home may have prevented this occurrence. The lunar surface crews felt that their activities on the moon provided enough exercise for a short duration mission but would have welcomed a simple, robust device for stretching and forearm strengthening exercise.

84. Develop a better preflight and in-flight forearm muscle-conditioning program for lunar crewmembers. In addition to the core stabilization program as described earlier in the illness/injury section, a strengthening program for the forearm muscles before and during the mission is necessary. Upper extremity exercises, specifically to strengthen and maintain shoulder strength and stamina, will be necessary in the preflight period and during the mission. As mentioned previously, operating the surface tools in partial gravity, particularly the drill, requires more force generated from the shoulders than needed in $1 \mathrm{~g}$.

\section{New vehicle design should allow a variety of different exercise capabilities} (hardware vs. cabin structure). The astronauts recommended examining the new spacecraft design to determine surfaces or structures within the vehicle to exercise various muscle groups. Also, a more robust (and lightweight) piece of equipment is needed. The crews performed isotonic exercises against the struts of the LM on the surface before EVAs. Another example of using the vehicle in novel ways to perform exercise included "running in place holding onto the couch," isometrics performed against cabin structures, etc. 
86. Put as many [exercise] capabilities in the vehicle as possible, because it will get used. Many crewmembers felt exercise capability throughout flight will be critical. A variety of exercises must be provided.

87. New exercise devices should be reliable, simple, and not develop excessive heat in use. The crew was concerned towards the end of the mission that they were going to "break the machine" and began tapering down the exercise duration and intensity to protect the equipment so that it would be available for reconditioning prior to re-entry.

\subsection{Food/Nutrition}

88. Mission activity (e.g., coast, rendezvous, lunar orbit, lunar OPS, etc.) will dictate what type and how much food will be consumed. Apollo diets offered 2100-2660 $\mathrm{kcal} / \mathrm{day}$, but the crews seldom obtained these required energy intakes. During busy mission phases, the crews often went without eating or drinking because of issues with preparing food or problems associated with the water system. They recommended that meal planners work with mission planners to coordinate easily accessible food that could be prepared quickly to ensure that crew energy needs are met throughout all mission phases. Specific examples of mission activity and appropriate food types include:

- High activity - wet packages, bite-sized snacks, canned foods

- Low activity - spoon-bowls, dry juice or meals (rehydratable) requiring mixing etc.

89. Plain water in large quantities needs to be available for lunar EVA. The crewmembers stated that they needed more plain water available for LEVA. As was mentioned in the EVA suit and Lunar Surface Operations section, the lunar crews often went 10 hours without a break after suiting up.

90. Optimize diet and food intake for overall performance during long duration missions.

91. An in-suit non-caffeinated solid or liquid carbohydrate food source for lunar EVA would be helpful.

92. Design adequate space and useful area in the new vehicles to store food packs during meals. Lack of available space and useful area to store food packs during meals made eating difficult. Food preparers need to be mindful of the difficulties associated with performing tasks in microgravity.

93. Spicy and salty foods are preferred items in the menu. Overall, the food lacked flavor or spice. Crews preferred the salty bite-sized snacks or other flavorful items as their taste perception changed in space compared to the preflight food testing.

94. Allow adequate time in the daily schedule for meals. Refer to comments in recommendation \# 88. 
95. Determine how different environmental factors (e.g., $\mathrm{O}_{2}$ concentration, cabin pressure) effect food flavor. Foods tested preflight tasted fine but were "absolutely unattractive in-flight." One crewmember who had flown both an Apollo and STS mission stated he had a poor experience with food during Apollo but the same food flown on shuttle was palatable and tasty. His experience raised the question of the effect of the 5.0 psia and $100 \% \mathrm{O}_{2}$ atmosphere of Apollo on food integrity or taste perception compared to the $14.7 \mathrm{psia}$ and $21 \% \mathrm{O}_{2}$ of the space shuttle. The future vehicles have a proposed cabin atmosphere of 7.6-8.0 psia at $30-32 \% \mathrm{O}_{2}$.

\subsection{Launch/Landing/Recovery Operations}

96. Provide adequate cooling capabilities for the crew on landing to mitigate the hot cabin contribution to crewmember seasickness. Considerable weight loss was attributed to sweating and dehydration that occurred on landing secondary to seasickness. Inadequate cabin/suit cooling after landing was cited as the primary contributor to both conditions. The future landing vehicle must have adequate cooling capabilities for the crews. The onset and severity of seasickness will be determined by the crew's ability to stay cool more than anything else.

97. Ground landings are discouraged. This was not a consensus statement among the crewmembers. A number of the Apollo astronauts, however, were adamant that a ground landing would likely kill the crewmembers. NASA has considerable experience with water landing, have never lost a crew by landing in the sea, and have a much larger margin of error for re-entry. Ground landings do not afford much error and may pose a threat to humans in populated areas with an off-trajectory re-entry profile. The dissenting Apollo astronauts, however, mentioned that we now have extensive experience via the shuttle with ground landings, and that perhaps water landings could be used to build confidence before moving forward with ground landings. It was also pointed out that the navigation capabilities to track the re-entering spacecraft were not well-developed or reliable whereas the navigation systems today are a proven technology and would ensure reliable land trajectories upon reentry.

98. Apollo seat configuration for water landings was adequate. The seats were adequate for re-entry despite force distributed throughout body. Impact was well distributed across the back. Couches and restraints were adequate for landing and launching from the Earth and moon in terms of side and head protection. All loose items need to be restrained; one crewmember sustained a scalp laceration after being struck in the head by an object that came loose when the capsule impacted the water.

99. Medication for motion sickness and fatigue should be available prior to re-entry. Scopolamine $0.3 \mathrm{mg} /$ Dexedrine $5 \mathrm{mg}$ were taken by several crewmembers prior to re-entry and again at splashdown to prevent motion sickness and to combat fatigue.

100. Sea state should be limited to $<6-8$ foot swells if recovery is to be delayed. Most of the Apollo astronauts were naval aviators or experienced pilots with one exception. Nearly all the astronauts experienced seasickness, some reporting the onset of symptoms 
within 30-60 seconds of the water landing. The crews strongly recommended that the recovery sea state be limited to less than 6-8 foot seas.

101. Have food and plain water within reach of buckled crewmembers for delayed recovery. Dehydration was a significant concern due to lack of suit or cabin cooling. Food and plain water will need to be readily available for the crews in sufficient amounts to sustain the crew until recovery teams can remove crew from the landing capsule.

102. Apollo CM hatch location and size was adequate for egress. Hatch location for landing egress was adequate. Apollo crewmembers denied having any trouble emerging from the capsule after landing. The crews offered a mixed response as to whether they would have been able to assist an injured crewmember in an emergency scenario. Crewmembers also recommended that the hatch on the re-entry vehicle open outward in response to the Apollo 204 hatch that opened inwardly preventing crew escape during the fire. However they pointed out that a hatch design that opens outward but does not seal with pressure is very dangerous, referring to the potential for cabin atmosphere leaks

103. All control panels and switches should be within reach of crewmembers during launch and landing. Regarding the control panels and switches, all required functions were within reach during high $\mathrm{g}$ and zero $\mathrm{g}$ in the Apollo CM. This was tested in centrifuge runs in the design and development phase. The same approach should be taken for the new launch and return vehicle.

104. Training for pad abort was adequate and should be continued. The slide wire abort works. One crewmember felt the egress route under the pad room in Apollo provided a faster and safer escape route than the slide wire.

105. Crew surgeon should be on the recovery vessel and not the helicopter. The rescue crew provides all the necessary skills for safely transferring the crew from the vehicle to the helicopter. The crew flight surgeon serves his/her purpose best on the recovery ship and should not be put at risk in the recovery aircraft.

\subsection{Flight Surgeon-Crew Interaction}

106. Crews encouraged the Flight Surgeon to "act as more of an advocate of the crew" than treat them as an experiment. Crews often felt the flight surgeon treated them as "an experiment" considering the demands the flight plan placed on them. Lack of PMC with flight surgeon limited the crew input regarding physiological functions and medication usage during flight. After one CMP was left hanging regarding his flight status due to an abnormal lab value 3 weeks prior to launch, the CDR and CMP both felt the flight surgeon was not looking out for the crew's "mental well being." The CDR emphasized that "emotional stress is one of the main issues [that the flight surgeon] needs to help minimize both preflight and in-flight for his/her crew." A number of crewmembers did state instances where their individual flight surgeon supported them above and beyond the call of duty and were grateful for their dedication to their crews. 
107. The collaboration established between the current flight surgeons and Apollo crewmembers should continue and be an example to future generations.

\subsection{DISCUSSION}

The purpose of this study was to identify Apollo operational issues that impacted crew health and performance. The specific goals of this project were to develop or modify medical requirements for new vehicles and habitats, to create a centralized database for future access, and to share relevant Apollo information with the multitude of entities at NASA and abroad participating in the exploration effort. Secondary objectives included using this information to validate current requirements and refresh knowledge regarding lunar operations. The database has been created to complete this study, and the information gleaned is currently being shared among NASA entities. What remains is to discuss the modification of exploration medical requirements based on the experiences of the Apollo astronauts.

The only experience that the human race has with manned lunar exploration is through the perceptions and memories of the 22 surviving Apollo astronauts. As such, their experience and knowledge is a vast resource that has been surprisingly untapped. This paper has attempted to extract and archive this resource. Underlying everything from the abstract to the conclusion was the ethos of "operationally driven outcomes." In other words, the focus was to determine how the positive and negative experiences of the Apollo astronauts can improve the mission operations of the Constellation crews. The authors diligently focused on extracting that which had potential operational relevance, so that the varied audience could come away from the paper with something tangible to incorporate into their exploration work. Also, as discussed in the Methods section, previous published data was exhaustively researched to prevent duplication of results and conclusions. Further, data contained within this paper has been reviewed for accuracy by the Apollo astronauts. Hence, the results are an attempt to achieve an untainted representation of the thoughts and recommendations of the Apollo astronauts themselves. The authors of the paper have simply acted as the "middle-men."

There are both strengths and limitations of the ability of these results to "develop or modify medical requirements for new vehicles and habitats." Are these events and challenges that occurred over 35 years ago applicable today? On Apollo missions, the astronauts were allowed to bring one cassette tape into space for morale purposes. Today astronauts can carry an Ipod with 80 Gigabytes and 20,000 songs. True, there are now new paradigms and new technologies, however, the authors (and the Apollo astronauts) feel that those who don't learn from history are bound to repeat it. Just as Sun Tzu's "Art of War" is as true and applicable today as it was in the $6^{\text {th }}$ century B.C., the lessons of the Apollo astronauts will find significance and relevance with future exploration missions. Limitations inherent to this study potentially include non-response bias and the volunteer effect, procedure bias, and recall bias. Also, there are limitations to the applicability of the 107 recommendations, some recommendations are "more relevant" than others. For example, there were many recommendations regarding the waste management system. 
Many of these issues have been vastly improved through years of shuttle and space station experience. These recommendations are somewhat "less relevant." However, in general, the recommendations in the categories of EMU/EVA Suit Operations, Lunar Surface Operations, and Lunar Radiation are "more relevant" due to the fact that they are related more closely to lunar exploration and have not yet been duplicated or improved upon. In the end, the relevance of each recommendation must be considered carefully and individually.

The principle findings of this study can be broken down into broad pervasive themes and themes relevant to each of the 11 recommendation categories and subcategories. Three themes were ubiquitous throughout the project. The first two, safety and mission accomplishment, were explicit and self-evident. These two ideas are intertwined, virtually impossible to separate, and at the core of every recommendation that was put forth. The third ever-present, but almost "unconscious" theme was one of human factors, and in particular, the idea that "the astronauts are only human." When analyzing the responses one gets the idea that the astronauts are imploring the establishment to acknowledge that they are humans, not robots or test subjects. This was evident with multiple recommendations spanning the 11 categories. For example, scheduling-related recommendations were made in 4 of the categories for a total of 23 recommendations. Likewise, 10 sleep-related recommendations were made in 3 categories and more generally, 26 recommendations for "rest and relaxation" were mentioned in 6 categories. Further evidence for the recognition of their limitations includes multiple recommendations for ensuring adequate "self-maintenance" via exercise, nutrition and fluid intake, and a higher level of waste and personal hygiene. Finally, the astronauts made multiple recommendations (7 in 6 categories) and requests regarding Flight Surgeon/Physician advocacy and intervention. Military pilots traditionally have had an apprehensive relationship with Flight Surgeons, hence the astronauts' appeal to seek assistance from someone who could potentially ground them should be considered significant. They even went so far as to unanimously recommend the addition of a physician-astronaut as a crewmember, with the thought being that a physician-astronaut would increase the comfort level among the crew, and could serve as a strong advocate for astronaut needs while in space. A final observation worth mentioning is that the astronauts' recommendations were very difficult to categorize. That is, a single recommendation such as "Improve glove flexibility, dexterity and fit, simultaneously involves operations, engineering, human factors, safety, and mission accomplishment. This brought to the forefront the uniquely interdisciplinary nature of manned space exploration and the broad appeal of this paper.

The Tables 3 through 14 list the Apollo astronauts' 107 recommendations followed by the current status and disposition of that recommendation. The status definitions are as follows:

In Practice

New Requirement
The recommendation is operational in current shuttle and ISS missions

The listed requirement was created as a direct result of the Apollo recommendations 
Requirement Modified

Requirement Validated

OpsCon Validated

Being Evaluated

Consider

Rejected
The listed requirement was revised as a result of the Apollo recommendations

The listed requirement was validated by the Apollo recommendations

The listed operational concept was validated by the Apollo recommendations

The recommendation is actively being analyzed for future requirements

The recommendation is known by involved parties, but there is no formal review for acceptance or rejection

The recommendation has been evaluated and subsequently rejected as a requirement

The emphasis of the recommendations varied through each of the 11 categories:

\section{EMU/EVA ISSUES}

EMU/EVA recommendations centered first and foremost on improving the functionality of the suit first and foremost and then focused on improving both the human factors integration as well as specific safety features. The most adamant of the suit recommendations and a consensus statement was to improve the dexterity of the glove. This recommendation had mission accomplishment and safety as the driving concerns. Similarly, the astronauts recommended increasing ambulatory and functional capability through increased suit flexibility and decreased mass and internal pressure. Theoretically this will have the added benefit of decreasing fatigue as well. The human factors recommendations revolved around consumables and excretion. They recommended insuit access to large amounts of high energy liquids and plain water, a Heads-up Display with consumable, biomedical, and navigation information on demand, and an improved urinary collection system. Safety concerns revolved around redundancy being built into the suit. In particular, they suggested a system to prevent helmet fogging under all circumstances, a self-sealing pressure garment in case of puncture, and a system to protect the zipper from abrasive lunar dust.

Spacesuit technology has improved over the years through shuttle and ISS experience, however, only the Apollo astronauts have the experience of operating in the lunar environment at $1 / 6$ gravity. As such, their insight is very relevant to exploration requirements.

As can be seen in the Table 3, the EVA Systems Project (ESP) and the Human Research Program (HRP) via the EVA Physiology Systems and Performance (EPSP) element is quite active with this set of Apollo recommendations. The EPSP and ESP is aggressively evaluating multiple recommendations and considering several others. EPSP has a systematic test plan that will address suit related issues and result in specific data backed recommendations for the optimal suit weight, mass, pressure, center of gravity, and kinematics (mobility) for lunar operations. Additionally, the EPSP and Exploration Medical Capability (ExMC) team have addressed the UCD issues and have developed improvements to the Maximum Absorbent Garment (MAG). 
Table 3: EMU/EVA Issues Recommendation Implementation

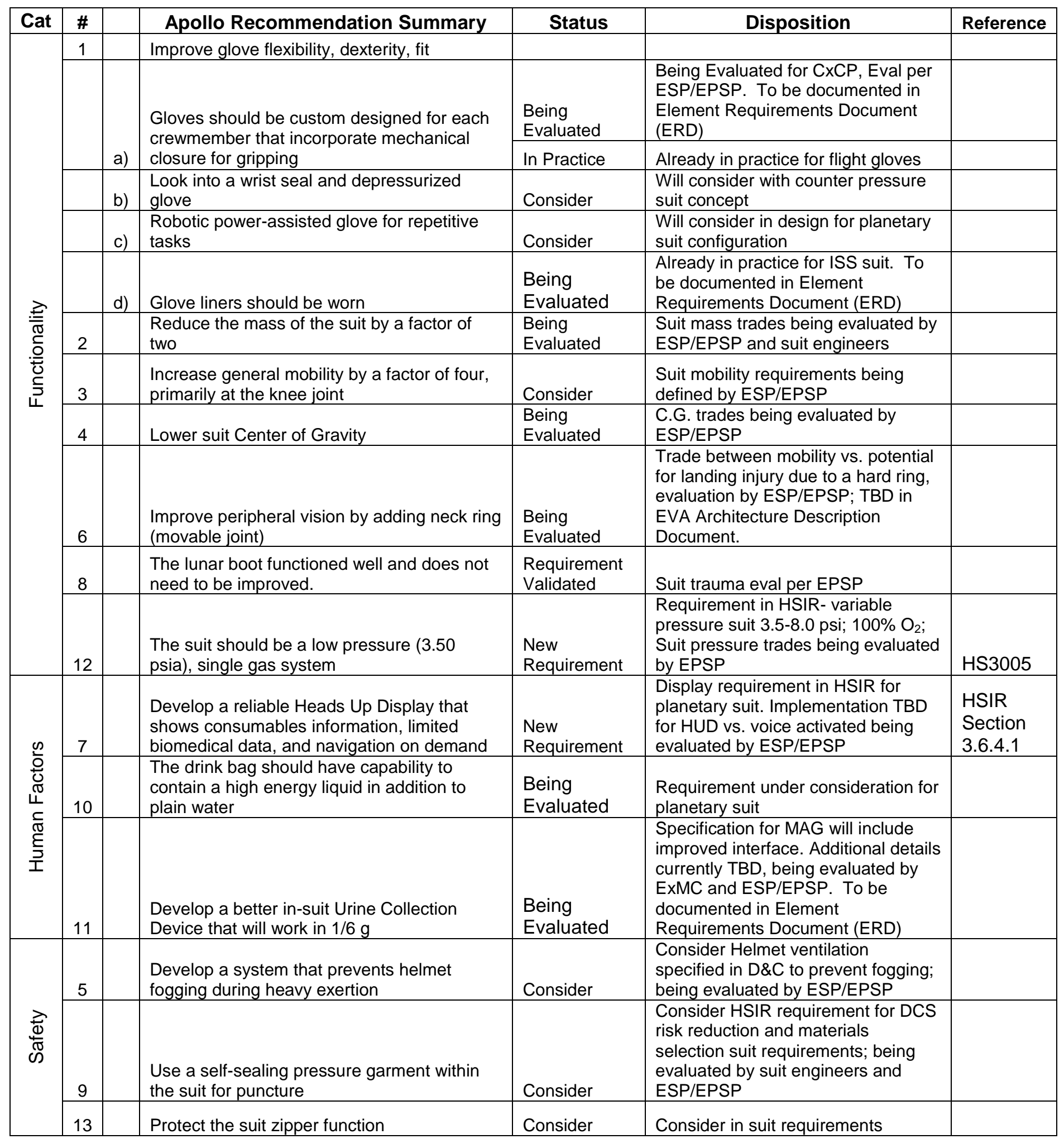




\section{EMU/EVA ISSUES}

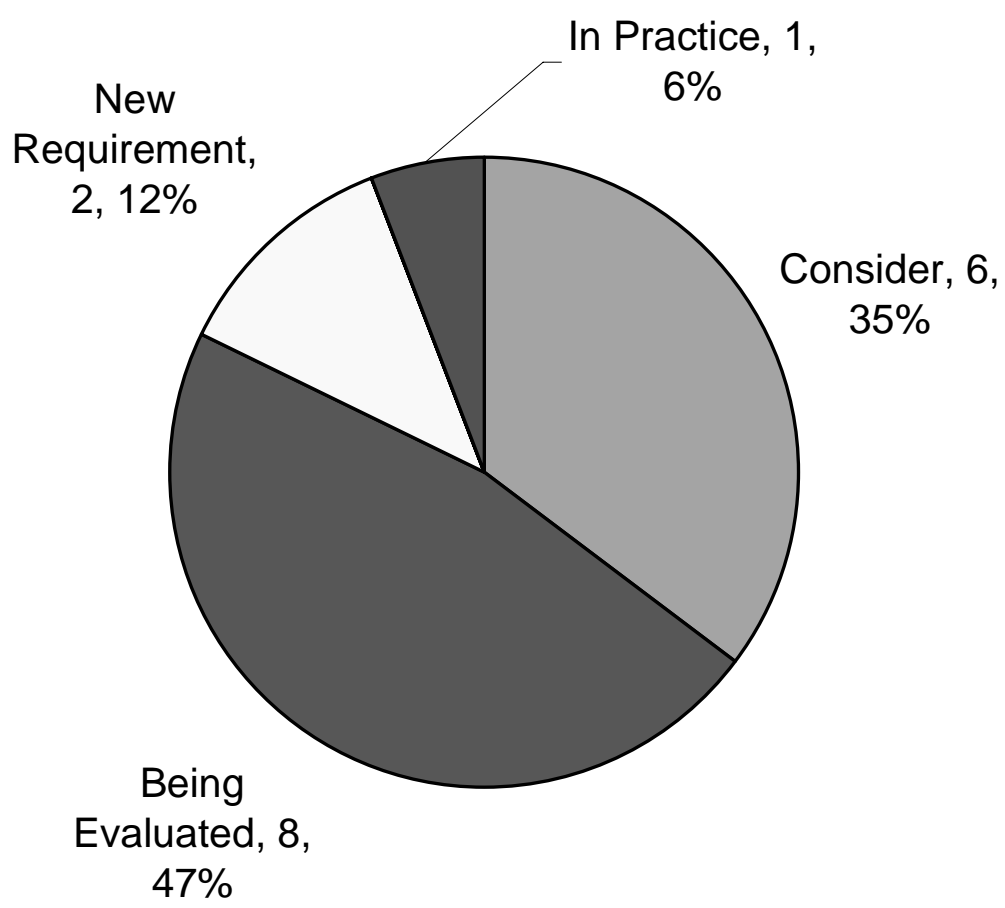

Figure 2. EMU/EVA Issues

\section{LUNAR SURFACE OPERATIONS}

Recommendations for lunar surface operations revolve around human factors, safety, and operational efficiency. Human factors and safety considerations were particularly intertwined in this category. A recurrent comment by the Apollo astronauts about operations on the lunar surface was an overwhelmingly packed schedule. For extended operations, the astronauts were adamant about decreasing the workload in the schedule. They suggested a maximum of 2 LEVAs within a 3 day period and a schedule with flexibility and "breathing room" built into it. They also commented that surface operations could begin once operationally feasible, that LEVAs should be one continuous event with ample food and liquids available before and during the event, and that the schedule should be front-loaded to minimize error and injury. Major risks identified were falls, rover operations, and navigating slopes in excess of 20-26 degrees. With suit functionality improvement, some of the risks identified will be reduced, one example being upper extremity injuries due to inability to visualize placement of an outstretched 
arm. To increase operational efficiency the astronauts recommended using HUD technology, robots for repetitive tasks, and the rover to recharge suits. They also felt that for extended operations, LSAM ingress and egress portals must be closely scrutinized. They emphasized with a consensus statement that the hatch size must comfortably accommodate pressurized suits and that engineers consider an airlock. In general, they felt that the familiarization training with partial gravity devices or aircraft, such as the POGO or parabolic flight, and analog training was sufficient.

The longest any of the astronauts spent on the moon was three days yet many of their recommendations inferred problem areas for extended lunar stays. Therefore, this category in particular is very relevant to future lunar exploration. Also, many of their recommendations are straight forward and difficult to counter. For example, guarding against overwork and ensuring food and water availability seems obvious, but implementation may not as straight forward during planning phases. Surprising recommendations included the astronauts' acknowledgement and requests for new technology (such as an iPod ${ }^{\circledR}$ ) that one might have thought to be outside of the paradigms of these mostly 1960s and 70s era astronauts. Also, multiple recommendations have already been implemented by virtue of shuttle and ISS operations. 
Table 4: Lunar Surface Operations Recommendation Implementation

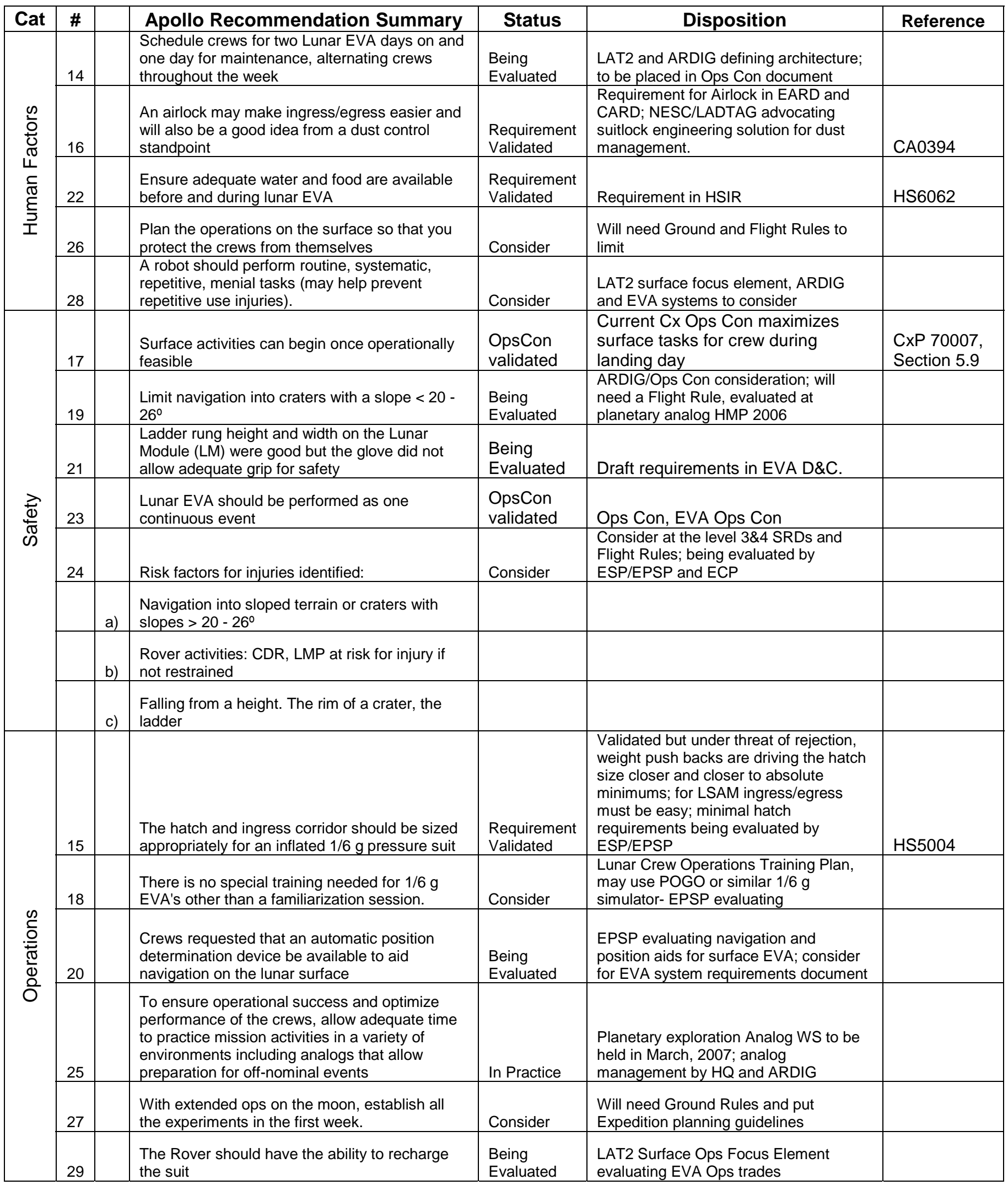




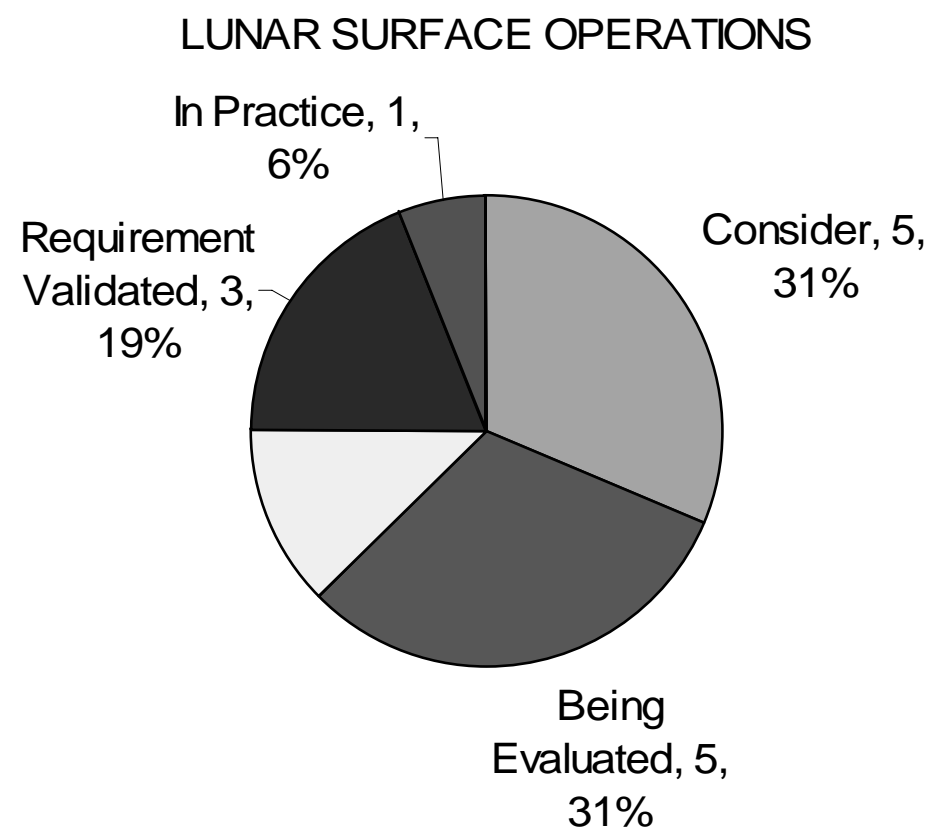

Figure 3. Lunar Surface Operations

\section{IN-FLIGHT ILLNESSES}

Recommendations addressing in-flight illness focused on pain, gastrointestinal dysfunction, and preventative screening. In particular, treatments or preventative measures were recommended for lower back and forearm pain and soreness, constipation and diarrhea, and heart disease. The two consensus statements in this category included therapy to relieve muscle soreness, especially in the forearms, and to include a physician crewmember to increase the comfort level among the crewmembers. This category also demonstrated the inter-disciplinary nature of space operations. For example, it was discovered that crewmembers intentionally constipated themselves with medications to reduce or completely prevent the need to use the poor waste management collection system. Another example is the forearm soreness. A well-designed glove would render this complaint a non-issue.

This category although significant, has less relevance due to improvements that have been implemented during Skylab, Shuttle, and ISS operations. All issues except the consensus related statement regarding a physician-astronaut are accounted for in Table 5. 
Table 5: In-Flight Illness Recommendation Implementation

\begin{tabular}{|c|c|c|c|c|c|}
\hline Cat & $\#$ & Apollo Recommendation Summary & Status & Disposition & Reference \\
\hline \multirow{5}{*}{ 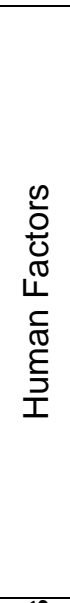 } & 30 & $\begin{array}{l}\text { Lower back pain should be treated with } \\
\text { aggressive pre-mission and in-flight core } \\
\text { strengthening program }\end{array}$ & $\begin{array}{l}\text { Being } \\
\text { Evaluated }\end{array}$ & $\begin{array}{l}\text { Cx Medical Operation Requirements } \\
\text { are in development }\end{array}$ & \\
\hline & 31 & $\begin{array}{l}\text { Therapy to relieve muscle soreness, } \\
\text { primarily in the forearms, must be } \\
\text { available (improved glove design may } \\
\text { assist this) }\end{array}$ & $\begin{array}{l}\text { Being } \\
\text { Evaluated }\end{array}$ & $\begin{array}{l}\text { Cx Medical Operation Requirements } \\
\text { are in development }\end{array}$ & \\
\hline & 32 & $\begin{array}{l}\text { Constipation: improve the waste } \\
\text { management collection system }\end{array}$ & $\begin{array}{l}\text { Requirement } \\
\text { Modified }\end{array}$ & $\begin{array}{l}\text { Requirement for waste management } \\
\text { in HSIR }\end{array}$ & $\begin{array}{l}\text { HSIR } \\
\text { section } \\
\text { 3.5.3.2 }\end{array}$ \\
\hline & 33 & $\begin{array}{l}\text { Screen for CAD prior to selection for } \\
\text { lunar missions }\end{array}$ & $\begin{array}{l}\text { Being } \\
\text { Evaluated }\end{array}$ & $\begin{array}{l}\text { Astronaut Medical Evaluation } \\
\text { Requirements Document (AMERD) } \\
\text { is being revised. }\end{array}$ & \\
\hline & 35 & $\begin{array}{l}\text { Adequate preventive measures and } \\
\text { treatment for diarrhea must be available }\end{array}$ & $\begin{array}{l}\text { Being } \\
\text { Evaluated }\end{array}$ & $\begin{array}{l}\text { Cx Medical Operation Requirements } \\
\text { are in development }\end{array}$ & \\
\hline $\begin{array}{l}0 \\
\stackrel{0}{0} \\
\substack{\pi \\
\Phi} \\
\frac{0}{0} \\
\end{array}$ & 34 & $\begin{array}{l}\text { A physician crewmember would increase } \\
\text { the comfort level among the } \\
\text { crewmembers and can be cross-trained } \\
\text { to do other activities }\end{array}$ & Consider & $\begin{array}{l}\text { Consider development of Crew } \\
\text { selection guidelines for Lunar } \\
\text { Outpost }\end{array}$ & \\
\hline
\end{tabular}

\section{IN-FLIGHT ILLNESS}

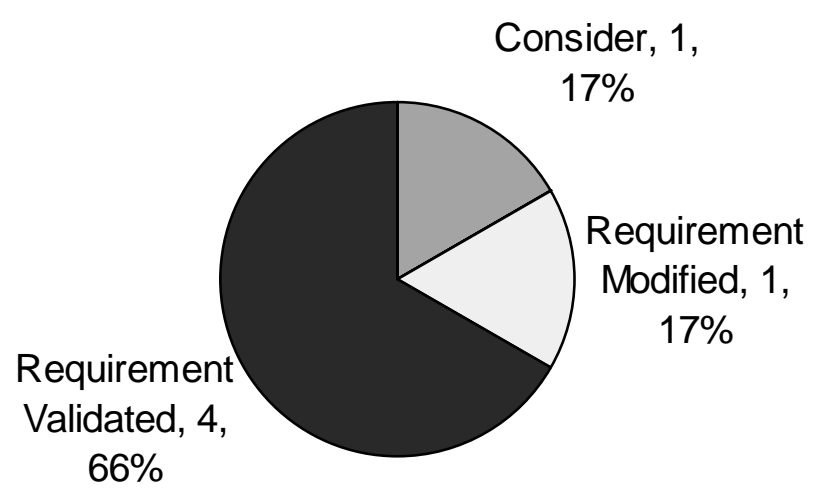

Figure 4. In-Flight IIIness 


\section{MEDICATION/MEDICAL KITS}

Recommendations focused on medications that would have improved operational efficiency and comfort. Recommendations for kit contents included allergy medications, saline eye drops, standard toiletries (nail clippers, lotions, etc.), headache analgesia, efficacious sleep medications, and an efficient decongestant delivery system. All of these items are currently accounted for or improved upon (i.e. eyewash is included in addition to saline drops) in the Constellation requirements.

\section{Table 6: Medication/Medical Kits Recommendation Implementation}

\begin{tabular}{|c|c|c|c|c|c|}
\hline Cat & \# & Apollo Recommendation Summary & Status & Disposition & Reference \\
\hline \multirow{7}{*}{$\begin{array}{l}\stackrel{0}{ \pm} \\
\stackrel{0}{ \pm} \\
\stackrel{0}{0}\end{array}$} & 36 & $\begin{array}{l}\text { A card in the medical kit to inform the } \\
\text { crew of the medication duration, } \\
\text { indication, and interaction with other } \\
\text { meds is needed }\end{array}$ & $\begin{array}{l}\text { Being } \\
\text { Evaluated }\end{array}$ & $\begin{array}{l}\text { Cx Medical Kit contents definition } \\
\text { TBD }\end{array}$ & \\
\hline & 37 & $\begin{array}{l}\text { Add non-sedating antihistamines for } \\
\text { allergy symptoms due to lunar dust } \\
\text { exposure }\end{array}$ & $\begin{array}{l}\text { Being } \\
\text { Evaluated }\end{array}$ & $\begin{array}{l}\text { Cx Medical Operation Requirements } \\
\text { are in development }\end{array}$ & \\
\hline & 38 & $\begin{array}{l}\text { Saline eye drops need to be available in } \\
\text { large quantities }\end{array}$ & $\begin{array}{l}\text { Being } \\
\text { Evaluated }\end{array}$ & $\begin{array}{l}\text { Cx Medical Operation Requirements } \\
\text { are in development (however, an } \\
\text { eyewash will be available as part } \\
\text { of the environmental health kit) }\end{array}$ & \\
\hline & 39 & $\begin{array}{l}\text { Provide items that are needed in daily } \\
\text { life, e.g., nail clippers, lotions, band-aids, } \\
\text { etc. }\end{array}$ & $\begin{array}{l}\text { Being } \\
\text { Evaluated }\end{array}$ & $\begin{array}{l}\text { Flight Crew Equipment contents } \\
\text { definition is TBD (individual } \\
\text { hygiene kit will be available) }\end{array}$ & \\
\hline & 40 & Sufficient analgesia to treat headaches & $\begin{array}{l}\text { Being } \\
\text { Evaluated }\end{array}$ & $\begin{array}{l}\text { Cx Medical Operation Requirements } \\
\text { are in development }\end{array}$ & \\
\hline & 41 & $\begin{array}{l}\text { Sleep medication must promote restful } \\
\text { sleep but not be too sedating }\end{array}$ & $\begin{array}{l}\text { Being } \\
\text { Evaluated }\end{array}$ & $\begin{array}{l}\text { Cx Medical Operation Requirements } \\
\text { are in development }\end{array}$ & \\
\hline & 42 & $\begin{array}{l}\text { An adequate delivery system for nasal } \\
\text { decongestants must be available for the } \\
\text { crewmembers }\end{array}$ & $\begin{array}{l}\text { Being } \\
\text { Evaluated }\end{array}$ & $\begin{array}{l}\text { Cx Medical Operation Requirements } \\
\text { are in development }\end{array}$ & \\
\hline
\end{tabular}




\section{MEDICATION/MEDICAL KITS}

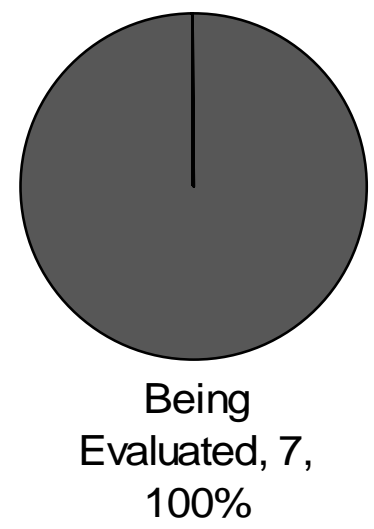

Figure 5. Medication/medical kits

\section{ENVIRONMENTAL IMPACTS}

Human factors and operational design were the two foci of the Environmental Impacts recommendations. Recommendations addressing human factors dealt with waste management, sleep, and consumables. The astronauts unanimously recommended the adaptation of the Skylab waste management system. They also wanted to see a device to allow for squatting for bowel movements, felt that the Apollo bag aperture and capacity both needed increasing, and would prefer that the galley and waste areas be separated. To foster restful sleep, the astronauts recommended minimizing environmental noise, having water available during sleep, increasing the sleeping bag size to allow for the "fetal position," and the incorporation of the CM sleep restraint system. Hot water capability was deemed essential and non-negotiable via a consensus statement. A food warmer was also considered desirable. Operational concerns centered on engineering redesign, a contingency input, and increasing efficiency. First and foremost, the crewmembers consensus was that astronaut participation in design and development is essential. Another consensus statement was to incorporate more reliable $\mathrm{CO}_{2}$ monitors. They also felt that the LSAM windows should be as small as possible and that there should be a system for clearing lunar dust from the cabin. A consensus statement resulting from the experience of Apollo 13 was to include thermal protective gear in the event of a contingency. The last recommendation was to utilize RFID tags for stowage items.

The recommendations brought to light some points that would have been missed just as they were during Apollo. For example, as a result of the recommendations thermal 
protection is being added to the crew equipment. Other changes and additions are shown in table 7.

Table 7: Environmental Impacts Recommendation Implementation

\begin{tabular}{|c|c|c|c|c|c|}
\hline Cat & $\#$ & Apollo Recommendation Summary & Status & Disposition & Reference \\
\hline \multirow{10}{*}{ 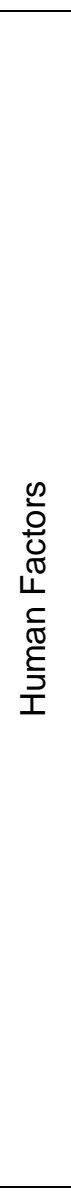 } & 43 & $\begin{array}{l}\text { Consider adapting the Skylab waste } \\
\text { management system into the new } \\
\text { vehicles }\end{array}$ & Consider & $\begin{array}{l}\text { Waste Management System } \\
\text { specification is in development }\end{array}$ & \\
\hline & 44 & $\begin{array}{l}\text { The sleep restraint system on the Apollo } \\
\text { CM worked well and should be } \\
\text { incorporated into the new vehicle design }\end{array}$ & Consider & $\begin{array}{l}\text { Requirement for sleep } \\
\text { accommodations in HSIR, details for } \\
\text { Level } 4 \text { document TBD }\end{array}$ & HS6104 \\
\hline & 45 & $\begin{array}{l}\text { Sleeping bag needs to be large enough } \\
\text { for crewmembers to get both knees to } \\
\text { their chest }\end{array}$ & Consider & $\begin{array}{l}\text { Requirement for sleep in HSIR, } \\
\text { details for sleeping bag are TBD }\end{array}$ & HS6104 \\
\hline & 47 & $\begin{array}{l}\text { Portable drinking water should be } \\
\text { available during sleep periods }\end{array}$ & Consider & $\begin{array}{l}\text { Requirement for potable water in } \\
\text { HSIR, the details for the portability of } \\
\text { water will be in a lower level } \\
\text { document }\end{array}$ & HS3025 \\
\hline & 48 & $\begin{array}{l}\text { Hot water capability for hygiene, } \\
\text { beverage and food preparation is } \\
\text { essential }\end{array}$ & $\begin{array}{l}\text { Requirement } \\
\text { Validated }\end{array}$ & Requirement in HSIR & HS3031 \\
\hline & 49 & $\begin{array}{l}\text { Apollo bag aperture and capacity needs } \\
\text { to be larger and easier to apply in } \\
\text { microgravity }\end{array}$ & Consider & & \\
\hline & 50 & $\begin{array}{l}\text { Create a device that would allow } \\
\text { crewmembers to assume a squatting } \\
\text { position in microgravity }\end{array}$ & Consider & $\begin{array}{l}\text { Waste Management System } \\
\text { specification is in development }\end{array}$ & \\
\hline & 51 & $\begin{array}{l}\text { Do not design the galley and waste } \\
\text { management areas together }\end{array}$ & $\begin{array}{l}\text { Requirement } \\
\text { Validated }\end{array}$ & $\begin{array}{l}\text { Requirement for separation of galley } \\
\text { and WCS in HSIR }\end{array}$ & HS6002 \\
\hline & 52 & $\begin{array}{l}\text { Minimize noise but do not eliminate it } \\
\text { (earplugs are an adequate } \\
\text { countermeasure for noise) }\end{array}$ & $\begin{array}{l}\text { Requirement } \\
\text { Validated }\end{array}$ & Acoustics requirements in HSIR & $\begin{array}{l}\text { HSIR } \\
\text { section } \\
3.2 .6 \\
\end{array}$ \\
\hline & 54 & A food warmer is desirable & $\begin{array}{l}\text { Requirement } \\
\text { Validated }\end{array}$ & Requirement in HSIR & HS6003 \\
\hline \multirow{6}{*}{ 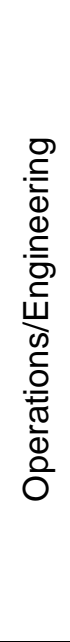 } & 46 & $\begin{array}{l}\text { Thermal protective clothing or } \\
\text { equipment should be available on board }\end{array}$ & Consider & $\begin{array}{l}\text { Flight Crew Equipment contents } \\
\text { definition }\end{array}$ & \\
\hline & 53 & $\begin{array}{l}\mathrm{CO}_{2} \text { monitoring device needs to be } \\
\text { robust and reliable }\end{array}$ & Consider & $\begin{array}{l}\text { Follow design of } \mathrm{CO} 2 \text { monitoring } \\
\text { device }\end{array}$ & \\
\hline & 55 & $\begin{array}{l}\text { Astronaut participation in the design and } \\
\text { development phases of the new } \\
\text { vehicles is essential }\end{array}$ & In Practice & $\begin{array}{l}\text { Currently in practice for } \mathrm{Cx} \text { for each } \\
\text { vehicle and requirements definition. }\end{array}$ & \\
\hline & 56 & $\begin{array}{l}\text { Radio Frequency ID tags should be } \\
\text { considered for stowage items }\end{array}$ & Consider & $\begin{array}{l}\text { Consider design solutions for stowage } \\
\text { tracking }\end{array}$ & \\
\hline & 57 & $\begin{array}{l}\text { Lunar Surface Ascent Module (LSAM) } \\
\text { windows should be designed to see only } \\
\text { what is necessary for landing and/or } \\
\text { rendezvous with IR protection }\end{array}$ & $\begin{array}{l}\text { Being } \\
\text { Evaluated }\end{array}$ & $\begin{array}{l}\text { Requirement in HSIR for non-ionizing } \\
\text { radiation exposure, consider for } \\
\text { LSAM window spec Level } 5 \text { document }\end{array}$ & $\begin{array}{l}\text { HSIR } \\
\text { section } \\
3.2 .8 .3\end{array}$ \\
\hline & 58 & $\begin{array}{l}\text { Design an efficient method for clearing } \\
\text { the lunar dust from the vehicle cabin }\end{array}$ & $\begin{array}{l}\text { Being } \\
\text { Evaluated }\end{array}$ & $\begin{array}{l}\text { HSIR will have a lunar dust exposure } \\
\text { limit. }\end{array}$ & \\
\hline
\end{tabular}




\section{ENVIRONMENTAL IMPACTS}

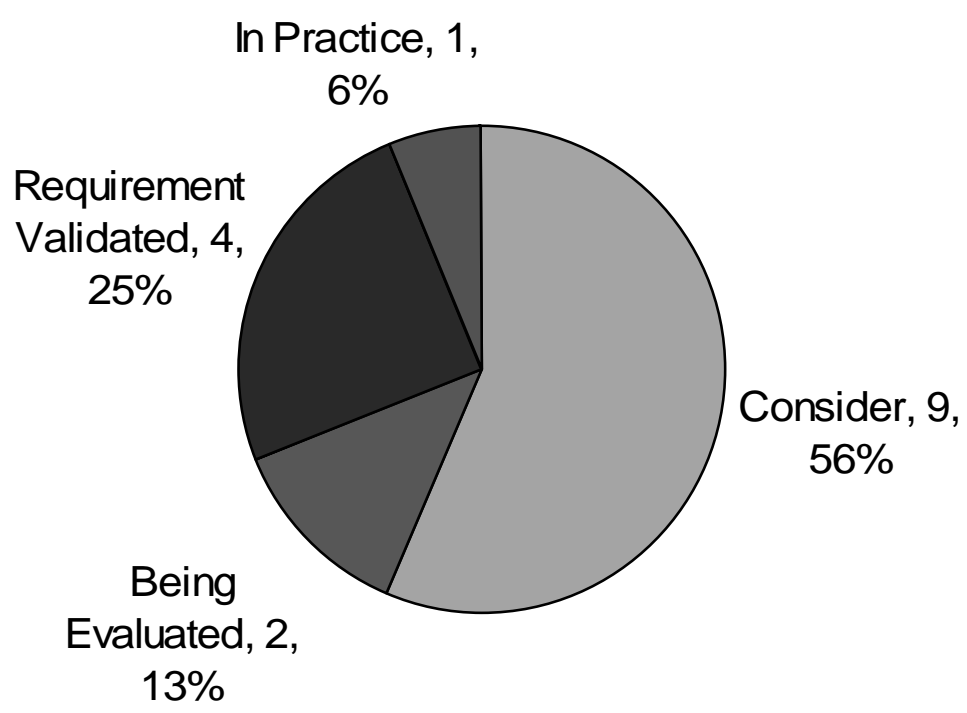

Figure 6. Environmental Impacts

\section{RADIATION}

Apollo astronauts were concerned about radiation detection and contingency plans. They stated that all vehicles, habitats, and suits should have radiation detectors and dosimeters built into them. They also recommended that the rover should contain a radiation shield, lunar astronauts should have the ability to create trenches for solar particle events, and that pharmacological radiation protectants should be made available.

Thanks to Skylab, the shuttle, and the ISS, there is a large body of operational knowledge regarding radiation in low Earth orbit; however, radiation on the surface of the moon is not as well defined. The Apollo astronauts were clearly concerned about radiation, and acknowledged that more research needs to be done in this area. 
Table 8: Radiation Recommendation Implementation

\begin{tabular}{|c|c|c|c|c|c|}
\hline Cat & \# & Apollo Recommendation Summary & Status & Disposition & Reference \\
\hline \multirow{2}{*}{$\begin{array}{l}\frac{}{0} \\
\stackrel{\underline{0}}{0} \\
\frac{\Phi}{0} \\
\stackrel{0}{0}\end{array}$} & 59 & $\begin{array}{l}\text { The lunar excursion vehicle should have an } \\
\text { active radiation detector with an automated } \\
\text { audible alarm that sounds when the dose } \\
\text { rate exceeds a predetermined level }\end{array}$ & $\begin{array}{l}\text { Requirement } \\
\text { Modified }\end{array}$ & $\begin{array}{l}\text { Rover development kicks off in } \\
\text { FY2012 }\end{array}$ & \\
\hline & 60 & $\begin{array}{l}\text { A Personal Radiation Dosimeter is a } \\
\text { requirement for all crewmembers and should } \\
\text { be designed into suit garments }\end{array}$ & Consider & $\begin{array}{l}\text { Radiation requirement in HSIR; Need } \\
\text { also in EVA system and suit } \\
\text { requirements document }\end{array}$ & \\
\hline \multirow{3}{*}{ 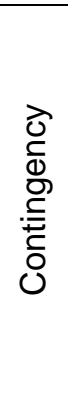 } & 61 & $\begin{array}{l}\text { The rover should be equipped with a } \\
\text { radiation shield }\end{array}$ & Consider & $\begin{array}{l}\text { Consider for rover requirements } \\
\text { document and ARDIG Level 2; being } \\
\text { evaluated by LAT2 surface element }\end{array}$ & \\
\hline & 62 & $\begin{array}{l}\text { Radiation protectants should be made } \\
\text { available to the crewmembers }\end{array}$ & $\begin{array}{l}\text { Being } \\
\text { Evaluated }\end{array}$ & $\begin{array}{l}\text { Cx Medical Kit contents definition } \\
\text { TBD - research not well funded by } \\
\text { NASA at present; some eval by } \\
\text { ExMC and EPSP }\end{array}$ & \\
\hline & 63 & $\begin{array}{l}\text { Create a trench with shovels or explosives to } \\
\text { protect the crew short term in the event of a } \\
\text { Solar Particle Event }\end{array}$ & Consider & $\begin{array}{l}\text { Consider for radiation protection Con } \\
\text { Ops; alternate strategies being } \\
\text { evaluated, }\end{array}$ & \\
\hline
\end{tabular}

\section{RADIATION}

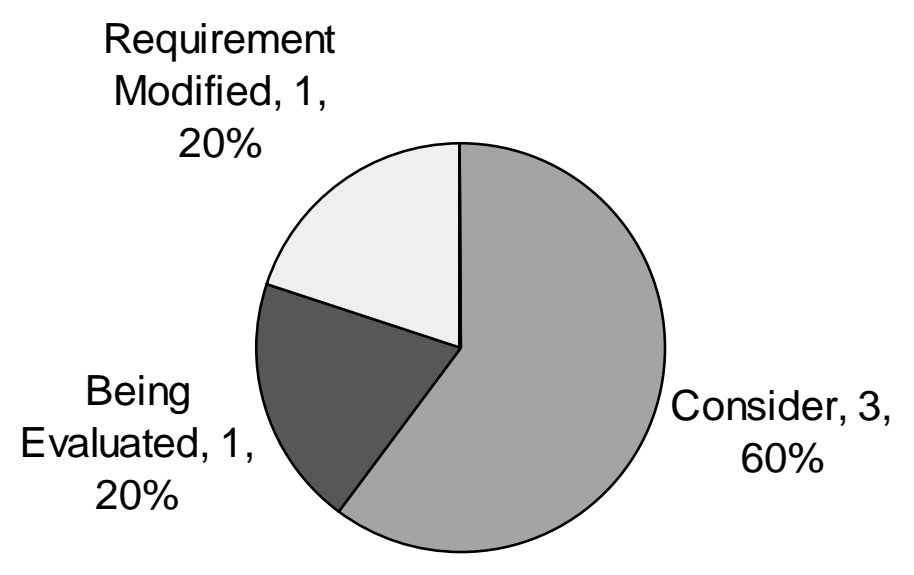

Figure 7. Radiation 


\section{PERFORMANCE/HUMAN FACTORS/CREW SCHEDULE}

Performance/Human Factors/Crew Schedule generated many recommendations. The recommendations can be broken down into mental (and physical) health concerns and operational concerns. The mental health recommendations dealt with rest and relaxation time, sleep, and psychological preparation. A rest and relaxation consensus statement called for 1 day per week for astronaut discretionary use and the implementation of mental and physical rest plans. Some astronauts also requested recreational activities to be available during down time. Interestingly, the astronauts also displayed empathy and concern for the workload of the mission control teams in the form of a recommendation. Regarding sleep, the astronauts stated that the crew sleep periods should be concurrent, that adequate capability for sleep on the lunar surface should be provided, and that sleep medication use should not be stigmatized. They also unanimously agreed that a minimum of 8 hours of sleep per day must be protected. Regarding psychological preparation and well-being for families, the astronauts unanimously agreed that educational and psychological services must be available to them. The Apollo astronauts also recommended that in the event a crewmember death during the mission, all involved must be prepared to "cut them loose." 
Table 9: Performance/Human Factors Recommendation Implementation

\begin{tabular}{|c|c|c|c|c|c|}
\hline Cat & \# & Apollo Recommendation Summary & Status & Disposition & Reference \\
\hline \multirow{7}{*}{ 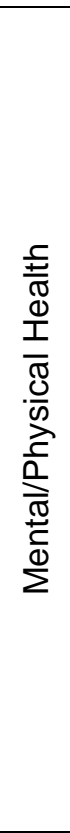 } & 64 & $\begin{array}{l}\text { Recreational activities need to be made } \\
\text { available for crews during Trans Lunar Coast } \\
\text { and Trans Earth Coast and the CMP during } \\
\text { lunar surface operations. }\end{array}$ & Consider & $\begin{array}{l}\text { Private audio and video requirement } \\
\text { in HSIR, recreational requirements in } \\
\text { development }\end{array}$ & $\begin{array}{l}\text { HS6075, } \\
\text { HS6076 }\end{array}$ \\
\hline & 65 & $\begin{array}{l}\text { Mental and physical rest plans should be } \\
\text { introduced into extended moon stays to allow } \\
\text { adequate rest between lunar EVA }\end{array}$ & Consider & & \\
\hline & 67 & $\begin{array}{l}\text { Use of sleeping medication should be } \\
\text { encouraged where appropriate }\end{array}$ & Consider & $\begin{array}{l}\text { Cx MORD and Cx Med Kit definition } \\
\text { TBD }\end{array}$ & \\
\hline & 69 & $\begin{array}{l}\text { Education and psychological services should } \\
\text { be available to the crewmember's families }\end{array}$ & Consider & $\begin{array}{l}\text { BHP Requirements in Cx MORD in } \\
\text { development }\end{array}$ & \\
\hline & 71 & $\begin{array}{l}\text { Provide adequate capabilities for sleeping on } \\
\text { the lunar surface }\end{array}$ & Consider & $\begin{array}{l}\text { Details for sleep station in LSAM are } \\
\text { TBD. }\end{array}$ & \\
\hline & 72 & $\begin{array}{l}\text { If a crewmember dies during the mission you } \\
\text { release the body }\end{array}$ & $\begin{array}{l}\text { Being } \\
\text { Evaluated }\end{array}$ & $\begin{array}{l}\text { Death management and NASA } \\
\text { policy under definition Cx MORD and } \\
\text { Ops Con }\end{array}$ & \\
\hline & 74 & $\begin{array}{l}\text { Consider the impact on the mission control } \\
\text { flight teams and take actions to ensure that } \\
\text { they are rested and provided for during the } \\
\text { lunar missions }\end{array}$ & Consider & $\begin{array}{l}\text { Consider for GRnC and MCC } \\
\text { handbook - TBD }\end{array}$ & \\
\hline \multirow{4}{*}{ 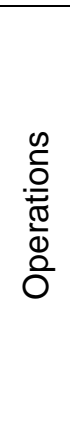 } & 66 & $\begin{array}{l}\text { Mission focus should be project-oriented and } \\
\text { not timelined }\end{array}$ & Consider & $\begin{array}{l}\text { Need to capture this philosophy in } \\
\text { Ops Con for lunar outpost missions } \\
\text { and GRnC TBD }\end{array}$ & \\
\hline & 68 & $\begin{array}{l}\text { Countermeasures to combat mental fatigue } \\
\text { are necessary throughout the mission }\end{array}$ & Consider & $\begin{array}{l}\text { Medical Operation Requirements are } \\
\text { in development. }\end{array}$ & \\
\hline & 70 & $\begin{array}{l}\text { Allow adequate time for all activities in the } \\
\text { schedule }\end{array}$ & Consider & Need GRnC entry for this - TBD & \\
\hline & 73 & $\begin{array}{l}\text { The authority structure is much more } \\
\text { significant than crew size when planning crew } \\
\text { size/makeup }\end{array}$ & Consider & $\begin{array}{l}\text { Consider development of Crew } \\
\text { selection guideline }\end{array}$ & \\
\hline
\end{tabular}




\section{PERFORMANCE/HUMAN FACTORS}

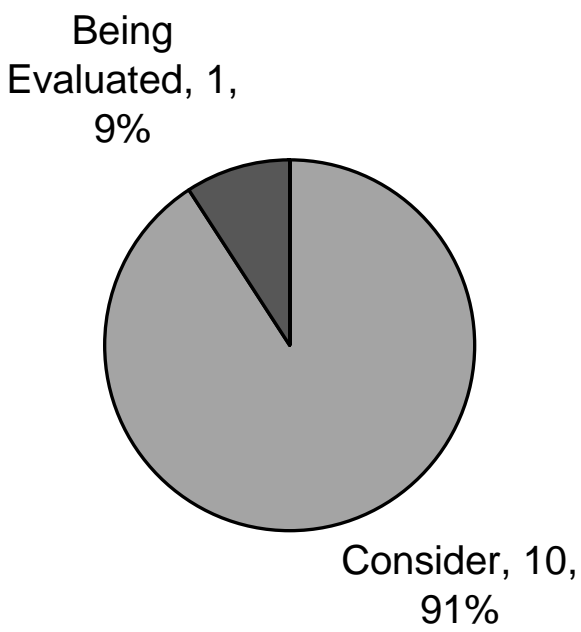

Figure 8. Performance/Human Factors

\section{CREW SCHEDULE}

Operational concerns overwhelmingly focused on scheduling issues. Crews stated that the preflight quarantine was very valuable and that the preflight training schedule must allow the crew time to focus on the mission. They also said that throughout the mission including preflight, countermeasures for mental fatigue are necessary and that adequate time for activities must always be provided. They recommended that the mission focus be project-oriented and not time-lined. The final recommendation emphasized the importance of the crew authority structure over all other concerns of crew resource management or crew composition. 
Table 10: Crew Schedule Recommendation Implementation

\begin{tabular}{|c|c|c|c|c|c|}
\hline Cat & \# & Apollo Recommendation Summary & Status & Disposition & Reference \\
\hline \multirow{2}{*}{ 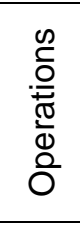 } & 75 & $\begin{array}{l}\text { Preflight quarantine is very valuable because it } \\
\text { allows time for simulations, exercise and rest. }\end{array}$ & Consider & $\begin{array}{l}\text { Need to be built into GRnC and crew } \\
\text { training plan; Preflight timeline is not } \\
\text { in development yet. }\end{array}$ & \\
\hline & 76 & $\begin{array}{l}\text { The pre-flight training schedule should allow for } \\
\text { crews to concentrate on issues that will be } \\
\text { used for the nominal mission }\end{array}$ & Consider & Consider for crew training plan & \\
\hline \multirow{3}{*}{ 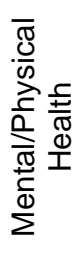 } & 77 & $\begin{array}{l}\text { Lunar crews should have one day a week for } \\
\text { "rest" (freedom to select their activity) }\end{array}$ & Consider & Need GRnC entry for this & \\
\hline & 78 & $\begin{array}{l}\text { An eight hour/day sleep period must be } \\
\text { protected in the daily schedule and must not be } \\
\text { compromised }\end{array}$ & Consider & Need GRnC entry for this & \\
\hline & 79 & $\begin{array}{l}\text { Crew sleep periods should be scheduled at the } \\
\text { same time }\end{array}$ & Consider & Need GRnC entry for this & \\
\hline
\end{tabular}

\section{CREW SCHEDULE}

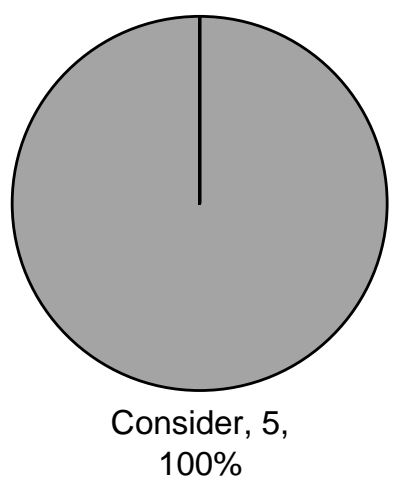

Figure 9. Crew Schedule

\section{EXERCISE}

Recommendations regarding exercise centered on scheduling concerns and the exercise equipment. The Apollo astronauts stated that exercise isn't required on trips less than 14 days from a strength/endurance perspective and that exercise prescriptions for short trips were likewise not necessary. Unanimously they stated that the opportunity to exercise must exist for rest and relaxation during all phases of the mission. They said exercise should be required for longer duration lunar missions but research still needs to be done to determine if $1 / 6 \mathrm{~g}$ alone provides any benefit to the musculoskeletal or cardiovascular system. They said that scheduling needs to allocate time for preflight conditioning and that a preflight and in-flight forearm conditioning program be included. The exercise equipment, Exer-Genie, on Apollo missions was considered sub-par, and the astronauts 
unanimously declared that new exercise devices should be reliable, simple, and safe. They also encouraged that as much exercise variety be built into the vehicle and equipment as possible.

Table 11: Exercise Recommendation Implementation

\begin{tabular}{|c|c|c|c|c|c|}
\hline Cat & \# & Apollo Recommendation Summary & Status & Disposition & Reference \\
\hline \multirow{4}{*}{ 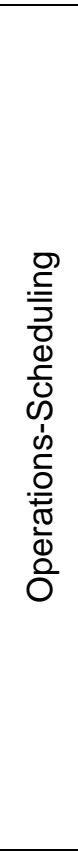 } & 80 & $\begin{array}{l}\text { Loosen the pre-mission timeline to } \\
\text { allow adequate time for pre-flight } \\
\text { conditioning program }\end{array}$ & Consider & $\begin{array}{l}\text { Need to be built into GRnC and } \\
\text { crew training plan; CxMORD has } \\
\text { preflight conditioning as does the } \\
\text { Space Flight Health Document }\end{array}$ & \\
\hline & 82 & $\begin{array}{l}\text { The flight surgeon/mission planners } \\
\text { should not plan specific exercise } \\
\text { prescriptions for short duration }(<14 \\
\text { days) mission }\end{array}$ & $\begin{array}{l}\text { Being } \\
\text { Evaluated }\end{array}$ & $\begin{array}{l}\text { Not consistent with SA position } \\
\text { (we say }<8 \text { days) HSIR } \\
\text { requirement for exercise for all } \\
\text { missions }>8 \text { days. }\end{array}$ & HS6032 \\
\hline & 83 & $\begin{array}{l}\text { Exercise is not necessary on short trips } \\
\text { ( } 14 \text { days or less) [from a fitness } \\
\text { standpoint], however, crews demanded } \\
\text { that the capability be available and } \\
\text { varied as much as possible for crew } \\
\text { "rest and relaxation" in all phases of the } \\
\text { mission }\end{array}$ & $\begin{array}{l}\text { Requirement } \\
\text { Modified }\end{array}$ & $\begin{array}{l}\text { Not completely consistent with } \\
\text { current requirement; HSIR } \\
\text { requirement to begin exercise as } \\
\text { soon as practical }\end{array}$ & HS6032 \\
\hline & 84 & $\begin{array}{l}\text { Develop a better pre-flight and in-flight } \\
\text { forearm muscle conditioning program } \\
\text { for lunar crewmembers }\end{array}$ & Consider & $\begin{array}{l}\text { ASCR pre-flight prep document to } \\
\text { be revised from current ISS } \\
\text { document for exploration missions. } \\
\text { Strength/endurance requirements } \\
\text { for mission tasks being developed } \\
\text { by ECP }\end{array}$ & \\
\hline \multirow{4}{*}{ 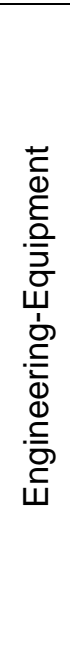 } & 81 & $\begin{array}{l}\text { A more robust (and lightweight) piece } \\
\text { of in-flight exercise equipment is } \\
\text { needed (The Apollo Exer-Genie was } \\
\text { unsatisfactory) }\end{array}$ & $\begin{array}{l}\text { Requirement } \\
\text { Validated }\end{array}$ & $\begin{array}{l}\text { Requirement in HSIR; Hardware } \\
\text { definition under evaluation by ECP }\end{array}$ & HS6032 \\
\hline & 85 & $\begin{array}{l}\text { New vehicle design should allow a } \\
\text { variety of different exercise capabilities } \\
\text { (hardware vs. cabin structure) }\end{array}$ & $\begin{array}{l}\text { Requirement } \\
\text { Modified }\end{array}$ & $\begin{array}{l}\text { Requirement in HSIR; need } \\
\text { outpost exercise requirements in } \\
\text { Level } 3 \text { Lunar Outpost } \\
\text { Requirements }\end{array}$ & HS6032 \\
\hline & 86 & $\begin{array}{l}\text { Put as many [exercise] capabilities in } \\
\text { the vehicle as possible, because it will } \\
\text { get used }\end{array}$ & Consider & $\begin{array}{l}\text { Need outpost exercise guidelines } \\
\text { in Level } 3 \text { Outpost Requirements; } \\
\text { Lunar Habitat Team earmarking } \\
\text { exercise area in habitat. H/w under } \\
\text { eval by ECP }\end{array}$ & \\
\hline & 87 & $\begin{array}{l}\text { New exercise device should be reliable, } \\
\text { simple and not develop excessive heat } \\
\text { in use }\end{array}$ & $\begin{array}{l}\text { Requirement } \\
\text { Modified }\end{array}$ & $\begin{array}{l}\text { Requirement in HSIR; Hardware } \\
\text { definition under evaluation by ECP }\end{array}$ & HS60321 \\
\hline
\end{tabular}




\section{EXERCISE}

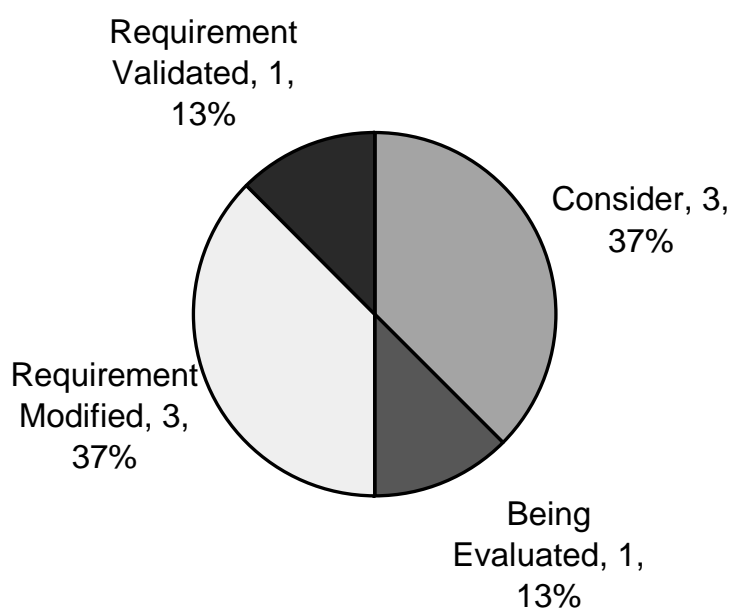

Figure 10. Exercise

\section{FOOD/NUTRITION}

The food/nutrition category garnered a number of recommendations. The astronauts commented on nutritional requirements, taste preferences, logistics, and operations. The astronauts unanimously agreed that mission activity dictates the type and amount of food that will be consumed. They also were unanimous in recommending ample water availability for LEVAs and stated that an in-suit source of carbohydrates would be helpful. They recommended that for long duration missions diet and consumption schedule would need to be carefully optimized. Regarding food flavor, the astronauts preferred spicy and salty foods and suggested research into how different environmental factors affect food flavor. There was unanimous agreement that Operations needs to schedule adequate time for meals and the new vehicle should allocate space to store food packs during meals.

Table 12: Food/Nutrition Recommendation Implementation

\begin{tabular}{|c|c|c|c|c|c|}
\hline Cat & \# & Apollo Recommendation Summary & Status & Disposition & Reference \\
\hline \multirow[t]{2}{*}{ 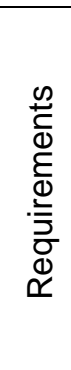 } & 88 & $\begin{array}{l}\text { Mission activity (e.g., coast, rendezvous, } \\
\text { lunar orbit, lunar ops) will dictate what type } \\
\text { and how much food will be consumed. } \\
\text { High Activity: wet packages, bite-sized } \\
\text { snacks, canned foods } \\
\text { Low Activity: spoon bowls, dry juice or } \\
\text { meals (rehydratable) requiring mixing, etc. }\end{array}$ & $\begin{array}{l}\text { Being } \\
\text { Evaluated }\end{array}$ & $\begin{array}{l}\text { Nutrition requirements will be in } \\
\text { Food system specification is in } \\
\text { development }\end{array}$ & \\
\hline & 89 & $\begin{array}{l}\text { Plain water in large quantities needs to be } \\
\text { available for lunar EVA }\end{array}$ & $\begin{array}{l}\text { Requirement } \\
\text { Validated }\end{array}$ & Requirement in HSIR & HS6063 \\
\hline
\end{tabular}




\begin{tabular}{|c|c|c|c|c|c|}
\hline \multirow[b]{3}{*}{ 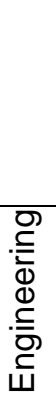 } & 90 & $\begin{array}{l}\text { Optimize diet and food intake for overall } \\
\text { performance during long duration missions }\end{array}$ & $\begin{array}{l}\text { Being } \\
\text { Evaluated }\end{array}$ & Requirements will be in HSIR & \\
\hline & 91 & $\begin{array}{l}\text { An in-suit non-caffeinated solid or liquid } \\
\text { carbohydrate food source for lunar EVA } \\
\text { would be helpful. }\end{array}$ & $\begin{array}{l}\text { Being } \\
\text { Evaluated }\end{array}$ & $\begin{array}{l}\text { Under evaluation by EPSP and } \\
\text { ExMC }\end{array}$ & \\
\hline & 92 & $\begin{array}{l}\text { Design adequate space an useful area in } \\
\text { the new vehicles to store food packs } \\
\text { during meals }\end{array}$ & Consider & $\begin{array}{l}\text { Stowage requirement in HSIR, } \\
\text { Stowage System specification is in } \\
\text { development }\end{array}$ & $\begin{array}{l}\text { HSIR } \\
\text { section } \\
3.5 .6\end{array}$ \\
\hline \multirow[b]{2}{*}{$\frac{\stackrel{ \pm}{\frac{\pi}{\sigma}}}{\Delta}$} & 93 & $\begin{array}{l}\text { Spicy and salty foods were preferred items } \\
\text { in the menu }\end{array}$ & Consider & Food system in development & \\
\hline & 95 & $\begin{array}{l}\text { Determine how different environmental } \\
\text { factors (e.g., } \mathrm{O}_{2} \text { concentration, cabin } \\
\text { pressure) effect food flavor }\end{array}$ & Consider & Need research topic for HRP & \\
\hline$\stackrel{2}{0}$ & 94 & $\begin{array}{l}\text { Allow adequate time in the daily schedule } \\
\text { for meals }\end{array}$ & Consider & Need GRnC entry for this & \\
\hline
\end{tabular}

\section{FOOD/NUTRITION}

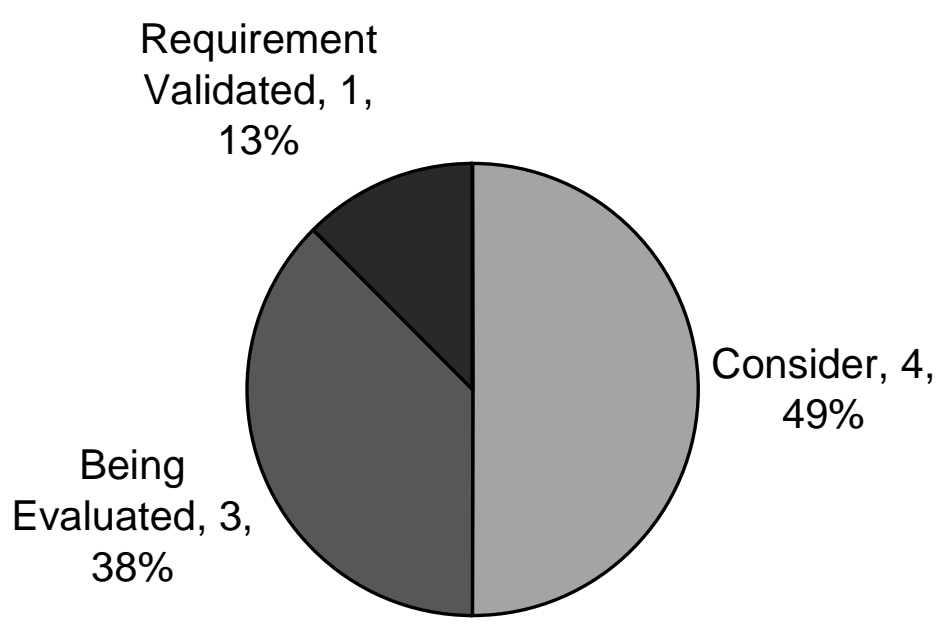

Figure 11. Food/Nutrition 


\section{LAUNCH, LANDING, AND RECOVERY OPERATIONS}

Launch/Landing/Recovery Operations was broken down into discussions regarding a sea recovery, operations, and engineering ergonomic concerns. Many of the astronauts discouraged ground landings and stated that cooling capability on landing was required to mitigate sea sickness. They also stated that food and water must be within reach of buckled crewmembers in the event of a delayed recovery. Additionally, they stated that the Apollo seats were adequate for water landings and that medications for motion sickness and fatigue should be available prior to re-entry. Operationally, the Apollo astronauts wanted to see a flight rule to limit sea state landings to $<6-8$ foot swells if recovery is to be delayed. It was also stated that the crew surgeon best fulfills his duty from the recovery vessel not the helicopter. Training for launch pad aborts were thought to be adequate. Regarding engineering ergonomics the astronauts felt that the $\mathrm{CM}$ hatch location and size were adequate and that all switches and panels should be reachable during launch and landing. With regards to the landing suits, the crews were in the constant wear garments, not the pressure suits. At some point the program decided that separation of the SM from the CM was not a true "change of configuration" that posed a significant hazard, hence they did not feel the need to wear the pressurized suits.

\section{Table 13: Launch, Landing, and Recovery Operations Recommendation Implementation}

\begin{tabular}{|c|c|c|c|c|c|c|}
\hline Cat & \# & & Apollo Recommendation Summary & Status & Disposition & Reference \\
\hline \multirow{4}{*}{ 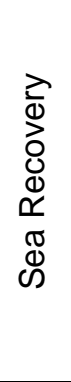 } & 96 & & $\begin{array}{l}\text { Provide adequate cooling capabilities for the } \\
\text { crew on landing to mitigate the hot cabin } \\
\text { contribution to crewmember sea sickness }\end{array}$ & $\begin{array}{l}\text { Being } \\
\text { Evaluated }\end{array}$ & $\begin{array}{l}\text { Cabin environment requirement in } \\
\text { HSIR; } 36 \text { hr post-landing tiger team } \\
\text { working details of ECLSS, suit, etc. }\end{array}$ & \\
\hline & 97 & & Ground landings discouraged & $\begin{array}{l}\text { Being } \\
\text { Evaluated }\end{array}$ & $\begin{array}{l}\text { Land vs. water tiger team weighing } \\
\text { trades }\end{array}$ & \\
\hline & 98 & & $\begin{array}{l}\text { Apollo seat configuration for water landings } \\
\text { were adequate: the restraint system needs } \\
\text { to include loose equipment items }\end{array}$ & $\begin{array}{l}\text { a. Consider } \\
\text { b. Req } \\
\text { validated }\end{array}$ & $\begin{array}{l}\text { a. Seat design still TBD } \\
\text { b. In HSIR }\end{array}$ & $\begin{array}{l}\text { b. HSIR } \\
\text { section } \\
3.5 .6\end{array}$ \\
\hline & 99 & & $\begin{array}{l}\text { Medication for motion sickness and fatigue } \\
\text { will be available prior to re-entry }\end{array}$ & Consider & $\begin{array}{l}\text { Medical Operation Requirements are in } \\
\text { development }\end{array}$ & \\
\hline \multirow{3}{*}{ 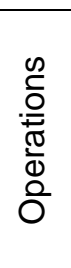 } & 100 & & $\begin{array}{l}\text { Flight rule should limit sea state to }<6-8 \text { foot } \\
\text { swells if recovery is to be delayed }\end{array}$ & Consider & $\begin{array}{l}\text { Cx DSNE defines sea state for vehicle; } \\
\text { Ground Ops con defines recovery } \\
\text { strategy }\end{array}$ & \\
\hline & 104 & & $\begin{array}{l}\text { Training for pad abort was adequate and } \\
\text { should be continued }\end{array}$ & Consider & Need to include in crew training plan & \\
\hline & 105 & & $\begin{array}{l}\text { Crew surgeon should be on the recovery } \\
\text { vessel and not the helicopter }\end{array}$ & Consider & $\begin{array}{l}\text { Details will be in Mission Operation Site } \\
\text { Implementation Plans (MOSIPs) }\end{array}$ & \\
\hline \multirow{4}{*}{ 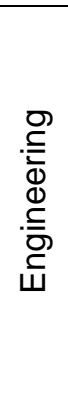 } & 101 & & $\begin{array}{l}\text { Have food and plain water within reach of } \\
\text { buckled crewmembers for delayed recovery }\end{array}$ & Consider & $\begin{array}{l}\text { Need to add requirement to HSIR and } \\
\text { CEV SRD and } 36 \text { hour post-survival } \\
\text { Tiger Team }\end{array}$ & \\
\hline & 102 & a) & $\begin{array}{l}\text { Apollo Command Module hatch location and } \\
\text { size was adequate for egress }\end{array}$ & $\begin{array}{l}\text { Requirement } \\
\text { Validated }\end{array}$ & $\begin{array}{l}\text { Hatch requirements in HSIR, vehicle } \\
\text { specific hatch dimension in SRD }\end{array}$ & HS5004 \\
\hline & & b) & $\begin{array}{l}\text { Hatch should open outward and seal with } \\
\text { pressure }\end{array}$ & Consider & Hatch design is TBD & HS5014 \\
\hline & 103 & & $\begin{array}{l}\text { All control panels and switches should be } \\
\text { within reach of crewmembers during launch } \\
\text { and landing }\end{array}$ & $\begin{array}{l}\text { Requirement } \\
\text { Validated }\end{array}$ & Cockpit requirements in HSIR; & $\begin{array}{l}\text { HSIR } \\
\text { section } \\
\text { 3.6.3.2 }\end{array}$ \\
\hline
\end{tabular}




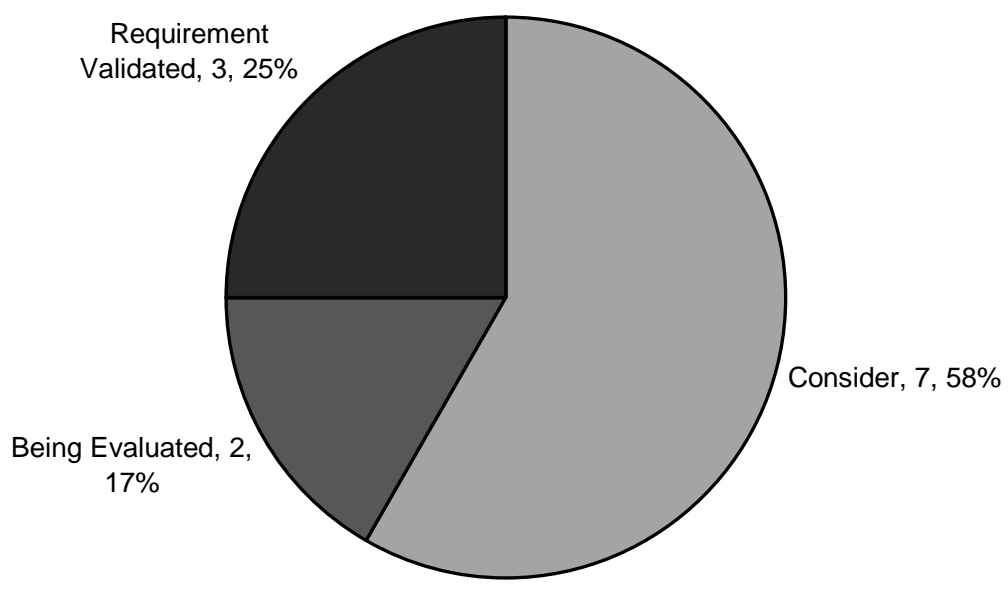

Figure 12. Launch, Landing, and Recovery Operations

\section{FLIGHT SURGEON-CREW INTERACTION}

The crews stated that the flight surgeon needs to act as an advocate for the crew and that the collaboration resulting from this interaction between the flight surgeons and the Apollo astronauts should continue and be an example to future generations.

Table 14: Flight Surgeon-Crew Interaction Recommendation Implementation

\begin{tabular}{|c|c|c|c|c|c|}
\hline Cat & \# & Apollo Recommendation Summary & Status & Disposition & Reference \\
\hline \multirow{2}{*}{ 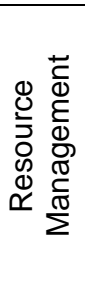 } & 106 & $\begin{array}{l}\text { Crew encouraged FS to "act as more of } \\
\text { an advocate of the crew" than treat them } \\
\text { as an experiment }\end{array}$ & In Practice & Currently in practice & \\
\hline & 107 & $\begin{array}{l}\text { The collaboration established between } \\
\text { the current flight surgeons and Apollo } \\
\text { crewmembers should continue and be an } \\
\text { example to future generations }\end{array}$ & Consider & Agree and concur & \\
\hline
\end{tabular}


FLIGHT SURGEON-CREW INTERACTION

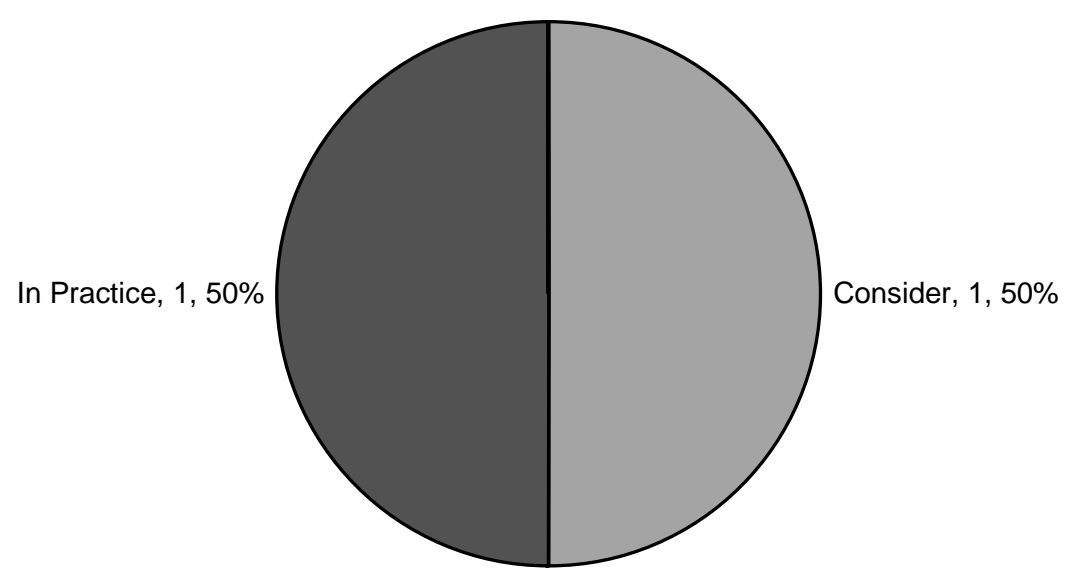

Figure 13. Flight Surgeon-Crew Interaction 


\section{SUMMARY DISPOSITION of RECOMMENDATIONS}

Overall, the 107 recommendations received were dispositioned into the following categories: consider, being evaluated, new requirements, requirement being modified, requirement validated, rejected, and in practice, The specific distribution of the recommendations is detailed in Table 15.

Table 15. Disposition of recommendations

\begin{tabular}{|l|c|c|}
\hline \multicolumn{1}{|c|}{ Category } & $\begin{array}{c}\text { Number of } \\
\text { Recommendations }\end{array}$ & Percentage \\
\hline Consider & 54 & $47 \%$ \\
\hline Being Evaluated & 34 & $30 \%$ \\
\hline New Requirement & 2 & $2 \%$ \\
\hline Requirement Modified & 5 & $4 \%$ \\
\hline Requirement Validated & 12 & $11 \%$ \\
\hline Ops Con Validated & 2 & $2 \%$ \\
\hline Rejected & 0 & $0 \%$ \\
\hline In Practice & 4 & $4 \%$ \\
\hline Totals: & $\mathbf{1 1 3}$ & $\mathbf{1 0 0 \%}$ \\
\hline
\end{tabular}

Note that a few recommendations were broken down into multiple recommendations. Therefore, 113 recommendations were dispositioned as opposed to 107 . It was determined that cumulatively $23 \%$ of the recommendations resulted in a validation or modification, or development of a new requirements or was currently in practice. While $77 \%$ of the recommendations are being considered or evaluated. Of this $77 \%$, being considered or evaluated, there is potential for additional requirements to be further modified, validated, or created. Hence, we see that many of the experiences of the Apollo astronauts have been considered relevant, and have impacted the exploration architecture. 


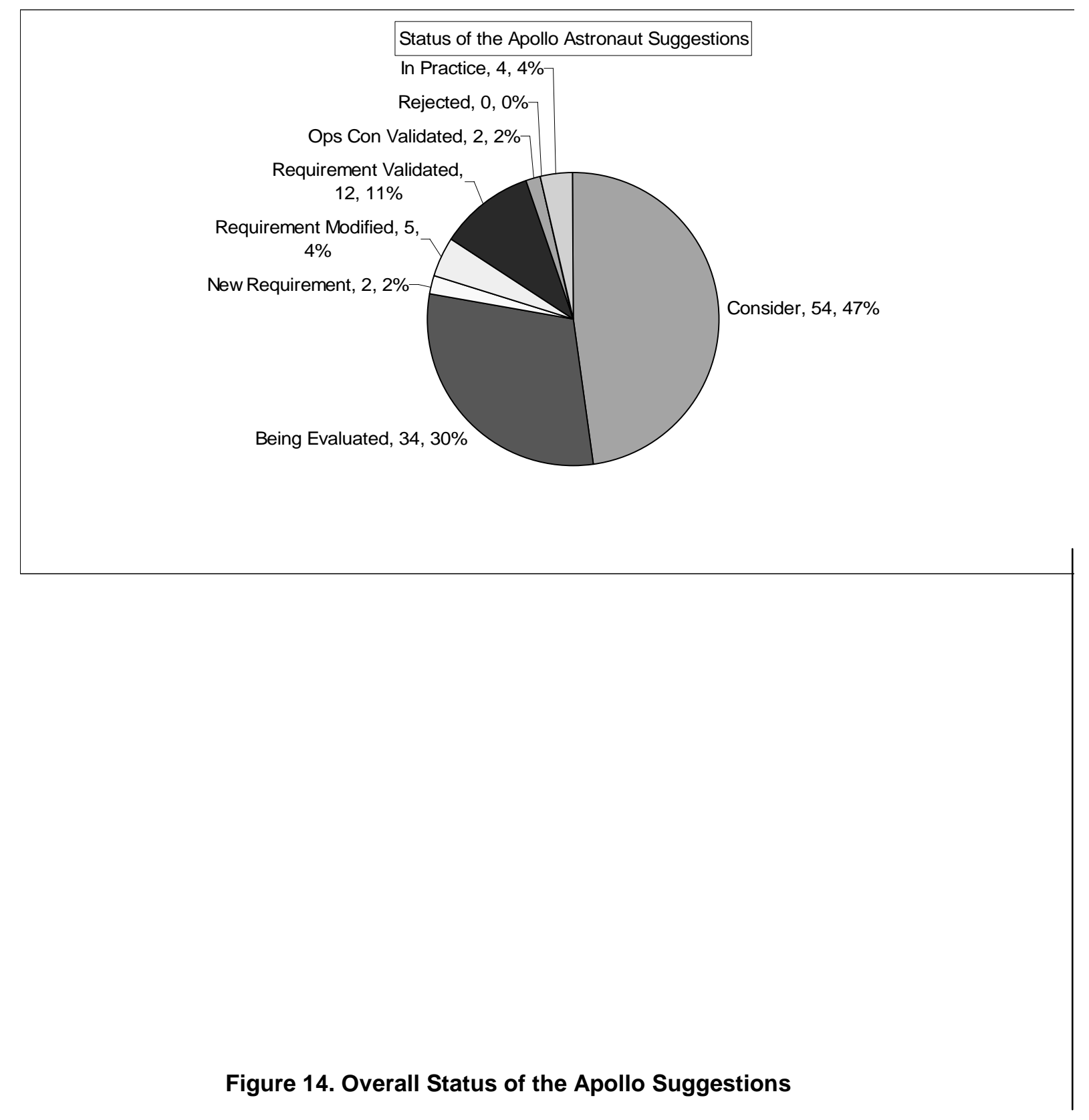




\subsection{CONCLUSION}

The Apollo Medical Operations Project was designed to identify relevant medical operational issues from the Apollo mission issues which had an impact on crew health and/or performance. The goals of this project were to develop or modify medical requirements for new vehicles and habitats, create a centralized database for future access, and to have the capability to share relevant Apollo information with various entities at NASA and abroad participating in the exploration effort. Secondary objectives included using this information to validate current requirements and refresh knowledge regarding lunar operations.

The theme of the Apollo astronauts' 107 recommendations is res ipsa loquitur or "the thing speaks for itself." As one of the astronauts said, "Start with what worked on Apollo, and then prove to me why something should be different." The authors likewise feel that the information gleaned from Apollo astronauts' operational experiences is relevant even though the exploration missions have objectives that differ. In other words, the exploration missions are not "Apollo 18." The recommendations contained within this document have broad implications for mission directors, engineers, astronauts, physicians, administrators, and anyone involved in exploration missions. Organizations within the Space Life Sciences Directorate such as the Human Research Program (HRP) have taken action in response to many of the recommendations. Currently, operational solutions to mission relevant problems and issues identified by the Apollo astronauts which affected crewmember health and/or performance are being developed. The HRP has funded specific programs, such as the EVA Physiology and Performance Project (EPSP), Exploration Medical Capabilities (ExMC) and Exercise Countermeasures Program (ECP) to develop hardware or systems based on the results of the Apollo Medical Operations Project. It is important to point out that the EPSP members are currently contributing to the Lunar Architecture Team (LAT) phase 2 study which is addressing issues such as crew habitat concerns, airlocks/suitlocks, suit and habitat radiation protection, EVA navigation and guidance, suit design, and operations.

It is the authors' vision that the recommendations presented here be evaluated by all relevant departments and that the appropriate recommendations become requirements resulting in improved mission operations. Currently, $23 \%$ of the recommendations have resulted in development, modification, or validation of requirements or are currently in practice, $77 \%$ are being considered or evaluated, and no recommendations have been rejected. It is incumbent on all who read this document to keep the $77 \%$ from falling by the waste side.

Future work in this area may includes ongoing dialogue with the Apollo astronauts and additional questionnaire follow-ups to solicit their opinions regarding specific mission operations and implementation of their recommendations. The authors hope that the operationally relevant outcomes of the Apollo Medical Operations Project and other studies like it will contribute significantly to the success of the nation's vision and the Constellation goal of exploring the moon, Mars, and beyond. 


\subsection{REFERENCES}

1. Taylor LA, Schmitt HH, et. al. The Lunar Dust Problem: From Liability to Asset. $1^{\text {st }}$ Space Exploration Conference, AIAA 2005-2510. 30 January-1 February 2005, Orlando, FL.

2. Connors MM, Eppler DB, Morrow DG. Interviews with the Apollo Lunar Surface Astronauts in Support of Planning for EVA Systems Design. NASA TM 108846. Ames Research Center, CA September, 1994.

3. Apollo Lunar Surface Journal (Online at http://history.nasa.gov/alsj/).

4. Lunar Sourcebook: A User's Guide to the Moon. Cambridge University Press 1991.

5. Biomedical Results of Apollo. NASA SP-368. Washington, D.C.1975.

6. Apollo Unmanned Missions (Online at http://wwwpao.ksc.nasa.gov/history/apollo/apollosat-unmanned.htm).

7. http://www1.jsc.nasa.gov/er/seh/ricetalk.htm

8. GWB Mandate for Space Exploration, January 2004 (Online at http://www.nasa.gov/pdf/55584main_vision_space_exploration-hi-res.pdf ).

9. Biomedical Results of Skylab. NASA SP-377. Washington, D.C. 1977)

10. Results of the Lunar Architecture Team (LAT) phase 1 study. (Online at)

11. Interview with Alan Bean (Online at http://sf.jsc.nasa.gov/pastproged.aspx).

12. Preliminary Science Reports (Online at http://www.history.nasa.gov/alsj/alsjpsrs.html)

13. Apollo Mission Reports (Online at http://history.nasa.gov/alsj/alsj-mrs.html).

14. Wagner SA. The Apollo Experience Lessons Learned for Constellation Lunar Dust Management. NASA/TP-20060213726. Johnson Space Center, September, 2006.

15. Berry CA. Medical Legacy of Apollo. Aerospace Med. 45(9):1046-1057, 1974.

16. What Made Apollo a Success? NASA-SP-287. NASA Scientific and Technical Information Office, Washington, D.C., 1971.

17. Smith MC, Rapp RM, et. al. Apollo Experience Report-Food Systems. NASATN-D-7720. Johnson Space Center, Houston, Texas, 1974.

18. Portee DSF, Trevino RC. Walking to Olympus: An EVA Chronology. NASA History Office, Washington, D.C., October, 1997.

19. Collins M. Carrying the Fire. Farrar, Straus, and Giroux, NY. 1974.

20. Schmitt HH, Reid DJ. Anecdotal Information on Space Adaptation Syndrome. NASA/Space Biomedical Research Institute USRA/Division of Space Biomedicine. July, 1985.

21. Recommendations for fluid replacement during prolonged exercise. American College of Sports Medicine's Guidelines for Exercise Testing and Prescription, $6^{\text {th }}$ Ed. Lippincott, Williams \& Wilkins, 2000. 
22. Williams DR, Johnson BJ. EMU Should Injury Tiger Team Report. NASA Technical Memorandum, available from the NASA Center for Aerospace Information (CASI), September, 2003.

23. Scheuring RA, Mathers $\mathrm{CH}$, et. al. In-flight Musculoskeletal Injuries in the U.S. Space Program: A Comprehensive Summary of Data and Injury Mechanism. 2007. Pending Publication.

24. Scheuring RA, Walton M, et. al. Recommendations from NASA's Operational and Research Musculoskeletetal Summit. Aviat., Space and Environ Med. Vol. 78, No. 3, March, 2007.

25. Radiation lessons from Apollo (Online at http://sf.jsc.nasa.gov/pastproged.aspx). 


\section{APPENDIX A \\ NON ATTRIBUTABLE ACCESS DATA RECORDS}




\section{Appendix A \\ Apollo Summit Non-Attributable Report}

\section{Source: \\ Topic: \\ Issue: \\ Description: \\ General \\ Comments: \\ Resolved: \\ If Resolved - how, when, where?}

BME logs

Lunar EVA

debrief

Don't get tired but thirsty. The thirst is due to dry throat in LM suit. Need more fresh water capacity in the suit.

Additional Is the air in the suit humidified enough? Did you have enough to drink in the suit? Questions: Was what you had adequate?

Summit Topic: Yes

\section{Source: \\ Topic: \\ Issue: \\ Description: \\ General \\ Comments: \\ Resolved: \\ If Resolved how, when, where?}

Additional Questions:
BME logs

Lunar EVA

EMU

EMU's also "hot"

Summit Topic: Yes

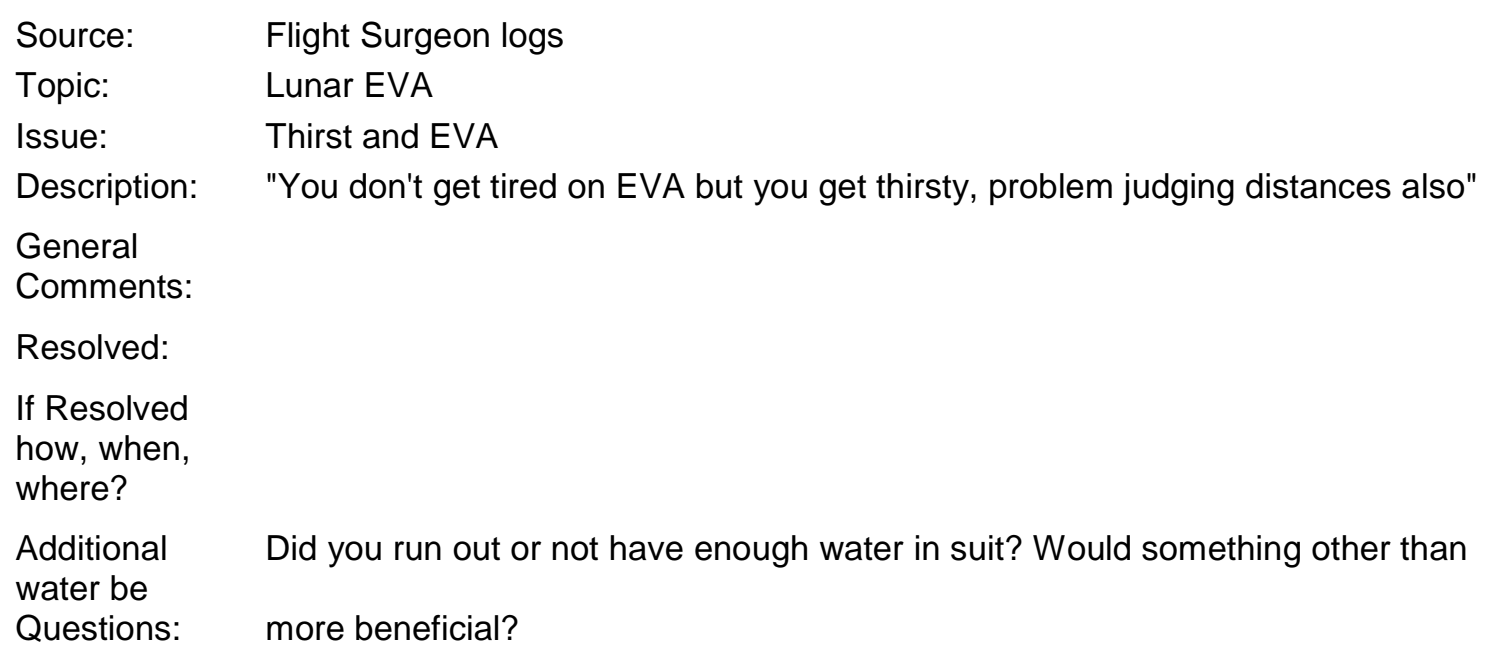




\section{Appendix A \\ Apollo Summit Non-Attributable Report}

Summit Topic: Yes

Source: $\quad$ Flight Surgeon logs

Topic: Lunar EVA

Issue: falling

Description: reports of falling several times during EVA

General

Comments:

Resolved:

If Resolved

how, when,

where?

Additional How could falling be prevented? Is the suit made to withstand falls?

Questions: How hard was the perceived fall?

Summit Topic: Yes

\section{Source: $\quad$ Flight Surgeon logs}

Topic: Lunar EVA

Issue: odor

Description: "Odor thought to be lunar material"

General

Comments:

Resolved:

If Resolved

how, when,

where?

Additional Was this so bad as to affect your mission performance?

Questions:

Summit Topic: Yes

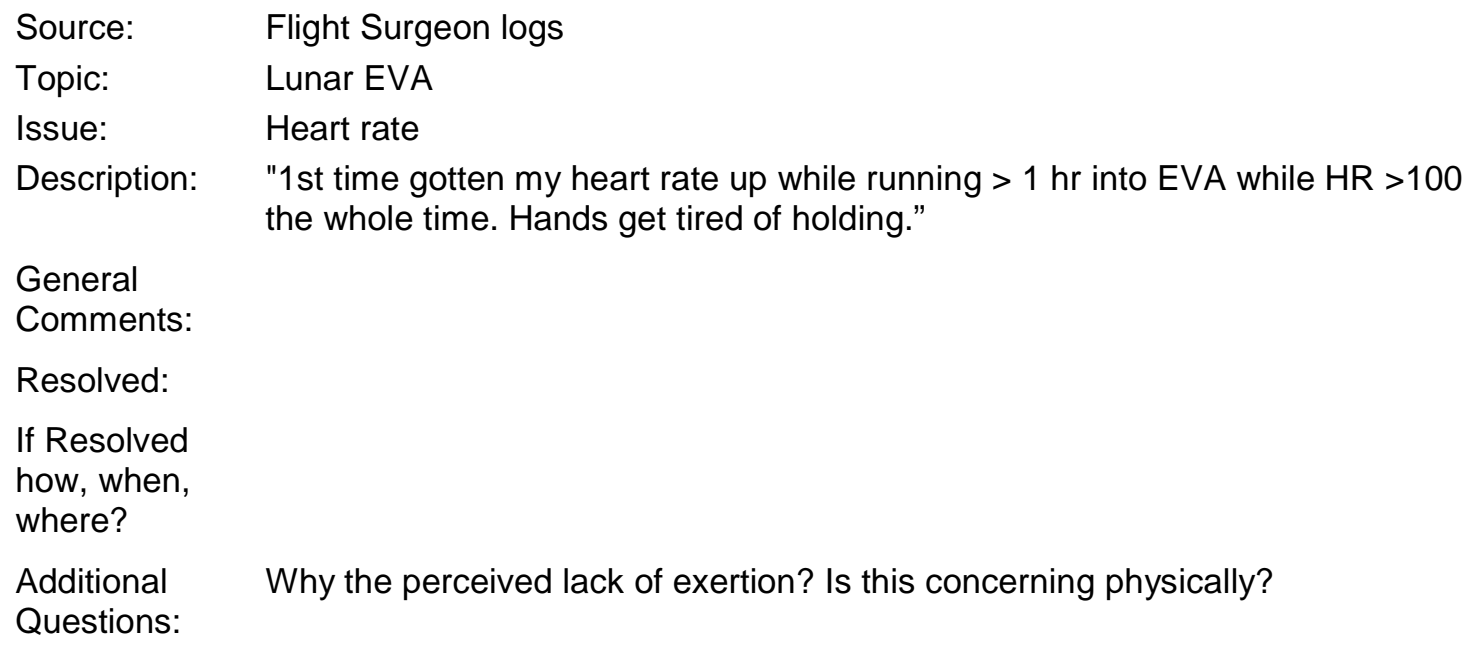

General

Comments:

Resolved:

If Resolved how, when, where?

Additional Why the perceived lack of exertion? Is this concerning physically?

Questions: 


\section{Appendix A Apollo Summit Non-Attributable Report}

Summit Topic: Yes

Source: Medical Mission Debriefs

Topic: Lunar EVA

issue: $\quad$ falling

Description: CDR: Falling over was no big deal. After the first ten minutes had no problem with staying vertical etc. "you adapt real well up there."

LMP: after 5 minutes of first EVA, didn't need to 'watch' CG, moving about was natural. You fall so slowly you have time to catch yourself usually.

CDR: Could have used a tether to go into a steep crater, maybe 20-25 degree slopes. Soil never had a tendency to slip out from underneath you. Never noticed feet slipping.

General

Comments:

Resolved:

If Resolved

how, when,

where?

Additional

Questions: Identify risk factors for injuries.

Summit Topic: Yes

\section{Source: $\quad$ Medical Mission Debriefs}

Topic: Lunar EVA

Issue: Sweating

Description: LMP: Couldn't work up a sweat during Moon-can't work that hard. On Earth in the centrifuge LMP could work hard enough to require MAX cooling in the suit, but rarely used a short period of intermediate cooling ( 3 times) on the moon

CDR: Used intermediate cooling very little, seated some, but not enough to notice wet feet or anything like that. Inner liners of gloves were always soaked, no good cooling down there.

General

Comments:

Resolved:

If Resolved

how, when, where?

Additional

Questions:

Summit Topic: Yes 


\title{
Appendix A Apollo Summit Non-Attributable Report
}

\author{
Source: $\quad$ Medical Mission Debriefs \\ Topic: Lunar EVA \\ Issue: heart rates \\ Description: Both CDR and LMP thought their EVA heart rate peaks were about $20 \mathrm{bpm}$ \\ below what monitored rates showed. \\ CDR: You will run wherever you move to on the Moon. So plan every 1200 feet \\ to stop and rest for about 2 minutes. \\ General Dr. Berry noted that during the short LM rest periods, the heart rate did not return \\ to a \\ Comments: resting rate before activity was resumed. CDR pointed out that during some of \\ the 'rest' periods, they were actually working hard, even though they weren't \\ running. There were always tasks that needed doing to meet the timeline. \\ Resolved: \\ If Resolved \\ how, when, \\ where? \\ Additional \\ Questions: Should lunar activity timeline be project oriented? \\ Summit Topic: Yes

\section{Source: Medical \\ Topic: Lunar EVA \\ Issue: workload \\ Description: LMP: Walking around was a low effort, "near the very lowest end of what you do on the bike." \\ "You can't seem to work too hard up there." Work is limited by the pressure suit. Max effort was either carry out the ASLEP or coming out of the crater. go fast on the bike." \\ CDR: Two times he was tired, one of the times more thirsty than tired, the other was a long run from Sharp crater over to Halo crater." Carrying weight (rocks or equipment) and climbing out of a crater required pacing and a stop of 1 hours in the LM unnecessarily when they could have been continuing the EVA. \\ CDR: never felt heart rate go above 100--could have gone all day at that work level \\ Second EVA involved more arm work, working with equipment, always moving. Heart rates higher on $2^{\text {nd }}$ EVA. While running CDRand LMP had HR $>170$. \\ LMP: Felt like 125 or so while running.} \\ Those max work levels were "about equal to a little more than half as hard as you \\ minute and a "shot of that intermediate cooling" was enough to go on. Spent 2 \\ General Hands tired after 2nd EVA \\ Comments: \\ Resolved: \\ If Resolved how, when, where? \\ Additional Questions: \\ Summit Topic: Yes
}




\title{
Appendix A Apollo Summit Non-Attributable Report
}

\author{
Source: $\quad$ Medical Mission Debriefs \\ Topic: Lunar EVA \\ Issue: Physical Effect \\ Description: a) Effort during LEVA was described as minimal or low-compared to exercise \\ effort on bicycle pre-flight \\ b) Only increase in physical effort came with climbing out of the crater and long \\ run between Sharp crater and Halo crater \\ -only required crew to rest for approximately a minute before resuming \\ activity. \\ -HR averaged $100 \mathrm{bpm}$, varied with exercise between 120-170 bpm, during \\ the $2^{\text {nd }}$ LEVA \\ -effort was similar to POGO training activity \\ -crew felt they could have easily performed EVA for an additional 3-4 hours \\ c) Sweat was minimal in the suit and was greatly reduced by adjusting vent/cover \\ to max \\ -hands did sweat in the gloves secondary to lack of cooling \\ -glove liners were soaked with sweat; apparently learned from Apollo 11 \\ experience \\ d) crew fell 1-2 times during LEVA, had no problems getting back up \\ e) shadow pattern made slopes look much steeper than it actually was \\ f) able to walk down 13 degrees decline to surveyor probe after problem with \\ slope angle resolved \\ g) surface is not like a desert but more like an ocean with troughs and waves. \\ Not level, more undulating \\ -navigation was difficult \\ h) LEVA was limited by fatigue, fluid intake and fluid in part from the suit, not \\ physiological limitation \\ i) Crews worked during surface rest periods, unbeknownst to the ground. This \\ accounts or the failure of their HR's to decrease while at "rest" \\ General \\ Comments: \\ Resolved: \\ If Resolved \\ how, when, \\ where? \\ Additional Do the crews feel the pre-flight EVA tripping problem adequately prepared them \\ Questions: $\quad$ for LEVA from an exercise capacity standpoint \\ Do crews need a device to better ascertain position of craters in shadows? Does \\ this raise a safety concern?
}

Summit Topic: Yes 


\section{Appendix A Apollo Summit Non-Attributable Report}

\section{Source: \\ Topic: \\ Issue: \\ Description: \\ General \\ Comments: \\ Resolved: \\ If Resolved how, when, where?}

Additional Questions:
Flight Surgeon logs

$$
\text { Lunar EVA }
$$

water usage

Crewmember reports $18 \%$ less $\mathrm{H} 2 \mathrm{O}$ used on CDR and $4 \%$ more $\mathrm{H} 2 \mathrm{O}$ on LMP

Summit Topic: Yes

\section{Source: $\quad$ Medical Mission Debriefs}

Topic: $\quad$ EVA suit

Issue: environmental cooling

Description: CDR felt strongly that the use of the Liquid Cooling Garment (LCG) by the LMP and CDR while in the LM, while preparing for and upon return from lunar EVA played a major role in reducing insensible and sensible water loss and helped them stay adequately hydrated. This led to a higher performance capability than if they had used LM air circulation for cooling. He compared the feeling of fatigue and dehydration on earth after using a backpack and air cooling when simulating EVA and the absence of such compromised condition after using the LCG for about 5 hours pre-and post EVA, while in the LM. There is a lot of metabolic work in donning and doffing the EVA suit that is not measured as there is no biomed monitoring during that time. It is important not to get behind with regards to hydration prior to beginning the actual lunar EVA.

Rather than leave the suit ASAP after an EVA, some maintenance and stowage tasks are best done in the suit. It is difficult to don and doff in the confines of the LM. The LCG is very helpful during this time.

General

Comments:

Resolved:

If Resolved

how, when, where?

Additional

Questions:

Summit Topic: Yes 


\section{Appendix A Apollo Summit Non-Attributable Report}

Source: $\quad$ Flight Surgeon logs

Topic: Lunar EVA

Issue: $\quad \mathrm{O} 2$

Description: Concern using too much $\mathrm{O} 2$ to last $7 \mathrm{HRS}$

General

Comments:

Resolved:

If Resolved how, when, where?

Additional How much extra O2 should we carry than the amount for the EVA? Questions:

Summit Topic: Yes

Source: $\quad$ Flight Surgeon logs

Topic: Lunar EVA

Issue: visor scratched

Description: Visor was scratched during EVA and this posed a problem if looking into sun on EVA

General

Comments:

Resolved:

If Resolved how, when, where?

Additional How did the visor get cracked? Should we carry spare visors for this purpose? Questions:

Summit Topic: Yes

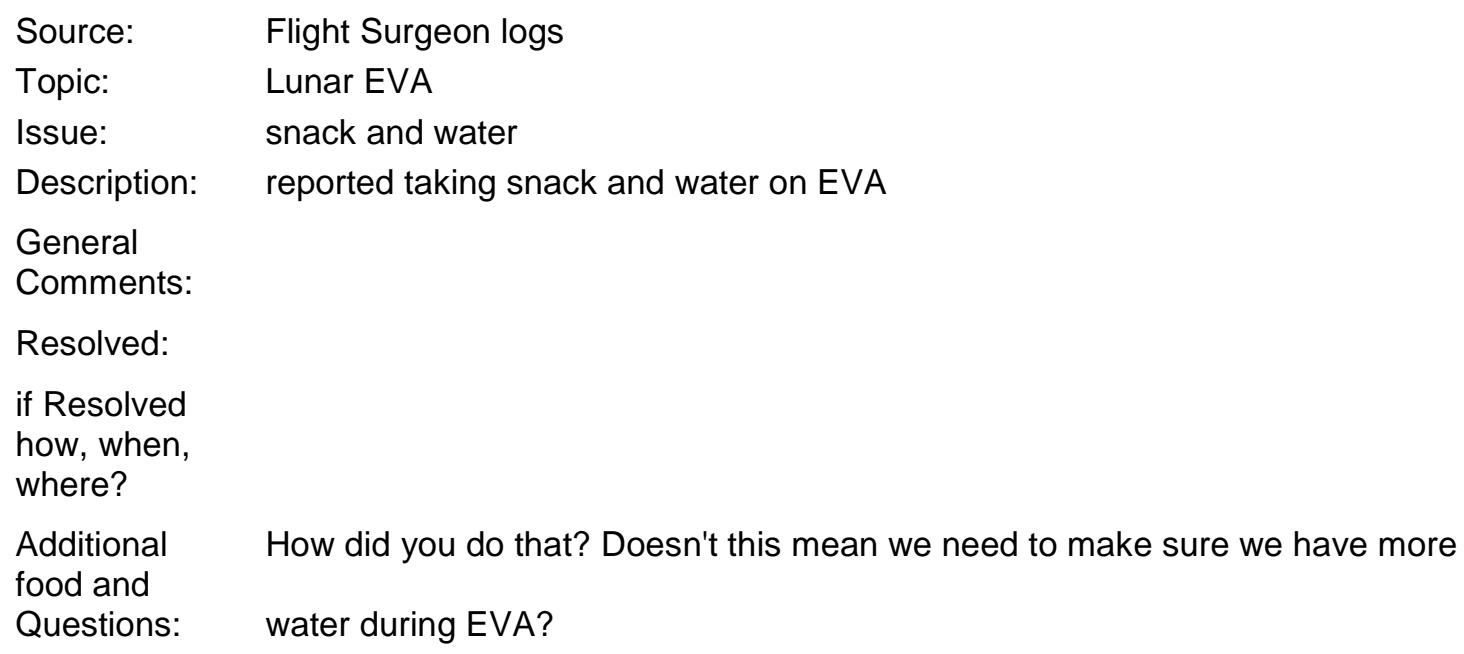


Summit Topic: Yes 


\section{Appendix A Apollo Summit Non-Attributable Report}

Source: $\quad$ Medical Mission Debriefs

Topic: Lunar EVA

Issue: $\quad$ EVA issues

Description: Removed all the pads from the EVA suit "every little bit of added material you put between you and what you're trying to that your work piece out there -a drill, a rock, a hammer -no matter what it is just removes dexterity from you. You put tape on there, that's another piece of material."

"felt we were very prepared to do the job." Taking a short break and having cold water to drink in the suit for 2-3 minutes and he was ready to go again. "I thought it couldn't have been better." On the first EVA "you got a tougher physical job to do" Learn your capabilities during first EVA and learn adaptation to $1 / 6 \mathrm{~g}$.

General

Comments:

Resolved:

If Resolved

how, when,

where?

Additional

Questions:

Summit Topic: Yes

\section{Source: Medical Mission Debriefs \\ Topic: Lunar EVA \\ Issue: $\quad$ EVA issues \\ Description: Hands very sore and fatigued after each EVA, but cleared overnight each time. Felt fit was good none-the-less.}

General

Comments:

Resolved:

If Resolved

how, when,

where?

Additional

Questions:

Summit Topic: Yes 


\section{Appendix A Apollo Summit Non-Attributable Report}

Source: $\quad$ Medical Mission Debriefs

Topic: Lunar EVA

Issue: $\quad$ EVA suit issues

Description: $\quad$ "perfect glove fit" But after EVA hands were very sore after getting out of suit and gloves. Looked like "a blood blister" on every fingernail-after the first EVA.

"They ached to the point that we soaked them in an empty food bag, filled it with water and just let our hands soak in cold water for 15 minutes." By next morning, "we're fine," no problems during 2nd EVA, but ached at end of EVA. At end of 3rd EVA, no problem.

Still has yellow marks under some nails during interview "that's just blood" During Gemini, he had hand soreness which took several weeks to clear.

General

Comments:

Resolved:

If Resolved

how, when,

where?

Additional

Questions:

Summit Topic: Yes

Source: $\quad$ Flight Surgeon logs

Topic: Lunar Dust

Issue: lunar dust

Description: Lunar dust described as fine powder

General

Comments: Ubiquitous in suit/cabin. Not easily cleaned.

Resolved: No

If Resolved

how, when,

where?

Additional

Questions:

Summit Topic: Yes 


\title{
Appendix A Apollo Summit Non-Attributable Report
}

\author{
Source: Medical Mission Debriefs \\ Topic: Lunar EVA \\ Issue: $\quad$ EVA Suit \\ Description: Key to success in the EVA suit \\ General Know how the human body works and to do as little work as possible we had to \\ Comments: constantly fight the suit to perform work. \\ Resolved: $\quad$ No \\ if Resolved - \\ how, when, \\ where? \\ Additional 1. Wear a suit that will get you down? (landing) \\ Questions: $\quad 2$. Explain the comment" Know how the human body works and to do as little \\ work as possible" for the use of the EVA suit during lunar EVA? \\ Summit Topic: Yes

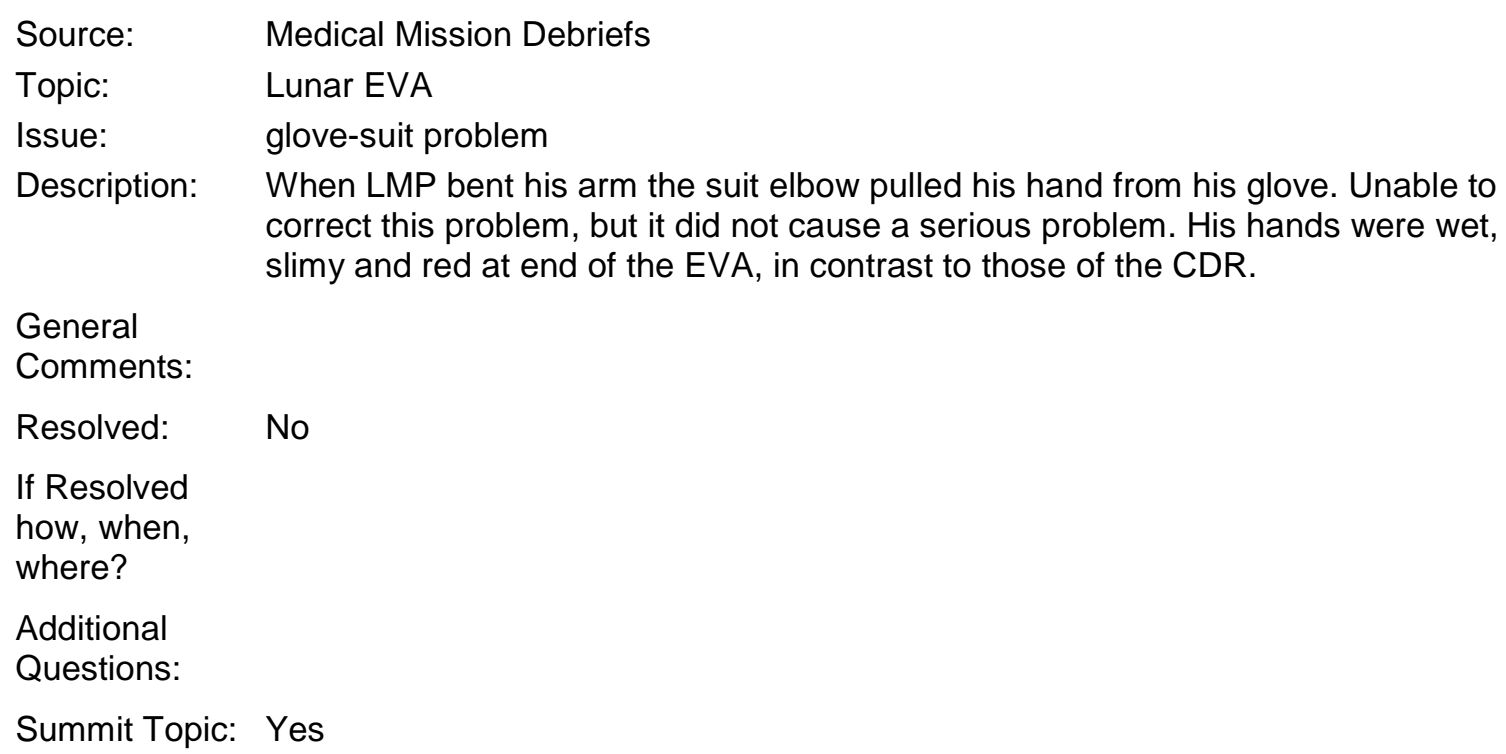

General

Comments:

Resolved: No

If Resolved

how, when,

where?

Additional

Questions:

Summit Topic: Yes 


\title{
Appendix A Apollo Summit Non-Attributable Report
}

\author{
Source: $\quad$ Medical Mission Debriefs \\ Topic: Lunar EVA \\ Issue: Duration \\ Description: p. 20: CDR: Could have gone appreciably longer, should the equipment permit it. \\ "Most of the time they were pretty low-level workloads, and those low-level \\ workloads I think you could do for a significant period of time." \\ LMP: "I think you could walk quite a long ways \\ CDR: walking is slow, but hopping lets you cover the ground a good bit faster, \\ but it is a higher workload. \\ General \\ Comments: \\ Resolved: \\ If Resolved \\ how, when, \\ where? \\ Additional \\ Questions: \\ Summit Topic: Yes

\begin{tabular}{|c|c|}
\hline Source: & Medical Mission Debriefs \\
\hline Topic: & Lunar EVA \\
\hline Issue: & EVA \\
\hline Description: & $\begin{array}{l}\text { a) Crew could have performed EVA longer if equipment permitted it. Workloads } \\
\text { were pretty reasonable, } \\
\text {-Crew could wait for long periods } \\
\text {-Walking Hopping -more efficient in EMU/EVA suit }\end{array}$ \\
\hline
\end{tabular} \\ General \\ Comments: \\ Resolved: \\ If Resolved \\ how, when, \\ where? \\ Additional 1. Would fewer but longer EVA be more efficient and save time? \\ Questions: $\quad 2$. Did crews bio reflect reasonable work or not? If not does this need to be \\ addressed? \\ 3. Did crews bio reflect hopping being more efficient than walking \\ Summit Topic: Yes
}




\section{Appendix A Apollo Summit Non-Attributable Report}

Source: $\quad$ Medical Mission Debriefs

Topic: $\quad$ EVA suit

Issue: $\quad$ water and thirst

Description: CMP: Felt thirsty at times. Juice consumption contributed to thirst.

CDR drank most of his in-suit water during 1st EVA

LMP drank most of his in-suit water during 1st EVA

CDR: "Anything you can do to make it easier is going to help increase the consumption." "Particularly during busy times."

General

Comments: $\quad$ Crew had limited $\mathrm{H} 2 \mathrm{O}$ carrying capacity in suit.

Resolved:

If Resolved

how, when,

where?

Additional

Questions:

Summit Topic: Yes

$\begin{array}{ll}\text { Source: } & \text { Flight Surgeon logs } \\ \text { Topic: } & \text { Lunar EVA } \\ \text { Issue: } & \text { fell } \\ \text { Description: } & \text { fell over rock dropped camera-tired and edgy }\end{array}$

General

Comments:

Resolved:

If Resolved

how, when,

where?

Additional

Questions: What factors contributed to crew fatigue on the lunar surface?

Summit Topic: Yes 


\section{Appendix A Apollo Summit Non-Attributable Report}

Source: $\quad$ Flight Surgeon logs

Topic: Lunar EVA

issue: seat belt

Description: seat belt got hooked up and caught. They weren't long enough. Took excessively long time to fasten.

General

Comments:

Resolved:

If Resolved

how, when,

where?

Additional Do you think the seat belt was designed inappropriately? Do they need to be Questions: longer?

Summit Topic: Yes

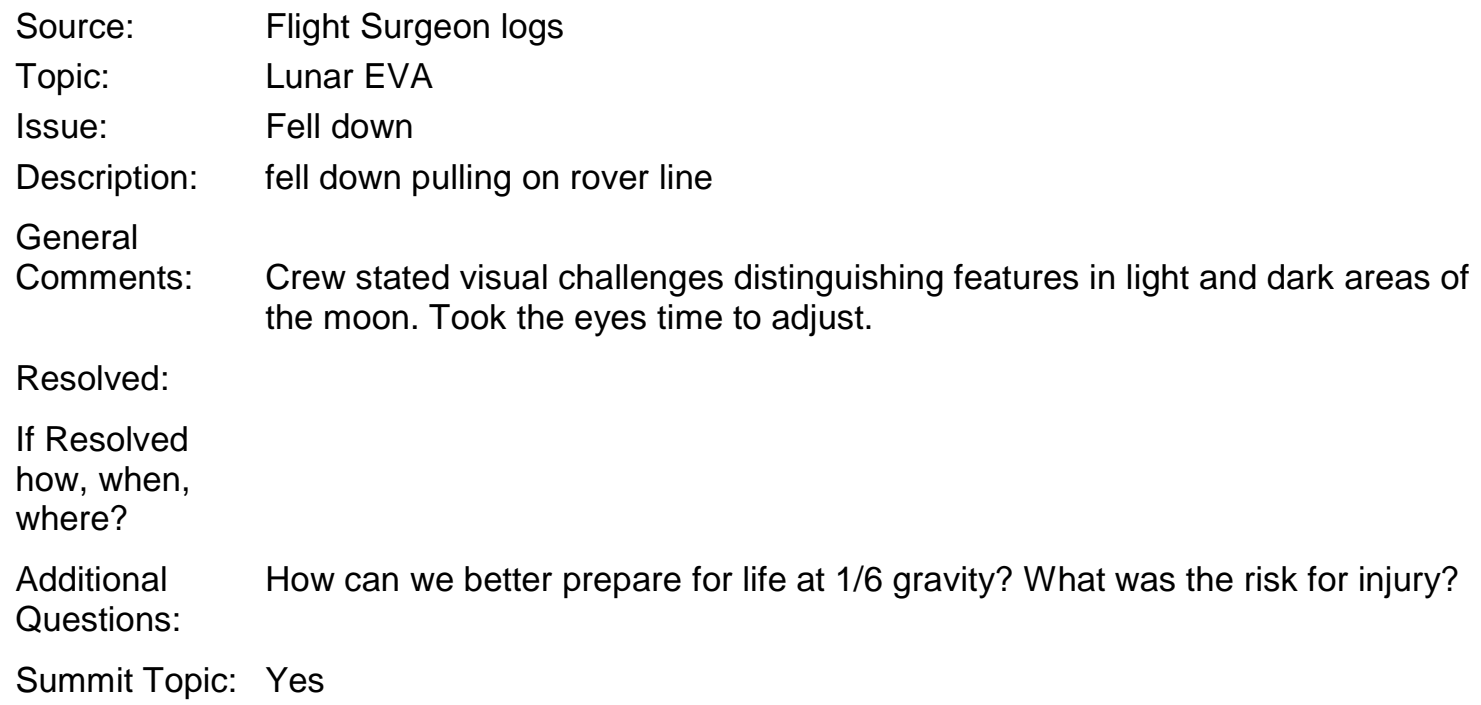

Resolved:

If Resolved

how, when, where?

Additional How can we better prepare for life at $1 / 6$ gravity? What was the risk for injury?

Questions:

Summit Topic: Yes

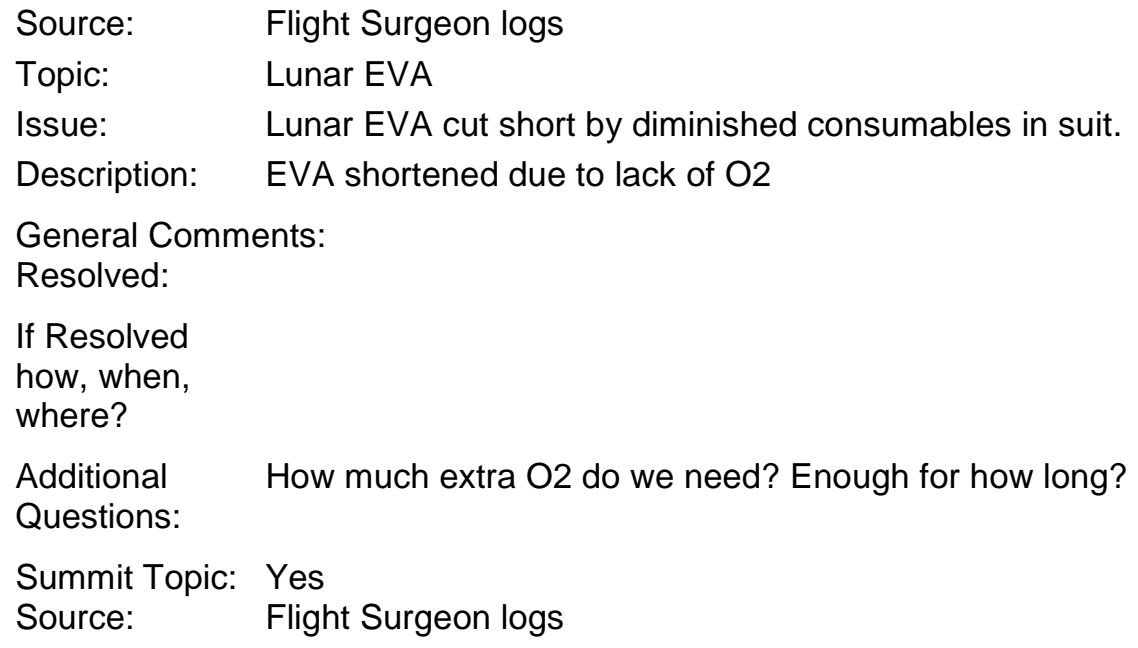




\section{Appendix A \\ Apollo Summit Non-Attributable Report}

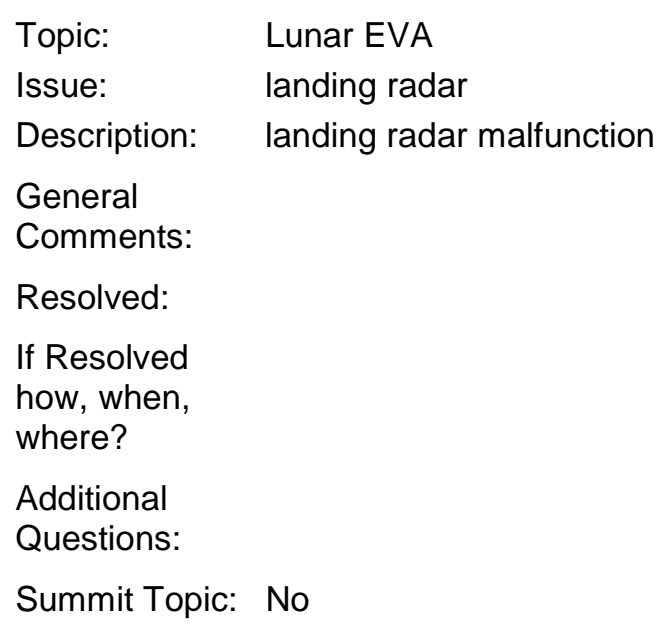

General

Comments:

Resolved:

If Resolved

how, when,

where?

Additional This makes plenty of water all the more important?

Questions:

Summit Topic: Yes 


\title{
Appendix A Apollo Summit Non-Attributable Report
}

\author{
Source: $\quad$ Medical Mission Debriefs \\ Topic: $\quad$ Lunar Surface Ops \\ Issue: $\quad$ Sleeping in the LM \\ Description: p. 14: CDR: lighting, noise and the temperature interfered with sleep in the LM on \\ the lunar surface. Glycol pump was very noisy. CDR and LMP preferred different \\ vehicle temperatures. Got about 2-3 hours of sleep. \\ General \\ Comments: Crew did not get adequate sleep on lunar surface, presumably because of \\ environmental factors. These can be easily fixed. \\ Resolved: $\quad$ No \\ If Resolved \\ how, when, \\ where? \\ Additional \\ Questions: \\ Summit Topic: Yes
Source: $\quad$ Medical Mission Debriefs
Topic: $\quad$ Lunar Surface Ops
Issue: Sample Boxes
Description: The surface sample boxes were difficult to close, requiring considerable energy expenditure
1. Biomed data revealed increased respiratory rate and heart rate: however, no numbers were provided \\ General \\ Comments: \\ Resolved: \\ If Resolved \\ how, when, \\ where? \\ Additional Should surface sample boxes be interchanged for bags that are then placed in \\ Questions: boxes to save time and energy expenditure? \\ Summit Topic: Yes
}




\title{
Appendix A \\ Apollo Summit Non-Attributable Report
}

\author{
Source: $\quad$ Medical Mission Debriefs \\ Topic: $\quad$ Lunar Surface Ops \\ Issue: $\quad$ Fatigue \\ Description: Crew reported minor leg fatigue with surface activity (not soreness) \\ General \\ Comments: Most noticeable with ambulation up and down sloped terrain. \\ Resolved: \\ If Resolved \\ how, when, \\ where? \\ Additional 1. What was exercise schedule like prior to landing on lunar surface? \\ Questions: $\quad 2$. Should Crew work out on treadmill with same "gravity/resistance" as they will \\ feel for their body mass and suit mass on the moon? \\ Summit Topic: Yes

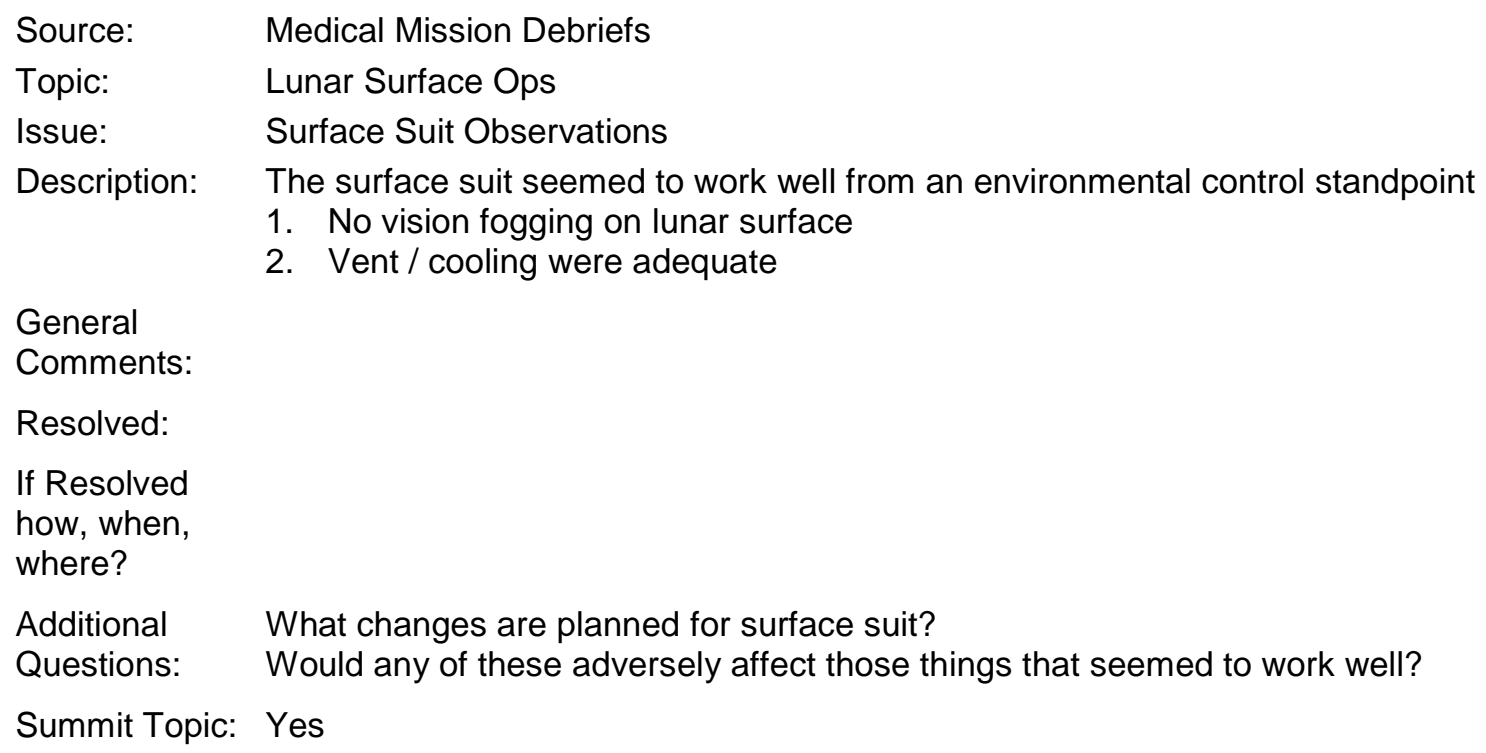

General

Comments:

Resolved:

If Resolved

how, when,

where?

Additional What changes are planned for surface suit?

Questions: Would any of these adversely affect those things that seemed to work well?

Summit Topic: Yes 


\title{
Appendix A \\ Apollo Summit Non-Attributable Report
}

\author{
Source: $\quad$ Medical Mission Debriefs \\ Topic: $\quad$ Lunar Surface Ops \\ Issue: Locomotion \\ Description: "Hopping" on the surface seemed to be the best way to get around with \\ consideration for: \\ 1. Time / distance traveled \\ 2. Energy expenditure \\ General \\ Comments: \\ Resolved: \\ If Resolved \\ how, when, \\ where? \\ Additional Can this/should this be practiced prior to arrival? \\ Questions: \\ Summit Topic: Yes

\footnotetext{
Source: $\quad$ Medical Mission Debriefs

Topic: $\quad$ Lunar Surface Ops

Issue: Waste Management (non-human)

Description: Used food packages, etc. need to be disposed of

General

Comments:

Resolved: unknown

If Resolved

how, when,

where?

Additional Was any garbage taken from the CM to the LM left on the surface? e.g., Urine

Questions: $\quad$ bags..... Crew described that item would be thrown out per "the plan"

Summit Topic: Yes
} 


\title{
Appendix A Apollo Summit Non-Attributable Report
}

\author{
Source: $\quad$ Medical Mission Debriefs \\ Topic: Lunar Surface Ops \\ Issue: $\quad$ Surface Views \\ Description: View of the surface from the LM window is different than through the visor on the \\ surface itself \\ -Looking into the sun toward the horizon was limiting secondary to loss of \\ contrast/resolution \\ a, Glare, brightness, etc. \\ -Re-directing gaze down from the sun helpful with surface details \\ -View in the shadows was good after re-adjustment from the light. However, the \\ light level in the shadow is really low \\ a. Comparable to the views in the pictures taken by the crew \\ b. Vision in the crater was acceptable \\ -Visors were used. both anterior vision in sunlight and inner vision \\ a. Blinder was used on occasion in the run \\ General \\ Comments: \\ Resolved: \\ If Resolved \\ how, when, \\ where? \\ Additional \\ Questions: \\ Summit Topic: Yes

$\begin{array}{ll}\text { Source: } & \text { BME logs } \\ \text { Topic: } & \text { Lunar Surface Ops } \\ \text { Issue: } & \text { increase HR }\end{array}$ \\ Description: $\quad$ CDR thinks he got his HR up during lunar surface activities. Legs not tired but \\ hands are secondary to glove fit issues. \\ General \\ Comments: \\ Resolved: No \\ If Resolved \\ how, when, \\ where? \\ Additional \\ Questions: \\ Summit Topic: Yes
}




\title{
Appendix A \\ Apollo Summit Non-Attributable Report
}

\author{
Source: $\quad$ Flight Surgeon logs \\ Topic: Lunar Surface \\ Issue: Ops bags \\ Description: Bags are breaking open \\ General \\ Comments: \\ Resolved: $\quad$ No \\ If Resolved \\ how, when, \\ where? \\ Additional Have these bags been corrected or no longer used? \\ Questions: \\ Summit Topic: Yes

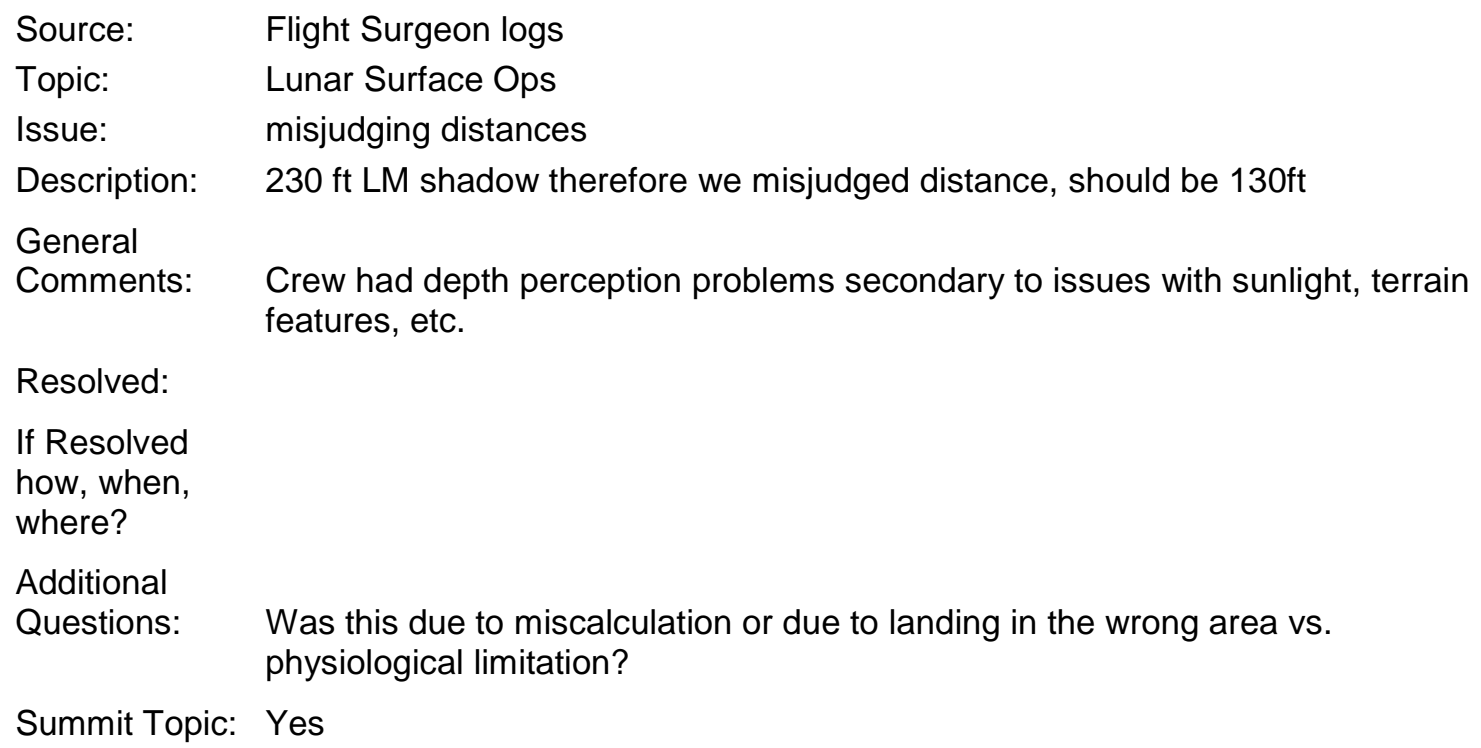

Resolved:

If Resolved how, when, where?

Additional

Questions: Was this due to miscalculation or due to landing in the wrong area vs. physiological limitation?

Summit Topic: Yes 


\section{Appendix A Apollo Summit Non-Attributable Report}

Source: $\quad$ Flight Surgeon logs

Topic: Lunar Surface Ops

Issue: movement

Description: Sink in further next to crater nice moving around up here you don't get tired

General

Comments:

Resolved:

If Resolved

how, when,

where?

Additional

Questions:

Summit Topic: Yes

Source: $\quad$ Flight Surgeon logs

Topic: Lunar Surface Ops

Issue: $\quad$ Sample bags

Description: Sample bags are splitting at the seams

General

Comments:

Resolved:

If Resolved

how, when,

where?

Additional

Questions:

Summit Topic: No

Source: $\quad$ Flight Surgeon logs

Topic: Lunar Surface Ops

Issue: Tools

Description: Tools getting hot to touch

General

Comments:

Resolved:

If Resolved

how, when, where?

Additional If you could feel it through your gloves how hot was it really? What are the Questions: expected temp ranges of the tools? Do we know why it got so hot?

Summit Topic: Yes 


\title{
Appendix A Apollo Summit Non-Attributable Report
}

\author{
Source: $\quad$ Medical Mission Debriefs \\ Topic: Lunar Dust \\ Issue: $\quad$ Exposure Observations \\ Description: a) Exposure caused nasal congestion, according to CDR and LMP \\ b) Dust floating every where in the LM upon return to 0 gravity. This prompted \\ the CDR/LMP to keep their helmets on \\ c) Dust particles got into their eyes causing irritation \\ d) Dust was ubiquitous, prompting the crew on board to box up item in the LM \\ and send across the hatch to the CMP. They functioned with canister closed \\ until transfer to keep the CM clean. \\ General \\ Comments: \\ Resolved: \\ If Resolved \\ how, when, \\ where? \\ Additional \\ Questions: What did the crew use to treat eye, nasal irritation? \\ Summit Topic: Yes

$\begin{array}{ll}\text { Source: } & \text { Medical Mission Debriefs } \\ \text { Topic: } & \text { Lunar Surface Ops } \\ \text { Issue: } & \text { fatigue } \\ \text { Description: } & \text { LMP: During EVA the right hand fatigued because of the suit valve (the glove and } \\ & \text { "pipe tangled up" Also unscrewing the core tubes and getting the caps off them } \\ & \text { was very fatiguing and that arm gave out. Carrying an instrument (lost in } \\ & \text { dictation) was tiring because it was cumbersome and flopping all around. It was } \\ & \text { heavy. The flopping of the weights and the longer distance to carry it than in sims } \\ & \text { made it difficult. }\end{array}$ \\ General \\ Comments: \\ Resolved: \\ If Resolved \\ how, when, \\ where? \\ Additional \\ Questions: \\ Summit Topic: Yes
}




\title{
Appendix A \\ Apollo Summit Non-Attributable Report
}

\author{
Source: BME logs \\ Topic: $\quad$ Lunar Surface Ops \\ issue: $\quad$ sleep \\ Description: drank well while on lunar surface, didn't take seconal tonight but recommended \\ to take seconal tonight though they feel they don't need it its still recommended \\ General \\ Comments: \\ Resolved: Yes \\ If Resolved \\ how, when, \\ where? \\ Additional \\ Questions: \\ Summit Topic: Yes

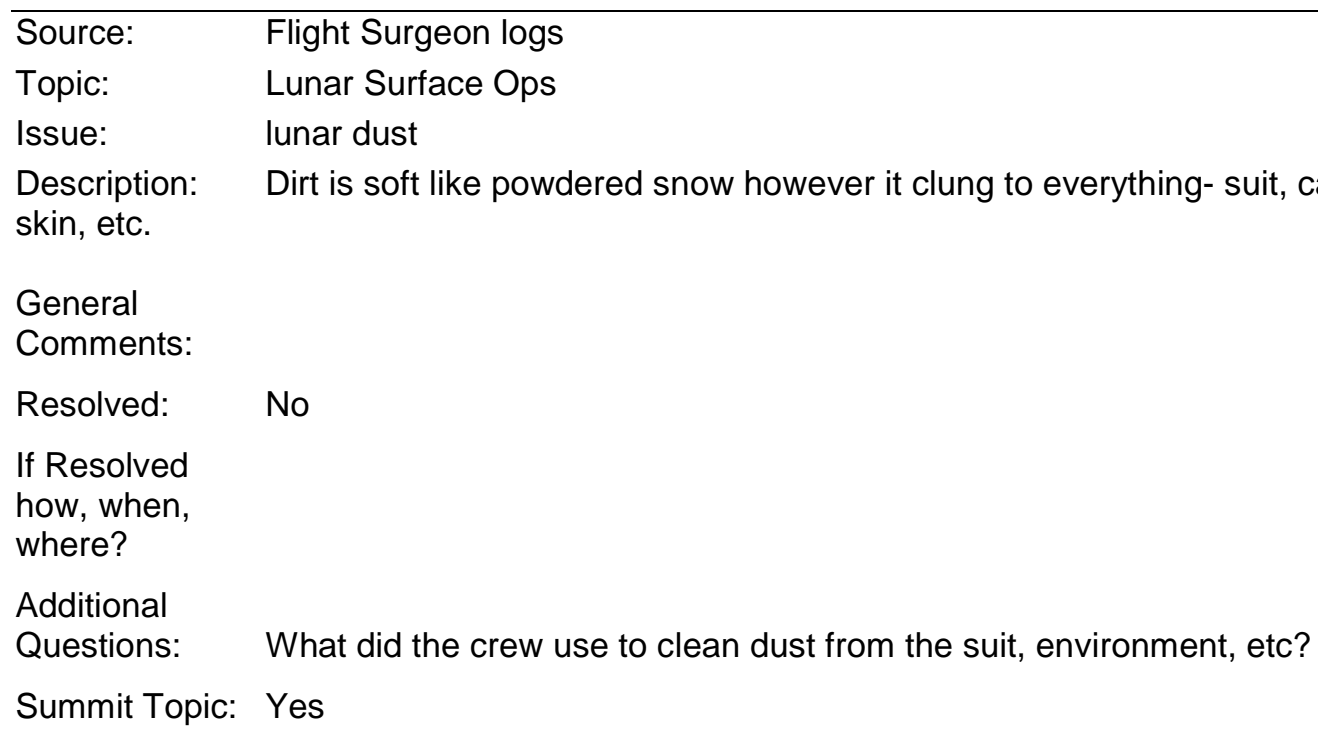

Additional

Questions: What did the crew use to clean dust from the suit, environment, etc?

Summit Topic: Yes

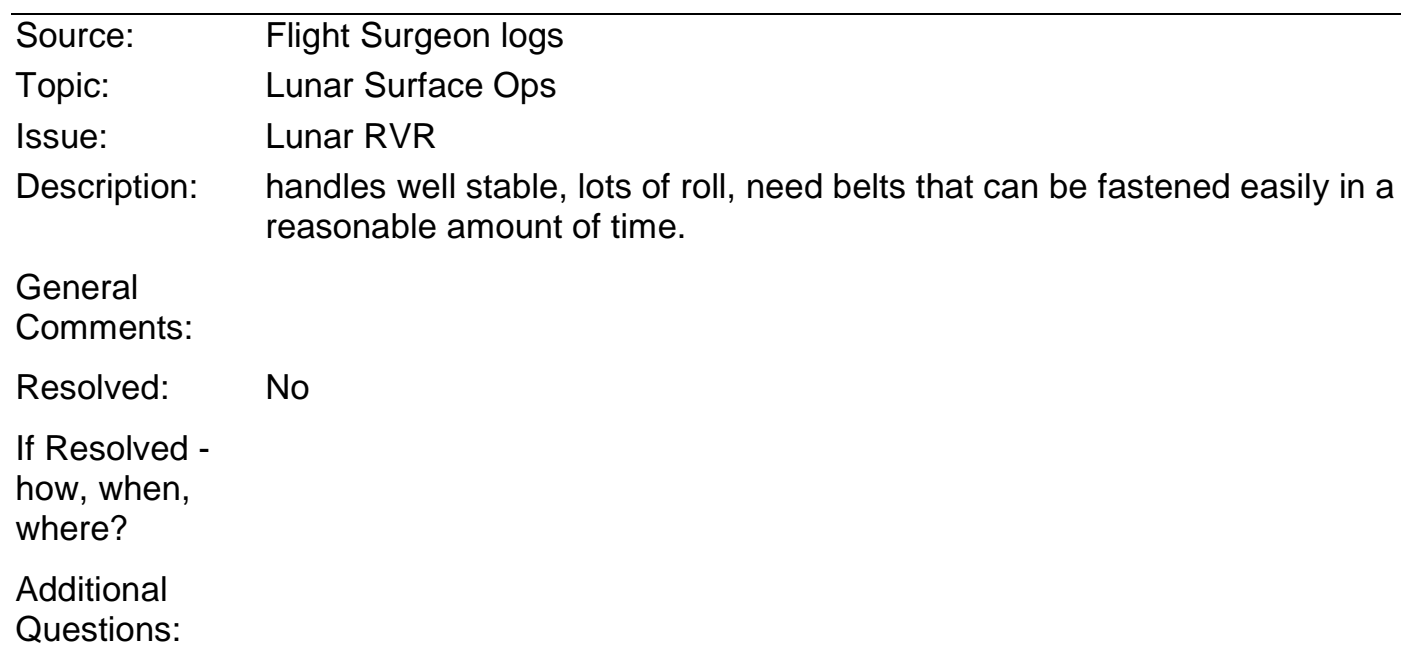

General

Comments:

Resolved: $\quad$ No

If Resolved where?

Additional Questions: \\ how, when,
}


Summit Topic: Yes 


\section{Appendix A Apollo Summit Non-Attributable Report}

Source: $\quad$ Flight Surgeon logs

Topic: Lunar Surface Ops

Issue: high sun angle

Description: high sun angle is warm against crew members body during lunar EVA.

General

Comments:

Resolved:

If Resolvedhow, when, where?

Additional

Questions: Did this become uncomfortable during lunar surface ops?

Summit Topic: Yes

$\begin{array}{ll}\text { Source: } & \text { Flight Surgeon logs } \\ \text { Topic: } & \text { Lunar Surface Ops } \\ \text { Issue: } & \text { dust contamination } \\ \text { Description: } & \text { so dirty can't see maps on EVA } \\ \text { General } & \\ \text { Comments: } & \text { The lunar dust was ubiquitous during lunar surface activities. }\end{array}$

Resolved:

If Resolved

how, when, where?

Additional Were the maps paper? Do they need to be laminate?

Questions:

Summit Topic: Yes

\footnotetext{
Source: $\quad$ Flight Surgeon logs

Topic: Lunar Surface Ops

Issue: smell

Description: fingers are sore and can smell Lunar dust in LM

General

Comments: Glove fit issues are a recurring problem noted in the debriefs and logs.

Resolved: No

If Resolved

how, when,

where?

Additional Should gloves be designed differently with the pressure in the suits so fingers are not

Questions: as sore?

Summit Topic: Yes
} 


\title{
Appendix A Apollo Summit Non-Attributable Report
}

\author{
Source: $\quad$ Flight Surgeon logs \\ Topic: $\quad$ Lunar Surface Ops \\ Issue: eating food \\ Description: while eating food it gets stuck in the suit-the food is good otherwise \\ General \\ Comments: \\ Resolved: $\quad$ No \\ If Resolved \\ how, when, \\ where? \\ Additional Do you feel food while on a EVA is necessary? Do you think it is worth the \\ Questions: trouble/hassle? Does it allow for a more prosperous EVA? \\ Summit Topic: Yes

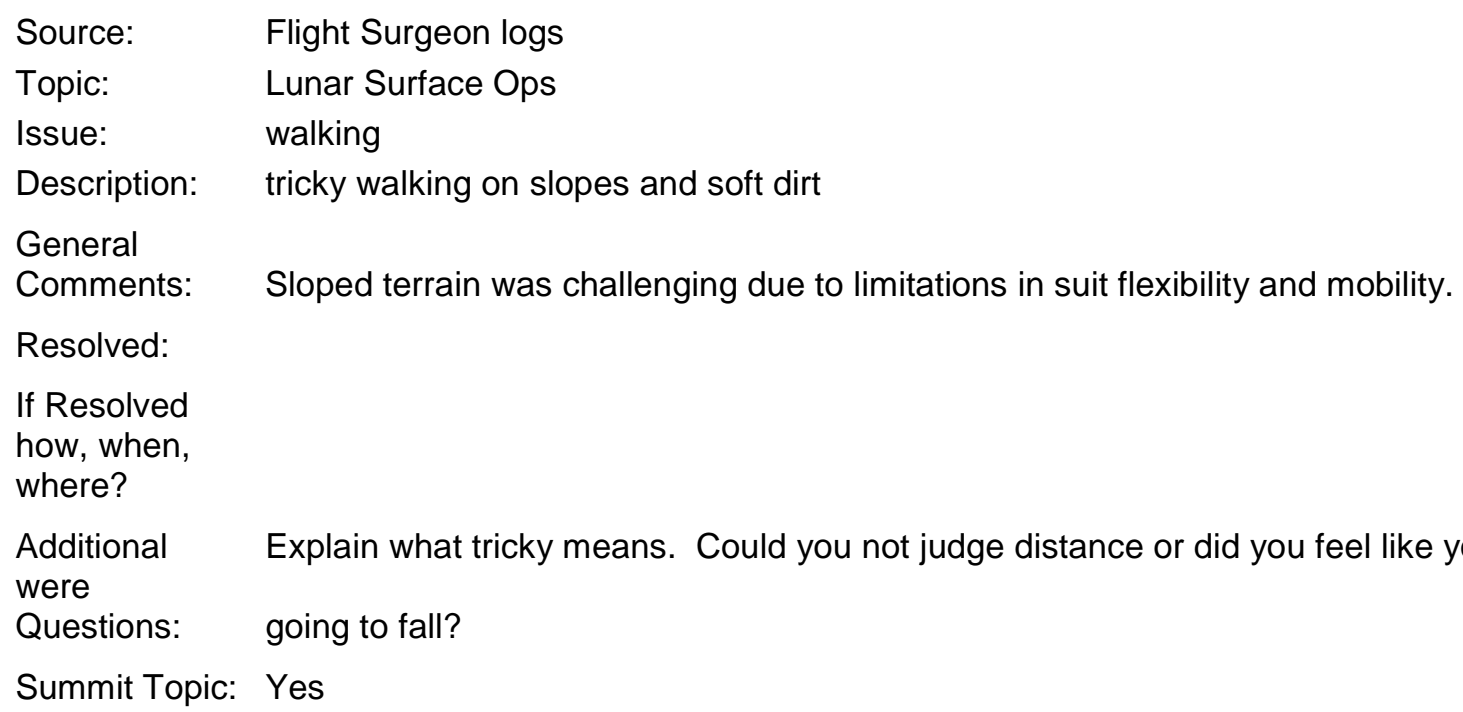

Source: $\quad$ Flight Surgeon logs

Topic: Lunar Surface Ops

Issue: camera dust

Description: so much dust on camera can't get polargraphic filter on

General

Comments:

Resolved:

If Resolved

how, when, where?

Additional How can we redesign the lens so that it is not bothered by the lunar dust? What Questions: about using compressed air?

Summit Topic: Yes 


\section{Appendix A Apollo Summit Non-Attributable Report}

Source: $\quad$ Flight Surgeon logs

Topic: Lunar Surface Ops

Issue: thirst

Description: crew will breakdown before stem? Need some gatorade could drink 3 gallons.

General

Comments:

Resolved:

If Resolved

how, when,

where?

Additional would providing gatorade be better than water in the suits? Do you feel moon

Questions: $\quad$ EVA is more taxing than space EVA?

Summit Topic: Yes

Source: $\quad$ Medical Mission Debriefs

Topic: $\quad$ Lunar Surface Ops

Issue: fatigue

Description: Never felt excessive fatigue. Any fatigue was relieved with short rest. Not as fatigued as during simular rock pile on Earth.

LMP: Never felt tired

CMP: "I was less tired when I got back in than I did before I went out."

Hardest work was using the drill during an EVA

General

Comments:

Resolved:

If Resolved

how, when,

where?

Additional

Questions:

Summit Topic: Yes 


\title{
Appendix A Apollo Summit Non-Attributable Report
}

\author{
Source: $\quad$ Medical Mission Debriefs \\ Topic: Lunar Surface Ops \\ Issue: sore hands \\ Description: LMP: after EVA1 fingers were very sore, as was wrist, where the sleeve rubbed. \\ General \\ Comments: \\ Resolved: \\ If Resolved \\ how, when, \\ where? \\ Additional \\ Questions: \\ Summit Topic: Yes

\begin{abstract}
Source: $\quad$ Medical Mission Debriefs
Topic: Lunar Surface Ops

Issue: lunar illumination

Description: Brightness of the lunar surface caused difficulty with vision. Felt sunglasses were OK, but "you can't operate with sunglasses. "Where you want the shielding is in the window. You want to pick up a pair of binoculars you don't look through sunglasses and do that very well."

General Note: the lunar brightness problems discussed here are when using assisted

vision

Comments: devices which gather light and focus it, increasing the retinal light intensity-binoculars and cameras. This suggests the 'fix' is filters, appropriate for the device, at the optical entrance, and filters at the viewing port as needed to protect the crew's eyes (there has been a retinal injury on the ISS secondary to multiple photography of the sunset with a $35 \mathrm{~mm}$ through the lens camera. The eye can gather and focus light sufficiently to multiply the retinal light intensity by 300,000 times the incident intensity.
\end{abstract} \\ Resolved: \\ If Resolved \\ how, when, \\ where? \\ Additional \\ Questions: \\ Summit Topic: Yes
}




\section{Appendix A \\ Apollo Summit Non-Attributable Report}

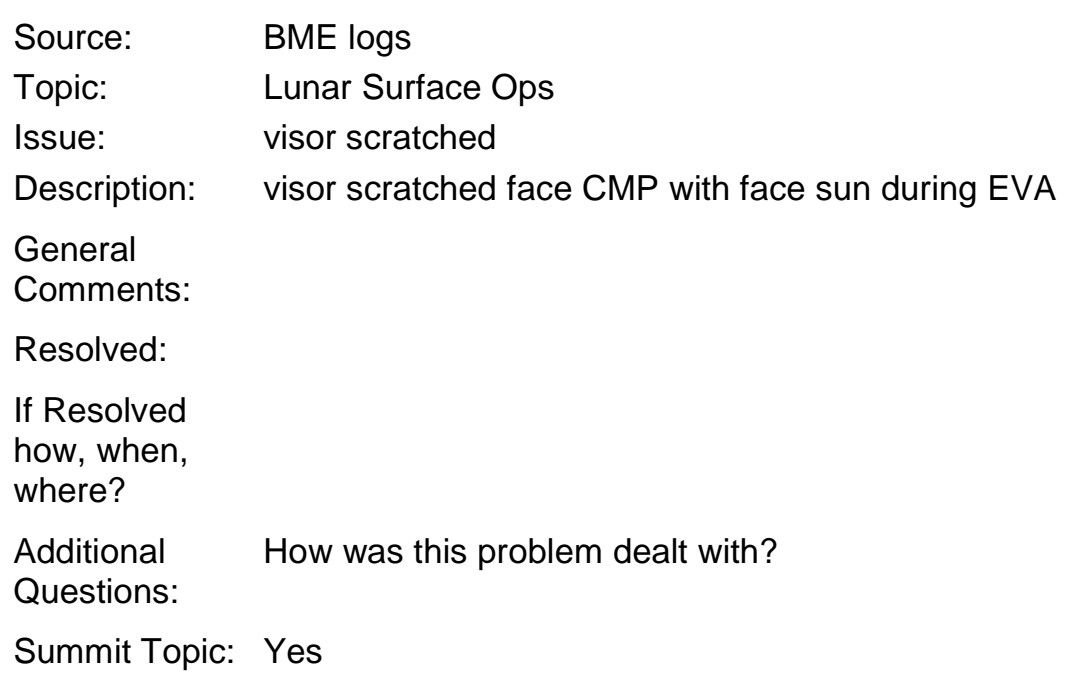




\title{
Appendix A Apollo Summit Non-Attributable Report
}

\author{
Source: $\quad$ Medical Mission Debriefs \\ Topic: Lunar Surface Ops \\ Issue: general \\ Description: $\quad$ Slept better in $1 / 6 \mathrm{~g}$, felt refreshed after sleeping, but not as refreshed prior to $3 \mathrm{rd}$ \\ EVA. CDR drank all his water during first 2 EVAs and $80 \%$ during $3^{\text {rd }}$ EVA. \\ Never ate the entire food bar, but most of the bar during first and second EVA \\ little in the bar during third EVA \\ LMP wasn't hungry or thirsty but used water to moisten his mouth. Both drank a \\ lot during prep for EVA \\ General \\ Comments: \\ Resolved: \\ If Resolved \\ how, when, \\ where? \\ Additional \\ Questions: \\ Summit Topic: Yes \\ Source: $\quad$ Flight Surgeon logs \\ Topic: Lunar Dust \\ Issue: lunar dust \\ Description: "they have become very respectful of lunar dust" \\ General \\ Comments: \\ Resolved: \\ If Resolved \\ how, when, \\ where? \\ Additional what are the problems we need to focus on fixing with lunar dust? \\ Questions: \\ Summit Topic: Yes
}




\section{Appendix A \\ Apollo Summit Non-Attributable Report}

Source: $\quad$ Flight Surgeon logs

Topic: Lunar Dust

Issue: dirt

Description: complains of "all of that dirt here again"

General

Comments:

Resolved:

If Resolved

how, when,

where?

Additional were you able to get rid of the dirt at all or not?

Questions: Does it pose a problem for the buttons on the ship?

Summit Topic: Yes

\footnotetext{
Source: $\quad$ Medical Mission Debriefs

Topic: $\quad$ Lunar Dust

Issue: $\quad$ stuffy nose from dust

Description: After first EVA had fullness in head and stuffy feeling. Took couple whiffs of Afrin before bed' with good effect.

Wore helmet when stowing lunar samples inside

No trouble clearing ears during re-entry

Comments:

Resolved:

If Resolved

how, when,

where?

Additional

Questions:

Summit Topic: Yes
} 


\section{Appendix A Apollo Summit Non-Attributable Report}

Source: $\quad$ Flight Surgeon logs

Topic: Illnesses/Injuries

Issue: Dripping nose

Description: CDR reports dripping nose; Treated with Actifed and 2 aspirin

General

Comments:

Resolved: Persisted throughout mission

If Resolved how, when, where?

Additional With colds, are symptoms being considered a normal part of space adaptation? Questions: How will our approach be different or the same on exploration mission?

Summit Topic: Yes

Source: $\quad$ Flight Surgeon logs

Topic: Illnesses/Injuries

Issue: $\quad$ PVC's prior to TLI burn

Description: 2 PVC'S prior to burn within $10 \mathrm{sec}$ of each other with no PVC's during burn

General Comments:

Resolved: Did not occur again.

If Resolved

how, when, where?

Additional Do we know how we will approach PVC's in crew during and before exploration Questions: missions?

Summit Topic: Yes

\footnotetext{
Source: $\quad$ Flight Surgeon logs

Topic: Illnesses/njuries

Issue: $\quad$ Ability to valsalva

Description: Crews had nasal congestion throughout the mission. They needed to be able to Valsalva on reentry but were unable to with helmets on. Concerned about eardrum hum.

General

Comments:

Resolved: $\quad$ Crew chose not to wear helmets on re-entry.

If Resolved

how, when, where?

Additional Will crew be able to Valsalva on reentry while wearing what they are supposed Questions: to?

Summit Topic: Yes

Source: Medical Mission Debriefs
} 


\title{
Appendix A \\ Apollo Summit Non-Attributable Report
}

\author{
Topic: Illnesses/Injuries \\ Issue: Health Concerns \\ Description: 1. "Cold" \\ a) ESD, rhinorrhea, nasal congestion \\ b) Valsalva was useful \\ 2. Little repeat of SMS syndrome \\ General b) Definitely need Kleenex on board for rhinorrhea \\ Comments: \\ Resolved: \\ If Resolved \\ how, when, \\ where? \\ Additional 1. Are these cold like symptoms different than symptoms experienced with fluid \\ Questions: shift? \\ 2. Can we have Kleenex on board? \\ Summit Topic: Yes

$\begin{array}{ll}\text { Source: } & \text { Mission Reports } \\ \text { Topic: } & \text { Illnesses/Injuries } \\ \text { Issue: } & \text { Recommendations } \\ \text { Description: } & \text { FR for crew health reporting: } \\ & \text { 1. State how crewmember feels } \\ & \text { 2. Medication used } \\ & \text { 3. Current symptoms } \\ & \text { 4. Do not take med unless consults with surgeon }\end{array}$ \\ General \\ Comments: \\ Resolved: \\ If Resolved \\ how, when, \\ where? \\ Additional \\ Questions: \\ Summit Topic: Yes
}




\section{Appendix A \\ Apollo Summit Non-Attributable Report}

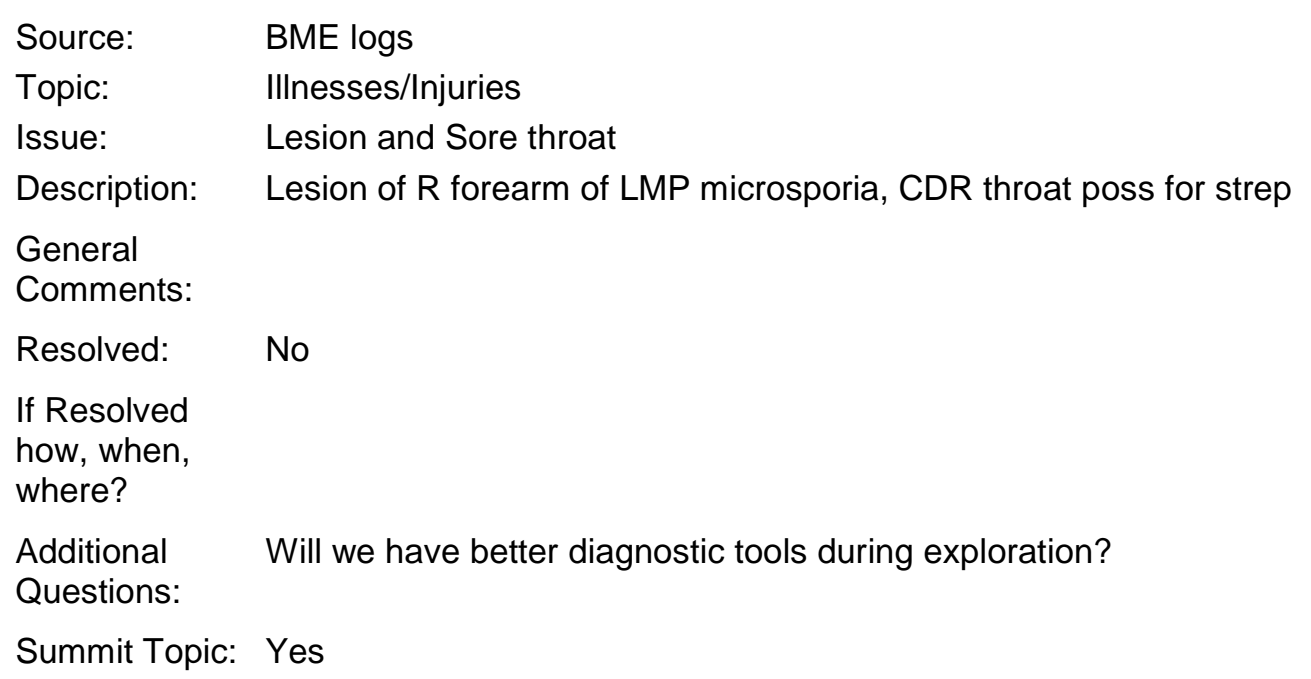

General

Comments:

Resolved:

If Resolved how, when, where?

Additional On longer exploration style missions will we want more diagnostic capabilities Questions: onboard?

Summit Topic: Yes

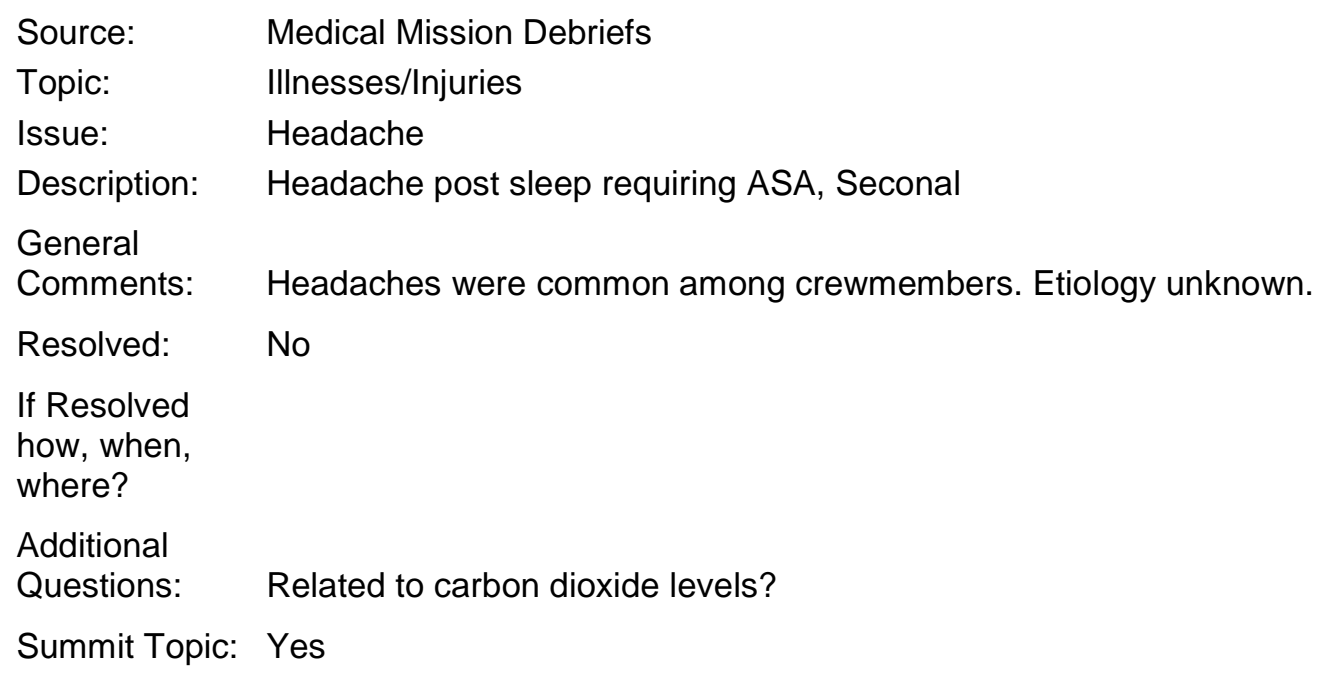




\title{
Appendix A Apollo Summit Non-Attributable Report
}

\author{
Source: Medical Mission Debriefs \\ Topic: Illnesses/Injuries \\ Issus: Constipation \\ Description: More psychological than physiological. The crew did not want to make a mess \\ with the waste management system. One crewmember went entire mission with \\ out BM. \\ Other crewmembers had some kind of problem with defecation post flight. \\ General Stools were pasty, not loose. No diarrhea. \\ Comments: \\ Resolved: \\ If Resolved \\ how, when, \\ where? \\ Additional 1. Is waste management system improved and more user friendly since Apollo? \\ Questions: $\quad$ 2. Can waste management system be used effectively by females? How would \\ this be designed? \\ Summit Topic: Yes

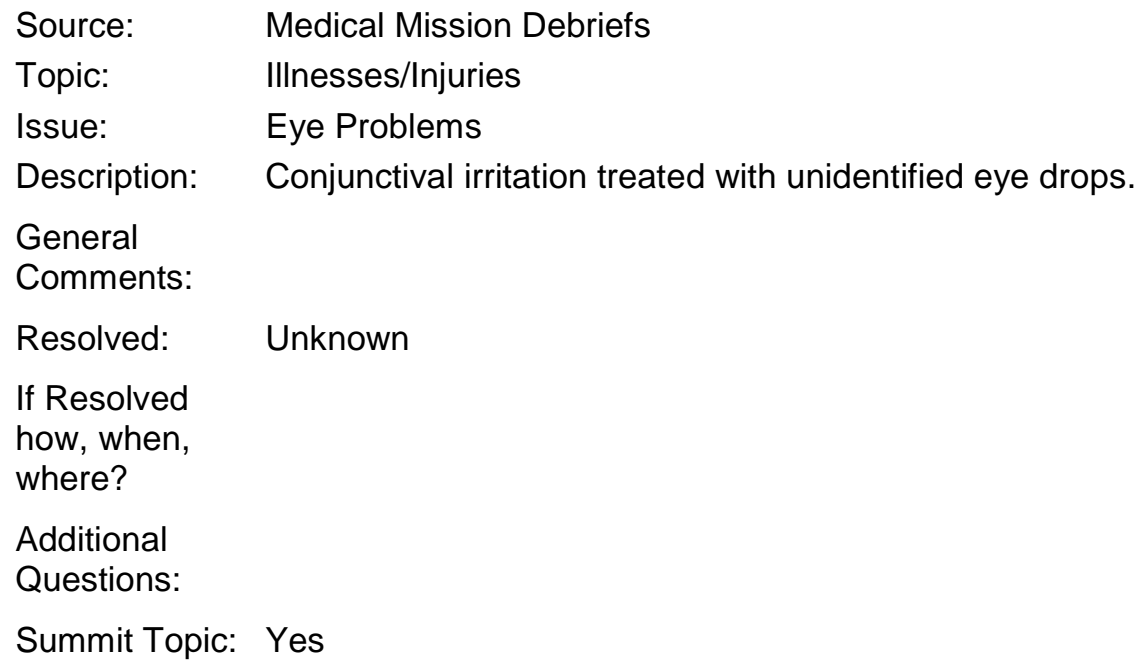




\section{Appendix A Apollo Summit Non-Attributable Report}

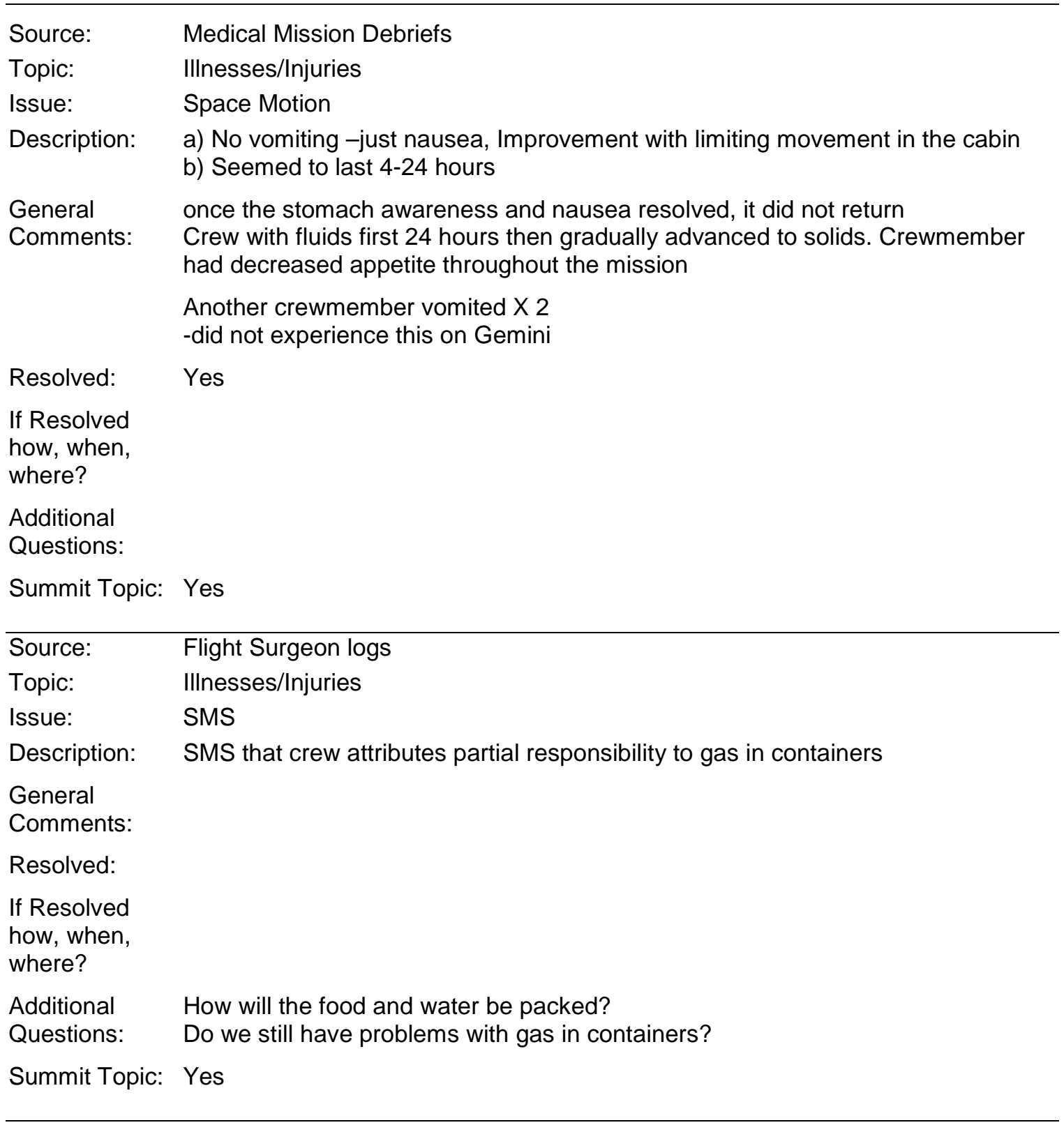

Source: $\quad$ Flight Surgeon logs

Topic: IIInesses/Injuries

Issue: Seborrheic dermatitis

Description: Face was red like wearing goggles

General

Comments:

Resolved:

If Resolved how, when, where?

Additional Did this affect the mission?

Questions:

Summit Topic: Yes 


\title{
Appendix A Apollo Summit Non-Attributable Report
}

\author{
Source: $\quad$ Medical Mission Debriefs \\ Topic: IIlnesses/Injuries \\ Issue: $\quad$ Space Motion Sickness \\ Description: LMP experienced significant SMS during the mission: tumbling sensation, \\ nausea and vomiting, anorexia, his head/neck get out of the suit helmet as in \\ "tumbling my gyros completely". \\ Vomiting episode. FD3 was not preceded by any parasympathetic cues, i.e., \\ cold sweats, stomach awareness, vertigo. \\ 2nd episode of vomiting occurred 4-4.5 hours after the first episode in the LM. \\ Traveling through the tunnel contributed to this. \\ -Symptoms improved steadily after second episode \\ -Appetite never returned for duration of Mission; \\ General Marazine slowly helped decrease symptoms for the first two days. \\ Comments: $\quad$ Limiting head movement and moving slowly were keys to preventing \\ dizziness/nausea. However some positions were unavoidable that triggered SMS \\ (i.e., putting heads into suit). \\ Resolved: \\ If Resolved \\ how, when, \\ where? \\ Additional \\ Questions: \\ Summit Topic: Yes \\ Source: $\quad$ Medical Mission Debriefs \\ Topic: Illnesses/Injuries \\ Issue: Back Pain \\ Description: a) Back pain for the first couple of days. Described as an "ache" on each side of \\ his lower back. \\ General Symptoms were relieved by curving back into fetal position, Symptoms more \\ noticeable \\ Comments: at night, CM would grab and hold onto his knees in the sleeping bag: \\ Resolved: \\ If Resolved \\ how, when, \\ where? \\ Additional What position or exercise workout was most effective to relieve back pain? \\ Questions: $\quad$ Do you think there is any pre-flight conditioning program or device to help \\ ameliorate the early in-flight pain \\ Summit Topic: Yes
}




\section{Appendix A \\ Apollo Summit Non-Attributable Report}

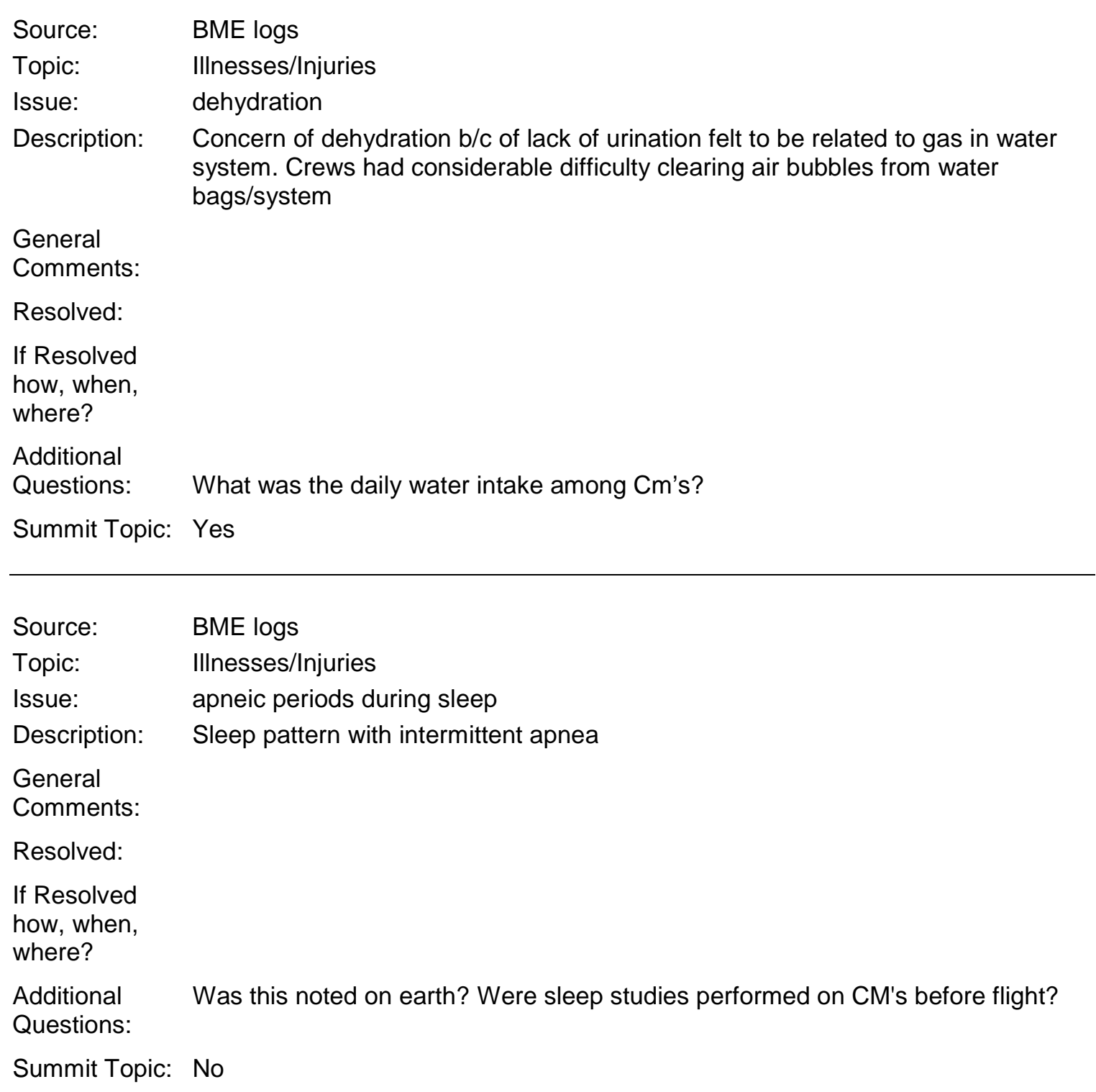




\section{Appendix A \\ Apollo Summit Non-Attributable Report}

Source: $\quad$ Flight Surgeon logs

Topic: Illnesses/Injuries

Issue: $\quad$ Fiberglass irritation

Description: Fiberglass irritation of skin causing itching

General

Comments:

Resolved:

If Resolved

how, when,

where?

Additional Can we keep the cause of the fiberglass from happening again?

Questions:

Summit Topic: Yes

Source: $\quad$ Medical Mission Debriefs

Topic: Illnesses/Injuries

Issue: $\quad$ Cause and Affect

Description: a) Conjunctival irritation secondary to environmental fiberglass. Circumstances not explained. Crew used eye drops, water X2 days without relief

b) Skin irritation on landing. No other explanation

treat it?

c) One crewmember with coughing episode. What was source and how did he

d) Biomed sensors caused patchy areas off olliculitis (pustule)

General

Comments:

Resolved:

If Resolved how, when, where?

Additional What was the source of the fiberglass? Is it still being used or will be used?

Questions:

Summit Topic: Yes 


\section{Appendix A Apollo Summit Non-Attributable Report}

Topic: IIInesses/Injuries

Issue: Health Concerns

Description: a) Lunar dust got in their eyes -Particle cleared on its own - did not require any eye drops

b) Took complained of nasal stuffiness throughout the flight. Took Ornade for symptomatic relief

c) Crew had no other complaint of illness before, during or after flight

d) Crew denied symptom

1. Mild loss of appetite $1^{\text {st }} 24-48$ hours

2. Minimized head and body movements

e) Crew noticed facial puffiness

f) Low back pain

1. Bringing knees into fetal position is a position of comfort; Stretching back is no good

2. It was hard to make the feeling in CMP back go away

3. Crew did not complain of back pain upon return to $1 \mathrm{~g}$

g) Dust material had distinctive "wet ashes" or gun powder smell to it

General

Comments:

Resolved:

If Resolved

how, when, where?

Additional Did the crew describe what exercises or positions improved or exacerbated the back

Questions: pain?

Summit Topic: Yes

Source:
Topic:
Issue:
Description:
General
Comments:
Resolved:
If Resolved
how, when,
where?

BME logs

Illnesses/Injuries

stuffy head

Additional Was this secondary illness or space adaptation?

Questions:

Summit Topic: Yes 


\section{Appendix A \\ Apollo Summit Non-Attributable Report}

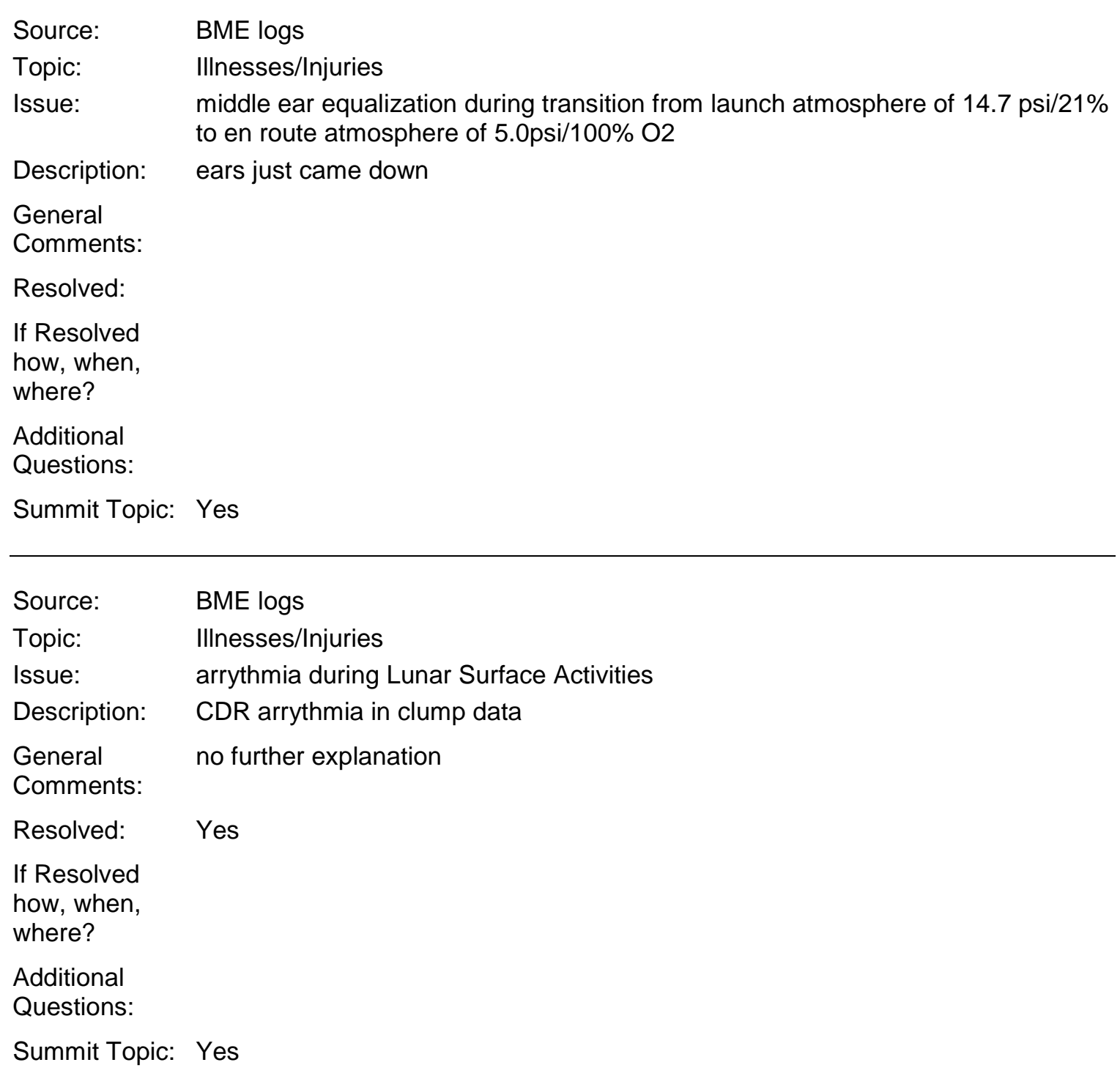




\section{Appendix A \\ Apollo Summit Non-Attributable Report}

$\begin{array}{ll}\text { Source: } & \text { BME logs } \\ \text { Topic: } & \text { Illnesses/Injuries } \\ \text { Issue: } & \text { PVC during Lunar EVA b/w CDR/LMP } \\ \text { Description: } & \text { PVC/ dysrhythmia } \\ \text { General } & \text { no further comment } \\ \text { Comments: } & \\ \text { Resolved: } & \text { Yes } \\ \text { If Resolved } & \\ \text { how, when, } & \\ \text { where? } & \\ \text { Additional } & \\ \text { Questions: } & \\ \text { Summit Topic: } & \text { No }\end{array}$

Source: $\quad$ Flight Surgeon logs

Topic: Illnesses/Injuries

Issue: $\quad T$ waves larger

Description: The t waves are excessively tall, increased rate- Is this artifact?

General

Comments:

Resolved:

If Resolved

how, when,

where?

Additional

Questions:

Summit Topic: No

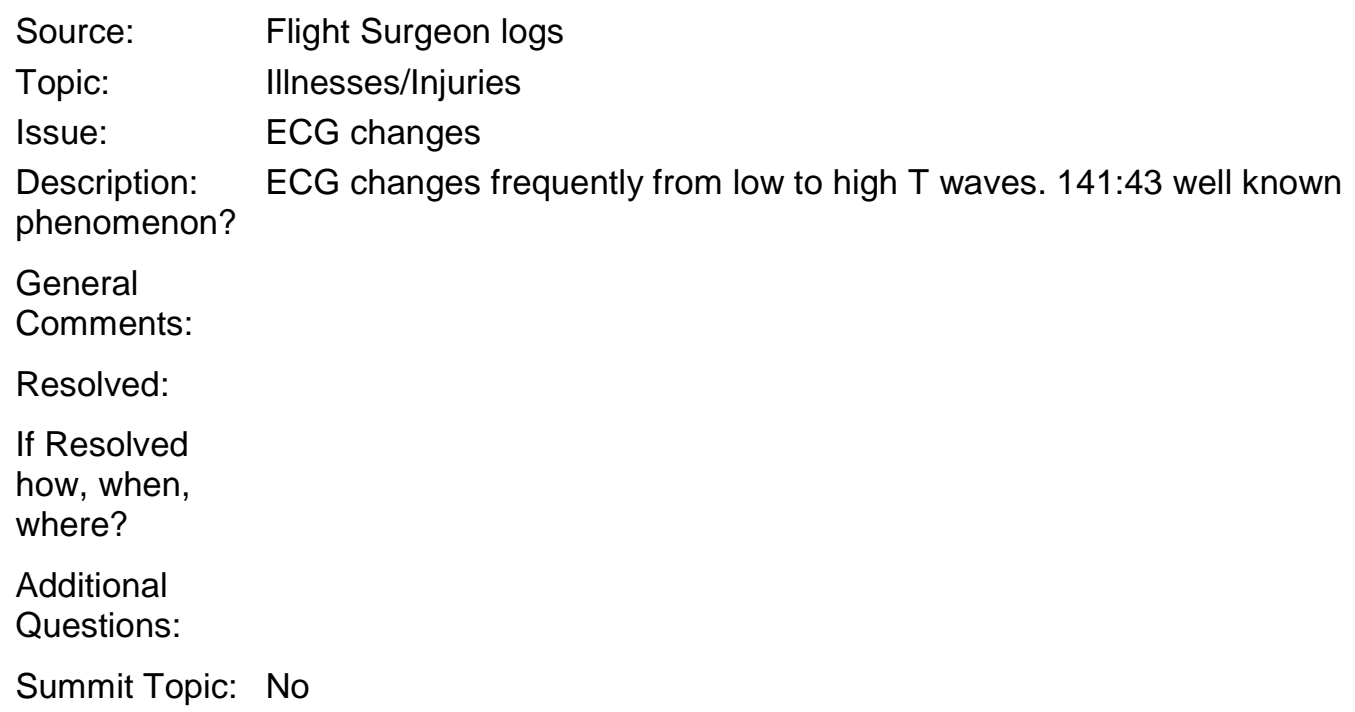




\section{Appendix A Apollo Summit Non-Attributable Report}

Source:

Flight Surgeon logs

Topic:

Illnesses/Injuries

Issue:

laceration

Description: splashdown

3/4 jagged laceration from camera which came from unstowed camera at

General

Comments:

Resolved:

If Resolved

how, when,

where?

Additional

Questions:

why was it not stowed away? Was there no room?

Summit Topic: Yes

Source: $\quad$ Flight Surgeon logs

Topic: Illnesses/Injuries

Issue: middle ear equalization

Description: My ears just came down an hour and half into eva

General

Comments:

Resolved:

If Resolved

how, when,

where?

Additional Is it difficult to equalize middle ear in suit? Was this a common occurrence? Did

Questions: you normally have problems clearing your ears?

Summit Topic: Yes

Source: $\quad$ Flight Surgeon logs

Topic: Illnesses/Injuries

issue: lesion

Description: Weeping lesion like poison ivy on sternal sensor

General

Comments:

Resolved:

If Resolved

how, when,

where?

Additional Was this a secondary infection? What does the crew member account for this?

Questions:

Summit Topic: Yes 


\section{Appendix A \\ Apollo Summit Non-Attributable Report}

Source: $\quad$ Flight Surgeon logs

Topic: Illnesses/Injuries

Issue: $\quad$ stuffy head

Description: LMP "stuffy head" due to O2 dryness take one actifed no and 1 before EVA

General

Comments:

Resolved:

If Resolved -

how, when,

where?

Additional How dry was the cabin?

Questions:

Summit Topic: Yes

Source: $\quad$ Medical Mission Debriefs

Topic: Illnesses/Injuries

Issue: motion sickness

Description: CMP: None of the Apollo 12 crew had any motion sickness, not during the flight nor in the Gulf, after splashdown

General

Comments: $\quad$ SMS was variable among $\mathrm{CM}$, ranging from non-existent to nausea/vomiting/anorexia.

Resolved:

If Resolved

how, when,

where?

Additional

Questions:

Summit Topic: Yes 


\section{Appendix A Apollo Summit Non-Attributable Report}

Source: $\quad$ Medical Mission Debriefs

Topic: IIlness/Injury

Issue: $\quad$ Physical Observations

Description: a) Urination, particularly at night was increased during the first few days of the mission

b) Crew made a conscious effort to drink lots of water on this mission, although this dropped off on the way home

c) Facial fullness, swelling was not noticeable on FD1, but improved "Just like standing on your head"

d) Crew described "coronal discharge" in great detail: flashes in their eyes during the mission, (or streaks of light)

-Noticed less CD if they faced toward the moon than away from it -typically occurred in one eye only

General

-Apollo $11 \mathrm{crew}$ described it but it wasn't in the mission debrief

Comments:

Resolved: $\quad \mathrm{N} / \mathrm{A}$

If Resolved

how, when,

where?

Additional 1. Does coronal discharge pose a problem?

Questions: $\quad$ 2. What was the average $\mathrm{H} 2 \mathrm{O}$ intake per $\mathrm{CM}$ per day?

Summit Topic: Yes 


\section{Appendix A Apollo Summit Non-Attributable Report}

Source: $\quad$ Medical Mission Debriefs

Topic: Illnesses/Injures

Issue: Physical Observations

Description: a) Back pain was noted in all 3 CM. FD0-3

b) Nasal congestion was a problem for all $3 \mathrm{CM}$

-crew related it to possible viral infections, exposure to lunar dust

-surgeon dismissed viral infection and related it to the $100 \% \mathrm{O} 2$ environment as it was reproducible in ground experiments -Crew tried to use Afrin (same problem as other crew experience with solution leaking out and decongestants)

Both CDR \& LMP -however, this condition resolved on the moon, only to return with entering $\mathrm{CM}$

c) CDR nasal congestion, HA, facial pain persisted through landing. Received tetracycline in the MQR for sinus infection

d) Lunar dust exposure caused conjunctival irritations

e) Biomed sensors resulted in skin irritation and vessicle formation around the electrode. - the vesicles developed into s. aureus pustule by the end of the mission

f) Crew commented that they experienced no post-landing MS. despite the fact that they had experienced MS with landing -training in the past.

General Comments:

Resolved:

If Resolved

how, when,

where?

Additional Crew exhibited painful/relieving postures during the interview but did not

Questions: articulate what there were. It is important for them to describe this as best as possible. Did it involve only the lumbar region or the entire spine?

Summit Topic: Yes 


\title{
Appendix A Apollo Summit Non-Attributable Report
}

\author{
Source: $\quad$ Medical Mission Debriefs \\ Topic: IIlnesses/Injuries \\ Issue: Head stuffiness \\ Description: LMP: 3-4 days prior to launch had head stuffiness, worsened during first half day \\ in flight. Blew his nose a lot and used Afrin, which cleared it for 4-8 hours. \\ Didn't think the Afrin spray bottle actually delivered anything in \\ weightlessness. After landing on the moon, his ears did not bother him \\ anymore. But he continued to use Afrin, though he was never symptomatic on \\ the moon. \\ CDR: Stuffy the 1st in flight day, was fine during the first EVA, but back in the LM \\ "I always have sinus trouble anyhow" Felt his nasal stuffiness after the 1st \\ EVA was secondary to "dirt." When pressurizing his suit for second EVA had \\ difficulty clearing his left ear. Subsequently his left sinuses and ears "had \\ mucous" which he attributed to lunar dust. Felt he was getting a cold "the \\ morning that we got up from coming back from the moon." The second day he \\ had other symptoms of a 'cold,' headache, myalgia. \\ CDR: noted he had a lot of dust exposure after returning to the LM, and docked \\ with the $\mathrm{CM}$ and transferred gear, etc. "The cabin was so full of junk floating \\ around in Zero G, I took off my helmet and I really blinded myself. I had \\ cinders in my eyes, and that stuff was all over everywhere." I told LMP not to \\ take his helmet off." Positive flow kept all of that stuff out of the command \\ module." \\ CDR: we kept the hatch closed. "I'd just pack one box in the proper bag, l'd open \\ the hatch, and l'd throw it to Dick. He'd give me the $\mathrm{LiOH}$ and we'd replace \\ that, and l'd leave the hatch closed." this helped keep the CM clean. Removed \\ suits in the LM and passed them across for stowage in the "L-shaped bag \\ "because they were so damn dirty." \\ General \\ Comments: \\ Resolved: No \\ If Resolved \\ how, when, \\ where? \\ Additional \\ Questions: \\ Summit Topic: Yes
}




\section{Appendix A Apollo Summit Non-Attributable Report}

Source: $\quad$ Flight Surgeon logs

Topic: Illnesses/Injuries

Issue: stuffy

Description: sounds stuffy $\mathrm{O} 2$ effect suspected

General

Comments: Crew members sounds.

Resolved:

If Resolved

how, when,

where?

Additional What countermeasures do we have for $\mathrm{O} 2$ drying out the crew?

Questions:

Summit Topic: No

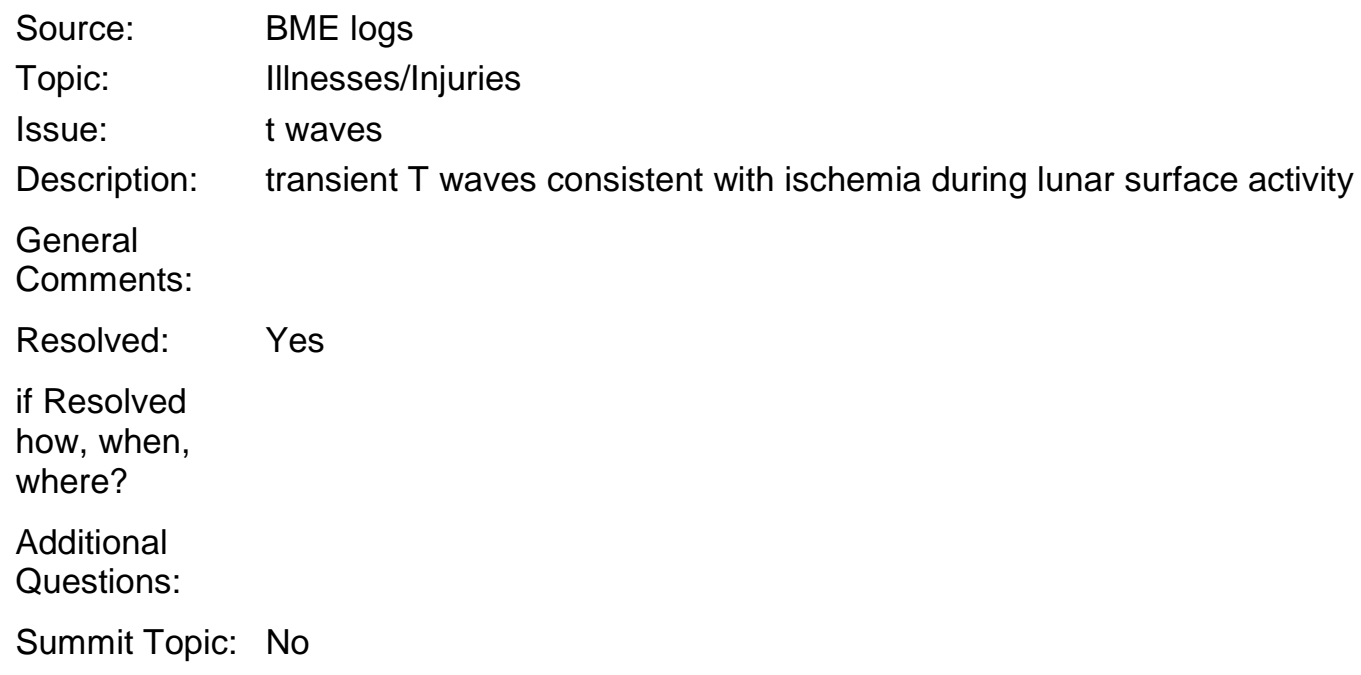

Source: $\quad$ Flight Surgeon logs

Topic: IIInesses/Injuries

Issue: rash

Description: 2-3 maculopapular lesions on buttocks

General

Comments:

Resolved: Yes

If Resolved

how, when, where?

Additional

Questions: What did crew attribute this to? How was it treated?

Summit Topic: No 


\section{Appendix A \\ Apollo Summit Non-Attributable Report}

Source: $\quad$ Flight Surgeon logs

Topic: illnesses/Injuries

Issue: rash

Description: 2 maculopapular lesions on the $L$ shoulder. Urinalysis WBC/HPF

General

Comments:

Resolved: No

If Resolved

how, when,

where?

Additional

Questions:

Summit Topic: No

Source: $\quad$ Flight Surgeon logs

Topic: Illnesses/Injuries

Issue: $\quad T$ wave change

Description: t wave change most likely due to respiration (occurred during rest?)

General

Comments:

Resolved:

If Resolved

how, when,

where?

Additional

Questions:

Summit Topic: No 


\section{Appendix A Apollo Summit Non-Attributable Report}

Source: Medical Mission Debriefs

Topic: Illnesses/Injuries

Issue: back discomfort

Description: CDR: Increasing relaxation state while awake helped reduce the back pain

CMP: "that small of the back problem was gone after a couple of days, and, in fact, I was kind of surprised at that." All three had back discomfort after the first night's sleep, all agreed it was back discomfort not "zero-g" sensations that interfered with sleep the first night.

Dr. Berry suggests the fetal position, CMP agrees.

General

Comments:

Resolved: No

If Resolved

how, when,

where?

Additional

Questions:

Summit Topic: Yes

$\begin{array}{ll}\text { Source: } & \text { BME logs } \\ \text { Topic: } & \text { Illnesses/Injuries } \\ \text { Issue: } & \text { PVC } \\ \text { Description: } & \text { PVC on lunar surface during surface activities. }\end{array}$

General

Comments:

Resolved:

If Resolved

how, when,

where?

Additional

Questions:

Summit Topic: No 


\section{Appendix A \\ Apollo Summit Non-Attributable Report}

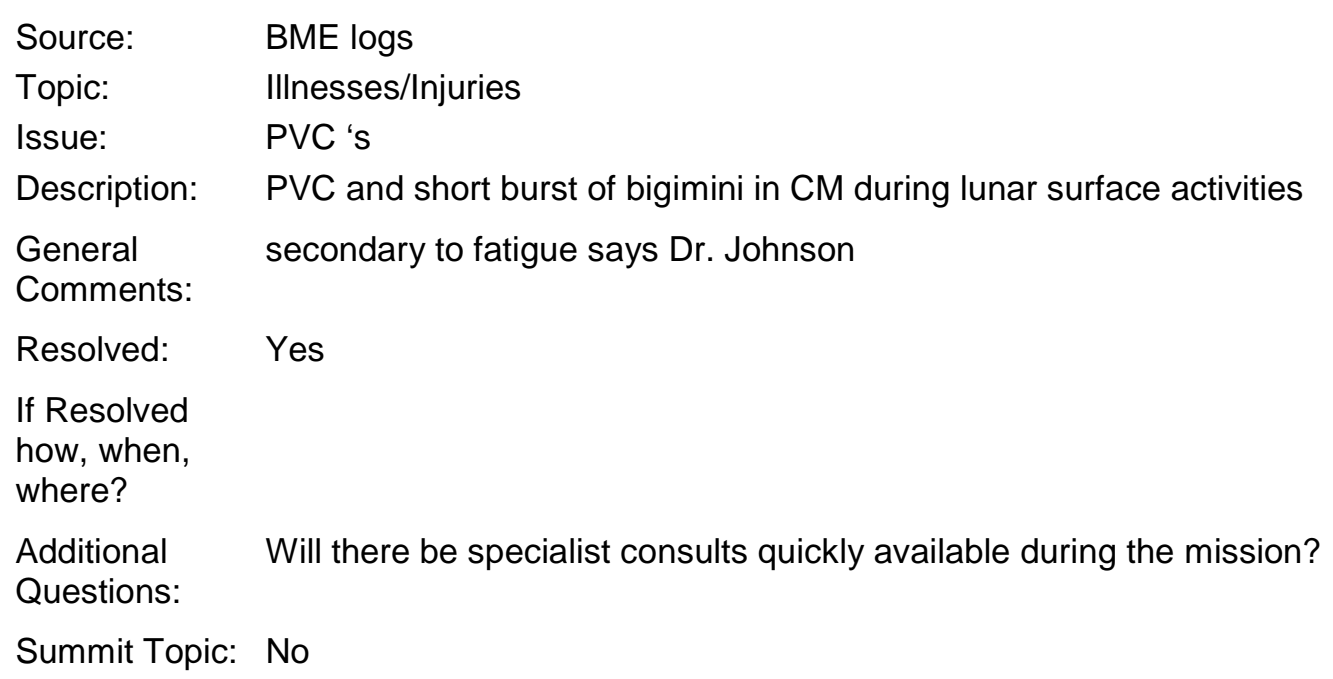




\section{Appendix A \\ Apollo Summit Non-Attributable Report}

Source: $\quad$ Flight Surgeon logs

Topic: Illnesses/Injuries

Issue: $\quad$ PVC

Description: CMP throwing numerous PVC during TLC.

General

Comments:

Resolved:

If Resolved

how, when,

where?

Additional

Questions:

Summit Topic: No

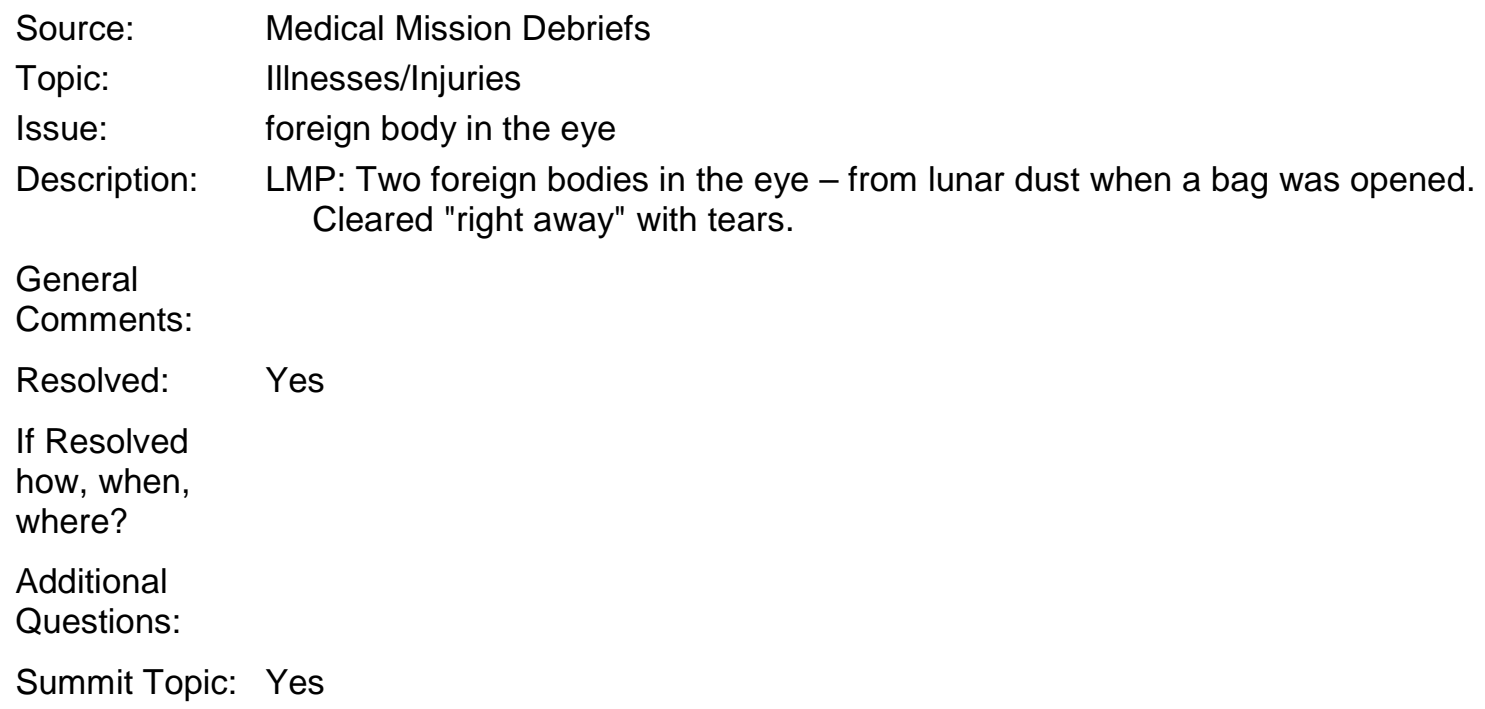

General

Comments:

Resolved: Yes

If Resolved

how, when,

where?

Additional

Questions:

Summit Topic: Yes

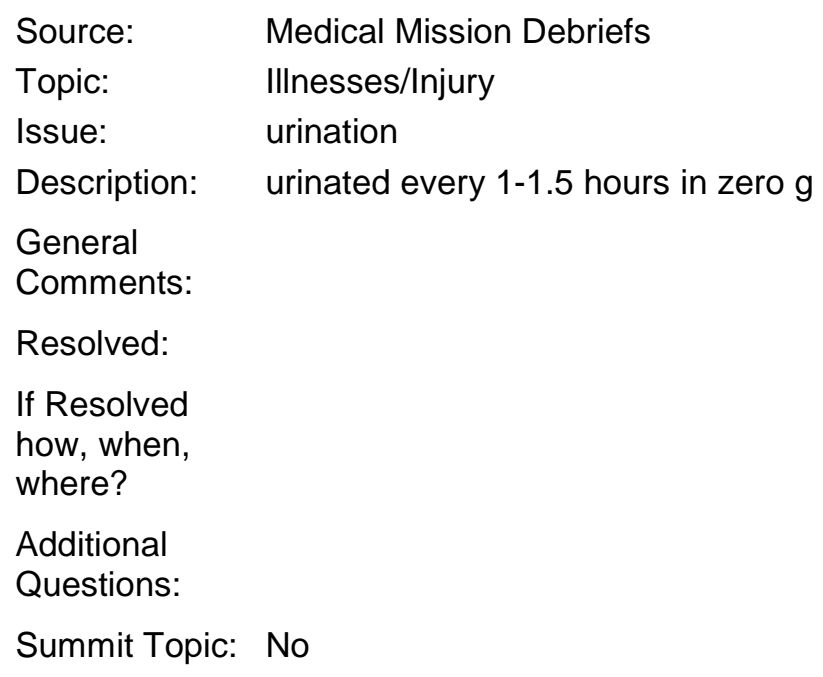




\title{
Appendix A Apollo Summit Non-Attributable Report
}

\author{
Source: Medical Mission Debriefs \\ Topic: IIlnesses/Injuries \\ issue: $\quad$ cardiac arrhythmia \\ Description: $\quad$ "There's no problem with that, there's no - there's no sign on any of you guys \\ because of anything like that; you can produce that in any individual. You kill \\ laboratory animals with that all the time, as an example. (Laughter)" \\ "I really think because then we - and then I think we ought to sometime this \\ afternoon if we get that done and off the thing then I think we can write a one- \\ liner right now that says exactly that, that say, okay, we've-all the exams have \\ been done; everybody is back and get off our back,.."
}

General

Comments:

Resolved:

If Resolved

how, when,

where?

Additional

Questions:

Summit Topic: No

\begin{abstract}
Source: Medical Mission Debriefs
Topic: Illnesses/Injuries

Issue: $\quad$ Flashes in visual field

Description: Crew saw flashes, as dots or flashes or streaks, CMP also saw them while asleep!?

Detailed description: "like a distant lightning flash in a cloud. It would sort of fill the whole eye. The bright dots were just that -bright while dots, some with halos and some without. The streaks were either pencil thin, clears freaks or fuzzy that went to think and then fuzzed out again." Moving in all different directions and they seemed to be randomly approaching. "The bright dots, you had the impression that they were coming at you..... the flashbulb type, it looked like what l'd call -the bright dots looks like a flashbulb going off. It's like the retinal photography except not quite that bright."

It looked like a cloud particle chamber where you see these things shooting through there. I had the feeling that the things were in the eye (LMP and CDR). CMP did not see them -possibly because of different shielding. Very brief, no after-effect, no color. Dots were very bright, very brief.
\end{abstract}

General ALFMED -Apollo Light Flash Moving Emulsion Detector --apparently worn by the Comments: astronaut. Didn't fit LMP well.

Resolved:

If Resolved how, when, where?

Additional

Questions:

Summit Topic: No 


\section{Appendix A Apollo Summit Non-Attributable Report}

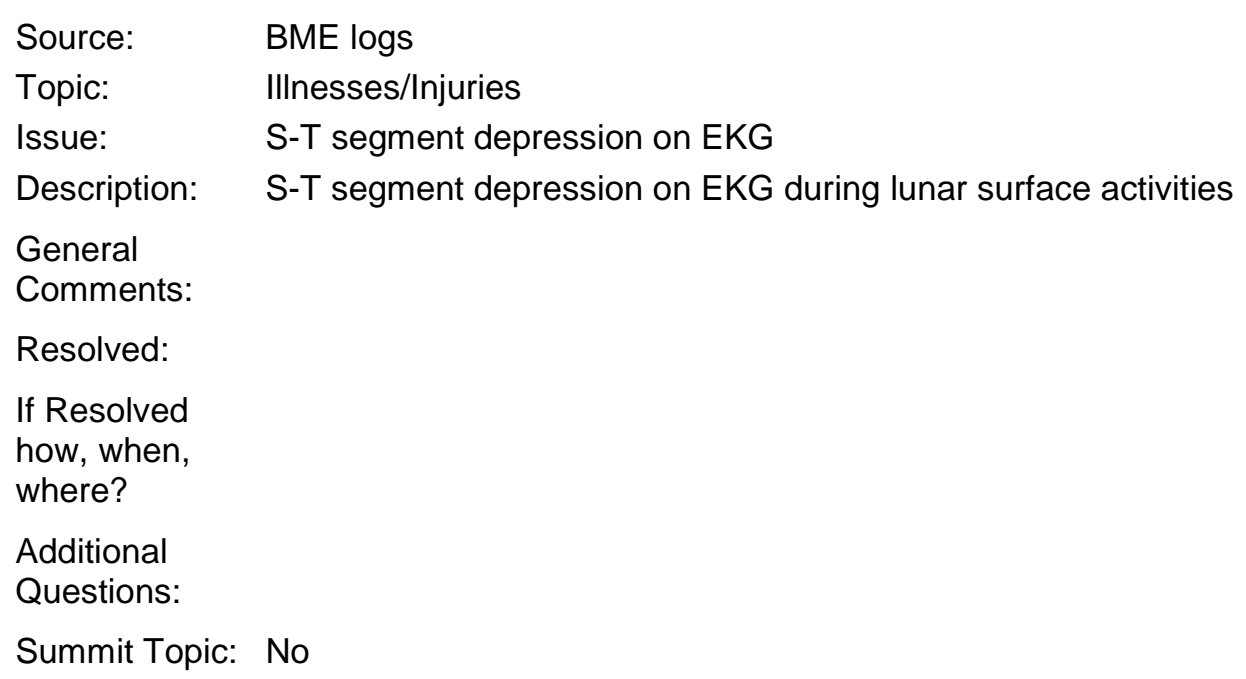

Additional

Questions:

Summit Topic: No

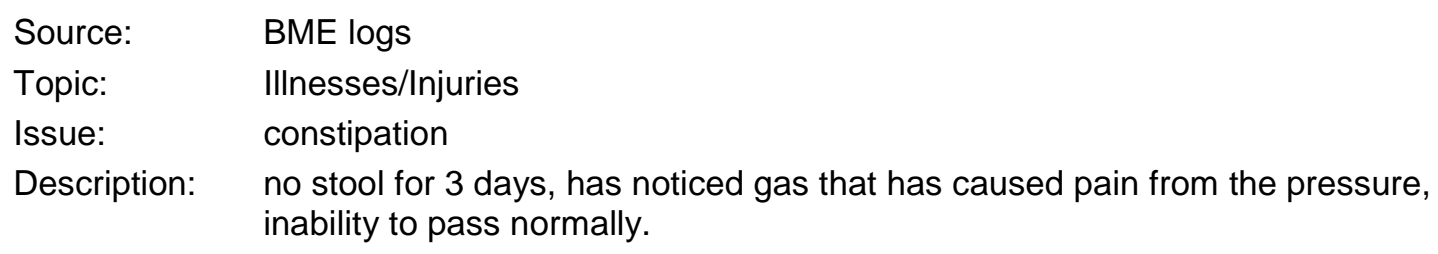

Resolved:

If Resolved

how, when, where?

Additional Questions:

Summit Topic: Yes 


\section{Appendix A \\ Apollo Summit Non-Attributable Report}

Source: $\quad$ Flight Surgeon logs

Topic: Illnesses/Injuries

Issue: gas

Description: gas problems wanted to take lomotil but FS says not without other symptoms

General

Comments:

Resolved:

If Resolved

how, when,

where?

Additional

Questions:

Summit Topic: Yes

Source: $\quad$ Flight Surgeon logs

Topic: Illnesses/Injuries

Issue: diarrhea

Description: loose stools or diarrhea by 2 crewmen

FS questions:

1 ) is it an infection-probably not. Too long from start of mission.

2) is it food? Contamination from broken bags of food makeup with high

amounts of electrolytes

3 ) is it in the water? Gas water separation or inadequate chlorination

General

Comments:

Resolved:

If Resolved

how, when,

where?

Additional

Questions:

Summit Topic: Yes 


\section{Appendix A Apollo Summit Non-Attributable Report}

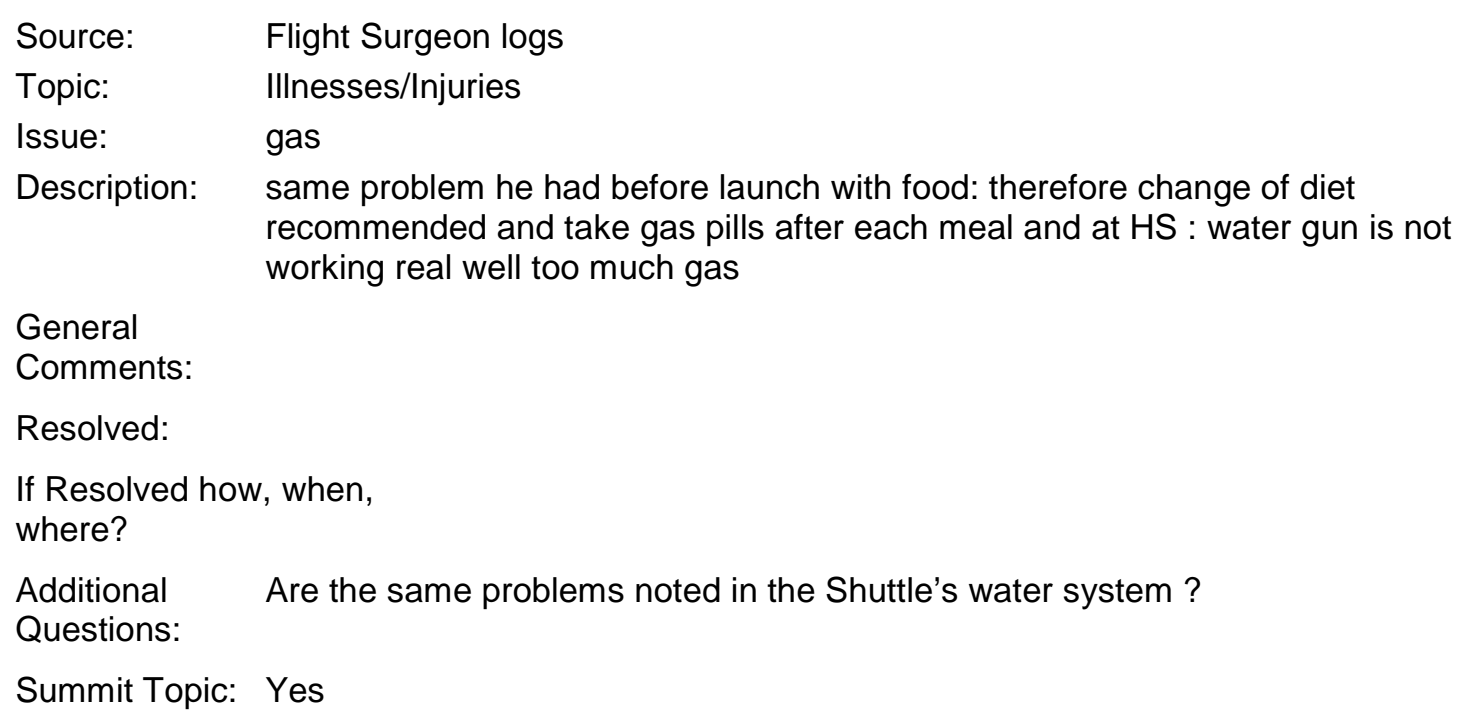

General

Comments:

Resolved:

If Resolved how, when, where?

Additional Are the same problems noted in the Shuttle's water system ?

Questions:

Summit Topic: Yes

$\begin{array}{ll}\text { Source: } & \text { Flight Surgeon logs } \\ \text { Topic: } & \text { Illnesses/Injuries } \\ \text { Issue: } & \text { coughing } \\ \text { Description: } & \text { coughing -O2 irritation vs dry cabin air. }\end{array}$

General

Comments:

Resolved:

If Resolved how, when, where?

Additional How was the air. Was it too dry?

Questions:

Summit Topic: Yes

$\begin{array}{ll}\text { Source: } & \text { Medical Mission Debriefs } \\ \text { Topic: } & \text { Illnesses/ Injuries } \\ \text { Issue: } & \text { cigarette? } \\ \text { Description: } & \begin{array}{l}\text { "Yeah, I was lighting a cigarette right after launch, right after dinner, and right } \\ \text { before lift off, and I never even felt like that." }\end{array}\end{array}$

General Comments:

Resolved:

If Resolved

how, when,

where?

Additional

Questions:

Summit Topic: No 


\title{
Appendix A \\ Apollo Summit Non-Attributable Report
}

\author{
Source: $\quad$ Medical Mission Debriefs \\ Topic: IIlnesses/Injuries \\ Issue: zero-g adaptation \\ Description: Got sick in every T-38 flight: Didn't get sick in zero-g. Just very tired, like he had \\ been up all night. Looking out the window gave false sensation of rolling \\ General \\ Comments: \\ Resolved: \\ If Resolved \\ how, when, \\ where? \\ Additional \\ Questions: \\ Summit Topic: No

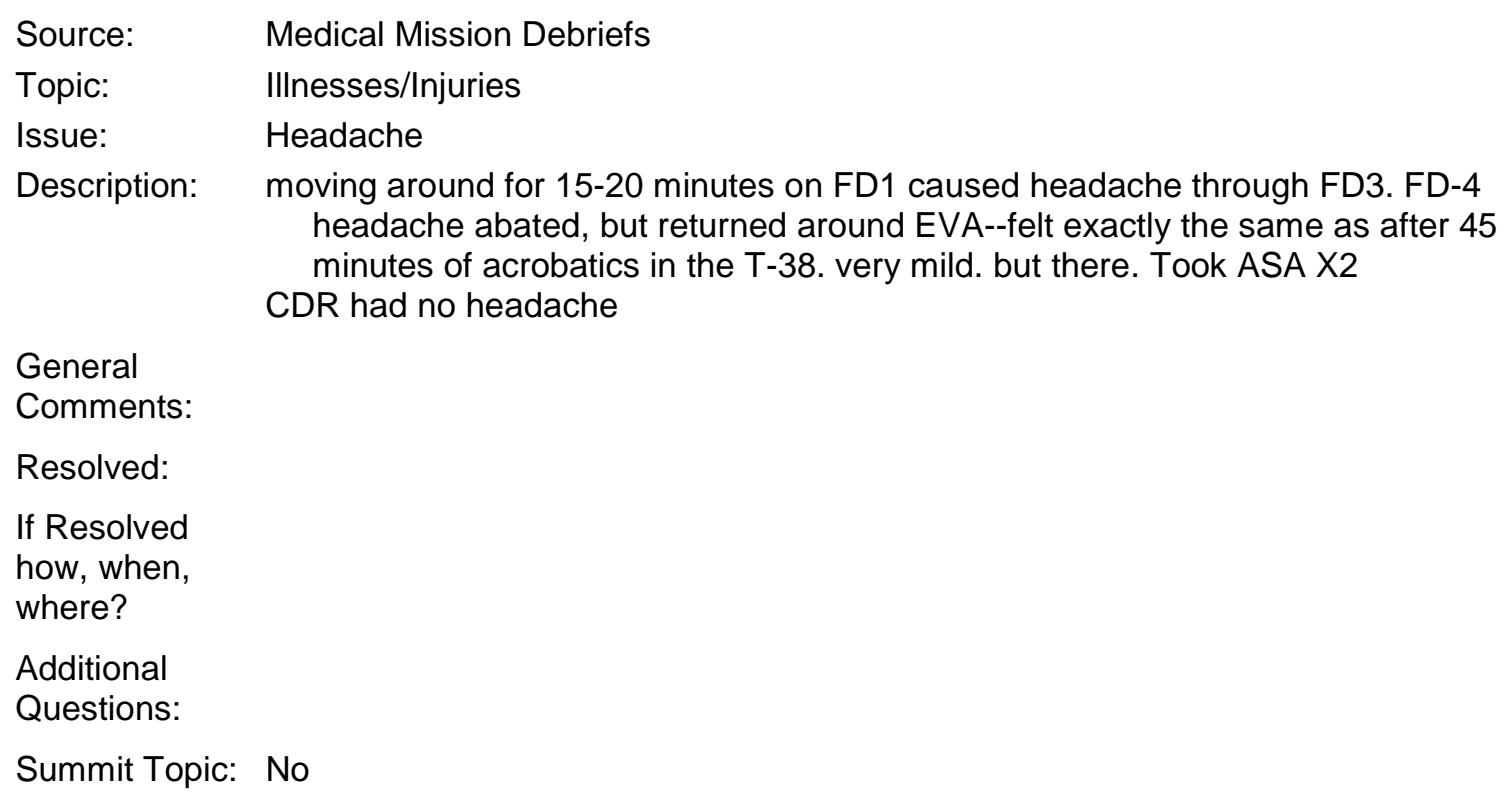

General

Comments:

Resolved:

If Resolved

how, when,

where?

Additional

Questions:

Summit Topic: No 


\section{Appendix A Apollo Summit Non-Attributable Report}

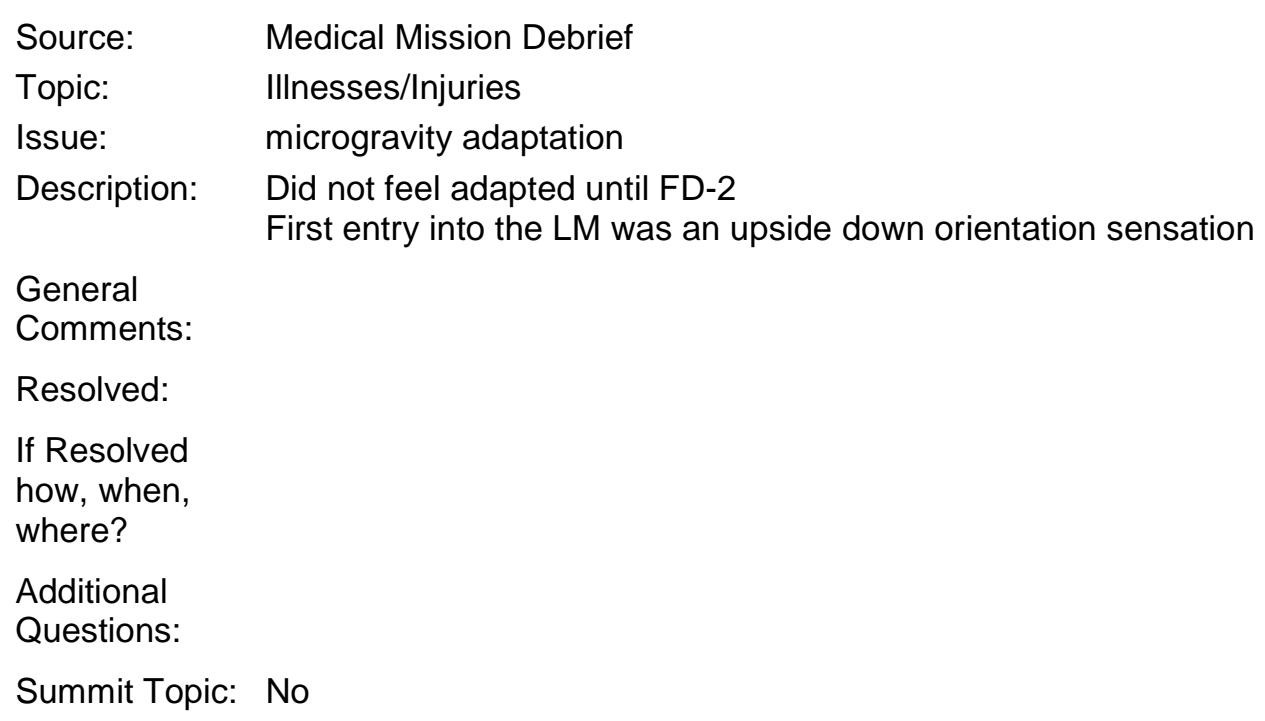

General

Comments:

Resolved:

If Resolved

how, when,

where?

Additional

Questions:

Summit Topic: No
Source: $\quad$ Flight Surgeon logs
Topic: Bioinstrumentation
Issue: $\quad$ Biomed data drop out
Description: CDR only CM with biomed data. The LMP/CMP had infrequent data reported to ground. Required waiver on launch.

General Comments:

Resolved:

If Resolved

how, when,

where?

Additional Are biomed data drops a problem currently with shuttle and ISS?

Questions: Will this still be an issue with Lunar exploration?

Summit Topic: Yes

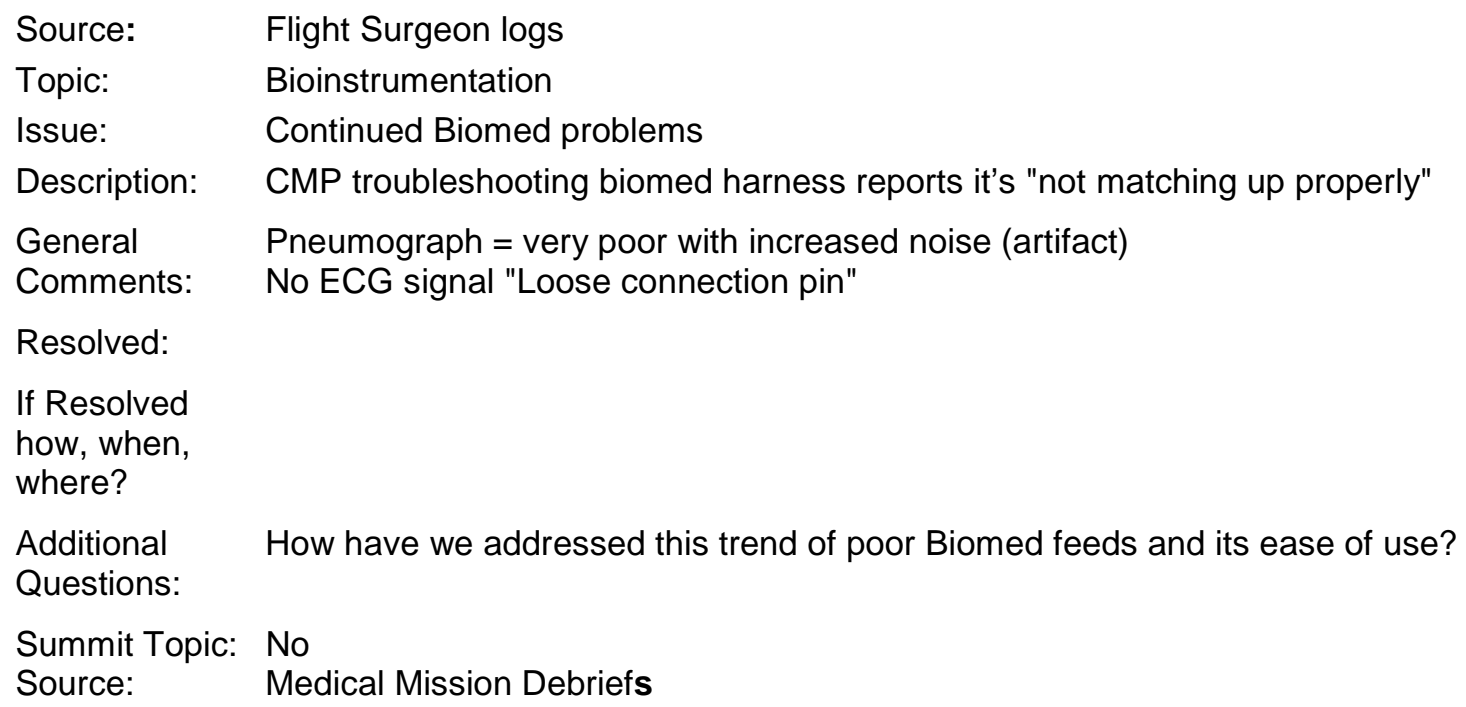




\section{Appendix A Apollo Summit Non-Attributable Report}

Topic: Bioinstrumentation

Issue: Design Observations

Description: a) Spiderweb-like configuration

b) Wires failed -signal conduction \& sensor

c) Harness/leads were fragile, not up to handling the crew activities/exercise

d) Biomed belt had to be removed for defecation (see General Comments)

e) Signal condition on OE became warm against his stomach requiring removal. Concerned him because of $100 \%$ O2 environment and undergarments were cotton. (See General Comments \& Additional Questions)

f) Band-to-band sound waves on ECG possibly secondary to failing electrical or lead disconnect.

General Biomed Belt: Difficulty with reconnecting signal conditions and comm adapter:

Comments: $\quad$ Plug interface did not male well possibly secondary to gas being trapped behind the rubber seal, shoving it off (en route)

Crewmember estimated the hardware temp was warm but not hot. Dr. Berry stated approximately 100 degrees Fahrenheit.

Resolved:

If Resolved

how, when,

where?

Additional

Fire hazard?

Questions:

Summit Topic: No

$\begin{array}{ll}\text { Source: } & \text { BME logs } \\ \text { Topic: } & \text { Bioinstrumentation } \\ \text { Issue: } & \text { Sensor irritating skin } \\ \text { Description: } & \text { Upper sternal sensor starting to irritate skin } \\ & \text { Conduit is hot/warm }\end{array}$

General

Comments:

Resolved:

If Resolved

how, when, where?

Additional Do current sensors used have same problems with skin irritations Apollo crew Questions: noticed? Do we have problems with temperature of sensors?

Summit Topic: No 


\section{Appendix A Apollo Summit Non-Attributable Report}

Source: BME logs

Topic: Bioinstrumentation

Issue: $\quad$ "Y" adapter failure

Description: $\quad Y$ adapter failure affected comm replaced with $T$ adapter 300 min of lost Biomed data of CDR in comparison to CMP and LMP

General

Comments:

Resolved:

If Resolved how, when, where?

Additional With exploration missions will we have plenty of replacement parts?

Questions:

Summit Topic: No

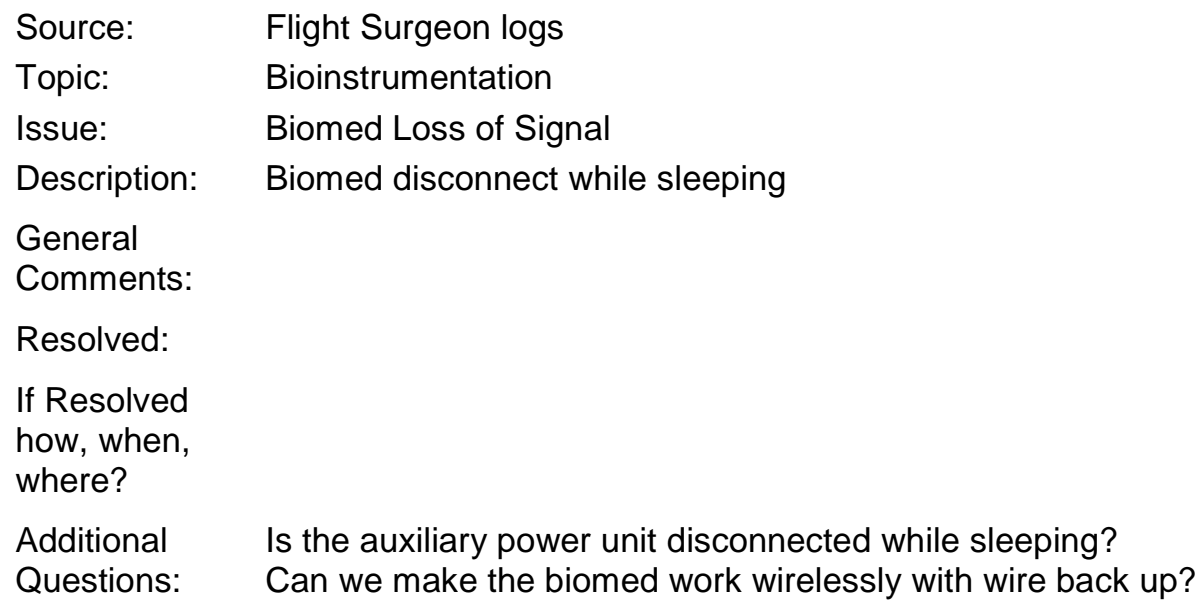

Summit Topic: No

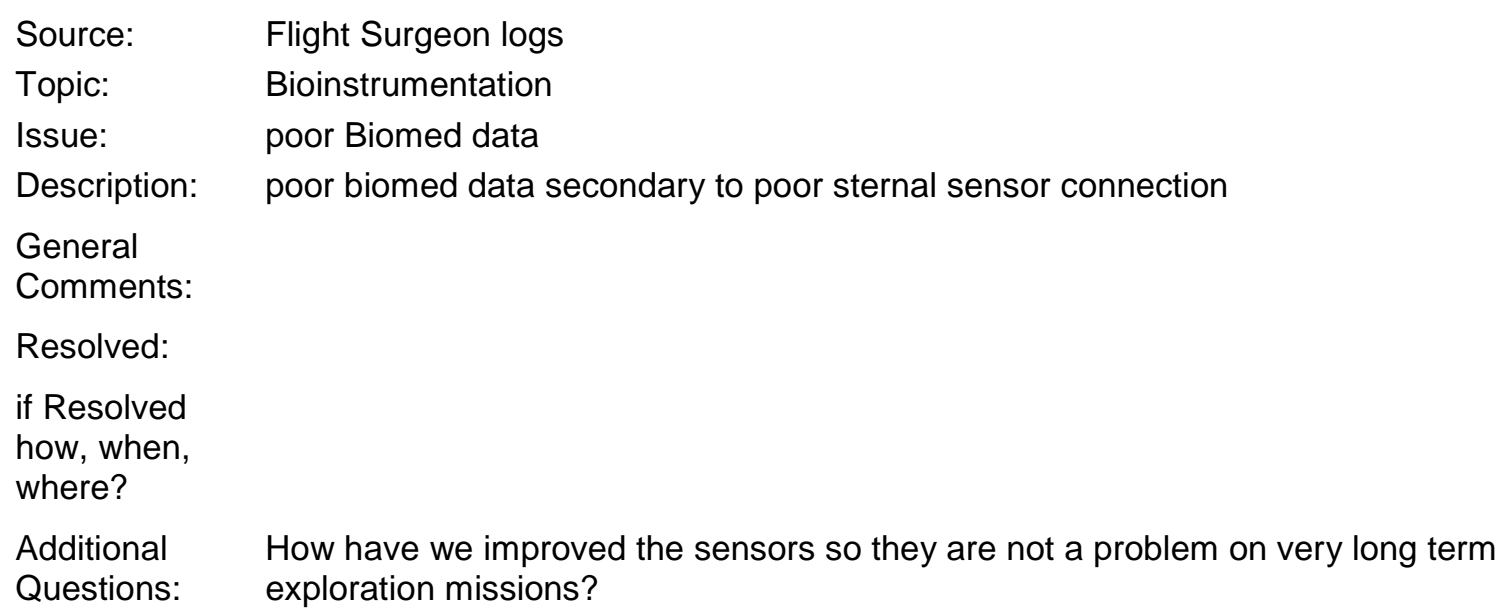

Additional How have we improved the sensors so they are not a problem on very long term Questions: exploration missions?

Summit Topic: No 


\title{
Appendix A Apollo Summit Non-Attributable Report
}

\author{
Source: $\quad$ Flight Surgeon logs \\ Topic: Bioinstrumentation \\ Issue: no cabin leak rate \\ Description: no cabin leak rate data available \\ General \\ Comments: \\ Resolved: \\ if Resolved \\ how, when, \\ where? \\ Additional How are we preparing to limit loss of data feeds? \\ Questions: What are our "acceptable limits" of lost data? \\ Summit Topic: No
}

\section{Source: $\quad$ BME logs}

Topic: Bioinstrumentation

Issue: Biomed probs

Description: EKG lost, EECOM thinks this whole stateside pass is a "Fiasco" and really had been "Screwed up" in several areas

General

Comments:

Resolved:

If Resolved

how, when,

where?

Additional How was biomed problems worse on the statsid pass?

Questions:

Summit Topic: No

Source: $\quad$ Flight Surgeon logs

Topic: Bioinstrumentation

Issue: $\quad$ sleep station hardware not functioning

Description: hardware not functioning in sleepstation so FS unable to identify if crew asleep

General

Comments:

Resolved:

If Resolved

how, when,

where?

Additional Would we be able to have wireless monitoring so this would not be a problem?

We

Questions: could have back up wire? 


\section{Appendix A \\ Apollo Summit Non-Attributable Report}

Summit Topic: No.

Source: $\quad$ Flight Surgeon logs

Topic: Bioinstrumentation

Issue: $\quad$ PCO2 sensor malfunction

Description: PCO2 sensor read $1.0 @$ launch therefore FS considers this a bias of $1=0$

General

Comments: Repeated malfunction of carbon dioxide sensor device

Resolved: No

If Resolved

how, when,

where?

Additional Do we need back up PCO2 detector?

Questions:

Summit Topic: Yes

Source: $\quad$ Flight Surgeon logs

Topic: Bioinstromentation

Issue: $\quad$ Faulty biomed sensor and leads

Description: LMP Biomed leads with bad connector at 2 and broken lead in 3

General

Comments:

Resolved:

If Resolved

how, when,

where?

Additional Are these problems that are noticed on ISS and Shuttle?

Questions:

Summit Topic: No

Source: $\quad$ Flight Surgeon logs

Topic: Bioinstrumentation

Issue: $\quad$ sensor discomfort

Description: The Sensors are drying out.

Itching and discomfort under the sensors

General

Comments:

Resolved:

If Resolved how, when, where?

Additional What options of application material do we have for sensors?

Questions: 


\section{Appendix A \\ Apollo Summit Non-Attributable Report}

Summit Topic: No

Source: $\quad$ Flight Surgeon logs

Topic: Bioinstrumentation

Issue: PRD

Description: CMP stated PRD was all fogged up

General

Comments:

Resolved:

If Resolved-

how, when,

where?

Additional Will we have back up PRD in case one doesn't work? Explain what caused this?

Questions:

Summit Topic: Yes

\begin{tabular}{ll}
\hline Source: & Medical Mission Debriefs \\
Topic: & Bioinstrumentation \\
Issue: & Electrode Observations \\
Description: & $\begin{array}{l}\text { a) Crew had problems with electrode paste drying cut around FD7-9. Result was } \\
\text { itchy and irritations } \\
\end{array}$ \\
& $\begin{array}{l}\text { b) Crew felt the mess and set-up with changing the electrodes/apply new paste } \\
\text { was more trouble than it was worth }\end{array}$ \\
General & $\begin{array}{l}\text { Recommend removing the electrodes for one day then re-applying in a staggered } \\
\text { Comments: }\end{array}$
\end{tabular}

Resolved:

If Resolved

how, when,

where?

Additional Is it desirable to change the electrodes out every day or every other day? Will

Questions: frequent changing of electrodes cause similar skin problems

Summit Topic: No

$\begin{array}{ll}\text { Source: } & \text { BME logs } \\ \text { Topic: } & \text { Bioinstrumentation } \\ \text { Issue: } & \text { Antenna problem } \\ \text { Description: } & \text { Antenna problem cause of loss of signal of biomed }\end{array}$

General Comments:

Resolved:

If Resolved

how, when,

where?

Additional Will we still have antennas on the CEV?

Questions:

Summit Topic: 


\section{Appendix A Apollo Summit Non-Attributable Report}

Source: $\quad$ Flight Surgeon logs

Topic: Bioinstrumentation

Issue: Biomed problems

Description: Problems with Biomed and PCO2 sensor problems

General

Comments:

Resolved: No

If Resolved

how, when,

where?

Additional

Questions:

Summit Topic: Yes

\section{Source: $\quad$ Medical Mission Debriefs}

Topic: Bioinstrumentation

Issue: Sensor Observations

Description: a) Sensor were irritating, caused backlog. Particularly once the crew took them off approximately FD4

b) Biomed ECG data was good throughout the mission

c) Crew does not appreciate daily server changes. Takes too much time

General Comments:

Resolved:

If Resolved

how, when, where?

Additional Are 4 sensors necessary? Can ECG and requests info be obtained with 2 or 3

Questions: e.g., Split electrodes (Gemini)?

Summit Topic: No

\begin{tabular}{ll}
\hline Source: & BME logs \\
Topic: & Bioinstrumentation \\
Issue: & O2 flow meter \\
Description: & O2 flow meter pegged full scale high \\
General & no more mention or explanation of this event \\
Comments: & \\
Resolved: & \\
If Resolved & \\
how, when, & \\
where? & \\
Additional & Was this not considered serious or is this within normal limits? Why no more \\
Questions: & mention of this? \\
Summit Topic: & No \\
Source: & BME logs
\end{tabular}




\section{Appendix A \\ Apollo Summit Non-Attributable Report}

Topic: Bioinstrumentation

Issue: Biomed loss

Description: Lost biomed on CDR and LMP

General

Comments:

Resolved:

if Resolved

how, when,

where?

Additional

Questions:

Summit Topic: No

\section{about it \\ General \\ Comments: \\ Resolved: \\ If Resolved \\ how, when, where?}

Source: BME logs

Topic: Bioinstrumentation

Issue: $\quad$ Electrode

Description: CMP told to renew electrode paste before bed and if it doesn't work will forget

Additional If we are alright to just forget about it do we even need to have it at all?

Questions: Is this statement because we are just so fed up with the sensors not working?

Summit Topic:

$\begin{array}{ll}\text { Source: } & \text { BME logs } \\ \text { Topic: } & \text { Bioinstrumentation } \\ \text { Issue: } & \text { biomed computer down } \\ \text { Description: } & \text { Biomed computer down }\end{array}$

General

Comments:

Resolved:

If Resolved

how, when,

where?

Additional

Questions:

Summit Topic: No 


\section{Appendix A \\ Apollo Summit Non-Attributable Report}

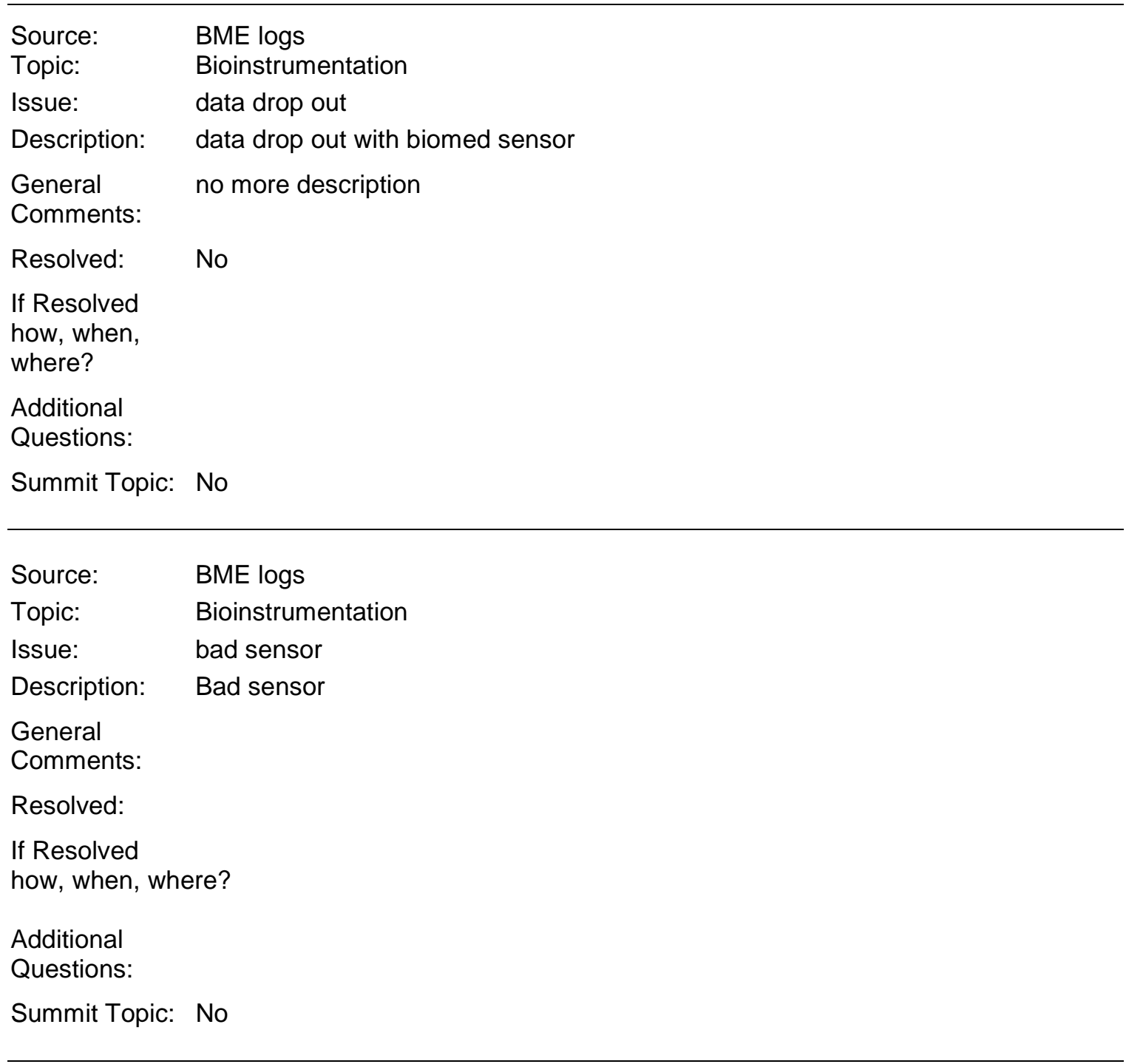

Source: $\quad$ Flight Surgeon logs

Topic: Bioinstrumentation

Issue: bio loss

Description: Com. Lost b/c of failure to change s/c omni antenna

General

Comments:

Resolved:

If Resolved

how, when, where?

Additional What kind of new technology will eliminate LOS because of antenna placement? Questions:

Summit Topic: No 


\title{
Appendix A \\ Apollo Summit Non-Attributable Report
}

\author{
Source: $\quad$ Flight Surgeon logs \\ Topic: Bioinstrumentation \\ Issue: leads \\ Description: LMP need sternal leads to be changed \\ General \\ Comments: \\ Resolved: No \\ If Resolved \\ how, when, \\ where? \\ Additional \\ Questions: \\ Summit Topic: No

\begin{abstract}
Source: $\quad$ Flight Surgeon logs
Topic: Bioinstrumentation

Issue: $\quad \mathrm{PCO} 2$ sensor

Description: PCO2 sensor malfunctioning. Notice of change not actual numbers, PCO2 sensor same problem as previous two missions, only goal should be to change sensor.

General note well that PCO2 malfunction was noted to be solved earlier? Is it or is it not?

Comments:

Resolved:

If Resolved

how, when,

where?

Additional has this problem been solved by calculation changes or is it a mechanical

Questions: $\quad$ problem? What PCO2 sensor is this the one sent down to ground or the one on the ship?

Summit Topic: Yes
\end{abstract}




\title{
Appendix A Apollo Summit Non-Attributable Report
}

\author{
Source: $\quad$ Flight Surgeon logs \\ Topic: Bioinstrumentation \\ Issue: $\quad$ PCO2 sensor explanation \\ Description: $\quad$ PCO2 anomaly of .8 to 1.5 jump due to calculation curve still set 14.7 psi but \\ cabin at 5:0 psi is this a separate anomaly from the recurrent malfunctions of \\ $\mathrm{PCO} 2$ \\ General \\ Comments: Recurring problem. \\ Resolved: No \\ If Resolved \\ how, when, \\ where? \\ Additional Does this explain all the multiple malfunctions? If so why then do we see them \\ Questions: still occurring later? \\ Summit Topic: Yes
Source: $\quad$ Medical Mission Debriefs
Topic: Bioinstrumentation
Issue:
Sensors
Description:
a) Sensors dried out requiring all new sensors to be put on. Much less cumbersome than cleaning them off and re-applying
b) Crew felt that bioinstrumentation sensor laboratory was unnecessary in the CM. $<14$ day mission
-Reported as uncomfortable, complicated equipment inside pressure suit -No requirement for \\ General \\ Comments: \\ Resolved: \\ If Resolved \\ how, when, \\ where? \\ Additional \\ Questions: \\ Summit Topic: No
}




\section{Appendix A Apollo Summit Non-Attributable Report}

Source: $\quad$ Flight Surgeon logs

Topic: Bioinstrumentation

Issue: biomed loss

Description: Biomed loss on CDR and LMP for the first night

General

Comments: Biomed drop outs continues across missions.

Resolved:

If Resolved

how, when,

where?

Additional

Questions:

Summit Topic: No

Source: $\quad$ Flight Surgeon logs

Topic: Bioinstrumentation

Issue: irritation

Description: irritation pustules on all sensor sites

General

Comments: Sensor pad, conduction paste caused skin irritation among most crewmembers.

Resolved: No

If Resolved

how, when,

where?

Additional

Questions:

Summit Topic: No

Source: $\quad$ Flight Surgeon logs

Topic: Bioinstrumentation

Issue: Loose connection

Description: loose connection in the CMP's bioharness

General

Comments:

Resolved:

If Resolved

how, when, where?

Additional

Questions:

Summit Topic: No 


\section{Appendix A \\ Apollo Summit Non-Attributable Report}

Source: $\quad$ Flight Surgeon logs

Topic: Bioinstrumentation

Issue: loss of sensor

Description: CDR loss of sensor

General

Comments:

Resolved:

If Resolved

how, when,

where?

Additional

Questions:

Summit Topic: No

Source: $\quad$ Flight Surgeon logs

Topic: Bioinstromentation

Issue: $\quad \mathrm{PCO} 2$

Description: PCO2 afunctional

General

Comments:

Resolved:

If Resolved

how, when,

where?

Additional Is this the same malfunction that has been noted since Apollo 9?

Questions:

Summit Topic: Yes

Source: $\quad$ Flight Surgeon logs

Topic: Bioinstrumentation

Issue: $\quad$ PCO2 gauge

Description: suspect that the PCO2 gauge may have failed

General

Comments:

Resolved:

If Resolved

how, when, where?

Additional How is this problem different than the same thing that happened in previous Questions: flights?

Summit Topic: Yes 


\section{Appendix A Apollo Summit Non-Attributable Report}

Source: $\quad$ Flight Surgeon logs

Topic: Bioinstrumentation

Issue: Sensor irritation

Description: CDR irritation at EKG site reattached somewhere else subtly changed wave form. This was reattached incorrectly

General

Comments:

Resolved:

If Resolved

how, when,

where?

Additional What was done incorrectly to cause this irritation? Was this a flaw in application Questions: of the instruments?

Summit Topic: Yes

Source: $\quad$ Flight Surgeon logs

Topic: Bioinstrumentation

Issue: $\quad$ request for no bioinstrumentation

Description: Crew requests no biomed tonight for better rest

General

Comments:

Resolved:

If Resolved how, when, where?

Additional "How did biomed affect sleep? How can we change this as to not affect sleep? Questions:

Summit Topic: Yes 


\title{
Appendix A Apollo Summit Non-Attributable Report
}

\author{
Source: $\quad$ Medical Mission Debriefs \\ Topic: Bioinstrumentation \\ Issue: Hardware Observations \\ Description: a) There was a problem with the biosensor apparently affecting the LMP. Unclear \\ about the details \\ -check FS/BME \\ -apparently the sensor dried out and got hard against the skin \\ b) Crew grew frustrated with the cumbersome taking the electrodes off, cleaning \\ and re-applying. Would rather replace sensors with new hardware. \\ c) Crew developed a rash including clear-fluid vesicles around the sensor site.
}

General

Comments:

Resolved:

If Resolved

how, when,

where?

Additional Did one of the wires develop a short in it causing it to get hot?

Questions: $\quad$ Crew questioned the need to monitor biomed data throughout the mission. If it is necessary, how do you best do it?

Summit Topic: No
Source:
Medical Mission Debriefs
Topic:
Bioinstrumentation
Issue:
monitoring time
Description: CMP: Don't need to be monitored so much. Don't need monitoring while asleep, or during the 3 day coast to the moon. Needless skin irritation and procedures that take a lot of time. Can't zip up in the sleeping bag with bioinstrumentation on.....
CDR: the past "boiled up under there." Got blisters. Started itching after only 4 hours, driving me crazy. "Every single one of them looked like poison ivy." Little whelps with fluid in them; like blisters. "Clear fluid in them. CDR had no reaction previously on Gemini flights, even wearing electrodes for 8 days.

General

Comments:

Resolved:

If Resolved how, when, where?

Additional

Questions: What and how long to monitor and what crew activities?

Summit Topic: No 


\section{Appendix A Apollo Summit Non-Attributable Report}

Source: $\quad$ Flight Surgeon logs

Topic: Bioinstrumentation

Issue: $\quad$ CO2 reading

Description: LM CO2 reading 12.5 our CO2 reading 11.4

General how important is accurate monitors that have been having a problem since

Apollo 9

Comments:

Resolved:

If Resolved

how, when,

where?

Additional

Questions:

Summit Topic: Yes

Source: $\quad$ Flight Surgeon logs

Topic: Bioinstrumentation

Issue: $\quad \mathrm{PCO} 2$ monitor

Description: $\quad$ PCO2 monitor $5.9 \mathrm{mmHg}$ although there is some possibility of the sensor failing

General the PCO2 monitor has been failing since Apollo

Comments:

Resolved:

If Resolved

how, when,

where?

Additional

Questions:

Summit Topic: No

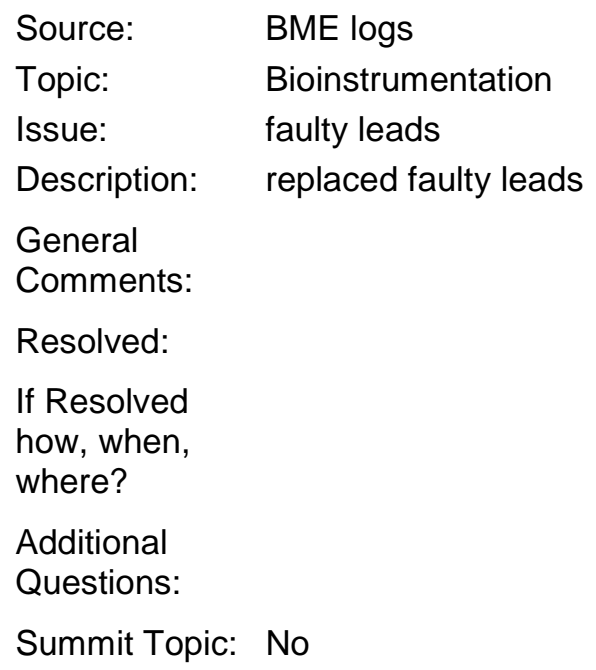

General

Comments:

Resolved:

If Resolved

how, when,

where?

Additional

Questions:

Summit Topic: No 


\section{Appendix A Apollo Summit Non-Attributable Report}

Source: $\quad$ Flight Surgeon logs

Topic: Bioinstrumentation

Issue: biomed harness

Description: will proceed without biomed harness if spare doesn't fix problem

General How important was it really if they were willing to proceed without it

Comments:

Resolved:

If Resolved

how, when,

where?

Additional

Questions:

Summit Topic: No

Source: $\quad$ Flight Surgeon logs

Topic: Bioinstrumentation

Issue: check

Description: Bioharness check

General I like to see they are now scheduling biohamess checks but unfortunately its like fixing

Comments: something that's not broke at this point.

Resolved:

If Resolved

how, when,

where?

Additional Did these checks help to keep you on schedule with other tasks?

Questions:

Summit Topic: Yes

Source: $\quad$ Flight Surgeon logs

Topic: Bioinstrumentation

Issue: leakage of paste

Description: Leakage of paste at sensor during biocheck

General

Comments:

Resolved:

If Resolved

how, when,

where?

Additional Did these biochecks help prevent problems? I don't see any mention of them in Questions: later missions were they stopped? If so, why?

Summit Topic: Yes 


\section{Appendix A \\ Apollo Summit Non-Attributable Report}




\section{Appendix A \\ Apollo Summit Non-Attributable Report}

Source: $\quad$ Flight Surgeon logs

Topic: Bioinstrumentation

Issue: BIOMED

Description: biomed lost recommended that he replace his EKG harness with a spare

General

Comments: Biomed data lost. Reconnected...

Resolved:

If Resolved

how, when,

where?

Additional It doesn't appear that scheduled biomed checks were that beneficial?

Questions:

Summit Topic: Yes

Source: $\quad$ Flight Surgeon logs

Topic: Bioinstrumentation

Issue: $\quad$ EKG stripped thread

Description: reports stripped thread on EKG signal conditioner

General no more information

Comments:

Resolved:

If Resolved

how, when,

where?

Additional Can you shed more light on this event?

Questions:

Summit Topic: Yes 


\section{Appendix A Apollo Summit Non-Attributable Report}

Source: $\quad$ Medical Mission Debriefs

Topic: Bioinstrumentation

Issue: $\quad$ Noisy signal on CDR at launch

Description: Intermittent loss of signal, then noise and low frequency baseline drift, which intermittently reverted to Clean signal

CDR: on second day "cleaned it, refilled it, and put a new sticky back on it and put it back on." Also changed the CWG adapter.

CDR noted the thread coupling between the sensor line/sensor harness and the best were stripped. It would apparently slip down. The connector at the signal conditioner was routinely disconnected for "bowel movements and for swabbing down and cleaning up process."

LMP: pulling clothes off to change or put on the LCG or use the blue bags, all undid the hose. Also removed. cleaned, refitted and replaced one sensor.

General.

Comments:

Resolved:

If Resolved

how, when,

where?

Additional

Questions:

Summit Topic: No

$\begin{array}{ll}\text { Source: } & \text { BME logs } \\ \text { Topic: } & \text { Bioinstrumentation } \\ \text { Issue: } & \text { bad sensor } \\ \text { Description: } & \text { Exercise period EKG bad or loose sensor }\end{array}$

General

Comments:

Resolved:

If Resolved

how, when, where?

Additional

Questions:

Summit Topic: No 


\section{Appendix A \\ Apollo Summit Non-Attributable Report}

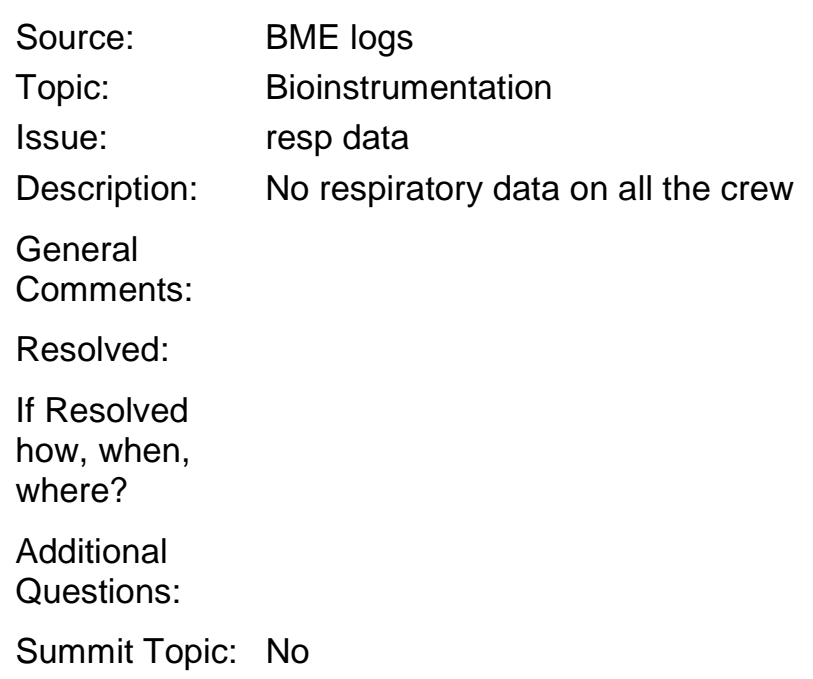

Additional

Questions:

Summit Topic: No

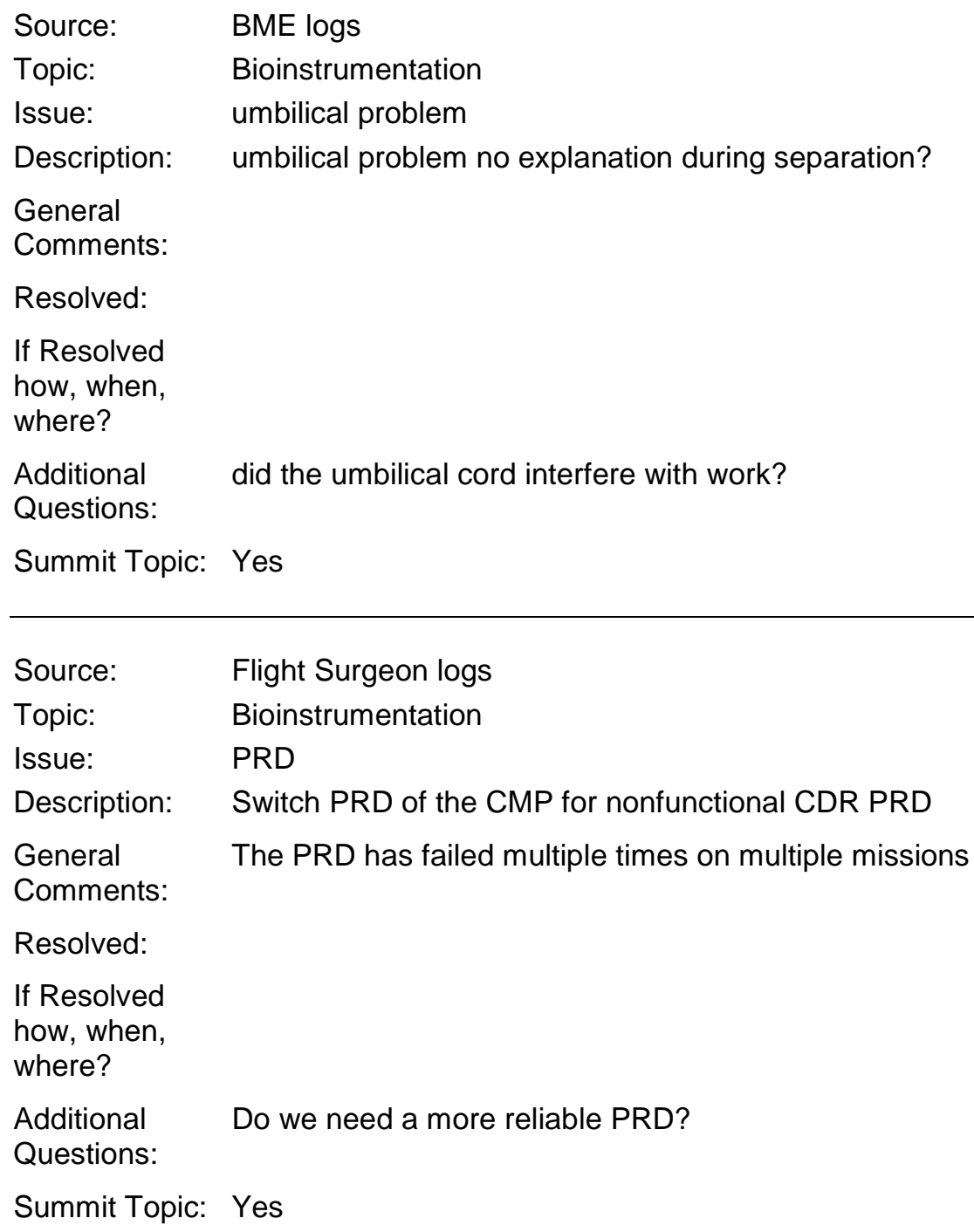




\section{Appendix A \\ Apollo Summit Non-Attributable Report}

Source: $\quad$ Flight Surgeon logs

Topic: Bioinstrumentation

Issue: umbilical not connected

Description: discovered umbilical not connected

General

Comments:

Resolved: $\quad$ No

If Resolved

how, when,

where?

Additional Was remembering to keep the umbilical a hassle? Would not having one be helpful?

Questions:

Summit Topic: Yes

Source: $\quad$ Flight Surgeon logs

Topic: Bioinstrumentation

Issue: poor ECG

Description: concern of poor ECG tracing explained to be secondary or lower bit frequency received

General

Comments:

Resolved: No

If Resolved

how, when,

where?

Additional Was there a problem with all the ECG tracings or just this one time?

Questions:

Summit Topic: Yes 


\section{Appendix A Apollo Summit Non-Attributable Report}

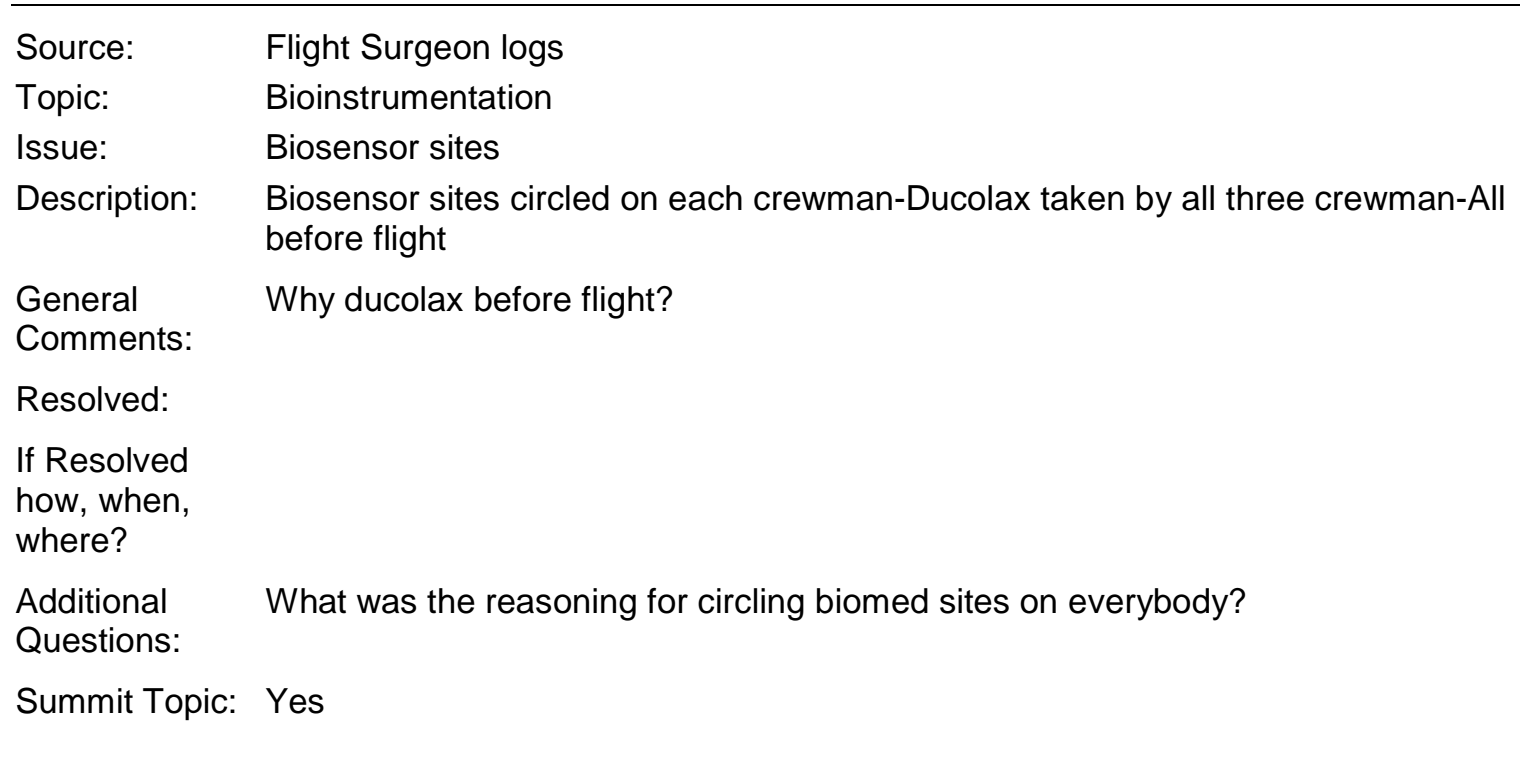
Source: $\quad$ Flight Surgeon logs
Topic: Bioinstrumentation
Issue: $\quad$ ZPN
Description: Bad ZPN-problem debrief gas expansion drives electrolytes out of the sponge causing increase sensitivity to lower cabin pressure than Apollo 9

General

Comments:

Resolved:

If Resolved

how, when, where?

Additional Are we still using the sponges? What gas pressure will the CEV be at? Could this Questions: problem potentially happen again?

Summit Topic: Yes

\begin{tabular}{ll}
\hline Source: & $\begin{array}{l}\text { Flight Surgeon logs } \\
\text { Topic: }\end{array}$ \\
$\begin{array}{l}\text { Bioinstrumentation } \\
\text { Issue: }\end{array}$ & $\begin{array}{l}\text { unplugged } \\
\text { Description: }\end{array}$ \\
& $\begin{array}{l}\text { Unplugged will wait 1-1.5 hrs before request...3 hrs later Request to " } \\
\text { biomed via the Flight Plan" }\end{array}$ \\
General Comments: \\
Resolved: \\
If Resolved \\
how, when, \\
where? \\
Additional \\
$\begin{array}{l}\text { Questions: } \\
\text { Summit Topic: }\end{array}$ \\
Source:
\end{tabular}




\section{Appendix A Apollo Summit Non-Attributable Report}

Topic: Bioinstrumentation

Issue: $\quad$ ZPN (respiration) electrode

Description: $\quad$ ZPN signal derived via an impedance measurement. The electrode, applied in a 14.7 psia atmosphere failed with depressurization to $5.0 \mathrm{psia}$. The electrode was removed and expanded gas removed from the sensor pad with manual pressure and the electrode re-applied and it functioned well after that.

General

Comments:

Resolved:

If Resolved

how, when, where?

Additional

Questions:

Summit Topic: No

\begin{tabular}{|c|c|}
\hline Source: & Medical Mission Debriefs \\
\hline Topic: & Bioinstrumentation \\
\hline Issue: & don-doff time required \\
\hline Description: & $\begin{array}{l}\text { 10-15 minutes. Could save } 10 \text { minutes of the time by packaging the sponges to } \\
\text { avoid having to cut six open to use five, and making the little sponges } \\
\text { somewhat larger than the holes. }\end{array}$ \\
\hline & Berry replies they will take "some lotion to do this?" \\
\hline & $\begin{array}{l}\text { Entire crew suggested a 'work station' for storage after doffing, and to assist next } \\
\text { donning of the electrode harness } \\
\text { Electrodes caused skin irritation }\end{array}$ \\
\hline
\end{tabular}

General

Comments:

Resolved:

If Resolved

how, when,

where?

Additional

Questions:

Summit Topic: Yes 


\section{Appendix A Apollo Summit Non-Attributable Report}

Source: $\quad$ Flight Surgeon logs

Topic: Bioinstrumentation

Issue: pneumogram

Description: pneumogram in operation-suspected sensor loss - will not connect

General

Comments:

Resolved: No

If Resolved

how, when,

where?

Additional

Questions:

Summit Topic: No

Source: $\quad$ Flight Surgeon logs

Topic: Bioinstrumentation

Issue: chest lead for ECG

Description: continued problem of sternal chest lead during EVA

General

Comments:

Resolved:

If Resolved

how, when,

where?

Additional

Questions:

Summit Topic: No

Source: $\quad$ Flight Surgeon logs

Topic: Bioinstrumentation

Issue: confusion

Description: confusion for several hours as to who is on biomed

General

Comments:

Resolved:

If Resolved

how, when, where?

Additional shouldn't this be a decoder as to whose information is being received on Questions: biomed?

Summit Topic: Yes 


\title{
Appendix A Apollo Summit Non-Attributable Report
}

\author{
Source: $\quad$ Medical Mission Debriefs \\ Topic: Bioinstrumentation \\ Issue: $\quad$ Sensors and leads \\ Description: Suggested a monitoring check before securing for sleep, so they don't get \\ awakened to fix a pre-existing problem, \\ Electrodes were modified after Apollo 15 to reduce skin irritation, but the process \\ of applying and removing electrodes was so time-consuming some crew \\ preferred to just leave them in place between monitoring sessions. \\ Itching was a problem and the itching interfered with sleeping for the CMP. Tape \\ was a problem for some. The allotted timeline of 2 minutes to don and doff \\ biomed sensors usually required about 20 minutes. \\ General CMP did not think the monitoring was justified, useful, or a good use of lunar \\ mission \\ Comments: time. Dr. Berry states: "I guess the first thing l'd like to say is that I am totally \\ amazed, after 10 trips of manned space flight, at the total lack of \\ understanding that you guys seem to have about why we did some of the \\ things that we did." Followed with a length, detailed explanation of \\ considerations other than 'operational' that influence biomedical activities. \\ Resolved: \\ If Resolved \\ how, when, \\ where? \\ Additional \\ Questions: \\ Summit Topic: No

\begin{tabular}{ll}
\hline Source: & BME logs \\
Topic: & Bioinstrumentation \\
Issue: & applying J and J cream \\
$\begin{array}{l}\text { Description: } \\
\text { cream }\end{array}$ & applying sensors states sensors may not stick well due to application of $\mathrm{J}$ and $\mathrm{J}$ \\
&
\end{tabular} \\ General \\ Comments: \\ Resolved: \\ If Resolved \\ how, when, \\ where? \\ Additional \\ Questions: \\ Summit Topic: No
}




\section{Appendix A \\ Apollo Summit Non-Attributable Report}

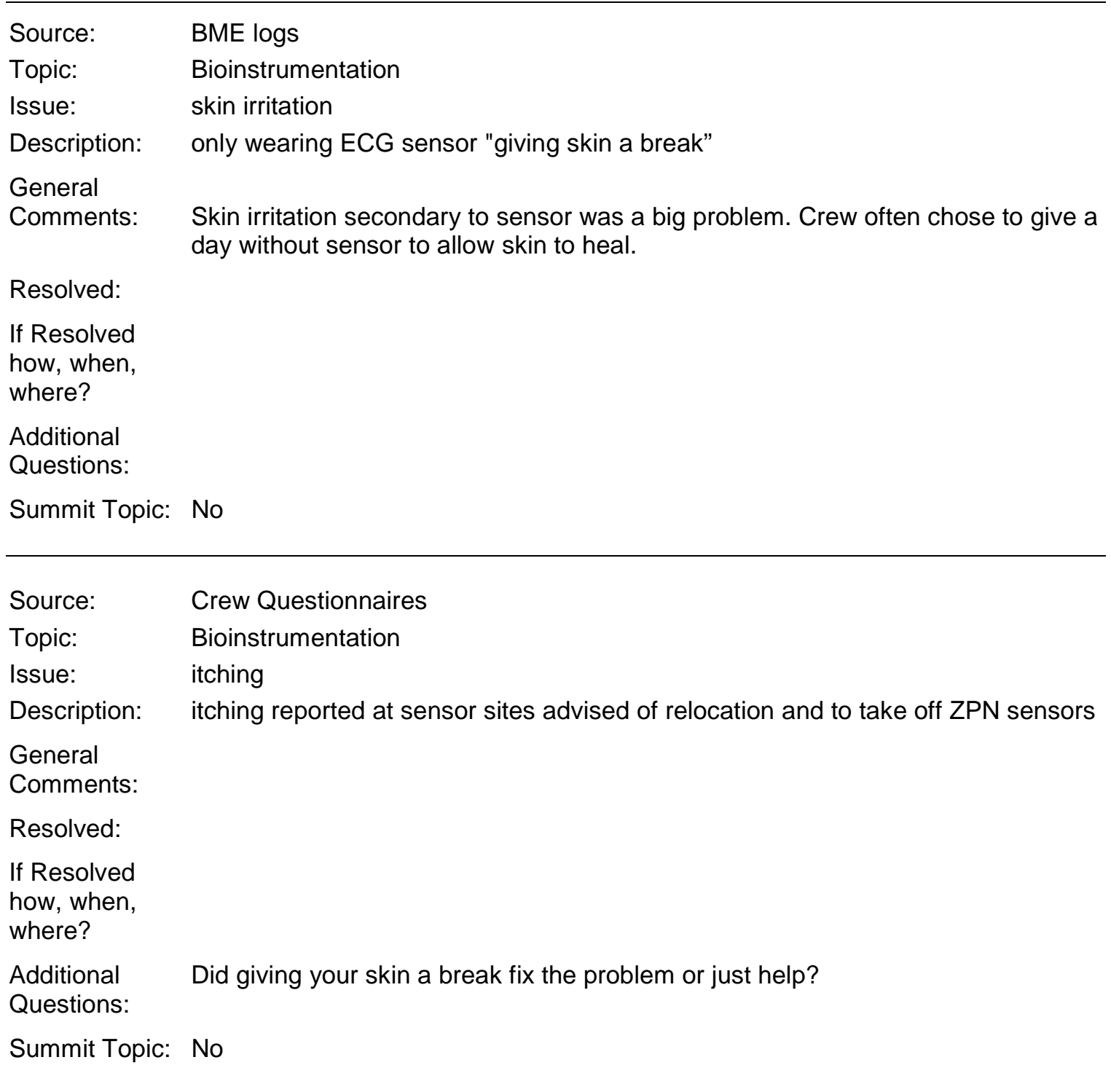

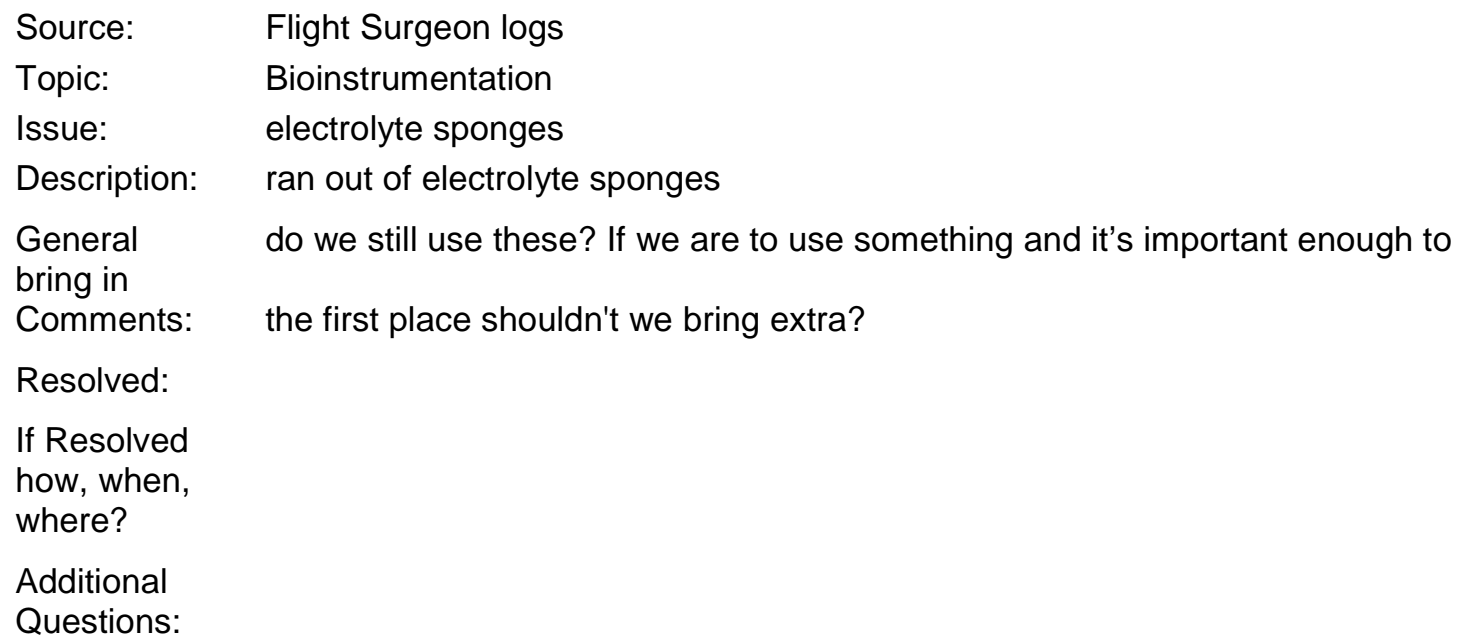




\section{Appendix A \\ Apollo Summit Non-Attributable Report}

Summit Topic: No

Source: $\quad$ Flight Surgeon logs

Topic: Bioinstrumentation

Issue: skin cream

Description: skin cream cleared up old sensor site

General

Comments:

Resolved:

If Resolved

how, when,

where?

Additional What was the skin cream?

Questions:

Summit Topic: Yes

Source: $\quad$ Medical Mission Debriefs

Topic: Bioinstrumentation

Issue: electrode drying

Description: biological electrodes dried out after about 12 hours. LMP recommended new electrolyte and procedures as the current system is unsatisfactory from both a skin irritation and a maintenance standpoint. Removal of the electrode revealed a brown scab underneath and no electrolyte paste. Skin electrodes in the CM were different from those in the LM.

General

Comments:

Resolved:

If Resolved

how, when, where?

Additional

Questions:

Summit Topic: No 


\title{
Appendix A Apollo Summit Non-Attributable Report
}

\author{
Source: Medical Mission Debriefs \\ Topic: Medication/ Medical Kits \\ Issue: $\quad$ Use \& Amount Dispensed \\ Description: a) Actifed for runny nose -threshold secretions (8) \\ b) Aspirin for general principles? (6-8) \\ c) Marezine for nausea -primary (BIG); secondary (prevention) \\ d) Dulcolax taken before flight \\ e) Dexedrine (1 dose) FD7 or so with minimal effect \\ f) Lomotil (2-3 doses) to intentionally delay BM after launch and during flight. \\ However. crew only felt it "quieted the stomach down" by approximately 8 \\ hours \\ g) Darvon (2) \\ h) Nasal emollient? \\ General BME log 58:00:xx 6 Actifed consumed, leaving 18 tabs for remaining mission \\ Comments: \\ Resolved: \\ If Resolved \\ how, when, \\ where? \\ Additional \\ Questions: How did kit arrangement, allotment of medications impact crew during the \\ mission? \\ Summit Topic: Yes
Source: $\quad$ Medical Mission Debriefs
Topic: Medication/ Medical Kit
Issue: Use and Amount Dispensed
Description: a) 24 tabs Actifed
b) 24 tabs antibiotic (urinary class) (See General Comments) \\ General Use of antibiotics. Flight Surgeon log - Symptoms treated only when definite \\ Comments: evidence of purulence and increased temp, then begin antibiotics \\ Use dexedrine for re-entry as decongestant and anti-lethargic agent \\ Resolved: \\ If Resolved \\ how, when, \\ where? \\ Additional \\ Questions: \\ Summit Topic: Yes
}




\section{Appendix A \\ Apollo Summit Non-Attributable Report}

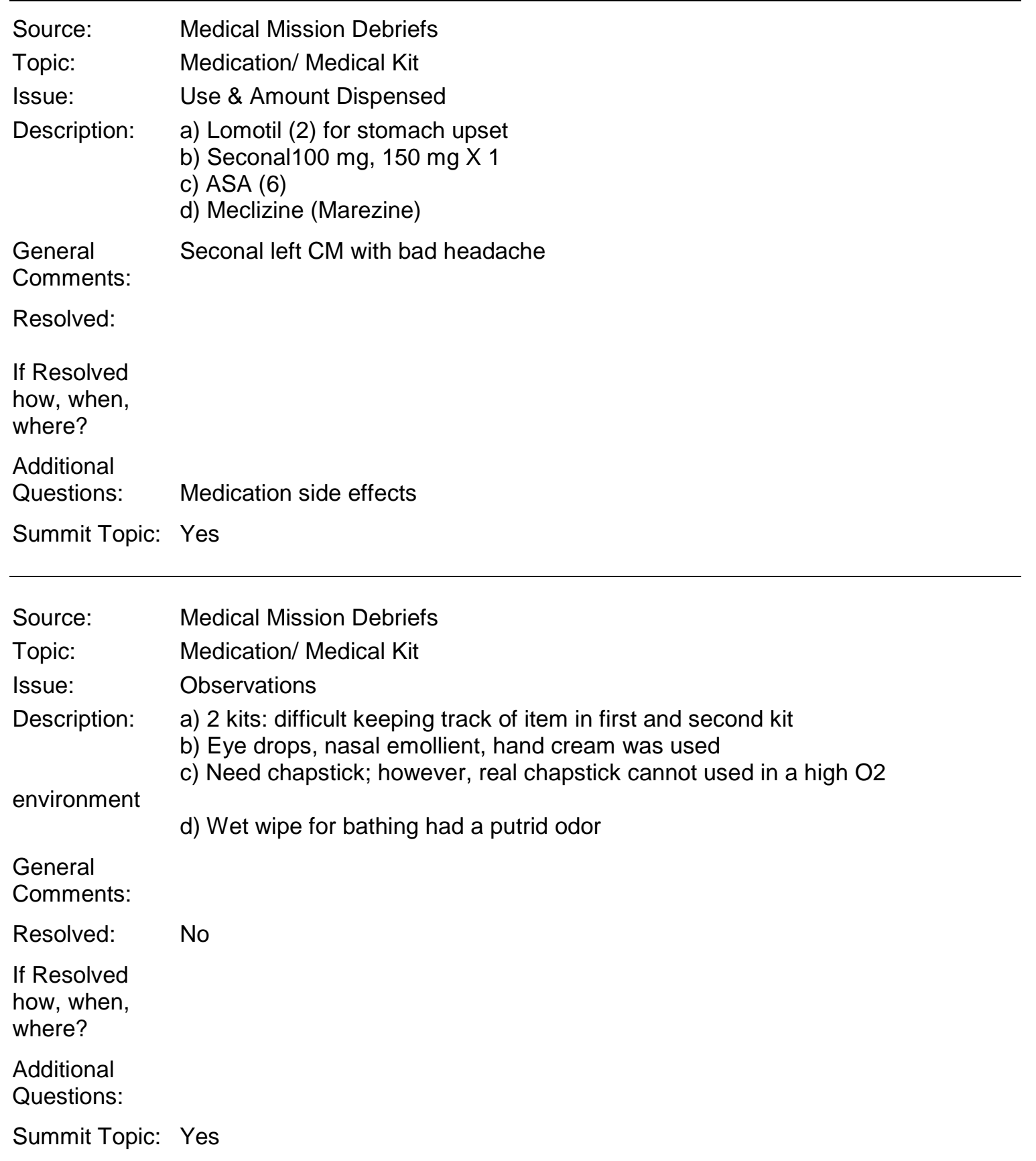




\section{Appendix A \\ Apollo Summit Non-Attributable Report}

Source: $\quad$ Flight Surgeon logs

Topic: Medications

Issue: Afrin bottle

Description:

General

Comments: Afrin bottle blows up when trying to open up bottle because not vacuum packed

Resolved:

If Resolved

how, when,

where?

Additional How will we pack Afrin in the CEV?

Questions:

Summit Topic: Yes

Source: $\quad$ Medical Mission Debriefs

Topic: Medications

Issue: Use and Amount Dispensed

Description: a) Marazine

1-pre--flight (LMP)

1-in-flight (LMP -1-1.5 in-flight)

b) LomotilFD3 (LMP)

c) Seconal

General

Comments: Confusion with medication durations, interactions

Resolved: No

If Resolved

how, when,

where?

Additional

Questions:

Summit Topic: Yes 


\title{
Appendix A Apollo Summit Non-Attributable Report
}

\author{
Source: $\quad$ Medical Mission Debriefs \\ Topic: Medication/ Medical Kit \\ Issue: $\quad$ Crew Observations \\ Description: a) Nose drops packed at 15 psi basically exploded in medical kit at 5.0 psi, \\ Same for the nose emollient. Big mess \\ b) The blister packs that the MEs were stored in also expanded/cracked. The \\ seconal caps welled like a balloon and pulled apart, sending tiny flakes all \\ over the cabin. \\ General b) Recommendations: Pack all MEs in vacuum. \\ Comments: \\ Resolved: No \\ If Resolved \\ how, when, \\ where? \\ Additional \\ Questions: \\ Summit Topic: Yes

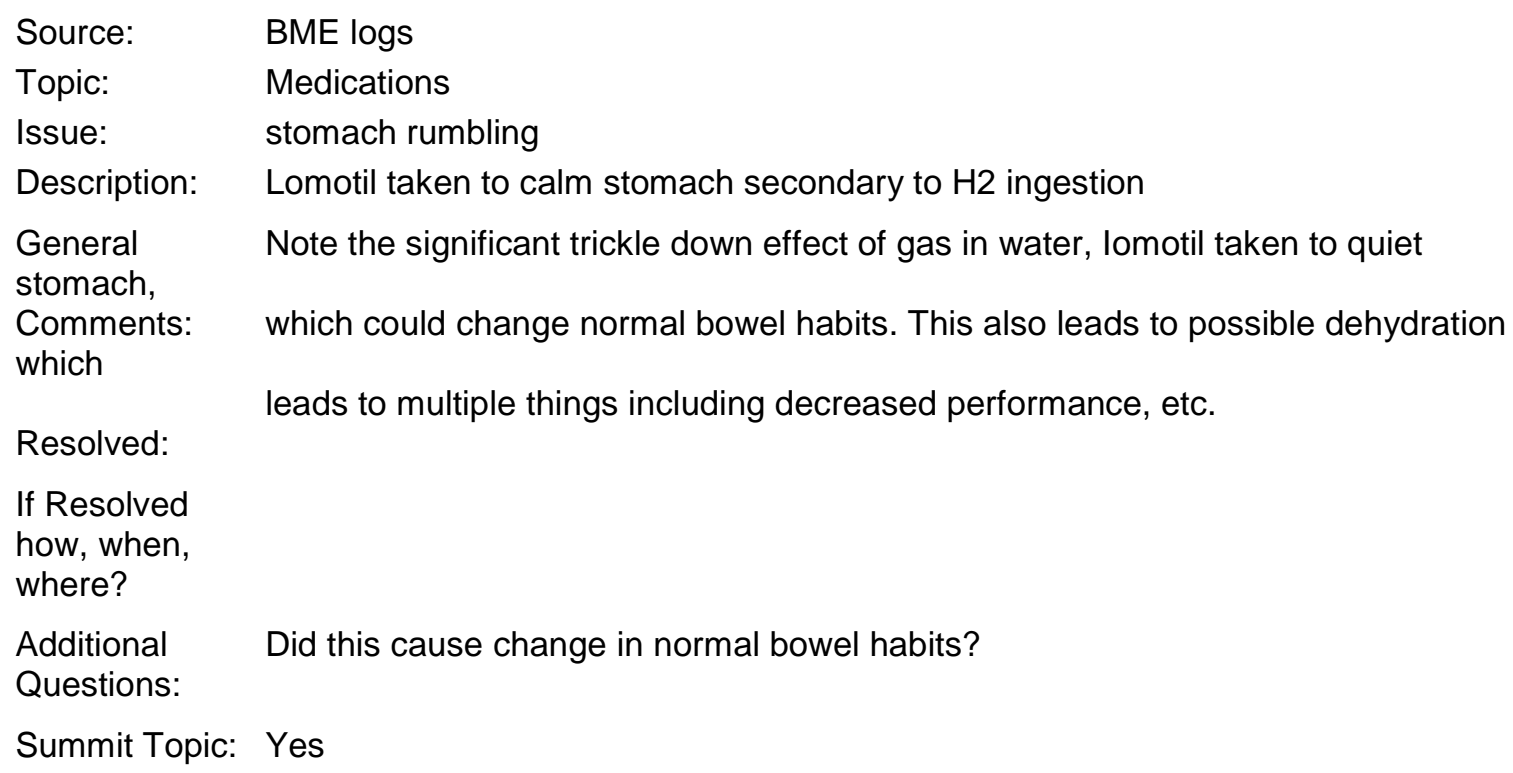

Additional Did this cause change in normal bowel habits?

Questions:

Summit Topic: Yes 


\title{
Appendix A Apollo Summit Non-Attributable Report
}

\author{
Source: $\quad$ Medical Mission Debriefs \\ Topic: Medical Kit \\ Issue: Medical Kit \\ Description: There did not appear to be any attempt to evacuate air from the Afrin, other \\ bottles. -Upon opening from the kit, the solution bubbled all over the outside. This \\ rendered the supply kit useless \\ General \\ Crew would like to have a fingernail clipper as part of the kit \\ Comments: \\ Resolved: \\ If Resolved \\ how, when, \\ where? \\ Additional Fingernail clippers would be essential in a longer mission and are there plans for \\ this? \\ Questions: Are Afrin and other such supplies packed decompressed/in a vacuum so as to \\ alleviate this problem? \\ Summit Topic: Yes

$\begin{array}{ll}\text { Source: } & \text { Medical Mission Debriefs } \\ \text { Topic: } & \text { Medications } \\ \text { Issue: } & \text { Ornade just prior to lift-off } \\ \text { Description: } & \begin{array}{l}\text { p 7: CDR: "recurring mild symptoms throughout the flight, nasal stuffing, nose } \\ \text { would be partially constricted on a couple of morning upon waking up; Did not } \\ \end{array} \\ & \begin{array}{l}\text { use any medications for it inflight. }\end{array}\end{array}$ \\ General \\ Comments: Nasal congestion concern for launch, especially with cabin pressure change from \\ $14.7 \mathrm{psi}$ to $5.0 \mathrm{psi}$ \\ Resolved: \\ If Resolved \\ how, when, \\ where? \\ Additional \\ Questions: \\ Summit Topic: Yes
}




\title{
Appendix A Apollo Summit Non-Attributable Report
}

\author{
Source: $\quad$ Medical Mission Debriefs \\ Topic: Medical Kit \\ Issue: $\quad$ fingernail clippers and other toiletry items \\ Description: p. 27: CMP: A pair of fingernail clippers would be very useful for hangnails, or \\ ripped fingernails, or removing lunar dust from beneath the nail beds. \\ Also need soap that smells good, rather than musty soap. Deodorant would be \\ useful, and a shaving kit. \\ General \\ CDR: soaking a little towel in hot water to wipe off with was very useful \\ Comments: \\ Resolved: \\ If Resolved \\ how, when, \\ where? \\ Additional \\ Questions: \\ Summit Topic: Yes \\ Source: $\quad$ Medical Mission Debriefs \\ Topic: Medications \\ Issue: Benzedrine, aspirin, etc. \\ Description: p.21: LMP: Took a Benzedrine prior to reentry and again on the water as \\ preventive for sea-sickness after learning of high waves and 6-foot swells at the \\ beach. Took an aspirin each night before going to sleep. \\ P. 25: CMP: Stated he feels Afrin, Lomofil, Aspirin and Dexedrine should be \\ taken by the crew whenever crew feels they need it, without any radio \\ communications. Stated he feels the CM is secure enough that missions up to 14 \\ days could be flown without any biomedical sensors. "To me the biomedical \\ sensoring is an unnecessary complication." \\ p. 27: CDR: some individual medications had not been decompressed and Afrin \\ bubbled out \\ General \\ Comments: \\ Resolved: \\ If Resolved \\ how, when, \\ where? \\ Additional \\ Questions: \\ Summit Topic: Yes
}




\title{
Appendix A Apollo Summit Non-Attributable Report
}

\author{
Source: $\quad$ Medical Mission Debriefs \\ Topic: Medications \\ Issue: Usage \\ Description: a) Lomotil to prevent BM night (11before landing and night before LM activity (2) \\ b) ASA was taken each night (2) for headaches and to help with sleep \\ c) Crew felt they did not want to report medication usage or their problems \\ because they did not want anyone to know about it (lack of PMC) \\ d) Crew felt that the following medication should be taken by the crew when the \\ crew feels and not required any radio comm with ground \\ Afrin \\ Lomotil \\ ASA \\ Dexedrine \\ General \\ Comments: \\ Resolved: \\ If Resolved \\ how, when, \\ where? \\ Additional Has the PMC arrangement with crew and FS ameliorated this concern? \\ Questions: $\quad$ Should the use of lomotil prophalactically so as not to be bothered during landing \\ be a concern? Do we need to develop another plan to assure crew? \\ Summit Topic: Yes

\begin{abstract}
Source: $\quad$ Medical Mission Debriefs
Topic: Medical Kit

Issue: Drug Observations

Description: a) Afrin solution leaked from bottle, similar to previous crew experience -Crew tried absorbing solution onto cotton ball and sniff to deliver medication to nasal mucosa, but this did not work too well

b) Actifed used for nasal congestion

c) Sleeping pills were taken first couple of days after notifying the ground -LMP would sleep approximately 5 hours, get up take one, sleep another 3-4
\end{abstract} \\ hours \\ d) Crew bothered about the lack of confidentiality to take and repeat medication \\ use \\ General \\ Comments: \\ Resolved: No \\ If Resolved \\ how, when, \\ where? \\ Additional \\ Questions: \\ Summit Topic: Yes
}




\title{
Appendix A Apollo Summit Non-Attributable Report
}

\author{
Source: $\quad$ Medical Mission Debriefs \\ Topic: Medications \\ Issue: $\quad$ privacy \\ Description: $\quad$ LMP: "... one of our big problems; if we take a goddamned aspirin up there, it \\ becomes an international incident. We object strenuously to it." \\ CMP: "Especially this flight crew, just flat-ass object to this type of thing. Now if \\ we can convert, and be able to talk to you like we can right now privately, \\ without the Jim Malone's or the Bill Heinz's (two news reporters) or the rest of \\ the world in on this god damned act, we'd do it. But l'll be god damned if I \\ wasn't damn reluctant to come up and say, I don't know why, maybe this is \\ just a personal thing with me, but I'm sure a lot of the other guys feel the same \\ way." \\ CMP: "Get in the posture where these things aren't flags as a god dammed \\ potential space problem and saying you ought not to be there because you \\ got a headache..., then I think we would feel more free to talk about it." Quotes \\ included to convey the depth of feeling of crew on this point. \\ CDR: Strongly argued for private conversations when the crew requests it. \\ Dr. Berry strongly concurred with the importance of crew being able to talk with \\ ground without unconstrained access to the rest of the world to the \\ conversation. \\ General \\ Comments: \\ Resolved: Yes \\ If Resolved \\ how, when, \\ where? \\ Additional \\ Questions: $\quad$ Private medical conferences (PMCs) between crew and surgeon are normal \\ operating procedure today. \\ Summit Topic: No

$\begin{array}{ll}\text { Source: } & \text { Medical Mission Debriefs } \\ \text { Topic: } & \text { Medications } \\ \text { Issue: } & \text { Medications for Sleep } \\ \text { Description: } & \begin{array}{c}\text { CDR and LMP: would not take medication to improve sleep even if they had } \\ \text { been available, CDR noted "You couldn't sit around in a hammock with the } \\ \end{array} \\ & \text { damn neck ring ... In the back of the neck:" }\end{array}$ \\ General \\ Comments: Sleep was fitful at best on the lunar surface. \\ Resolved: \\ If Resolved \\ how, when, \\ where? \\ Additional \\ Questions: How could sleep be eventful in the suit? \\ Summit Topic: Yes
}




\title{
Appendix A \\ Apollo Summit Non-Attributable Report
}

\author{
Source: Medical Mission Debriefs \\ Topic: Medications \\ Issue: Afrin bubbles \\ Description: There are always a lot of bubbles in the Afrin nasal spray. \\ General \\ Comments: \\ Resolved: No \\ If Resolved \\ how, when, \\ where? \\ Additional \\ Questions: \\ Summit Topic: Yes \\ $\begin{array}{ll}\text { Source: } & \text { Medical Mission Debriefs } \\ \text { Topic: } & \text { Medical Kit } \\ \text { Issue: } & \text { Sunglasses } \\ \text { Description: } & \begin{array}{l}\text { Used prescription sun glasses. Used reading correction in low light, Difficult to } \\ \text { read small print cards } \\ \text { Used them in the LM and a couple of time in the CMS, perhaps a total of 6-8 }\end{array}\end{array}$ \\ times, \\ General p. 34: LMP: Cross sun visibility is great. Up-sun visibility is obscured by glare. \\ Down- \\ Comments: sun "all the gentle subtle rolling and shadowed craters, they just disappear on \\ you." \\ Same as with the photographs. \\ Resolved: \\ If Resolved \\ how, when, \\ where? \\ Additional \\ Questions: \\ Summit Topic: No
}




\title{
Appendix A Apollo Summit Non-Attributable Report
}

\author{
Source: Medical Mission Debriefs \\ Topic: Medications \\ Issue: $\quad$ Nose drops \\ Description: LMP: 1 drop in each nostril worked for 10-12 hours, for nasal stuffiness. \\ CDR: nose drops helped with the mucous but not the overall fullness sensation \\ CMP thinks he used too much 3 hours prior to reentry, with eye tearing and \\ sensation in his sinuses. \\ Didn't notice any tachycardia with its use. \\ General No ear problems at all. Cleared well with pressure changes. \\ Comments: \\ Resolved: \\ If Resolved \\ how, when, \\ where? \\ Additional \\ Questions: \\ Summit Topic: No

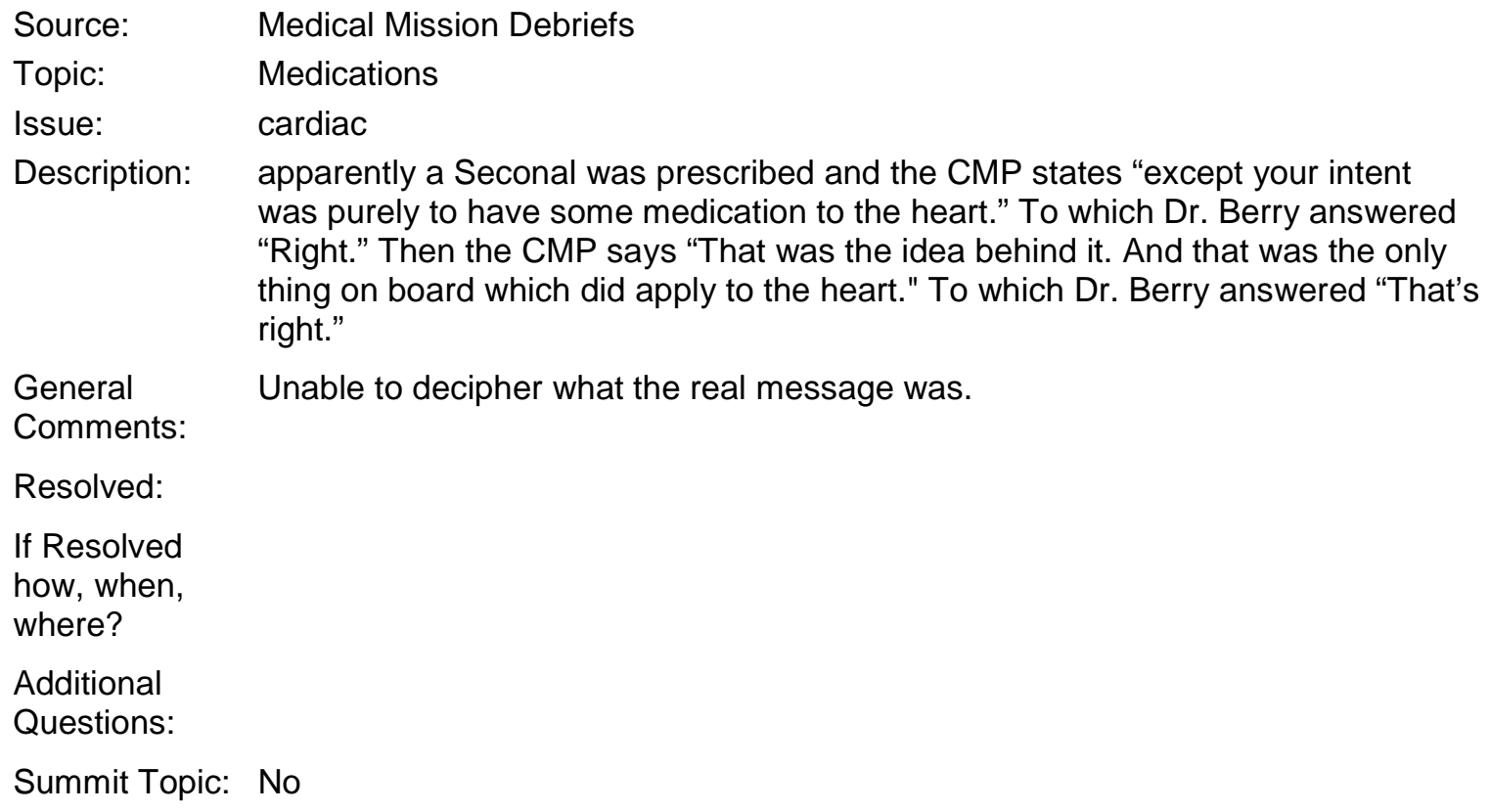

Resolved:

If Resolved how, when, where?

Additional

Questions:

Summit Topic: No 


\title{
Appendix A Apollo Summit Non-Attributable Report
}

\author{
Source: Medical Mission Debriefs \\ Topic: Medications \\ Issue: Potassium \\ Description: Concern that potassium powder were contributing to the frequency of bowel \\ movements and loose stools \\ "We're overdoing it" with regards to going to the bathroom enough. "The fact is it \\ was unbelievable, abdominal bloating, 'gas pains" and flatus were also a \\ problem. The odor was "terrible." \\ General Bowel movements were sources of difficult hygienic collection and stowage and \\ crew \\ Comments: preferred to minimize them. \\ Resolved: No \\ If Resolved \\ how, when, \\ where? \\ Additional \\ Questions: \\ Summit Topic: Yes

$\begin{array}{ll}\text { Source: } & \text { Medical Mission Debriefs } \\ \text { Topic: } & \text { Medications } \\ \text { Issue: } & \text { Seconal use } \\ \text { Description: } & \text { CMD took two seconal, which were the only use of that during the flight. } \\ & \text { CDR took biomeds, including ASA. } \\ & \text { General purpose topical skin cream was only other med used. }\end{array}$ \\ General \\ Comments: Seconal was very sedative which was a very undesirable side effect. \\ Resolved: \\ If Resolved \\ how, when, \\ where? \\ Additional \\ Questions: \\ Summit Topic: No
}




\section{Appendix A \\ Apollo Summit Non-Attributable Report}

\begin{tabular}{ll}
\hline Source: & BME logs \\
Topic: & Medications \\
Issue: & gas pill \\
Description: & $\begin{array}{l}\text { discussion on how to take gas pills consider chewing them, etc...? Conference on } \\
\text { whether or not to talk about Gas problem }\end{array}$ \\
General & \\
Comments: & \\
Resolved: & \\
If Resolved & \\
how, when, & \\
where? & \\
Additional & \\
Questions: & \\
Summit Topic: & No \\
\hline $\begin{array}{l}\text { Source: } \\
\text { Topic: }\end{array}$ & BME logs \\
Issue: & Medications \\
Description: & Nausea indication \\
& label of Dexadrine and Scopolamine says nausea because it used to contain \\
General & Compazine...used for gas because Gas pill couldn't be found \\
Comments: & \\
Resolved: & \\
If Resolved & \\
how, when, & \\
where? & \\
Additional & \\
Questions: & \\
\hline Summit Topic: & Yes \\
\hline
\end{tabular}

Source: $\quad$ Flight Surgeon logs

Topic: Medications

Issue: gas pills

Description: took 3 gas pills yesterday

General

Comments:

Resolved:

If Resolved how, when, where?

Additional

Questions: 


\section{Appendix A \\ Apollo Summit Non-Attributable Report}

Summit Topic: No

Source: $\quad$ Flight Surgeon logs

Topic: Medications

Issue: nausea pill

Description: medication labeled nausea pills actually medicine for motion sickness

General

Comments:

Resolved:

If Resolved

how, when,

where?

Additional

Questions:

Summit Topic: No

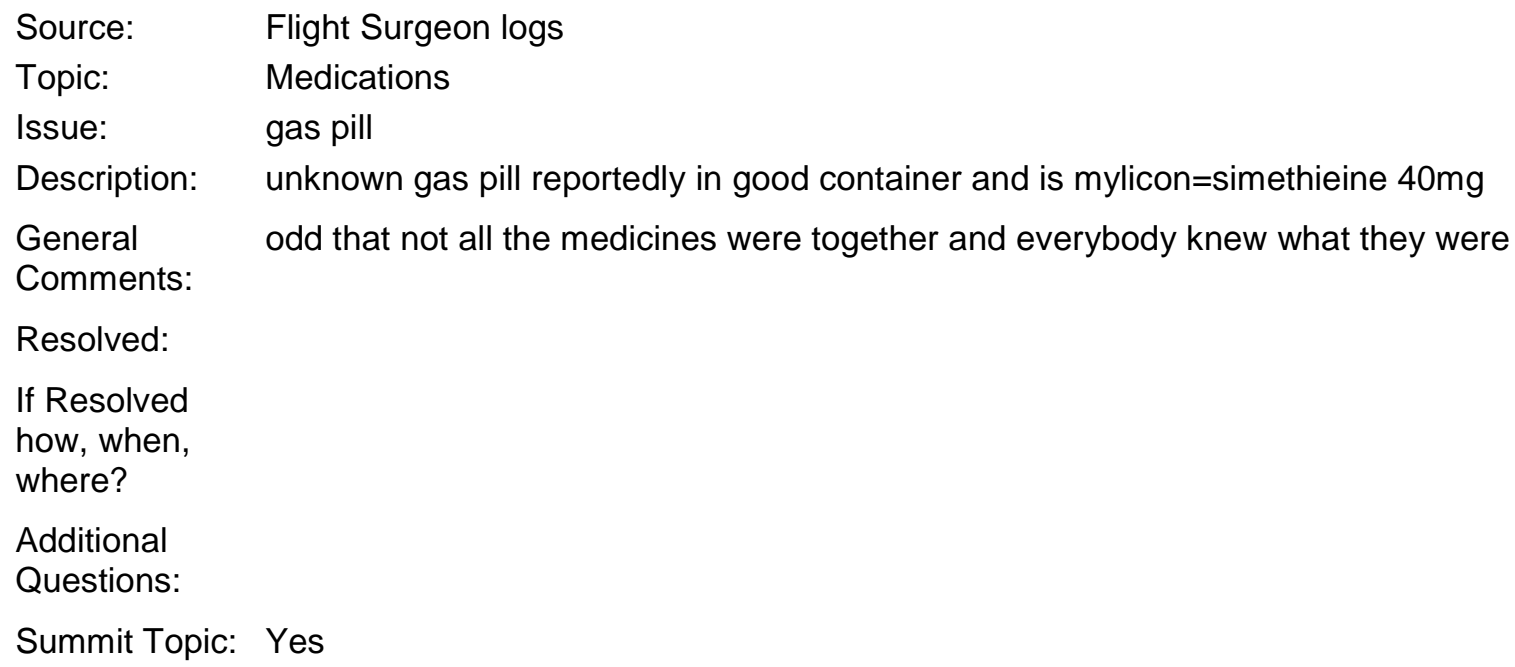

Additional

Questions:

Summit Topic: Yes

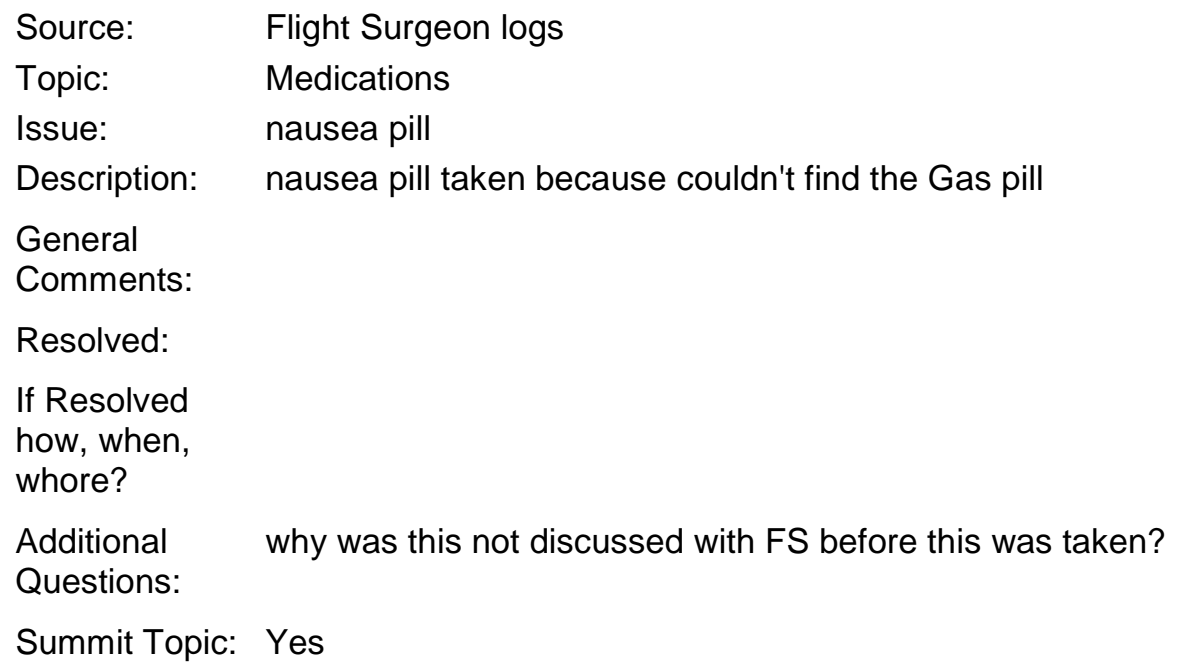

Additional why was this not discussed with FS before this was taken?

Questions:

Summit Topic: Yes 


\section{Appendix A \\ Apollo Summit Non-Attributable Report}

\begin{tabular}{ll}
\hline Source: & Medical Mission Debriefs \\
Topic: & $\begin{array}{l}\text { Medications } \\
\text { Issue: }\end{array}$ \\
$\begin{array}{l}\text { itch on arm } \\
\text { Description: }\end{array}$ & $\begin{array}{l}\text { Used skin cream on arm to relieve itch during night, CDR used the cream as an } \\
\text { after shave cream }\end{array}$ \\
General & \\
Comments: \\
Resolved: \\
If Resolved \\
how, when, \\
where? \\
Additional \\
Questions: \\
Summit Topic:
\end{tabular}

Source: $\quad$ Flight Surgeon logs

Topic: Environmental

Issue: Observable Elements

Description: Brown gunk"-in $\mathrm{H} 2 \mathrm{O}$ injector port threads

General Possible identification of "brown gunk"

Comments: $1 . \quad$ Molybdenum disulfide (MOS2)

2. Graphite

3. Sodium Silicate

4. $\mathrm{H} 2 \mathrm{O}$

5. Dried Lubricant

Resolved:

If Resolved

how, when,

where?

Additional 1. Does this present a safety issue?

Questions:

Summit Topic: No 


\title{
Appendix A Apollo Summit Non-Attributable Report
}

\author{
Source: Medical Mission Debriefs \\ Topic: Environmental \\ Issue: $\quad$ Cabin Temperature \\ Description: Crew felt it was too cold in the CM cabin (cabin temp ranges 67-75 degrees \\ Fahrenheit) and may have contributed to their physical symptoms -stuffy noses, \\ rhinorrhea, etc. \\ General \\ Comments: \\ Resolved: \\ If Resolved \\ how, when, \\ where? \\ Additional What are the cabin temperatures during rest and activity and can these be \\ Questions: \\ adjusted? \\ Summit Topic: Yes \\ Source: Medical Mission Debriefs \\ Topic: Environmental \\ Issue: Waste Management \\ Description: a) Requires approximately 45 minutes from start to end in case there are any \\ problems \\ b) Fecal cannister would be helpful \\ General BM Log: For defecation the crew had to strip the underwear off, requiring the \\ biomed \\ Comments: sensors to be removed. Resolved. \\ Resolved: \\ If Resolved \\ how, when, \\ where? \\ Additional Fecal bag recommendation : Calibrations of "crew member anus with respect to \\ the \\ Questions: front of the sticky part"? \\ Summit Topic: Yes
}




\section{Appendix A Apollo Summit Non-Attributable Report}

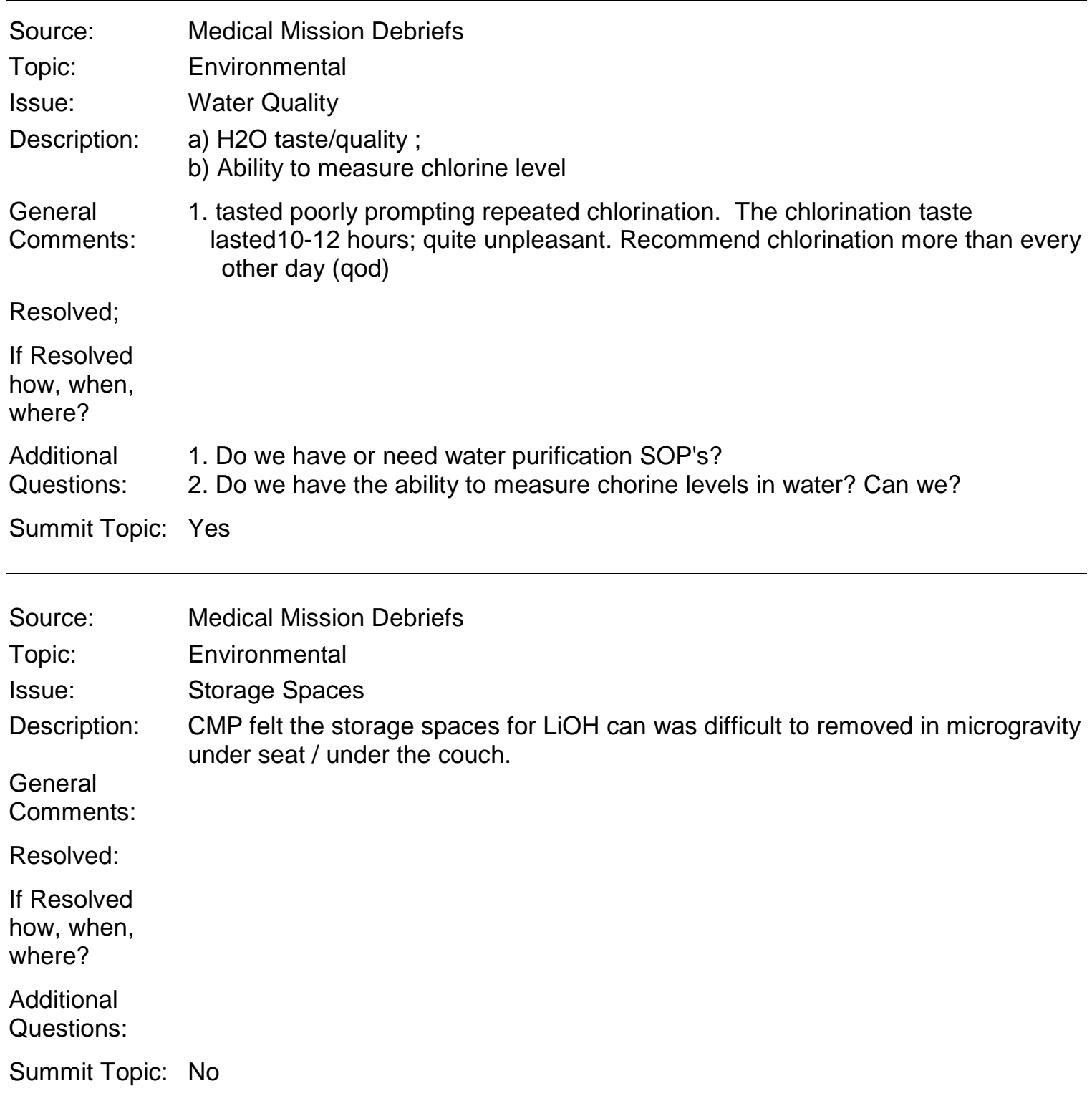

\section{Source: BME logs \\ Topic: Environmental \\ Issue: Difficulty seeing stars \\ Description: difficult to see stars from the onboard Navigation system}

General Comments:

Resolved:

If Resolved how, when, where?

Additional Why was it difficult to see the stars and how can we design the CEV to make it Questions: easier and better?

Summit Topic: Yes 


\section{Appendix A \\ Apollo Summit Non-Attributable Report}

Summit Topic: Yes

Source: $\quad$ Flight Surgeon logs

Topic: Environmental

Issue: $\quad$ Decreased cabin temp

Description: Cabin temp decreased from 77-61 prior to entry.

General

Comments:

Resolved:

If Resolved

how, when,

where?

Additional How can we better stabilize temperature on the CEV in comparison to Apollo?

Questions:

Summit Topic: Yes

Source: $\quad$ Flight Surgeon logs

Topic: Environmental

Issue: Personal Radiation Dosimeters readings

Description: PRD readings should be done prior to entering Van Allen Belts.

General

Comments:

Resolved:

If Resolved

how, when,

where?

Additional When are PRD readings scheduled?

Questions: How will these PRD readings interact with other scheduled events?

Summit Topic: Yes

Source: $\quad$ Flight Surgeon logs

Topic: Environmental

Issue: waste dumps

Description: Waste Dumps causes increase in "pseudo stars" which makes star sightings impossible.

General

Comments:

Resolved:

If Resolved

how, when, where?

Additional When should we design our waste dumps so as not to cause a problem with star Questions: sighting? 


\section{Appendix A \\ Apollo Summit Non-Attributable Report}

Summit Topic: Yes 


\title{
Appendix A Apollo Summit Non-Attributable Report
}

\author{
Source: $\quad$ Medical Mission Debriefs \\ Topic: Environmental \\ Issue: $\quad$ Space Craft Issues \\ Description: a) Space craft temperature at launch was 45 degrees Fahrenheit. Crew was in \\ suit but was still c/o cabin being too cold \\ b) Noise level on launch made it very difficult to communicate with crew or round \\ for approximately 42 seconds \\ 1. Noise during setup periods: cabin fans were unacceptably loud. Interfered \\ with sleep period. Cabin itself was quiet except when CMs were talking \\ c) $\mathrm{H} 2 \mathrm{O}$ out of gun tasted like chlorine and was disgusting \\ d) Urine collection system was lousy: smells, messy, makes urination an \\ unpleasant experience \\ 1. Collection condom gets sticky \\ 2. Relief tube set up to dump it over the side? \\ 3. Was the most unpleasant part of the mission \\ e) lousy system, created a mess every time it was used \\ f) Pack the bathing towels wet with antibacterial soap \\ g) Dental care was good \\ h) How much $\mathrm{H} 2 \mathrm{O}$ is in a "click"? Crew stated they drank "100 clicks per day" \\ General Suggestion for Sleep: Use blinders at night for sleep \\ Comments: $\quad$ Suggestion for $\mathrm{H} 2 \mathrm{O}$ : Mix the $\mathrm{H} 2 \mathrm{O}$ with one of the juice drinks \\ Suggestion for fecal dollection: Chemical toilet tore place overboard dump \\ system; Odor in cabin was bad following a BM. \\ Resolved: $\quad$ No \\ If Resolved \\ how, when, \\ where? \\ Additional How can these issues be improved? (see email correspondence in addition to \\ Questions: \\ recommendations) \\ Summit Topic: Yes

\section{Source: \\ Topic: \\ Issue: \\ Description: \\ General \\ Comments: \\ Resolved: \\ If Resolved \\ how, when, \\ where?} \\ BME logs \\ Environmental \\ $\mathrm{O} 2$ flow problems \\ $\mathrm{O} 2$ surge, out of limits \\ Fuel cell $\mathrm{O} 2$ flow is high \\ Additional \\ Questions: \\ Have these $\mathrm{O} 2$ problems been addressed? \\ Summit Topic: No
}




\section{Appendix A Apollo Summit Non-Attributable Report}

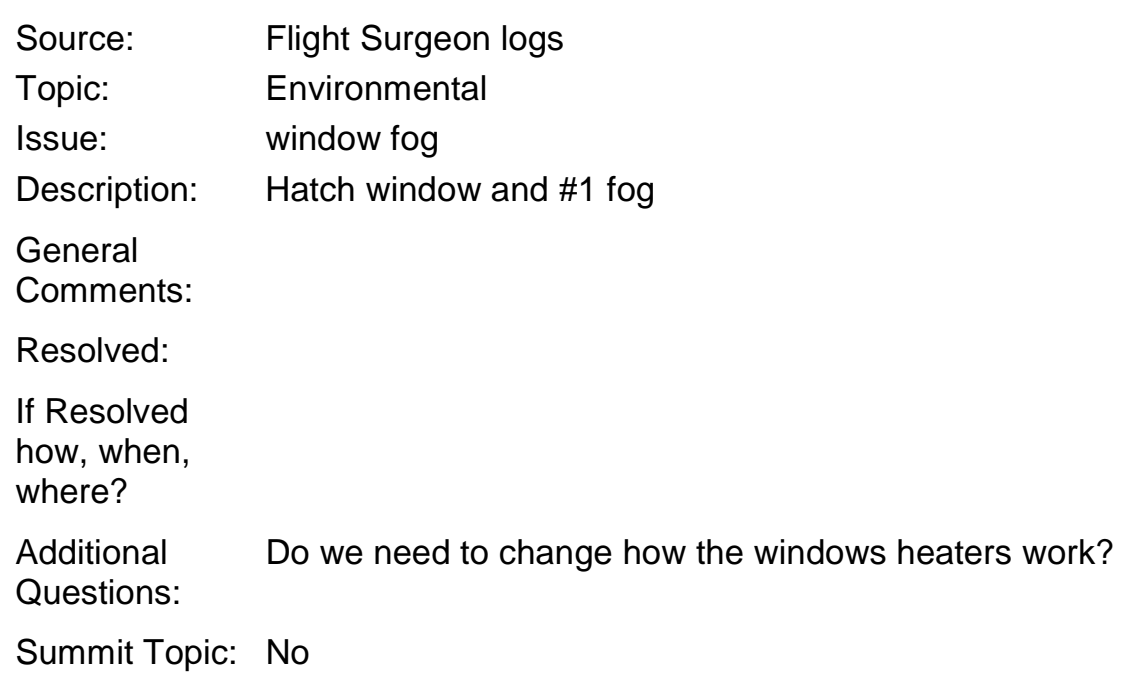




\title{
Appendix A Apollo Summit Non-Attributable Report
}

\author{
Source: $\quad$ Flight Surgeon logs \\ Topic: Environmental \\ Issue: $\quad \mathrm{LiO2}$ canister \\ Description: CDR forgot to change LiO2 canister \\ General Comments: \\ Resolved: \\ If Resolved \\ how, when, \\ where?
}

Additional Is there a better method of removing $\mathrm{CO} 2$ out of the air?

Questions: Does the changing of these canisters seem to be awkward use of time?

Summit Topic: No

\begin{tabular}{|c|c|}
\hline Source: & Medical Mission Debriefs \\
\hline Topic: & Environmental \\
\hline Issue: & Design Observations \\
\hline Description: & $\begin{array}{l}\text { a) Sleeping Bag did not have enough room for } \\
\text { b) Traveling through the tunnel to the Lunar Mo } \\
\text { everything is reversed from the Command }\end{array}$ \\
\hline $\begin{array}{l}\text { General } \\
\text { strapped } \\
\text { Comments: }\end{array}$ & $\begin{array}{l}\text { It sounds like the crew was very uncomfortable } \\
\text { down in the couch, }\end{array}$ \\
\hline \multicolumn{2}{|l|}{ Resolved: } \\
\hline \multicolumn{2}{|l|}{$\begin{array}{l}\text { If Resolved } \\
\text { how, when, } \\
\text { where? }\end{array}$} \\
\hline $\begin{array}{l}\text { Additional } \\
\text { Questions: }\end{array}$ & $\begin{array}{l}\text { How were in-flight position, for comfort accomp } \\
\text { It appeared that the LMP had to put on the suit }\end{array}$ \\
\hline Summit Topic: & Yes \\
\hline Source: & Medical Mission Debriefs \\
\hline Topic: & Personal Hygiene/ Environmental \\
\hline Issue: & Defecation Issues \\
\hline Description: & Crew preferred to strip naked to move bowels. \\
\hline $\begin{array}{l}\text { General } \\
\text { Comments: }\end{array}$ & Same complaint in earlier Apollo missions \\
\hline Resolved: & No \\
\hline $\begin{array}{l}\text { If Resolved } \\
\text { how, when, } \\
\text { where? }\end{array}$ & \\
\hline $\begin{array}{l}\text { Additional } \\
\text { Questions: }\end{array}$ & \\
\hline Summit Topic: & Yes \\
\hline
\end{tabular}




\title{
Appendix A Apollo Summit Non-Attributable Report
}

\author{
Source: Medical Mission Debriefs \\ Topic: Environmental \\ Issue: Design Observations \\ Description: a) Sleeping Bag did not have enough room for crew to assume "fetal position" \\ b) Traveling through the tunnel to the Lunar Module was disorienting because \\ everything is reversed from the Command Module \\ General It sounds like the crew was very uncomfortable secondary to back pain when \\ strapped \\ Comments: down in the couch, \\ Resolved: \\ If Resolved \\ how, when, \\ where? \\ Additional How were in-flight position, for comfort accomplished in the couch? \\ Questions: It appeared that the LMP had to put on the suit each mission. Why? \\ Summit Topic: Yes

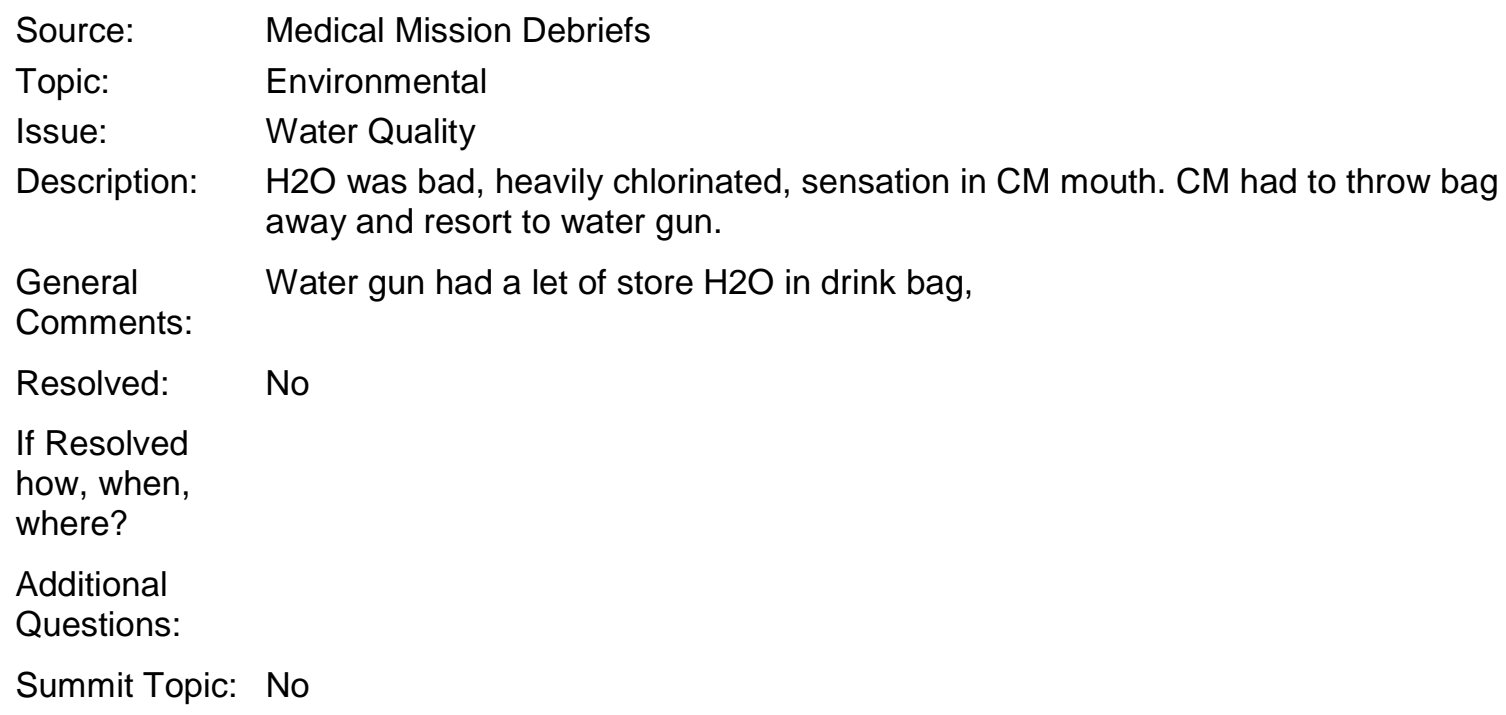

Additional

Questions:

Summit Topic: No 


\title{
Appendix A \\ Apollo Summit Non-Attributable Report
}

\author{
Source: BME logs \\ Topic: Environmental \\ Issue: $\quad$ Frequent thruster firings \\ Description: "Complains of frequent thruster firing" \\ General This kept CM from Sleeping/getting deep restful sleep \\ Comments: \\ Resolved: \\ If Resolved \\ how, when, \\ where? \\ Additional What was the cause of these thruster firings? How can we change the sleeping \\ Questions: environment in order to assure a deep restful sleep without unwanted \\ disturbances? \\ How will we assure being able to wake CM if needed \\ Summit Topic: Yes

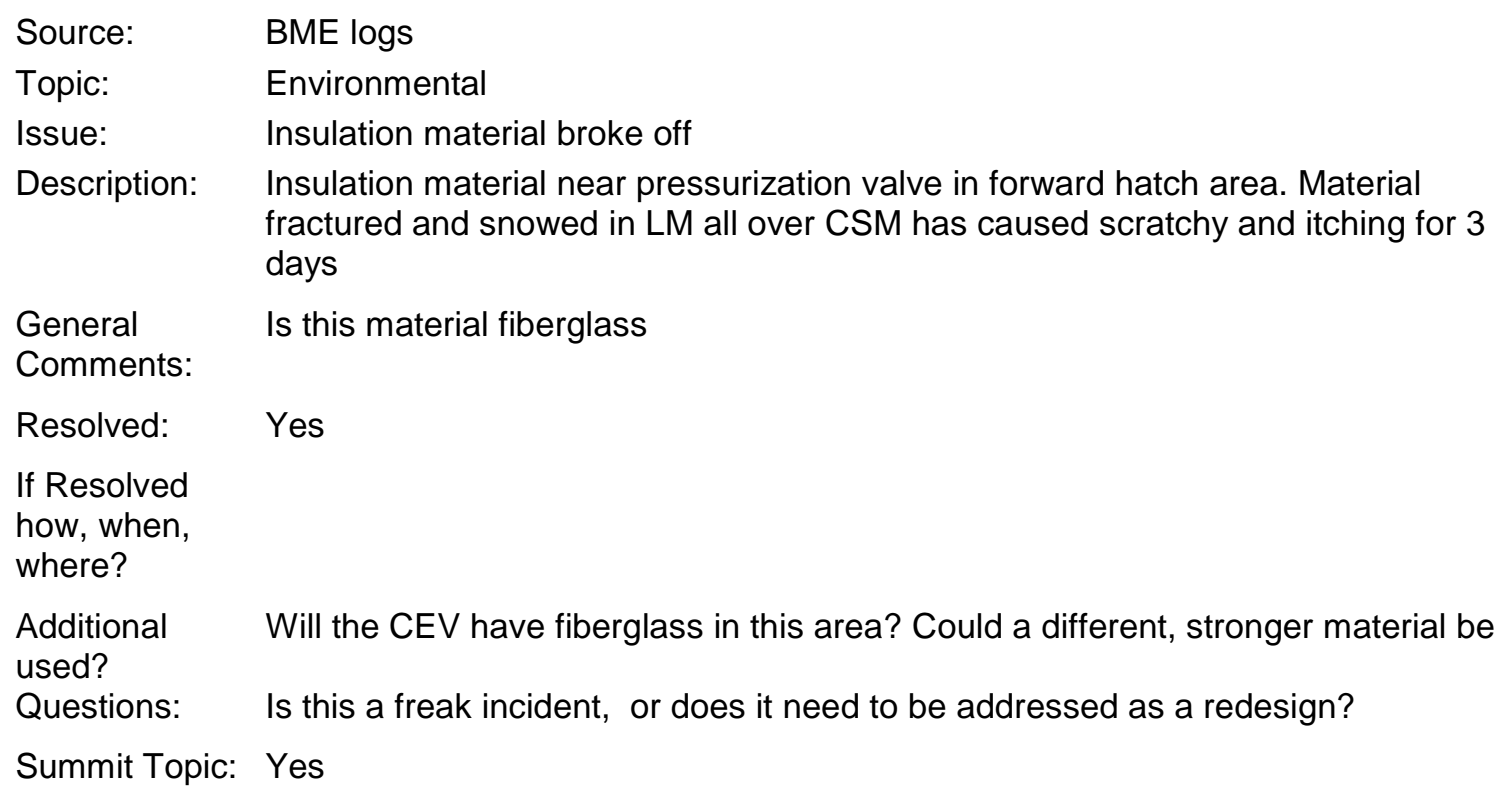

Additional Will the CEV have fiberglass in this area? Could a different, stronger material be used?

Questions: Is this a freak incident, or does it need to be addressed as a redesign?

Summit Topic: Yes 


\section{Appendix A Apollo Summit Non-Attributable Report}

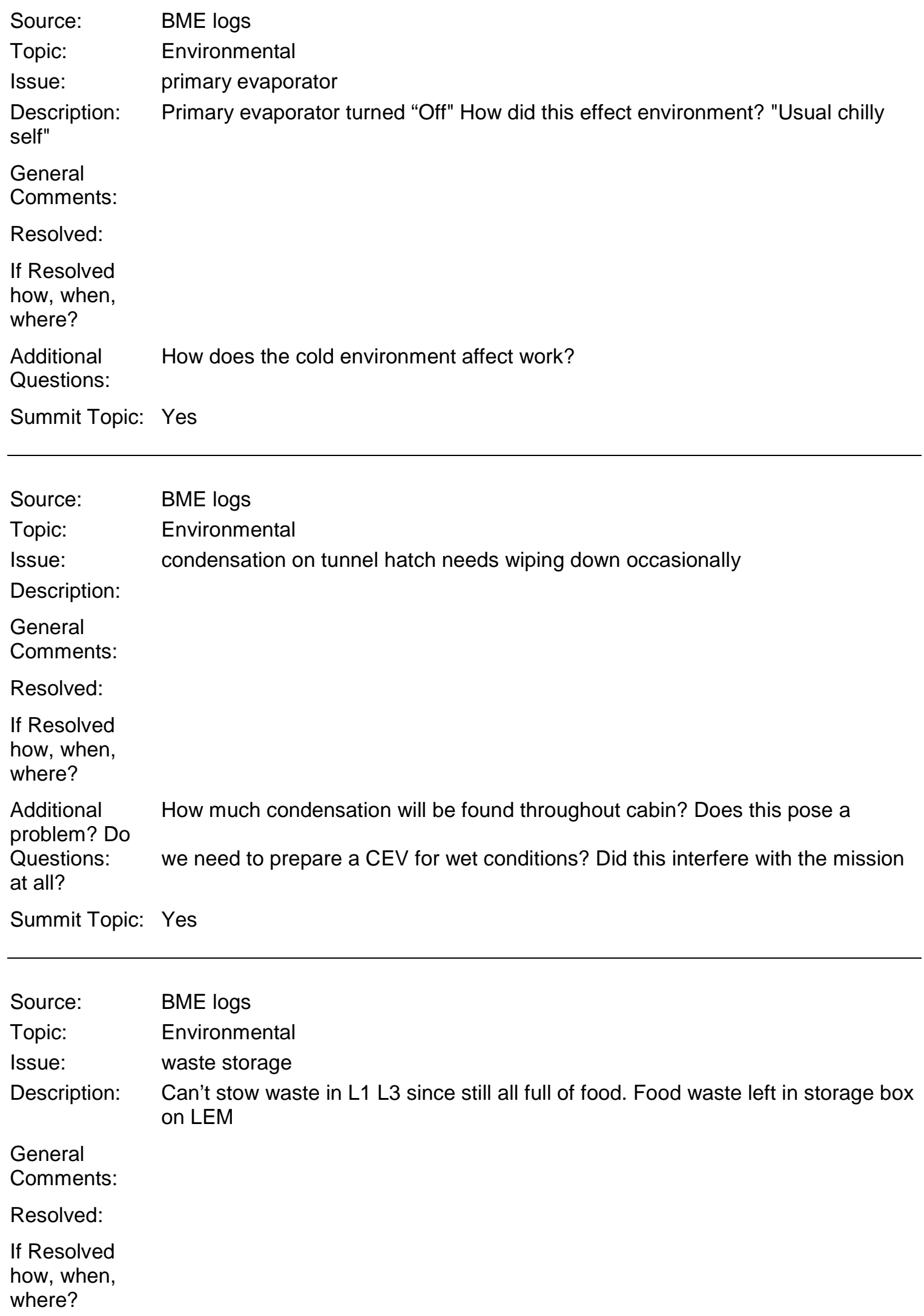

General

Comments:

Resolved:

If Resolved how, when, where? 


\section{Appendix A \\ Apollo Summit Non-Attributable Report}

Additional How should we or should we approach waste/garbage storage especially in light

Questions: of longer exploration missions? How often was this a problem?

Summit Topic: Yes 


\section{Appendix A Apollo Summit Non-Attributable Report}

Source: $\quad$ Flight Surgeon logs

Topic: Environmental

Issue: Chlorination of water

Description: Confusion on rather to open inlet or not during chlorination. Therefore got a slug of Very chlorinated water

General

Comments:

Resolved:

If Resolved

how, when,

where?

Additional Rather we use chlorine or iodine we should have it brutally simple on how and Questions: when to use?

Summit Topic: Yes

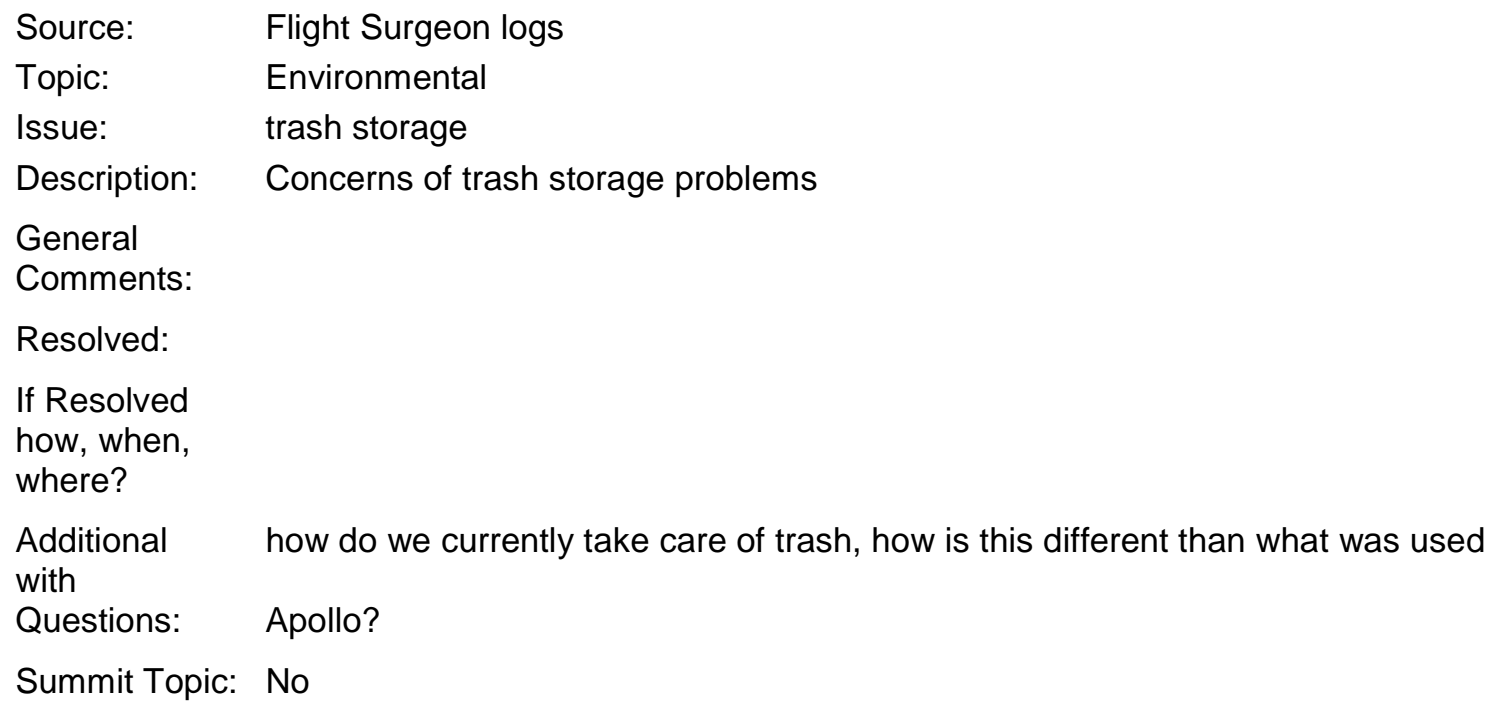

Additional how do we currently take care of trash, how is this different than what was used with

Questions: Apollo?

Summit Topic: No

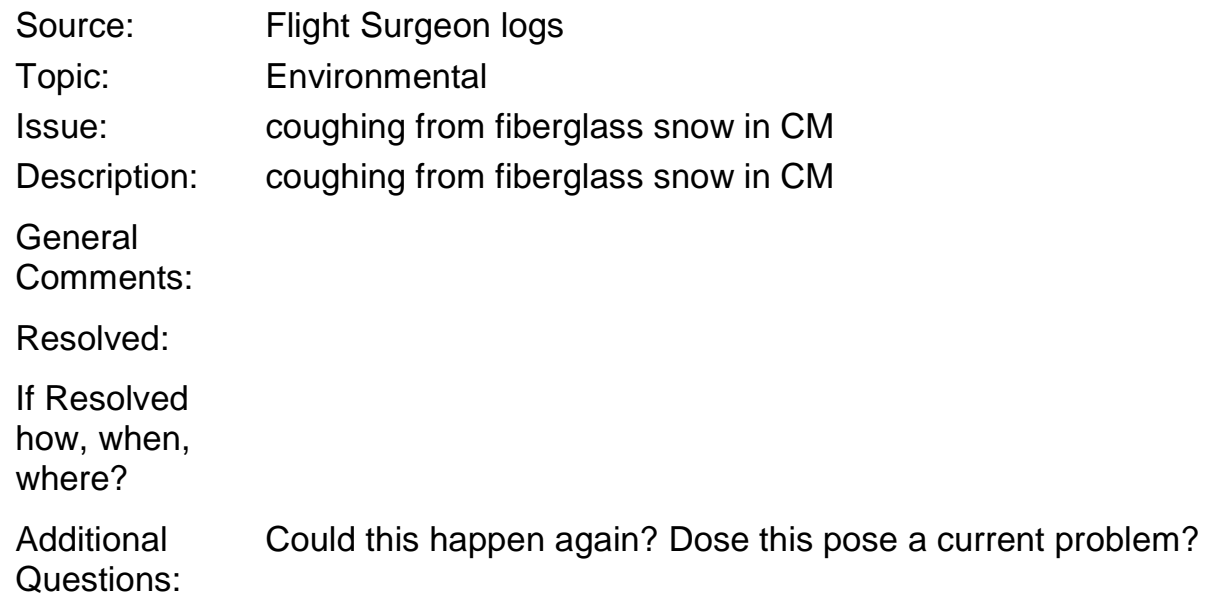




\section{Appendix A \\ Apollo Summit Non-Attributable Report}

Summit Topic: Yes 


\section{Appendix A \\ Apollo Summit Non-Attributable Report}

Source: $\quad$ Flight Surgeon logs

Topic: Environmental

Issue: $\quad$ Thruster awakens CMP

Description: CMP awakens each time thruster fires

General

Comments: Sleep was sporadic and frequently interrupted

Resolved:

If Resolved

how, when,

where?

Additional Will our countermeasures for Comm interrupting sleep also help with Thruster Questions: interruptions?

Summit Topic: Yes

Source: $\quad$ Flight Surgeon logs

Topic: Environmental

Issue: fiberglass snowstorm

Description: $\quad$ "Snow storm of insulation material is in LM "Snow in CSM also" Like Fiberglass

General

Comments:

Resolved:

If Resolved

how, when,

where?

Additional Where did this fiberglass come from?

Questions: How did this happen?

Summit Topic: Yes 


\title{
Appendix A Apollo Summit Non-Attributable Report
}

\author{
Source: Medical Mission Debriefs \\ Topic: Environmental \\ Issue: $\quad$ Space Craft Issues \\ Description: a) Water chlorination process is to be done within 12 hours of launch, if the crew \\ launches on time. The chlorine valve is left closed from launch. Chlorine \\ applied to the systems lasts 12 hours; however, the crew had not used the \\ system, which extended $>12$ hours. \\ b) Bubbles found in the water bag likely because $\mathrm{O} 2$ gas diffused across the \\ bladder. The problem was fixed by de-aerating the water before launch in the \\ bladder. \\ c) Rested good according to crew. \\ d) Crew started out drinking approximately 3 lbs of water per day. Gradually this \\ was increased to normal range of 7-7.5 lbs per day. \\ e) Hot water had more gas in it than the cold water. \\ f) Waste management reported that it was a "mess"
}

General

Comments:

a) Make sure you chlorinate with the valve open, otherwise, very light level of chlorine in water. Need to pay particular attention to this in the event of delayed launch.

b) Crew was upset by the presence of gas in the water system because it was passed into the stomach creating fullness and flatulence. Preventing eating.

c) Urine output was twice a day secondary to low oral water intake according to crew. However, volume was considerable filling urine tank with each void.

d) Urine collection was dumped overboard. Crew reported they opened the dump valve before voiding. The suction created was not strong enough

e) The urine bag, if used, caused back pressure.

f) CDR suggested designing a diaphragm at an angle to prevent back splash.

g) Crew was very concerned about voiding ability during time-critical OPS the amount of time it took to get set-up for a voiding dump.

Resolved: $\quad$ Yes- gas bubbles in water system

if Resolved -

how, when, where?
Additional
a) Is it necessary to chlorinate the system if it hasn't been used yet?
Questions:
b) What about fuel cell water? Was this a problem?
c) What is Ammonia, germicide, fungicide, detergent and deodorant used in?

Summit Topic: Yes 


\section{Appendix A \\ Apollo Summit Non-Attributable Report}

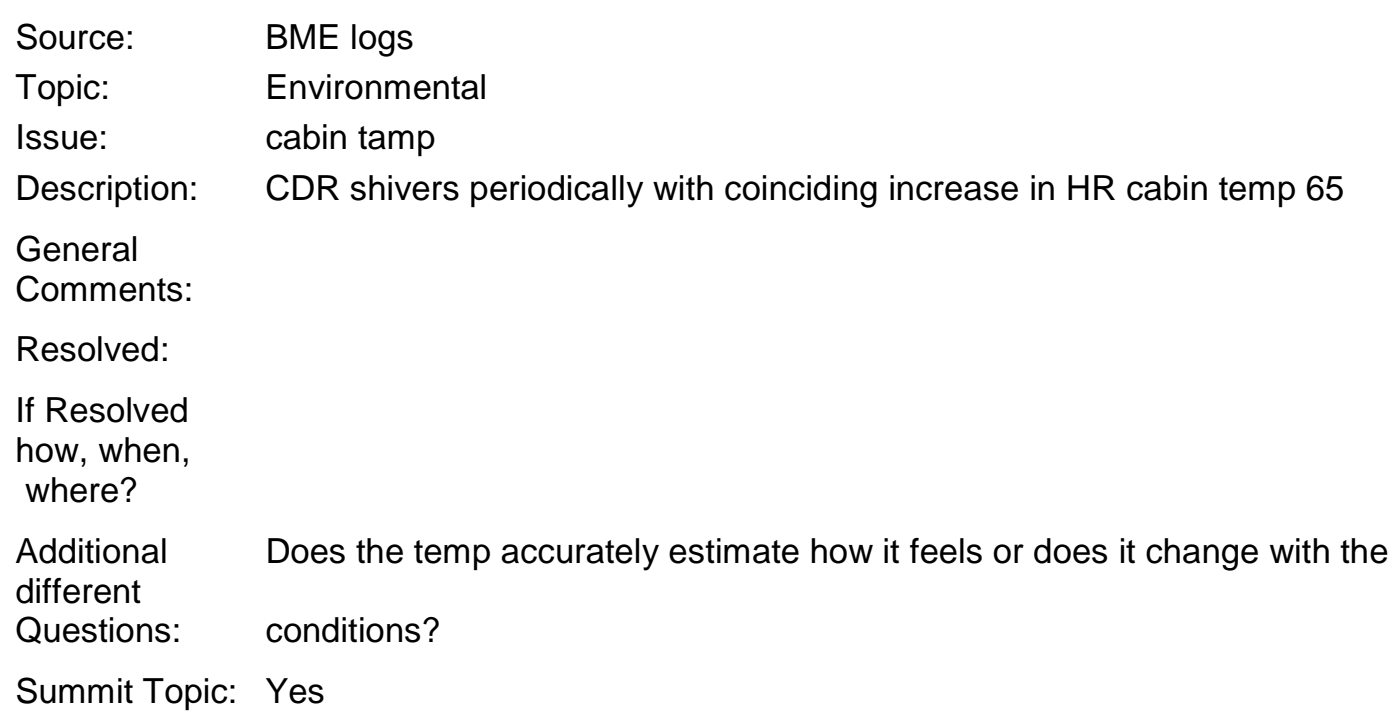

Questions:

Summit Topic: No 


\title{
Appendix A Apollo Summit Non-Attributable Report
}

\author{
Source: $\quad$ Flight Surgeon logs \\ Topic: Environmental \\ issue: $\quad$ O2 flow rate \\ Description: $\quad \mathrm{O} 2$ flow rate transducer is suspected of having failed. Plan to close waste \\ management valve tonight in order to recruit PTC without thruster activity for \\ better crew sleep. \\ General This statement is confusing it seems as though they are talking about 2 different \\ things. \\ Comments: \\ Resolved: \\ If Resolved \\ how, when, \\ where? \\ Additional Is the $\mathrm{O} 2$ transducer or sensor a problem similar to the $\mathrm{PCO} 2$ sensor? \\ Questions: \\ Summit Topic: No

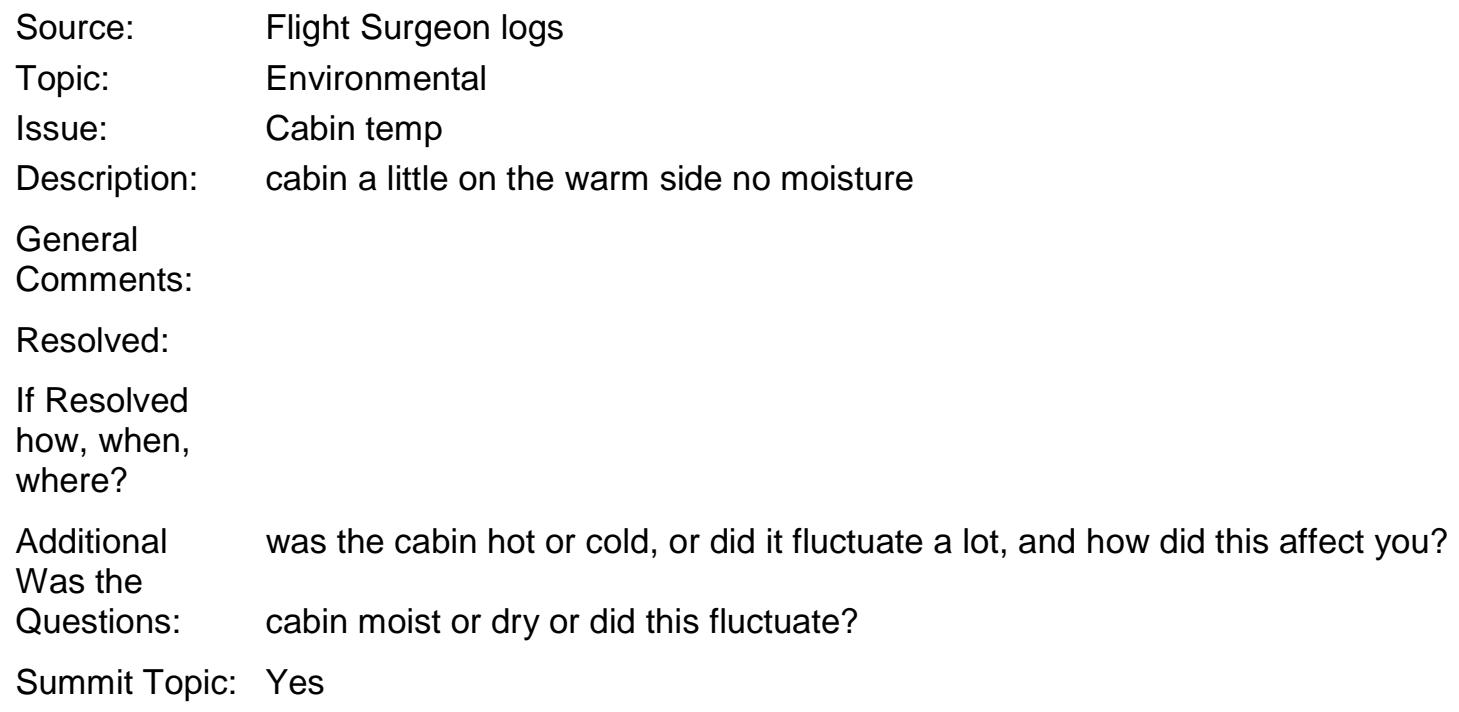




\title{
Appendix A Apollo Summit Non-Attributable Report
}

\begin{abstract}
Source: $\quad$ Medical Mission Debriefs
Topic: Personal Hygiene/ Environment

Issue: $\quad$ Urine collection system

Description: p.25: LMP: The urine and feces collection systems are lousy. The odors inside the cockpit are quite bothersome. No good way to wash after a BM. Need some atmosphere control. "I think the gases in the hydrogen and the water just circulate through your system so you end up passing a tremendous amount of volume of gas in there." Fixing these areas would "make it a lot more livable." CDR: We have vacuum outside that could be used with a well-designed urinal.
\end{abstract}

General

Comments: In general, the WCS was broken.

Resolved: No

If Resolved

how, when, where?

Additional

Questions:

Summit Topic: Yes
Source: $\quad$ Medical Mission Debriefs
Topic: Environmental
Issue: Waste Management
Description: a) BM's were reported by crew -approximately 2 per $\mathrm{CM}$ during the mission
b) Crews performed house cleaning in two ways:
system
1. Took hose blowing air out and directed dust toward the accumulation

\section{Cleaned filter screen}
c) CDR got thirsty during mission -drank a lot of water. Tried to avoid beverages as they were too sweet
d) No problems with urination ( from physiological standpoint)
e) Urine and feces collection system is lousy. Crew would prefer no bag at all
f) Odors in cabin were awful -SOLUTION: Circulate cabin gasses
g) Shaving was cumbersome. Could not get your face wet enough
h) Improved wet wipes, preferred soap

General

Comments:

Resolved:

If Resolved how, when, where?

Additional Crew describes something floating in cabin during conversation of BM frequency. Questions: What were they talking about? Dust vs.?

Summit Topic: Yes 


\section{Appendix A \\ Apollo Summit Non-Attributable Report}

\begin{tabular}{ll}
\hline Source: & Medical Mission Debriefs \\
Topic: & Personal Hygiene/ Environment \\
Issue: & Crew Preferences \\
Description: & a) Deodorant in hygiene kit \\
& $\begin{array}{l}\text { b) Preferred wet wipes (recommendation since Gemini, Apollo 7) } \\
\text { c) Vacuum bottle for arm grab sample to locate source of the odors }\end{array}$
\end{tabular}

General

Comments:

Resolved:

If Resolved

how, when,

where?

Additional

Questions:

Summit Topic: No

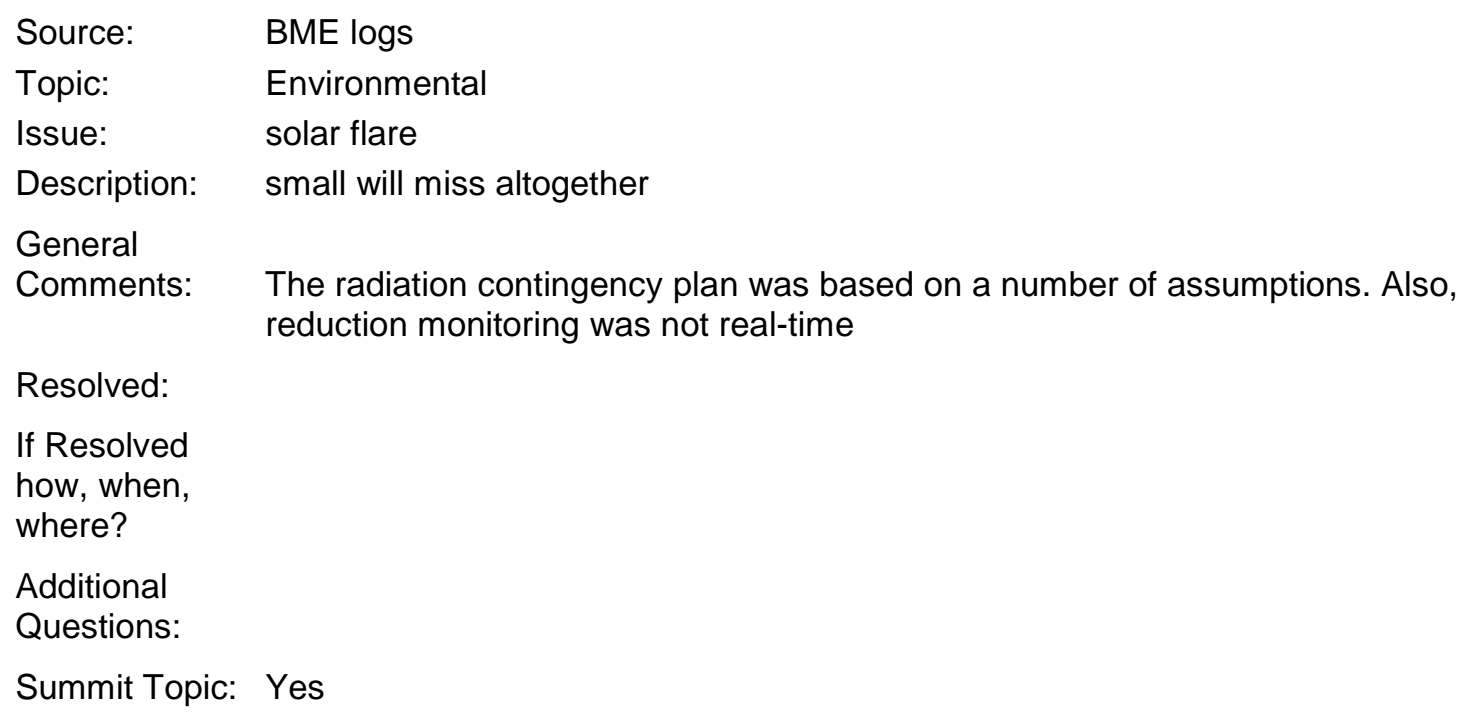

Additional

Questions:

Summit Topic: Yes 


\section{Appendix A \\ Apollo Summit Non-Attributable Report}

Source:
Topic:
Issue:
Description:
General
Comments:
Resolved:
If Resolved
how, when,
where?

Additional Were the window heaters working? Did you have window heaters? How common Questions: of a problem was this?

Summit Topic: Yes

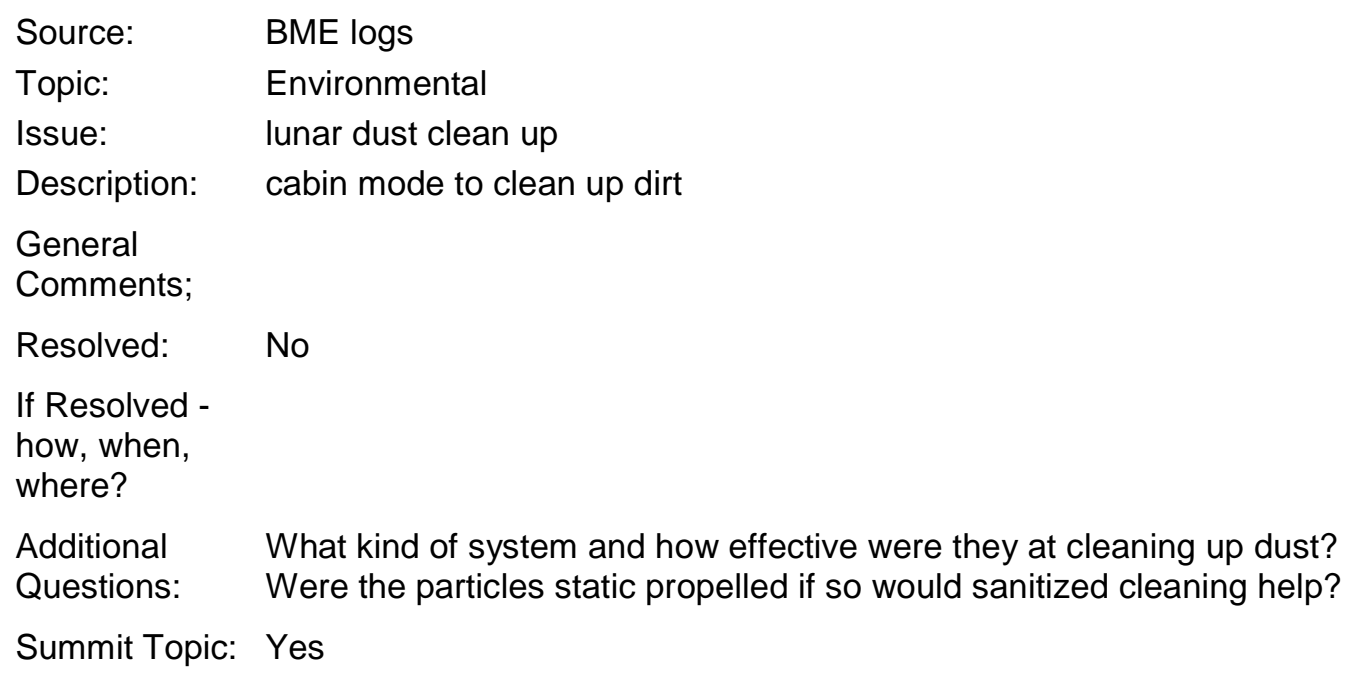

\section{Source: $\quad$ BME logs}

Topic: Personal Hygiene/ Environment

Issue: $\quad$ urine dump

Description: Leaving urine dump open most of the time because it doesn't flush well

General

Comments:

Resolved:

If Resolved

how, when, where?

Additional Was this because the filter was clogged? Did this cause adverse effects during the

Questions: mission like an increase in leak rate?

Summit Topic: Yes 


\section{Appendix A \\ Apollo Summit Non-Attributable Report}




\title{
Appendix A \\ Apollo Summit Non-Attributable Report
}

Source: $\quad$ Flight Surgeon logs

Topic: Environmental

Issue: solar flare

Description: $\quad 25 \%$ chance of solar flare

General

Comments:

Resolved:

If Resolved

how, when,

where?

Additional Will shielding on the CEV Be better in light of exploration style missions?

Questions:

Summit Topic: Yes

\author{
Source: $\quad$ Flight Surgeon logs \\ Topic: Environmental \\ Issue: Solar flare \\ Description: Solar flare possibility of $40 \%$ \\ General \\ Comments: Radiation detection capability \\ Resolved: \\ If Resolved \\ how, when, \\ where? \\ Additional \\ Questions: \\ Summit Topic: Yes
}

Source: $\quad$ Flight Surgeon logs

Topic: Environmental

Issue: solar flare

Description: small solar flare no increase in radiation

General

Comments:

Resolved:

If Resolved

how, when,

where?

Additional

Questions:

Summit Topic: Yes 


\section{Appendix A Apollo Summit Non-Attributable Report}

Source: $\quad$ Flight Surgeon logs

Topic: Environmental

Issue: ASA heater

Description: ASA heater may not be cycling

General

Comments:

Resolved:

If Resolved how, when, where?

Additional Was it cycling or not? What caused you to think it wasn't? Questions:

Summit Topic: No

Source: $\quad$ Flight Surgeon logs

Topic: Environmental

Issue: sunburst

Description: sunburst radiation to be determined

General

Comments:

Resolved:

If Resolved

how, when, where?

Additional

Questions:

Summit Topic: No

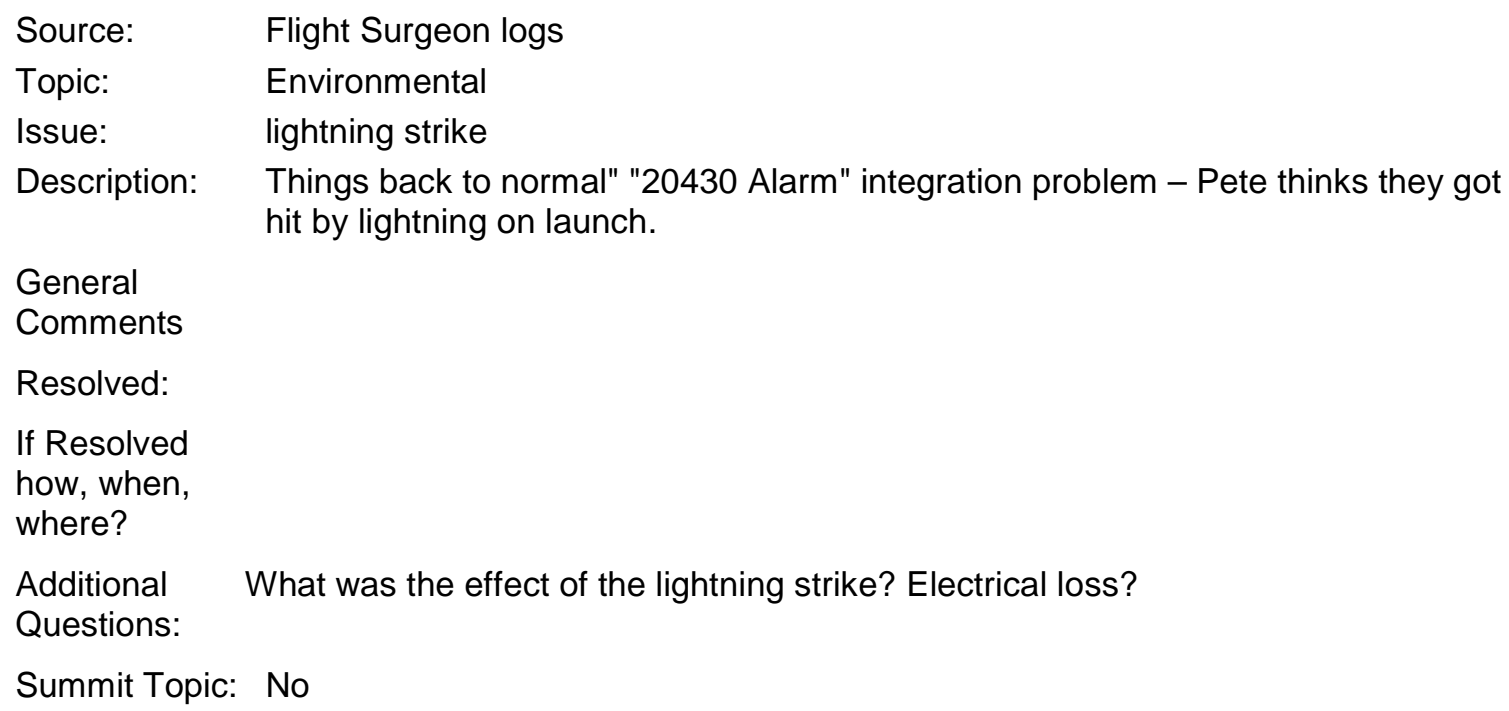

General

Comments

Resolved:

If Resolved

how, when,

where?

Additional What was the effect of the lightning strike? Electrical loss?

Questions:

Summit Topic: No 


\section{Appendix A Apollo Summit Non-Attributable Report}

Source: $\quad$ Flight Surgeon logs

Topic: Environmental

Issue: urine dump

Description: failing of 2 nd urine filter. 1 st urine filter failed 4 days ago, Ask if they can dump without filter. No it would clog use another system

General

Comments:

Resolved:

If Resolved

how, when,

where?

Additional How many spare urine filters will we need? Was this a common problem?

Questions:

Summit Topic: Yes

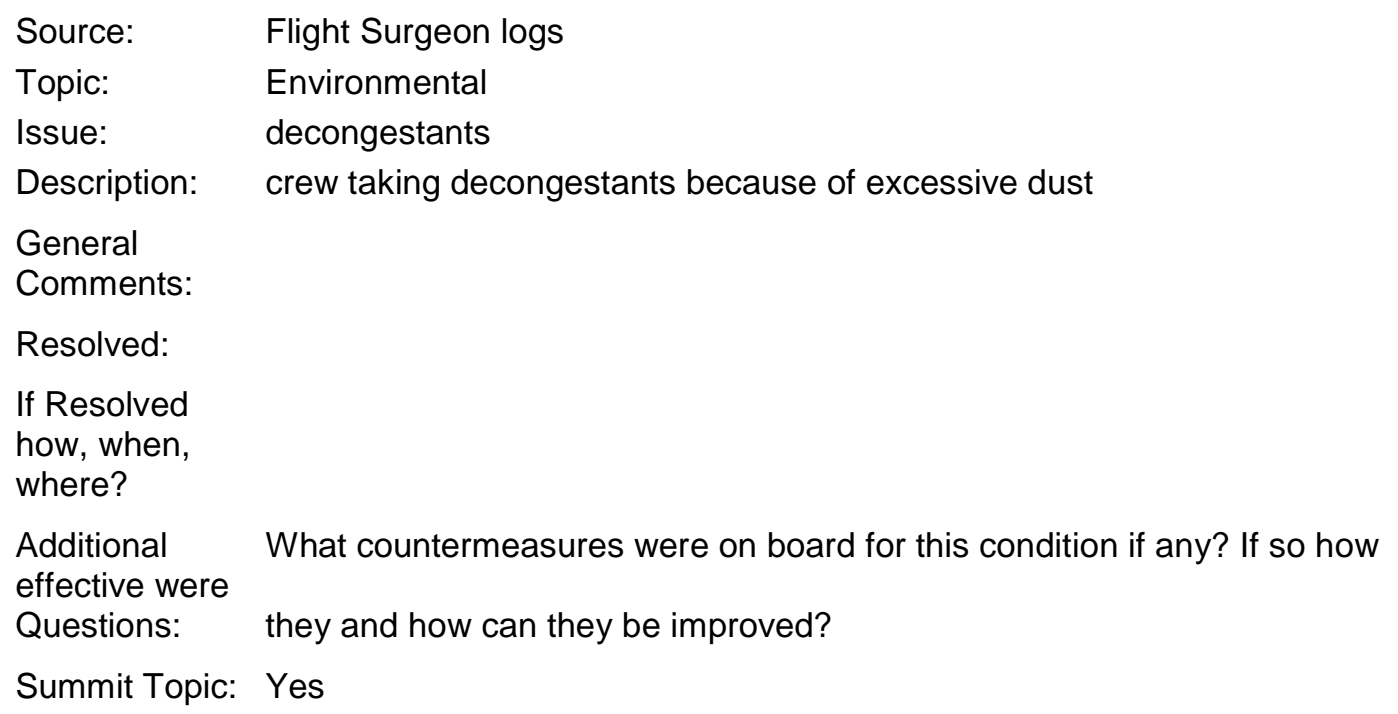

Resolved:

If Resolved how, when, where?

Additional What countermeasures were on board for this condition if any? If so how effective were

Questions: they and how can they be improved?

Summit Topic: Yes

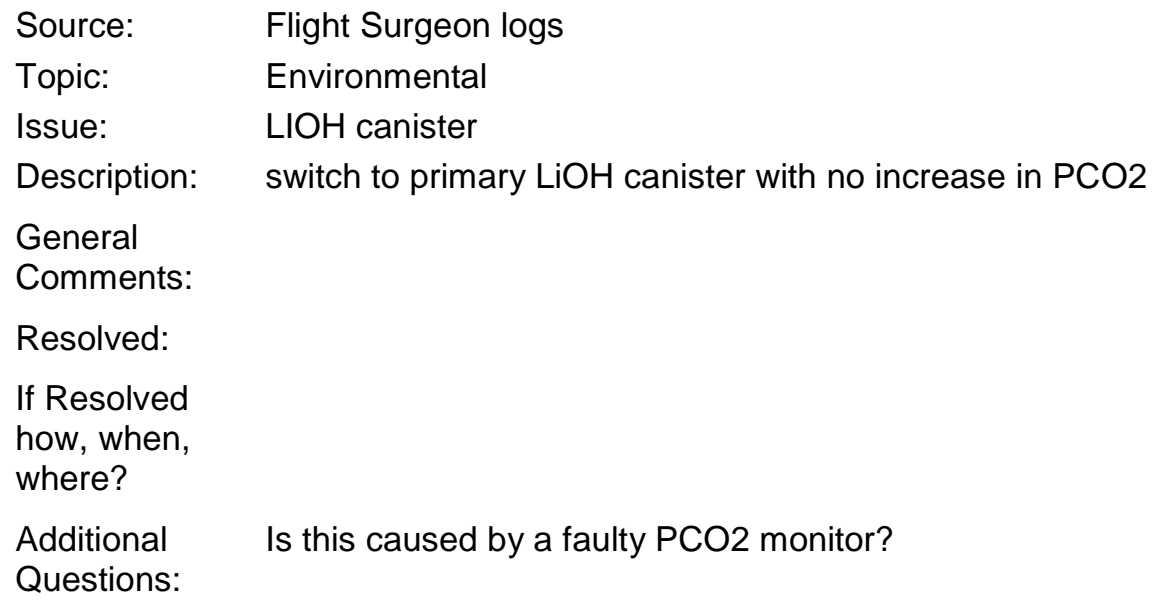




\section{Appendix A \\ Apollo Summit Non-Attributable Report}

Summit Topic: Yes

Source: $\quad$ Flight Surgeon logs

Topic: Environmental

Issue: urine dump

Description: urine dump-takes a long time for it to dissipate-it just hangs on

General

Comments:

Resolved:

If Resolved

how, when,

where?

Additional What problems did this cause?

Questions:

Summit Topic: Yes

Source: $\quad$ Flight Surgeon logs

Topic: Environmental

Issue: window

Description: white deposit build up on the outside of the windows

General

Comments:

Resolved:

If Resolved

how, when,

where?

Additional What was this was it ice? Did it obstruct vision?

Questions:

Summit Topic: Yes

Source: $\quad$ Flight Surgeon logs

Topic: Environmental

Issue: $\quad \mathrm{LiOH}$ canister

Description: on back side of moon PCO2 went up to $7.0 \mathrm{mmHg}$ they switched to secondary canister and a drop to $0 \mathrm{mmHg}$

General

Comments:

Resolved:

If Resolved how, when, where?

Additional Was this caused by a failed canister? If so do we carry spare? Questions: 


\section{Appendix A \\ Apollo Summit Non-Attributable Report}

Summit Topic: Yes

Source: Medical Mission Debriefs

Topic: Environmental

Issue: Radiation

Description: The crew received 200 mrads upon return to the Earth

General

Comments:

Resolved:

If Resolved

how. when,

where?

Additional What did the crew receive upon return to Earth that gave them 200 mrads? Was

this an

Questions: $\quad$ X-ray? Was this totally necessary or could this have been adequately evaluated using some other modality?

Summit Topic: Yes

Source: Medical Mission Debriefs

Topic: Environmental

Issue: Waste Management

Description: a) Crew highly recommends creating a device that would allow them to assume a squatting position to have a BM

-"Make the guy's BM like as close to the way he is used to living, and provide the least possible facilities"

b) Crew preferred urinating into the device used for this mission over previous mission, where they urinated in a bag after placing a condom on the penis.

General

Comments: This complaint extended across the mission.

Resolved: No

If Resolved

how, when,

where?

Additional

Questions: $\quad$ Please provide specific examples of breakdowns in $\mathrm{H} / \mathrm{W}$ and suggest areas for improvement.

Summit Topic: Yes 


\title{
Appendix A \\ Apollo Summit Non-Attributable Report
}

\author{
Source: Medical Mission Debriefs \\ Topic: Environmental \\ Issue: Part II \\ Description: Noise was loud, but tolerable (adaptable) \\ General \\ Comments: Crew complained of noise level in LM, stating it interfered with sleep, \\ concentration. \\ Resolved: \\ If Resolved \\ how, when, \\ where? \\ Additional How noisy was it on the LM? \\ Questions: $\quad$-CMP could hear background noise \\ -Repressing the LM cabin was louder \\ Summit Topic: Yes

\footnotetext{
Source: $\quad$ Medical Mission Debriefs

Topic: Environmental

Issue: Part I

Description: a) Water system seemed to be functioning well especially the cold water. Crew did not complain of any bubbles in the system

canister

b) Lunar dust did not appear to be filtered from the environment from the $\mathrm{LiOH}$

c) Mobility was important issue, especially to the Gemini veterans

General

Resolved: Yes, apparently.

If Resolved

how, when, where?

Additional What changes occurred in the water system between Apollo 7-11 and 12 to

Questions: improve this problem with bubble/gas formation?

Summit Topic: Yes
} \\ Comments:
}




\section{Appendix A Apollo Summit Non-Attributable Report}

Source: Medical Mission Debriefs

Topic: Environmental

Issue: $\quad \mathrm{LiOH}$ canister changes

Description: Crew forgot to make the $\mathrm{LiOH}$ change just after leaving lunar orbit. About 12 hours later, the change was made. No consequence to the late change.

General

Comments:

Resolved:

If Resolved

how, when, where?

Additional

Questions:

Summit Topic: No

Source: $\quad$ Medical Mission Debriefs

Topic: $\quad$ Personal Hygiene/ Environment

Issue: bathroom facilities

Description: CMP: ".. I think the key to this thing is if you can make the guy's life as close to the way he's used to living, and provide the facilities, the easier it's going to be for him." "the fact that we had something that we could put a stream of water into, just like we do here, made that whole operation seem a hell of a lot better."

General

Comments: Highlights the issues associated with Apollo WCS.

Resolved: No

If Resolved

how, when, where?

Additional

Questions:

Summit Topic: Yes 


\title{
Appendix A Apollo Summit Non-Attributable Report
}

Source: $\quad$ Flight Surgeon logs

Topic: Personal Hygiene/ Environment

Issue: $\quad$ wet wipes and fecal bags

Description: Wet wipes and fecal bags don't have any velcro on stem and subsequently leak. Crew found using this system very difficult and messy.

General

Comments:

Resolved:

If Resolved how, when, where?

Additional What will be using during exploration?

Questions: How would velcro help fecal bags and wet wipes?

Summit Topic: Yes

\author{
Source: $\quad$ Medical Mission Debriefs \\ Topic: $\quad$ Personal Hygiene/ Environment \\ Issue: Bowel movements \\ Description: LMP: one BM before LM activation, one after the return \\ CMP: one BM the day before LOI and one the day after TEl. \\ CDR: one and an eighth.(?) \\ General \\ Comments: Crew noted difficulty with using WCS, specifically in ability to assume squatting \\ position, no odor control, etc. \\ Resolved: $\quad$ No \\ If Resolved \\ how, when, \\ where? \\ Additional \\ Questions: \\ Summit Topic: Yes
}




\section{Appendix A Apollo Summit Non-Attributable Report}

$\begin{array}{ll}\text { Source: } & \text { Medical Mission Debriefs } \\ \text { Topic: } & \text { Environmental } \\ \text { Issue: } & \text { Lunar Module }\end{array}$

Description: LMP: ".. It looks to me like big problem is the dirt, you've got to keep the dirt from bothering your suit. If you can do that, you're going to have a good time up there at the moon." The noise required a night or so to accommodate to, then was OK, "like taking the country boy out into the city. Couldn't sleep when he hears the

General trains, and the cars the first night but he does get used to it."

Comments:

Resolved: No

If Resolved

how, when,

where?

Additional

Questions:

Summit Topic: Yes

\begin{tabular}{|c|c|}
\hline Source: & Medical Mission Debriefs \\
\hline Topic: & Environmental \\
\hline Issue: & Flashing lights \\
\hline Description: & $\begin{array}{l}\text { CDR: "We closed our eyes and faced the moon, when we were orbiting it } \\
\text { because it would be more-you get less discharges facing the moon than away } \\
\text { from it." "Get either a streak (strikes the eyeball parallel) or a flash (strikes the } \\
\text { eyeball perpendicular)" LMP: I saw them in either eye or in both eyes. }\end{array}$ \\
\hline
\end{tabular}

General

Comments:

Resolved: No

If Resolved

how, when,

where?

Additional

Questions:

Summit Topic: No 


\title{
Appendix A Apollo Summit Non-Attributable Report
}

Source: $\quad$ Medical Mission Debriefs

Topic: Environmental

Issue: Salutory effect of vehicle volume

Description: CDR: "The thing that was different between Gemini and Apollo that I noticed right off the bat, nobody ever stopped moving when we were awake." "I think that's one of the reasons, the fact that you're free, and everything, I felt a whole lot better than I did on any of those Gemini rides. I mean, I could tell I was going down hill a log on those things, on every day that went by, it didn't matter whether it was a short one or a long one. But I never felt that way on this, I really felt good. But we all moved, and somebody was -you were always moving something."

CMP:" I felt better in 10 days in this one that I did in 3 days in Gemini, by far, a hell of a lot better."

General The increased vehicle volume of the Apollo TEl configuration had a definite Comments: salutory effect on crew, compared to the confined volume of the Gemini vehicle.

Resolved:

If Resolved how, when, where?

Additional What inferences can be made regarding even longer-duration missions?

Questions:

Summit Topic: Yes

\author{
Source: $\quad$ Flight Surgeon logs \\ Topic: Environmental \\ Issue: Radiation \\ Description: Goofed and left PRN on stowed PGA's \\ General \\ Comments: Radiation monitors were frequently "left behind" by CM on lunar surface. \\ Resolved: \\ If Resolved \\ how, when, \\ where? \\ Additional \\ Questions: How can you incorporate this device in the suit? \\ Summit Topic: Yes
}




\section{Appendix A \\ Apollo Summit Non-Attributable Report}

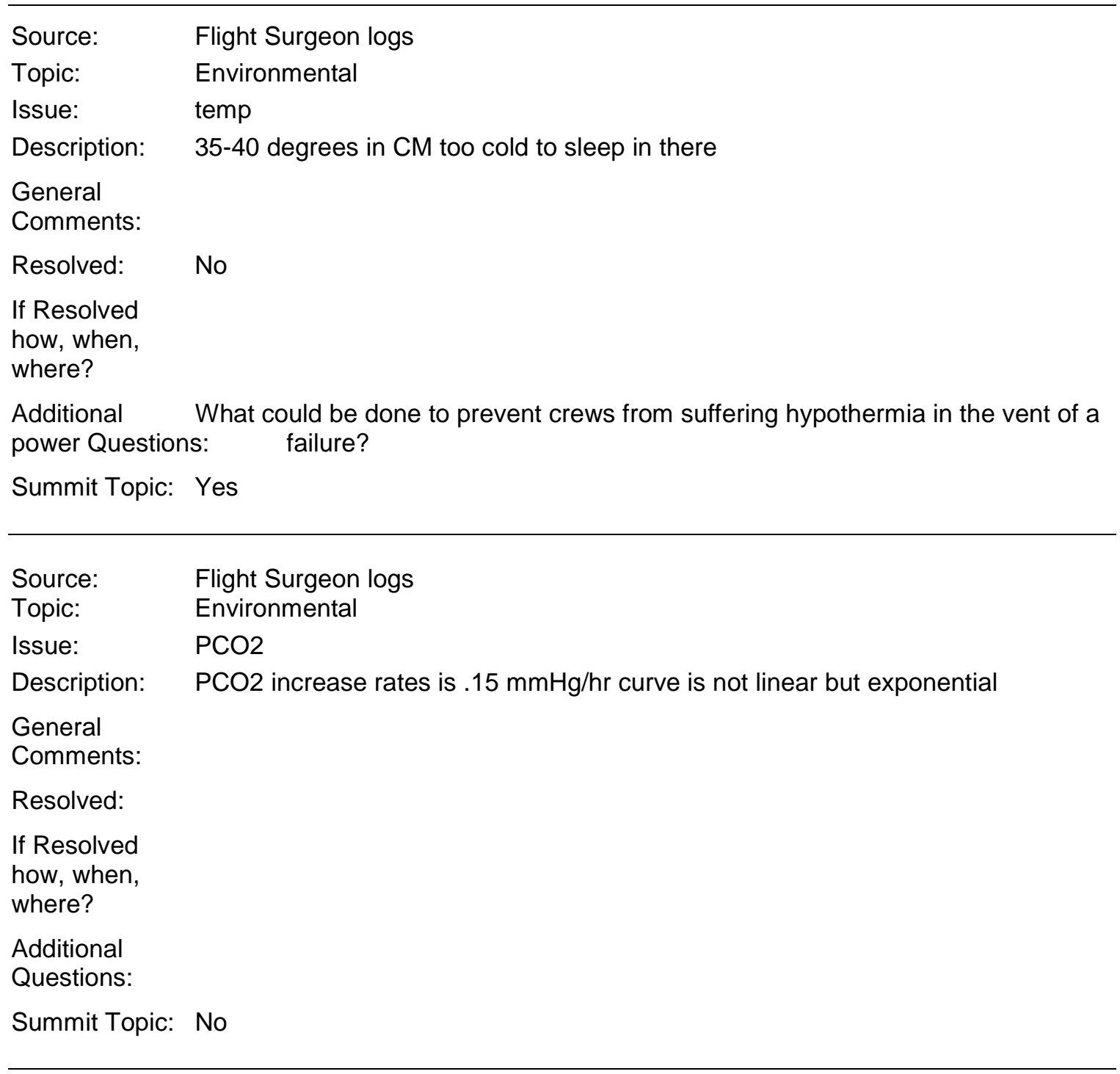

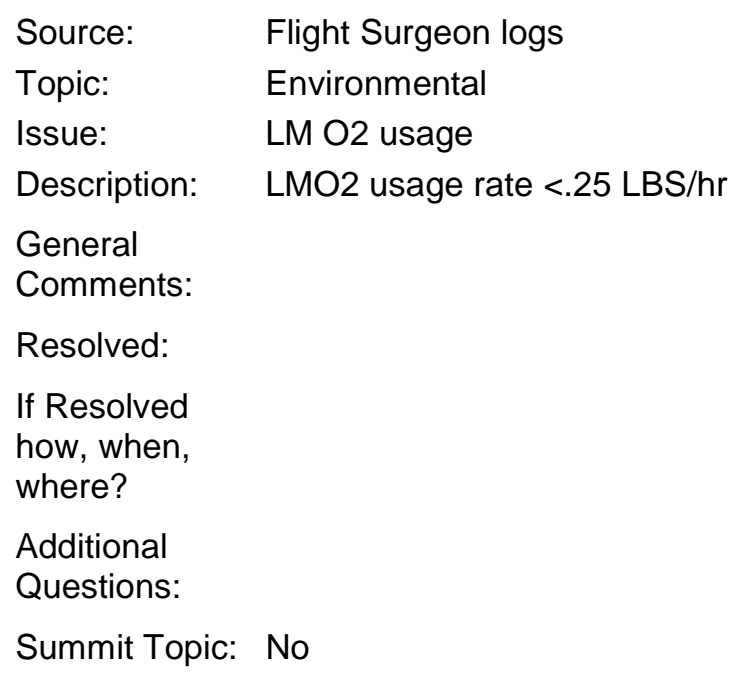

Additional

Questions:

Summit Topic: No 


\title{
Appendix A Apollo Summit Non-Attributable Report
}

\author{
Source: $\quad$ BME logs \\ Topic: $\quad$ Environmental \\ Issue: $\quad$ CSM cabin pressure \\ Description: A lot of discussion on fall in CSM cabin pressure over past hour to $4.5 \mathrm{psi}$. \\ terminating $\mathrm{O} 2$ flow test \\ General \\ Comments: \\ Resolved: \\ If Resolved \\ how, when, \\ where? \\ Additional What was the cause of this? \\ Questions: \\ Summit Topic: Yes

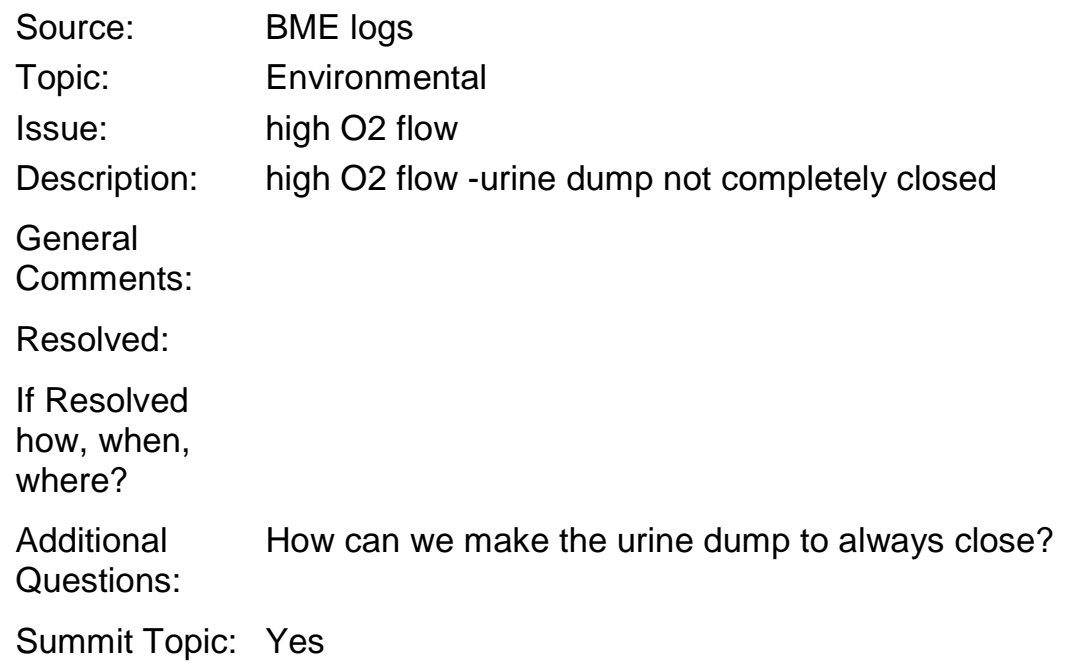 \\ Resolved: \\ If Resolved \\ how, when, \\ where? \\ Additional What temp values should we go by to determine temperature and comfortability? \\ Questions: \\ Summit Topic: Yes
}




\section{Appendix A \\ Apollo Summit Non-Attributable Report}

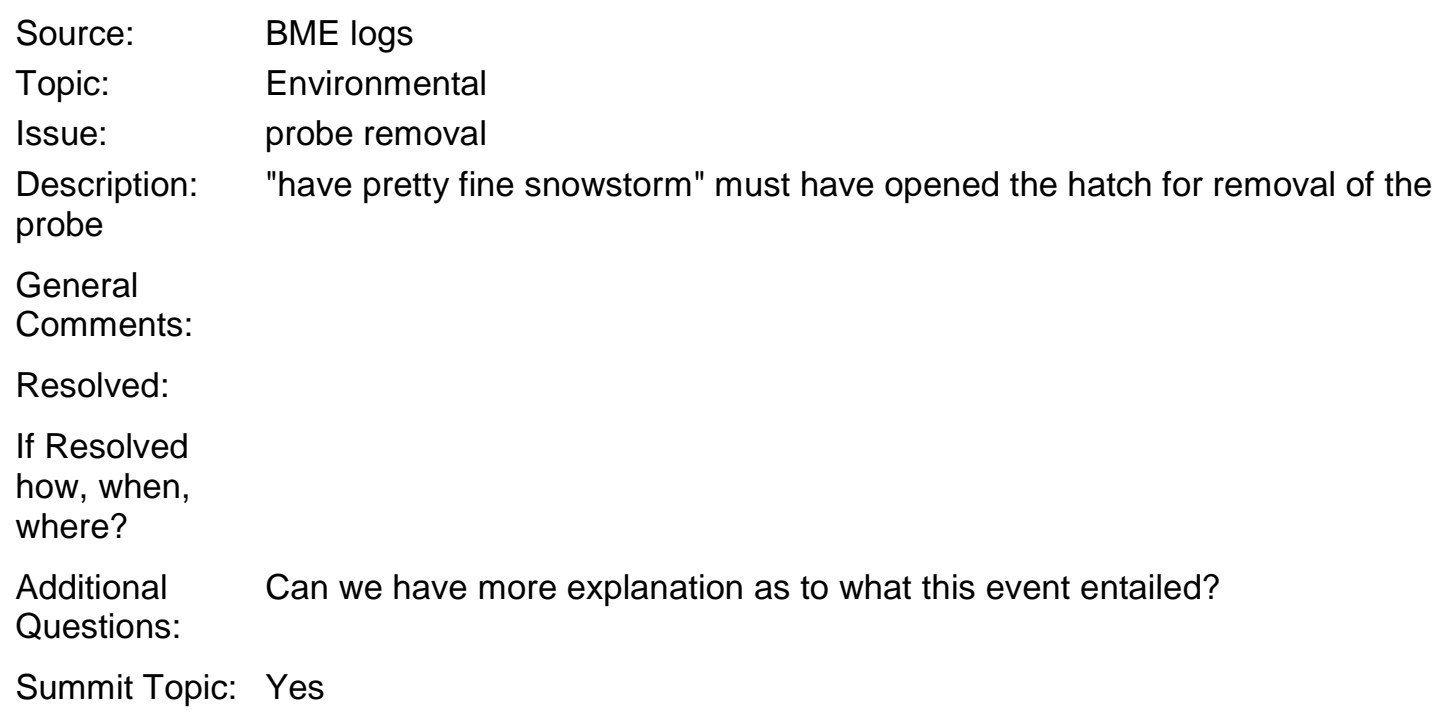

Source: $\quad$ Flight Surgeon logs

Topic: Environmental

Issue: $\quad$ High $\mathrm{O} 2$ flow alarm

Description: High $\mathrm{O} 2$ Flow alarm

General

Comments:

Resolved:

If Resolved

how, when, where?

Additional Do we know what caused this?

Questions:

Summit Topic: No 


\section{Appendix A \\ Apollo Summit Non-Attributable Report}




\title{
Appendix A Apollo Summit Non-Attributable Report
}

\author{
Source: $\quad$ Flight Surgeon logs \\ Topic: Environmental \\ Issue: $\quad$ O2 flow \\ Description: O2 Flow rate high \\ General cause undetermined \\ Comments: \\ Resolved: \\ If Resolved \\ how, when, \\ where? \\ Additional Was this caused from the urine dump not closing like it had been from other \\ Questions: flights? \\ Summit Topic: Yes
Source: $\quad$ Medical Mission Debriefs
Topic: $\quad$ Personal Hygiene
Issue: Bowel movements
Description: Had first BM on 8th mission day! Wore a bag for about 12 hours prior to EVA without result.
CDR had BM on 3rd and 7th days.
All agreed defecation and collection were "gross, and markedly unsatisfactory from a hygiene and civilized aspect.
CMP had first BM at 80 hours into flight. Next was the day after TEI \\ General \\ Comments: \\ Resolved: \\ If Resolved \\ how, when, \\ where? \\ Additional \\ Questions: What specifically could be done to improve the WCS? \\ Summit Topic: Yes
}




\title{
Appendix A Apollo Summit Non-Attributable Report
}

\author{
Source: Medical Mission Debriefs \\ Topic: Environmental \\ Issue: In-suit urine collection \\ Description: Urine drain line kinked "apparently" all the time. \\ General \\ Comments: \\ Resolved: \\ If Resolved \\ how, when, \\ where? \\ Additional \\ Questions: \\ Summit Topic: No
}

$\begin{array}{ll}\text { Source: } & \text { Medical Mission Debriefs } \\ \text { Topic: } & \text { Environmental } \\ \text { Issue: } & \text { Visual flashes } \\ \text { Description: } & \text { LMP: very sharp flashes, straight,..., instantaneously,.. } \\ & \text { CDR: "The single streak and the double shot appeared to be very clear to me." } \\ & \text { CMP: "quite clear...most of my streaks appeared to be on the periphery... } \\ & \text { CDR: ...side, from left to right. "generally random" } \\ & \text { LMP: couldn't really correlate a pattern out of it. } \\ & \text { LMP: a couple looked like lightning in a cloud } \\ \text { General } & \text { Some flashes were streaks, some were pinpoint, some were larger 'blobs' During } \\ \text { Comments: } & \text { a test period, some eyes were open, some closed. LMP described 18, CDR had } \\ & \text { 14 and CMP had 8 visual flashes } \\ & \text { On three occasions two persons reported a flash simultaneously } \\ & \text { After very bright ("nova or super nova") flashes a 'halo' effect was described } \\ & \text { Crew described the flashes as 'definitely' in their eyeball, not in the cabin. } \\ & \text { CDR: no preferred orientation of flash }\end{array}$

Resolved:

If Resolved

how, when,

where?

Additional

Questions:

Summit Topic: No 


\section{Appendix A \\ Apollo Summit Non-Attributable Report}

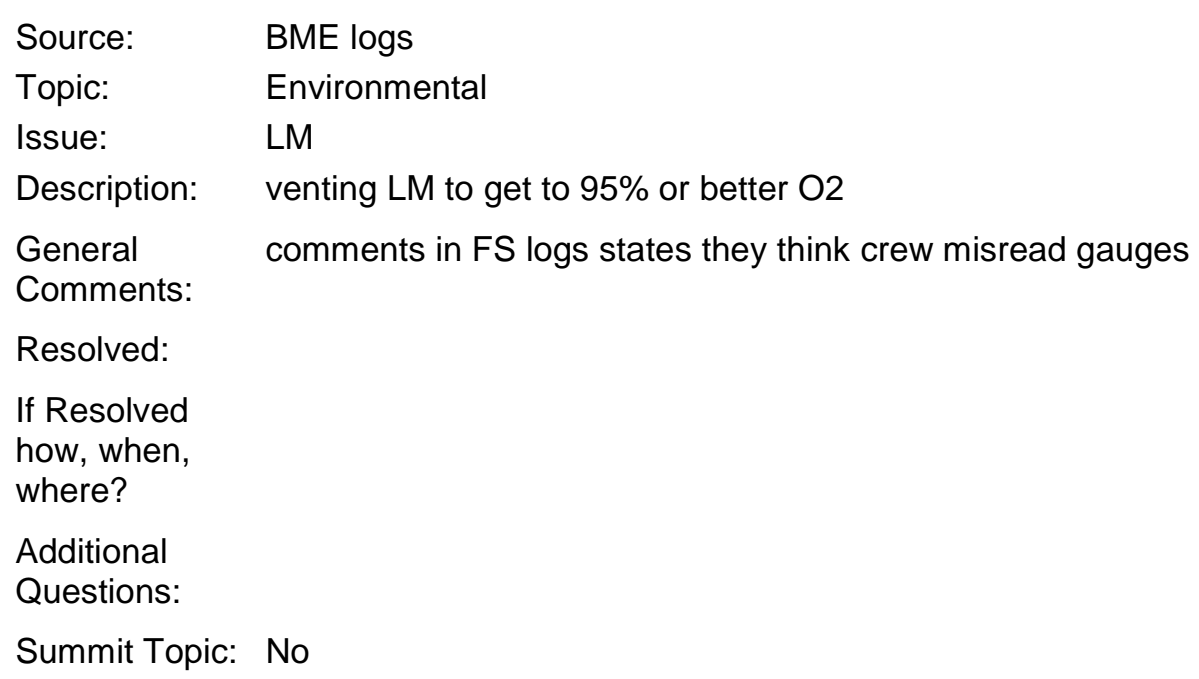

General

Comments:

Resolved:

it Resolved

how, when, where?

Additional Why did it take 2 pressurizations/enrichment procedures to get this? How many Questions: do we expect to achieve this?

Summit Topic: Yes 


\section{Appendix A Apollo Summit Non-Attributable Report}

Source: $\quad$ Flight Surgeon logs

Topic: Environmental

Issue: low $\mathrm{O} 2$

Description: info from SPAN-Cabin O2 88\%-Estimated O2 at end of SEVA 91-92\%-continue $\mathrm{O} 2$ enrichment procedure

General

Comments:

Resolved:

If Resolved

how, when,

where?

Additional What caused the low $\mathrm{O} \%$ ?

Questions:

Summit Topic: Yes

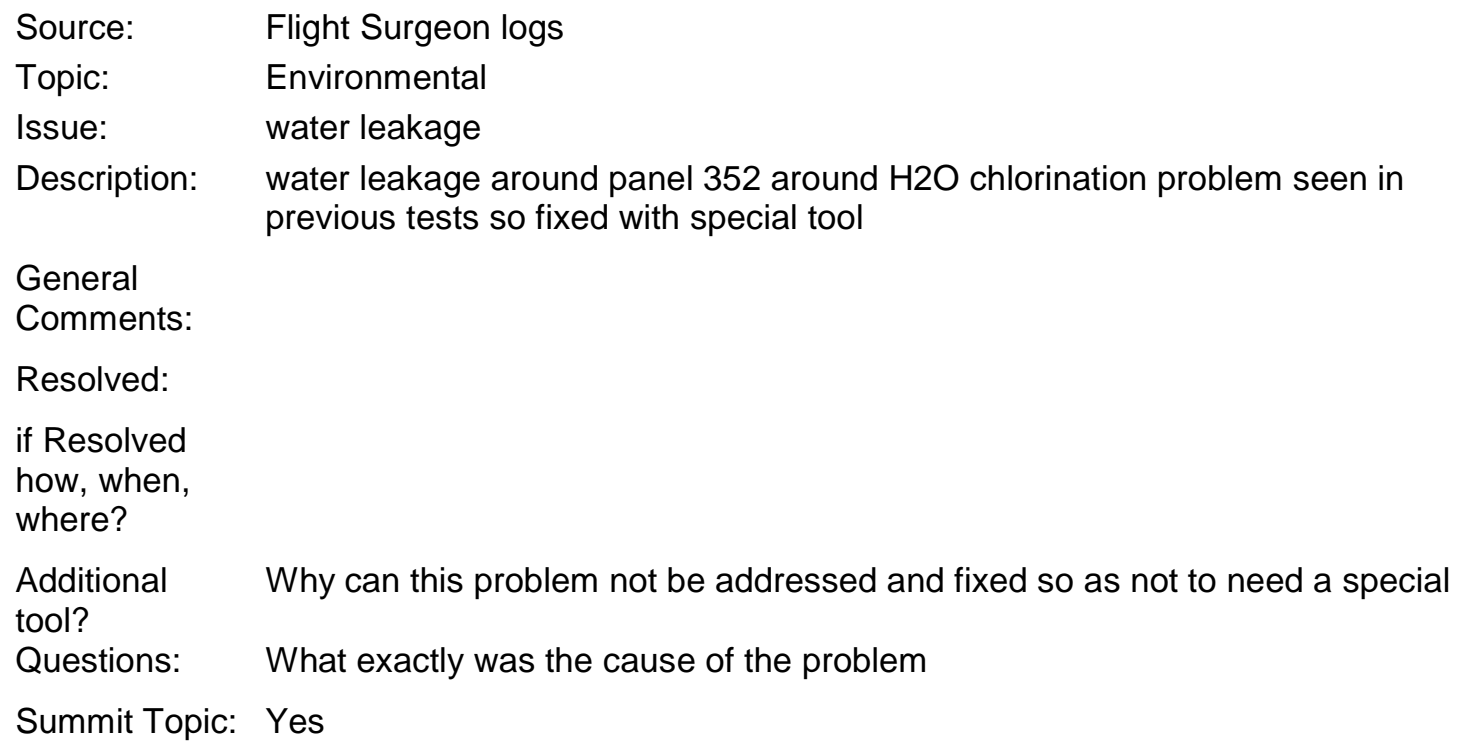

General

Comments:

Resolved:

if Resolved

how, when, where?

Additional Why can this problem not be addressed and fixed so as not to need a special tool?

Questions: What exactly was the cause of the problem

Summit Topic: Yes 


\title{
Appendix A Apollo Summit Non-Attributable Report
}

\author{
Source: $\quad$ Flight Surgeon logs \\ Topic: Environmental \\ Issue: leak rate \\ Description: leak rate so high in LM -may bleed pressure in $\mathrm{O} 2$ tanks so low that it will \\ eliminate EVA-3 \\ General urine valve was open -quick disconnect not capped \\ Comments: \\ Resolved: \\ If Resolved \\ how, when, \\ where? \\ Additional \\ Questions: \\ Summit Topic: Yes

$\begin{array}{ll}\text { Source: } & \text { Medical Mission Debriefs } \\ \text { Topic: } & \text { Environmental } \\ \text { Issue: } & \text { Radiation monitors } \\ \text { Description: } & \text { There were three different types of radiation monitors: } \\ & \begin{array}{l}\text { 1) kept in EVA suit pockets } \\ \text { 2) super D on the wall, a large instrument }\end{array} \\ & \text { 3) three small packages in their garment } \\ \text { General } & \text { "certainly not coordinated" "you ought to settle down to one system and } \\ \text { prescribe some } & \begin{array}{l}\text { positioning of the suit so that we can keep hold of them." *When we took the suits } \\ \text { Comments: } \\ \end{array} \\ & \begin{array}{l}\text { off, we stuck them down in the suits and then we'd get all them out and they'd } \\ \text { been buried there all that time." }\end{array}\end{array}$ \\ Resolved: \\ If Resolved \\ how, when, \\ where? \\ Additional \\ Questions: \\ Summit Topic: Yes
}




\section{Appendix A \\ Apollo Summit Non-Attributable Report}

Source: $\quad$ Medical Mission Debriefs

Topic: Personal Hygiene/Environmental

Issue: bowel movements

Description: "about every other day" but not tracked.

One person missed three days, but averaged every other day.

General

Comments:

Resolved:

If Resolved

how, when,

where?

Additional

Questions:

Summit Topic: No

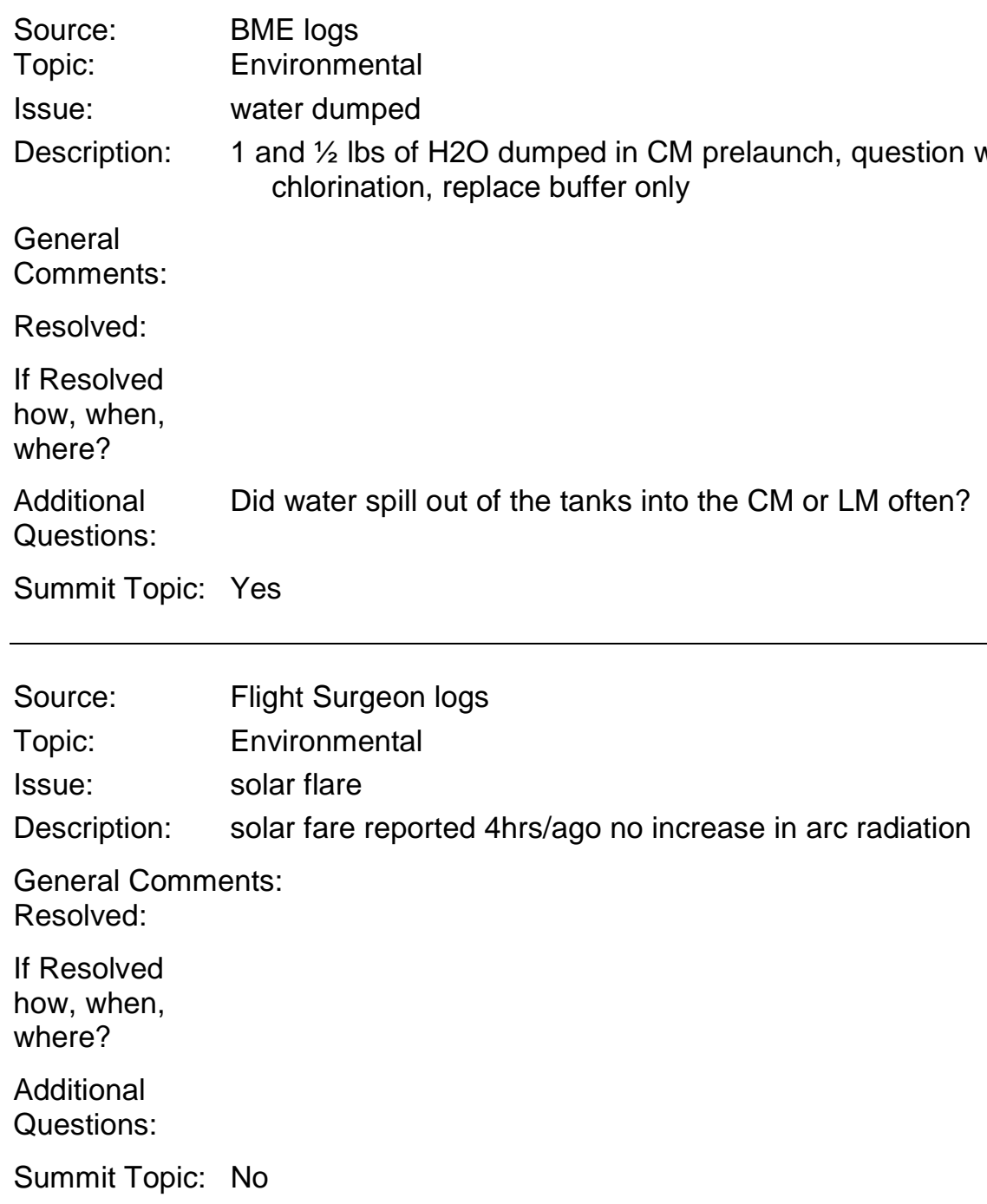

General

Comments:

Resolved:

If Resolved

how, when, where?

Additional Did water spill out of the tanks into the CM or LM often?

Questions:

Summit Topic: Yes 


\title{
Appendix A Apollo Summit Non-Attributable Report
}

\author{
Source: Medical Mission Debriefs \\ Topic: Environmental \\ Issue: urine collection \\ Description: The collection of urine samples was seriously impaired by the urine collection \\ system which resulted in urine soiling of individuals, spilling in the vehicle and \\ difficulty with the check valve. "CM didn't work at all." "The data is meaningless." \\ "Does a guy want to pee all over himself or does he want to log your satisfactory \\ flow rates? You're going to get one or the other. You are not going to get both, \\ not with that kind of system." Dr Berry: "What do you mean by that, CM? They \\ get "stickier and stickier" as the mission progresses. \\ General \\ Comments: \\ Resolved: No \\ If Resolved \\ how, when, \\ where? \\ Additional \\ Questions: \\ Summit Topic: Yes

\begin{abstract}
Source: $\quad$ Medical Mission Debriefs
Topic: Environmental

Issue: water bags

Description: There were air bubbles in the water which also changed the water taste.Crew estimated $20-30 \%$ of bag volume was air. Far more gas in hot water than cold water Juice bags were not filled every time, estimated water gun strokes were used to add water to juice bags. Water gun was not consistent, difficult. Filling the bag up before you can drink was operationally involvement and particularly not useful at night. Had to drink the entire bag once you started -no wetting your mouth or partial drinks per thirst level
\end{abstract}

General

Comments:

Resolved: No

If Resolved

how, when,

where?

Additional

Questions:

Summit Topic: Yes 


\title{
Appendix A Apollo Summit Non-Attributable Report
}

\author{
Source: Medical Mission Debriefs \\ Topic: Environmental \\ Issue: urine collection \\ Description: New procedures which crew felt were incorrect, could not be discussed because \\ there was no private communication and "you can't discuss these things in a \\ rational manner. You have to do them. Although that was a dumb procedure. \\ General \\ Comments: \\ Resolved: \\ If Resolved \\ how, when, \\ where? \\ Additional \\ Questions: \\ Summit Topic: No

$\begin{array}{ll}\text { Source: } & \text { Medical Mission Debriefs } \\ \text { Topic: } & \text { Environmental } \\ \text { Issue: } & \text { new fecal bags } \\ \text { Description: } & \text { "We'd like to go back to the old ones and take the finger out." Not clear what that } \\ & \text { means. } \\ & \text { Fecal bags were returned to earth. They were not gas-tight and were completely } \\ & \text { filled. Concerned about bags bursting during EVA. Not compatible with an } \\ & \text { operational mission. Is there any justification for it? Consider the health } \\ & \text { hazard if a bag bursts. "You'll never get that place cleaned up, never." } \\ & \text { You could jettison them during an EVA. "Unfortunately, there is only one bag," so } \\ & \text { you can't throw it away. }\end{array}$ \\ General \\ Comments: \\ Resolved: \\ If Resolved \\ how, when, \\ where? \\ Additional \\ Questions: \\ Summit Topic: Yes
}




\title{
Appendix A \\ Apollo Summit Non-Attributable Report
}

\author{
Source: BME logs \\ Topic: Environmental \\ Issue: $\quad$ windows fogging \\ Description: window fogging with moisture from excessive breathing \\ General \\ Comments: \\ Resolved: No \\ If Resolved \\ how, when, \\ where? \\ Additional How often did the windows fog? \\ Questions: \\ Summit Topic: Yes

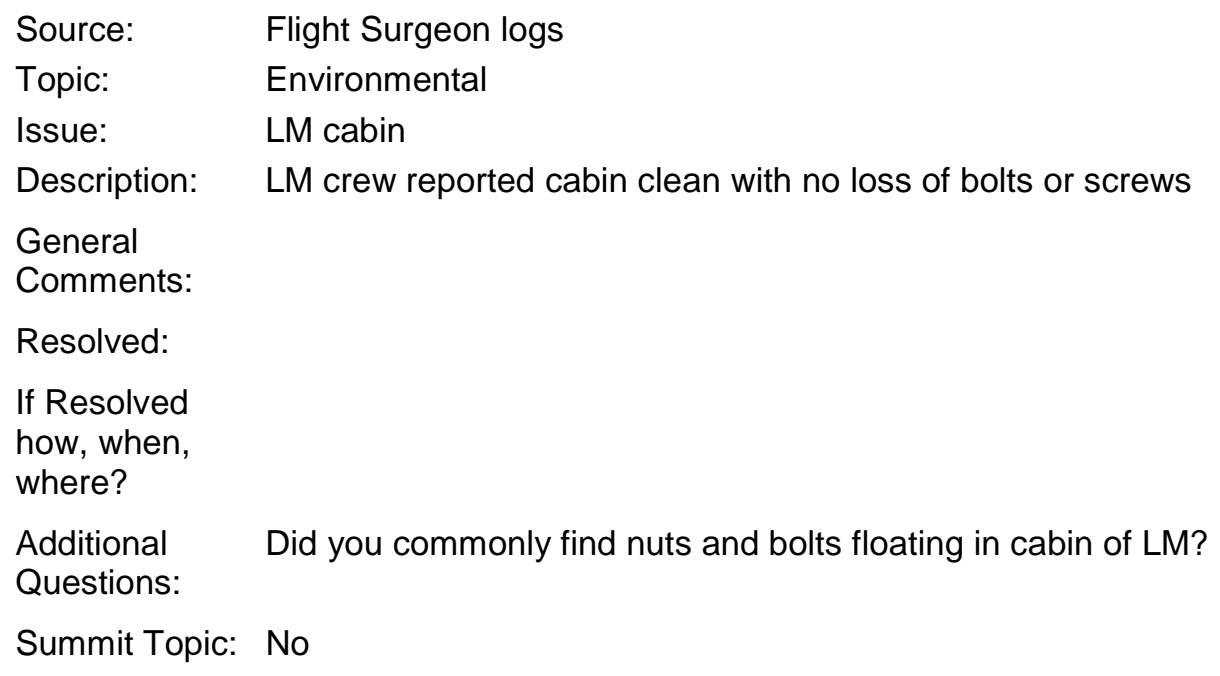




\title{
Appendix A Apollo Summit Non-Attributable Report
}

\author{
Source: $\quad$ Medical Mission Debriefs \\ Topic: Environmental \\ issue: $\quad$ urination system \\ Description: Back pressure in the urination system required straining to overcover the check \\ valve. This resulted in urine remaining in the condom receptacle and no way \\ to dispose of it except to blot it, requiring a lot of blotting. Lots of air bubbles in \\ the sample container, which reduced sample volume \\ The condom which rolled onto the penis for urination, were completely \\ unsatisfactory during flight uses. Discussed at length later in the debriefs. \\ General Medical interview changed the subject \\ Comments: \\ Resolved: \\ If Resolved \\ how, when, \\ where? \\ Additional \\ Questions: \\ Summit Topic: Yes

\footnotetext{
Source: $\quad$ Medical Mission Debriefs

Topic: Environmental

Issue: eating, sanitation

Description: Must support "human eats on earth", "Human being food," refrigerator, oven, etc. Must support defecation and urination like a human being, whether that means a toilet or some new design, and reduce medical samples of eating, defecation, urination.

Must provide showers, clothes

These things are essential to longer duration and doing the job

"The Apollo is too small. We need to treat a human in space like a human being, and not a guinea pig. Really need hot and cold food

General Need to be able to clean the body periodically, internally and externally--

psychologically

Comments: improves your outlook:

Resolved:

If Resolved

how, when,

where?

Additional

Questions:

Summit Topic: No
} 


\section{Appendix A Apollo Summit Non-Attributable Report}

Source: $\quad$ Medical Mission Debriefs

Topic: Work/Rest Schedule

Issue: Sleep Observations

Description: a) Sleep was fitful for the first three nights and last night before re-entry

b) Daily cycle shifting for upcoming events (rendezvous, burn, etc.) made sleeping on schedule difficult

c) Bring ear plugs, blinders during sleep shift. Also consider having all three CM sleep at same time, or $2 \mathrm{CM}$ sleep and one CM minding the store

d) CM went through 5 days with 4-5 hours sleep, felt fatigued throughout the mission:

e) "Timeline was terrible". Careful review of the flight plan reveals that the crew was working twelve days in a ten day mission

f) Crew slept between 5-7 hours per work day at best

General

Comments:

Resolved:

If Resolved

how, when,

where?

Additional 1. Sleep cycle shifting?

Questions: $\quad 2$. Do the astronauts need to get used to sleeping with ear plugs and Blinders before leaving? If so how long

Summit Topic: Yes

\section{Source: $\quad$ Flight Surgeon logs}

Topic: Work/Rest Schedule

Issue: $\quad$ Sleep interrupted by comm

Description: Can we cover our ears with plugs or something since comm is interrupting sleep

of or

CM's.

General

Comments:

Resolved:

if Resolved

how, when,

where?

Additional What countermeasures will we have to help with noise waking crew up while

Questions: $\quad$ trying to

Summit Topic: Yes 


\title{
Appendix A Apollo Summit Non-Attributable Report
}

\author{
Source: $\quad$ Medical Mission Debriefs \\ Topic: Work/Rest Schedule \\ Issue: Sleep Observations \\ Description: a) Crewmember did not feel the pre-flight sleep period was long enough -was \\ sleepy on launch \\ b) Work / rest cycle could be improved \\ c) Sleep cycle / deprivation affected the crew performance -Average 2 hours \\ continuous sleep (see General Comments and Additional Questions) \\ d) Crew preferred being wedged into something to feel secure for sleep \\ Sleep restraint device was outstanding \\ General Work / Rest Cycle Suggestions: Simultaneous sleep cycle during landing phase \\ Comments: $\quad 1$. Window cover ups \\ 2. Turn out lights \\ 3. $2 \mathrm{CM}$ in sleep restraint and one asleep with headset on -Ground would not call \\ up except impending gimbal lock or other emergency \\ 4. Ground automatically switch all $40 \mathrm{MNI}$ antennas \\ Resolved: \\ Another crewmember gives a good description of the sleep cycle \\ If Resolved \\ how, when, \\ where? \\ Additional How can work/rest cycle be specifically improved? \\ Questions: How was crew performance affected by sleep deprivation \\ Summit Topic: Yes

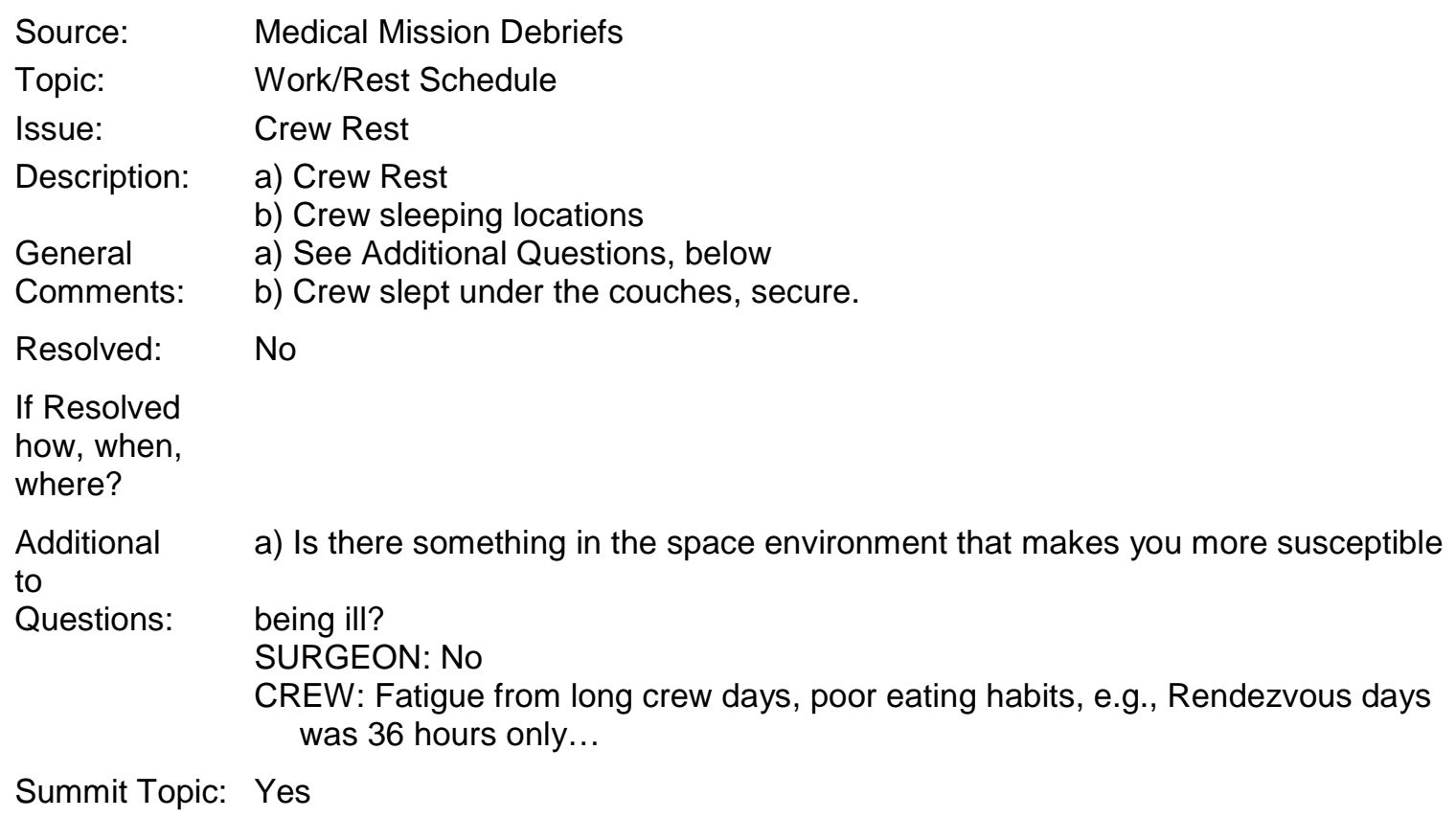




\title{
Appendix A Apollo Summit Non-Attributable Report
}

\author{
Source: $\quad$ Medical Mission Debriefs \\ Topic: Work/Rest Schedule \\ Issue: Sleep Observations \\ Description: a) Crew slept simultaneously during the return portion of the mission \\ b) Felt rest time was adequate with all 3 crew members asleep at the same time. \\ -Crew felt there was little work to do on return and could sleep simultaneously \\ without concerns -Wanted to be well rested for re-entry -Crew activities during \\ staggered sleep was disturbing -Crew felt both disconnecting comm hardware \\ General \\ Comments: \\ Resolved: \\ If Resolved \\ how, when, \\ where? \\ Additional On extended missions is simultaneous sleep better than staggered? If so, are the \\ Questions: $\quad$ scheduled projects amendable to this? \\ Summit Topic: Yes \\ Source: $\quad$ Medical Mission Debriefs \\ Topic: Work/Rest Schedule \\ Issue: Sleep Observations \\ Description: a) Crew reports that they slept well in CM on the way out \\ 1. Each CM slept under individual couches and sleeping bag \\ b) Sleep in the LM on the surface was fitful for a number of reasons (2-3 hours \\ most) \\ Noise-glycol pump in LM \\ Lighting \\ Temperature -cold next to floor \\ Lack of comfortable places to sleep \\ Dust accumulation on the floor \\ General Temperature problem: Whatever the problem was on the Lunar surface was not \\ Comments: anticipated on the ground \\ Resolved: No \\ If Resolved \\ how, when, \\ where? \\ Additional \\ Questions: \\ Summit Topic: Yes
}




\section{Appendix A \\ Apollo Summit Non-Attributable Report}

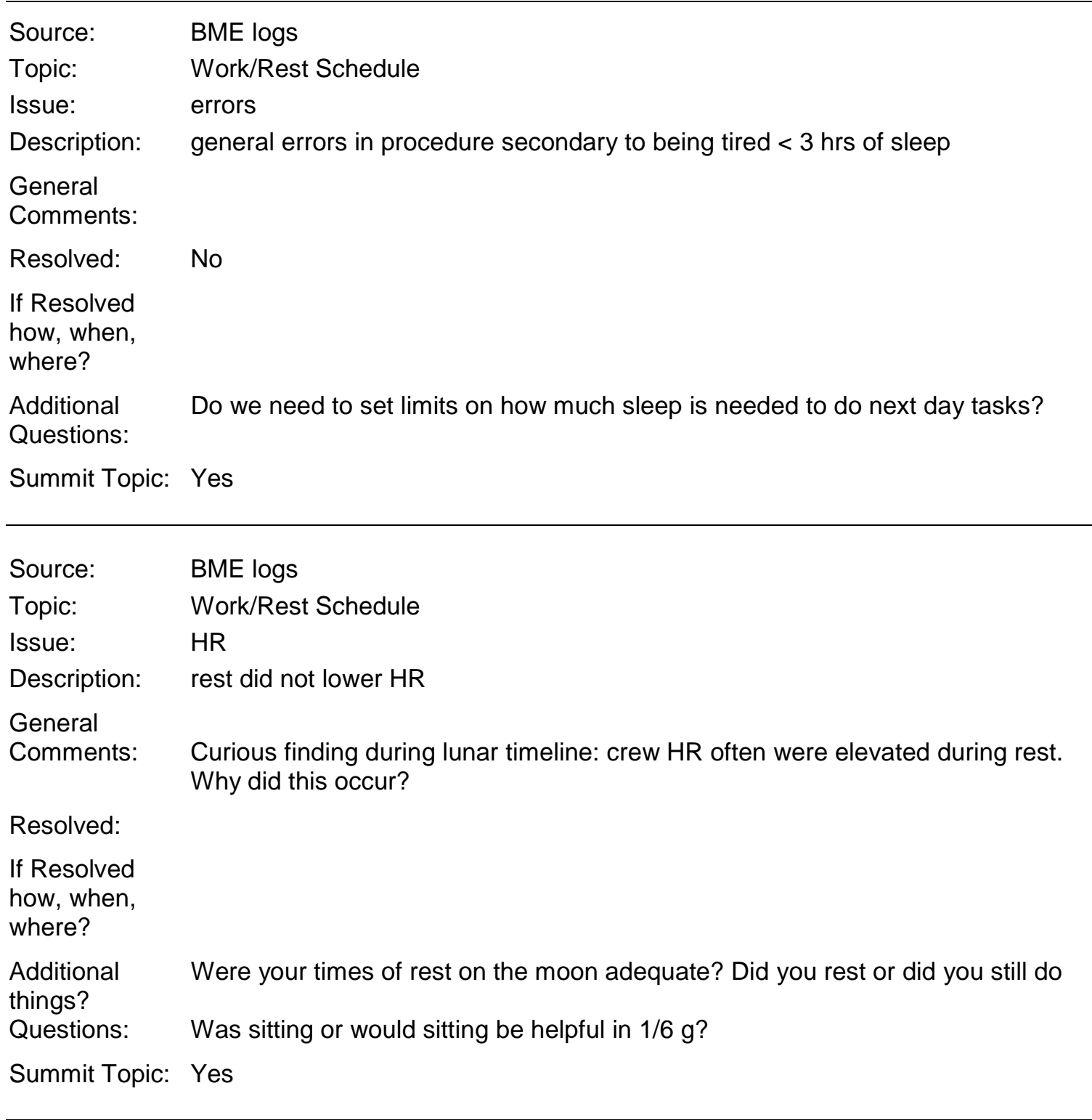

\footnotetext{
Source: $\quad$ BME logs

Topic: Work/Rest Schedule

Issue: $\quad$ sleep breathing

Description: Cheyne-stokes breathing with deep sleep

General understandable due to decrease $\mathrm{CO} 2$ decreasing respiratory drive?

Comments:

Resolved: No

If Resolved how, when, where?

Additional Is this a normal respiratory phenomenon? Questions:
} 


\section{Appendix A \\ Apollo Summit Non-Attributable Report}

Summit Topic: Yes

Source: $\quad$ Flight Surgeon logs

Topic: Work/Rest Schedule

Issue: $\quad$ tracking mistakes

Description: Crew making mistakes on tracking secondary to lack of sleep?

General

Comments: Crew timeline needs to allow more frequent rest periods.

Resolved:

If Resolved

how, when,

where?

Additional

Questions:

Summit Topic: Yes

Source: $\quad$ Flight Surgeon logs

Topic: Work/Rest Schedule

Issue: poor sleep

Description: Did not sleep well in LM

General not expounded on

Comments:

Resolved:

If Resolved

how, when,

where?

Additional What caused you not to sleep well?

Questions:

Summit Topic: Yes 


\title{
Appendix A Apollo Summit Non-Attributable Report
}

\author{
Source: $\quad$ Medical Mission Debriefs \\ Topic: Work/Rest Schedule \\ Issue: $\quad$ Sleep, Work \& Rest Observations \\ Description: a) Crew slept a lot, between 7-10 hours, but described it as a "light sleep. \\ Typically woke early at least 1 hour before schedule \\ b) LMP would sleep 5 hours, take a sleeper then return to sleep for 3.4 hours \\ c) Reverse Schedule -crew extended FD1 as long as possible to adjust to \\ reversed day-night flight plan \\ d) Scheduled 10 hour sleep period were more than adequate \\ e) Work days were typically 14-15 hours \\ f) Crew suggests not eating dinner before going to bed. Apparently that is how \\ meals were scheduled in the flight plan \\ g) Crew felt the work/rest was reasonable, allowed them to accomplish what they \\ needed and rested \\ h) On the lunar surface, sleep/rest is a minor issue, The busy pace and minimal \\ rest did not effect their limit of efficiency. However, this would become an \\ issue with extended-duration ops. \\ i) Sleep in the LM on the Lunar Surface was okay.
}

General Comments:

Resolved:

If Resolved how, when, where?

Additional Did you think you could function/sleep in the LM for $>$ ? days on the lunar

Questions: $\quad$ surface? Crew seemed to think so

Summit Topic: Yes

\begin{abstract}
Source: $\quad$ Medical Mission Debriefs
Topic: Work/Rest Schedule

Issue: sleep

Description: CMP: slept best with the couch flat, in the sleeping bag (it got cold at night) and pull the straps down. LMP: usually slept 5 hours at end of day, wake up, take a sleeping pill. Without the pill, didn't get back to sleep --thinking about the flight CMP: Difficulty sleeping on first night, back uncomfortable. CDR: Had no back pain during flight, but for about 4 days post-flight, in the Mobile Quarantine Facility (MQF) was hobbling, secondary to back pain.
\end{abstract}

General

Comments: Several CM had back pain during their mission.

Resolved: No

If Resolved

how, when, where?

Additional

Questions: What in-flight activities relieved back pain severity?

Summit Topic: Yes 


\title{
Appendix A Apollo Summit Non-Attributable Report
}

\author{
Source: $\quad$ Medical Mission Debriefs \\ Topic: Work/Rest Schedule \\ Issue: Insomnia \\ Description: CMP" "...and I was always having a muscle twitch in my legs and -“ \\ LMP: "... at that bag parts I had the feeling I was going to ricochet right out of the \\ side of the wall." (missing part of transcript obscure full meaning) \\ "I'd watch him in his sleep, He'd be in there in there sleeping on me in the bag, \\ and boy all of a sudden he'd just shot around and sort of...And every night \\ he'd... and he'd talk sometimes too in his sleep. your really hit those things \\ that - I knew that I know that that's beyond what you normally - " \\ General \\ Comments: \\ Resolved: \\ If Resolved \\ how, when, \\ where? \\ Additional \\ Questions: \\ Summit Topic: Yes

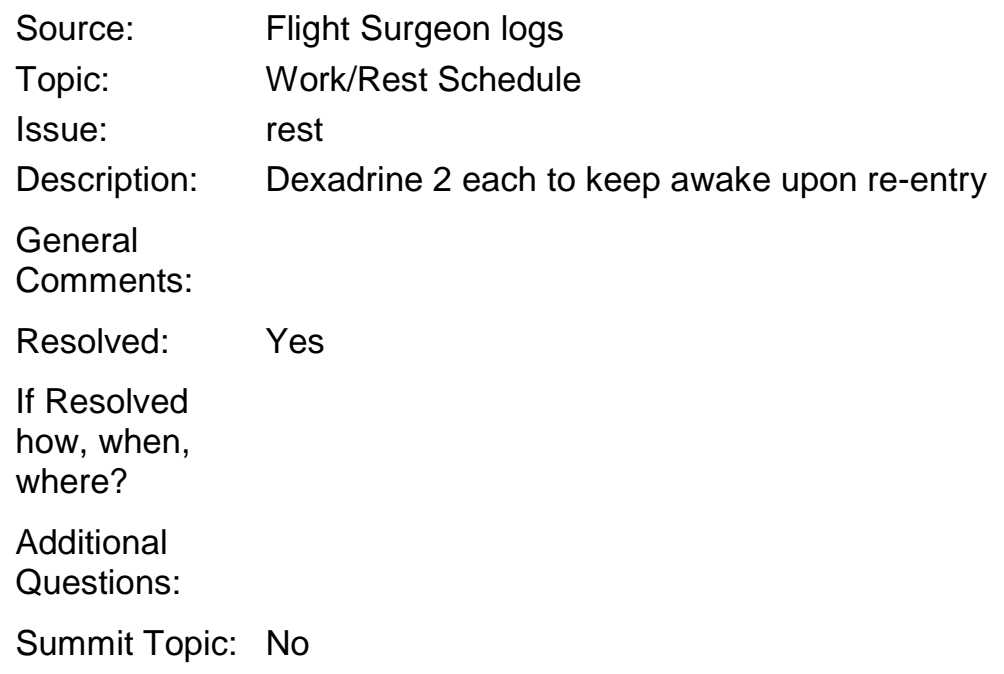

Additional

Questions:

Summit Topic: No 


\section{Appendix A \\ Apollo Summit Non-Attributable Report}

Source: $\quad$ Flight Surgeon logs

Topic: Work/Rest Schedule

Issue: mistakes

Description: mistakes on read back secondary to lack of sleep

General

Comments:

Resolved:

If Resolved

how, when,

where?

Additional

Questions:

Summit Topic: No

$\begin{array}{ll}\text { Source: } & \text { BME logs } \\ \text { Topic: } & \text { Work/Rest Schedule } \\ \text { Issue: } & \text { 23hr day } \\ \text { Description: } & \text { 23hr day crew worked }\end{array}$

General

Comments:

Resolved:

If Resolved

how, when,

where?

Additional

Questions:

Summit Topic: No

Source: $\quad$ BME logs

Topic: Work/Rest Schedule

Issue: poor sleep

Description: crew didn't sleep well and ground had to ask for sleep report

General

Comments: Poor sleep on the lunar surface multifactorial.

Resolved:

if Resolved

how, when,

where?

Additional

Questions:

Summit Topic: Yes 


\section{Appendix A \\ Apollo Summit Non-Attributable Report}

Source:
Topic:
Issue:
Description:
General
Comments:
Resolved:
If Resolved
how, when,
where?

BME logs

Work/Rest Schedule

Mattress

Sleep "hard mattress"

Additional

Questions:

Can you explain how the hard mattress makes sleeping in space difficult?

Summit Topic: Yes

\section{Source: $\quad$ Flight Surgeon logs}

Topic: Work/Rest Schedule

Issue: Cat Naps

Description: Cat naps were useful for some crewmembers, especially for those who could not get restful sleep during their sleep period

General

Comments:

Resolved: No

If Resolved-

how, when,

where?

Additional How was this observed HR or EKG? Is this reason for us to adjust schedule?

Questions:

Summit Topic: Yes

Source: $\quad$ Flight Surgeon logs

Topic: Work/Rest Schedule

Issue: sleep

Description: $4 \mathrm{hrs}$ of dozing mostly within the lunar module

General this was a night before EVA

Comments:

Resolved:

If Resolved

how, when,

where?

Additional Why was it so hard to sleep on lunar surface? Lack of space? Environment?

Questions: Excitement? Why didn't you take medication?

Summit Topic: Yes 


\section{Appendix A \\ Apollo Summit Non-Attributable Report}

Source: $\quad$ Flight Surgeon logs

Topic: Work/Rest Schedule

Issue: light flashes

Description: Light flashes in eyes of both CDR and LMP 4 hrs of sleep then awakened

General

Comments:

Resolved:

If Resolved

how, when,

where?

Additional Did these light flash experiments interfere with sleep?

Questions:

Summit Topic: Yes

Source: $\quad$ Flight Surgeon logs

Topic: Work/Rest Schedule

Issue: 23-24 hr day

Description: crew sleeping after a busy 23-24hr day

General

Comments:

Resolved:

If Resolved

how, when,

where?

Additional What causes these long days and what can we do to fix this?

Questions:

Summit Topic: Yes 


\section{Appendix A Apollo Summit Non-Attributable Report}

Source: $\quad$ Medical Mission Debriefs

Topic: Work/Rest Schedule

Issue: sleep

Description: LMP: LMP and CDR" on reserves."

CDR: 2nd day out "we weren't really sleeping along too well," we slept better after TEl -probably the best night in terms of continuous sleep.

LMP: felt I was on reserves. "I felt very strongly that I was on reserves, that physically I was going down hill. And it was of some concern to me that I wasn't getting enough sleep, "But sleeping to me was a very insecure experience."

General

Comments:

Resolved: No

If Resolved

how, when,

where?

Additional

Questions:

Summit Topic: Yes

\section{Source: $\quad$ BME logs \\ Topic: Work/Rest Schedule \\ Issue: capcom awakens crew \\ Description: capcom awakens crew during sleep period with non-essential information. \\ General \\ Comments: Crew sleep was poor. Inadvertent calls from Capcom or purposeful calls but not necessary need to be stopped.}

Resolved:

If Resolved

how, when,

where?

Additional

Questions:

Summit Topic: No 


\section{Appendix A Apollo Summit Non-Attributable Report}

Source:

Flight Surgeon logs

Topic:

Work/Rest Schedule

Issue:

tired

Description:

sounds tired?

General

no more explanation

Comments:

Resolved:

If Resolved

how, when,

where?

Additional was being tired a real factor during the mission?

Questions:

Summit Topic: Yes

Source: $\quad$ Flight Surgeon logs

Topic: Work/Rest Schedule

Issue: awaken early

Description: $\quad$ Crew needs to be awakened early for SC attitude adjustment FS didn't like this but understood and felt one of CM was awake do to HR. FS not asked by flight director

General

Comments:

Resolved:

If Resolvedhow, when, where?

Additional

Questions:

Summit Topic: No

Source: $\quad$ Flight Surgeon logs

Topic: Work/Rest Schedule

Issue: without suit

Description: sleeping with suit off is the secret

General

Comments:

Resolved:

If Resolved how, when, where?

Additional Is the best rest without suit, or more beneficial than the time saved/extra time sleeping Questions: in the suit? 


\section{Appendix A \\ Apollo Summit Non-Attributable Report}

Summit Topic: Yes

Source: $\quad$ Flight Surgeon logs

Topic: Work/Rest Schedule

Issue: lost sleep secondary to TV

Description: Crew repeatedly disrupted $\mathrm{t} / \mathrm{c}$ the OSO was very confused about how to get camera to retract. FD disgusted and angry b/c delayed onset of sleep

General

Comments:

Resolved:

If Resolved

how, when,

where?

Additional How often did PR events get in the way of sleep and the mission? How this Questions: $\quad$ problem be combated?

Summit Topic: Yes

\section{Source: \\ Topic: \\ Issue: \\ Description: \\ General \\ Comments: \\ Resolved: \\ If Resolved how, when, where?}

Additional Questions:

Summit Topic: Yes

\section{Flight Surgeon logs}

Work/Rest Schedule

tired

"Yesterday we finally got a chance to catch our breath"

Would missions be more successful if timelines weren't so hectic?

\section{Summit Topic: Yes}

\section{Source:}

Flight Surgeon logs

Topic:

Work/Rest Schedule

Issue: sleep timeline

Description:

sleep timeline not to be disturbed by LM trouble

General

Comments:

Resolved:

If Resolved how, when, where?

Additional

Questions: 


\section{Appendix A \\ Apollo Summit Non-Attributable Report}

Summit Topic: No 


\title{
Appendix A \\ Apollo Summit Non-Attributable Report
}

\author{
Topic: Work/Rest Schedule \\ Issue: problems sleeping \\ Description: seconal didn't help \\ General \\ Comments: \\ Resolved: \\ If Resolved \\ how, when, \\ where? \\ Additional \\ Questions: \\ Summit Topic: Yes
}

\section{Source: $\quad$ Flight Surgeon logs \\ Topic: Work Rest Schedule \\ Issue: Sleep \\ Description: "sleep better if orients himself to the side" complained of nasal congestion secondary to lunar dust}

General Comments:

Resolved:

If Resolved

how, when,

where?

Additional Explain this sleep position in detail was the LM well suited for this?

Questions:

Summit Topic: Yes

$\begin{array}{ll}\text { Source: } & \text { Medical Mission Debriefs } \\ \text { Topic: } & \text { Physiological Function } \\ \text { Issue: } & \text { fluid shift } \\ \text { Description: } & \text { p. 7:CMP:P loss of appetite first two days } \\ & \text { CDR: less fullness of head, etc. than on previous flights. } \\ & \text { LMP: puffiness underneath eyes and face }\end{array}$

General Comments:

Resolved:

If Resolved

how, when, where?

Additional

Questions:

Summit Topic: No 


\title{
Appendix A Apollo Summit Non-Attributable Report
}

\author{
Source: $\quad$ Medical Mission Debriefs \\ Topic: Physiological Function \\ issue: sunglasses \\ Description: CDR had a headache during first couple of revs in lunar orbit which he attributed \\ to moon gazing. "You need to protect your eyes." Dr. Berry points out the \\ sunglasses are USAF issue $\mathrm{N}-15$ type, neutral density filter, $15 \%$ \\ transmission. These have plastic lenses, USAF have glass lenses. \\ While on lunar EVA, this was not a problem \\ Crew did not agree that the sample $\mathrm{N}-15$ sunglasses presented at the debrief \\ were the same as what they flew with. \\ General \\ Comments: \\ Resolved: \\ If Resolved \\ how, when, \\ where? \\ Additional \\ Questions: \\ Summit Topic: No

\begin{abstract}
Source: $\quad$ Medical Mission Debriefs
Topic: Physiological Function

Issue: $\quad$ Vision on the lunar surface

Description: Can see very well-particularly cross-sun. Not much contrast over large distances, difficult to discern horizon sometimes. Very bright looking into the sun, lots of glare. Initially going into a shadow it takes about 15 seconds for vision to accommodate, after that accommodation improves, but out of the shadow is so bright LMP doubts full reduced lighting accommodation occurred. Could see into craters "pretty well." Intermittently used the outer visor, used mostly when looking into the direction of the sun. No particular problems expressed.
\end{abstract} \\ General \\ Comments: \\ Resolved: \\ If Resolved \\ how, when, \\ where? \\ Additional \\ Questions: \\ Summit Topic: Yes
}




\title{
Appendix A \\ Apollo Summit Non-Attributable Report
}

\author{
Source: $\quad$ Medical Mission Debriefs \\ Topic: Physiological Function \\ Issue: upper body fullness \\ Description: Had noticeable facial fullness on the first day of zero-g. "It's just like you're \\ standing on your head." Resolved after about 24 hours. Had blood-shot eyes the \\ first day. \\ General \\ Comments: \\ Resolved: Yes \\ If Resolved \\ how, when, \\ where? \\ Additional \\ Questions: \\ Summit Topic: No

\begin{tabular}{|c|c|}
\hline Source: & Medical Mission Debriefs \\
\hline Topic: & Physiological Sleep \\
\hline Issue: & Function \\
\hline Description: & $\begin{array}{l}\text { Averaging about } 5-7 \mathrm{hr} \text { sleep, Thinks } 6 \text { hours per night is sufficient } \\
\text { CDR disagreed thought } 6 \text { hours per night would not be enough for more than a } \\
\text { week or two }\end{array}$ \\
\hline
\end{tabular} \\ General \\ Comments: \\ Resolved: \\ If Resolved \\ how, when, \\ where? \\ Additional \\ Questions: \\ Summit Topic: No
}




\title{
Appendix A Apollo Summit Non-Attributable Report
}

\author{
Source: BME logs \\ Topic: Human Factors \\ Issue: naps on watch \\ Description: suspected several naps on watch \\ General \\ Comments: \\ Resolved: \\ If Resolved \\ how, when, \\ where? \\ Additional How will we crew get better sleep during sleep time so they stay awake during \\ Questions: watch? What can we do to help them stay awake on watch? \\ Summit Topic: Yes \\ Source: Medical Mission Debriefs \\ Topic: Human Factors \\ Issue: Radiation \\ Description: a) This crew had more radiation exposure than previous Apollo missions due to \\ trajectory \\ -the course through the VA belts exposed them to major radiation on the way \\ to the Moon. \\ -estimated to be about 2 times the radiation exposure of Apollo 8 (7,9 were \\ LEO) \\ -570 mrads's or 0.57 rads \\ b) Estimate of exposure from SPE will be approximately 400 rads skin dose and \\ 50 rads dep the dose = lunar surface exposure

$\begin{array}{lll}\text { General } & \text { COMPARISON: Head x-ray } & 82-220 \text { mrad's } \\ \text { Comments: } & \text { Leg x-ray } & 440 \text { mrad's } \\ & \text { Arm x-ray } & 127 \text { mrad's } \\ & \text { Gl series } & 790 \text { mrad's } \\ & \text { Dental } & 16,380 \text { mrad's }\end{array}$ \\ Resolved: \\ If Resolved \\ how, when, \\ where? \\ Additional 1. Do we have a plan to control radiation exposure for longer lunar missions \\ Questions: $\quad$ where radiation exposure is higher to begin? \\ Summit Topic: Yes
}




\section{Appendix A Apollo Summit Non-Attributable Report}
Source:
Medical Mission Debriefs
Topic:
Human Factors
Issue:
Post Flight Quarantine
Description:
a) Pre-flight exposure to illness is critical to post-flight condition to ensure that any post-flight illness was not due to lunar exposure
b) It is critical in the preflight period to allow the crew to slow down in the schedule so as not to lower their resistance to infection,
c) It will be difficult to ascertain if either this was some latent infection, pre-flight exposure, or lunar exposure

General

Comments:

Resolved:

If Resolved

how, when,

where?

Additional

Should pre-flight quarantine be longer than current 7 days on a longer mission?

Questions:

Should this be 21 days instead? If it should be longer, should crew be quarantined with family to help with mental downside to isolation? If so, should family be removed from quarantine 1 week prior to so crew can mentally prepare

Summit Topic: Yes
Source:
Medical Mission Debriefs
Topic:
Human Factors
Issue:
Crew Health and Performance
Description: a) During DF 0-2, and last 3 days, coming home the crew kept occupied. But in between they felt they had nothing to do.
-Wish they had brought recreation materials along: Books, music
b) CMP felt that he was responsible for the state the ship during the transit time; that the activity was his and LMP could relax during the transit, but he was always on task
c) CMF was concerned by the flight plan change after the Lunar landing had a $\mathrm{CM}$ been at the end of his work day - and he was very tired. Probably not a good idea.
d) Crew recommended doing something to keep the CMP occupied
-Comm helps tremendously, especially briefs on every events -MSFN relay was the best thing CMP had
-Crew Suggest for long duration mission wake the SC environment as normal as it is down on Earth (similar to F. Hansen's experience)

General

Comments: Crew health and performance issues during TLC and TEC are key issues for all missions to consider.

Resolved: $\quad$ No

If Resolved

how, when, where?

Additional

Questions:

How do you help the crew mentally and physically prepare for 20-24 hour work days? 


\section{Appendix A Apollo Summit Non-Attributable Report}

Summit Topic: Yes

Source: $\quad$ Medical Mission Debriefs

Topic: Human Factors

Issue: $\quad$ Lunar Surface Operations, Mission Ops

Description: Crewmember Observations from debriefs

1. Mission objective was to make contact with Surveyor spacecraft launched approximately February 1967 -need to demonstrate ability to land at a chosen destination

2. "Leadership" was what enabled the Apollo team to accomplish its goals.

3. NASA should let people know that space travel is a dangerous business. When you are at the Earth's edge of technology, exploration is a dangerous business i.e., Magellan started with 240 males and 3 ships; they returned 3 years later with 26 males. Magellan was killed in the Philippines 150 people die/day in auto accident. No one stops driving their car

4. Space suit worked well with the exception of the glove, lack of waist mobility.

5. First few moments after stepping on the moon, make sure you hold onto the handrail for balance. The first couple of moments are pretty wobbly. It takes 3 minutes

6. Look ahead at the ground to be able to visualize craters and boulders. Otherwise, it is possible to trip on a rock. You cannot visualize your feet in the helmet.

7. Rocks existed under the surface dust. easy to trip and fall. The surface is not uniform

8. Lunar Resources Apollo 12 Preliminary Surface Report

Crew observations and experiments

-Apollo 12 technical report debrief

-Give Kranz book

-Neil Armstrong book

${ }^{*}$ Confidence comes from reading these reports.

9. Do not re-design lunar tools. They worked for the jobs that had to be performed

10. Hand got tired early from picking up rocks. Re-design gloves.

11. Lunar dust is like ground down lead. Similar to the grindings in a pencil sharpener. -"tenacious" made zipper sticky

12. Suit cooled off quickly, efficiently

13. Moon is not magnetic - compass would not work. Never had a gyroscope navigation system

14. Support from the space program will come from appealing to middle -America

e,g., Al Shephard hitting the golf ball; Scott dropping banana and feathers to demonstrate Galileo's principles

* Do things on the moon that connect and are of interest to folks on the Earth

15. Volume of the LM was never a problem

16. Don't solve problems that aren't really problems, e.g. lunar boots

17. No health related issues with the Lunar dust

18. Lighting in the SC was adequate

19. Earthlight was noticeable, a pretty blue

20. Rover did not have headlamp and shouldn't - Going into a dark crater a shadow is a bad idea

21. Apollo 12 did not have any contingency plan for a SPE on the surface

22. Exercise countermeasures capability for short moon ( $1 / 6 \mathrm{~g}$ \} should be limited

23. Being a good team member is appreciated/admire the other team members (Pete Conrad)

General Comments:

Resolved:

If Resolved how, when, where? 


\section{Appendix A Apollo Summit Non-Attributable Report}

Additional 1. Are suits designed to withstand inevitable falls? Is there a backup safety

Questions: device to the suit in case of falls that may harm suit? 2. Would packs be useful

Summit Topic: Yes

on lunar surface, would they improve hopping or slow it down?

Source: Medical

Topic: Human Factors

Issue: $\quad$ Isolation of CMP during Lunar Ops phase

Description: CMP: "You know, it's not too far removed from the prison camp environment. You're stuck up there alone and you're by yourself, you sit and contemplate your own damn misery, and you're out there so damn far away from everything else it could have conceivably been a problem."

CDR: "These CMP fellows on 28-day missions and things like that are really going to need that recreation. I never pushed for it when I was working CMP, but, boy, right now l'd be in there hustling to get some good music and good tape recorders and some books,..that 28 days is going to be a long, long time."

CDR: "..the happiest I saw CMP in a long time was the day we got back up to the command module.

We got in that.., and closed the door and he was so happy, he was dancing and jumping around,"

CMP: "It was amazing to me, I was really happy. *

General Comments:

Resolved:

If Resolved

how, when, where?

Additional How can the environment be improved within the vehicle limitation for mass and Questions: volume?

Summit Topic: Yes 


\title{
Appendix A Apollo Summit Non-Attributable Report
}

\author{
Source: Medical Mission Debriefs \\ Topic: Human Factors \\ Issue: Books \\ Description: CMP: "We were just going to flat smuggle in paper back books put them in our \\ suit pockets." Unidentified: "I've said it every goddamn time after the first flight \\ that I went on, I was a dumb ass for not taking a book." \\ All crewmembers thought reading would help relax them and help them get to \\ sleep quicker. \\ LMP: particularly important for the CMP who is alone for 3 days. He needs \\ his relax time, all need relax time. And the CMP pilot needs to be occupied \\ General \\ Comments: Recreational activities/equipment is a request made by most CM. \\ Resolved: $\quad$ N/A \\ If Resolved \\ how, when, \\ where? \\ Additional \\ Questions: \\ Summit Topic: Yes

\section{Source: $\quad$ Medical Mission Debriefs \\ Topic: Human Factors \\ Issue: Change in activities} \\ Description: $\quad$ LMP: The CMP had a very long day, doing similar tasks for nearly 24 hours. The \\ lunar surface crew had a major change in activity after beginning descent to the \\ Moon surface, "We did the flying part of the work, and at kind of the end it was \\ almost a celebration after 5 days of sitting in that spacecraft, to get outside and \\ walk around and move your arms and do a little work, it was like going out and \\ playing golf or playing tennis. It was a big change from the other kind of work \\ and it was damn enjoyable." \\ General \\ Comments: \\ Resolved: No \\ If Resolved \\ how, when, \\ where? \\ Additional \\ Questions: \\ Summit Topic: Yes
}




\title{
Appendix A Apollo Summit Non-Attributable Report
}

\author{
Source: $\quad$ Medical Mission Debriefs \\ Topic: Human Factors \\ Issue: $\quad$ circadian shift after launch \\ Description: LMP: Felt staying up as long as possible the first flight day helped do the diurnal \\ reversal. Ten hour sleep periods were more than adequate -used some of the \\ time the chat in the evenings, do housekeeping functions, etc. Working hours \\ were long. \\ CDR: Lost track of all Earth time." Got on our own cycle." They were motivated to \\ work on the lunar surface after all the work and training that preceded the \\ actual mission. Didn't want to spend lunar time sleeping. \\ LMP: during lunar stay, sleep was impaired by the discomfort of the suit --should \\ sleep without the suit. \\ CMP: was very tired the first night in orbit because of the long day, which was \\ close to 24 hours. \\ LMP: "... I think you ought to get the guys out of the suit, and you ought to give \\ them a man's blanket, if that Beta cloth Mickey Mouse thing they killed us \\ with, if I'd have slept in that it wouldn't have worked, but if you gave a guy a \\ good roll blanket I couldnt've really slept in that LM if I hadn't been so \\ uncomfortable in my suit." "I'm sure that I would have slept a good 7 hours \\ had I not been uncomfortable in the suit.., if it hadn't been screwed to my \\ shoulders like it was." \\ CMP: had to do a plane-change burn just prior to going to bed, resulted in a very \\ long day for the CMP "I knew I was hanging on the ragged edge for being \\ tired." "I was so much over tired that I couldn't go to sleep right away." "always \\ having the muscle twitches in my legs" Dr Berry: "It was close to 24 hours."
}

General

Comments:

Resolved: No

If Resolved how, when, where?

Additional

Questions:

Summit Topic: Yes
Source:
Flight Surgeon logs
Topic:
Human Factors
Issue:
prelaunch quarantine
Description:
Dr. Jernigan notify FS MOCR that a contractor suit technician had acute gastroenteritis and failed to report this. Was not in contact with crew but handle suit.

\section{General}

Comments:

Resolved:

If Resolved

how, when,

where?

Additional

Questions: 


\section{Appendix A \\ Apollo Summit Non-Attributable Report}

Summit Topic: No 


\section{Appendix A Apollo Summit Non-Attributable Report}

Source:
Topic:
Issue:
Description:
General
Comments:
Resolved:
if Resolved
how, when,
where?

Additional Why was it heavier than expected? Was training not adequate for $1 / 6$ G? Should Questions: we prepare differently?

Summit Topic: Yes
Source: $\quad$ Flight Surgeon logs
Topic: Human Factors
Issue: $\quad$ pressure misread
Description: believed crew originally misread change pressure gauge but venting was done right so probably more $\mathrm{O} 2$ rich than ever

General

Comments:

Resolved:

If Resolved how, when, where?

Additional what makes them think crew misread gauge?

Questions:

Summit Topic: Yes

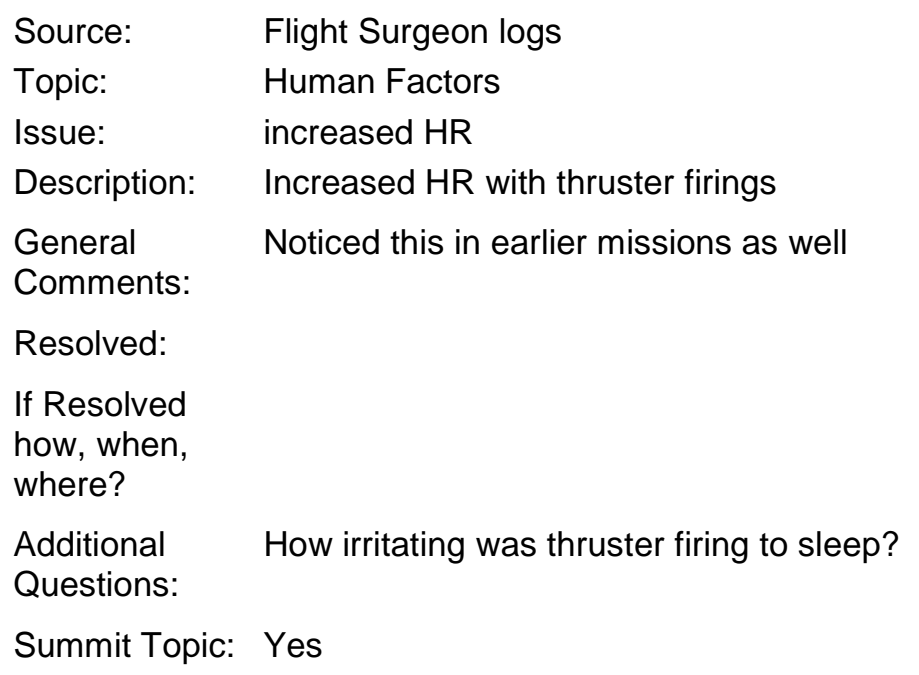




\section{Appendix A \\ Apollo Summit Non-Attributable Report}

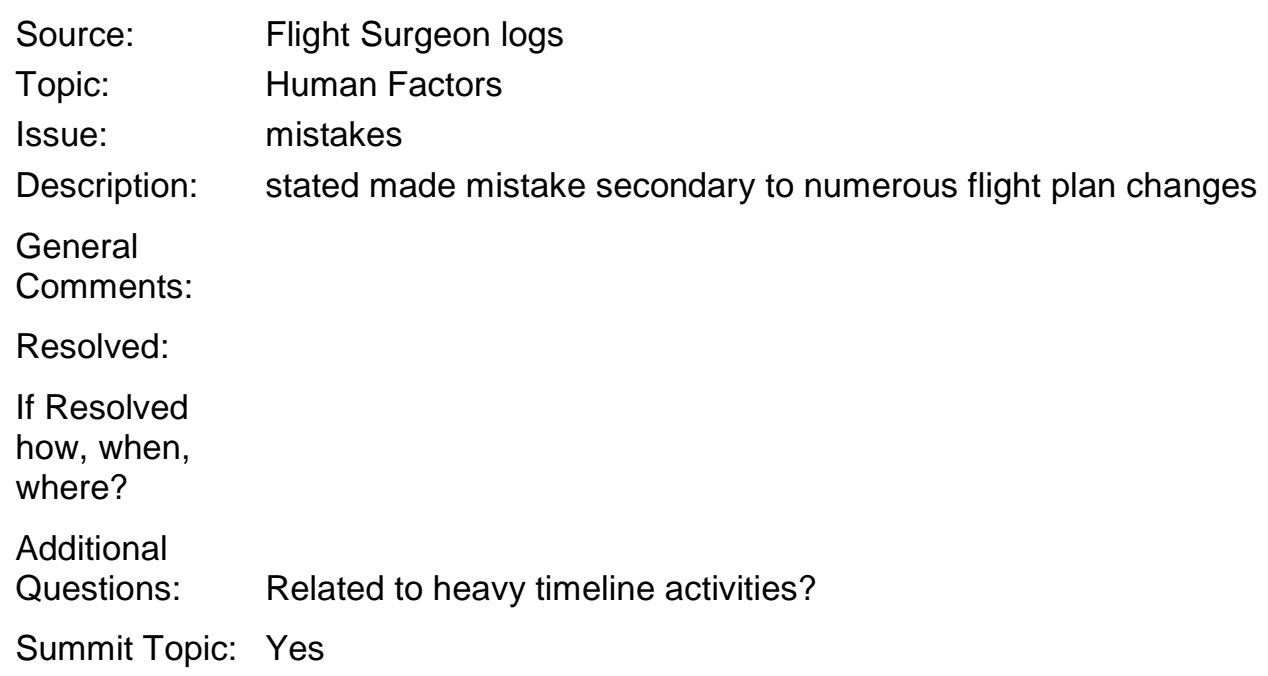

Summit Topic: No 


\section{Appendix A Apollo Summit Non-Attributable Report}

Source: $\quad$ Medical Mission Debriefs

Topic: Behavioral health and performance

Issue: mental health

Description: "We appeared to be $100 \%$ concerned about the physical welfare of the crew and physical data we get back and little or no concern about the mental welfare and the mental well being of the crew and taking account little or not at all those agonizing, frustrating, many things that get on people's nerves whether they be urine drops floating in someone's eyeball or whether they be cutting extra pieces of Velcro off to be able to save food or handling garbage or whatever it may be. And these are things we've got to consider. Mental welfare, to me, fits hand in hand with the physical welfare, and until we begin to realistically consider all those factors then I think we've got a long way to go in space flight."

General

Comments:

Resolved:

If Resolved how, when, where?

Additional

Questions:

Summit Topic:

$\begin{array}{ll}\text { Source: } & \text { Medical Mission Debriefs } \\ \text { Topic: } & \text { Human Factors } \\ \text { Issue: } & \text { sleep } \\ \text { Description: } & \text { CDR -initially preferred head support and no arm floating } \\ & \text { IMP -no problem with positioning } \\ & \text { CMP -difficulty awakening and getting going after sleep }\end{array}$

General

Comments:

Resolved: No

If Resolved

how, when,

where?

Additional

Questions:

Summit Topic: Yes 


\title{
Appendix A Apollo Summit Non-Attributable Report
}

\author{
Source: Medical Mission Debriefs \\ Topic: $\quad$ Exercise \\ Issue: $\quad$ Exercise/Observations . \\ Description: a) Started Day FD2 \\ b) $45 \mathrm{~min} /$ day \\ c) Types of exercise: \\ 1. Feet in stirrups -straighten out 2. Arch back with feet in stirrups 3. Minimal \\ arm exercises. 4. Ergometer. 5. Power lifting while on the bike \\ General 1.Recommend no specific time schedule - just do it on your own \\ Comments: $\quad 2$. Markedly improved back pain/ankle pain \\ 3. Equipment \\ 4. Stretching \\ 1 .Post-landing "Achilles tendon was tight, needed period of time to readjust" \\ 5.Positioning \\ 1. Fetal position is position of comfort \\ Resolved: No \\ If Resolved Improved (back pain/ankle pain) \\ how, when, \\ where? \\ Additional 1. The Big Four? \\ Questions: $\quad$ 2. Pulse rate never got up with exercise: CMP approximately 105 BPM @ 177 \\ $+50$ \\ 3. Exercise could use some improvements. Concern about the exergenie \\ wearing out? \\ Summit Topic: Yes \\ Source: $\quad$ Flight Surgeon logs \\ Topic: $\quad$ Exercise \\ Issue: exerciser broke \\ Description: "Crewmember broke the Apollo exer-genie with use." \\ General \\ Comments: Device was frail, could not withstand frequent use \\ Resolved: No \\ If Resolved \\ how, when, \\ where? \\ Additional How long is the exercise equipment slated to last on an exploration mission? \\ Questions: \\ Summit Topic: Yes
}




\title{
Appendix A Apollo Summit Non-Attributable Report
}

\author{
Source: $\quad$ Medical Mission Debriefs \\ Topic: $\quad$ Exercise \\ Issue: $\quad$ Equipment and Technique \\ Description: a) The exercise device (cycle ergometer) got real hot during use. Crew describes \\ it getting "dangerously hot". Even before CM got tired of using it. Unable to \\ touch device or store it safely secondary to heat accumulation \\ b) Crew felt having an exercise device, especially last 5 days of mission was \\ beneficial for return to gravity \\ c) Crew felt just tensing leg muscles against same resistance (pushing against \\ bottom of "LEB") was helpful. \\ General \\ Comments: \\ Resolved: \\ If Resolved \\ how, when, \\ where? \\ Additional Is cycle ergometer the same design as the one that will be used in future or \\ presently? \\ Questions: \\ Summit Topic: Yes \\ Source: $\quad$ Medical Mission Debriefs \\ Topic: $\quad$ Exercise \\ Issue: $\quad$ Exercise Observations \\ Description: a) LMP got his heart rate up to $177 \mathrm{bpm}$ using the exer-genie \\ 1. Apparently moving arms/legs against the device before it got too hot. \\ 2. Used parts of the CM -"struts" \\ 3. Ran in place in couch. \\ General \\ Comments: \\ Resolved: \\ If Resolved \\ how, when, \\ where? \\ Additional What phase of the mission was the exerciser used? \\ Questions: \\ Summit Topic: Yes
}




\section{Appendix A \\ Apollo Summit Non-Attributable Report}

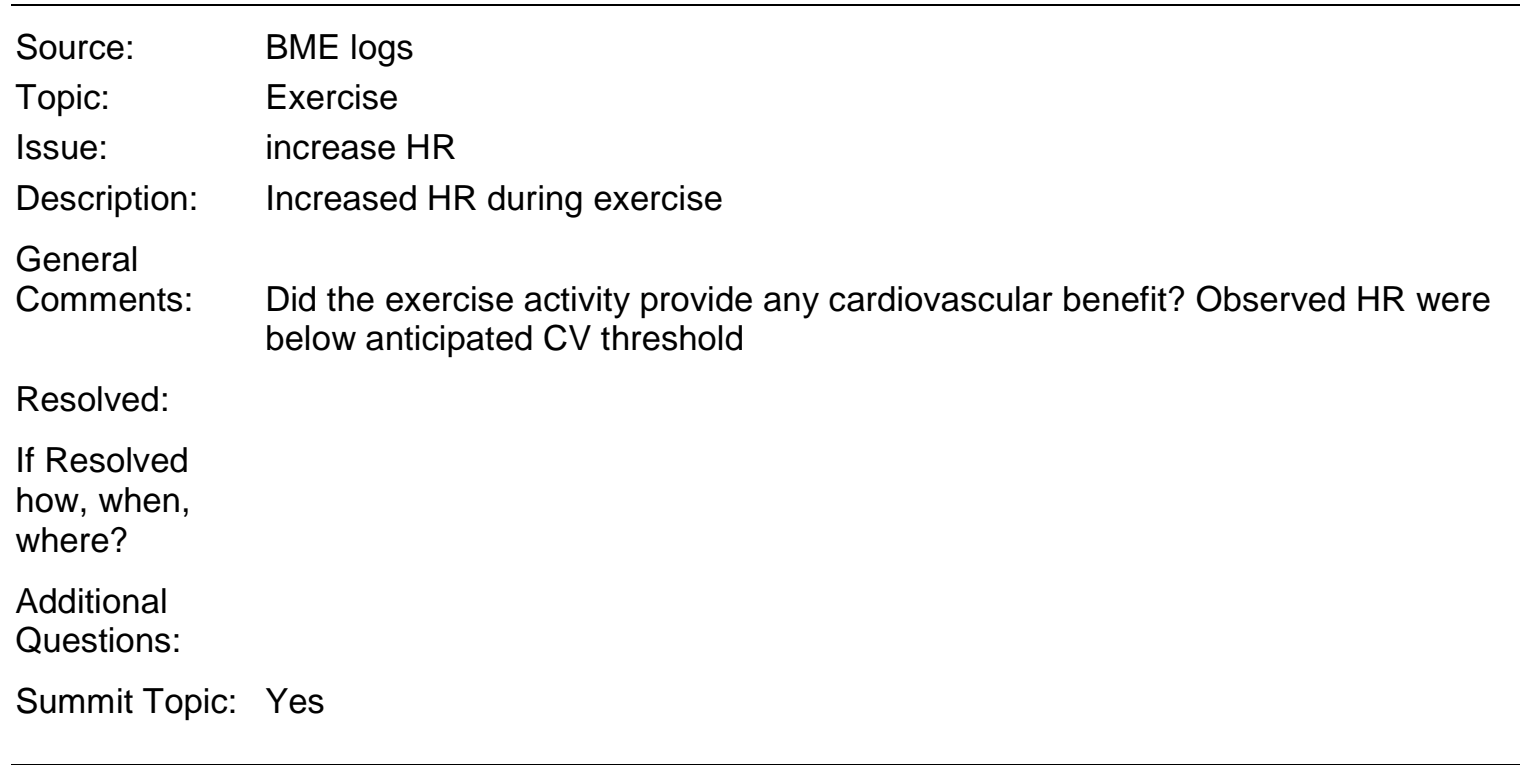

Source:
Topic:
Issue:
Description:
General
Comments:
Resolved:
If Resolved
how, when,
where?

Additional How and why did exercise pull the biomed cable loose?

Questions:

BME logs

Exercise

exercise

Summit Topic: Yes

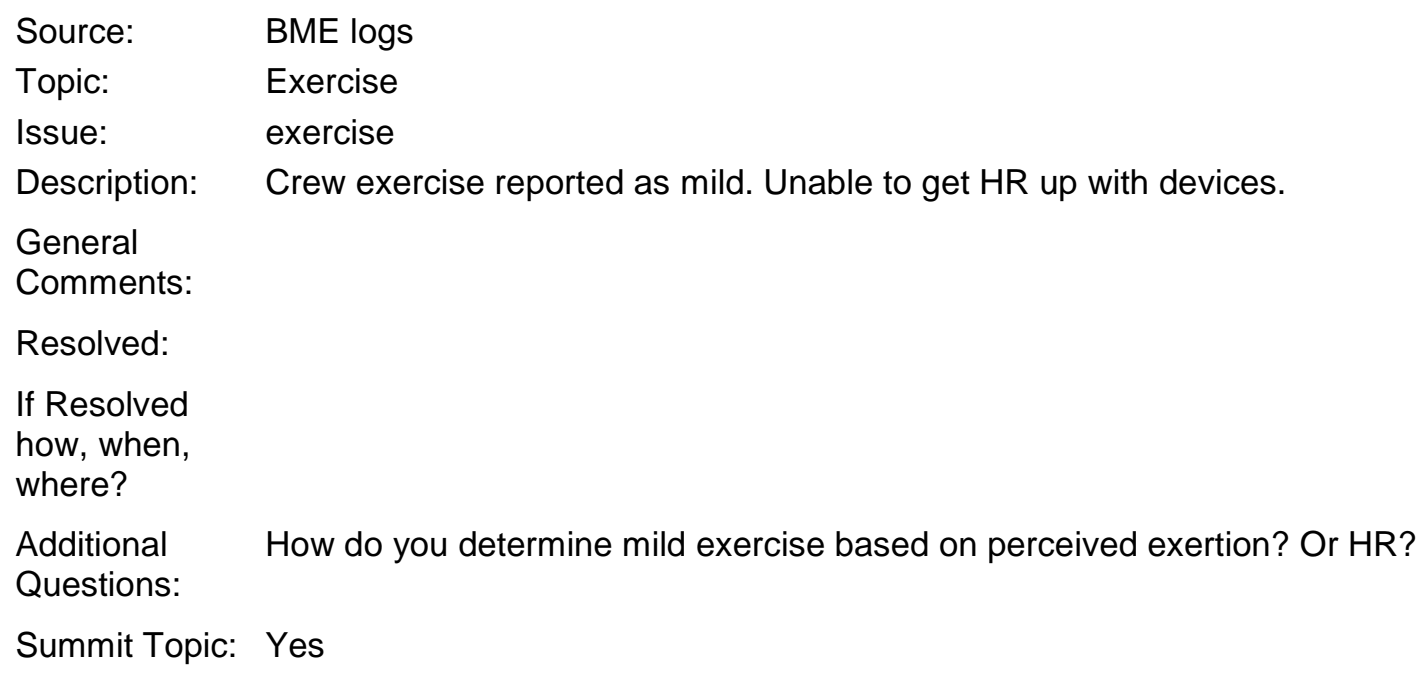




\title{
Appendix A \\ Apollo Summit Non-Attributable Report
}

\author{
Source: $\quad$ Medical Mission Debriefs \\ Topic: $\quad$ Exercise \\ Issue: $\quad$ Exercise Observations \\ Description: HR never approached the rates observed in $1 \mathrm{~g}$ in the gym \\ General \\ Comments: \\ Resolved: N/A \\ If Resolved \\ how, when, \\ where? \\ Additional How important is it to exercise effort short-duration ( $<14$ days) lunar missions? \\ Questions: $\quad$-if it is, what is the goal exercise countermeasures (e.g., CV tone, neurovest, \\ postural tone, etc) \\ Summit Topic: Yes \\ $\begin{array}{ll}\text { Source: } & \text { Medical Mission Debriefs } \\ \text { Topic: } & \text { Exercise } \\ \text { Issue: } & \text { heart rate during exercise } \\ \text { Description: } & \text { CMP: never got over } 90 \text {, but we limited to avoid perspiring } \\ & \text { CDR: got to } 120 \text { 'guess I got lazy or something. Worked as hard as he wanted to } \\ & \text { and the rate would be about } 120 .\end{array}$ \\ General \\ Comments: \\ Resolved: \\ If Resolved \\ how, when, \\ where? \\ Additional \\ Questions: What was the thermal/condensation load limiting perspiration with exercise? \\ Summit Topic: Yes
}




\section{Appendix A \\ Apollo Summit Non-Attributable Report}

Source: $\quad$ Flight Surgeon logs

Topic: $\quad$ Exercise

Issue: $\quad$ exercise

Description: LMP may be on exerciser but HR not very high

General Crew unable to generate elevated HR because of limitations of device and concern for $100 \%$ O2 environment.

Comments:

Resolved:

If Resolved

how, when,

where?

Additional What makes us think we were on exercise not on Biomed monitor?

Questions:

Summit Topic: Yes

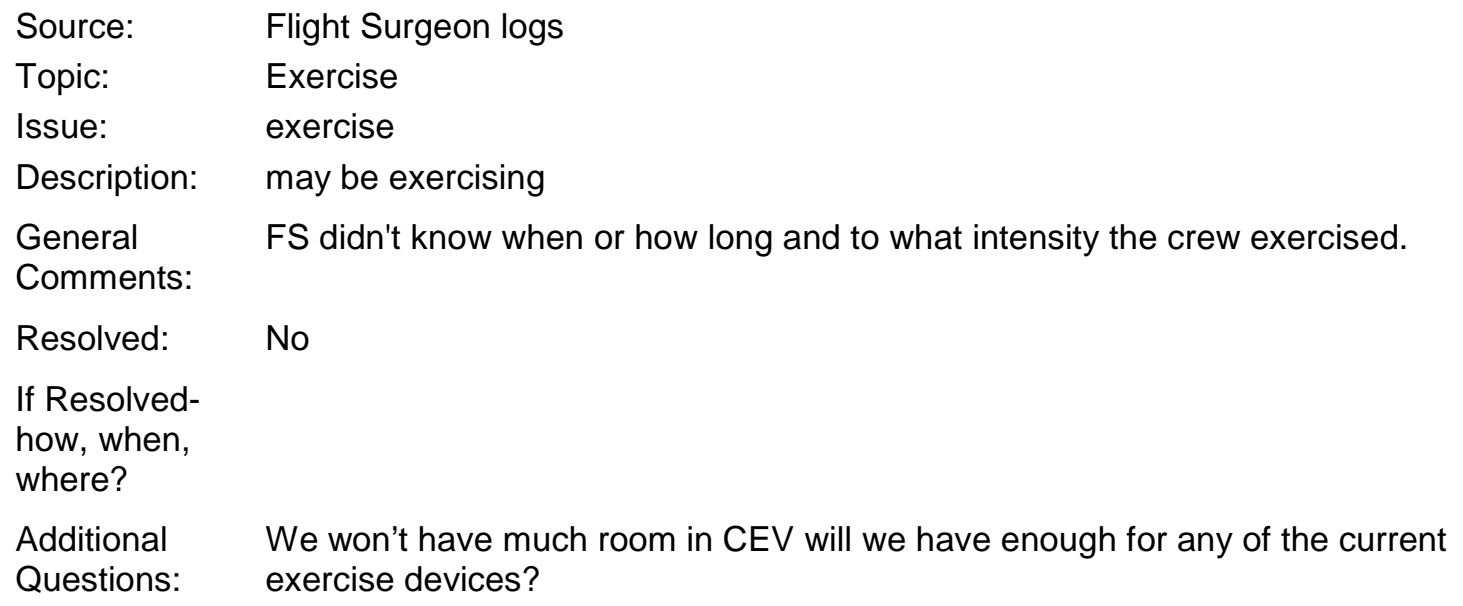

Additional We won't have much room in CEV will we have enough for any of the current Questions: exercise devices?

Summit Topic: Yes 


\section{Appendix A Apollo Summit Non-Attributable Report}

Source:

Topic:

Issue:

Description:

General

Comments:

Resolved:

If Resolved

how, when, where?

Additional

Questions:

Summit Topic: Yes

\section{Medical Mission Debriefs}

\section{Exercise}

debrief of individual exercise regimens

CDR: his goal was a 10 minute period daily, exclusive of the 2-day lunar surface activity, for both he and the LMP. The CMP was to do that exercise each day. The Exer-gym was to be used, beginning with 1) legs with feet in the two loops and hands controlling the friction device, from a crouch to a full stretchout. Then 2) hold the fixed loops and use the legs on the movable loops, then 31 hold the fixed loop with the toes and use the biceps and movable loops. These exercises designed to work the "Big 4."

Did not exercise the first day out. While it is in the flight plan, the day is too busy. CDR expressed opinion that the contribution of the 10 minute exercise pedods was "down in the noise level" compared to the basic workload of the 30 hours of work on the lunar surface, including the EVAs.

When Dr. Berry said "you don't really need it on that first day anyway," LMP differed, suggesting it "would probably have alleviated some of the sore back muscles that first day if we had gone ahead and done it, in my case, anyhow." CDR specified exercise prior to lunch every day as the most efficient schedule time.
LMP limited exercise intensity to just below generating a sweat, felt heart rate increase and increased respiration, but "it's not a vigorous exercise, more of a tension exercise." Did a hard, slow pull. 


\title{
Appendix A Apollo Summit Non-Attributable Report
}

\author{
Source: $\quad$ Medical Mission Debriefs \\ Topic: $\quad$ Exercise \\ Issue: exercise routine \\ Description: CDR: goal was about 10 minutes per day exercise for lunar surface activity days \\ for the CDR and LMP. For CMP, ten minutes each day. Planned to use the \\ Exer-genie device. Missed the first day out -not on schedule, \\ LMP thought first day exercise might have helped avoid his sore back muscles \\ the first day. \\ LMP felt he increased his heart rate and breathing rate --tried to avoid "cracking \\ a sweat." \\ CMP didn't work up a sweat -exercised 5-10 minutes per day, CDR: benefit of \\ exercise "was down in the noise level for the CDR and LMP." \\ General \\ Comments: \\ Resolved: N/A \\ If Resolved \\ how, when, \\ where? \\ Additional \\ Questions: \\ Summit Topic: Yes

\section{Source: $\quad$ Medical Mission Debriefs \\ Topic: Exercise \\ Issue: Description of CMP rout \\ Description: Perhaps 5-10 minutes at lowest level. "finally got around to getting it and doing some exercise on it." Missed one day on the way out and did not exercise at all in lunar orbit. "Barely got in the one exercise a day that we did on the way home. "Didn't hit the Exer-gym as much as I probably should have." The work schedule did not permit much exercise time.} \\ General \\ Comments: Crew schedule did not provide formal exercise time. \\ Resolved: \\ If Resolved \\ how, when, \\ where? \\ Additional \\ Questions: \\ Summit Topic: Yes
}




\section{Appendix A \\ Apollo Summit Non-Attributable Report}

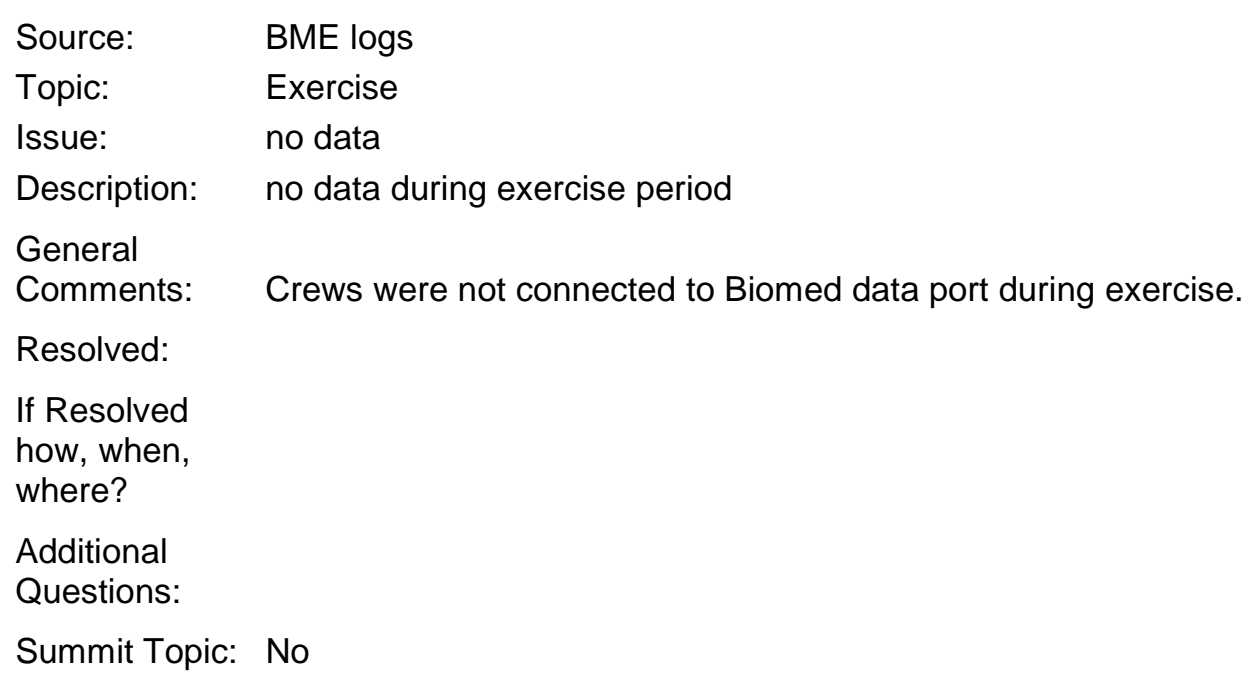

Additional

Questions:

Summit Topic: No

$\begin{array}{ll}\text { Source: } & \text { BME logs } \\ \text { Topic: } & \text { Exercise } \\ \text { Description: } & \text { all exercising off line }\end{array}$

General

Comments: Crews were not connected to Biomed data port during exercise.

Resolved:

If Resolved

how, when, where?

Additional

Questions: If they are offline and exercising how does that help us?

Summit Topic: No

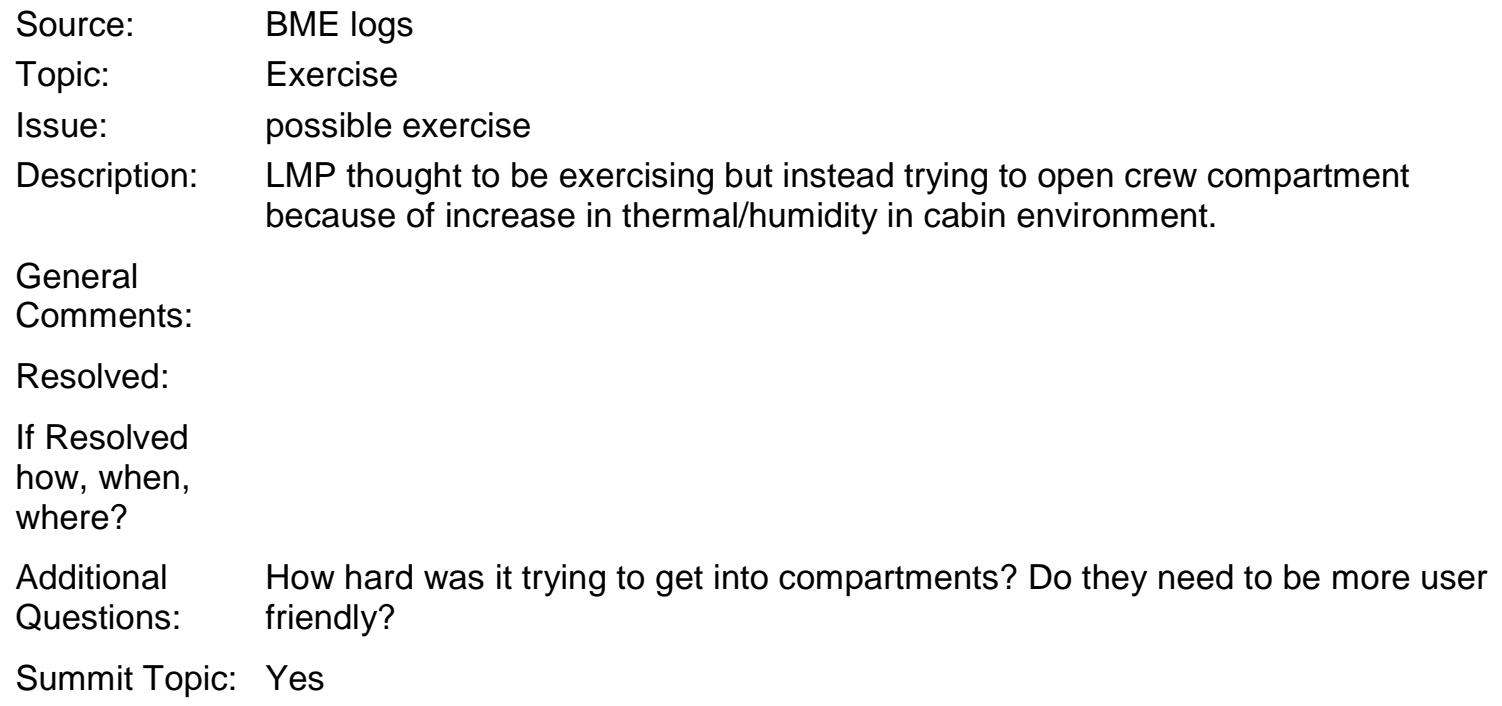

General

Comments:

Resolved:

If Resolved

how, when, where?

Additional How hard was it trying to get into compartments? Do they need to be more user Questions: friendly?

Summit Topic: Yes 


\section{Appendix A Apollo Summit Non-Attributable Report}

Source: $\quad$ Flight Surgeon logs

Topic: $\quad$ Exercise

Issue: exercise

Description: crew reports exercise though no increase in HR

General

Comments: Crews were limited by poor exercise capability and concern over impacts $(100 \%$
O2).

Resolved:

If Resolved

how, when,

where?

Additional Do you know what types of exercise increased HR and what types didn't?

Questions:

Summit Topic: Yes

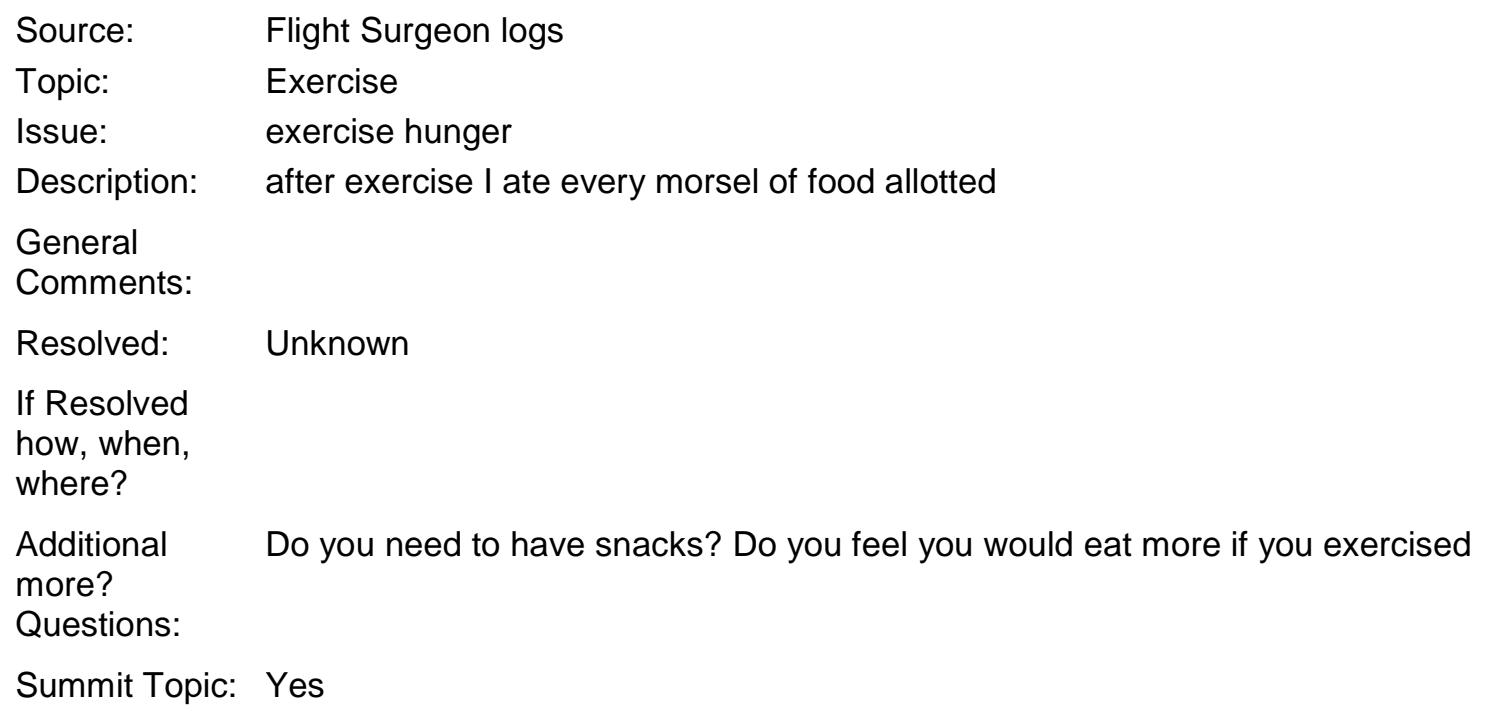

Source: $\quad$ Flight Surgeon logs

Topic: $\quad$ Exercise

Issue: loose sensors

Description: $\quad$ exercising with HR120 EKG sensors became loose during this activity

General

Comments:

Resolved:

If Resolved how, when, where?

Additional Are the biomed sensors most needed during activity or rest? Questions: 


\section{Appendix A \\ Apollo Summit Non-Attributable Report}

Summit Topic: Yes 


\title{
Appendix A Apollo Summit Non-Attributable Report
}

\author{
Source: $\quad$ Medical Mission Debriefs \\ Topic: $\quad$ Exercise \\ Issue: how much \\ Description: CMP: first 3 days worked with the Exer-genie, 3 periods every 2 days, maybe. \\ Each period 15 or 20 minutes. In lunar orbit, 2 periods a day, $10-15$ min of \\ each spent running in place, using the center couch. And 5-10 min of each \\ period working with the Exer-genie for a total of 20-30 minutes, 2 periods a \\ day. Used 'straight' exercise with the Exer-genie. Not much increase in heart \\ rate with the Exer-genie, but more with the running. \\ CDR and CMP neither could get heart rate over 80 with the Exer-genie. \\ No exercise after the EVAs or on way home. Too busy cleaning up and stowing. \\ CDR: exercised once a day on the way out, using the Exer-genie until it \\ appeared to wear out. Did deep knee bends with feet against the bulkhead, \\ hands against the struts and pushed against his arms. Pull up to about 100 \\ with that. Exercise period about 5 minutes. \\ LMP: Exer-genie once daily for maybe 10 minutes on way out, on the way back \\ strained against the seat restraint until it failed. \\ General A bungee to the floor for running in place would help, they thought \\ Comments: \\ Resolved: \\ If Resolved \\ how, when, \\ where? \\ Additional \\ Questions: \\ Summit Topic: Yes

\section{Source: $\quad$ Medical Mission Debriefs \\ Topic: $\quad$ Exercise \\ Issue: sweating \\ Description: CDR: never sweated except when running in place after about 10-12 minutes, and in gloves after EVA \\ LMP: after EVA-1 noticed gloves were wet from sweat \\ CDR: after an EVA drank directly from the water gun, was very thirsty and after EVA drank until satisfied.} \\ General \\ Comments: \\ Resolved: \\ If Resolved \\ how, when, \\ where? \\ Additional \\ Questions: \\ Summit Topic: Yes
}




\section{Appendix A \\ Apollo Summit Non-Attributable Report}

\begin{tabular}{ll}
\hline Source: & Flight Surgeon logs \\
Topic: & Exercise \\
Issue: & exercise \\
Description: & exercise period \\
General & no information on exercise \\
Comments: & \\
Resolved: & \\
If Resolved & \\
how, when, & \\
where? & \\
Additional & \\
Questions: & \\
Summit Topic: & No
\end{tabular}

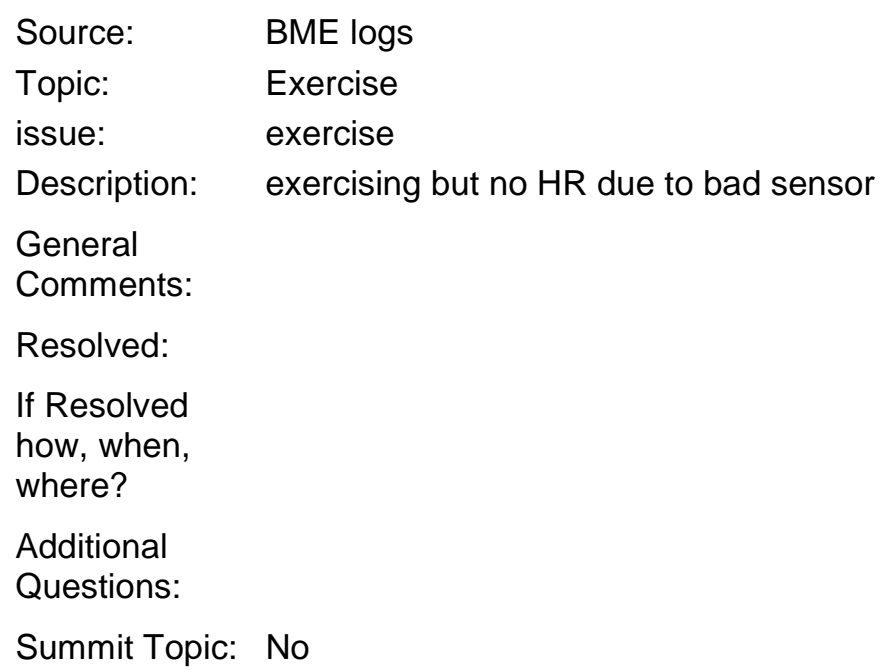

General

Comments:

Resolved:

If Resolved

how, when, where?

Additional was this an effective or rewarding method of exercise?

Questions:

Summit Topic: Yes 


\section{Appendix A \\ Apollo Summit Non-Attributable Report}

Source: $\quad$ Flight Surgeon logs

Topic: $\quad$ Exercise

Issue: increased HR

Description: HR increased most likely exercising

General very little documentation on exercising in Apollo.

Comments:

Resolved: Unknown

If Resolved

how, when,

where?

Additional

Questions:

Summit Topic: Yes

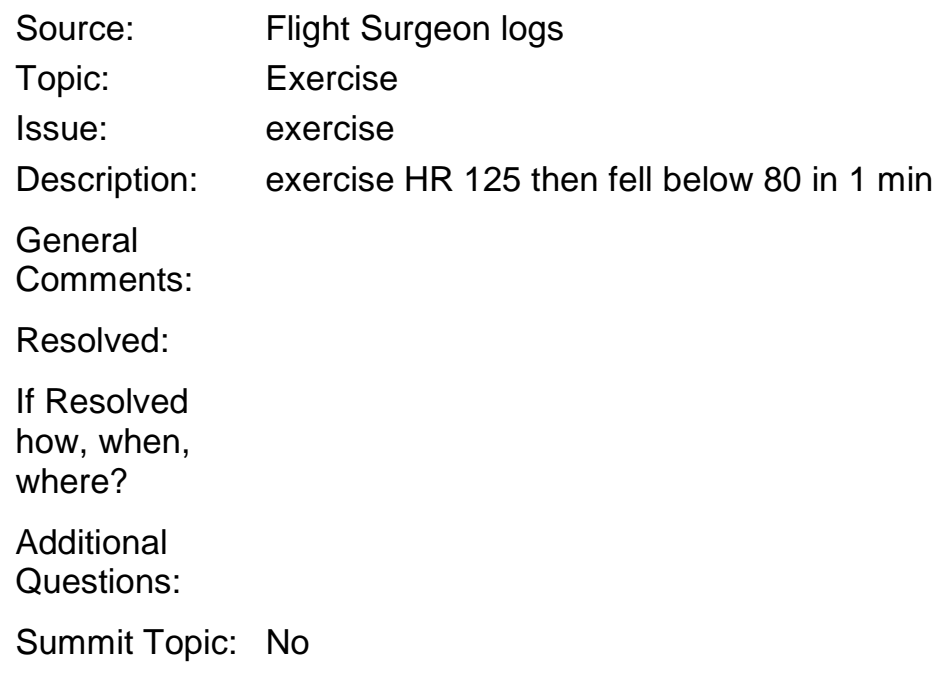

Source: $\quad$ Flight Surgeon logs

Topic: Exercise

Issue: exercise

Description: running in place HR 130 for 1 min exercise unspecified for 4 min average $H R$

General

Comments:

Resolved:

If Resolved how, when, where?

Additional What were the limitations to exercise?

Questions:

Summit Topic: Yes 


\section{Appendix A \\ Apollo Summit Non-Attributable Report}

Summit Topic: Yes

Source: $\quad$ Flight Surgeon logs

Topic: $\quad$ Food/Nutrition

Issue: Delete $\mathrm{H} 2 \mathrm{O}$ Chlorination

Description: Chlorine limit is $5 \mathrm{ppm}$ but cannot be confirm by taste, as Chlorine does not mix uniformly throughout tank.

Will discard the first 5 clicks of $\mathrm{H} 2 \mathrm{O}$ before taste

General Secondary to overwhelming chlorine amount in solution.

Comments:

Resolved:

If Resolved

how, when,

where?

Additional Will Chlorine used in the Apollo era be used for exploration vehicles or newer

Questions: lodine for potable water sterilization?

Summit Topic: Yes

\section{Source: \\ Topic: \\ Issue: \\ Description: \\ General Comments: \\ Resolved: \\ If Resolved \\ how, when, \\ where?}

Additional

Questions:

\section{BME logs}

Food/Nutrition

$\mathrm{H} 2 \mathrm{O}$

$\mathrm{H} 2 \mathrm{O}$ smells like a bucket of Clorox

Related to inability to adequately stir chlorine in the water tanks after application.

Summit Topic: No 


\title{
Appendix A Apollo Summit Non-Attributable Report
}

\author{
Source: $\quad$ BME logs \\ Topic: $\quad$ Food/Nutrition \\ Issue: potable $\mathrm{H} 2 \mathrm{O}$ tank \\ Description: Potable $\mathrm{H} 2 \mathrm{O}$ tank quantity decrease possible rupture? \\ General \\ Comments: \\ Resolved: \\ If Resolved \\ how, when, \\ where? \\ Additional Did the potable water tank rupture? Or has it ever? \\ Questions: Do we have a back up if it does? Can we repair it if it does?
}

Summit Topic: No
Source: $\quad$ Medical Mission Debriefs
Topic: $\quad$ Food/Nutrition
Issue: $\quad$ Crew Preferences \& Observations
Description: a) Variety is more important than getting what you like. They were on a 4 day rotation
b) Avoid high calorie foods - unclear why this is the case. Apparently these food types were packed because of the mass-power-volume issues
c) Food items (beef, chicken sandwich) was "crumbly" -quite a bit of crumbs in the cockpit
d) Orange juice, clam chowder package broke or split. Crew prefers the soup
e) Ham \& applesauce "grew thick"
General Specific Food Notations:
Comments: $\quad$ 1. Pudding, cookies sweet cinnamon toast, chocolate drinks, heavily sweetened fruit drinks
2. Meat dishes were desirable, especially bacon squares
3. CM believe they would have gotten more total calories if lighter foods were

available

4. Cut down total calories from $2,500 /$ day to $2000-2200$ day

5. Choose more dehydrated foods and less bite-sized foods. Crew got sick of them towards the end of the mission

6 . The $\mathrm{H} 2 \mathrm{O}$ gun was very hard to operate -got stuck often. Also heavy Chlorine taste secondary to inadequate stirring after ever 12 hours of application.

Resolved:

If Resolved how, when, where?

Additional

Questions:

Summit Topic: Yes 


\section{Appendix A Apollo Summit Non-Attributable Report}

Source: $\quad$ Flight Surgeon logs

Topic: $\quad$ Food/Nutrition

Issue: $\quad \mathrm{H} 2 \mathrm{O}$ smells like a bucket of Clorox

Description: Cont. problems with Chlorination

General

Comments:

Resolved:

If Resolved

how, when,

where?

Additional

Questions:

Summit Topic: No

Source: $\quad$ Medical Mission Debriefs

Topic: Food/Nutrition

Issue: $\quad$ Crew Preferences and Observations

Description: a) Food was mediocre in taste -tasted the same

b) Crew avoided the "bite food". Either too sweet or too dry -Two crewmembers much preferred the food on Gemini VII / XII -Exception was the Christmas dinner -turkey was good -Shrimp cocktail was delicious

c) Preparation of food: unclear how certain foods were prepared

d) Crew wanted between meal drinks (not H2O)

e) Grape juice was OK

Orange juice was poor

Banana pudding was poor (tastes like airplane dope)

Coffee was not good

General

Comments:

Resolved:

If Resolved

how, when,

where?

Additional How were foods prepared?

Questions:

Summit Topic: Yes 


\section{Appendix A Apollo Summit Non-Attributable Report}

Source: $\quad$ Flight Surgeon logs

Topic: $\quad$ Food/Nutrition

Issue: $\quad$ water sample in LM

Description: $\quad$ LM water sample had lodine content of $2.3 \mathrm{ppm}$ with microorganism isolated. Filter gun will have to be used.

General

Comments:

Resolved:

If Resolved

how, when,

where?

Additional Was lodine used instead of chlorine? What are the ranges of acceptable iodine?

How

Questions: do we plan on keeping water supply from being contaminated?

Summit Topic: Yes

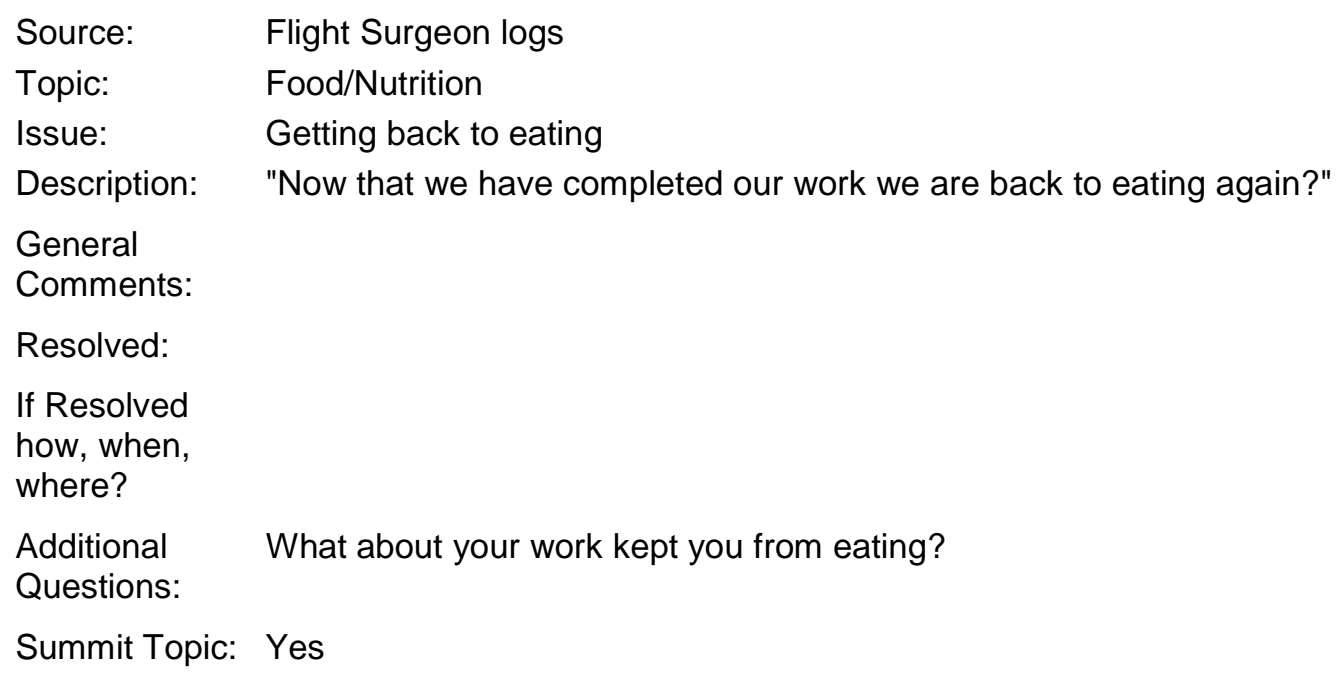




\title{
Appendix A Apollo Summit Non-Attributable Report
}

\author{
Source: Medical Mission Debriefs \\ Topic: $\quad$ Food/Nutrition \\ issue: $\quad$ Food \\ Description: a) Fruit cocktail / peaches were really good \\ b) gas bubbles form in the food bags and were difficult to remove. (see Additional \\ Questions) \\ General Crew described it as distasteful to have a bag full of bubbles intermixed with food \\ or \\ Comments: $\quad$ "liquid. It was difficult to "burp". You felt blocked with no mechanism to relieve \\ it. \\ Resolved: \\ If Resolved \\ how, when, \\ where? \\ Additional Why was this a problem? \\ Questions: Could something simple like gas $x$ prevent this problem? \\ Summit Topic: Yes

$\begin{array}{ll}\text { Source: } & \text { BME logs } \\ \text { Topic: } & \text { Food/Nutrition } \\ \text { Issue: } & \text { water/H2 } \\ \text { Description: } & \text { "I took } 8 \text { gulps of water } 4 \text { of which were air" } \\ \text { General } & \text { This sums up the problem nicely } \\ \text { Comments: } & \end{array}$ \\ Resolved: \\ If Resolved \\ how, when, \\ where? \\ Additional \\ Questions: \\ Summit Topic: Yes
}




\section{Appendix A Apollo Summit Non-Attributable Report}

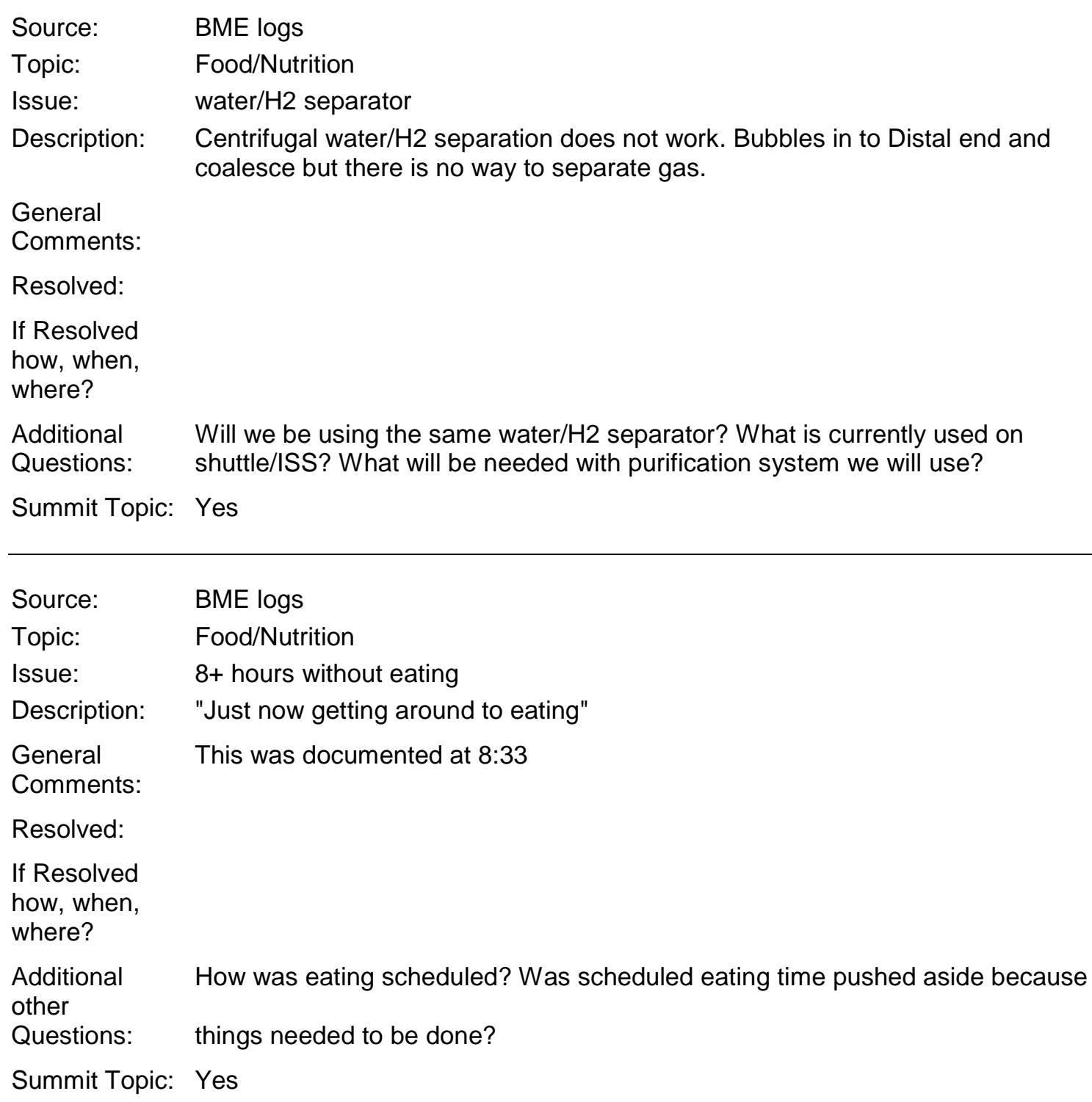




\title{
Appendix A Apollo Summit Non-Attributable Report
}

\author{
Source: $\quad$ Medical Mission Debriefs \\ Topic: $\quad$ Food/Nutrition \\ Issue: $\quad$ Food Preferences and Observations \\ Description: a) The crew mixed $\mathrm{H} 2 \mathrm{O}$ with grape juice to kill the awful chlorine taste in the \\ water \\ b) Stomach fullness from the gas in the water and busy mission schedule \\ precluded 3 meals per day. Crew averaged an a.m. and p.m. meal, however, \\ rarely felt hungry. Exception was rendezvous day where they had gone \\ approximately ?? hours between meals \\ c) "Meat Stick" - Turkey and gravy, dried fruits were well-liked by the Crew \\ d) Plain bread was preferred over rye without condiments. Rye seeds took on \\ peculiar odor \\ e) Fruit preparation was also well-liked \\ f) Food preparations was cumbersome. Crew preferred the food packs with \\ great-beef stew, chicken \& rice. Also, food delivery was an issue. Eating \\ spaghetti and meatballs out of a tube was not desirable \\ g) Once food was prepared, the lack of availability of useful areas to store water, \\ food packs, etc., made eating difficult, i.e., each packet had to be finished \\ otherwise, it would float away...one crewmember stated "you have no place to \\ put it" \\ h) Boiling point of water at 5.0 psi is 154 degrees Fahrenheit plus or minus 4 \\ degrees-Steam in water contributed to gas problem \\ i) Crew recommended for Apollo to have many wet pack meal readily available \\ and vacuum seal items like bread, snack, etc. Benefit = ready made, no prep \\ time and easily available. \\ General Crew was unsure secondary to lack of sensation of hunger secondary to gas in \\ Comments: stomach from the water. Also they felt that physically they weren't working that \\ hard. \\ Resolved: \\ If Resolved \\ how, when, \\ where? \\ Additional \\ a) What does the crew feel the demands are with regards to eating / calories in? \\ Questions: \\ b) There is a question about a mistake that shouldn't have happened, but details \\ are unclear \\ c) Also with juice, some sort of filter as it is consumed to prevent bubble \\ formation \\ Summit Topic: Yes
}




\title{
Appendix A Apollo Summit Non-Attributable Report
}

\author{
Source: $\quad$ Medical Mission Debriefs \\ Topic: $\quad$ Food/Nutrition \\ Issue: chlorination procedures \\ Description: p. 4: LMP: crew were given incorrect instruction for chlorination of water, \\ resulting in the chlorine solution not getting out of the tubing and into the water \\ tank. \\ P.7: CDR: The water tanks was the most annoying thing on the whole flight. "it's \\ ridiculous." " my stomach was too distended to drink sufficient water and eat \\ normally. \\ P.8:CDR: Never felt hungry during flight, except after transition docking TLI \\ because of no opportunity for meal. \\ IMP: once or twice during the mission felt stomach was hungry. \\ General \\ Comments: Water system was bad \\ Resolved: No \\ If Resolved \\ how, when, \\ where? \\ Additional \\ Questions: \\ Summit Topic: Yes

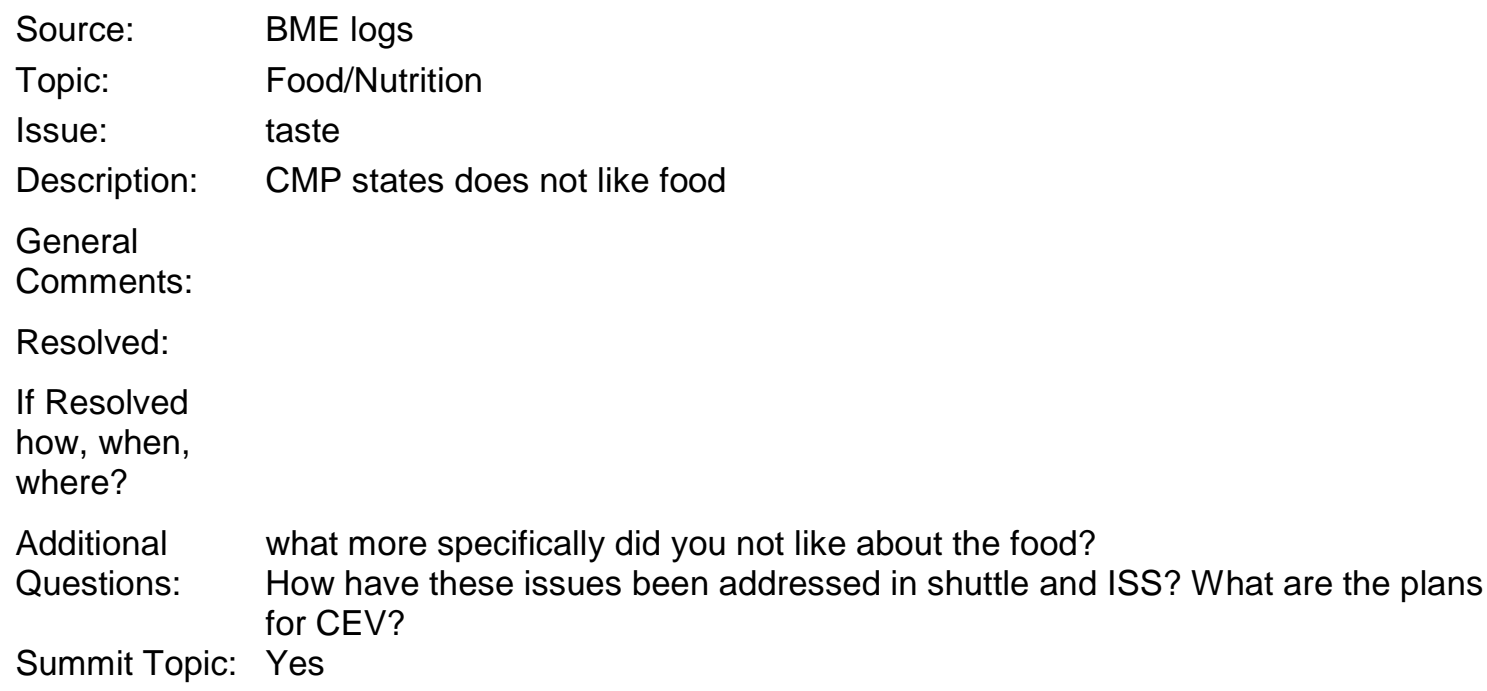




\section{Appendix A \\ Apollo Summit Non-Attributable Report}

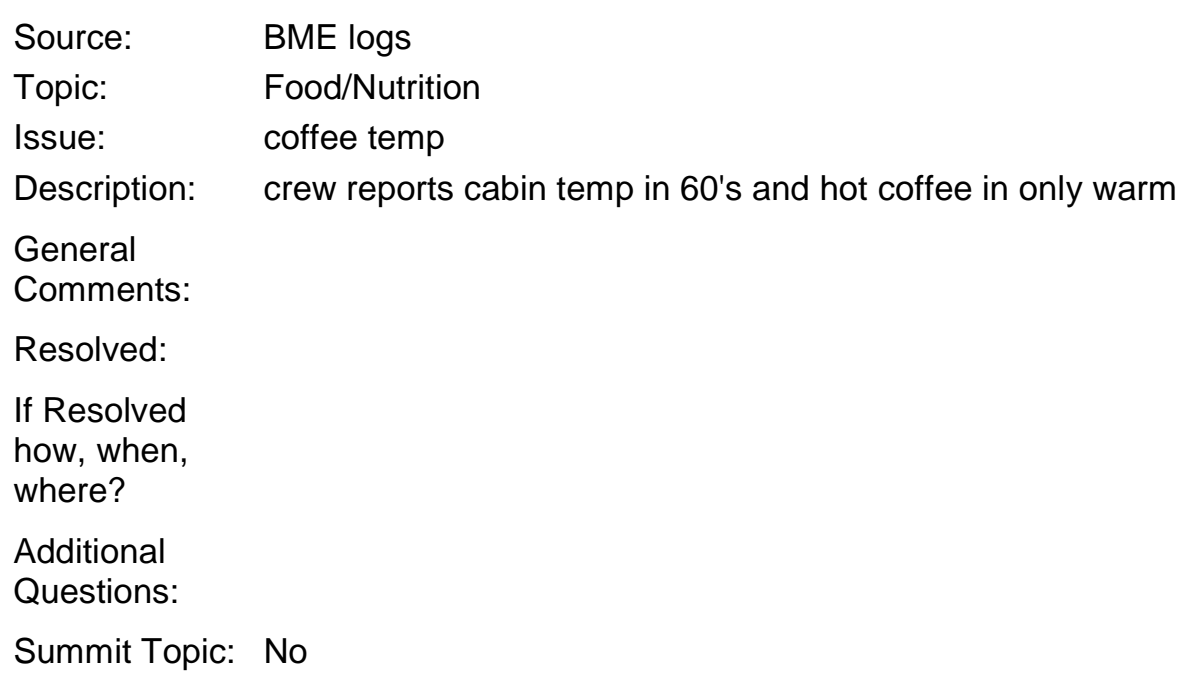

Additional

Questions:

Summit Topic: No

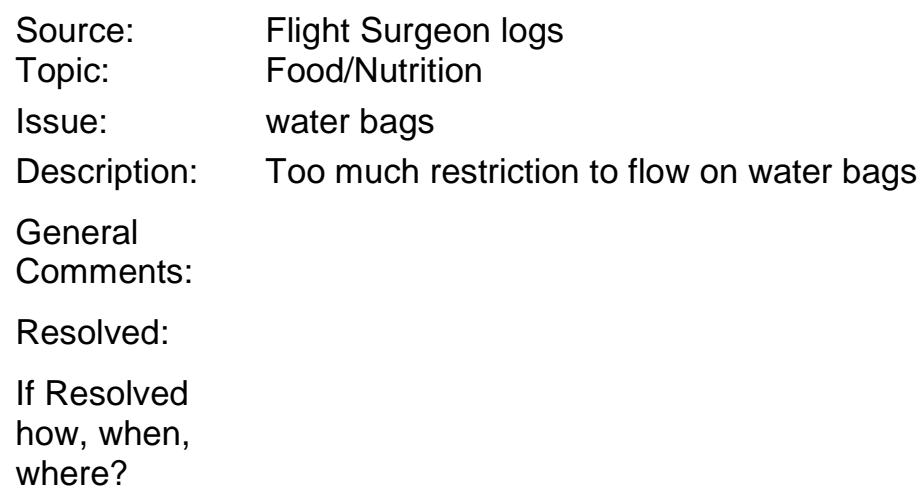

Additional So we have fixed the gas in the water but created a new problem? Is this an Questions: improvement or just a change of big problems?

Summit Topic: Yes

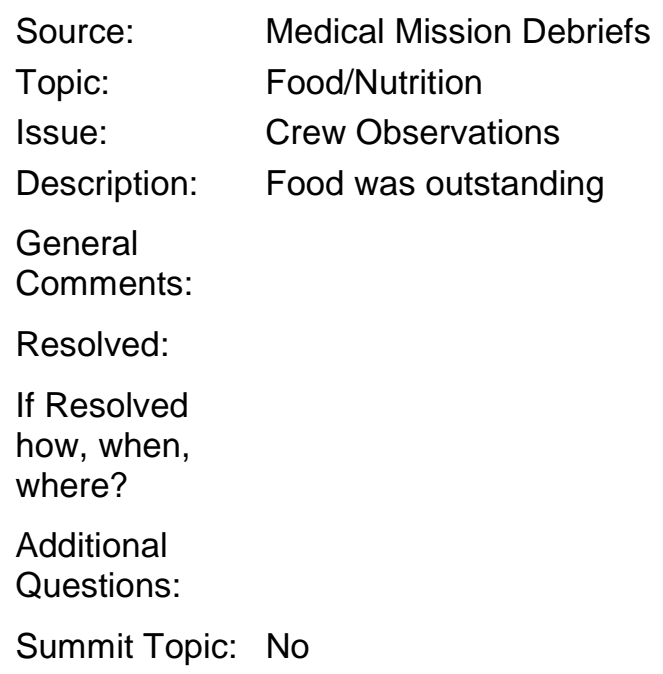




\section{Appendix A \\ Apollo Summit Non-Attributable Report}

Source: $\quad$ Flight Surgeon logs

Topic: $\quad$ Food/Nutrition

Issue: water

Description: water is the same with and without filter

General

Comments:

Resolved:

If Resolved

how, when,

where?

Additional Explain same? Did it taste the same or same temp?

Questions: do you think this indicates the filter wasn't working?

Summit Topic: Yes

Source: $\quad$ Flight Surgeon logs

Topic: $\quad$ Food/Nutrition

Issue: water filter

Description: Concern of water gun filter by crew-filter taken off

General Fear of filter be contaminated? It was alluded to but not directly said?

Comments:

Resolved:

If Resolved

how, when,

where?

Additional What caused you to question the filter on the flight and not before?

Questions:

Summit Topic: Yes 


\title{
Appendix A Apollo Summit Non-Attributable Report
}

\author{
Source: $\quad$ Medical Mission Debriefs \\ Topic: $\quad$ Food/Nutrition \\ Issue: appetite \\ Description: CDR: Lost 8 pounds on *Gemini $11^{*}$ and 2 pounds on Apollo 12. "I ate everything \\ in sight and it tasted great. I ate everything in the LM, and I ate all the (LMP) \\ food, he wouldn't eat it. I ate everything." \\ LMP: drank a lot of water on lunar surface, drank and ate less after that. \\ "Powered down on the way home." Very little required activity on the way \\ back to Earth --slept a lot. \\ General \\ Comments: Appetite among $\mathrm{CM}$ was highly variable, but general all $\mathrm{CM}$, with one exception, \\ lost weight. \\ Resolved: $\quad \mathrm{N} / \mathrm{A}$ \\ If Resolved \\ how, when, \\ where? \\ Additional \\ Questions: \\ Summit Topic: Yes \\ Source: $\quad$ Medical Mission Debriefs \\ Topic: $\quad$ Food/Nutrition \\ Issue: Water \\ Description: Cold water did not have excessive bubbles, but hot water did. \\ General \\ Comments: \\ Resolved: \\ If Resolved \\ how, when, \\ where? \\ Additional \\ Questions: \\ Summit Topic: No
}




\title{
Appendix A \\ Apollo Summit Non-Attributable Report
}

\author{
Source: $\quad$ Flight Surgeon logs \\ Topic: Food/Nutrition \\ Issue: food usage \\ Description: use foods that don't need rehydrating so as to conserve water \\ General \\ Comments: Crew had to ration $\mathrm{H} 2 \mathrm{O}$ during missions. \\ Resolved: \\ If Resolved \\ how, when, \\ where? \\ Additional \\ Questions: Was $\mathrm{H} 2 \mathrm{O}$ conservation a problem? \\ Summit Topic: Yes \\ Source: $\quad$ Flight Surgeon logs \\ Topic: Food/Nutrition \\ Issue: last nights food \\ Description: About eating last night's half can of tuna already opened? \\ General \\ Comments: \\ Resolved: \\ If Resolved \\ how, when, \\ where? \\ Additional Did you have enough food that you could snack on if you were hungry outside of \\ Questions: meal times? \\ Summit Topic: Yes
}




\title{
Appendix A Apollo Summit Non-Attributable Report
}

\author{
Source: $\quad$ Medical Mission Debriefs \\ Topic: $\quad$ Food/Nutrition \\ Issue: $\quad$ Food packaging \\ Description: CMP: Available time was more a determinant of eating than was the societal \\ factor of other crew eating at the same time. During the transit to the moon, \\ there is more time for eating than in lunar orbit, when there is very little time, \\ particularly when one needs to troubleshoot equipment, etc. \\ One can get to canned packs quickly and so that's what you eat when you are in \\ a hurry, rather than re-hydrated packs. \\ CMP lost ten pounds while remainder of crew lost about 1 pound each. CMP \\ attributed his weight loss during mission to a poor diet the last few weeks prior \\ to launch, when he drank 2-3 beers in the evenings. \\ CDR: compared the food intake with the activity level -- when activity level is \\ high, "wet packs and cans" is all you have time for. Food preparation could be \\ time consuming, limiting consumption during high activity times. \\ CMP: all bite-sized packages were consumed -"that was the best thing we had." \\ Tasty and quick. "You just flip that off and a can of juice, and you could go at \\ it."
}

General

Comments:

Resolved: No

If Resolved

how, when,

where?

Additional

Questions:

Summit Topic: Yes

\section{Source: $\quad$ Medical Mission Debriefs \\ Topic: $\quad$ Food/Nutrition \\ Issue: $\quad$ water and juice consumption \\ Description: LMP: drank from water gun "every time I went past it." Consciously pushing fluid intake. Preferred juices to water, although water tasted fine, too. Usually drank two juices a meal. \\ CDR: "decided I was going to do everything I could to end up in as good shape as I could at the end of the mission, which included keeping the fluid intake and the food intake up as well as the exercise."}

General

Comments:

Resolved: No

If Resolved

how, when,

where?

Additional

Questions:

Summit Topic: Yes 


\section{Appendix A \\ Apollo Summit Non-Attributable Report}

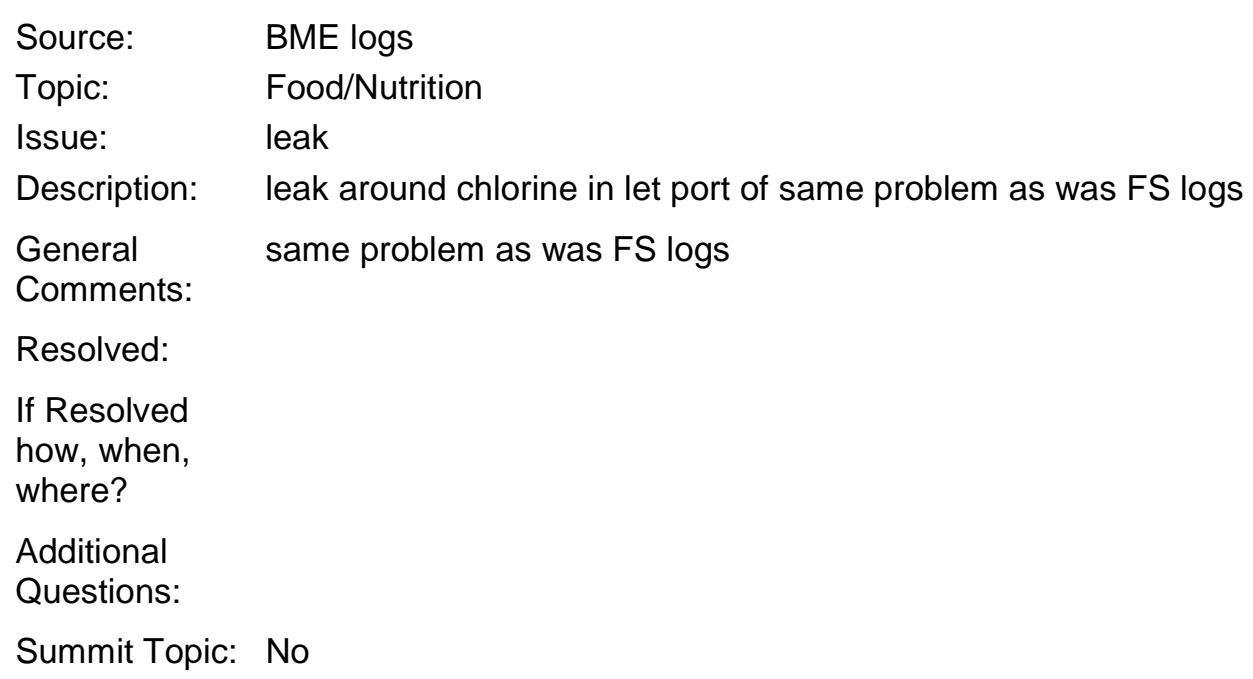




\section{Appendix A Apollo Summit Non-Attributable Report}

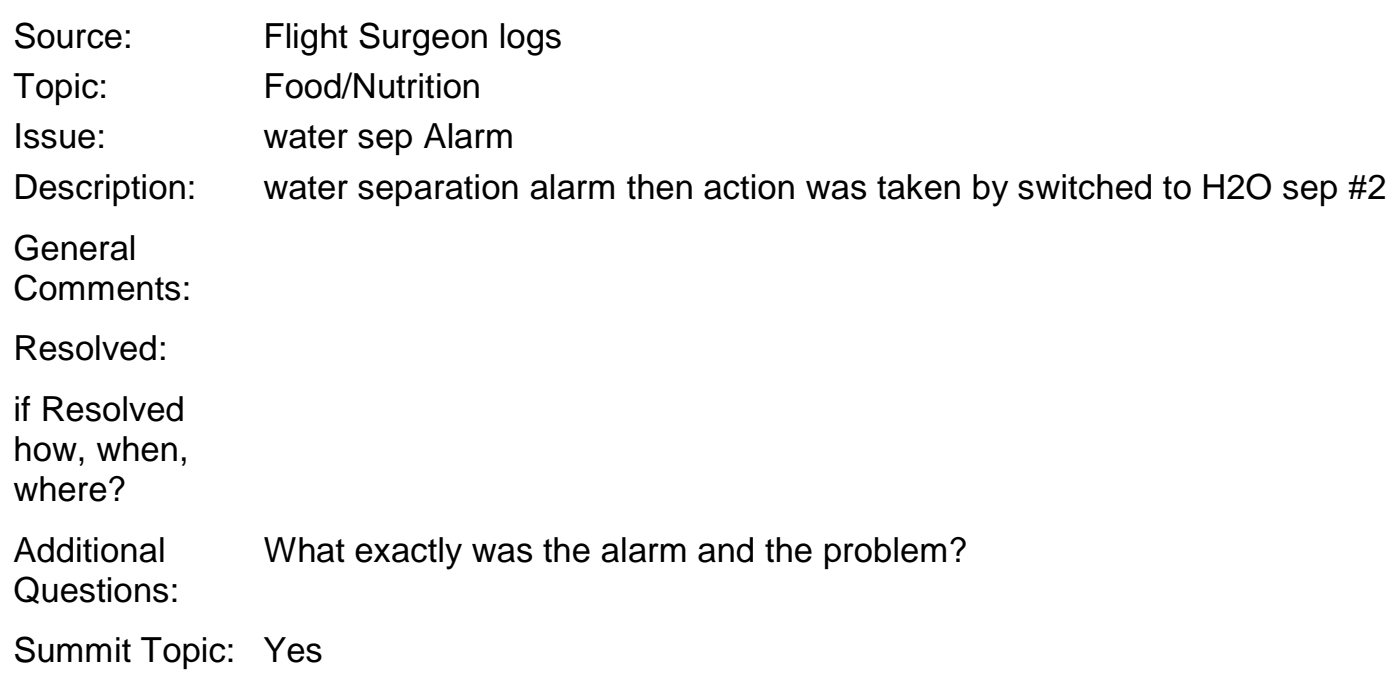




\section{Appendix A \\ Apollo Summit Non-Attributable Report}

Source: $\quad$ Flight Surgeon logs

Topic: $\quad$ Food/Nutrition

Issue: $\quad$ Filter

Description: Bacterological filter broke. Crewmember says feels iodine levels and decay levels adequate therefore filter not necessary in this case

General

Comments:

Resolved: Unknown

If Resolved

how, when,

where?

Additional Now did we fix the filter so it didn't break again? What caused it to break?

Questions:

Summit Topic: Yes

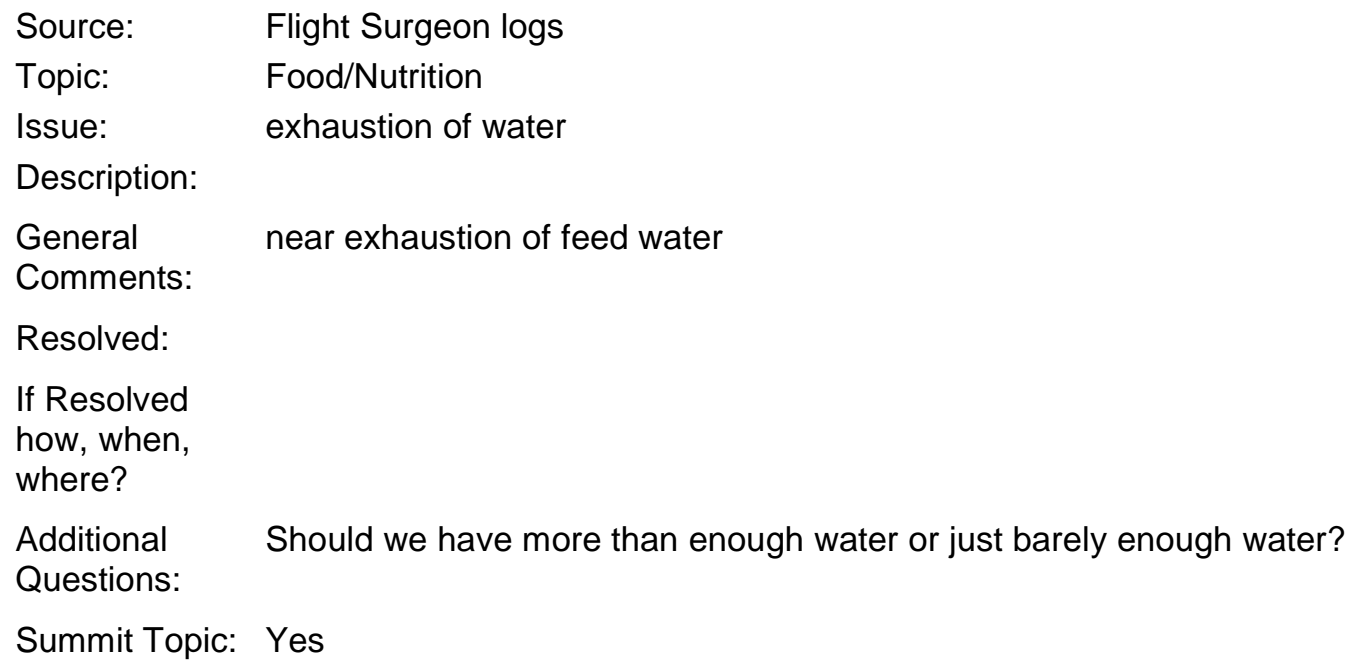

Summit Topic: Yes 


\title{
Appendix A Apollo Summit Non-Attributable Report
}

\author{
Source: $\quad$ Medical Mission Debriefs \\ Topic: $\quad$ Food/Nutrition \\ Issue: $\quad$ not enough food in the LM \\ Description: CDR and LMP stated there was not enough food in the LM and that scheduled \\ meals every 10 hours was not enough. \\ They drank and ate everything that was available in the LM \\ General \\ Comments: \\ Resolved: No \\ If Resolved \\ how, when, \\ where? \\ Additional \\ Questions: \\ Summit Topic: Yes

\section{General \\ Comments: \\ Resolved: \\ If Resolved \\ how, when, \\ where?} \\ Source: $\quad$ BME logs \\ Topic: $\quad$ Food/Nutrition \\ Issue: $\quad \mathrm{Cl}$ ampule \\ Description: Chlorine ampule didn't go in right, in taking out water bubbled out. Everyone \\ thinks it's an old problem, Debating what to do should they stay up another \\ hour \\ Additional Was this an old problem, if so how can we fix it so it stops? \\ Questions: \\ Summit Topic: Yes
}




\section{Appendix A Apollo Summit Non-Attributable Report}

Source: $\quad$ Flight Surgeon logs

Topic: $\quad$ Food/Nutrition

Issue: $\quad$ Potassium intake

Description: Potassium intake has been low and would like for you to be sure to increase your juice intake but concerned how crew will react to this so just ask them to drink more juice

General

Comments: Crew required to take $130 \mathrm{meq} \mathrm{uCl} / \mathrm{day}$ which caused loose stools.

Resolved:

If Resolved

how, when,

where?

Additional How should we approach nutrition issues with a exploration crew?

Questions:

Summit Topic: Yes

Source: $\quad$ Flight Surgeon logs

Topic: $\quad$ Food/Nutrition

Issue: $\quad$ food bags

Description: one of the food bags didn't hold its vacuum

General

Comments:

Resolved:

If Resolved

how, when,

where?

Additional

Questions:

Summit Topic: No

\footnotetext{
Source: $\quad$ Flight Surgeon logs

Topic: Food/Nutrition

Issue: big meals

Description: meals are big "could feed a roman army"

General

Comments:

Resolved:

If Resolved

how, when, where?

Additional Were the meals big because you weren't as hungry or because they were big?

Questions: Would you like more smaller meals?
} 


\section{Appendix A \\ Apollo Summit Non-Attributable Report}

Summit Topic: Yes 


\section{Appendix A \\ Apollo Summit Non-Attributable Report}

Source: $\quad$ Flight Surgeon logs

Topic: $\quad$ Food/Nutrition

Issue: Increased water consumption

Description: crews consumption up markedly 8 lbs above

General

Comments:

Resolved:

If Resolved

how, when,

where?

Additional Should crews have plenty of excess water? Did you feel you were drinking a lot?

Questions:

Summit Topic: Yes

\footnotetext{
Source: $\quad$ Flight Surgeon logs

Topic: $\quad$ Food/Nutrition

Issue: didn't eat lunch

Description: didn't have time to eat lunch during high mission activities such as rendezvous, docking, etc.

General

Comments:

Resolved:

If Resolved

how, when,

where?

Additional Did, you often not have time for lunch or was this just a busy time with things

taking too

Questions: long?

Summit Topic: Yes
} 


\title{
Appendix A Apollo Summit Non-Attributable Report
}

\author{
Source: $\quad$ Medical Mission Debriefs \\ Topic: $\quad$ Food/Nutrition \\ Issue: $\quad$ water air separator \\ Description: A cigar shaped item, presumably a water-gas separator, made of plastic, leaked \\ secondary to a crack and could not be used. CMP points out it was never tested \\ in the spacecraft preflight, which was a violation of procedures. Item is not \\ described in the text sufficiently to identify it. \\ General \\ Comments: \\ Resolved: \\ If Resolved \\ how, when, \\ where? \\ Additional \\ Questions: \\ Summit Topic: No \\ Source: $\quad$ Medical Mission Debriefs \\ Topic: $\quad$ Food/Nutrition \\ Issue: $\quad$ in-suit water bag \\ Description: The in-suit water bag cannot be inserted after the suit is donned -must be \\ inserted prior to donning. CDR was therefore unable to drink during EVA \\ truncated discussion about "eating" in the suit. \\ LMP: had free orange juice in his suit. Bag was squeezed between his chest and \\ the suit, the microphone Orange juice floated under the comm carrier, down \\ the mike boom, onto the visor "and it went just everywhere." Each time the \\ astronaut bend forward, orange juice leaked out into the suit. \\ Bag can be vented in $1 / 6$ gravity, but leaks through the vent hold in zero gravity \\ and can't be vented. \\ General CDR and LMP suggested a "stopper in there", "like those Skylab things." \\ Comments: \\ Resolved: \\ If Resolved \\ how, when, \\ where? \\ Additional \\ Questions: \\ Summit Topic: Yes
}




\title{
Appendix A Apollo Summit Non-Attributable Report
}

\author{
Source: Medical Mission Debriefs \\ Topic: $\quad$ Food/Nutrition \\ Issue: $\quad 14.7$ psi canned peaches \\ Description: "anything (packaged) in 14 psi is a mistake in a spacecraft." \\ These were packaged for Skylab but flow in the 5.0 psia Apollo CM. \\ "If I had had any indication that there was anything above 5 psi in those cans, I \\ would never have let those things off the ground." \\ CMP: "If I were an octopus, I'd be a fine candidate for this program. But to eat my \\ meal l've got to have too many hands."
}

General

Comments:

Resolved:

If Resolved

how, when,

where?

Additional

Questions:

Summit Topic: Yes

$\begin{array}{ll}\text { Source: } & \text { Medical Mission Debriefs } \\ \text { Topic: } & \text { Food/Nutrition } \\ \text { Issue: } & \text { food packaging } \\ \text { Description: } & \text { "Those cans are a hazard. You tear the lids off those things and that's like a knife } \\ & \text { just floating around the spacecraft." } \\ & \text { Speaker observed opening cans which are sitting on a tray. A tray was not part of } \\ & \text { Apollo. } \\ & \text { After use, a germicide pill was placed in the can. CMP discarded the whole thing } \\ \text { in a fecal bag. Once a can or package was opened, the entire contents had to } \\ \text { be eaten because there was no way to dispose of partial contents, which } \\ \text { could float throughoutt the cabin if not properly stowed. Liquids which were } \\ \text { conductive posed electrical threats for shorting out circuits. Can tops posed a } \\ \text { laceration threat, Crumbs posed an ocular foreign body threat. Multiple items } \\ \text { could not be manually controlled in zero-g during the eating process. After } \\ \text { eating, the small, compressed volume of packaging is now a much larger } \\ \text { volume, no longer compressed and fitted into a container. A trash compactor } \\ \text { is needed. Used food packaging was wrapped and taped into a ball which } \\ \text { was stored in a jettison bag. The planned trash stowage volume was rapidly } \\ \text { exceeded. }\end{array}$

General

Comments:

Resolved:

If Resolved

how, when,

where?

Additional

Questions:

Summit Topic: Yes 


\section{Appendix A Apollo Summit Non-Attributable Report}

Source: $\quad$ Medical Mission Debriefs

Topic: $\quad$ Food/Nutrition

Issue: food packaging

Description: If soup was not "thick" it tended to move up the liner package edge and out, moving down the outside. Air bubble in fact tended to be in the middle with no way to remove it.

Concern about electrical conductivity of soups, etc., getting on wiring in the CM Beverage packages leaked around the valve

Defective heat sealing of cocoa bags, which ruptured when filling with the water gun was attempted.

General

Comments:

Resolved:

If Resolved

how, when,

where?

Additional

Questions:

Summit Topic: No

$\begin{array}{ll}\text { Source: } & \text { Flight Surgeon logs } \\ \text { Topic: } & \begin{array}{l}\text { Food/Nutrition } \\ \text { food bags }\end{array} \\ \begin{array}{l}\text { Issue: } \\ \text { Description: }\end{array} & \text { food bags "blown up" } \\ \text { General } & \\ \text { Comments: } & \text { Trapped air expanded during } \\ \text { Resolved: } & \\ \text { If Resolved } & \\ \text { how, when, } & \\ \text { where? } & \end{array}$

Additional what caused the food bags to blow up?

Questions:

Summit Topic: No 


\title{
Appendix A \\ Apollo Summit Non-Attributable Report
}

\author{
Source: $\quad$ Flight Surgeon logs \\ Topic: Food/Nutrition \\ Issue: restraints \\ Description: some trouble with food restraints \\ General no further explanation \\ Comments: \\ Resolved: \\ If Resolved \\ how, when, \\ where? \\ Additional \\ Questions: \\ Summit Topic: No
}
Source: $\quad$ Flight Surgeon logs
Topic: Food/Nutrition
Issue: better intake with juice bags
Description: reported slightly better intake with juice bags than water
General
Comments: Juice killed the awful chlorine taste that crews were subject to in the $\mathrm{H} 2 \mathrm{O}$
system.

Resolved:

If Resolved

how, when,

where?

Additional Would you have better fluid intake with juices than just water?

Questions:

Summit Topic: Yes

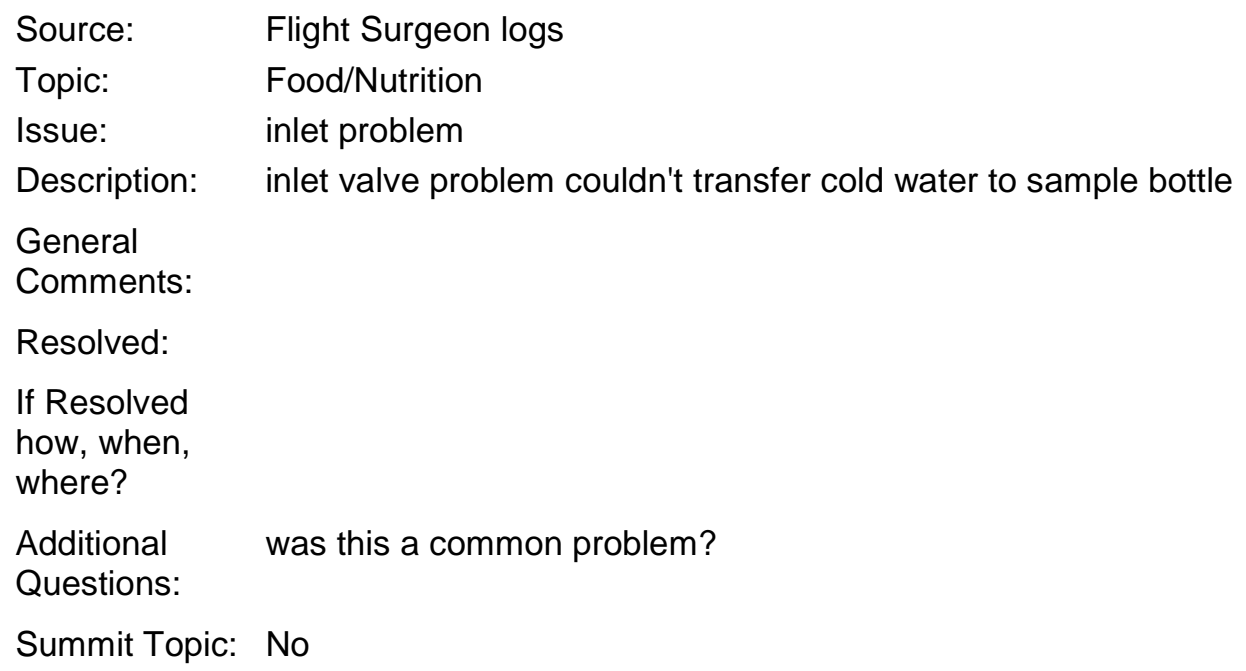




\section{Appendix A Apollo Summit Non-Attributable Report}

Source: $\quad$ Flight Surgeon logs

Topic: Food/Nutrition

Issue: water taste

Description: potable water bad taste b/c rubber hose between ship and SML's

General

Comments:

Resolved:

If Resolved

how, when,

where?

Additional Did water taste like drinking through rubber hose? The CEV design crew should Questions: be cognizant of this point

Summit Topic: Yes

\footnotetext{
Source: $\quad$ Medical Mission Debriefs

Topic: $\quad$ Food/Nutrition

Issue: drinking water from water system

Description: crew cut off the 'fill' end, filled the juice container with water, then put the water bag nozzle or valve into that and drank --less messy, could turn it off when you wanted. Far superior (page 18) Bags were very successful, no leaking valve

General very much liked fresh canned fruit, need to provide way to open without contents Comments: escaping initially

Resolved:

If Resolved

how, when, where?

Additional

Questions:

Summit Topic: Yes
} 


\section{Appendix A \\ Apollo Summit Non-Attributable Report}

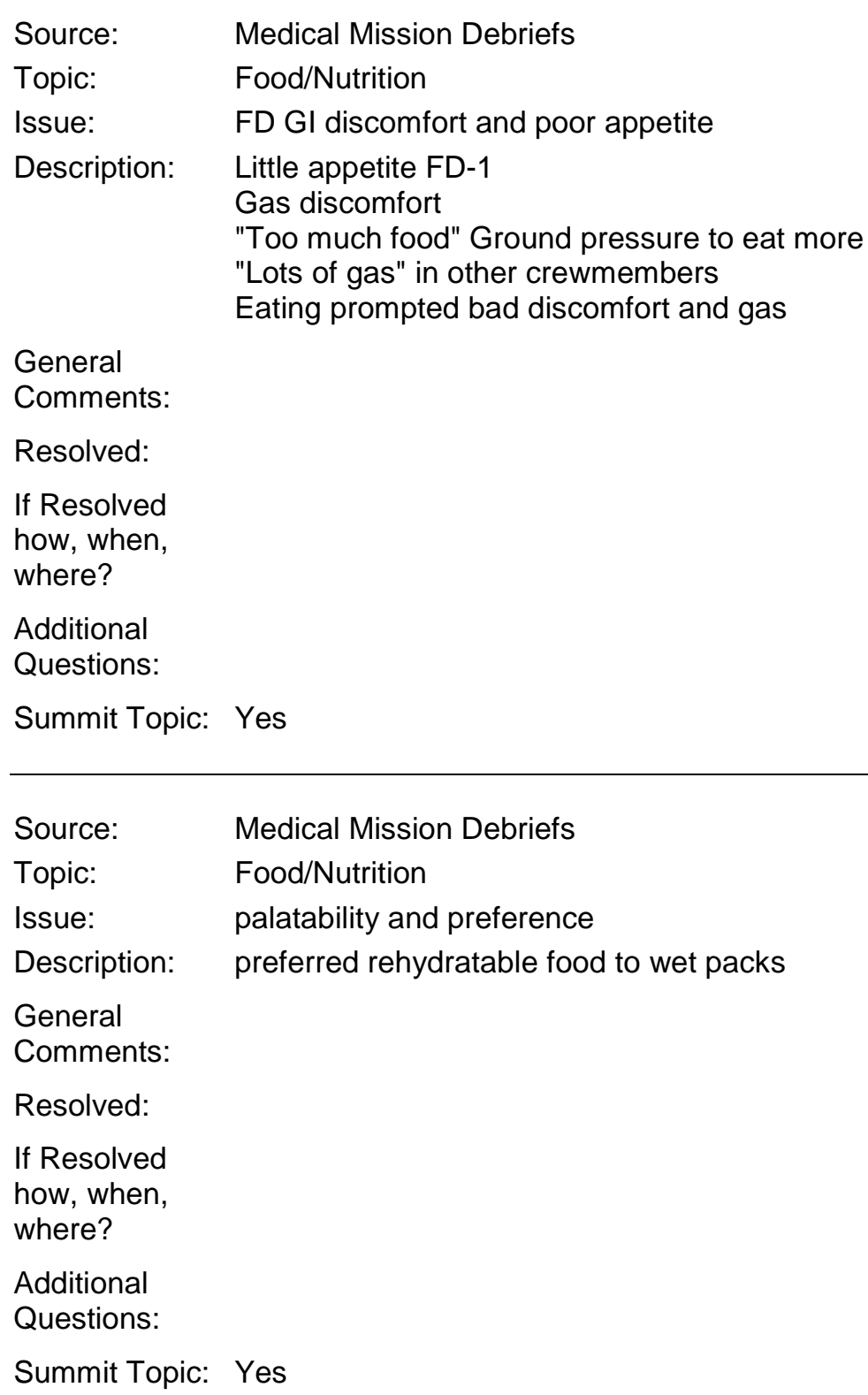

Source: $\quad$ Medical Mission Debriefs

Topic: Food/Nutrition

Issue: $\quad$ FD Gl discomfort and poor appetite

Description: Little appetite FD-1

Gas discomfort

"Too much food" Ground pressure to eat more

"Lots of gas" in other crewmembers

Eating prompted bad discomfort and gas

General

Comments:

Resolved:

If Resolved

how, when,

where?

Additional

Questions

Summit Topic: Yes

Resolved:

If Resolved

how, when,

Additional

Summit Topic: Yes 


\title{
Appendix A Apollo Summit Non-Attributable Report
}

\author{
Source: $\quad$ Medical Mission Debriefs \\ Topic: $\quad$ Food/Nutrition \\ Issue: food quantity consumption \\ Description: $\quad$ "I'm convinced when you get in flight and your heart powers down and you do \\ less work, you just eat less. And you go in a power-down state; three meals a \\ day in a 16 hour day approaches absurdity," \\ Consumed wet packs like gangbusters. \\ Some wet packs need to be hot, they would have been much more palatable. \\ General \\ Comments: \\ Resolved: \\ If Resolved \\ how, when, \\ where? \\ Additional \\ Questions: \\ Summit Topic: No

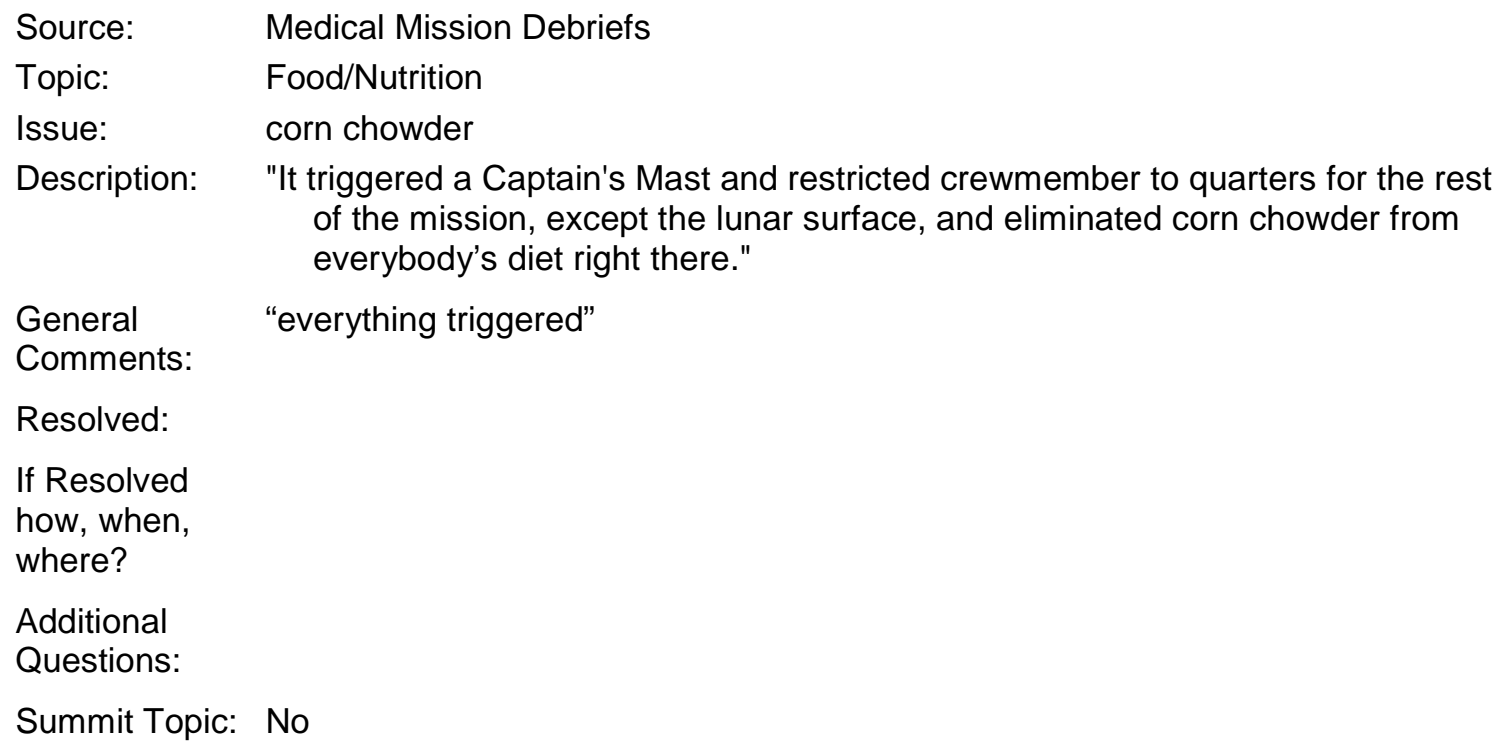

Resolved:

If Resolved

how, when, where?

Additional

Questions:

Summit Topic: No 


\section{Appendix A \\ Apollo Summit Non-Attributable Report}

Source: $\quad$ Medical Mission Debriefs

Topic: $\quad$ Food/Nutrition

Issue: distaste for instant breakfast and the coke

Description: "just totally developed a distaste for that chocolate taste." "It hit my belly, and it was just like an explosion."

General

Comments:

Resolved:

If Resolved

how, when,

where?

Additional

Questions:

Summit Topic: No

Source: $\quad$ Medical Mission Debriefs

Topic: $\quad$ Food/Nutrition

Issue: gas

Description: Took Mylicon prior to EVA for gas symptoms

General

Comments:

Resolved:

If Resolved

how, when,

where?

Additional

Questions:

Summit Topic: No 


\section{Appendix A Apollo Summit Non-Attributable Report}

Source: $\quad$ Medical Mission Debriefs

Topic: Launch/Re-entry Issues

Issue: Re-entry Observations

Description: a) Development of Drogue chute was impressive but not intolerable

b) Sea sickness was a problem on re-entry secondary to being upside down for approximately 15 minutes. Meclizine was little help for nausea

c) Cabin was very hot and uncomfortable in the suits on re-entry (See Additional Questions)

d) No ventilation in the cabin on re-entry.

General

Comments: Crew will require cooling in suit/cabin for greater than 30 minute stays before recovery.

Resolved: No

If Resolved

how, when, where?

Additional What could have been done differently to make re-entry more comfortable and Questions: less distressing?

Summit Topic: Yes

$\begin{array}{ll}\text { Source: } & \text { Medical Mission Debriefs } \\ \text { Topic: } & \text { Launch/Re-entry } \\ \text { Issue: } & \text { Re-Entry Observations } \\ \text { Description: } & \text { a) Seats were adequate despite the force of re-entry throughout the body } \\ & \text {-no injuries were reported } \\ & \text {-impact was taken by the fiat of the back } \\ & \text { b) Sensation of spaceflight pitching up during re-entry as g's increased }\end{array}$

General Max g's were approximately $6.8-7.0$

Comments:

Resolved: No

If Resolved

how, when,

where?

Additional Duration of $6.8-7.0 \mathrm{~g}$ force?

Questions:

Summit Topic: Yes 


\section{Appendix A \\ Apollo Summit Non-Attributable Report}

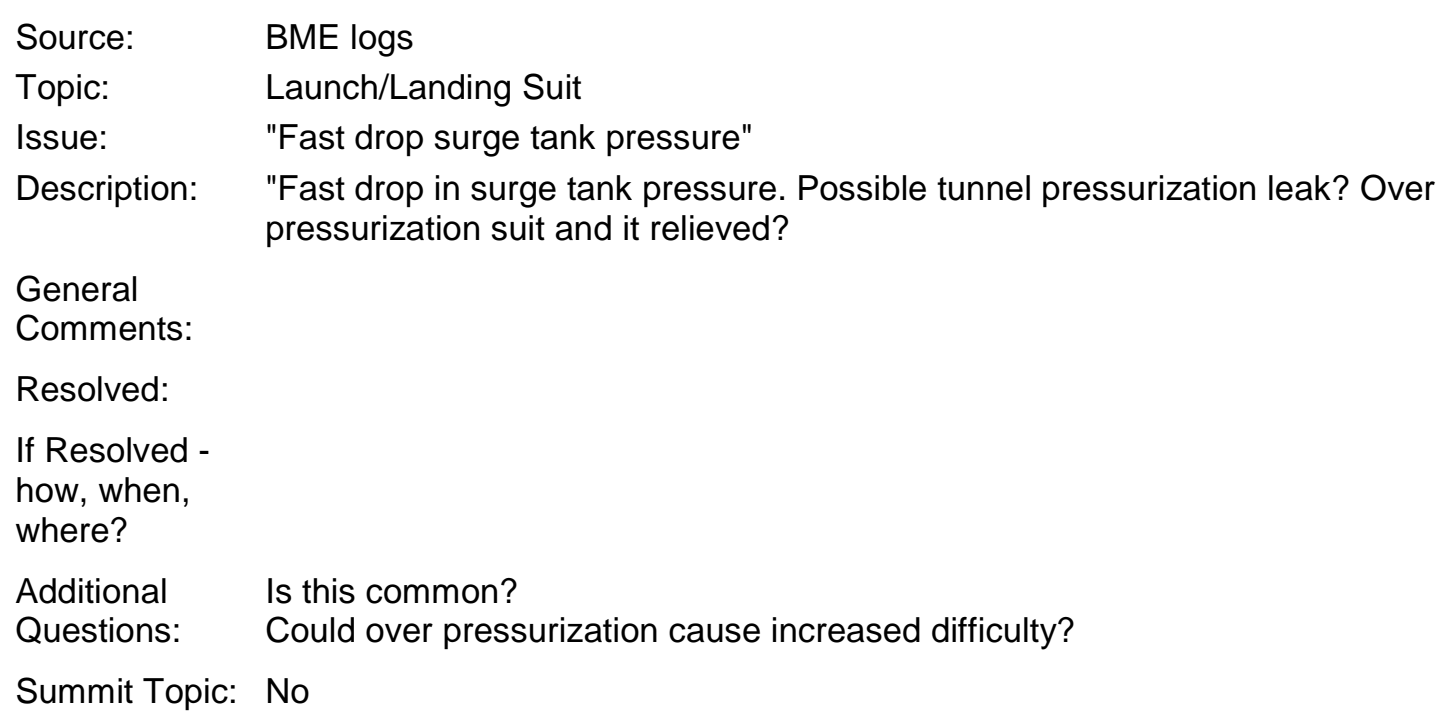

General

Comments:

Resolved:

If Resolved how, when, where?

Additional Is this common?

Questions: Could over pressurization cause increased difficulty?

Summit Topic: No

Source: $\quad$ BME logs

Topic: Launch/Landing Suit

Issue: $\quad$ long time preparing for Interface Verification Test

Description: "takes to long to prepare for IVT"

General

Comments:

Resolved:

If Resolved

how, when, where?

Additional How much more time do we need to schedule?

Questions:

Summit Topic: Yes

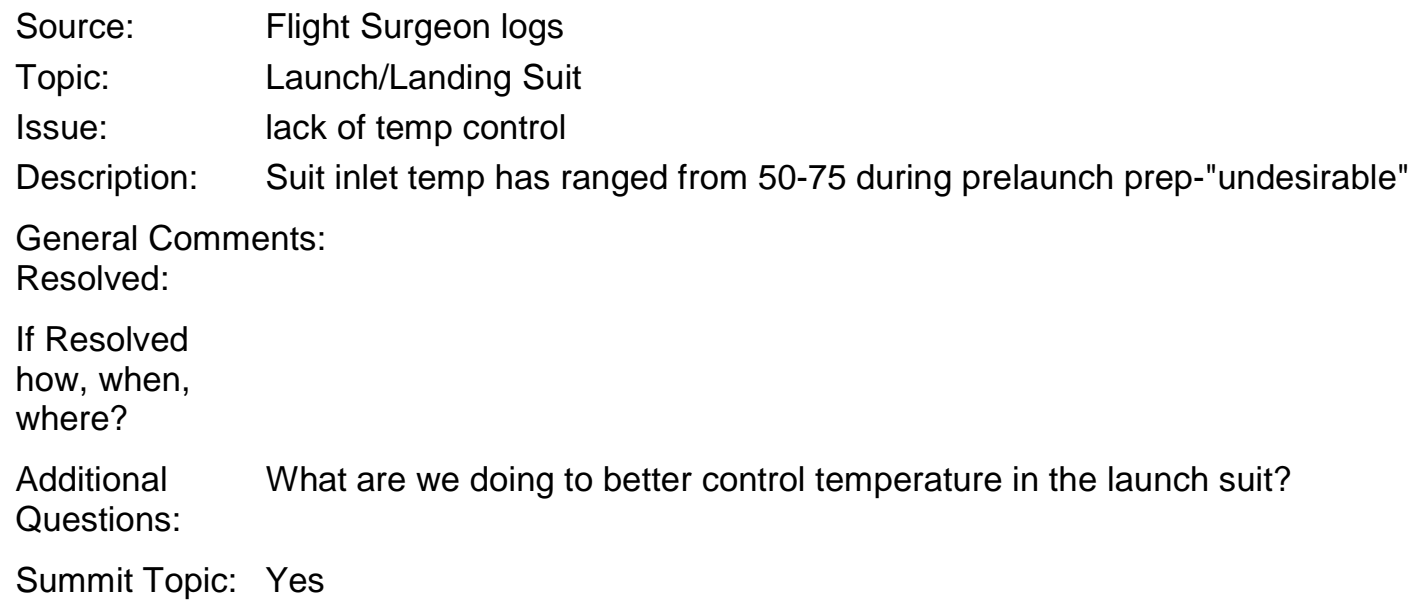




\title{
Appendix A Apollo Summit Non-Attributable Report
}

\author{
Source: $\quad$ Medical Mission Debriefs \\ Topic: Launch/Landing Suit \\ Issue: Suit Problems \\ Description: a) Fastening helmet is difficult, Why? \\ b) Suits were bad, helmets were bad, gloves were bad, underwear was bad! (No \\ details given) \\ c) Need to be able to administer medications/aside from just $\mathrm{H} 2 \mathrm{O}$ in the suit. \\ d) $\mathrm{H} 2 \mathrm{O}$ in suite -cyclic accumulation problem-blue hoses had $\mathrm{H} 2 \mathrm{O}$ condensate. \\ e) Recommend to leave helmet/neck ring disconnected in re-entry so CM can \\ clear their ears, If $\mathrm{CM}$ unable to run hand into helmet, they may enter without \\ bubble helmet. This would require padding under neck against the headrest \\ for support and protection. \\ General \\ Comments: \\ Resolved: \\ If Resolved - \\ how, when, \\ where? \\ Additional 1. Why was fastening helmet difficult? \\ Questions: $\quad 2$. What made the Suits were bad, helmets were bad, gloves were bad, \\ underwear was bad \\ 3. What Mode do you need to administer in the shuttle? Engineer can we do \\ this? \\ Summit Topic: Yes

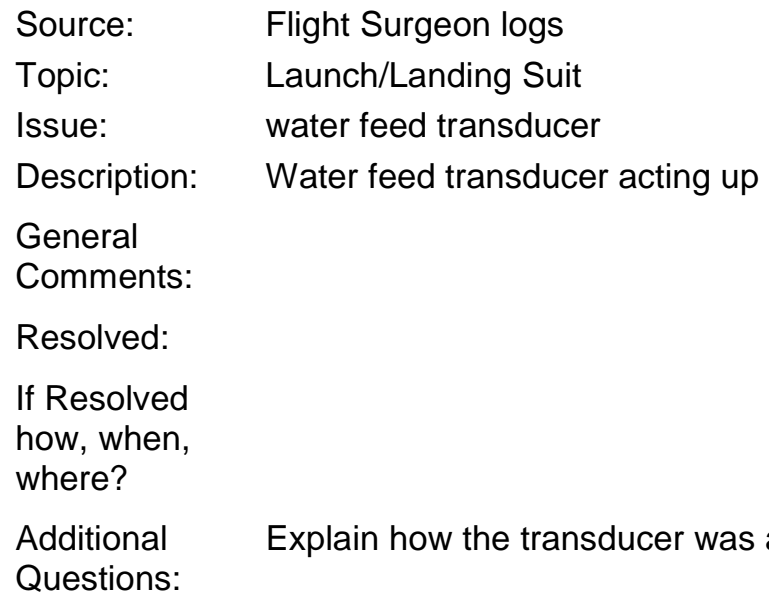 \\ Summit Topic: No
}




\section{Appendix A Apollo Summit Non-Attributable Report}

Source: $\quad$ Flight Surgeon logs

Topic: Launch/Landing Suit

Issue: $\quad$ warm hands in suit

Description: Hands are noted to be warm in suit but rest of body is comfortable

General

Comments:

Resolved:

If Resolved

how, when,

where?

Additional Why? How much of aerobism? would this be during exploration missions? How Questions: could we fix it?

Summit Topic: Yes

\section{Source: $\quad$ Medical Mission Debriefs \\ Topic: $\quad$ Launch/Landing Suit \\ Issue: Design Observations \\ Description: a) Taking the suit off/putting it on triggered SMS secondary to head/neck flexion required to get into suit. Ames would go in first, approximately 20 seconds later the head could pop through. During this time, CMP had definite symptoms of tumbling forward.}

General

Comments:

Resolved:

If Resolved

how, when.

where?

Additional Was this avoidable, either by suit position changes or delaying suite donning/doffing?

Questions:

Summit Topic: Yes 


\title{
Appendix A \\ Apollo Summit Non-Attributable Report
}

\author{
Source: $\quad$ BME logs \\ Topic: Launch/Landing Suit \\ Issue: temperature \\ Description: Crewmember reported they were cool and requested suit exchanger bypass \\ General \\ Comments: \\ Resolved: \\ If Resolved \\ how, when, \\ where? \\ Additional What was cool? Were you yourselves cool in the suit? Explain temperature \\ variations in \\ Questions: \\ suit? \\ Summit Topic: Yes

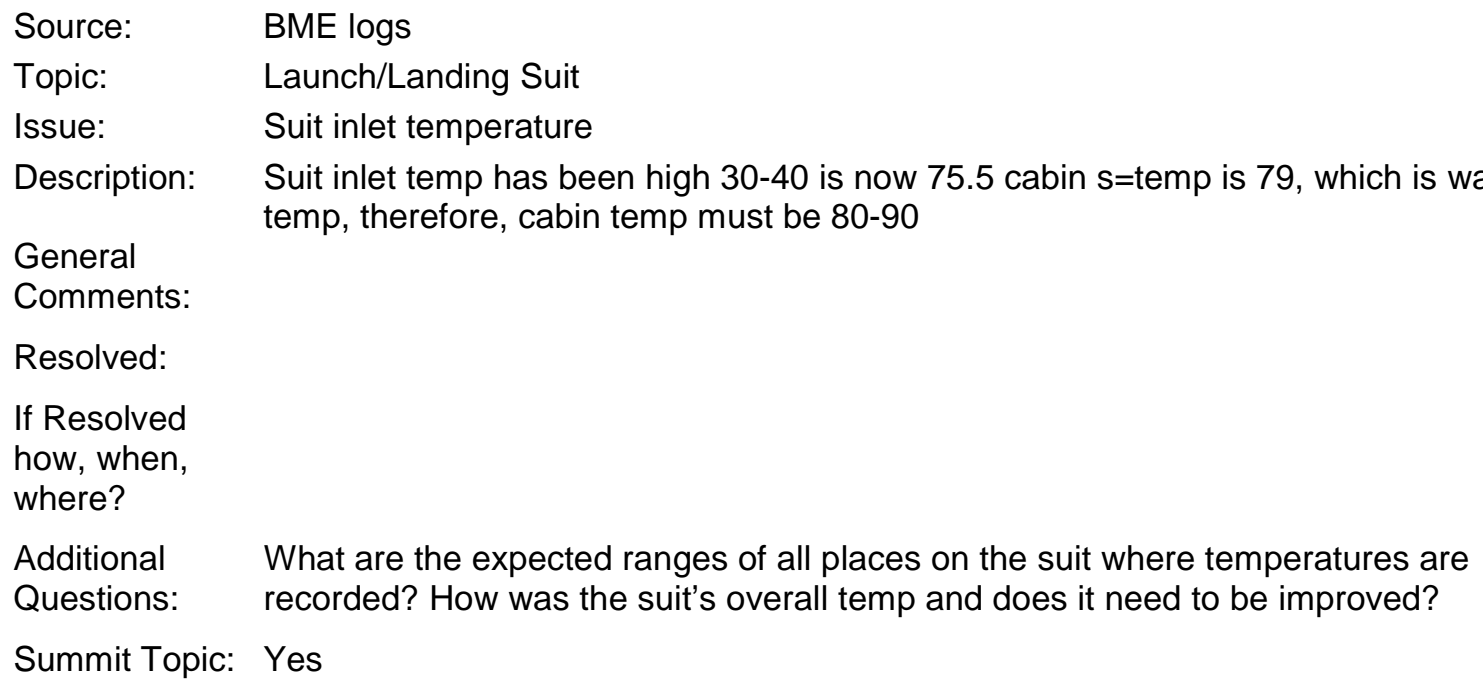

Resolved:

If Resolved

how, when, where?

Additional What are the expected ranges of all places on the suit where temperatures are Questions: $\quad$ recorded? How was the suit's overall temp and does it need to be improved?

Summit Topic: Yes 


\section{Appendix A \\ Apollo Summit Non-Attributable Report}

\section{General \\ Comments: \\ Resolved: \\ If Resolved how, when, where?}

Source: Medical Mission Debriefs

Topic: Launch/Landing Suit

Issue: Design Observations

Description: UCD took considerable time to use while in suit.

Additional Is it possible to design a urine collection device in cabin that can be used while crew is Questions: $\quad$ in suit without having to zipper down? i.e., long hose connected to overboard dumps that could connect to suit device

Summit Topic: Yes

\section{Source: \\ Topic: \\ Issue: \\ Description: \\ General Comments: \\ Resolved: \\ if Resolved how, when, where?}

BME logs

Launch/Landing Suit water found in suit

Water found in CDR suit on landing

Additional Questions: why the question?

Summit Topic: No 


\title{
Appendix A \\ Apollo Summit Non-Attributable Report
}

\author{
Source: BME logs \\ Topic: Launch/Landing Suit \\ Issue: $\quad \mathrm{H} 2 \mathrm{O}$ in suit loop \\ Description: $\quad \mathrm{H} 2 \mathrm{O}$ in suit loop yesterday in LM. Crew reports $\mathrm{CO} 2$ secondary then $\mathrm{H} 2 \mathrm{O}$ \\ secondary to that after $5 \mathrm{~min}$ \\ General \\ Comments: \\ Resolved: \\ If Resolved \\ how, when, \\ where? \\ Additional How is the sensor linked to the $\mathrm{H} 2 \mathrm{O}$ ? \\ Questions: \\ Summit Topic: No

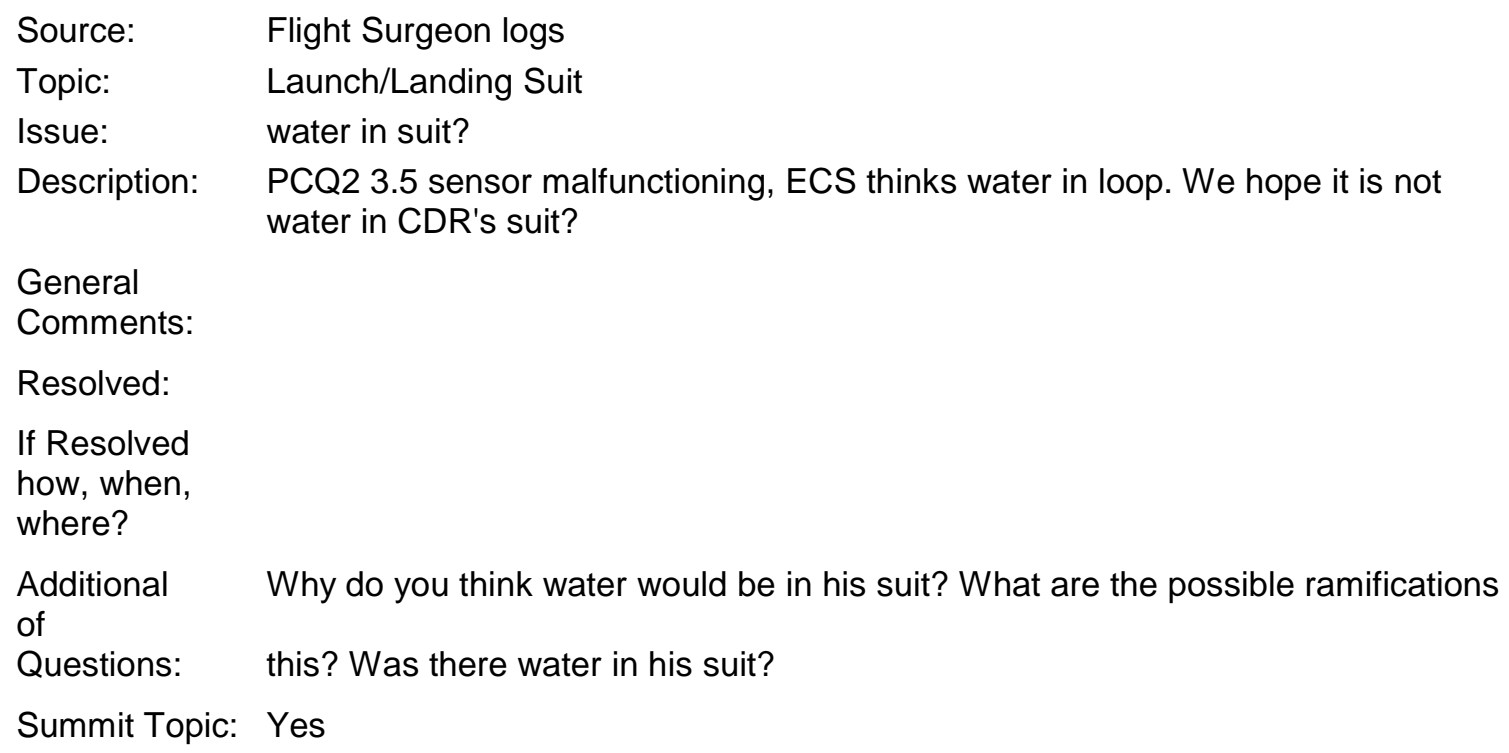

General

Comments:

Resolved:

If Resolved

how, when,

where?

Additional Why do you think water would be in his suit? What are the possible ramifications

of

Questions: this? Was there water in his suit?

Summit Topic: Yes 


\title{
Appendix A Apollo Summit Non-Attributable Report
}

\author{
Source: $\quad$ Flight Surgeon logs \\ Topic: $\quad$ Launch/Landing Suit \\ issue: $\quad$ Temp \\ Description: CSM cabin temp 58 suit inlet temp 39.5 glycol temp control failed to regulate \\ General this seems horribly cold didn't this adversely affect the crew \\ Comments: \\ Resolved: \\ If Resolved \\ how, when, \\ where? \\ Additional How did these temperatures affect the mission? It seems as if there were wild \\ Questions: temperature changes do you think this affected how you felt? \\ Summit Topic: Yes

\begin{abstract}
Source: $\quad$ Medical Mission Debriefs
Topic: Lunar Dust

Issue: dust problems

Description: $\quad$ 2: CDR: "We were quite dirty, lot of dust on suits, particularly up the legs to the knees, and the gloves and arms. "Pretty much black like we'd been working in be able to remove helmet because of floating dust in zero $\mathrm{g}$

LMP: slept on floor, "wiped up the floor with your suit

Crew brought back the outer suit liner and the EVA gloves. When gloves were removed after EVA, hands became contaminated with dust. also got dust particles in the eyes, but it was not difficult to clear the eyes. Wiped down with tissue or towels. Took several days to get fingernail bed clean. Before returning to the CM, stripped down and wiped off with a wet towel.
\end{abstract} \\ powdered graphite..." Seemed to be clinging to us." Banged feet against the strut \\ and a lot of dust fell off our feet. Concerned that once back in orbit they would not \\ General \\ Comments: \\ Resolved: No \\ If Resolved \\ how, when, \\ where? \\ Additional \\ Questions: \\ Summit Topic: Yes
}




\section{Appendix A \\ Apollo Summit Non-Attributable Report}

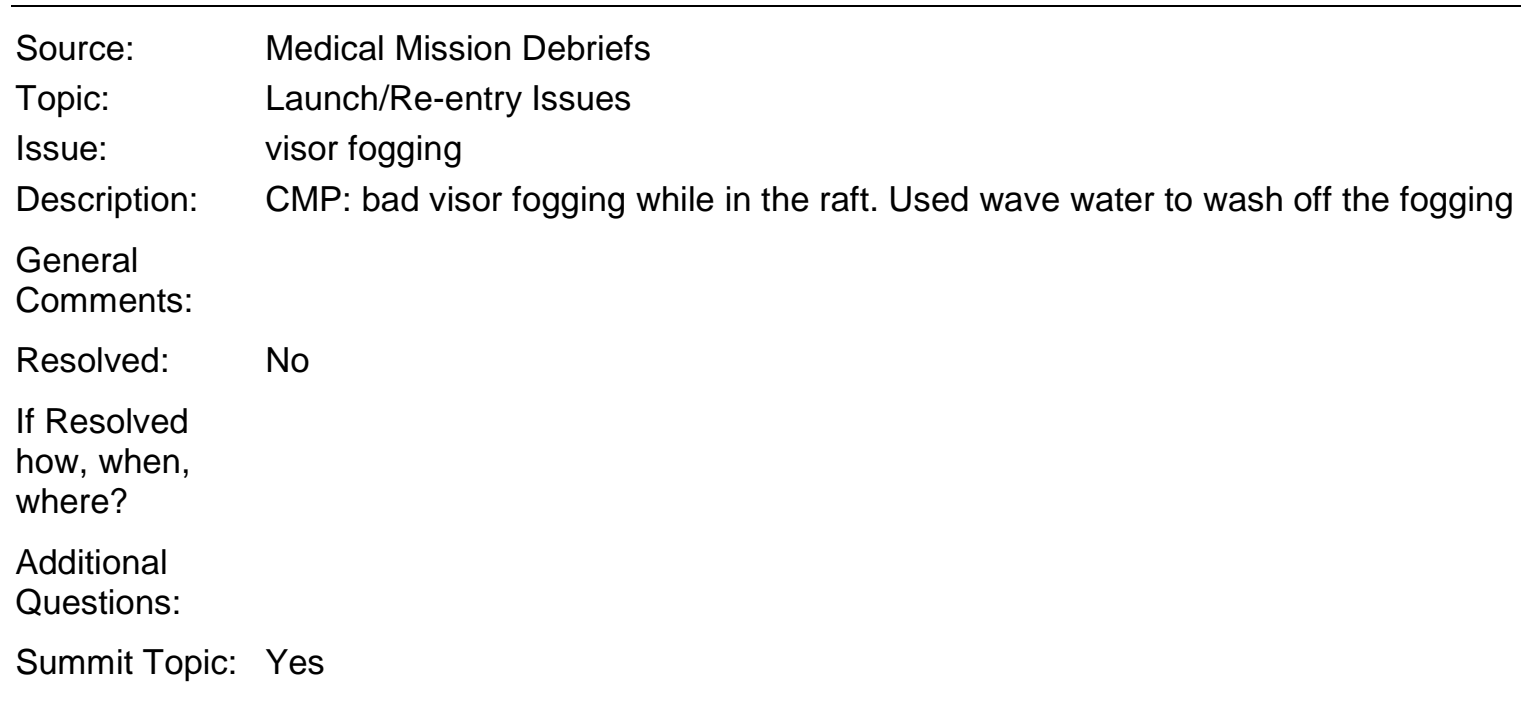

$\begin{array}{ll}\text { Source: } & \text { Medical Mission Debriefs } \\ \text { Topic: } & \text { Launch/Re-entry Issues } \\ \text { Issue: } & \text { Landing Observations } \\ \text { Description: } & \text { a) Crew complained of fogging of vision while waiting on BIG raft post landing. } \\ & \text { They were unable to clear it from the outside } \\ & \text {-Crew was concerned about safety in transfer from raft to cage } \\ & \text { b) Almost a quart of sea water entered into each leg from the BIG } \\ & \text { c) Crew would like to do away with the BIG } \\ \text { d) Benzedrine taken for MS upon landing } \\ \text {-no MS experience on landing }\end{array}$

General

Comments:

Resolved:

If Resolved

How, when,

where?

Additional Did the crew suffer any post-landing illnesses?

Questions:

Summit Topic: Yes 


\title{
Appendix A Apollo Summit Non-Attributable Report
}

\author{
Source: $\quad$ Medical Mission Debriefs \\ Topic: Launch/Landing Suit \\ Issue: Suit Observations \\ Description: a) Crew did not experience tumbling sensation getting into or out of the suit as \\ other crews had \\ b) Commander reported his hands "got wet and red as blood" during lunar EVA \\ c) Crew was able to bend down to knees and get up without problem \\ General \\ Comments: \\ Resolved: \\ If Resolved \\ how, when, \\ where? \\ Additional Were the Commander's hands getting wet and red as blood a suit fit issue? Did \\ this \\ Questions: $\quad$ cause a problem? Or LMP? \\ Summit Topic: Yes
Source: $\quad$ Medical Mission Debriefs
Topic: $\quad$ Lunar Dust
Issue: Lunar Dust Observations
Description: Crew reports that they were quite dirty with dust upon return to LM
1. Suits were covered with dust to the knees and gloves
2. Dust seemed to settle on floor in LM even upon return to microgravity
3. Crew did not need to don their helmets in microgravity
4. Very fine grained material
5. Dust covered the gloves and was rubbed off onto their hands. They were not wearing glove liners
6. Crew would wipe off with tissue, then wet a towel and wipe off following removing the LPG
7. Dust was not noticeable in CM following the LM docked \\ General \\ Comments: \\ Resolved: \\ If Resolved \\ how, when, \\ where? \\ Additional Should crews wear glove liners to prevent getting dust on their hands? Is there \\ plans for \\ Questions: containing dust? i.e., carpeting? \\ Should crew some how wash off before returning in LM? \\ Summit Topic: Yes
}




\section{Appendix A \\ Apollo Summit Non-Attributable Report}

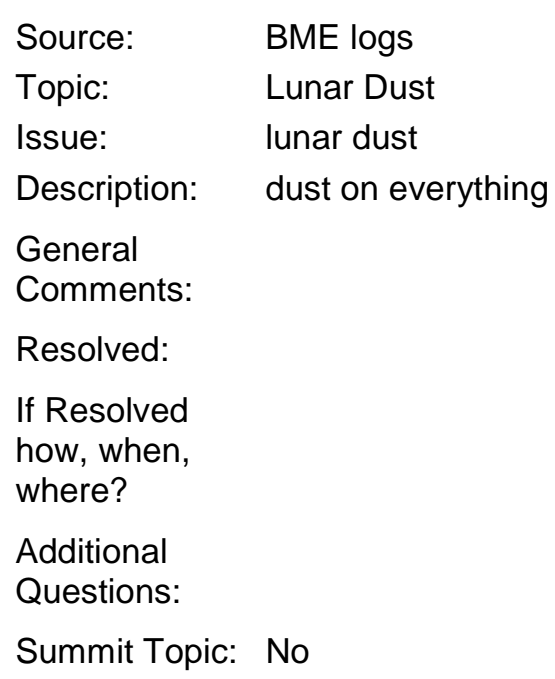

Additional

Questions:

Summit Topic: No

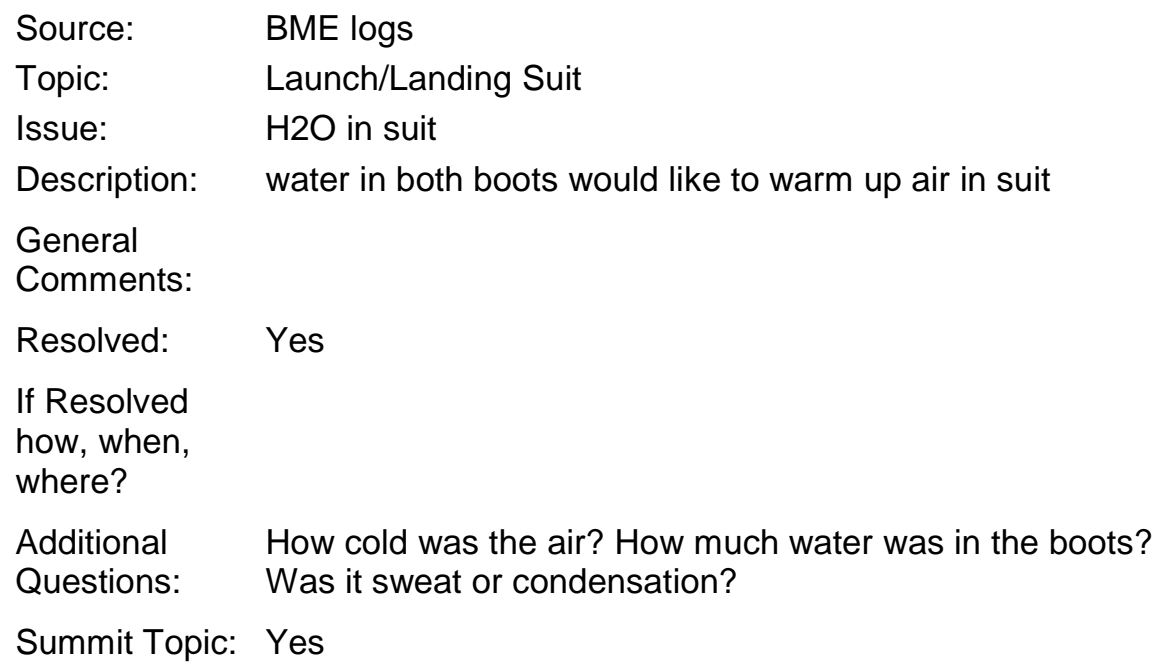

\section{General \\ Comments: \\ Resolved: \\ If Resolved \\ how, when, \\ where?}

Source: $\quad$ BME logs

Topic: Launch/Landing Suit

Issue: $\quad \mathrm{H} 2 \mathrm{O}$ in suit

Description: $\quad \mathrm{H} 2 \mathrm{O}$ in suit may just be cold air causing sensation of liquid against the skin.

Additional How cold air accounts for $\mathrm{H} 2 \mathrm{O}$ in the suit? How cold was the air. Was it a Questions: problem?

Summit Topic: Yes 


\title{
Appendix A Apollo Summit Non-Attributable Report
}

\author{
Source: $\quad$ Flight Surgeon logs \\ Topic: Launch/Landing Suit \\ Issue: suit temp \\ Description: Suit Temp \\ General \\ Comments: \\ Resolved: \\ If Resolved \\ how, when, \\ where? \\ Additional What was the expected and allowable suit temperatures? \\ Questions: \\ Summit Topic: Yes \\ Source: $\quad$ Flight Surgeon logs \\ Topic: Launch/Landing Suit \\ Issue: pressure change \\ Description: Suit change in pressure sensor failure \\ General \\ Comments: \\ Resolved: \\ If Resolved \\ how, when, \\ where? \\ Additional What caused this? \\ Questions: \\ Summit Topic: Yes

\section{Source: $\quad$ Flight Surgeon logs} \\ Topic: Launch/Landing Suit \\ issue: $\quad$ water in suit \\ Description: lots of water in his boots and shirt hoses \\ General this continues to be a problem and a concern this was also a problem in Apollo11 \\ Comments: \\ Resolved: \\ If Resolved \\ how, when, \\ where? \\ Additional how did the design changes that took place after Apollo 11 not fix the problem \\ Questions: that was there on apollo 11. \\ Summit Topic: Yes
}




\title{
Appendix A Apollo Summit Non-Attributable Report
}

Source: $\quad$ Flight Surgeon logs

Topic: Launch/Landing Suit

Issue: $\quad$ water in suit

Description: "where is all the water coming from in my suit loop. I think it's cold air. The air is extremely cold with moisture In it, Making helmet fog.

General

Comments:

Resolved:

If Resolved

how, when,

where?

Additional What happened to the suit to cause this malfunction? How did this affect the Questions: mission?

Summit Topic: Yes

$\begin{array}{ll}\text { Source: } & \text { BME logs } \\ \text { Topic: } & \text { Launch/Landing Suit } \\ \text { Issue: } & \text { HR } \\ \text { Description: } & \text { HR to } 160 \text { during suit integrity check problem } \\ \text { General } & \text { Could this have been a bad connection? } \\ \text { Comments: } & \end{array}$

Resolved:

If Resolved how, when, where?

Additional

Questions:

Summit Topic: No

\author{
Source: $\quad$ Flight Surgeon logs \\ Topic: $\quad$ Launch/Landing Suit \\ Issue: stale air \\ Description: air is getting stale in this suit \\ General \\ Comments: \\ Resolved: Unknown \\ If Resolved \\ how, when, \\ where? \\ Additional \\ Questions: \\ Summit Topic: Yes
}




\title{
Appendix A Apollo Summit Non-Attributable Report
}

\author{
Source: $\quad$ Flight Surgeon logs \\ Topic: Launch/Landing Suit \\ Issue: leaking \\ Description: suit leaking \\ General no more info on this if it was beyond what was expected \\ Comments: \\ Resolved: \\ If Resolved \\ how, when, \\ where? \\ Additional Did the suit routinely leak more than expected \\ Questions: \\ Summit Topic: Yes
Source: $\quad$ Medical Mission Debriefs
Topic: $\quad$ Launch/Re-entry Issues
Issue: heaviness feeling and 'footing'
Description: CDR: for about 30 seconds after landing, after un-strapping and on the LEB, felt heavy the first couple of steps. Did 10-12 deep knee bends and "was right back home again." Never felt heaviness again. Never felt light-headed
LMP: had fewer tasks during re-entry $g$ and was very aware of g-forces. Also felt heaviness after splashdown, which evolved very rapidly. While exiting the helicopter on the ship, "didn't have the sureness of footing that I would like to have. Never felt light-headed. Footing was sure within an hour: Stumbled once on way to the Medical quarantine facility. Never had mobility problems like the Russians had after their 8 days. \\ General \\ Comments: \\ Resolved: \\ If Resolved \\ how, when, \\ where? \\ Additional \\ Questions: \\ Summit Topic: Yes
}




\section{Appendix A Apollo Summit Non-Attributable Report}

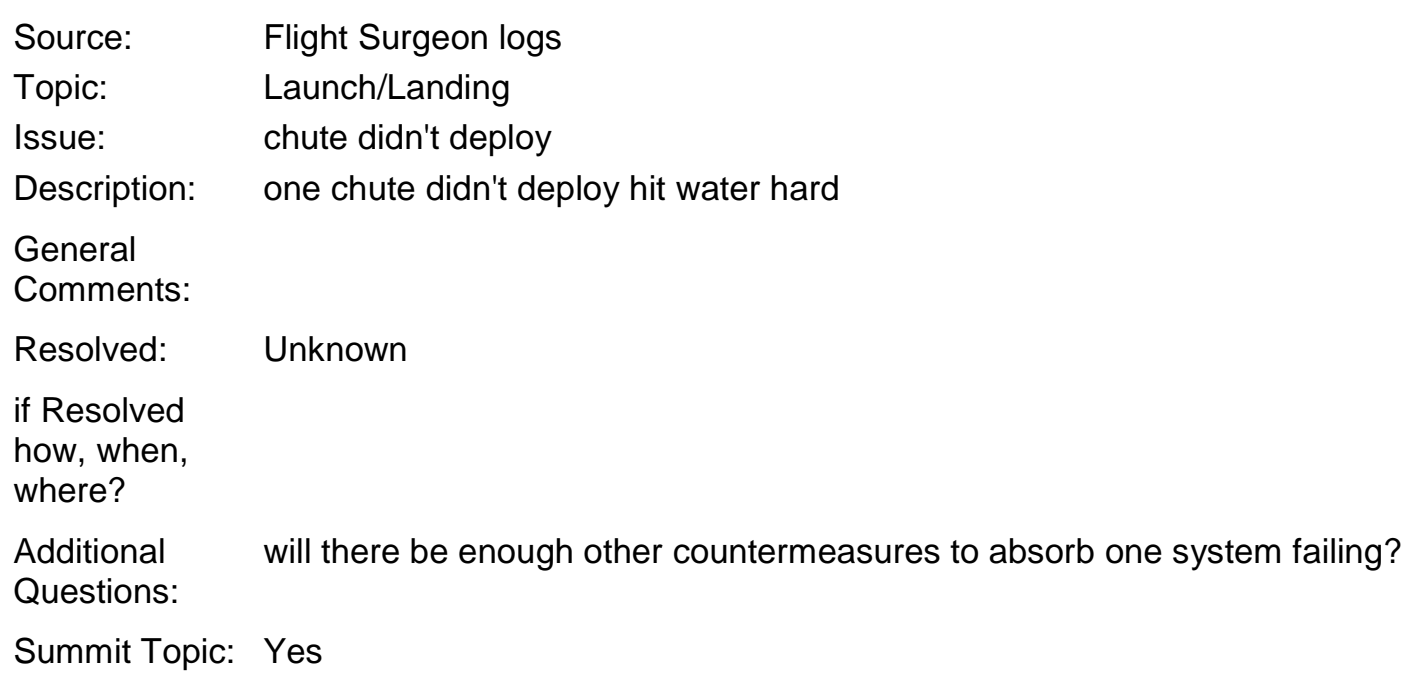

Source: $\quad$ Flight Surgeon logs

Topic: Launch/Landing Suit

Issue: pressure leak

Description: found 0.3 psi leak over 1 min rechecked to be .1 psi leak

General

Comments:

Resolved:

If Resolved

how, when, where?

Additional

Questions: What is the source of the leak?

Summit Topic: Yes

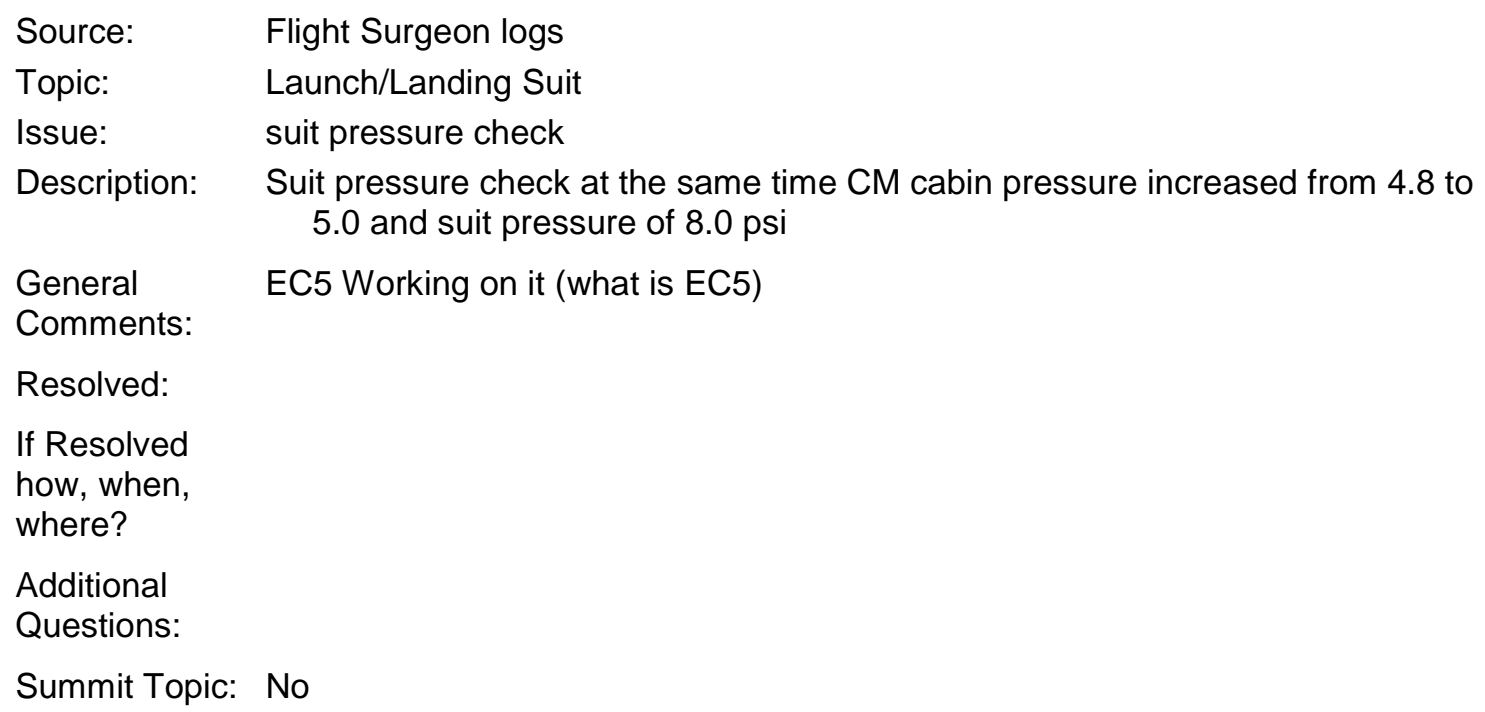




\section{Appendix A Apollo Summit Non-Attributable Report}

Source: $\quad$ Flight Surgeon logs

Topic: Launch/Landing

Issue: Suit condensation

Description: Condensation reported in suit

General

Comments:

Resolved:

If Resolved

how, when,

where?

Additional Was this a problem even though it has been around for several of the Apollo Questions: missions?

Summit Topic: Yes

Source: $\quad$ Medical Mission Debriefs

Topic: $\quad$ Launch/Re-entry Issues

Issue: $\quad$ adaptation to $1 \mathrm{~g}$

Description: GMP: 5 minutes to adjust to $1 \mathrm{~g}$

CDR: 5-10 minutes adjust to $1 \mathrm{~g}$. No vestibular feeling at all, On the helicopter, everyone put their flying suit on and were stable enough to stand on one leg while doing it. Did notice the ship motion which took several hours to adapt to.

General

Comments:

Resolved:

If Resolved

how, when,

where?

Additional

Questions:

Summit Topic: Yes 


\section{Appendix A \\ Apollo Summit Non-Attributable Report}

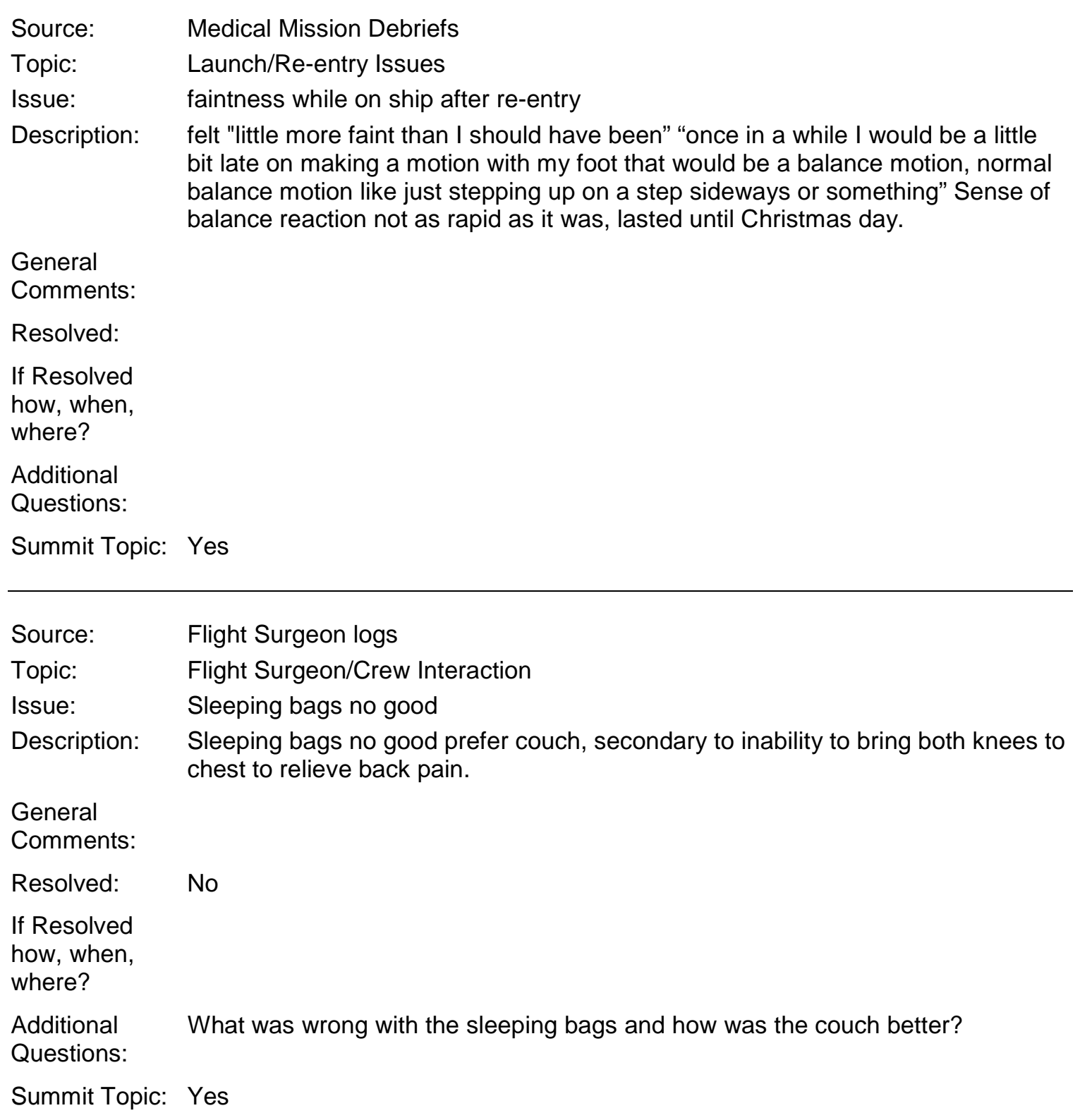




\section{Appendix A Apollo Summit Non-Attributable Report}

Source: $\quad$ Flight Surgeon logs

Topic: $\quad$ Flight Surgeon/Crew Interaction

Issue: $\quad$ Cold symptoms treatment

Description: Crew asked about using Rx if symptoms of sinus drainage and ear pain. FS

General concerned about lack of fever to diagnose a sinus infection

Comments:

Resolved: $\quad$ Advised crew to continue nasal decongestants. No antibiotics without fever

If solved

how, when,

where?

Additional Will our medical approach differ for exploration missions from what we see now?

Questions:

Summit Topic: Yes
Source: $\quad$ Medical Mission Debriefs
Topic: $\quad$ Flight Surgeon/Crew Interaction
Issue: $\quad$ Crew Observations
Description: a) Crewmember felt surgeon was not concerned about in-flight Illness (cold)
b) Limit discussion of problems to individuals who are intimately familiar with the problem and the solution (problem with lack of PMC)
c) "Communications were bad because too many people got into the act (Hot Biomed harness)
d) Crewmember encouraged FS to act as more of an advocate of the crew than "as an experiment"-with regards to the flight plan demands on the crew. (see General comments)
e) Crew concerned FS was withholding antibiotics for sinus infection.

$\begin{array}{ll}\text { General } & \text { Apparently, the crew was asked to do an unscheduled TV show-Crewmember } \\ \text { Comments: } & \text { saw that two other crewmembers refused to do it. Surgeon needs to be sensitive } \\ \text { to that. }\end{array}$

Resolved:

If Resolved

how, when, where?

Additional What was the PMC schedule for this mission? *Notes scribbled on the side of FS Questions: Log possibly at 97:23 as PMC with crew health status reported.

Summit Topic: Yes 


\title{
Appendix A Apollo Summit Non-Attributable Report
}

\author{
Source: $\quad$ Medical Mission Debriefs \\ Topic: $\quad$ Flight Surgeon/Crew Interaction \\ Issue: $\quad$ Crew Observations \\ Description: a) Logging $\mathrm{H} 2 \mathrm{O}$ use is a waste of time. Just remind the crew periodically that \\ space flight can dehydrate you and drink $\mathrm{H} 2 \mathrm{O}$ frequently \\ b) Logging food usage is a waste of time. The crew ate when they wanted, what \\ they wanted and were too busy to log everything \\ c) Crew photos -naked -were objectionable. \\ General \\ Comments: \\ Resolved: No \\ If Resolved \\ how, when, \\ where? \\ Additional \\ Questions: \\ Summit Topic: Yes \\ Source: $\quad$ BME logs \\ Topic: $\quad$ Flight Surgeon/Crew Interaction \\ Issue: Slosh or vibrations \\ Description: "Can really feel slosh peak rate @ $40 \%$ then little closure just before end" \\ General \\ Comments: \\ Resolved: \\ If Resolved \\ how, when, \\ where? \\ Additional Is this an expected difficulty? \\ Questions: \\ Summit Topic: No
}




\section{Appendix A Apollo Summit Non-Attributable Report}

Source: $\quad$ Flight Surgeon logs

Topic: $\quad$ Flight Surgeon/Crew Interaction

Issue: $\quad$ comment on docking ship

Description: "that wasn't a docking that was an eye test?"

General

Comments:

Resolved:

If Resolved how, when, where?

Additional What made it an eye test and how could we fix this?

Questions:

Summit Topic: Yes

Source: $\quad$ Flight Surgeon logs

Topic: Launch/Landing Suit

Issue: time allowed

Description: Not enough time for suiting up

General

Comments:

Resolved:

If Resolved

how, when, where?

Additional How much time was given and how much was needed?

Questions:

Summit Topic: Yes

\section{Source: $\quad$ Flight Surgeon logs}

Topic: $\quad$ Flight Surgeon/Crew Interaction

Issue: $\quad$ CSM with LM jettison

Description: "a lot of pitch yaw and roll in CSM with LM Jettison"

General

Comments:

Resolved:

If Resolved

how, when, where?

Additional Was this a usual occurrence?

Questions:

Summit Topic: Yes 


\section{Appendix A \\ Apollo Summit Non-Attributable Report}

Summit Topic: Yes

Source: $\quad$ Flight Surgeon logs

Topic: $\quad$ Flight Surgeon/Crew Interaction

Issue: fuel cell \#2 problems

Description: Fuel cell \#2 problems condenser exhaust cycling every on again every $10^{\text {th }}$ cycle triggers waster alarm. Changes in 8-10 degrees in temp

General

Comments:

Resolved:

If Resolved

how, when,

where?

Additional What were these problems and does this pose a problem?

Questions:

Summit Topic: Yes

Source: $\quad$ Flight Surgeon logs

Topic: $\quad$ Flight Surgeon/Crew Interaction

Issue: $\quad$ LIO2 canister change

Description: Crew advised of PCO2 of $3.0 \mathrm{mmHg}$, Canister change was not done?

General

Comments:

Resolved:

If Resolved

how, when, where?

Additional Was the LIO2 canister change a hassle that kept you distracted from other more Questions: valuable parts of the mission?

Summit Topic: Yes

\footnotetext{
Source: $\quad$ BME logs

Topic: $\quad$ Flight Surgeon/Crew Interaction

issue: lightning

Description: Thinks they were hit by lightning after take off

General

Comments:

Resolved:

If Resolved how, when, where?

Additional Are there abort procedures well within lightning stroke range?

Questions:
} 


\title{
Appendix A \\ Apollo Summit Non-Attributable Report
}

Summit Topic: Yes

Source: $\quad$ Flight Surgeon logs

Topic: $\quad$ Flight Surgeon/Crew Interaction

Issue: $\quad$ interior lights

Description: interior lights not being turned off by the hatch closure circuit

General

Comments:

Resolved:

If Resolved

how, when,

where?

Additional Was this problem addressed?

Questions:

Summit Topic: No

\author{
Source: $\quad$ Medical Mission Debriefs \\ Topic: $\quad$ Flight Surgeon/Crew Interaction \\ Issue: Medical Privacy Observations \\ Description: Crew objects strongly to the fact that they have no private medical conferencing \\ with F/S \\ -Any medication used for any condition is broadcast to the MCC/public \\ -Because of this, the normal "doctor-patient relationship" \\ SOLUTION: Dr. Berry will have a PMC between the crew -F/S in the AM and PM \\ General \\ Comments: \\ Resolved: \\ If Resolved \\ how, when, \\ where? \\ Additional \\ Questions: \\ Summit Topic: No
}




\section{Appendix A Apollo Summit Non-Attributable Report}

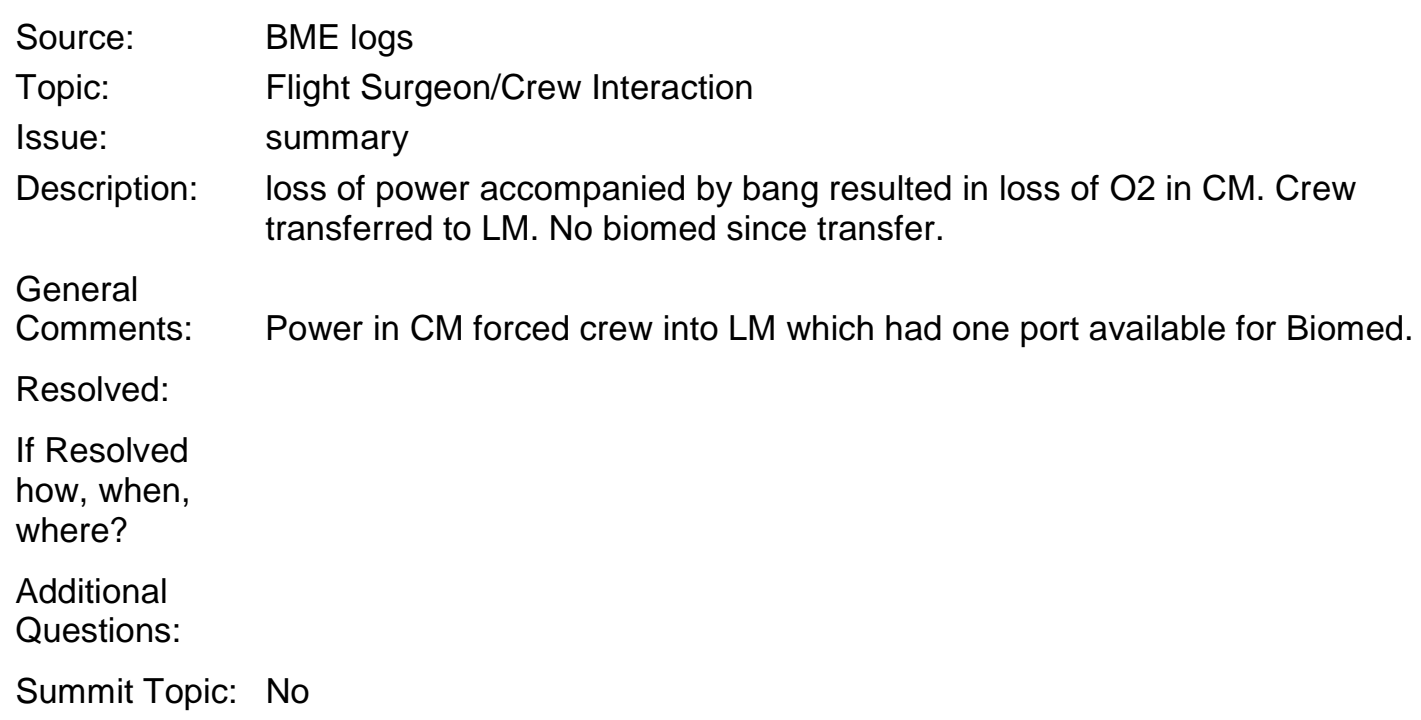

\section{Source: $\quad$ Flight Surgeon logs}

Topic: $\quad$ Flight Surgeon/Crew Interaction

Issue: $\quad$ waste dump

Description: waste water dump has ice crystals look like a snowstorm

General

Comments:

Resolved:

If Resolved

how, when, where?

Additional Did this cause navigation problems? If not why was it noted were the ice crystals Questions: concerning?

Summit Topic: Yes

\section{Source: $\quad$ BME logs}

Topic: $\quad$ Flight Surgeon/Crew Interaction

Issue: $\quad$ VCTA

Description: reports blockage of VCTA but feels that he has reserve space EVA

General

Comments:

Resolved:

If Resolved

how, when, where?

Additional

Questions: Can you have better explanation of this situation?

Summit Topic: Yes 


\section{Appendix A Apollo Summit Non-Attributable Report}

Source: $\quad$ Flight Surgeon logs

Topic:

Flight Surgeon/Crew Interaction

Issue:

$$
\text { tired }
$$

Description: $\quad$ Flight controllers say crew is tired-but sound good to flight surgeon-Flight controllers are tired, however

General It seems paramount that flight controllers are well rested.

Comments:

Resolved:

If Resolved how, when, where?

Additional

Questions: What was the crew's recollection of FC duty requirements and how would fatigue effect their performance?

Summit Topic: Yes

\section{Source: $\quad$ BME logs}

Topic: $\quad$ Flight Surgeon/Crew Interaction

Issue: $\quad$ FS denied request by FD

Description: $\quad$ FS denied request to ask crew PRD's by FD saying "no" radiation report today"

General

Comments:

Resolved:

If Resolved how, when, where?

Additional

Questions:

Summit Topic: No

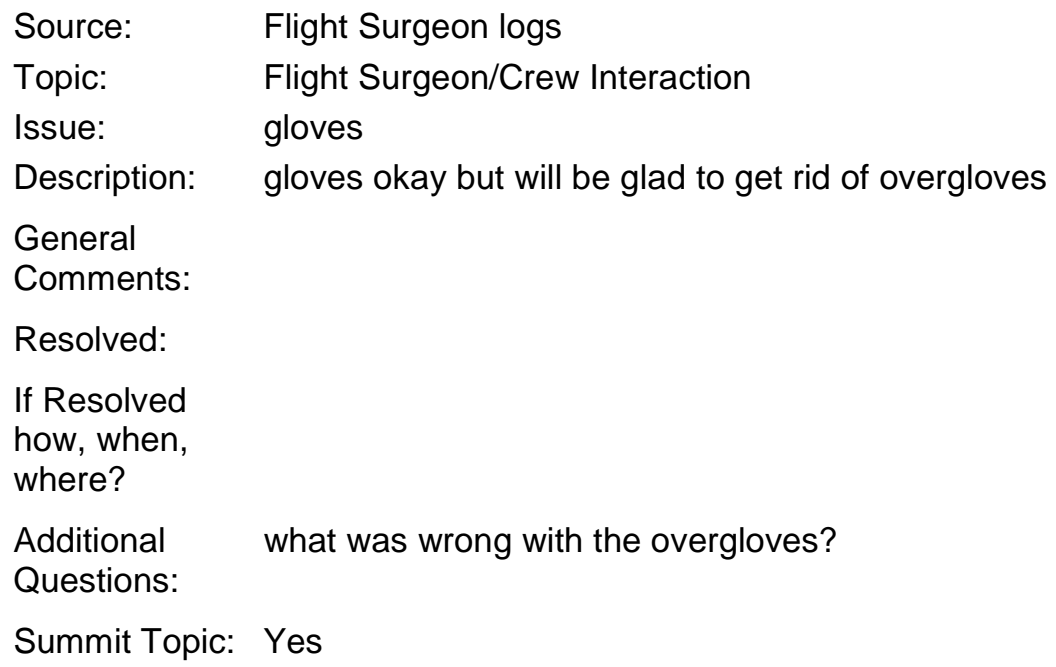




\section{Appendix A Apollo Summit Non-Attributable Report}

Source: $\quad$ Flight Surgeon logs

Topic: $\quad$ Flight Surgeon/Crew Interaction

Issue: $\quad$ FS commentary

Description: $\quad$ FS commentary -what about a procedure card to help with doing a clinical ECG or what might approximate a clinical ECG w/o augmented leads with our sternal harness?

General

Comments:

Resolved:

If Resolved

how, when,

where?

Additional Questions:

Summit Topic: No

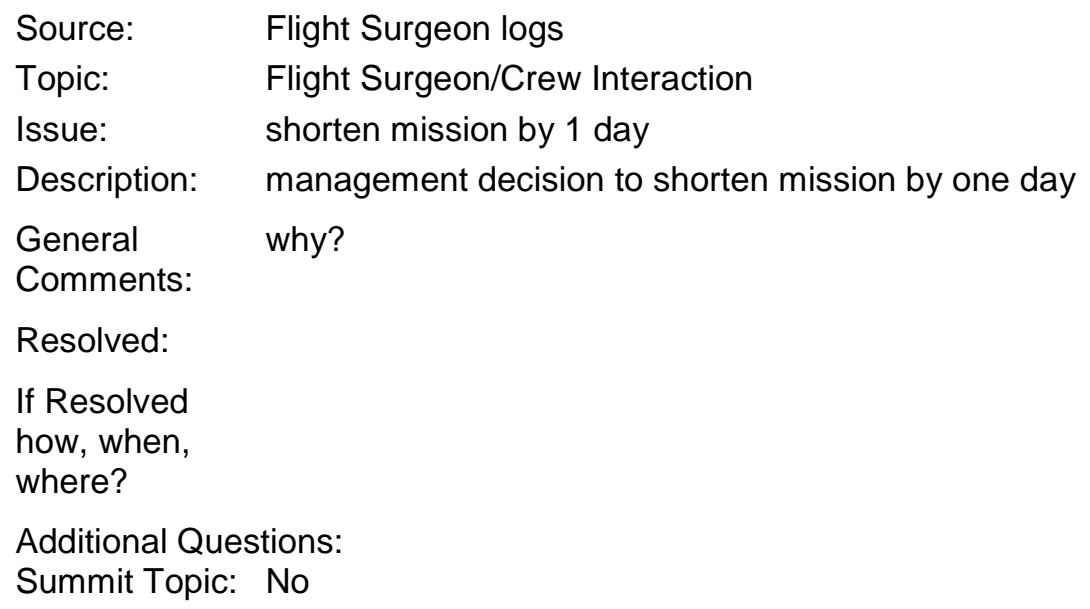

Additional Questions:

Summit Topic: No

Source: $\quad$ Flight Surgeon togs

Topic: $\quad$ Flight Surgeon/Crew Interaction

Issue: amount of citrus

Description: Mission commentary "CM's unhappy about amount of oranges and citrus they are eating and how it gave them the Farts!"

General

Comments: Crews were required to take more potassium in diet to mitigate cardiac dysrhythmia.

Resolved:

If Resolved how, when, where?

Additional

Questions:

Summit Topic: No 


\section{Appendix A Apollo Summit Non-Attributable Report}

Source: $\quad$ Flight Surgeon legs

Topic: $\quad$ Flight Surgeon/Crew Interaction

Issue: $\quad$ urine dump

Description: crew reports all urine collected in a bag and then dumped and it was difficult to know when the dump was complete Capcom said forget it but crewmember said neither cap or crew is running this program but he is and he wants start and stop times, $1 \mathrm{st}$ bag $7 \mathrm{sec} 2$ nd bag $28 \mathrm{sec} 3 \mathrm{rd}$ bag $16 \mathrm{sec}$ big big bag 1 min and $35 \mathrm{sec}$

General

Comments:

Resolved:

If Resolved

how, when, where?

Additional was the crew not using the urine dump each time they went to the bathroom? if Questions: $\quad$ so was it that bad? What was wrong with it?

Summit Topic: Yes

\section{Source: $\quad$ Flight Surgeon logs}

Topic: $\quad$ Flight Surgeon/Crew Interaction

Issue: $\quad$ IMU

Description: IMU failure

General

Comments:

Resolved:

If Resolved

how, when, where?

Additional How did the IMU fail? Was this common?

Questions:

Summit Topic: Yes 


\section{Appendix A Apollo Summit Non-Attributable Report}

Source: $\quad$ Flight Surgeon logs

Topic: $\quad$ Flight Surgeon/Crew Interaction

Issue: no landing

Description: No Circ. No landing this Rev b/c of CSM problem "operable locks? Operation drive motor is no go?

General cant really read hand writing? Kind of confused

Comments:

Resolved:

If Resolved

how, when,

where?

Additional

Questions:

Could you explain what caused this problem?

Summit Topic: Yes

\section{Source: $\quad$ Medical Mission Debriefs}

Topic: $\quad$ Flight Surgeon/Crew Interaction

Issue: Inadequate preflight

Description: Crew felt they were shut out from participation in preflight communication and planning of the interface of medical data collection requirements and their procedures, such as urine collection, fecal collection and sensor management.

General Dr, Berry retorted, "Well, XXXX, there were some tiny problems and we won't -I Comments: $\quad$ won't try to horse foot around here to see who did what to whom in that area." CMP: "I think you missed the point of what they were bitching about."

Resolved:

If Resolved how, when, where?

Additional

Questions:

Summit Topic: Yes 


\section{Appendix A Apollo Summit Non-Attributable Report}

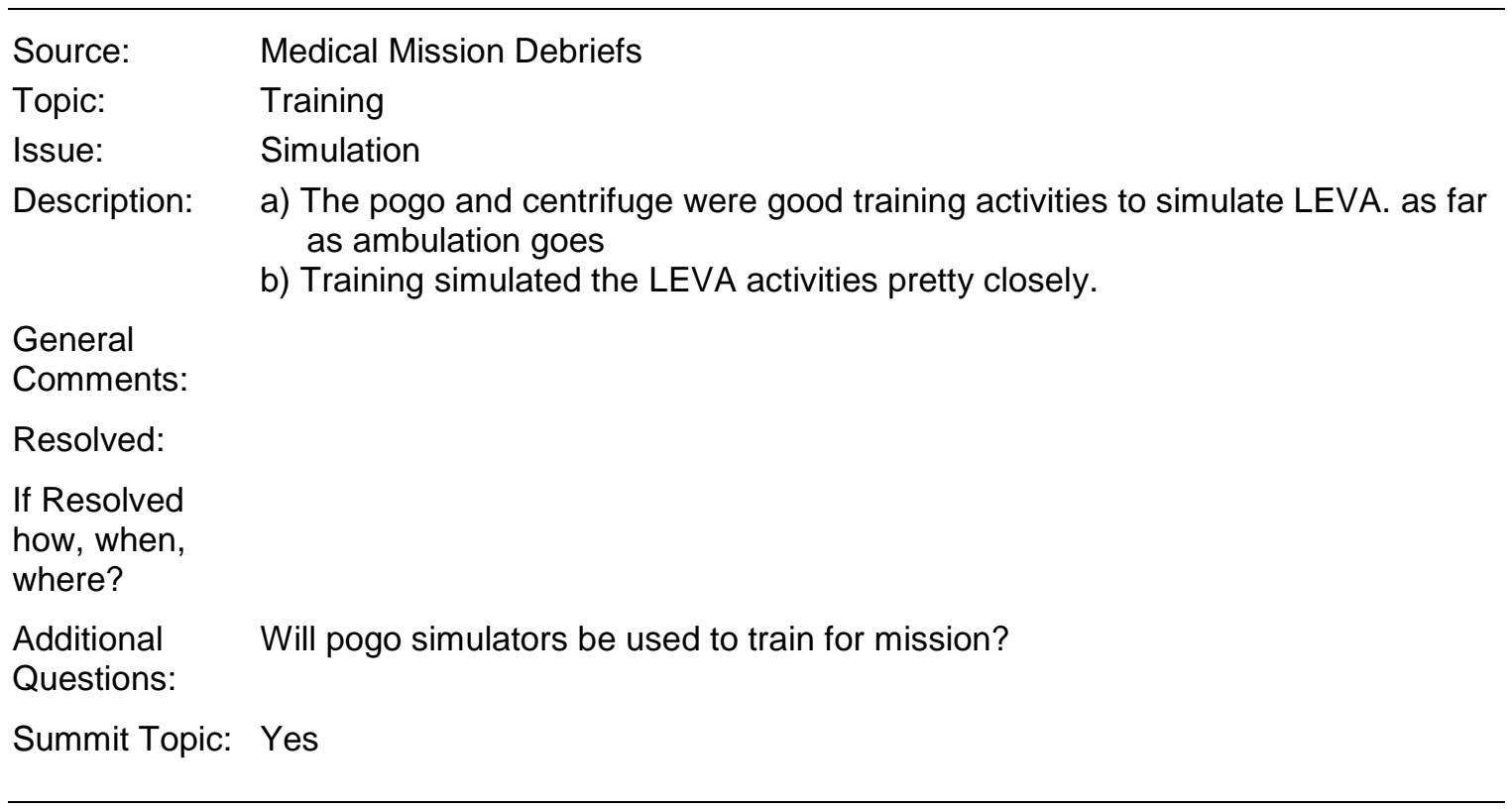

Source: $\quad$ Flight Surgeon logs

Topic: $\quad$ Training

Issue: docking problems

Description: 4th attempt to capture with probe unsuccessful

General

Comments:

Resolved:

If Resolved

how, when, where?

Additional Was the probe a hindrance in all Apollo missions during docking?

Questions:

Summit Topic: Yes

\begin{tabular}{ll}
\hline Source: & Flight Surgeon logs \\
Topic: & Training \\
Issue: & Docking \\
Description: & $\begin{array}{l}4 \text { unsuccessful docking try with probe try to dock with probe retracted "hard dock } \\
\text { finally accomplished" }\end{array}$
\end{tabular}

General Comments:

Resolved:

If Resolved

how, when,

where?

Additional Was docking with probe better than without?

Questions:

Summit Topic: Yes

Source: Medical Mission Debriefs 


\section{Appendix A Apollo Summit Non-Attributable Report}

Topic: $\quad$ Training

issue: $\quad$ EVA work vs sim training for EVA

Description: p. 25: LMP: An order of magnitude easier than our $1 G$ training. Never really felt tired. Stayed well-hydrated. Managed the plan!

CDR: easier to get around on the lunar surface, travel faster and easier. Did not feel uncomfortable at all during EVA-1. During EVA-2 was aware of workload effect on respiration rate. Did not feel 'overheated.' Noted a little sweating, probably limited by the Liquid Cooling Garment (LCG)--used medium flow in LCG when he felt sweaty or flush. Took short rests only on the steepest slopes of the crater, then proceeded "Never really felt like I was behind the power curve as far as the total workload was concerned."

CDR noted their 2-day workload was, in his opinion, "about as heavy a workload as anybody ought to do.

General Dr. Berry noted heart rates over 150 at times for the CDR and LMP during EVAs. Heart Comments: rates slowed with rest during the EVA.

LMP affirmed that if consumables were increased they could increase and extend their EVAs.

Resolved:

If Resolved

how, when,

where?

Additional

Questions:

Summit Topic: Yes

\section{Source: $\quad$ Medical Mission Debriefs}

Topic: $\quad$ Training

Issue: $\quad$ Education of crew on Med requirements and rationale

Description: CDR: Medical training has been left to the last seven weeks prior to launch. Crew has not understood the rationale or specifics of requirements such as why the need for repeated 24-hour urine collection and multiple blood draws, Suggested early in the training syllabus medical time should be allotted to define the medical requirements, their rationale and their goal, including the theoretical underpinning, the mechanics and the protocol. At this time in the program, "medical requirement" still have not been formalized in any document.

General

Comments:

Resolved:

If Resolved how, when, where?

Additional

Questions:

Summit Topic: Yes 


\section{Appendix A Apollo Summit Non-Attributable Report}

Source: $\quad$ Flight Surgeon logs

Topic: $\quad$ Flight Surgeon/Crew Interaction

Issue: $\quad$ Skylab drink bag

Description: $\quad$ "Skylab drink bag helpful because you can use it on all other drink bags

General

Comments:

Resolved:

If Resolved

how, when,

where?

Additional Is this drink bag still used? Why was it helpful?

Questions:

Summit Topic: Yes

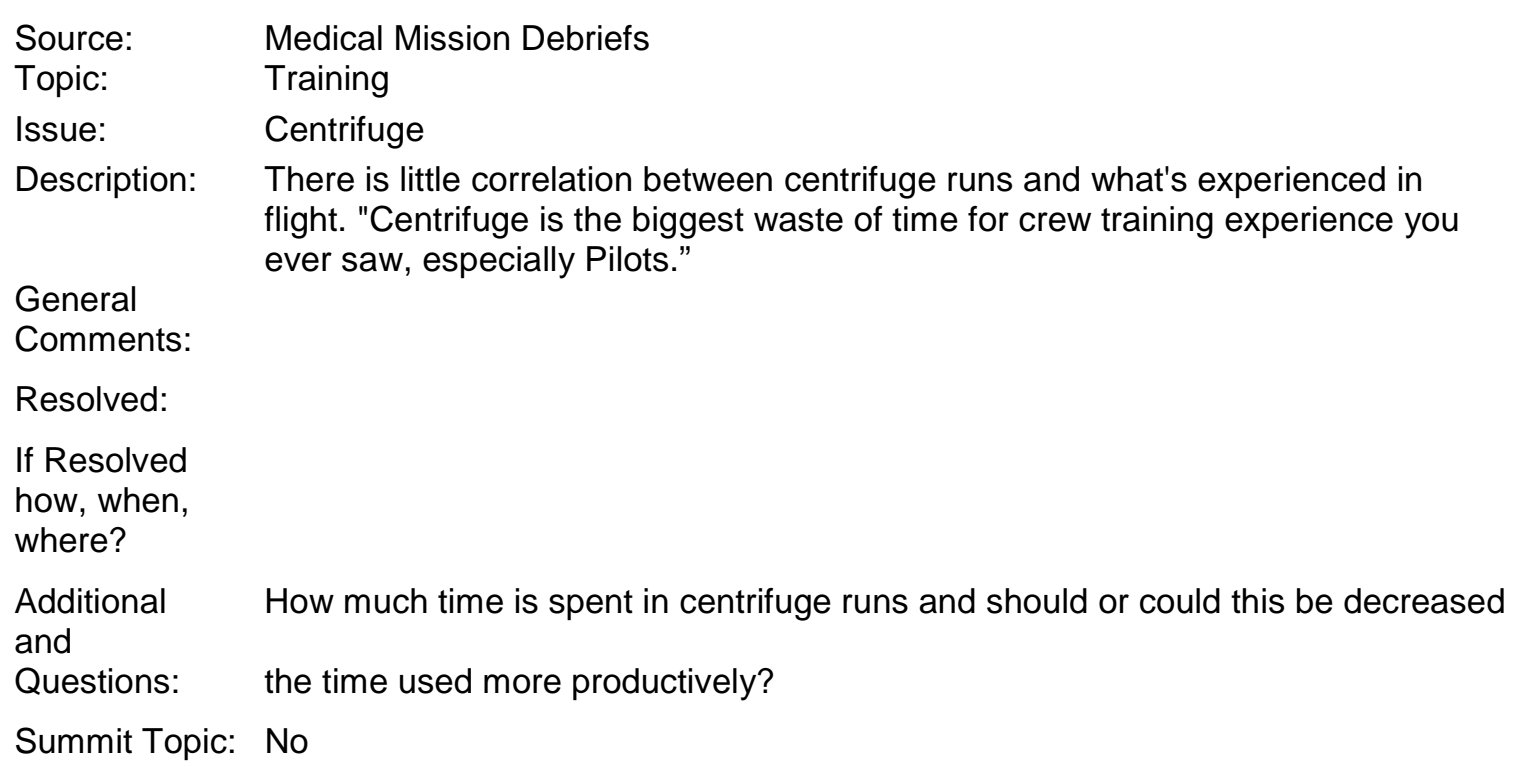




\title{
Appendix A Apollo Summit Non-Attributable Report
}

\author{
Source: $\quad$ Medical Mission Debriefs \\ Topic: $\quad$ Training \\ Issue: $\quad$ Fatigue \\ Description: a) The crew was very fatigued (mentally) prior to launch secondary to very busy \\ training schedule. Work day days typically began at 07600 and would end with \\ debrief at 2200-0000 each night. Approximately three weeks before launch. \\ General a) Solution: Train/work late for a fixed launch date or flexible launch date once \\ the work \\ Comments: is done. Other options is to skip non-essential meetings \\ Crew Recommendation: Crew recommended that the crew should use the 1st \\ couple of months before launch for simulation training only; including sleep/rest, \\ exercise and eating. That's it. Get all the technical briefings, systems briefings, \\ and physicals done at L-60 or L-90. Also having simulations as your only planned \\ event 60 day's before a mission would leave room for unplanned events i.e., \\ some days will require 10-12 hours for sims, other days only 3-4 hours \\ Resolved: \\ If Resolved \\ how, when, \\ where? \\ Additional What is "single air test training"? \\ Questions: \\ Summit Topic: Yes

\section{Source: $\quad$ Medical Mission Debriefs} \\ Topic: $\quad$ Training \\ Issue: $\quad$ Training Observations \\ Description: a) Work crew in simulator only 6 weeks before launch. \\ General Remove all but the most important safety briefings. Ensure that the crew can \\ have as \\ Comments: relaxed a schedule before their launch. \\ Resolved: \\ If Resolved \\ how, when, \\ where? \\ Additional \\ Questions: \\ Summit Topic: Yes
}




\section{Appendix A \\ Apollo Summit Non-Attributable Report}

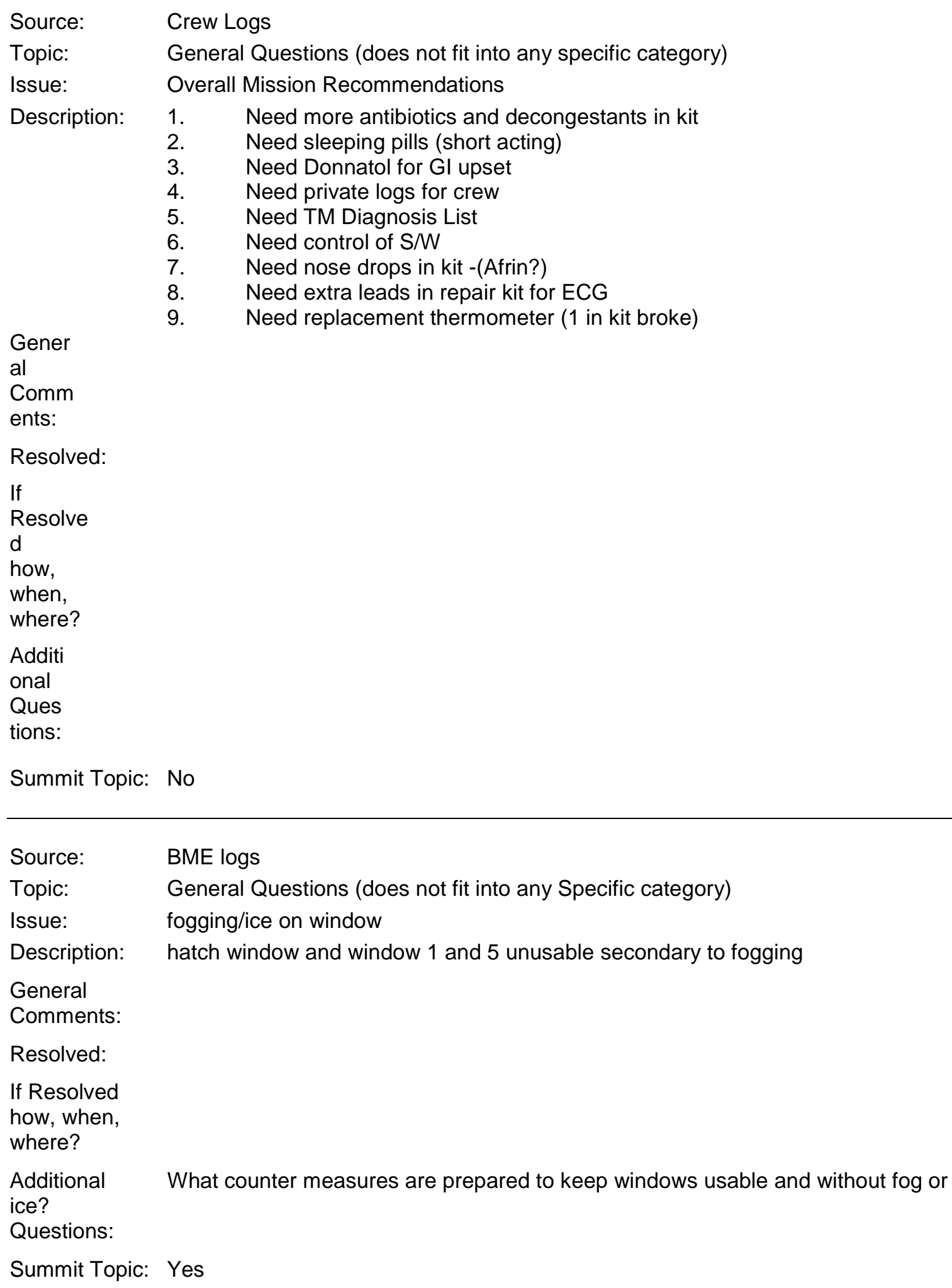

Summit Topic: No 


\section{Appendix A Apollo Summit Non-Attributable Report}

Source: $\quad$ Flight Surgeon logs

Topic: $\quad$ General Questions (does not fit into any specific category)

Issue: window heaters

Description: window heaters turned off because too hot

General

Comments:

Resolved:

It Resolved how, when, where?

Additional Do we need automatic turn off and turn on for window heaters?

Questions: $\quad$ Could this be a safety hazard?

How did you determine those window were too hot?

Summit Topic: Yes

Source: $\quad$ Flight Surgeon logs

Topic: $\quad$ General Questions (does

issue: $\quad$ S-IC vibrations

Description: Comments about S-IC vibrations

General

Comments: Crews concerned over vigorous shaking during stage S-11 phase

Resolved:

If Resolved how, when, where?

Additional Is this a normal occurrence?

Questions:

Summit Topic: No

Source: $\quad$ BME logs

Topic: $\quad$ General Questions (does not fit into any specific category)

Issue: $\quad$ CDR LMP prelaunch health

Description: CDR took ornade for slight injection of nasal mucosa LMP took ornade for slight injection of right TM

General there are some differences between this and FS logs report

Comments:

Resolved: $\quad$ Crew had minor nasal congestion prior to launch. Required oral decongestants.

If Resolved how, when, where?

Additional

Questions: 


\section{Appendix A \\ Apollo Summit Non-Attributable Report}

Summit Topic: No

Source: $\quad$ Flight Surgeon logs

Topic: $\quad$ General Questions (does not fit into any specific category)

Issue: pictures

Description: pictures help but not like seeing it

General

Comments:

Resolved:

If Resolved

how, when,

where?

Additional Is there any new data that would help prepare along with pictures and

topographic

Questions:

maps?

Summit Topic: No

Source: $\quad$ Flight Surgeon logs

Topic: $\quad$ General Questions (does not fit into any specific category)

Issue: Docking probe

Description: Docking Probe is hot

General Comments:

Resolved:

if Resolved

how, when,

where?

Additional What caused the docking probe to be hot? How hot was Hot? Was this common

on all

Questions: the flights?

Summit Topic: Yes

Source: BME logs

Topic: General Questions (does not fit into any specific category)

Issue: explosion

Description: loss of power and bang venting noted all crew HR went 60 to 125-130

General

Comments:

Resolved: Yes

If Resolved

how, when,

where?

Additional

Questions:

Summit Topic: No 


\section{Appendix A Apollo Summit Non-Attributable Report}

Source: $\quad$ Flight Surgeon logs

Topic: General Questions

Issue: switch failure

Description: launch system review complete early cut off in SII stage secondary to low combustion sensors to be activated and shut down

General

Comments:

Resolved: $\quad \mathrm{N} / \mathrm{A}$

If Resolved

how, when,

where?

Additional

Questions:

Summit Topic: No

Source: $\quad$ Flight Surgeon logs

Topic: $\quad$ General Questions (does not fit into any specific)

Issue: engine burn

Description: burn complete "not too much push accelerometer shows nothing"

General

Comments:

Resolved: $\quad$ N/A

If Resolved

how, when,

where?

Additional

Questions:

Summit Topic: No

\section{Source: $\quad$ Flight Surgeon logs}

Topic: $\quad$ General Questions (does not fit into any specific category)

Issue: $\quad$ CSM power

Description: $\quad$ CSM completely powered down, we will not know CO2 level in CM, splash down at 73 or $82 \mathrm{hrs}$, no problem with $\mathrm{O} 2$ plenty although $\mathrm{CO} 2$ limited

General Comments:

Resolved: Unknown

If Resolved

how, when,

where?

Additional

Questions:

Summit Topic: No

Source: $\quad$ Flight Surgeon logs 


\section{Appendix A \\ Apollo Summit Non-Attributable Report}

Topic:

Issue:

Description:
General Questions does not fit into any specific category)

CSM O2

CSM $3.54 \mathrm{lbs} \mathrm{O} 2=10 \mathrm{hrs}$

$3 \mathrm{lbs}=8 \mathrm{hrs}$

LM $63 \mathrm{lbs}$ rate of $.6 \mathrm{lbs} /$ hour

LM CO2 reserve with existing $\mathrm{LIOH}$ canister $57 \mathrm{hrs}$ at average rate

General

Comments:

Resolved:

If Resolved

how, when, where?

Additional

Questions:

Summit Topic: No

Source: $\quad$ Flight Surgeon logs

Topic: $\quad$ General Questions (does not fit into any specific category)

Issue: $\quad$ "probe investigations"

Description: Discussions of "probe investigation" utilizing TV, may wait till after they sleep

General

Comments: Probe investigation-will remove probe drouge and inspect-TV record with live TV it time lines to MCC

Resolved:

If Resolved

how, when,

where?

Additional

Questions:

Summit Topic: No 


\section{Appendix A \\ Apollo Summit Non-Attributable Report}

Source: $\quad$ Medical Mission Debriefs

Topic: $\quad$ General Questions (does not fit into any specific category)

Issue: $\quad$ transcript errors

Description: There are a number of transcript errors in the initial10 pages:

should be 'salt-depleting' rather than soft-depleting'

asymptotic should be 'acidotic'

positive nitrogen should be 'positive hydrogen'

General Extended discussion of how to use medical findings of return to preflight levels to

end NY

Comments: Times adverse stories and congressional negative reaction to manned flights. A rather rambling discourse.

Resolved:

If Resolved

how, when,

where?

Additional

Questions:

Summit Topic: No 


\section{APPENDIX B NON-ATTRIBUTABLE PANEL DISCUSSION \& POST-PANEL RESPONSES}

\section{7-9 June, 2006}




\section{Table of Contents}

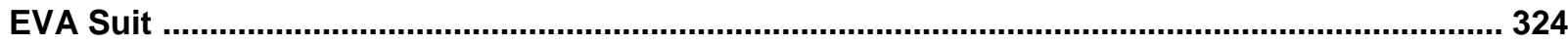

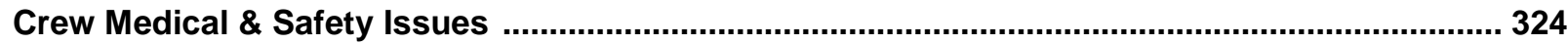

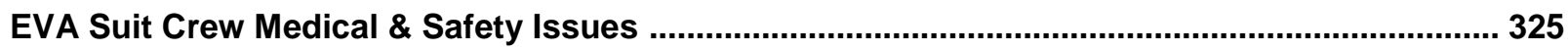

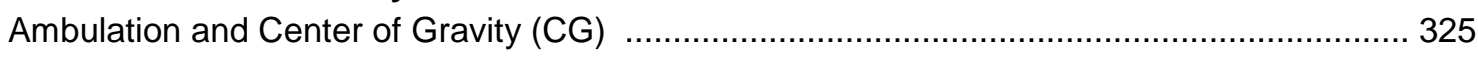

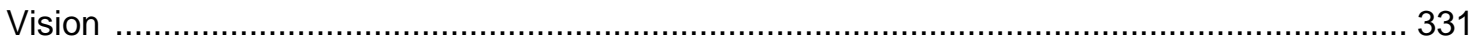

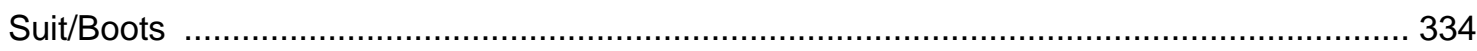

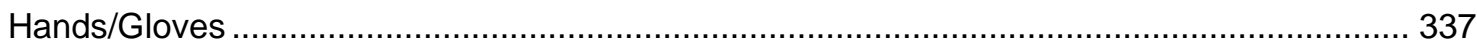

Physiology/Performance/Hydration/UCD/DCS/Thermal .................................................. 340

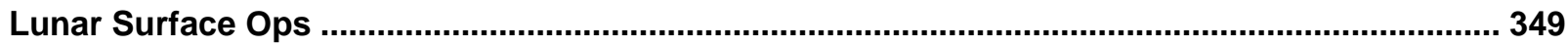

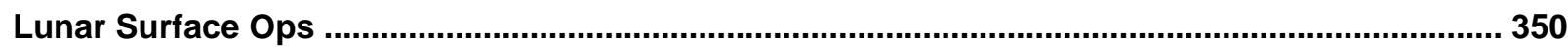

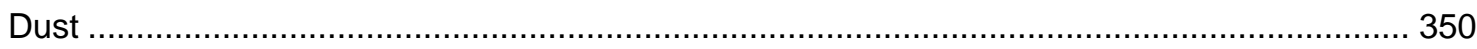

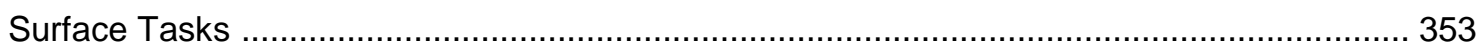

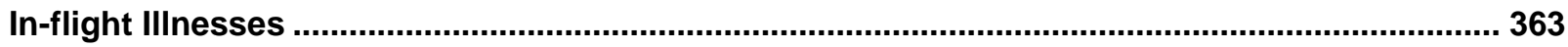

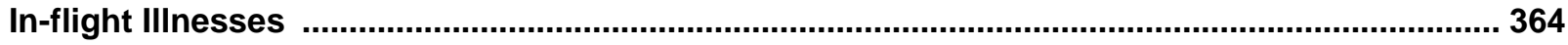

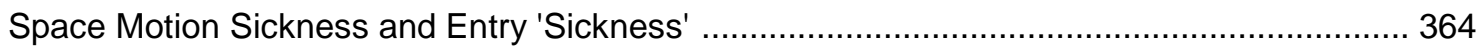

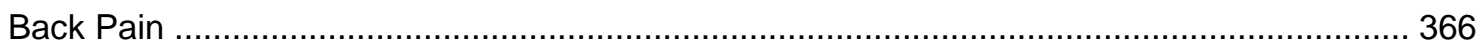

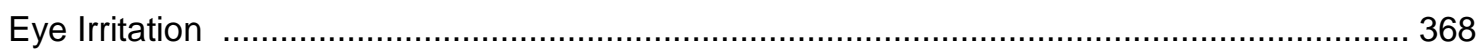

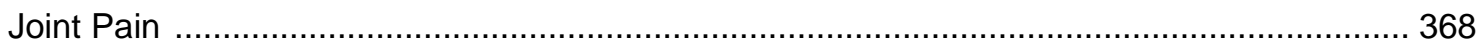

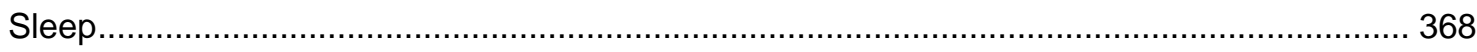

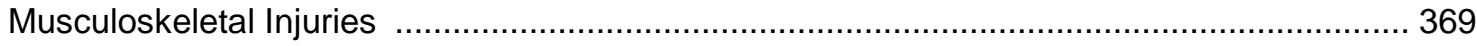

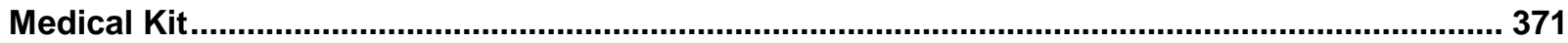

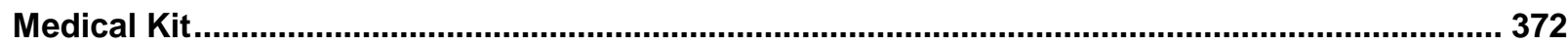

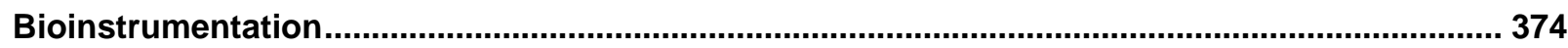

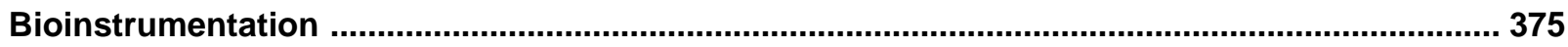

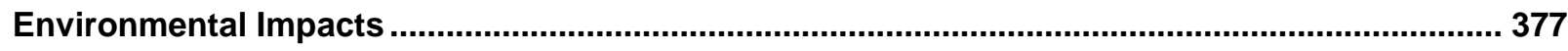

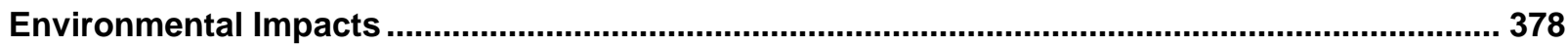

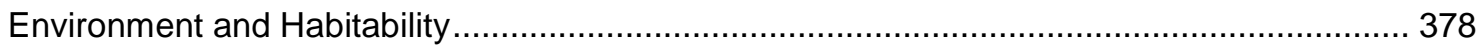

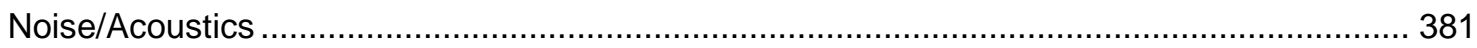

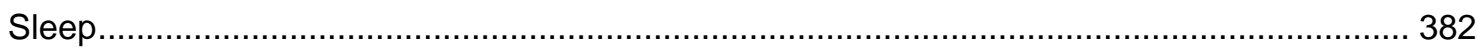

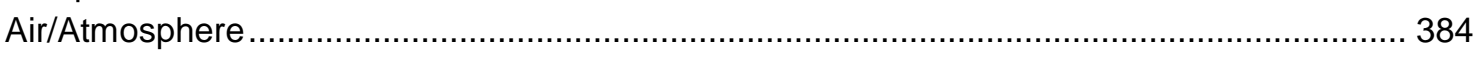

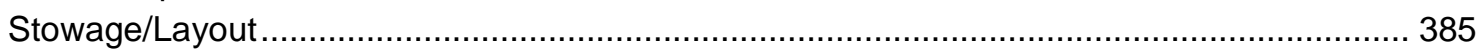

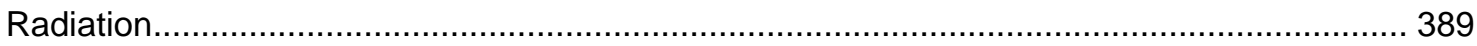

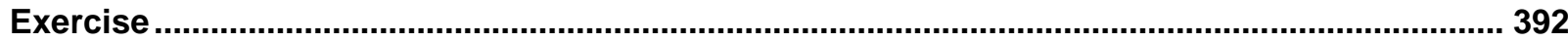

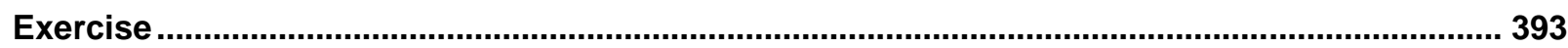

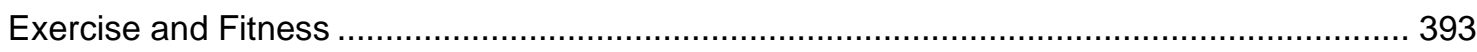

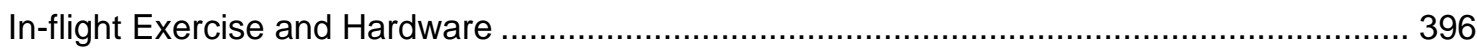

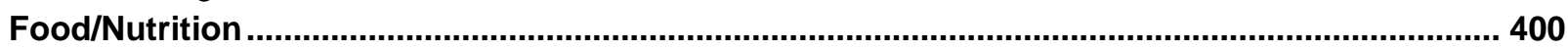

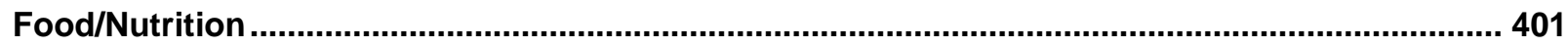

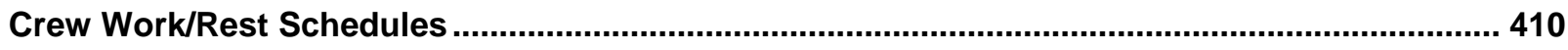

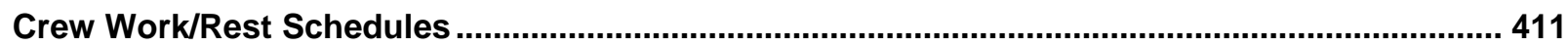

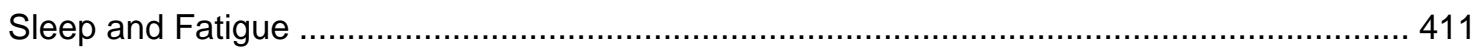

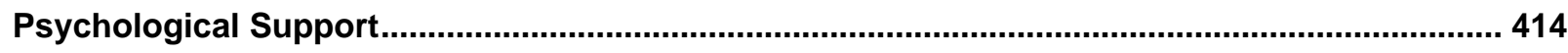

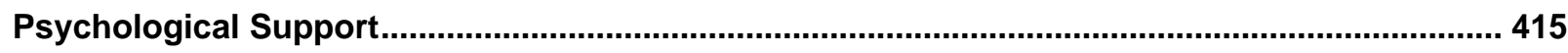

Crew Scheduling and Task Loading Crew Scheduling and Task Loading ................................ 417

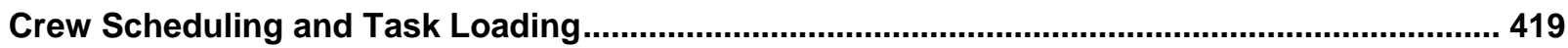




\section{EVA Suit}

\section{Crew Medical and Safety Issues}




\title{
EVA Suit Crew Medical \& Safety Issues
}

\author{
Ambulation and Center of Gravity (CG)
}

1. What do you recall about the CG of suit during walking vs. during stationary working? Would it have been better if the CG was low and forward vs. high and aft?

It probably would be better if CG was a little lower, but the human body will adapt regardless. Reducing the size and weight of the backpack would help solve the problem. Backpack and suit on Apollo weighed 194 pounds.

Reduce the mass of the suit by a factor of two, general mobility by a factor of four. Glove needs to be like a human hand.

Don't make moving the CG your primary priority. Move the CG only if it becomes convenient to do so while taking care of other issues like reducing the mass of the suit, etc. Human beings are very adaptable and we were certainly comfortable by the third excursion.

You automatically leaned forward when you were standing and you learned how to run at a fairly significant velocity with dynamic stability.

\section{Post-Summit Questionnaire Responses}

Soldiers for thousands of years put the weight on their backs.

2. Debriefs imply loping was the most biomechanically efficient form of movement. Was this in part from suit restrictions, or was it the most natural movement in 1/6 $\mathrm{g}$ ? Was the workload perceived as higher with walking slowly vs. quicker loping or hopping?

It was a natural response to take the easier way to move which was by loping or skipping. Always try to set up a dynamic motion.

The metabolic cost was less with skipping than with walking. It took more time and was more difficult to walk. It was very comfortable in the $1 / 6 \mathrm{~g}$ environment. Crewmembers adapted quickly and were comfortable within 5-10 minutes and got better with each excursion. It didn't interfere with the efficiency of operations, even in the early part of an excursion. There were many factors that cut efficiency, but that was not a major one.

Ambulation tended to be somewhat variable with each individual and whether they ultimately selected the most efficient way to do it will be determined in the tests that are being conducted. 
A cross-country ski technique was used by one crewmember that had quite a bit of cross-country skiing experience, but the films showed that others tended to develop the same method.

Some liked hopping or skipping instead.

There is an ongoing quantitative analysis looking at speed and efficiency using biomedical and photographic data from Apollo and this is a good effort. There are a number of sequences that can be used from the television data so crews can be advised on what might be the most energy-efficient way to move. With the equipment available now one can decide what will work best. You can give them good advice on that.

Post-Summit Questionnaire Responses

No responses

a. Obviously you preferred to hop and we're seeing in the testing that you're metabolically more efficient going at faster speeds. If you're trying to do detailed observations and so forth where you don't want to go fast, did you feel compromised in the suit? In other words, the suit is set up to go fast and it's optimized metabolically for that. Did you feel compromised when you were trying to work at a station or area to bend over and pick things up, etc?

Due to the design of the suit, you didn't normally bend over. That's why there was a need for tools with long handles. If you really wanted to get down close to something, you'd just go down as a push-up or lean against a rock.

Bending the knee was in the suit.

Some crewmembers mentioned that it was fatiguing to go uphill, which is probably because they were trying to bend their knees. We need a better knee joint.

\section{Post-Summit Questionnaire Responses}

CMP: his EVA was from the orbiting CSM. Neither weight nor mobility was a problem.

\section{b. Did you feel that the hip mobility was adequate?}

As you can see from the video footage, we were running, and the motion was primarily at the hip. It was easy and ankle mobility was good as well. The problem was primarily with the knee. 


\section{Post-Summit Questionnaire Responses}

No Responses

3. Did any muscles feel more fatigued than you would have expected, during ambulation, for the degree of exertion? If so, which muscle groups?

Hills seemed steeper and tougher to climb on the lunar surface and loping couldn't be used. It was fatiguing to walk uphill.

General fatigue was experienced, with thigh muscles specifically affected.

\section{Post-Summit Questionnaire Responses}

No responses

4. Was there any particular muscular strain noted when trying to slow down, or stop, from a quick lope?

No, however the stop needed to be anticipated.

Post-Summit Questionnaire Responses

No responses

5. Did you feel the suit was too heavy, too light, or about right?

It was substantially too heavy.

A lightweight suit would be easier to operate and much more comfortable.

Assembling the suit was a complicated process, partly due to the small area allocated in the module. If a larger area was available, it may have been easier.

Post-Summit Questionnaire Responses

No responses

a. What about the mass issue when it comes to your movement and your ability to negotiate turns and things of that nature? 
You adapt to the fact that you have a lot of inertia relative to normal walking or hiking on Earth, because the mass certainly hasn't changed and you have to be conscious of that.

Your total weight is only about sixty pounds, even though you're carrying around 370 pounds of mass. You adapt to that, but on the other hand it is one of the reasons why you work harder than you would like to on the moon. It takes energy to climb a slope or something like that. You'd like to use that energy for more productive tasks.

\section{Post-Summit Questionnaire Responses}

No responses

\section{b. What would you recommend as a target mass reduction?}

My target for mass reduction has always been a factor of $1 / 2$, but anybody can come up with a number.

There are some advantages to having some mass, particularly if you don't fix the flexibility of the knees. You can use that mass to help you bend the knees, but I assume that there will I be a much more mobile leg than we had during Apollo.

Thinking in terms of Mars, I hope we will build a new heritage for suits. There are other suit issues, since the $3 / 8$ gravity is a significant increase over $1 / 6$.

\section{Post-Summit Questionnaire Responses}

No responses

\section{c. Do you think you could have a suit that was too light? Picture yourself working on the moon with an ultra light suit. It strikes me that somewhere between microgravity and $1 / 6 \mathrm{~g}$ you're going to want some restraint to do work.}

Hypothetically you could have too little mass, but again you would adapt to that. If you need to push against something, you just lean more. You depend on the adaptability of the human beings to take advantage of whatever situation they are in and $1 / 6 \mathrm{~g}$ is an environment you can take advantage of.

It's something you can test, if it doesn't cost too much. Assume there would be an energy savings by reducing the mass. This would be a distinct advantage over anything else that might be a problem.

Reducing the mass of the suit is probably not an important goal, as much as improving the glove.

\section{Post-Summit Questionnaire Responses}


No responses

6. What were the characteristics of the suit walking up or down slopes? Any muscular strain noted?

Ambulating down slopes was difficult because it was hard to arch the back in the 4.26 psi pressure suit.

Hopping or parallel skiing was actually used to ambulate down slopes. It was necessary to be more cautious going downhill. If you lost control, you could possibly roll down the hill.

No muscle strain occurred while hopping or parallel skiing.

Post-Summit Questionnaire Responses

3.75 psi pressure suit (not 4.26)

7. What were the characteristics of the suit climbing up and down the ladder? Any muscular strain noted?

The ladder did not cause a problem, although glove improvements would have decreaded the concern of falling. It might be helpful to have a line attached to you so you wouldn't fall off. On the ladder, the suit issue was getting through the hatch.

\section{Post Summit Questionnaire Responses}

No responses

8. Based on experience with the LM ladder, would a taller ladder be a significant concern for falls and loss of balance? If so, how to mitigate.

Better glove performance is probably the most important, although we really didn't have any problems going up and down the ladder. We actually didn't use the steps, but would just grab the rails and slide down and you tend to pull yourself up with your hands more than with your feet. That was partly because of the low mobility in the knee.

If it is a weight trade-off of any significance, don't worry about the rails. The sides of the ladder provide all the gripping surface that you need.

We learned a lot about how to get equipment and ourselves in and out of the lunar module. At first, we used a clothesline or pulley system to get equipment out. We quickly abandoned that and just started dropping it to the person that was already on the ground. 
You start doing things in a much more efficient manner once you learn that height is not an issue in $1 / 6 \mathrm{~g}$. You just shove the equipment out the hatch and the other crewmember takes care of it.

Some equipment was hung with a strap on the side of the module.

The rung width and height on LEM were good.

Post-Summit Questionnaire Responses

No responses

9. Did the body postures required to navigate the LM hatch for ingress/egress cause undue muscular strain?

There was no strain on the back or other muscles and no residual soreness in any muscles. The back had to be arched and the heart rate went up.

The design of the hatch was the problem. Crewmembers had difficulty maneuvering through and one of the primary reasons was that the DSKY of the primary navigation and guidance was directly above the hatch. That is one thing you would hit and you didn't want to hit it very hard.

The suit was the max limit with the backpack. You had to arch your back to fit in and crewmembers had to help each other get through. The highest heart rate occurred while getting in and out of the hatch.

You need a hatch that is sized appropriately for an inflated $1 / 6 \mathrm{~g}$ pressure suit. If changes are made in terms of mass mobility, it will be a non-issue in the future.

If an airlock is used in the next lunar lander design, it may make ingress and egress easier and will also be a good idea from a dust control standpoint.

\section{Post-Summit Questionnaire Responses}

This hatch thing was obviously easier in $0 \mathrm{~g}$.

10. Debriefs implied resting in the suit while standing was comfortable. For future EVA ops, would some form of resting seated bench, or tripod support offer any advantage during rest periods (aside from sitting in a rover seat)?

The suit was self-supporting. You can rest your arms on the suit. 
There was no feeling of the need or opportunity to rest. Psychologically we didn't want to use the time because we were already behind.

A suggestion was made for suits to be custom-made for each individual crewmember. Need to have custom sized utility suits available as well.

\section{Post-Summit Questionnaire Responses}

No responses

\section{Did you experience any 'vertigo' during entry into a $1 / 6 \mathrm{~g}$ field, and with activities on the lunar surface?}

Minimal or no symptoms occurred.

However, the crews' remarked in the debriefs that they were "wobbly" upon initial contact with the lunar surface. This was short-lived and did not result in any compromise in their gait or ability to perform activities.

\section{Post-Summit Questionnaire Responses}

No responses

\section{What aspects of the suit were specifically troubling in performing} routine tasks with regard to workload and injury?

See information above regarding glove issues, suit mass, lack of flexibility in the knee joints.

\section{Post-Summit Questionnaire Responses}

The primary issues were glove tactility, suit mobility, contingency capabilities and crew controls.

- The great amount of energy needed to move around

- First attributed to the fact that mis-fitting suit joints were not co-located with the subject's joints

- Every motion required compressing the suit volume, a potentially fatiguing activity, this didn't turn out to be as bad as we'd thought but it took a long time to figure out what were our real issues.

- Our test program did not identify any knee joint problems -two reasons. 1) testing was done standing up, climbing stairs and walking. 2) given the weight of the EMU, having a semi-rigid knee joint actually made life easier for us.

\section{Vision}

1. Was the field of view out of the helmet adequate to see displays (in terms of near/far vision factors)? Was the view adequate to avoid trip hazards and maintain footing? 
Was the horizon reference in your peripheral vision adequate, with the side shades down, to ensure good vision and balance?

Everything was visible, however would have liked more peripheral vision. It was less efficient to have to turn your body rather than just turn your head. Peripheral vision should be improved. It did not interfere with functionality, just needed to turn your body.

It was difficult to know what the other crewmember was doing and you would have to turn from your task to view crewmember.

Visibility was also limited because you couldn't bend over easily and you had the camera in front of you. Hopefully we will have a far less bulky camera system that you can point and shoot. There was a tendency to work around those kinds of difficulties and we were able to do that, but they were still there.

\section{Post-Summit Questionnaire Responses}

More head movement would have been good

You don't have to be in lunar environment to know this

\section{a. You had mentioned that you couldn't see your feet and you adapted to that, but all things being equal would it be better if you could see your feet?}

It is always better to be able to see your feet, but when you're walking normally you usually are anticipating several steps ahead and you can do that on the moon, too.

\section{Post-Summit Questionnaire Responses}

Do you do this on Earth?

b. In deep sea diving, there are helmets that have a neck ring and it has a liner that fits to your head so you can turn you head, rather than your whole body. Do you think that feature would be worth looking into on a lunar suit?

Yes, look into that. It's always going to be more efficient to be able to turn your head.

\section{Post-Summit Questionnaire Responses}

Obvious 


\section{Given possible new in-helmet Heads Up Display (HUD) technology, would such displays be valuable, or potentially distracting and contribute to slips/falls?}

The complexities and desired information of the HUD should be considered and should not be a distraction. The checklist would be a nice feature to have.

The HUD and other fancy things are nice, but I question whether the complexity and reliability over long-term flight is really going to help or hinder. You have to have back-up systems that are somewhat manual. We had back-up systems right down the line. The more complicated you get with how you get information to the suited crewmember, the more risk you run of losing that system, so be careful.

Dr. Jones responded: We talked about simplicity and that's a really good point, but at the same time we're trying to diminish the overhead that the crew had and if you have to strain to look down at a cuff checklist, it's taking your time. If we could do it in a way that's pretty easy for you, we'd like to do that as long as it's reliable and tested.

Determine the benefit, cost, and reliability of the system. If it turns out that it's not reliable or when you start to work with it you find it can be done just as well with a cuff checklist as with a HUD, then change your approach.

A reliable HUD displaying consumable information or feedback when depleting key resources or medical information could be useful

\section{Post-Summit Questionnaire Responses}

Reliability is a big factor.

As the fighter pilot

\section{a. You mentioned that it would be nice to have the ability to call up displays, not that you wanted them constantly running with a lot of confusing information, but using an auditory cue call up information you wanted to see. Would this be helpful?}

Yes, the HUD primarily should be presenting the operational information that you need at the instant. If you want to see oxygen, you say "oxygen" and it appears.

\section{Post-Summit Questionnaire Responses}

Cost 


\section{$\underline{\text { Suit/Boots }}$}

1. What tasks were the most fatiguing to perform in the suit? What tasks required the most dexterity?

Tasks related to the hands were the most fatiguing.

Tasks requiring finger dexterity, such as holding anything tight (i.e., hammers, drills, changing camera settings), were especially difficult and fatiguing.

More flexibility in the glove is necessary.

\section{Post-Summit Questionnaire Responses}

Better gloves needed. Head mobility would reduce body motion.

2. Within the limits of the suit, did the posture used for kneeling activities cause back/leg strain? What level of knee padding would be advised for protection?

Kneeling used extra energy. If the suit was more flexible, kneeling would be used more often.

Kneeling allows you to be closer to whatever is being worked on; however, it could exacerbate the dust problem.

\section{Post-Summit Questionnaire Responses}

No responses

3. Were there any pinch points, pressure points, or areas of abrasion in the suit?

A lot of abrasion and scraping occurred in the hands and gloves and at times caused blood under the nails and pulled them off at the quick.

This occurred only on the lunar surface, not training.

The skin on the back of the knuckles was abraded in some crewmembers, never in training, only on the moon

This could have been incapacitating for future EVAs if had been doing repeated ones.

Fix the Gloves! -possibly due to lack of use of comfort glove and hands being soaked with sweat in the glove. 


\section{Post-Summit Questionnaire Responses}

No. On a 40 minute EVA from the CSM

4. Did the boots provide adequate traction and tactile feedback to your feet for maintaining good ambulation control?

There were no problems with the boots. There was no concern about ankle sprains or injuries with falls. You may find places on the moon where you're going to be walking over bare rock, although that isn't very likely. In that case, you'll find the little spheres of glass in the regolith will cause it to be slippery and the boots don't deal with that very well. If you get off the ladder and put your foot directly on the side of a boulder, it was slick, but this will very rarely be a problem.

Post-Summit Questionnaire Responses

No responses

\section{a. With respect to the boot, did you feel like you were getting enough information to have a stable gait? The boots were hard on the bottom, with galoshes over them.}

They were very comfortable. It never seemed that the boot was causing any difficulty.

The lunar regolith is a very efficient transmitter of acoustical energy and you can actually feel somebody hammering on a core probe through your boots, if you are close enough. The energy is focused and it goes through the soil very efficiently.

\section{Post-Summit Questionnaire Responses}

No responses

\section{b. In regards to the coefficient of friction on the surface, did you feel slippery on the regolith?}

It was never slippery on the regolith. It has a very high bearing strength. It has been tamped by micrometeorites over a very long period of time.

The upper layer is a little looser with less bearing strength, so that gives you a grip.

Also, every particle is like a tiny piece of Velcro. It hooks with every other particle, so the coefficient of friction is pretty high within the regolith material itself. 


\section{Post-Summit Questionnaire Responses}

No responses

5. Was ankle support adequate to avoid ankle injuries with unequal footing?

There were no issues. Always observant as to where you were placing your foot so as not to have any injuries.

Lighter weight suit may have more vulnerability. The suit gave a sense of support and protection.

\section{Post-Summit Questionnaire Responses}

No responses

6. Were there any pressure points with boot inserts or with the lunar boot instep strap? Was arch support adequate? Would proper arch support designs be advised for frequent EVA activities?

No discomfort with the boot.

\section{Post-Summit Questionnaire Responses}

No responses

7. Did the lunar boots provide adequate thermal comfort?

Yes.

Post-Summit Questionnaire Responses

No responses

8. What lunar surface EVA activities (e.g., egress down the ladder, ingress, use of tools, rover ops, etc) do you feel pose the greatest risk for injury?

The Lunar Rover pilot was at greatest risk. He would be the first one to get hit when driving on the side of a hill. 
The commander on the high end was concerned about falling over.

\title{
Post-Summit Questionnaire Responses
}

No responses

\section{What features in future suits would be most beneficial to reduce workload, and reduce the potential for injury and falls?}

\author{
As discussed above, \\ Gloves \\ knee flexibility, \\ mass.
}

Put pads in the knees for kneeling on the regolith.

Also use a self-sealing pressure garment, to take care of a small puncture. Post-Summit Questionnaire Responses

Test Operations

- During testing - subjects were never matched to the suits - difficult to sort out if problems were due to design or mis-fitting suits

- Before unloading the suit with artificial load relief, take a look at the impact they have on test operations. The use of load relief was so obnoxious that when it came time to do our final thermal-vacuum tests, I elected to work unencumbered by load relief. I thought the potential for getting tangled up in pulleys, cables, etc. that I could not see or reach, was a greater hazard than the risk of losing suit pressure and having the whole thing fall on me.

\section{a. Discuss soft suits versus hard suits and the trade off.}

From the Apollo crew point-of-view, there is a tendency to favor the soft suits, but we didn't have much experience with the hard suits.

Everybody should be objective enough to look at it. The next set of explorers will need to determine what they like best and weigh the advantages against the disadvantages.

\section{Post-Summit Questionnaire Responses}

No responses

\section{Hands/Gloves}

1. Did certain activities on the moon cause finger/hand pain vs. fatigue? 
The most fatiguing part of the tasks was repetitive gripping which caused fatigue in the musculature of the forearm.

The crewmembers were unable to specify cause of problem.

There were issues with not only fingernails being pulled back (onycholysis), but also a situation of skin being abraded from the top of the knuckles.

\section{Post-Summit Questionnaire Responses}

No responses

\section{Were hand/finger issues on the moon different than any issues encountered during ground training runs?}

We saw no trauma in training, though muscle fatigue occurred. Training sessions weren't as long as the lunar sessions, though.

The very long terrestrial sessions developed the same kind of problem, so it's either a duration problem or in some cases it may be related to the dimensions of your hand, which needs to be looked at.

Energy, time, and money should be spent to take a serious look at how to improve the glove. Although there have been improvements for Shuttle and Station, the gloves probably aren't as far along as they need to be for exploration activities on the moon or Mars.

Another part of the problem is pressure of the glove. The lower the pressure, the less strength it takes to manipulate.

If you decide to move back towards a single gas low pressure oxygen system, you need to realize there are complications in doing that system because of things that have happened since Apollo.

We tried to list all the operational advantages to having a low pressure single gas system and that is well worth a very hard second look.

\section{Post-Summit Questionnaire Responses}

No responses 


\section{Any specific glove touch-temperature issues when handling materials? (ladders, tools, rock specimens, controls)?}

No, although thermal input from the sun was felt at one point.

\section{Post-Summit Questionnaire Responses}

With improved insulation, don't forget that once the insulation heats up, it's really hard to remove the thermal content. One of our final tests was to demonstrate I could pick up a two hundred something degree rock and hold it for 15 seconds or so. Using a metal bar heated to the desired temp, I was able to grasp and hold for I 0 seconds or so until the inside of the glove became very hot. Fortunately, since the suit didn't fit, I was able to pull my hand entirely out of the glove.

4. Did any dust get into the inside of the suit between EVAs in the LM? Was there any cumulative skin irritation on the hands or elsewhere from dust exposure between EVAs? Did this affect a subsequent EVA? Did the EVA aggravate any irritation?

No problems, except dust accumulated in the neck rings.

Post-Summit Questionnaire Responses

and wrist rings on $\mathrm{A}-16$.

5. What, if any, feature of the space suit gloves would be most beneficial to improve with regard to hand injuries?

The hands were not used in any significant way. Efficiency was probably no more than about ten percent of the use of the hand.

Step back with a clean sheet design of the glove with the goal of getting as close to normal dexterity and use of the hands as possible.

Crewmembers had difficulty with repetitive grasping because it caused fatigue in the forearm muscles. The longer you're out there, the more problems you have.

And, almost everybody on the moon had problems with fingernails.

Spend some money and time working the glove issues, adding dexterity, lowering the pressure in the suit, if possible, as well as trying to diminish fatigue from gripping tasks and to diminish trauma to the hands.

Make easy to don and doff; give room in the airlock if you have room to get the suit on easily, if you are going to do frequent EVAs.

Recommendations for the glove: 
- Consider the inherent design of the gloves.

- Possibly a robotic hand could be used or a mechanically-augmented, powerassist glove for repetitive tasks.

- Modify fit and size. Properly fit the gloves to the crewmembers after they are designed and assigned to them. One crewmember had his gloves cinched up so tight that he lost all of his fingernails when he got back. It wasn't due to the glove, but because he had them fitted so tight.

\section{Post-Summit Questionnaire Responses}

Look at a wrist seal and depressurized glove. Perhaps even for temporary use on challenging tasks.

- Gloves were the most obvious challenge - required a significant level of thermal protection.

- Multilayer insulation worked on the back, but the palm and interior required a thermal barrier that could withstand abrasion and compression.

- The real issue was simply the need to compress the palm side insulation.

- Perhaps contemporary materials will allow developing a thin, flexible mesh with high conductivity that could be used to interface with an active heat rejection system for future explorers.

\section{a. Unanticipated changes occurred in $1 / 6 \mathrm{~g}$ environment that contributed to the problems with the gloves on the moon's surface. Could you elaborate on that?}

It may be related to the length of time in the glove, since the fingernail problems did not occur during training.

Once fitted for the gloves, the crewmembers were left on their own to figure out how best to use them and that was appropriate, but with experience the crews could be advised of what may work and may not and test various things.

Even wearing silk liners and cutting nails as short as possible, the fingernail problems were not prevented.

The fingernails still scraped against the bladder. With a bare hand in the glove (without silk liners), severe chafing was experienced by at least one crewmember.

There are many nuances that are probably worth exploring, even with a new designed glove.

\section{Post-Summit Questionnaire Responses}

No responses

\section{Physiology/Performance/Hydration/UCD/DCS/Thermal}

1. Would you like to know your own heart rate, metabolic rate, or other physiological information during an EVA?

We could feel what was happening with our bodies and responded accordingly. 
Intermittent feedback was received from CAPCOM regarding suit information/consumables and it was acceptable.

A heads-up display would be acceptable, esp. with verbal request for heart rate, esp. on Mars when don't have mission control watching over you.

It may have helped one of the lunar EVA crewmembers to have heart-rate information as he was going too fast and injured himself during a coring activity.

\section{Post-Summit Questionnaire Responses}

Would have helped on Gemini IX and XI.

Potassium depletion was a problem. Some way of monitoring condition would be good.

GT-XI - Heart rate is not a reliable indication of work load. Perhaps the most important physiological parameter is hydration.

\section{Describe your food and water intake prior to the EVA terms of amount and timing?}

We always had breakfast before going out.

We ate fairly well on the moon, but it would have been nice to have more water available, if only in the event of a contingency. Some crewmembers may have been conservative with the available water, but that was wrong. In desert survival, you learn that you should drink the water you need when you have it, rather than partialing it out.

There was a consensus among the crewmembers that having a larger water supply would have been helpful and useful.

You lose a lot of moisture, even with the LCG.

It would be important to have some food available, something that could provide a good lunch.

The fruit bar mounted inside the suit was sometimes problematic because you couldn't always get to it.

A liquid drink with energy nutrients might be an option, as long as it doesn't contain caffeine.

Once suited up, we sometimes went 10 hours without a break. Adrenalin was a factor and we had a lot to do. If it is convenient to get to, having a solid or liquid carbohydrate would be helpful.

Don't overcomplicate things. Keep it as simple as you possibly can because human beings can adapt to these kinds of situations very easily. 


\section{Post-Summit Questionnaire Responses}

It would be a good thing if there were a simple, non-invasive, way to evaluate hydration in real time. It's been my experience that you have to force yourself to drink often, especially in the suit, because it's generally a nuisance task.

3. How thirsty did you become during an EVA? By the end of an EVA?

See \#2 above.

Post-Summit Questionnaire Responses

No responses

4. Did you feel the amount of water in the bag was sufficient

It would have been nice to have more

Post-Summit Questionnaire Responses

No responses

5. Given adequate compatibility with the suit, do you feel other liquids such as Gatorade or juices should be a crew option for the drink bag? (In light of the Apollo 16 orange juice leak in preparing for EVA \#2)

High energy drink with nutrition would be good, but it's nice also to have some plain water.

Post-Summit Questionnaire Responses

AW: Need to keep chemical balance in body.

6. Debriefs show a number of crewmembers found the food stick valuable? Any comments on satisfying hunger, providing energy, ease of access?

The fruit bar mounted inside the suit was sometimes problematic because you couldn't always get to it, but it's nice to have something solid to eat. 


\section{Post-Summit Questionnaire Responses}

No responses

7. Please comment on the efficiency of the Urine Collection Device (UCD) during EVA? Was there irritation from the device which was exacerbated by movement in the suit?

What we had was adequate, but you should continue to consider better ways to do it.

The condom catheter was undersized.

If there is a better system that is not gender specific, then we should consider it very seriously and test it to see if it will work in $1 / 6 \mathrm{~g}$.

The wicking diaper system does not work well in $1 \mathrm{~g}$, but may possibly work well in weightlessness. If we can improve it significantly, then we should.

\section{Post-Summit Questionnaire Responses}

What does gender specific mean?

The UCD was only used for EVA; operations - lunar surface, etc. The CM was equipped with a relief tube. Haise did wear his UCD on 13 and it resulted in a urinary infection. For EVA operations I don't see how you can improve the device.

8. Do you have suggestions for urine collection with frequent EVAs and mixed gender crews?

See \#7 above.

\section{Post-Summit Questionnaire Responses}

Have fun with this one.

9. Apollo 10: Crew was very concerned about voiding difficulties during timecritical ops. Crew suggested creating a device made of aluminum to plug into the suit to facilitate voiding with the suit on. In particular, a UCD that can be used with the suit on without having to zipper-down. What was this device, and was it ever developed?

Were not aware that is was ever flight tested.

Post-Summit Questionnaire Responses 
Apollo 10 was not normal!!

10. Was the Liquid Cooling Garment (LCG) wet at the end of an EVA? If so, where was it wet and did it cause any skin irritation through the comfort garment?

The air cooling systems were not adequate for more than an hour, however, there was very good cooling from liquid cooling, even to the point of overcooling if you let it run full up.

The liquid cooling garment was wet from sweat after each EVA and we let them air dry on our bodies.

Post-Summit Questionnaire Responses

No responses

11. Were you ever over-cooled by the LCG?

Yes, see \#10 above.

\section{Post-Summit Questionnaire Responses}

No responses

12. Was the suit and helmet adequate in providing thermal protection? Were there any thermal cold or hot spots?

There were no hot spots, except on one occasion which was actually quite comfortable. When driving to the station, one crewmember stated his arm was in the sun for a significant period of time (30-40 minutes), heating tired arm muscles which felt quite therapeutic.

Post-Summit Questionnaire Responses

Suit was OK, helmet cooling from $\mathrm{O} 2$ flow was OK.

13. How strong was the concern regarding Decompression Sickness (DCS), or did you feel that it had been eliminated through design?

One crewmember questioned if there was only one case, if it wasn't another issue and whether it was misdiagnosed. However, in questioning the affected 
crewmember, he absolutely felt it was DCS. He feels he is a "3-sigma" individual in his sensitivity to DCS. He bases his belief on an experience in an altitude chamber where he had pain in his left knee which spontaneously resolved upon repress. During his Gemini X mission he experienced pain in the same knee that was similar but more severe than what he experienced during the altitude chamber exposure. It started with capsule depress and went away over a period of several hours. Again in Apollo 11 on capsule depress he had a similar pain (location and character). It resolved spontaneously over several hours and was not severe enough to interfere with activities. He denies other episodes of knee pain during altitude exposure. He denies significant injury to this knee though he admits to numerous minimal sports injuries during his lifetime.

Crewmembers started prebreathe right away, as soon as the helmets were on.

Crewmembers suggested not only having low pressure in the suit, but also low pressure in the habitat. There would be many engineering and operational issues to consider.

You're going to have to bite the bullet and continue to use the PVS system and try to work at the lowest pressure possible to get the prebreath, to something that is inconsequential and somehow monitor the potential developing maximum levels. Take a hard look at whether you can gradually migrate back to PVS.

\section{Post-Summit Questionnaire Responses}

No responses

\section{What were the contingency plans for any DCS symptoms?}

We talked about this with the docs, and in general we did not worry about it because of the

$100 \%$ oxygen environment of the LEM.

\section{Post-Summit Questionnaire Responses}

No responses

\section{Any retrospective symptoms of DCS that may not be previously accounted for by suit fit pain or musculoskeletal strain?}

In my aircraft, I quit prebreathing for well over an hour and I had some decompression as well. If you're going to launch with some nitrogen in your cabin, maybe you just have to extend the prebreathe. 


\section{Post-Summit Questionnaire Responses}

No

16. Do you feel the pre-flight EVA exercise training program adequately prepared you for EVA, from an exercise capacity standpoint? How much more hand/arm exercise training would you have incorporated into your routine?

Yes in general it was adequate, however one area to improve both pre-flight and maybe on the way out is conditioning the forearms, esp. gripping.

\section{Post-Summit Questionnaire Responses}

Not on Gemini, but was in good shape for Apollo. Restraint systems in orbit a must.

17. Would you prefer one long EVA session, or two shorter sessions on a given day should the "work-efficiency" index be favorable? Ratio of: time of EVA/time of pre/post EVA activity) A break between EVAs would allow rest, hydration, food, replanning, etc. in the LSAM.

One long session would be the preferable way of operating, even if you're there longer than we were. Crewmembers preferred to keep going as long as the system would allow.

It's time-consuming to break the EVA up with a repress in the habitat, and then depress to go out again, including performing many checks.

\section{Post-Summit Questionnaire Responses}

Obvious

18. How many daily EVAs in a row, for a given set of crewmembers, would you feel be possible without undue physical stress or fatigue? (taking into consideration level of ambulation, task difficulty, etc)

Could do three days in a row but better to do every other day or two days in a row then off for one.

\section{Post-Summit Questionnaire Responses}


No responses

\section{a. You mentioned that you had alternate EVA days. If there were 4 crewmembers available to go out, would it make more sense to have all 4 out on a given day and then a day off? Or 2 out one day and 2 out the next day, so that you are doing continuous EVAs?}

Although you should be flexible to be able to do one or the other depending on the objectives, the preference would be to alternate 2 and 2 . That would enable mission control from the cabin during Mars expeditions. If you get used to doing this on the moon, it will be easier on

Mars. Crewmembers could alternate every other day, then allow one day off each week for whatever they want to do.

Keep in mind that a 6-month mission is very different than a 3-day mission. An actual plan for a 45-day Mars surface stay has been developed and copies are available. It should be left up to the real-time operational planning team, but if everything is going nominally throughout the mission, then alternating EVAs and teams will be an efficient way to operate.

\section{Post-Summit Questionnaire Responses}

No responses

\section{b. So, there should not be an attempt to plan EVAs day after day, but leave it up to real-time planning and some autonomy of decision-making should be left to the crew?}

Plan the operations on the surface so that you protect the crew from themselves. The crews will work too hard to try to get everything done and they'll risk becoming dehydrated and having serious physiological problems. Work out a schedule with the crews ahead of time, but excessive workloads on consecutive days is going to hurt somebody so leave some autonomy to the crews.

With extended ops on the moon, you should try to establish all the experiments in the first week or so, and then allow the crew to just have a day to do R\&R on the surface, just for the sake of being on the moon and recharging their batteries, so to speak. The schedule could be one day on and one day off, or two days on and one day off, but guard against crewmembers overworking themselves. If you go too long on a field exploration, you could be taking more risk than necessary.

You have to be careful with pre-launch activities, as well, to make sure problems don't exist when crewmembers launch. 


\section{Post-Summit Questionnaire Responses}

No responses

19. What other suit changes would you advise to reduce workload, or mitigate injuries/strains, for the next generation suit not already discussed above?

Lighter, better gloves, more mobile.

\section{Post-Summit Questionnaire Responses}

Gloves, knees \& in general better mobility

Our goal was to make the suit operation as autonomous as possible and providing confidence in its contingency capabilities. If we're going to send folks out, we need to provide a modicum of protection against life threatening events, no matter how improbable.

- Rather than carry large quantities of $\mathrm{O} 2$ it would be worth exploring the ability to create a self sealing layer on the inside of the suit to stem the loss of pressure. It doesn't have to be a perfect barrier, just enough to minimize the leakage due to minor punctures, leaks, cracks, etc.

- The most debilitating event can be one that allows the helmet to fog. It may be worth while to develop a way to periodically spray pure $\mathrm{O} 2$ on the front of the helmet, which can also reduce the local $\mathrm{CO} 2$ concentration during periods of exertion.

- The cooling system should also be self sealing with regard to leaks.

- Retain ability to make/break gas connection in a vacuum and provide contingency $\mathrm{O} 2$ on rovers, etc.

- Always use the buddy system when conducting an EVA.

a. One of the things we are struggling with for exploration is whether we should have one suit that can be reconfigured for different phases of the mission or do we go with two suits? Do you have any thoughts with your experience?

It depends on how the suit design turns out and if you can get in and out of it quickly. One crewmember commented that there should be only one suit. All operations should be performed in one suit that is easy to operate and flexible.

\section{Post-Summit Questionnaire Responses}

One suit if possible. 


\section{Lunar Surface Ops}




\section{Lunar Surface Ops}

\section{Dust}

1. Describe any issues that arose due to lunar dust entry into the vehicle?

We dusted but there was still dust everywhere. It smelled like gunpowder, however you would get desensitized to it. Suits would have to be doffed before entering the vehicle.

Post-Summit Questionnaire Responses

Yes

2. Approximately how much lunar dust lingered inside the vehicle?

Dust is cleared rapidly in the cabin by lithium hydroxide. Dust is very abrasive and there are jagged fragments. The dust on the surface was a problem because it covered all your gear, visors, etc.

Post-Summit Questionnaire Responses

The ECLSS intake system that intakes and redistributes the air.

a. A lot of the debriefs said that after they got back in microgravity that dust caused a lot of problems, so we are particularly looking at how the dust was cleared, symptoms, causes, etc. On some missions, the dust was like a cloud, but on others it was cleared fairly adequately by the lithium hydroxide ventilation system. We are curious why dust was a problem on some vehicles, but not on others. What were the differences in the ECLSS systems between the different vehicles, or is it a difference in volume, etc.?

The amount of dust that came back after landing should have been pretty consistent. Maybe some crewmembers cleaned more than others, or the ventilation system differed vehicle to vehicle.

\section{Post-Summit Questionnaire Responses}

Not so at all with the rover fender failure.

A-16 lost a rover fender.

So did Apollo 15.

Apollo 17 lost one on the first EVA and it was repaired. 
How about different landing locations with different characteristics. Vehicles were alike!

3. Crews reported that they were quite dirty with lunar dust upon return to the LM. Dust was difficult to remove from any surface, particularly the hands and fingers. This contributed to getting dust in the eyes. Glove liners were not used on Al1-13 mission, but were worn on subsequent missions. What type of material in the glove liner would best prevent the type of contamination you described? What other measures could be taken to protect the crew from dust contamination prior to doffing the suit?

Lunar dust was embedded between skin and nail beds on all fingers. It was from handling

rocks inside the lunar module. No glove liners on early missions, hard to get dust from under

fingernails in those cases.

It took six weeks to grow out. the lunar dust from the nails.

Beta cloth, fractured silica, and silk were mentioned as possible better materials for glove liners.

There are many reasons why you don't want lunar dust in your equipment or anywhere else. Consider it from an engineering context, rather than the impact on humans. Take the angle of prevention.

\section{Post-Summit Questionnaire Responses}

No responses

4. Did the inhaled lunar dust particles result in any specific symptoms (allergic reactions, sneezing, tearing, nasal irritation, coughing, sore throat, congestion, or other symptoms)?

The dust smelled of gunpowder.

Helmets were not removed until the particles settled and went away.

There was dust in the mucous membranes of one crewmember that caused stuffiness and a changed voice, but it didn't seem like dust produced an inherent problem.

The dust clears once it is in the environmental control systems.

No medications were used for symptoms, but today Claritin could be taken.

We had bigger problems with fiberglass irritation.

Studies are being conducted on silicosis and this is important work. 
Post-Summit Questionnaire Responses

What is this fiberglass problem? Law suit pending.

5. If you experienced inhalation irritation from exposure to lunar dust particles, how long did these effects last? If you put on a mask to reduce the irritation, how long did it take for symptoms to disappear? Did the irritation cause any decrement in your ability to perform tasks?

Sinus problems went away after the third EVA, so it wasn't a major issue.

This was contradicted in the following statement: During sampling for the microbiology program, exposure to lunar dust from the suits caused a reaction that worsened with each of the 3 sampling periods. The first exposure caused a stuffy nose and watery eyes. Lab results showed about $5 \%$ eosinophilias and a couple basophilia. On the second exposure, there were more symptoms of watery eyes and stuffy nose. Eosinophilias went up to $9 \%$ and there were some basophiles. On the third exposure, it was impossible to stay inside the spacecraft long enough to get the sample due to extremely watery eyes. In order to get the sample, it was necessary to get out, take a deep breath, then return to get the sample. Again, there was a $9 \%$ eosinophilia and $5 \%$ basophilia. Others performed the same function after the return of other missions and had no reaction.

Dr. Jones stated that it was interesting that it didn't passivate during the transport. There will obviously be individual variation in the response and we may have to do susceptibility testing before flight.

Post-Summit Questionnaire Responses

What the hell!!

6. What skin effects were caused by lunar dust? Specifically, was there any redness of skin, itching or any other specific symptoms that you can recall?

None.

Post-Summit Questionnaire Responses

Yes 


\section{What eye irritation did you experience? Specifically, was there any redness of eyes, itching or any other specific symptoms that you can recall?}

Not any significant, did get some in eyes, but more of a nuisance. Put suits back on in one flight to prevent breathing the dust. One CDR wouldn't let dusty suits into CM until bagged, due to dust.

\section{Post-Summit Questionnaire Responses}

Yes. Why do CDR get the credit -when CMP did it! A-12

\section{Were dermal and ocular effects lasting? If so, for how long; and did this cause any decrement in ability to perform tasks?}

No. As far as prolonged exposure to lunar dust, experimentation on Earth will not resemble the in situ properties of lunar dust, so we have to be careful about the conclusions we draw. We need to work from an engineering point of view to develop a layer of defense. Engineering actually worked pretty well on Apollo, whether advertently or inadvertently. The bearings on the lunar rover showed no symptoms on any of the missions.

Although it doesn't seem to have had an effect on the crewmembers, we had very limited exposure. Chronic exposure is very different than short-term exposure.

The lithium hydroxide filters seemed to pick up the dust fairly quickly. If you think it's important, the lithium hydroxide canisters in the CSMs could be analyzed to see how much actually got in the cabin. The sub-micron sized particles may be most worrisome physiologically for humans, but it is really unknown.

There needs to be a layer of defense to protect not only the crew, but also the equipment. The EVA suits may be used hundreds of times and dust will be a major factor in that. We saw dust scratches on our neck and wrist rings. It is extraordinarily penetrating dust.

There were differences in the landing sites relative to the nature of the dust, but it is unknown whether there are significant differences from a physiological standpoint.

\section{Post-Summit Questionnaire Responses}

No responses

\section{Surface Tasks}




\section{Apollo 12: The CDR/LMP stated the shadow pattern over the terrain/crater edges gave the illusion that the slope was much steeper than it actually was.}

Reflective light in the shadows isn't as evident as on earth. Craters did appear steeper visually. We knew we had to go down into that crater, so it gave us concern.

There is a general visual phenomenon, there isn't good reference for your eyes and the estimation of distance is off. All sorts of ambiguities on the moon (i.e., slopes, terrains, sun shadows, bland environment). No environmental references like on the Earth (i.e., trees, houses, poles).

A comment was made regarding the length of a crewmembers shadow because it always

looked shorter and it was needed as a reference. The shadow was calculated prior to the

EVAs and could be used as a baseline. After a period of time adjustment does occur.

\section{Post-Summit Questionnaire Responses}

No responses

\section{a. What is the steepest incline you tried to navigate?}

The steepest incline encountered was a 20-26 degree slope. If it was steeper, we would not have made an attempt.

The degree you could operate at safely depends on the task. It is easier to decide to go up a hill, because it is more difficult cooling down.

There was concern for falling down slopes. Also if went down a steep slope, you couldn't be sure that you could get back up.

\section{Post-Summit Questionnaire Responses}

No responses

\section{b. If there was a lighter suit, would you feel safer or be able to go up a higher slope?}

It was coming down that was a situation to be more cautious.

\section{Post-Summit Questionnaire Responses}

No responses 
2. How did the crew negotiate descending down the craters with this illusion, did it really cause a problem or was it an interesting observation?

See \#1 above.

Post-Summit Questionnaire Responses

No Responses

3. If it was a potential problem navigating the lunar surface, what would be the recommendation for eliminating this problem for future crews?

Can always follow your tracks back to the habitat. INS possibly.

Post-Summit Questionnaire Responses

No Responses

4. During the lunar EVA, the crews often worked harder during "rest" periods (as evidenced by heart rate data) than during work periods. However, the crew did not feel this level of physical activity pushed them to their exercise capacity limits.

Many crews worked as hard or harder during rest periods because that was our time to catch up. The EVAs always had more scheduled than you could do in the time allotted.

Didn't have time to rest. Recommend doing EVA for 2 days then rest the third, so don't make fatigue mistakes.

EVA is not as safe if you are mentally fatigued.

Post-Summit Questionnaire Responses

Yes. Unless looking for an intervelometer.

Heart rate is not a reliable indication of work load.

5. Although the crews did not report feeling physically challenged during the lunar EVA'S, can you offer any insights on how you might have felt carrying out this surface activity timeline over the course of 7-14-30 days?

The most important issue is to get enough rest. If you fall behind in your sleep, there is potential trouble.

It is difficult to sleep, you doze and the adrenalin is pumping too much to sleep heavily. 
Several crewmembers worked a 30-hour day. As long as the crew is given time of their own, that is the main issue, and they can use it as deemed necessary whether it is sleep or not. Sleep is an individual thing.

Privacy is needed for sleep. Crewmembers get comfortable when adapted.

Circadian rhythm was not important on the moon.

Mental and physical rest plans should be introduced. Should have planned breaks and rotations, maybe alternating flight crews and plans.

\section{Post-Summit Questionnaire Responses}

RG: Yes

\section{How do you feel the pre-flight EVA training program prepared you for lunar EVA?}

The POGO and centrifuge training were beneficial. There is no special training needed for $1 / 6 \mathrm{~g}$ EVAs.

Adaptation occurs quickly regardless, You learned your limitations.

You did as much as you could to get in shape. ALSEP training in 1-g was excellent. $0-\mathrm{g}$ training was more important than $1 / 6 \mathrm{~g}$. Only need a $1 / 6-\mathrm{g}$ fam session.

\section{Post-Summit Questionnaire Responses}

No Responses

\section{What would you do differently in your training for these longer surface sorties?}

There may be more tasks you need to train for. Task-specific training for specialized operations is optimal.

Mission focus should be project-oriented and not timelined. The crew needs to have more freedom. Leave time for unexpected activities.

\section{Post-Summit Questionnaire Responses}

No Responses 


\section{What does the crew consider were risky tasks during LEVA?}

Puncturing the suit was considered the biggest risk. Even though it was puncture safe, it was still a concern in a new environment. If a suit actually got penetrated, look into something that causes a self-seal. Self-seals are used in the military.

The only other concern was if your zipper was not working, broken, leaking, etc.

Another concern was hand fatigue. Some experiments could have been deployed robotically.

\section{Post-Summit Questionnaire Responses}

Yes

\section{a. What activities had the highest risk of falls/injuries?}

Going down slopes, esp. if carrying heavy objects, possibly driving rover on sloped terrain.

\section{Post-Summit Questionnaire Responses}

No Responses

b. Discuss any particular muscoskeletal strains...back, abdomen, legs...related to falls or slips.

Note: Apollo 12: Visual spatial distortions/disorientation due to certain sun angles on sloping terrain

\section{Apollo 15: Drilling for core samples and establishing a port for heat flow experiment at the end of EVA \#3}

\section{Apollo 15: CDR deciding not to wear seat belt on rover to save transit time back to LM at the end of EVA \#2}

In the video, it was obviously taking energy and this all starts from the pre-mission decision that at this particular station, one crewmember was to do some individual sampling while the other crewmember performed some necessary housekeeping at the Rover.

Because my hands were tired and because I didn't have a good sense of how much pressure was putting on the bag, I dropped the bag. So, I was in the process of trying to first of all recover the samples that fell out of the bag and a number of things. This was just a whole set of bad decisions in pre-flight planning, as well as in operations, and I hope that with that kind of experience we will never do that again. 


\section{Post-Summit Questionnaire Responses}

No Responses

c. Along the same token, you said that none of these falls really caused any significant strain, impact, injury?

No, the main consequence was that you got dirtier than you should have.

Over time, you could see the dust migrate up the suit.

In terms of hazard, you're falling as if you're only $1 / 6$ your height, so you don't hit very hard and you're in an extremely strong suit.

\section{Post-Summit Questionnaire Responses}

No Responses

d. So, when you fell, did it hurt at all

No, due to the rugged suit we were in, if had a lighter or more flexible suit then maybe.

\section{Post-Summit Questionnaire Responses}

No Responses

e. One of the things that we need to be careful of as we do this testing on the ground with the POGO system, our center of mass is moving at 160 , but we're in the suit under $1 \mathrm{~g}$, so our impression of a fall under those conditions is probably different in reality?

Yes, and you have to take into account the workloads. You're still moving in a 1 $\mathrm{g}$ field, so you're doing $1 \mathrm{~g}$ work with your arms and legs.

Tests are being conducted in the $\mathrm{KC} 135$ with a $1 / 6$ parabola to obtain quantitative net rate versus speed.

Post-Summit Questionnaire Responses 
Yes. But be careful -you always start from a stable position

9. Does single-man parallel ops over 2-man teamed ops for deploying experiments and equipment reduce the risk for falls or other potential injuries?

Never felt physically at risk. The configuration for deploying the experiments is not a factor.

Post-Summff Questionnaire Responses

No Responses

a. Is it safer to operate tools independently or with another person?

Do not send one person out alone unless it's an emergency or mandatory.

\section{Post-Summit Questionnaire Responses}

No Responses

10. From a crew performance standpoint, with consecutive daily lunar surface EVAs being considered, is there a better time during the crew day to schedule these events?

The EVAs should be based on the sun availability. It gets hotter at high noon due to the sun. OK to do EVA in Earthshine periods, light is adequate.

\section{Post-Summit Questionnaire Responses}

How do they know?

11. In terms of reducing crew physical workload would a robotic "companion" on EVAs have proved useful or more cumbersome? What about a low tech walking golf cart solution? Could robotics reduce your workload or reduce fatigue?

A robot should perform routine, systematic, repetitive, menial tasks. This will free the crewmember for other tasks.

Post-Summit Questionnaire Responses

No Responses 
12. What was the impact of lunar dust? How much was "tracked in" on the suits during lunar EVA and what impact did it have on vehicle systems and crew health?

See dust issues above.

Post-Summit Questionnaire Responses

No Responses

13. What part of the lunar surface EVA caused you to expend the most energy? Metabolic studies seem to point to the last $\mathbf{3 0}$ minutes of the EVA, where the crew was ingressing the vehicle. Do you believe this contributed to fatigue and was there a risk of injury?

The hatch should be made where you can go straight in. Make so you don't have to arch your back and tilt the backpack in order to get back in. It's a volume configuration issue.

The risk is death if you can't get back in.

Post-Summit Questionnaire Responses

No Responses

14. What was your optimal speed on the surface above a brisk walk?

Half again as fast was average speed. Routinely measured at 6 kilometers an hour.

Can lope quicker on the moon than briskly walk on Earth. Up to $10 \mathrm{~km}$ for an hour.

Post-Summit Questionnaire Responses

No Responses

a. You also mentioned that you would like to see suit recharge capability on the Rover?

In future Rovers, you should have the ability to recharge your suit or at least live off of Rover consumables when you're driving or working around it. This will require a change in engineering, as well as a change in mission rule. It will be a design challenge, particularly in that dust environment. 
And it wouldn't be just the Rover, there may be other activities, particularly when you get to a lunar base phase, where you're going to be doing things outside, but in a fairly fixed position near the base/habitat. You will have to live off of a different set of consumables.

It's one way to reduce the mass of the suit. It's also a way to extend the duration of your activities.

Another advantage is that if you decide that you're going to protect yourself against a solar particle event while you're some distance away from any pre-positioned shelter and you're going to use some method of excavating a trench to reduce the exposure envelope as well as possibly even live underneath the Rover for a few hours as additional protection, then you would like to have an extension of your consumable supply.

\section{Post-Summit Questionnaire Responses}

Yes. Not a bad idea.

\section{b. We also discussed that you thought it would be acceptable to have a deployable shield for radiation protection on the Rover?}

You should certainly do some conceptual designs and determine the consequences. There may be unintended consequences terms of $\mathrm{CG}$, rollover, etc.

\section{Post-Summit Questionnaire Responses}

Roll the dice.

\section{c. Comment on driving the lunar Rover in your suits. How comfortable was that? It often looked precarious when going up and down on the lunar surface.}

It was very comfortable driving in the suits.

The wrist motion was very good. You'd just rest your hand on the controller and you could move it and guide the Rover very well. It was a very effective transportation system and was easy to use.

There is a problem with visibility on the moon because when you're driving down sun you have no shadow definitions and you have to adjust either your speed or move in a zigzag pattern to avoid a hazard.

The one thing we would have liked to have is some kind of an automatic position determination so that you could save time looking for where you were actually trying to go. We spent quite a bit of time trying to find the right crater patterns. 
With a GPS system available, we would have saved some time.

\section{Post-Summit Questionnaire Responses}

No Responses

\section{d. How long could you maintain your pace? What would you modify on the flight plan?}

Work two days, then rest on the third day. When fatigued, you make mistakes and are not as safe as you think you are.

Take a day off after EVA and get your suits prepared for the next EVA.

Come up with a formula to give people mental as well as physical relief. You can maintain this effort for short periods of time, but not for extended timelines. There are good operational reasons for having people alternate EVAs. there are several things to be done on a day off, flight planning, etc, not necessarily a true day off.

\section{Post-Summit Questionnaire Responses}

- Perhaps the most important recommendation would be to stop trying to maximize every minute of surface time with pre-planned timelines, etc.

- The ISS folks seem to have learned this

- If you want to explore, let the probers pick their own pace and focus.

- The next set of missions should not be short sorties, but part of an ongoing program.

\section{e. If the ladder from the habitat were higher, would you have concerns?}

Would make the ladder wider, possibly with a rail.

\section{Post-Summit Questionnaire Responses}

No Responses 


\section{In-flight IIInesses}




\section{In-flight Illnesses}

\section{Space Motion Sickness and Entry 'Sickness' and Disorientation}

1 How strong were your symptoms and were they still present during transfer to the lunar surface?

Symptoms were felt the first day, however it is individualistic. (One crewmember commented that in his experience approximately $1 / 3$ to $1 / 2$ of the crewmembers experienced symptoms.)

Space motion and space adaptation are two different things.

Crewmembers worked through the symptoms and felt that it did not impair their work performance.

Most of the symptoms are gone within a couple of days and crewmembers felt adapted to the new environment.

Preflight measures were not taken to prevent Space Adaptation Syndrome. (There was a recommendation to consider pressure points.)

Crewmembers took preflight measures by flying T-38s, but it is unclear whether this helped or not.

There were no reports of problems during Mercury or Gemini, but it may be that they just didn't mention it to the flight surgeons

Many countermeasure were considered. Flying was one method.

There was probably still some stomach awareness, however.

During Gemini, felt "punk" for 24 hours, that is "didn't feel like going dancing".

Early Apollo only felt punk 2-3 hours, but late Apollo it was gone after an hour.

\section{Post-Summit Questionnaire Responses}

Fluid shifts to head almost immediately upon arrival on orbit. Found that sinuses tended to stop frequently and sometimes for prolonged duration. Annoying only. During Shuttle, we noticed that five minutes on the treadmill would immediately clear the sinus.

\section{a. Can we do anything to use other countermeasures effectively?}


Since symptoms decrease with subsequent missions, it may be advisable to fly crewmembers with previous microgravity experience. However, there is some contradiction in the following crewmember comments:

- "On early flights I had a great time, but later on I got very sick."

- "Same for me...symptoms came later with training cycles. Not sure why."

- "It luckily didn't happen to me. It's individual. There must be a way, through history, to get a getter definition of this problem."

- "I've never experienced motion sickness in my life."

\section{Post-Summit Questionnaire Responses}

Yes. Find a way to predict.

2. Did you notice 'vertigo' or disequilibrium during LEM ops and post landing on the moon? Comment specifically on accomplishing tasks in the LM during entry and landing, and accomplishing tasks in the immediate post landing period on the moon. Comment specifically on accomplishing tasks in the LM during entry and landing on moon symptoms.

See response to questions 11, above, Ambulation and CG issue above One crewmember stated that it is a function of the inner ear or it could be the emotional state.

"It may be a psychological thing."

Post-Summit Questionnaire Responses

Yes

3. How would you compare your 'stability' while walking in $1 / 6 \mathrm{~g}$ vs return to Earth and $1 \mathrm{~g}$ ?

Easier to ambulate at $1 / 6 \mathrm{~g}$, it is wonderful. We need a little time to get our sea legs when got back, otherwise no real issue.

Post-Summit Questionnaire Responses

No Responses

4. Some crew found transferring from CM to LM disorientating, and reported that it may have contributed to SMS. Are there any orientation cues or suggestions in the design of the two vehicles that may help minimize or ameliorate this disorientation? Given the current architecture for the CEV LSAM, how could your suggestions be implemented? 


\section{Post-Summit Questionnaire Responses}

Don't worry about it.

Practice in the KC-135 or C-9 in zero $\mathrm{g}$ in the $\mathrm{CM}$ to LM simulators

Yes, slightly disorienting -but not the source of SMS. Just interesting. Perhaps have a training setup where transfer can be done, even unsuited. In Apollo we had no such device -on CM or LM, but not combined. Therefore it was mostly unfamiliarity with what's where.

We did not have a problem with this issue. I think the answer is "Believe Your Eyes" and don't move fast, especially your head. Training issue!

Find crews that orient by sight not by mental gymnastics.

\section{Back Pain}

1. Crew described significant back pain during the first couple of days of the mission. To the best of your memory, can you describe the back pain in terms of location, character, intensity, exacerbating and alleviating position or exercise most effectively relieved the pain?

One crewmember commented that his back never felt better than it did in $0 \mathrm{~g}$ and he never used the fetal position as a therapeutic technique.

The Exer-Genie was used for deconditioning. "It was also nice for the spirit and a good way to relax."

Back pain may be related to elongation of the spine, but this is not yet clear.

Back problems were not necessarily discussed with Flight Medicine because Apollo crewmembers thought it was due to sleeping problems.

However Dr. Ross stated that several Apollo crewmembers did complain of lowgrade, chronic back pain. The problems were non-disk related. Some crewmembers improved, however some did not. Massage and exercise helped alleviate the pain somewhat, as well as getting into a fetal position.

Military history was also a consideration. Some crewmembers had problems from low back to cervical spine, including injuries. $90 \%$ are lumbar spine problems that seem to be related to piloting high-performance jet aircraft. It is important to discuss this with consultants that can provide the correct types of therapy.

It could be that back pain is not "space normal" and we need to determine what we can do about it.

\section{Post-Summit Questionnaire Responses}


I don't believe lower back pain is due to military/jet experience. I think it is related to offloading of Ig upper body weight. Lower back definitely went into spasms.

Fetal position felt good but may not be good therapy.

Yes.

2. Considering the configuration and constraints of the CEV (e.g., $5.0 \mathrm{cu}^{3}$ volume) compared to the Apollo CM, how would you advise the crew/engineers to design the couches/exercise equipment, sleep compartments or restraints to help minimize back pain symptoms?

Strengthen the abdominal muscles to prevent back pain. Doing lots of sit-ups seems to help. Develop preflight exercise protocols.

"Low back pain cannot be designed out, Take Motrin and go on."

The ASCR program can lessen the risk of injury. The ASCRs are very aware of these problems and are paying attention to this with preventive measures. Core strengthening pre-and in-flight helps. This will be used for long-duration flight. Creativity will be necessary for implementing the program in a constrained environment. The Exer-Genie was the only piece of hardware in Apollo. It had problems due to heat build-up in the rope during use.

The crewmembers considered it a threat if heat built up after too much use.

Examine the spacecraft to determine what can be worked with or against to get the proper exercise. Dr. Ross reported that a multi-disciplinary approach is being taken to work on training and preflight injuries/anomalies for prevention rather than cure. This includes engineers, astronauts, suit techs, ASCRs, etc.

\section{Post-Summit Questionnaire Responses}

The Exer-Genie did not work. Call me for a detailed explanation.

No. The Exer-Genie was misused. It is isometric not dynamic -no heat should be present.

3. Did the CDR/LMP experience any low back pain on the lunar surface? Were there any positions or exercises that the crew performed that improved their symptoms? If so, what were they?

\section{Post-Summit Questionnaire Responses}

Not me. 


\section{Eye Irritation}

1. Apollo 10: Conjunctival irritation occurred in the CM secondary to fiberglass in the cabin. Required the crew to use saline eye drops. Source of the fiberglass or circumstances not explained in the debrief. What was the source of the fiberglass in the cabin? Was the eye irrigation system adequate to clear the irritation?

Fiberglass irritation was mentioned above, however crewmembers did not elaborate.

\section{Post-Summit Questionnaire Responses}

Not on our flight

Was there fiberglass present?

\section{Joint Pain}

1. The Apollo $11 \mathrm{CMP}$ described onset of left line pain after launch, similar to that experienced on Gemini $X$ and in altitude chamber testing. The cabin atmosphere and oxygen concentration being considered for CEV/LSAM/ Lunar habitat will involve a gradual decompression, although the exact AP is still under debate. Although the CMP's symptoms were not attributed to dysbarism by the flight surgeons, it is certainly suggestive of this condition. Can the CMP describe in detail the symptoms and events surrounding his joint pain. What recommendations can the crew offer for the atmospheric parameters being considered to CEV/LSAM?

See EVA q. 13.

\section{Post-Summit Questionnaire Responses}

I have listened carefully \& still believe my symptoms indicate nitrogen in left knee. No problem for me.

\section{Sleep}

1. Did the coronal discharges interfere with sleep i.e., sleep onset, efficiency, etc? Was there a particular mission phase that the discharges were more noticeable?

Noticed flashes more when closed eyes, before went to sleep.

\section{Post-Summit Questionnaire Responses}

We did an experiment for flashes. Did not interfere with sleep. 
Find a way to make taking sleeping pills not a sign of weakness in an astronaut's mind. A sleeping pill should be thought of as a chemical tool.

Yes. No effect at the time?

\section{Musculoskeletal Injuries}

1. What injuries or aches and pains were most common following EVA? How could you reduce the likelihood of injury?

Soreness in the forearms was the most common, but usually was better by the next day.

\section{Post-Summit Questionnaire Responses}

No responses

2. How did you 'rehab' or recover from injuries" What preflight preparation reduced these symptoms? Did any injuries interfere with task performance? What injuries and aches and pains were unexpected?

\section{Post-Summit Questionnaire Responses}

Had wrist ring cut on right wrist to bone - used no fix until return.

No injuries.

None

3. On the lunar surface, did you ever experience a fall that produced a 'hard' landing? Did equipment ever fall on you?

No. Falls on the lunar surface were "gentle."

There was little concern for injury except falling onto a piece of equipment or breaking your visor.

\section{Post-Summit Questionnaire Responses}

No responses

4. We hope to design out, as much as possible, risk of trauma and injury, so that we can reduce the potential need for acute medical care. For example, better suit design could reduce the likelihood of shoulder and hand injuries. Do you have any suggestions for how we might do this, and what hardware and tasks might be redesigned to reduce these risks? 


\section{Post-Summit Questionnaire Responses}

Fit the suit to the person -new gloves that incorporate mechanical closure for gripping without fatigue.

Better glove design -squeeze more tennis balls?

Suits much more critical for extended stay on surface.

Better suit design but also design exercises that strengthen muscle \& joints effected

5. Did the design of spacesuits for lunar work allow you easy movement, or was it difficult to maneuver?. Did these difficulties contribute, in your opinion, to susceptibility to falls while working on the lunar surface?

A lighter suit would reduce the inertia for movement and make it easier to standup.

\section{Post-Summit Questionnaire Responses}

The UCD was only used for EVA; operations on the lunar surface, etc. The CM was equipped with a relief tube. XXXX did wear his UCD on 13 and it resulted in a urinary infection. For EVA operations I don't see how you can improve the device. 


\section{Medical Kit}




\section{Medical Kit}

1. Considering the configuration and constraints of the CEV, do you think you could reconstitute a drug in that environment? In other words, if the drug was in a powder format, could you reconstitute it into a solution using normal saline or another diluent that would be provided in the kit?

This should not be a problem in microgravity and certainly not on the lunar surface.

\section{Post-Summit Questionnaire Responses}

Would be okay if the way was to add water.

Yes.

2. You mentioned in debriefs that blister packs were an issue because they expand during depressurization. We currently use pill bottles and Ziploc bags to pack medications into the current generation of kits. Using your experience and knowledge from Apollo, is there anything we would take into consideration with the design of the next generation of kits given the space in the CEV?

Provide items that are needed in daily life, such as lotions, bandaids for minor abrasions, Tylenol, mild sleeping pills, etc.

Having a physician crewmember would increase the comfort level.

"Always have a doctor." cross train physicians to perform other activities on the mission.

"Cross train fighter pilot to be a geologist on the moon."

\section{Post-Summit Questionnaire Responses}

Yes.

a. The kits for Apollo were very small and basic. What is your impression of the new kits today?

An example was shown and a crewmember commented on the large size and inquired about the contents. Dr. Jones stated that it contains blood pressure equipment, diagnostic capability, etc. More capability planned for the lunar kit to deal with contingencies. 
Thought should be adequate.

\section{Post-Summit Questionnaire Responses}

Did not see it.

There is no question that a medicine to combat fatigue should be on board spacecraft. We took Dexedrine just before reentering the atmosphere to make sure its effect would stay with us throughout the landing. Take the medicine too early and their effectiveness would end and increase the fatigue. We were asked to take Dexedrine to combat fatigue. I did not because I was worried about a crash that might come when it wore off. It frankly was not necessary as the excitement of the upcoming entry and stress of the CM power up generated a lot of adrenalin. So I was very alert for that final entry phase of the Mission without any drug boost. 


\section{Bioinstrumentation}




\section{Bioinstrumentation}

1. Do you have any suggestions as to how we could improve the means by which we monitor (Heart Rate, metabolic rate) astronauts on the lunar surface, given our current system is almost identical to what you used in Apollo?

Wrist pulse monitors would be helpful. It would be good to have facilities for the crew to be healthy and well, especially if a physician crewmember is not a member of the crew. This

would allow monitoring from the ground.

The Heads Up Display (HUD) can overload people. It is not necessary crewmembers' blood pressure, etc. The displays should be simplified. consumables information and rate of use is okay. For other non-critical data, let a Caution and Warning bell ring, then check it out.

\section{Post-Summit Questionnaire Responses}

Yes. In addition to monitoring how about treatment.

2. Upon reviewing the lunar surface films from the archives, it can be seen that the abilities to ambulate and perform tasks were a human factors challenge. In many instances you had to slow down due to physical exertion required for the tasks. Surgeon and Biomedical Consoles monitored this activity to help forecast consumables and overall stress on the crew. Given the advances in technology over the last $\mathbf{4 0}$ years, do you believe that if you were given accurate metabolic rate information and suit consumable data, that future astronauts would be able to "self regulate" their EVA activities in an autonomous fashion?

Yes this could help for missions on Mars.

\section{Post-Summit Questionnaire Responses}

Yes

3. There were several times the suit Caution and Warning system notified astronauts that they were exceeding the thermal transfer capacity of the suit cooling system. During many of those times we did not see an excessive heart rate. The crew medical debriefs did not discuss this detail in depth since it was mostly a suit ECLSS issue. Do you recall anytime when you were really tired and the suit $\mathrm{C}+\mathrm{W}$ was nominal or any circumstances when the $\mathrm{C}+\mathrm{W}$ had a temperature warning and you were not tired? 


\section{Post-Summit Questionnaire Responses}

No, was never "very tired."

No., never happened to me.

Not on my suit Apollo 12 


\section{Environmental Impacts}




\section{Environmental Impacts}

\section{Environment and Habitability}

\section{Temperature}

a. How comfortable was cabin temperature in the CM and the LM? Cold, warm, OK, or depends on mission phase?

The temperature was comfortable and never seemed to be an issue during Apollo missions. Crewmembers slept in the LCGs and didn't use a cover. It was more difficult during Gemini "because it was way too hot".

\section{Post-Summit Questionnaire Responses}

Yes. It was okay.

Yes. Way too hot? Not a concern.

The temperature was well balanced in the $\mathrm{CM}$ utilizing heat from the electronic systems and dissipating excess heat by a radiator. On 13, however, with most of the electrical systems shut down, we were losing heat faster than the sun could provide. The temperature gradually dropped to about $34^{\circ} \mathrm{F}$ by the time we reentered the atmosphere. We could have put on our pressure suits but they were too bulky for three men in the LM. It appears shuttle crews operate in-flight in shorts and tee shirt. If that will be the uniform on lunar flights, I suggest some thermal protection in case of electrical failure.

\section{b. What was the temperature control like in the $\mathrm{CM}$ while in the suits at vacuum on the suit loop?}

It was fine. The biggest temperature concern was staying cool and not getting sick before getting picked up at landing.

On the lunar surface, the suits were very uncomfortable and should have been removed to get some rest. This could have jeopardized the mission.

Be careful trying to design for the exceptional circumstance, need to train well enough to be able to react to the situation.

\section{Post-Summit Questionnaire Responses}

Yes. Okay

Yes. What is this getting sick? 


\section{c. Would thermal protective clothing have been adequate?}

Yes, you should consider what is already onboard, maybe simply a thermal blanket. If the suit was easier to get on, it wouldn't have been an issue.

Some crewmembers stated that they wish they had taken the time to unstow the suits.

\section{Post-Summit Questionnaire Responses}

Yes

One can certainly design for improved sound suppression and add thermal blankets that would support an emergency power down such as we had on Apollo 13. The issue is added weight. That would have to be a part of a design trade study. Trying to provide comfort like at home and handling extreme emergencies might compromise accomplishing the basic mission because of weight growth.

\section{Waste Management}

a. Did you have any experience in the development of the "fecal canister" in the $\mathrm{CM}$ and do you know why it was never flown?

It worked fine, however it could have been a little bigger.

Diarrhea needs to be prevented in $0 \mathrm{~g}$ to eliminate mess and time-consuming cleanup. Systems should be designed differently for $0 \mathrm{~g}$ versus positive gravity.

First determine what should be used on the moon, then work on the vehicle.

\section{Post-Summit Questionnaire Responses}

No.

No. There was no fecal canister--just bags.

b. The urine collection device caused problems on virtually every mission. What specific problems did you encounter?, What are your recommendations for improving the device for CEV/LSAM waste management systems?

There were no problems with the UCD, however you want to sit on the moon not strap a bag to you. Have to know not going to move bowels on EVAs. Dr. Kerwin suggested using the Skylab system, since it worked great in $0 \mathrm{~g}$ and in $1 / 6 \mathrm{~g}$ it doesn't need airflow. Problem solved! All participants concurred. System must be customized for both men and women. Diaper is good for urine during EVAs, however cannot defecate in EVA suit. 
Apollo 8 did a urine dump and it turned into snow. It was a navigation issue.

"The Agency is trying to make everything perfect." It is not possible to think of everything that may go wrong. "Crewmembers are willing to suffer under certain circumstances."

\section{Post-Summit Questionnaire Responses}

Yes. Did not have a problem Yes. Don't poop!!

c. Was it acceptable to have a bag for outbound and return, as long as there was no "off-nominal output"?

Off nominal output was dominated by surface tension. It adhered and moved. Fix it!

\section{Post-Summit Questionnaire Responses}

No Responses

d. Waste management issues dominated much of the debriefs. The crews reported that they felt it "uncivilized". Although it depends on the crew, some crewmembers stated that they considered themselves explorers and felt they could put up with anything. That might be why some debriefs did not have complaints. You can put up with anything for two weeks, but it would be different on very long-duration missions. What can we do better, other than make the bag bigger?. We know mixed crews will also complicate things.

Calcium balance studies were being done that required crewmembers to collect waste.

Don't make it a requirement to save it, just dispose of it all, including the blue bag.

Everything would be fine if crewmembers had the time to do it, could clean it up, and didn't have to save it.

\section{Post-Summit Questionnaire Responses}

Yes. Not a big problem. Dispose of collection bag before entry. Yes. Uncivilized? What the hell is this!! Take them camping in the woods for a few weeks!! Wimps need not apply 
e. Do you feel a need to separate your area for food preparation (galley) from waste management? It was designed to take up limited space. What should be done about this?

The crewmembers felt there was no choice in this situation.

\section{Post-Summit Questionnaire Responses}

No. Nothing

Space limits dictate. We can live with that.

Yes. Separate for the weak of heart.

\section{Noise/Acoustics}

1. Noise level in the CM was unacceptably loud, interfering with sleep periods. What mechanical systems were responsible for the noise (e.g. cabin fans, glycol pumps)?

Inverters were noisy, but a pleasant. sound because it meant everything was working. Earplugs worked. High screeching noises were unacceptable.

Crewmembers didn't seem to be too concerned with the noise and stated that it did not keep them awake. The absence of sound would have been more uncomfortable.

Minimize noise, but don't eliminate it. There are noise-canceling devices today.

\section{Post-Summit Questionnaire Responses}

No. I liked the background noise for sleeping.

Yes. White noise is good.

I personally was not bothered by the noise level in the CM on 8 and the CM was shut down on 13. It seems to me, the orbiters being much larger than the CM the noise levels should be lower. On Apollo, we had ear plugs for communications and were helpful in reducing noise to the ear.

\section{a. Was there a threat to hearing?}

No, there was not enough sound to threaten hearing. The iPods are a concern now, but didn't exist on Apollo. 


\section{Post-Summit Questionnaire Responses}

Yes.

2. Was hearing protection or noise attenuating devices available for the crew? Did they work adequately?

\section{Post-Summit Questionnaire Responses}

Had none. Needed none. (Maybe that's why I'm deaf now.)

No.(no hearing protection was used)

We had the Snoopy earphone caps -I never was bothered by noise.

Don't think so, but would not use anyway.

Not available. Not needed

\section{Sleep}

1. Some crew preferred being wedged into something to feel secure for sleep. The sleep restraint system was outstanding. How can these important considerations be incorporated into the CEV/LSAM design, based on your experience in the CM/LM?

There is good technology today. No reason to re-invent the wheel."

After approximately 3-4 nights of adaptation and excitement, gave in and went to sleep.

Pillows and comfort items are important.

Sleeping in the hammock was comfortable, although frequently awoke to check things. $1 / 6 \mathrm{~g}$ solves problems.

\section{Post-Summit Questionnaire Responses}

No. Used hammock for about 3 days, then did not bother with it. Slept mostly in couch after that.

Yes

The sleep restraint system worked fine in Apollo and I suspect they worked just as well in the orbiters. For lunar surface, hammocks could be rigged in the LM. You will have to ask others on how good they were. 
a. Are there any other comments about sleep, besides the ones discussed above?

One crewmember reported a loss of proprioceptive that kept him from going to sleep in the first rest period after launch. He realized he could not feel where his arms and legs were and how much muscle tension it took to get them back. This only occurred during the first sleep period and he never noticed it again after that.

That first half hour rest period was a "fascinating experience".

Another crewmember stated that using the restroom at night always woke up other crewmembers.

\section{Post-Summit Questionnaire Responses}

Fetal position felt good for sleep but the sleeping bag allowed only one knee to be raised at a time. (I) Make sleeping bag large enough to get both knees up, (2) Provide strap to hold knees up. As I drifted off to sleep, I would release my knee \& it would wake up.

Yes

\section{Air/Atmosphere}

1. The lunar crews stated the moon dust had a distinct "wet ashes or gunpowder" odor upon return to the LM. Were these odors/fumes noxious, i.e., did the crew experience any reactions to this odor?. Was it cleared by the LM ventilation? Were there other sources of dust and particulates in the CM or LM? Was lunar dust noticeable in the CM?

See dust issues above.

\section{Post-Summit Questionnaire Responses}

Yes

a. Were there any problems with air or water quality? Was there a need for point-of-use filtering or biocide? For air contaminants, what would you recommend that we monitor for?

CO2 levels should be monitored in the air.

Chlorine in the water was an issue during one early Apollo mission, however it was resolved in later missions.

Crewmembers didn't notice a problem with the water if it was mixed with food. Chlorination and ionization technologies should be reviewed for future missions. 
Gas-permeable bags had bubbles, but this has been resolved.

Chlorination is not an issue now. Information can be obtained from the debriefs.

The crewmembers reported headaches and wondered if they were caused by $\mathrm{CO} 2$.

\section{Post-Summit Questionnaire Responses}

CO2 most important.

Yes.

\section{b. Were $\mathrm{CO} 2$ measurements reliable?}

CO2 monitoring was unreliable and the readings were no good.

\section{Post-Summit Questionnaire Responses}

No. Didn't know this!! 


\section{Microbial}

A discussion was held regarding the build up of microbials in closed vehicles and how this would be managed. Topical wound care treatments, such as Neosporin, should not be used routinely, but only for high-risk wounds that are at risk for infection. There may be changes in wound healing during space flight, so it is not yet known how this will be handled for future exploration. Topicals were more resistant to loss of potency. This is a big issue for long-duration space flight. Topicals will be available, but not necessarily used for routine wounds.

It is not known if antibiotics will remain active and useful in space. One audience member commented that it may be like "Civil War" medicine without antibiotics. If one crewmember had an organism, all the others would get it.

Dr. Fischer stated that we don't know how absorption occurs during space flight. This is a major issue that needs to be addressed. Dr. Jones stated, however, that there have been some cases of in-flight infections that have been successfully treated with the medications flown. There is more capability now and prevention is the best approach. A different design is needed for urine collection.

\section{Stowage/Layout}

1. In emergency suit donning cases such as cabin depress, was there adequate time to allow retrieval of suits, to install the docking hatch, to reposition the seats, etc.; if new designs would have helped, any suggestions on how to reduce the amount of loose equipment that must be found and installed, etc.

Design a plan to don suit rapidly.

It must be done sequentially (Note: unless cabin volume accommodates two crew donning simultaneously)

It might have been possible to do two at a time donning the suit, but it still would have been difficult.

A self-sealant is necessary.

(There was an additional, emergency garment during Gemini 7.)

\section{Post-Summit Questionnaire Responses}

Yes

Yes. Depends on leak rate, but why is he pressurized? 


\section{Docking hatch opening and stowage options}

Make sure the hatch is created to comfortably accommodate a crewmember in a pressurized suit.

\section{Post-Summit Questionnaire Responses}

Yes

Yes

3. Stroking pallet (struts up vs. down); clearance options for moving about underneath and for potential maintenance / IFM scenarios

Do what is ideal for the mission. Obviously, space is needed. The Command Module is good.

\section{Post-Summit Questionnaire Responses}

Yes

Yes

4. Were there any issues/lessons learned with respect to reach or field of view to switches, controls, windows \& displays during high-g and zero-g; did you participate in any ground-based centrifuge or zero-g flights and how did that prove useful in the design of these areas?

$0 \mathrm{~g}$ was an asset when trying to reach for things. Take advantage of 0 gravity in designing.

The CM was confined, but still had reaching ability.

Get more astronaut participation at the design phase. Need to have operational consideration during the design and development stages.

\section{Post-Summit Questionnaire Responses}

Zero-G flights most useful. Better than pool for many operations.

Yes 
5. In the case of a side on landing on a wave or ground landing of the same, would the Apollo seat and restraint system have been adequate; any suggestions on how to design it now?

\section{Post-Summit Questionnaire Responses}

Do not do ground landings unless you want to kill the crew(s). Seat design should allow for impacts on waves.

Keep the seat belts tight! Don't overly complicate it. Look at Russian designs.

Yes. I believe the system would have been okay. We did not stroke seats on landing with 2 chutes.

Apollo design was good for both!!

6. Recommendations on stowage of items in irregular spaces/in creative ways; how would you design it now?

\section{Post-Summit Questionnaire Responses}

Think about putting REID tags on each (or each important stowage item. This would allow quick electronic indication of each item's location; even if misplaced after initial stowage.

Stow items as needed in volumes

Yes

Apollo was good!! Map

7. During EVA prep or post, were there any issues with umbilical plug-in locations, tangling with other umbilicals \& people, umbilicals too short, long, correct number of each, etc.

No significant issues on LEM, but give plenty of space to don/doff.

\section{Post-Summit Questionnaire Responses}

Okay

8. Describe challenges of nominal and/or emergency suit donning in zero-G \& suit stowage, given the small size of the spacecraft. 


\section{Post-Summit Questionnaire Responses}

Practice, practice, practice, Apollo 16 crew did don and doff at least 6 times in LM simulator.

It was tight but doable. $0 \mathrm{~g}$ feels like bigger space than $1 \mathrm{~g}$.

Tight quarters no big problems.

See 7 above.

9. Describe any limitations or good points in the use of the windows to see the horizon during nominal and off-nominal ascent/entry as well as their use in viewing the LEM docking target during a rendezvous.

\section{Post-Summit Questionnaire Responses}

Windows should be designed to see what you need to see to land and/or rendezvous and no more

Yes. Good visibility for docking. Used horizon as Entry attitude, Good!

Apollo was adequate.

Be very careful about Pls who want to have windows without IR protection. It's an insidious trap with potentially serious consequences a filter.

10. Can you describe egress, human factors issues that have crew health and safety impacts?

\section{Post-Summit Questionnaire Responses}

The egress ingress of the LM was the most difficult because you had to arch your back over the ascent stage engine bell in the cockpit.

None, not anticipated.

Question is, what!!

11 Are there any suggestions to create privacy for mixed crews during the waste and fecal collection processes; how was privacy created during Apollo, did you go under the seat pallet, use fabric barriers, etc.

\section{Post-Summit Questionnaire Responses}

No privacy allowed. No room for it. Providing privacy in the CEV is dangerous to crew survival. The CEV should be 4.5 meters max diameter.

Just went to LEB -but tbr space, not privacy.

No. We were ready for this and did not seek privacy as I recall. 
No privacy -but how do families live? Some privacy required -private space vs. practicality -don't be bashful!!

12. With regard to having hot \& cold water and a food warmer, how important is it to have these items vs. the precious space they occupy in the tight cabin confines; would this be considered a necessary comfort item in cases where there a lots of crew in a small space for several days, i.e., 6 crew to ISS?

\section{Post-Summit Questionnaire Responses}

Not a big deal. We had it in Apollo

We had hot \& cold water. New meals w/warmer would be nice but not critical.

Hot \& cold water is a must -food warmer is desirable.

\section{Radiation}

1. With regards to lunar surface operations, in the event of a solar event, can you describe any difficulties you may have had returning to a safe haven? What ideas can you offer on creating a safe haven in a remote area?

Put shielding that you can pull out on your rover, or maybe something you can hide under-perhaps dig a trench and sit in it.

\section{Post-Summit Questionnaire Responses}

Yes

2. Medical operations and regulatory requirements mandate that each crew wear a crew personal dosimeter (small device that measures radiation exposure level at the surface of the body) at all times throughout the mission. The crewmember's evaluated exposure could be artificially high or low if the CPD is not worn. Can you suggest pre-flight or in-flight actions that would improve crew compliance with always wearing CPD?

\section{Post-Summit Questionnaire Responses}

Attach it to suit garments so the crew persons don't have to locate it, find it and put it on. Make it invisible?

No. Training! 
We always wore ours. Make it a mission requirement.

3. The crew can play a crucial role in managing their in-flight radiation exposures. This could be as simple as sleeping in well-shielded locations. Do you agree that the crew should actively manage their radiation exposure during a mission by monitoring their exposure and modifying their shielding? If radiation protective nutritional supplements or pharmaceutical agents were approved for spaceflight, would you consider using them?

Yes having the information about incoming radiation could help.

If protectants can work or reduce the health impact, then yes, we should have them available.

\section{Post-Summit Questionnaire Responses}

Yes

Yes

4. Current radiation detection technologies provide the ability for crew readout of real-time radiation levels, customizable alarms, and "hot and cold spot" mapping of the vehicle's habitable volume. Do you have preferences or advice on how these readouts or alarms should be designed? Would you have found this information useful during enhanced space weather events (SPEs)? Or during times when there is a loss of communications?

Should have active radiation detectors with alarms that sound when the dose gets too high for safety, so you can get back or find a safe place.

\section{Post-Summit Questionnaire Responses}

Yes

Yes

5. Active radiation monitoring either integrated into the suit or a rover would provide necessary dose information (i.e., rising radiation levels during a SPE) while EVA to provide for operational decisions that would work to ensure that the crewmember's dose is maintained within limits. Would you have a preference for where the monitoring device would be located? 
They should be attached to each suit.

\section{Post-Summit Questionnaire Responses}

Yes. Each suit

Yes.

\section{a. There is a plan for warning dosimeters as a means of early radiation detection and alert. How do you feel about this?}

There is no problem with having these on the suits, however it may be too late once the alarm sounds.

How do you get a true forecast and warning system? It would be interesting to have more details.

\section{Post-Summit Questionnaire Responses}

Early warning is key.

Yes. Solar flare detection is a must.

b. Advance warning is currently very limited and there are issues with donning suits rapidly and plugging in umbilicals. How could this be made better?

The crewmembers did not remember problems with the connect/disconnect systems.

They had no problems in training or with the attachments and the disconnect systems may be even better now.

They were hot miked during prep and de-prep and those transcripts are available. Comments would have been made if there were problems.

It would have been difficult to get the suits on any faster than they did. If they tried too quickly, such as in the case of an emergency, they would have skipped some checks.

There were issues with waste management. Going back to the moon would be like "camping out", but Mars would be a problem.

\section{Post-Summit Questionnaire Responses}

No problem with normal donning -Don't have experience with panic mode. Yes. 


\section{Exercise}




\section{Exercise}

\section{Exercise and Fitness}

1. Did you feel physically fit prior to the mission, and did you have good strength and endurance while on the lunar surface?

Post-Summit Questionnaire Responses

Yes, we had exercise protocols in the ground and glove boxes to strengthen your hands.

Yes and N/A

Yes

Yes, but I slept poorly -If I could do it all again, I would take a sleeping pill (I do not use them on Earth).

Yes.

2. Did you feel more 'winded and fatigued' that you expected? Did you feel more unbalanced' or uncoordinated than expected while working on the surface?

We got tired, but we were pumped up with adrenaline. Probably would wear off for long missions.

\section{Post-Summit Questionnaire Responses}

No Responses

3. What do you see as the role of pre-flight conditioning? What is your opinion of its importance to mission success for these short duration trips?

- Make requirements known and plan time in the schedule to meet them.

- Loosen the timeline.

- Apollo crewmembers always scheduled time for running. Strength exercising was done at night on our own.

\section{Post-Summit Questionnaire Responses}

Good comments

Yes. 
4. Are there any aspects of your preflight or in-flight exercise training that you would change to better prepare you for your mission tasks?

Post-Summit Questionnaire Responses

No.

People are bright -give them imagination \& they'll take care of themselves.

Size the flight suit slightly longer than the training suit. There must be accurate data by now.

No. Training adequate.

5. In terms of physical capabilities -what were the hardest and easiest tasks that you had to perform during lunar EVAs?

Repetitive hand gripping and forearm activities. Getting things out of the cases when they had been baked in was also tricky.

\section{Post-Summit Questionnaire Responses}

No Responses

6. Were there any physical tasks that you couldn't do or had to modify substantially from the original mission description due to fatigue or injury or other factors?

There was some mental fatigue.

"There were short periods of time when mental attitude went into idle because there weren't any exceptional observations."

Post-Summit Questionnaire Responses

Not for me. (no mental fatigue)

Yes.

7. Was your task load and recovery time coupled well for your mission as a whole? Was it coupled well on a day-by-day basis (versus too easy or too hard)? If not, did inadequate rest between demanding tasks contribute to fatigue and/or injury?

Have two teams working EVAs on alternate days.

Give crewmembers time off with no responsibilities.

EVA day should not be all planned out.

Give objectives and allow crew to dictate their day to accomplish their tasks. 


\section{Post-Summit Questionnaire Responses}

Yes.

a. During EVA day would it have been better to have a break during an EVA? Go out and come back in and go back out?

Do not break a day in half at all. Once out there, get it all done, no interruptions. If you

have a suit that can allow you to be out longer, there might be a concern.

Once you get into a project you lose track of time. Contact with the ground is necessary and you have to have discipline.

Post-Summit Questionnaire Responses

Yes.

8. Given your physical condition immediately post Landing, would you have been able to (1) egress unassisted from the Apollo capsule and (2) assist an injured crewmember with egress in an off-nominal, emergency scenario?

Yes, we could have gotten out, as well as assisted an injured crewmember.

Felt physically fit enough to do this unless there were high seas-could not do in those cases.

Post-Summit Questionnaire Responses

Yes

Yes.

9. How long did it take to return to normal daily activities following the mission?

- One crewmember felt normal almost immediately. Generally returned to normal activities within 48 hours.

- Another crewmember stated three days later he felt normal.

Post-Summit Questionnaire Responses

About 3 days to feel normal. About 2 weeks to fully recover conditioning.

Yes. 
In-flight Exercise and Hardware

1. The Exer-Genie is mentioned in several of the debriefs. Did you use it? If so, in what configurations, for how long per session, and during what mission phase (e.g., surface, outbound, return phases)? Can you expand on its negative and positive impact? Do you think it was helpful in maintaining fitness or strength?

- The consensus is you don't need exercise on short trips (14 days or less).

- Exercise is important preflight.

- EVAs provide enough exercise.

- Having it there is fine for those who want it, should not be a mandatory protocol to use it.

- It is useful to have the knowledge that there are certain exercises to reduce fatigue.

- Exercise feels good.

Post-Summit Questionnaire Responses

Yes. Didn't work after a couple days. Retained heat.

Yes. Learn how to use the device

2. Exercise was reported to improve low back pain during the mission. Crews mentioned specific exercises but were unclear how they performed them. Can you describe the types of exercises you performed? Considering the design for the CEV/LSAM, can you explain how you might perform them in this environment? Did it help with back pain or stiffness related to confines of the vehicle?

In addition to the Exer-bike during early Apollo, we did some running in place and isometrics. It can relieve less in your muscles.

Exercise should be available without getting in the way of the other crewmembers.

Post-Summit Questionnaire Responses

Yes. Used outer couch rails to do pushups. Moving back as in sit-ups helps.

Yes

3. The crews mentioned that they did not want to perspire during exercise in the cabin, and backed off on the intensity to prevent perspiration from forming. What was your concern with perspiration?

Hygiene was a concern because there were no showers and not a lot of towels. We didn't have these wet wipes to clean up with on the earlier missions. 
On later missions the "wet" wipes had a bad odor.

\section{Post-Summit Questionnaire Responses}

Don't recall a problem. Filter good at removing odors.

Yes. No concern.

4. Were there any stress relief/psychological benefits from using the ExerGenie? Did its use impact other crewmember activities (due to small space in which exercise could be performed)?

Yes the exercise can be a stress reliever or just put you in a better mood. Exercise can have a beneficial effect during the whole mission, just don't have specific schedules for it, let us do it as RnR.

\section{Post-Summit Questionnaire Responses}

No

Yes

5. Do you think formal exercise is required on a two-week lunar mission to perform EVA tasks and to maintain fitness for egress on return?

- Should not be a man mandatory protocol

- Should be physically and mentally ready

- "Would like to through by people who understand muscle."

Post-Summit Questionnaire Responses

Helps relieve minor aches, but not necessary on short flights.

No not required.

a. The crewmembers have indicated that they do not want scheduled exercise periods on the timeline. They want to exercise on their own time. Is there anything else to add?

No exercises were done for bone density during Apollo. This would be a problem on long-duration missions.

When the Exer-Genie was no longer used, crewmembers performed push-ups and ran in place. 


\section{Post-Summit Questionnaire Responses}

Yes

6. Volume and upmass will be limited in exploration vehicles/habitat as it was on the Apollo vehicles. Given the limitations this will impose on possible exercise devices, are there any specific types of exercise (stretching vs. aerobic vs. resistance-type) that should be a priority for lunar sortie and lunar habitat missions?

\section{Post-Summit Questionnaire Responses}

Aerobic probably the best for long duration surface missions.

Watch out for devices that depend on friction -ours got so hot that it eventually destroyed the cord. It's dangerous.

No. Stretching best

Don't know

Any exercises that can be provided WRT space -h EVAs provide enough

7. Apollo 7: The crew suggested the Exer-genie could use some improvements. What type of improvements would you recommend and how can these improvements be incorporated into the devices planned for CEV/LSAM?

It needs to be reliable and simple to use.

\section{Post-Summit Questionnaire Responses}

No. Good device on Earth. Need something else in space. And know how to use it.

a. A more robust (and lightweight) piece of equipment is needed. Are there any comments to help in development?

Put as many capabilities in the vehicle as possible, because it will get used.

Exercise throughout flight will be critical. A variety of exercises must be provided.

\section{Post-Summit Questionnaire Responses}

Yes. 
8. Several crews stated that the exercise device got hot during sub-maximal use. The heat generated prevented stowage secondary to the crew's concern of a fire hazard. What part or parts of the device generated this heat? How would you suggest designing the device differently to obtain maximal workloads and be safe, considering the mass/volume constraints of the CEV/LSAM?

Heat was generated in the rope.

A crewmember asked what will be done one week prior to returning, in order to counteract SAS during short flights. It was explained that high-intensity training will be used. The body should be worked hard so it counteracts orthostatic intolerance.

The blood volume needs to return to what it was originally.

The ASCRs work with the crewmembers individually and provide prescriptions for exercise. Although they do not monitor them daily, they do provide a program for them to use.

A discussion was held regarding how to get cardio for the entire pulmonary system with the differences between $1 / 6 \mathrm{~g}$ and $1 \mathrm{~g}$ ?

$G$ suits were discussed. The Russians use lower body pressure cuffs.

Exercise must be performed on the surface, as well. Decrements have not been completely eliminated in space flight so far.

\section{Post-Summit Questionnaire Responses}

See above -Friction of rope on control spindle -inherent to design. Don't depend on friction on a small surface.

The rope on our Exer-Genie stretched. Friction clutch got hot

Yes 
Food/Nutrition 


\section{Food/Nutrition}

1. Initial allocation of space for food supplies on Apollo missions was 5003 cubic inches. Baseline food and packaging requirements were 4830 cubic inches. Over time, the food system volume values increased. By Apollo 14, the average volume/man/day was 188 cubic inches. This equates to a total of 7896 cubic inches required. Where was the extra food stored?

- The regular meals were stowed in one compartment in the left hand equipment bay.

- The problem was not stowage, but it was the garbage requiring twice the volume of the initial stowage.

- The radiated food was in foil and there were no hard containers.

- There was a lack of flavor or spice in the food. The bacon squares were the best food. It was something to stimulate the taste buds and for the flavor itself.

\section{Post-Summit Questionnaire Responses}

Yes

2. How did the additional 2893 cubic good get stored? Was all the food stowed together? Were only hard-sided containers used for food storage?

See \#1 above.

\section{Post-Summit Questionnaire Responses}

don't remember

3. If you had to rank the overall importance of the contribution of each of the following to eating during flight how would you rank (very important, somewhat important or not important): 1 . Lack of taste; 2 . Lack of time; 3. Don't think it's critical if I lose a little weight; 4. Don't particularly like the food; 5 . Food is somewhat difficult to prepare; 6 . Sometimes nausea or gastrointestinal distress makes eating unappealing; 7. Lack of "social" interaction detracts from food intake.

\section{Post-Summit Questionnaire Responses}

The normal newer MREs are adequate. Rating the above is weird.

6512437

(1) v.I., (2) N.I., (3) N.I., (4) N.I., (5) I., (6) N.I., (7) N.I.

(I) Very important, (2) Very important, (3) Somewhat important, (4) Very important,

(5) Very important, (6) Very important, (7) Not important. 
(1) Somewhat important, (2) Not important. (3) Not important -drink water, (4) Not you select your own, (5) Very, (6) Not, (7) Not.

4. There is some discussion not to have hot or cold water and/or a food warmer on the CEV.

Hot water is an absolute necessary on both vehicles.

Hot food is more comforting than cold food.

Find out how the original wet packs were put together.

Post-Summit Questionnaire Responses

Hot food is very important. Warmers may not be critical. Yes.

5. How important would you say heating your food was/will be during a short duration mission (less than 7 days) or a longer mission (more than 7 days)?

See \#4 above.

Post-Summit Questionnaire Responses

Very important

Yes.

6. How important would you say cooling your food items was/will be during a short duration mission (less than 7 days) or a longer mission (more than 7 days)?

\section{Post-Summit Questionnaire Responses}

Unknown -Preservation for fresh items for long missions will need a refrigerator.

Not critical

Cool what? -ice cream -water -ice tea! Get real.

7 , Were there any vehicle environmental changes during a mission that you recollect there being a change in food temperature that was either positive or negative? 


\section{Post-Summit Questionnaire Responses}

No. No.

RG: No.

8. Was there any concern on the relative locations of the hygiene and waste areas and food stowage/galley area?

No we had to eat in the same place we pooped, but that is not the best situation, we just had to do it.

\section{Post-Summit Questionnaire Responses}

No.

Yes.

9. Was there any issue with EVA performance due to quantity or quality?

Lunch and plenty of water was needed on EVA

Post-Summit Questionnaire Responses

No.

Yes

10. It has been reported that bread packages often burst when the vehicle was depressurized, There was also report of an incident with chocolate pudding.

Post-Summit Questionnaire Responses

Fix the packages. No real problem.

a. Did you observe other products (especially wetpacks) that also lost packaging integrity during this time or at any other time during a mission?

No regular packages had any problems. 


\section{Post-Summit Questionnaire Responses}

No.

The LM water gun leaked because a thread from one of our beta cloth garments or stowage bags got lodged in the valve opening. It was a very slow dribble. After getting fixed, it did not impede our delivery of $\mathrm{H} 2 \mathrm{O}$. I feel we got dehydrated because we lost our hot water source when we shut down the CSM. As a result we did not subsequently consume any of the powdered, freeze dry food and hence a loss of a lot of water one gets that way. We lived off the "wet packs" and cookie \& bread cubes from the snack area. Secondly, with the low work load floating around in Zero $\mathrm{g}$ and the cold environment we just didn't get as thirsty as we normally would. I know that Jim is quoted as saying that we deliberately rationed our water. I can state that I did not ration, but obviously did not consume as much water as I should have.

\section{b. Were you instructed to discard these items?}

\section{Post-Summit Questionnaire Responses}

No

No

11. Apollo 10: How would suggest developing meal plan/food choices for timecritical activities to allow you to get necessary calories and fluid in a convenient manner?

\section{Post-Summit Questionnaire Responses}

What we do now in the Shuttle is adequate.

A-12, 13, 14, 15, 16, 17. What's with $10 ?$

12. Did it mean anything to be able to see the food through the packaging?

It helped to pick some things out, usually we could only tell by the labels.

\section{Post-Summit Questionnaire Responses}

No. Labels were okay.

No. You selected the menu. 
13. Did you crave certain foods or types of foods?

Spicy and salty foods.

Post-Summit Questionnaire Responses

Coffee

Bean needed pasta.

\section{a. Was the food bland? Would you have preferred spicier foods?}

Not if it would cause a diarrhea problem. Just more flavor in the foods.

A crewmember commented that they were told they would get individual menus, but that did not happen.

Post-Summit Questionnaire Responses

Yes, more taste

No.

14. How important was it for you to time out at least once a day and eat together?

We were on the same schedule for eating, sleeping, etc.

Post-Summit Questionnaire Responses

No. Very

Yes.

15. Did the lack of appetite or space sickness affect your performance during the mission?

Post-Summit Questionnaire Responses

No

No

You betcha! But/and it went away.

Yes on Skylab for 4 to 5 days. 
No.

16. What do you consider to be the major impediments to eating and maintaining weight during flight?

Post-Summit Questionnaire Responses

An overly ambitious timeline

Time to do it

For me SMS

None. if you eat your plan.

Food taste and the time it takes to prepare and clean-up Eating ok, dehydration

It's my impression that the food in Apollo was uniformly OK preflight and absolutely unattractive in flight. I did not have that experience in Shuttle. Makes me think it is either $\mathrm{O} 2$ toxicity, reduced pressures, or, less likely, unaccelerated flight.

\section{a. The crewmembers lost weight routinely...some lost 8-10 pounds. What can we do to make the food more palatable?}

We were debriefed extensively. All of this information is available.

\section{Post-Summit Questionnaire Responses}

Weight loss was mostly due to sweating, \& air cooling after landing in suits in the ocean. If liquid cooling was available, the loss would have been 2 lbs at the most.

TV dinners would be good.

Yes. Weight loss!

b. How important do you feel that it is to get sufficient calories in a day? Please provide an example (if any) of the importance of nutrition and food intake.

You need enough food to maintain your strength and alertness. One crewmember didn't lose any weight.

Post-Summit Questionnaire Responses

Yes. Need the energy

Yes. Adequate calories provided. 
c. Do you feel that it is important to have a preflight eating plan that optimizes nutrition for the best possible nutritional status before flight?

\section{Post-Summit Questionnaire Responses}

Sure

No.

Just have the food taste like what it says it is.

Yes

Maybe

Yes

d. What is your attitude about supplements in general? If you were shown data that a supplement such as omega 3 fatty acids would be protective against certain health issues would that convince you to take the supplement?

Supplements could be good if stowage is a problem, no issue with using them.

\section{Post-Summit Questionnaire Responses}

No

Yes

Yes

e. Would data on the timing of exercise to food intake affect your behavior if shown that one type of eating pattern helped to maintain muscle mass more than another eating pattern?

Post-Summit Questionnaire Responses

Probably not

No

Maybe

Yes

Yes,

maybe

Yes 
f. How important do you think optimal diet and food intake is to your overall performance?

\section{Post-Summit Questionnaire Responses}

Not very on short duration missions.

For long missions, it is important.

Adequate is good -nothing more here.

Very

Very important

Very

g. How important do you believe that rehab post flight might be if optimal diet and exercise were combined?

Post-Summit Questionnaire Responses

Not needed for lunar surface ops if crews do EVAs as much as practical.

Very

Very

h. Considering current packaging configurations, do you believe there to be any advantage/disadvantage relate to preparation and consumption as compared to Apollo-type packaging?

Wet-packs.

\section{Post-Summit Questionnaire Responses}

Packaging much better now.

Skylab cans were better -bags are tough -not appetizing.

Don't really know

Yes

i. Though rehydratables and wetpacks (currently known as thermostabilized and irradiated) required more resources than bite-size (cubes) items, do you believe there were specific bite-size items that were of high enough quality to compete for selection/provisioning? 
Wet packs were best. They were good and they were easy to use. Rehydratable foods were fine. We liked most of the foods. Basically, it was trail food. It is probably much better today than it was then.

\section{Post-Summit Questionnaire Responses}

No, maybe snacks

Yes

\section{Pharmaceuticals}

In response to a question from a crewmember about how to qualify a pharmaceutical for space flight, Dr. Jones explained that most medications are tested on crewmembers prior to flight, however this does not account for possible altered characteristics in a new environment.

Dr. Fischer stated that there is no evidence that drugs have had different effects in space than on Earth. It may be necessary to alter the dose and/or the route of delivery, but it has the same effect.

Dr. Pool stated that we do not have a well-established understanding about this issue and we need to obtain the information somehow. We must target the specific information that we want, obtain the norms, and get an idea of what to do.

A number of experiments will take place, including bisphosphonates. This drug is really not intended for this population, but rather for osteoporotic women, so it is unknown how it will effect this population. We will be looking at calcium excretion and other bone markers, etc.

We will need to be able to archive urine and blood. We will also be looking at hydroxyfolie. 


\section{Crew Work/Rest Schedules}




\section{Crew Work/Rest Schedules}

\section{Sleep and Fatigue}

1. The Apollo 15-17 lunar crews felt they were able to sleep and function adequately in the LM during the lunar surface ops for their $31+$ hours on the moon, although they didn't sleep more than 3-4 hours at a time. What changes would the crew make in the LM to preserve sleep/daily activities for missions of 7-14-30 days? Should there be a hard fixed sleep period of 8-10 hours? What would be a nominal workday length?

- Give crewmembers a scheduled sleep period (eight hours of rest where nothing is scheduled).

- Staggered sleep distracts others from sleeping when one crewmember is moving around.

- Cannot dictate sound sleep, but must give crewmembers private time.

- A crewmember commented that "Circadian rhythm has nothing to do with space."

- Changing back and forth (sleep shifting) is not desirable

Consider mental fatigue and physical fatigue separately. Although there was not a great deal of physical fatigue, the mind was being used quite a bit. You can sometimes wear your brain out before your body is fatigued.

It took about 3 days to get adjusted to weightlessness and be able to sleep. The head is not stabilized on the pillow in $1 / 6 \mathrm{~g}$, So you feel like you're falling off, but you get adjusted to the feeling.

There are terrestrial examples of circadian rhythm shifts in new environments (i.e., long-duration cave habitation). There are shifts when you leave the Earth's surface.

In space, the Schumann Resonance Frequency (SRF) must be considered. Discussions should be held with experts who have studied this.

The impact of the workload of mission control support personnel is also a factor. They need defined sleep periods and time off to keep the mission functioning.

It might be worth looking at the work cycles of Mission Control operations during Mir.

The crewmembers commented that the Apollo 13 crew was still able to function, even though they were the most sleep deprived of all missions.

The flight surgeons should be advocates for the crews.

The 8-hour sleep period should not be compromised even if the crew doesn't use all of it because they are just dozing part of the time. 


\section{Post-Summit Questionnaire Responses}

Yes

2. The crews slept in their suits during surface ops for Apollo 11 through 14 and reported that suit discomfort led to a poor quality of sleep. Apollo 15 and subs slept outside of the suits, yet still reported less-than-optimum sleep. Can this be attributed to scheduling, environmental noise, lighting, tasks, ground communication, sleep shifting or difficulty in relaxing in a strange environment, or did other factors contribute?

\section{Post-Summit Questionnaire Responses}

I slept great. If folks are worried about the machinery failing, they won't sleep well. Even with pills, Charlie didn't sleep too good.

Fear of not being alert if an emergency came up -This can't work for long duration stays.

3. Sleep deprivation and fatigue caused by a host of factors was mentioned in medical debriefs. These factors included excessive cabin noise, comm. interruptions, sleep shifts, cold temperatures, and staggered schedules. How was crew performance and morale adversely affected by sleep deprivation and fatigue? Were critical operational activities impaired (e.g., TLI and TEI burns, lunar orbit, re-entry preparation)? What suggestions do you have to avoid such problems on future lunar missions?

- Apollo 13 , were most affected by sleep deprivation, but were able to perform.

- We stuck to the plan. Didn't feel anyone wasn't performing to their level. It was not an issue.

- More attention was paid to the schedules than to crewmembers' sleep time.

- At one point, the decision was made to stop work completely and go to sleep on Apollo 13. There was a physiological and mental need to stop and sleep so we told the ground stop we have to go to sleep. It turned out to be the best decision in order to continue. Mental fatigue is a bigger factor than physical.

\section{Post-Summit Questionnaire Responses}

Apollo 15 crew slept at same time -and on Houston time. Made normal work day and sleep much easier. No diurnal shift.

Yes 


\section{Nearly all Apollo crews reported being tired on launch date, and medical debriefs indicate an intense pre-launch training schedule that caused fatigue, Can you suggest a reasonable training schedule 6-8 weeks before the launch date that will allow crews to launch adequately rested?}

- The last week of training was mentally fatiguing because continually training for things that would not occur. The training schedule should allow for crews to concentrate on things that will be used for the nominal mission.

- Contradictory comment: "Don't remember saying they were tired at launch."

The crew planning timeline is critically important. Private communications have revealed a sense of frustration in crews trying to fit everything in. There must be a suitable plan in order to avoid serious operational problems caused by fatigue.

Dr. Pool stated that we should not take what was done during Apollo and use it as a model for Mars.

The crewmembers pointed out, however, that the lessons learned during earlier Apollo missions were helpful in later missions. The problems were still present during Skylab, however the timeline again improved in later missions.

The crew schedule should have slack early in the mission to allow time for learning/training.

The crewmembers reported that they were fatigued on launch day, due to the timeline for pre-launch training. They felt that much of the mental fatigue was due to the amount of non-essential training that was not operationally relevant.

One crewmember stated, however, that it was often the crewmembers who were asking for briefings if they needed additional information.

The timeline was sometimes less structured by the trainers than by the crewmembers themselves. The launch environment must be improved.

The pre-launch quarantine was helpful since there was time that wasn't scheduled. It allowed time for physical and mental recovery.

\section{Post-Summit Questionnaire Responses}

Just taper off the final week.

Yes. Schedule off time as part of prelaunch activities.

Yes. No wimps allowed. 


\section{Psychological Support}




\section{Psychological Support}

1. An Apollo 12 debrief mentions a wish for recreational materials, such as books or music, during travel to and from the moon as there were stretches of time with little to do. Looking back, what effects would having access to such items meant for you? Is access to such items needed for the future missions?

"Don't remember having any time on my hands."

It is very desirable to know what is going on in the world itself, news, sports, etc. Give me some way of getting this information in order to relax. "Send me the newspaper. Allow me to live there the way I live here. In the morning, I have a cup of coffee and read the newspaper."

Maybe having electronic books would be good.

Little things will frustrate you and hinder performance.

\section{Post-Summit Questionnaire Responses}

A plus

We carried a tape machine and played music. Made living more normal.

Yes

a. Regarding time alone after dropping others off on the lunar surface, what would make this more comfortable? Crewmembers reported that they liked the extra time, but wanted recreational activities when traveling to and from the Earth. In designing the CEV, what could be brought along to provide activities for the crew?

The CEV should be made as autonomous as possible.

It is important to engage the mind on these trips. One crewmember reported that they did their own navigation and this gave them something to do. There are opportunities to look out the window. One crew used the $x$-ray spectrometer to take a picture of something that turned out to be a black hole.

One crewmember stated that he wouldn't change a thing, since he had no problems passing the time. He enjoyed the time off and there are always housekeeping activities in the command module that need to be done.

\section{Post-Summit Questionnaire Responses}

Talk it over with crew. Some might like to play chess with opponents on Earth. I was very comfortable. Had a heavy workload and enjoyed the time.

Yes 
2. During the debriefs the lunar missions CMPs offered candid insight into the isolation and boredom they faced after the CDRJ LMP left for the moon until their return. What steps would you offer to ameliorate these concerns for future lunar crews?

\section{Post-Summit Questionnaire Responses}

I never felt isolated or bored. Obviously an individual matter.

$X X$. in the $A-X X$ CM was $100 \%$ busy the whole time. If you know the moon, there should be plenty of experiments to do while going around up there.

Teddy bears

I was okay. Good to get rid of those 2 guys for awhile.

Would not worry about this -Have them take music and books and books on tape or CDs.

I never felt isolated nor bored. Getting rid of XXXX \& XX for 42 hours was great but still glad to see them come back! ! You had to be there.

I thought that the solo time was really precious. In fact. routine operational chores and flight plan maintenance was a nuisance. To get around this, we had Hank Hartsfield (CSM Capcom) run the flight plan when we had AOS so I could look out the window and contemplate what there was to observe. I'd resume flight plan responsibility on the back side. Thanks to some superb geology training, you could see an awful lot and test various hypotheses. And I didn't have to listen to country and western music! 


\section{Crew Scheduling and Task Loading}




\section{Crew Scheduling and Task Loading}

1. In designing future mission scenarios, what are your recommendations for optimizing operational success and crew health for each of the mission durations (including task loading, task timelines with recovery, conditioning to prepare for tasks and off-nominal events, etc.)?

\section{Post-Summit Questionnaire Responses}

Practice, practice on the surface in suits where the tasks are defined and duplicated just like on the moon.

Allow time for all activities such as eating, resting, exercise, experiments, etc. We were preoccupied with the science.

Subject is far reaching and requires a great deal of discussion -Different positions have different responsibilities, i.e., CDR, CMP, LMP, Payload Spec, Mission Spec, EVA, etc. all different stressors.

2. Were there any additional stressors, unique to Apollo and lunar surface vs. LEO? Are there any other Apollo/Moon unique factors to consider with regard to psychological preparation, support and scheduling?

A person should be left to figure it out themselves. You prepare yourself. You were probably mentally ready when you were selected. Once you volunteer, those decisions are gone and you are ready to go.

After Apollo 1 or 13 we all could have left but no one did. As far as any programs, if you need a program you have the wrong people.

Getting everything done in the time you had to get it done was the highest stressor. Time is the greatest asset and enemy. You never have enough of it.

You get to the point where you have to perform and the biggest fear was screwing up and making the wrong decisions. "Thou shalt not screw up, first commandment."

\section{Post-Summit Questionnaire Responses}

Yes

a. What are the merits and demerits of the two weeks in quarantine postflight? 
There is disagreement about postflight quarantine. Some believe there is no possibility of anything surviving in a lunar surface environment that could be brought back and be dangerous to human beings. Others believe the postflight quarantine was justified because there may be unknowns. There was a question about why 21 days was the chosen period. Microbiologists advised that 21 days was about the maximum incubation period for any epidemics the world had seen. At the time, they didn't know about AIDS and other long-duration microorganisms that don't show up for a long time.

There was agreement that the quarantine allowed for postflight briefings and other activities to take place in a more tranquil environment without outside distractions.

Preflight quarantine is very valuable. From an operational point of view, it removed a large number of distractions from the last three weeks of preparations and the crews were much more rested.

\section{Post-Summit Questionnaire Responses}

Reduce the party load, although not critical.

Yes. Leprosy -21 days arbitrary (edited response) 


\section{APPENDIX C \\ APOLLO MEDICAL OPERATIONS \\ PROJECT RECOMMENDATIONS EXCEL SPREADSHEET}




\section{Apollo Medical Operations Project recommendations}

\section{EMU/EVA SUIT}

Gloves should be custom designed for each crewmember that

1 incorporate mechanical closure for gripping

2 Look into a wrist seal and depressurized glove

3 Robotic power-assisted glove for repetitive tasks

4 Glove liners should be worn

5 Reduce the mass of the suit by a factor of two Increase general mobility by a factor of four, primarily at the

6 knee joint

7 Lower suit Center of Gravity

8 Improve peripheral vision by adding neck ring (movable joint) Develop a reliable Heads Up Display that shows consumables Display requirement in HSIR for planetary 9 information, limited biomedical data, and navigation on demand suit.

The lunar boot functioned well and does not need to be

10 improved.

The drink bag should have capability to contain a high energy

11 liquid in addition to plain water

Develop a better in-suit Urine Collection Device (UCD) that will Requirement in HSIR, spec's for MAG will 12 work in $1 / 6 \mathrm{~g}$

The suit should be a low pressure (3.50 psia), single gas

13 system

14 Protect the suit zipper function

Develop a system that prevents helmet fogging during heavy

15 exertion

16
Already in practice for flight gloves

Will consider with counter pressure suit concept

Will consider in design for planetary suit configuration

Already in practice, to be continued in $\mathrm{Cx}$ D\&C

Suit mass trades being evaluated by EPSP

Suit mobility requirements being defined by EPSP

C.G. trades being evaluated by EPSP

Requirement in Design \& Construction document

Boot requirements in D\&C

Requirement in HSIR for planetary suit include improved interface.

Requirement in HSIR- variable pressure suit 3.5-8.0 psi; 100\% O2

Consider in D\&C specs

Consider Helmet ventilation specified in $\mathrm{D} \& \mathrm{C}$ to prevent fogging

Consider HSIR requirement for DCS risk
6 Use a self-sealing pressure garment within the suit for puncture reduction Materials selection in D\&C 


\section{Apollo Medical Operations Project recommendations LUNAR SURFACE OPERATIONS \\ STATUS}

Schedule crews for two Lunar EVA days on and one day for

17 maintenance, alternating crews throughout the week

The hatch and ingress corridor should be sized appropriately

18 for an inflated $\mathrm{l} / 6 \mathrm{~g}$ pressure suit

An airlock may make ingress/egress easier and will also be a

19 good idea from a dust control standpoint

20 Surface activities can begin once operationally feasible There is no special training needed for $1 / 6 \mathrm{~g} \mathrm{EVA}$ 's other than a

21 familiarization session.

22 Limit navigation into craters to $<20-26^{\circ}$ slope

23 Rover activities: CDR, LMP at risk for injury if not restrained

24 Risk for injury; Falling from a height; ladder, rim of a crater Ladder rung height and width on the Lunar Module (LM) were

25 good but the glove did not allow adequate grip for safety Ensure adequate water and food are available before and

26 during lunar EVA

27 Lunar EVA should be performed as one continuous event Plan the operations on the surface so that you protect the

28 crews from themselves

With extended ops on the moon, establish all the experiments

29 in the first week.

30 The Rover should have the ability to recharge the suit Crews requested that an automatic position determination

31 device be available to aid navigation on the lunar surface

A robot should perform routine, systematic, repetitive, menial

32 tasks (may help prevent repetitive use injuries).

Allow adequate time to practice mission activities in a variety of environments including analogs that allow preparation for off33 nominal events

34 Allow adequate time in the schedule for all activities
LAT and LAT defining architecture; to be placed in Ops Con document

Requirement for minimal hatch size in HSIR

Requirement for Airlock in EARD and CARD

Ops Con includes surface tasks for crew during landing day

Lunar Crew Training Plan

Ops Con; will need a Flight Rule

Consider for Rover requirements document; Medical contingency Ops

Need Flight Rule; Medical contingency Ops Con

Revised handhold requirements in HSIR

Requirement in HSIR

Ops Con

Will need Ground and Flight Rules to limit

Will need Ground Rules and put

Expedition planning guidelines

Consider for Rover requirements document

Consider for EVA system requirements document

Consider for EVA system requirements document

Planetary exploration Analog WS to be held in March,

Need GRnC entry for this 


\section{Apollo Medical Operations Project recommendations}

\section{IN-FLIGHT ILLNESS}

STATUS

Lower back pain should be treated with aggressive pre-mission

35 and in-flight core strengthening program

Cx MORD

Therapy to relieve muscle soreness, primarily in the forearms,

36 must be available (improved glove design may assist this)

Constipation: improve the waste management collection

37 system

38 Screen for CAD prior to selection for lunar missions

Cx Medical Kit contents definition

Requirement for waste management in HSIR

Medical standards now required for long duration flight

A physician crewmember would increase the comfort level among the crewmembers and can be cross-trained to do other

39 activities

Adequate preventive measures and treatment for diarrhea

40 must be available

\section{MEDICATION/MEDICAL KITS}

Consider development of Crew selection guidelines

Cx Medical Kit contents definition

\section{STATUS}

A card in the medical kit to inform the crew of the medication

41 duration, indication, and interaction with other meds is needed

Add non-sedating antihistamines for allergy symptoms due to

42 lunar dust exposure

Saline eye drops need to be available in large quantities

(however an eyewash will be available as part of the

43 environmental health kit)

Provide items that are needed in daily life, e.g. nail clippers,

44 lotions, band-aids, etc. (individual hygiene kit will be available)

45 Sufficient analgesia to treat headaches

Cx Medical Kit contents definition

Cx Medical Kit contents definition

Sleep medication must promote restful sleep but not be too

46 sedating

Cx Medical Kit contents definition

Flight Crew Equipment contents

definition, currently included in long

duration flight crew kits for ISS

Cx Medical Kit contents definition

Cx Medical Kit contents definition 


\section{Apollo Medical Operations Project recommendations}

\section{ENVIRONMENTAL IMPACTS}

Consider adapting the Skylab waste management system into

47 the new vehicles

The sleep restraint system on the Apollo CM worked well and should be incorporated into the new vehicle design (Sleeping bag needs to be large enough for crewmembers to get both

48 knees to their chest)

49 Drinking water should be available during sleep periods Lunar Surface Ascent Module (LSAM) windows should be designed to see only what is necessary for landing and/or

50 rendezvous with IR protection

Thermal protective clothing or equipment should be available

51 on board

Minimize noise but do not eliminate it (earplugs are an

52 adequate countermeasure for noise)

$53 \mathrm{CO} 2$ monitoring device needs to be robust and reliable

54 A food warmer is desirable

Astronaut participation in the design and development phases

55 of the new vehicles is essential

56 items

Radio Frequency ID tags should be considered for stowage

Hot water capability for hygiene, beverage and food

57 preparation is essential

Apollo bag aperture and capacity needs to be larger and easier

58 to apply in microgravity

Create a device that would allow crewmembers to assume a

59 squatting position in microgravity

Do not design the galley and waste management areas

60 together

\section{RADIATION}

Vehicle should have an active radiation detector with an automated audible alarm that sounds when the dose rate

61 exceeds a predetermined level

A Personal Radiation Dosimeter is a requirement for all

62 crewmembers and should be designed into suit garments

63 The rover should be equipped with a radiation shield

Radiation protectants should be made available to the

64 crewmembers

Create a trench with shovels or explosives to protect the crew 65 short term in the event of a Solar Particle Event

\section{STATUS}

Requirement for waste management in HSIR

Requirement for sleep in HSIR

Requirement for potable availability at all times in HSIR

\section{Consider for LSAM req'sdocument}

Flight Crew Equipment contents definition

Acoustics requirements in HSIR

Requirement in HSIR

Requirement in HSIR

Currently in practice for $\mathrm{Cx}$ for each vehicle and requirements definition.

Consider for CxP level 4 and 5 documents- design solutions for stowage tracking

Requirement in HSIR

Contingency waste collection requirement in HSIR- do
document

Requirement in HSIR

Requirement for separation in HSIR

\section{STATUS}

Requirement in HSIR

Requirement in HSIR; Need also in EVA system and suit requirements document Consider for rover requirements document

Cx Medical Kit contents definition research ongoing but poorly funded

Consider for radiation protection Con Ops; perhaps use alternate strategies 


\section{Apollo Medical Operations Project recommendations}

\section{BEHAVIORAL HEALTH AND PERFORMANCE}

Preflight quarantine is very valuable that allows time for sim

66 time, exercise and rest.

Recreational activities need to be made available for crews during Trans Lunar Coast and Trans Earth Coast. CMP during

67 lunar surface operations.

Lunar crews should have one day a week for "rest" (freedom to

68 select their activity)

Mental and physical rest plans should be introduced into extended moon stays to allow adequate rest between lunar

69 EVA

70 Mission focus should be project-oriented and not timelined

71 Provide adequate capabilities for sleeping on the lunar surface

72 If a crewmember dies during the mission you cut him/her loose In planning crew size/makeup, the authority structure is much

73 more significant than crew size

The pre-flight training schedule should allow for crews to

74 concentrate on issues that will be used for the nominal mission Consider for crew training plan An eight hour/day sleep period must be protected in the daily

75 schedule and must not be compromised

76 Crew sleep periods should be scheduled at the same time Use of sleeping medication should be encouraged where

77 appropriate Countermeasures to combat mental fatigue are necessary

78 throughout the mission

Education and psychological services should be available to

79 the crewmember's families

\section{STATUS}

Need to be built into GRnC and crew training plan; CxMORD

BHP Req's in HSIR

Need GRnC entry for this

Need GRnC entry for this

Need to capture this philosophy in Ops

Con for lunar outpost missions

Sleep requirements in HSIR

Need to develop Med Code 0 Ops Con

and Cx MORD

Consider development of Crew selection guideline

Need GRnC entry for this

Need GRnC entry for this

Need to Cx MORD

Cx Medical kit definition

BHP Requirements in HSIR 


\section{Apollo Medical Operations Project recommendations EXERCISE}

Loosen the pre-mission timeline to allow adequate time for pre- Need to be built into GRnC and crew

80 flight conditioning program

A more robust (and lightweight) piece of in-flight exercise

81 equipment is needed than the Apollo Exer-Genie

The flight surgeon/mission planners should not plan specific

82 exercise prescriptions for short duration (<14 days) mission

Exercise is not necessary on short trips (14 days or less) [from a fitness standpoint], however crews demanded that the capability be available and varied as much as possible for crew HS

83 "rest and relaxation" in all phases of the mission

Develop a better pre-flight and in-flight forearm muscle conditioning program for lunar crewmembers in addition to the

84 core stabilization program

New vehicle design should allow a variety of different exercise 85 capabilities (hardware vs. cabin structure)

New exercise device should be reliable, simple and not

86 develop excessive heat in use

\section{FOOD/NUTRITION}

Mission activity (e.g., coast, rendezvous, lunar orbit, lunar ops) will dictate what type and how much food will be consumed.

High Activity: wet packages, bite-sized

snacks, canned foods. Low Activity: spoon bowls, dry juice or

87 meals (rehydratable) requiring mixing, etc.

Plain water in large quantities needs to be available for lunar

\section{EVA}

Optimize diet and food intake for overall performance during

89 long duration missions

An in-suit non-caffeinated solid or liquid carbohydrate food

90 source for lunar EVA would be helpful.

Design adequate space an useful area in the new vehicles to

91 store food packs during meals

92 Spicy and salty foods are preferred items in the menu

93 Allow adequate time in the daily schedule for meals

Determine how different environmental factors (e.g. O2

94 concentration, cabin pressure) effect food flavor training plan; CxMORD

Requirement in HSIR; Need h/w spec definition at level 4 and 5

Not consistent with SA position (we say $<8$ days).; HSIR req's for exercise for all missions $>8$ days.

HSIR requirement to begin exercise as soon as practical

CxMORD; ASCR pre-flight prep

Requirement in HSIR; need outpost exercise requirements added

Requirement in HSIR; Need h/w spec definition at level 4 and 5

\section{STATUS}

Nutrition requirements in HSIR; CxMORD; Need food system requirements at level 4 and 5

Requirement in HSIR

Requirement in HSIR

Requirement in HSIR

Stowage requirement in HSIR

Food system requirement at level 4 and 5

Need GRnC entry for this

Need research topic for HRP 


\section{Apollo Medical Operations Project recommendations}

\section{LAUNCH, LANDING, AND RECOVERY OPS}

Provide adequate cooling capabilities for the crew on landing to Cabin environment req in HSIR; $36 \mathrm{hr}$ mitigate the hot cabin contribution to crewmember sea

95 sickness

96 Ground landings discouraged

Apollo seat configuration for water landings were adequate:

97 the restraint system needs to include loose equipment items

Medication for motion sickness and fatigue will be available

98 prior to re-entry

99 Hatch should open outward and seal with pressure

Sea state should be limited to $<6-8$ foot swells if recovery is to 100 be delayed

Have food and plain water within reach of buckled

101 crewmembers for delayed recovery

Apollo Command Module hatch location and size was

102 adequate for egress

All control panels and switches should be within reach of 103 crewmembers during launch and landing

104 Training for pad abort was adequate and should be continued Crew surgeon should be on the recovery vessel and not the 105 helicopter

\section{FLIGHT SURGEON-CREW INTERACTION}

Crew encouraged FS to "act as more of an advocate of the 106 crew" than treat them as an experiment

The collaboration established between the current flight surgeons and Apollo crewmembers should continue and be an 107 example to future generations

\section{STATUS}

post-landing tiger team working details of ECLSS, suit, etc. need CR to CEV SRD

Land vs. water tiger team weighing trades Seat req's in HSIR; CEV SRD (previously in crew cockpit document)

CxMORD; Medical Ops Con

Hatch requirements in HSIR

CEV SRD defines sea state for vehicle;

Ground Ops con defines recovery strategy

Need to add requirement to HSIR and CEV SRD

Hatch requirements in HSIR

Cockpit requirements in HSIR; CEV SRD and Crew Cockpit document

Need to include in crew training plan

Ops Con

STATUS

Currently in practice

Roger and concur 


\section{APPENDIX D \\ APOLLO MEDICAL KITS FROM BIOMEDICAL RESULTS OF APOLLO}




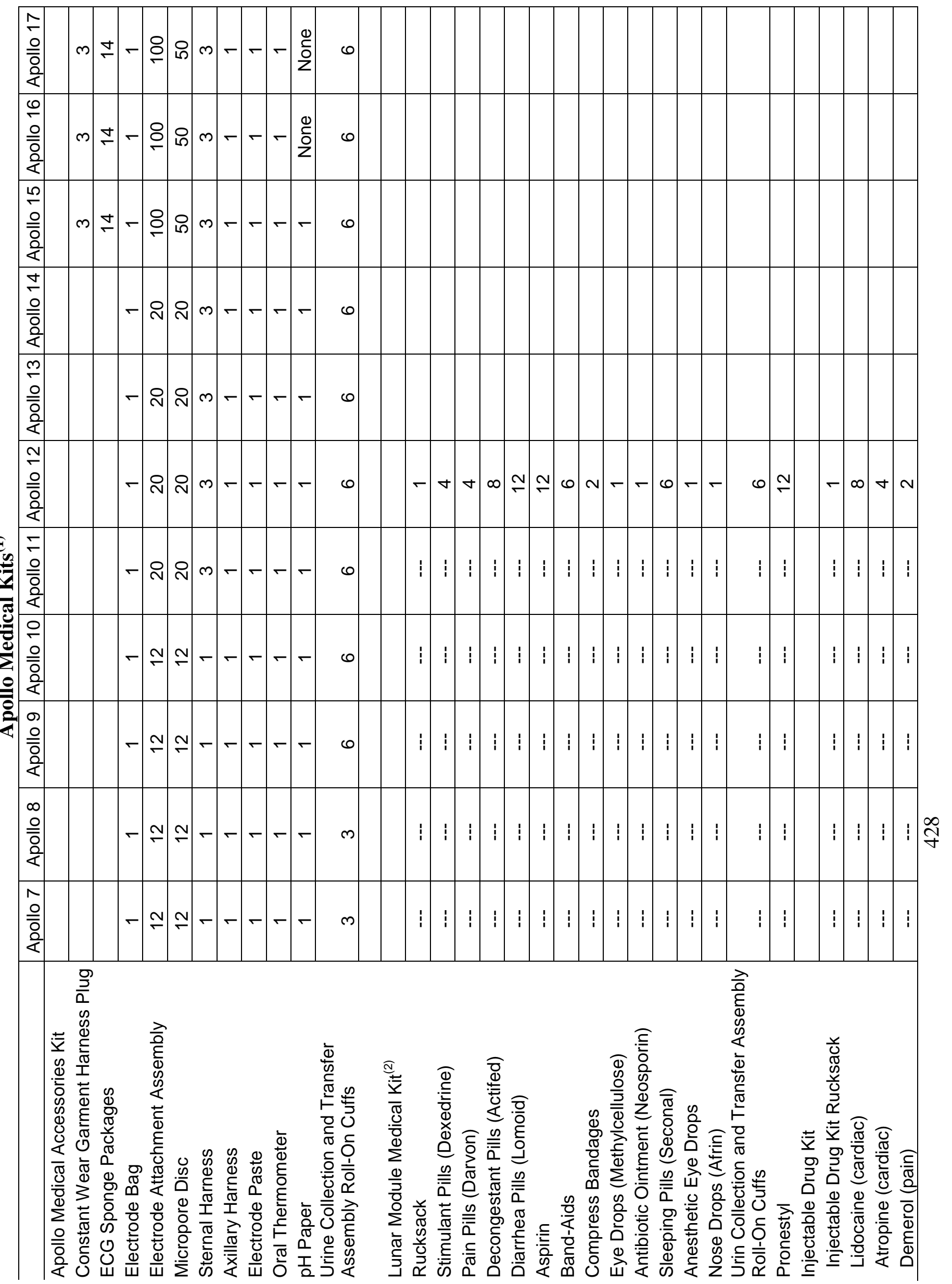




\begin{tabular}{|c|c|c|c|c|c|c|c|c|c|c|c|c|c|c|c|c|c|c|c|c|c|c|c|c|c|c|c|}
\hline $\begin{array}{l}\bar{c} \\
\text { o을 } \\
\overline{0} \\
\end{array}$ & $\stackrel{9}{?}$ & $=?$ & ㅇำ & $\stackrel{\mathbb{N}}{\underset{N}{N}}$ & $\bar{\Sigma}$ & $\stackrel{ }{2}$ & 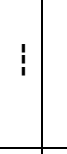 & $\vdots$ & 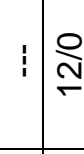 & $\stackrel{?}{\infty}$ & ธ & 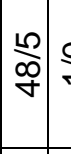 & $\stackrel{ }{r} \stackrel{\subsetneq}{\Re}$ & $\begin{array}{c}\stackrel{2}{N} \\
\text { ¿ }\end{array}$ & 이 & $\underset{\sim}{\stackrel{0}{\Sigma}}:$ & $\frac{m}{m}$ & 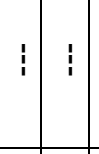 & 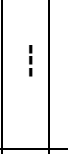 & 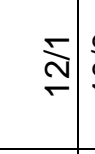 & 웜요 & $\vdots$ & 이 & 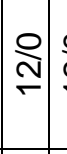 & 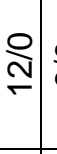 & $\frac{?}{6}$ & \\
\hline $\begin{array}{l}0 \\
\frac{0}{0} \\
\overline{0} \\
\frac{0}{<} \\
\end{array}$ & ని & $!$ & ลิ & $\underset{\mathbb{N}}{\stackrel{N}{N}}$ & ते & $\Sigma$ & 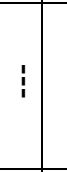 & $!$ & 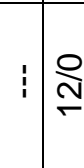 & $\mid \begin{array}{l}0 \\
\infty \\
-1\end{array}$ & 이 & 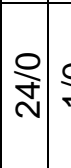 & 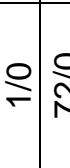 & 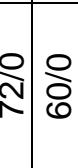 & 잉 & $\stackrel{m}{\stackrel{m}{N}}:$ & ९) & 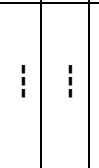 & 1 & $\stackrel{?}{\stackrel{⿰}{ }}$ & ợ & 1 & 이 & 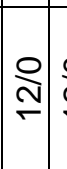 & 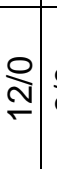 & ô & 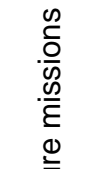 \\
\hline $\begin{array}{l}\text { L } \\
0 \\
\overline{0} \\
\frac{0}{<} \\
\end{array}$ & $\stackrel{?}{\rightarrow}$ & $\vdots$ & ลำ & $\begin{array}{c}\mathbb{N} \\
\underset{N}{N}\end{array}$ & న & $\stackrel{ }{=}$ & $\stackrel{\circ}{\text { ले }}$ & $\stackrel{\rho}{\stackrel{\rho}{~}}$ & 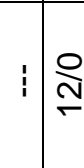 & 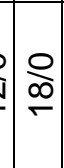 & 이 & 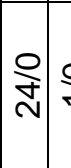 & $\stackrel{ㅇ ㅗ ㄱ ~}{\Upsilon}$ & 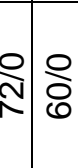 & ○ి & \begin{tabular}{l|l}
$\stackrel{9}{a}$ & $\vdots$ \\
& 1
\end{tabular} & 六 & ! & $i$ & $\stackrel{?}{\stackrel{N}{\subseteq}}$ & 웜음 & $!$ & $!$ & $\vdots$ & $\vdots$ & $\vdots$ & 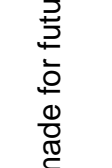 \\
\hline $\begin{array}{l} \pm \\
\frac{J}{0} \\
\overline{0} \\
\frac{0}{<} \\
\end{array}$ & ㅇำ & 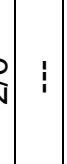 & $\stackrel{?}{\mathrm{~N}}$ & $\underset{\mathbb{N}}{\mathbb{N}}$ & 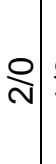 & $\stackrel{ }{\rightarrow}$ & 이 & $\stackrel{\rho}{\stackrel{\rho}{~}}$ & $\mid \stackrel{ }{\stackrel{N}{-}}$ & 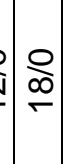 & 옹 & 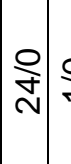 & 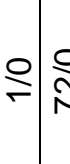 & న్ & 잉 & $i$ & ले & $!$ & $i$ & $\stackrel{ }{\stackrel{9}{ }}$ & ồ & ○ે & $i$ & $\vdots$ & 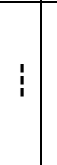 & 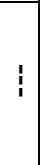 & 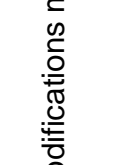 \\
\hline $\begin{array}{l}\frac{m}{2} \\
\frac{0}{\overline{0}} \\
\frac{0}{<} \\
\end{array}$ & $\stackrel{゚}{\text { N }}$ & $!$ & ลิ & $\underset{\underset{N}{N}}{\stackrel{N}{N}}$ & నิ & $\stackrel{ }{\rightarrow}$ & $\stackrel{ }{\text { 잉 }}$ & $\frac{P}{m}$ & : & $\stackrel{\Gamma}{\mathbb{N}}$ & 옹 & 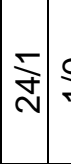 & 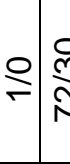 & 足 & 옹 & \begin{tabular}{l|l}
$\stackrel{9}{n}$ & $:$ \\
& 1
\end{tabular} & $\stackrel{?}{m}$ & 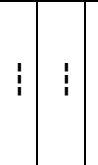 & $i$ & $\stackrel{\mathbb{N}}{\underset{\leftarrow}{N}}$ & 옹요 & $\vdots$ & $!$ & 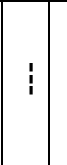 & $\vdots$ & 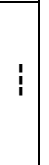 & 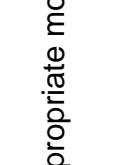 \\
\hline $\begin{array}{l}\simeq \\
\frac{0}{0} \\
\overline{\overline{0}} \\
\frac{0}{<} \\
\end{array}$ & $\stackrel{?}{\text { N }}$ & & ลิ & $\stackrel{\mathbb{N}}{\underset{N}{N}}$ & 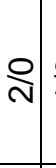 & $\stackrel{ }{\rightarrow}$ & 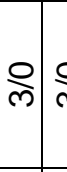 & $\frac{\mathrm{P}}{\mathrm{m}}$ & 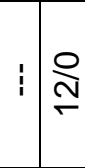 & 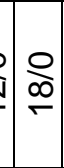 & $\left(\begin{array}{c}\infty \\
\delta \\
6\end{array}\right.$ & 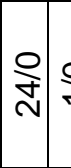 & $\stackrel{2}{r} \frac{c}{\Omega}$ & \begin{tabular}{l|l}
$\mathbf{N}$ & $:$ \\
& $:$
\end{tabular} & 옹 & \begin{tabular}{l|l}
$\stackrel{\theta}{\sim}$ & $\vdots$ \\
& $:$
\end{tabular} & $\bar{\kappa}$ & 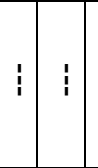 & 1 & 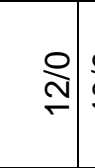 & 吕 & 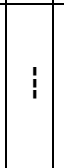 & $!$ & 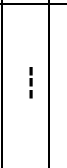 & $\vdots$ & $!$ & 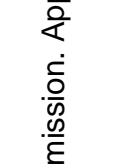 \\
\hline 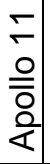 & $\stackrel{?}{\text { N }}$ & & 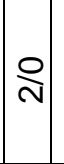 & $\stackrel{\mathbb{N}}{\underset{N}{N}}$ & 욤 & $\stackrel{ }{\rightarrow}$ & $\stackrel{ }{\text { m) }}$ & & 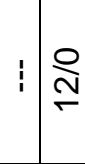 & 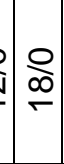 & 잉 & 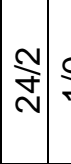 & 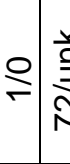 & \begin{tabular}{c|c}
$\underset{N}{N}$ & $:$ \\
& $:$
\end{tabular} & 옹 & \begin{tabular}{l|l}
$\stackrel{9}{n}$ & $\vdots$ \\
& 1
\end{tabular} & $\stackrel{?}{m}$ & $i$ & $i$ & $\stackrel{0}{\stackrel{0}{\subseteq}}$ & 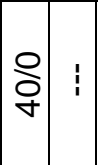 & $\vdots$ & $i$ & 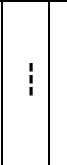 & $!$ & 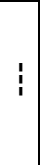 & 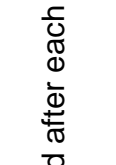 \\
\hline $\begin{array}{l}\text { 을 } \\
\text { o } \\
\overline{0} \\
\frac{0}{4} \\
\end{array}$ & $\stackrel{ }{\mathrm{N}}$ & & 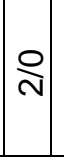 & $\underset{\underset{N}{N}}{\stackrel{N}{N}}$ & $\stackrel{ }{?}$ & $\stackrel{ }{=}$ & $\stackrel{ }{\text { 이 }}$ & 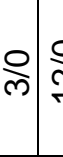 & 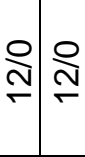 & 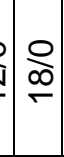 & $\begin{array}{l}N \\
\delta \\
0\end{array}$ & 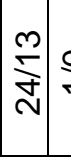 & 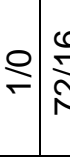 & \begin{tabular}{c|c}
$\substack{0 \\
N}$ & $\stackrel{0}{10}$ \\
\hdashline
\end{tabular} & 용 & $\stackrel{?}{\stackrel{2}{N}}:$ & $\stackrel{ }{m}$ & ! & 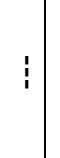 & $!$ & $!$ & $!$ & $i$ & $\vdots$ & $!$ & 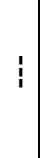 & $\begin{array}{l}\frac{3}{0} \\
\frac{0}{2} \\
\frac{0}{0}\end{array}$ \\
\hline $\begin{array}{l}0 \\
0 \\
\overline{0} \\
\frac{0}{<}\end{array}$ & $\stackrel{\circ}{\text { N }}$ & & 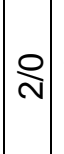 & $\underset{\mathbb{N}}{\stackrel{N}{N}}$ & 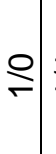 & $\Sigma$ & 일 & $\frac{\mathrm{O}}{\mathrm{e}}$ & 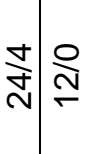 & 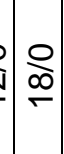 & 氐 & 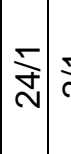 & $\stackrel{\Sigma}{\stackrel{\Im}{\curvearrowright}}$ & \begin{tabular}{c|c}
$\stackrel{N}{N}$ & $\stackrel{P}{\stackrel{N}{N}}$
\end{tabular} & 잉 & 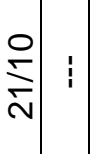 & 部 & ! & $\stackrel{?}{?}$ & $!$ & $!$ & $\vdots$ & 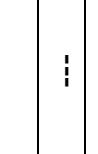 & $\vdots$ & $\vdots$ & 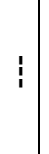 & 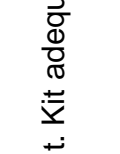 \\
\hline $\begin{array}{l}\infty \\
0 \\
\overline{0} \\
\frac{0}{<}\end{array}$ & $\stackrel{N}{\mathrm{~N}}$ & & 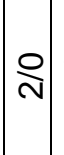 & $\stackrel{\mathbb{N}}{\underset{N}{N}}$ & 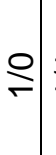 & $\Sigma$ & 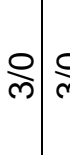 & $\stackrel{\rho}{\text { ल) }}$ & 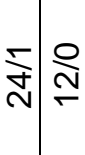 & $\stackrel{?}{\infty}$ & 잉 & $\underset{\substack{m \\
\sim}}{f}$ & $\stackrel{\Sigma}{\mathrm{N}} \frac{\alpha}{\mathfrak{r}}$ & \begin{tabular}{c|c}
$\substack{N\\
}$ \\
$\stackrel{\mathrm{f}}{\mathrm{N}}$
\end{tabular} & 옹 & 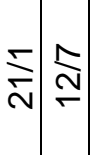 & 이 & 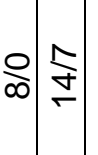 & 1 & $i$ & $!$ & $\vdots$ & $i$ & $\vdots$ & $\vdots$ & 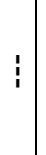 & 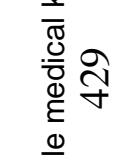 \\
\hline $\begin{array}{l}1 \\
0 \\
\overline{0} \\
\text { aे } \\
\end{array}$ & స & & న & $\underset{\mathbb{N}}{\stackrel{N}{N}}$ & 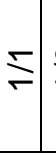 & $\stackrel{ }{\rightarrow}$ & 이 & 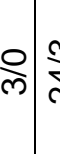 & 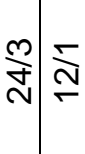 & $\stackrel{\mathbb{N}}{\mathbb{N}}$ & $\mid \begin{array}{c}\mathbf{N} \\
\stackrel{d}{N}\end{array}$ & $\underset{\substack{\sim \\
\sim}}{\sim}$ & 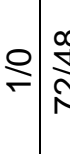 & 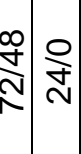 & : & 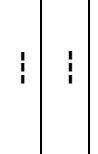 & $\vdots$ & $!$ & 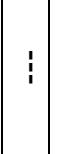 & 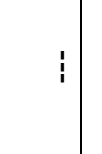 & $!$ & $\vdots$ & $!$ & $\vdots$ & $!$ & 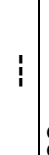 & ભ \\
\hline & 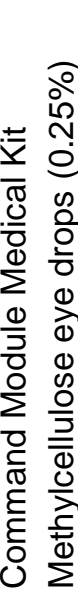 & & 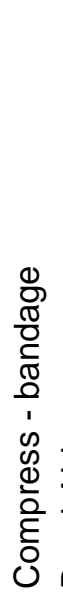 & 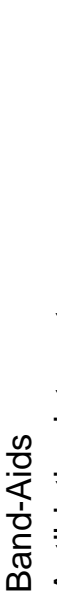 & 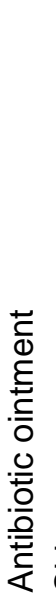 & 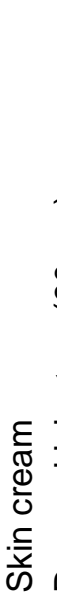 & 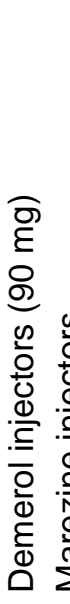 & 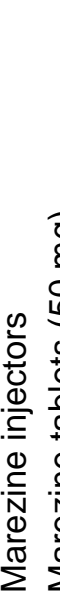 & 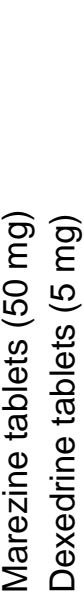 & 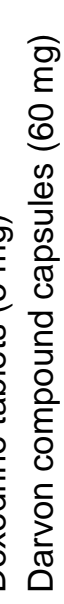 & 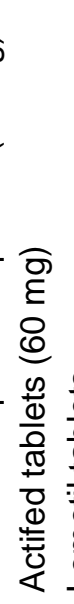 & 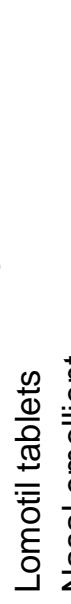 & 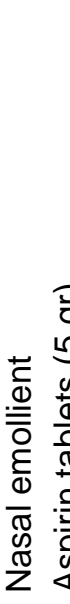 & 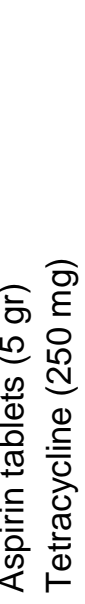 & i. & 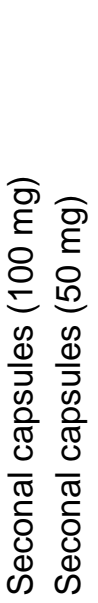 & 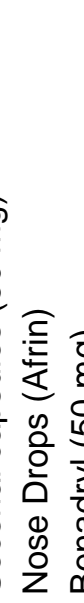 & 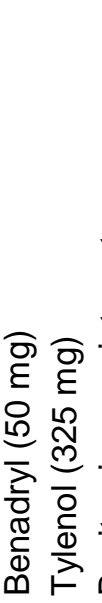 & 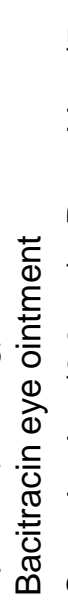 & 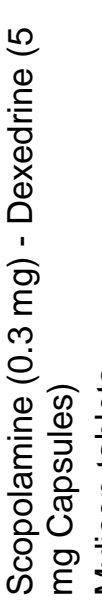 & 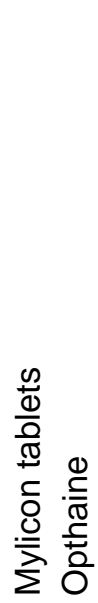 & 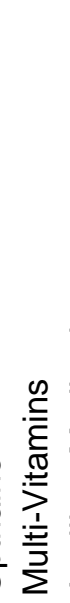 & 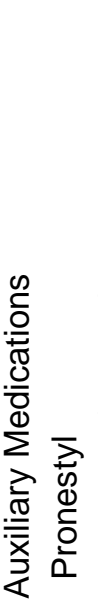 & 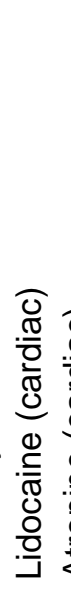 & 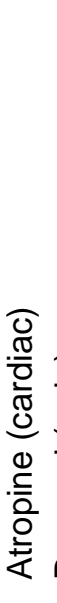 & & 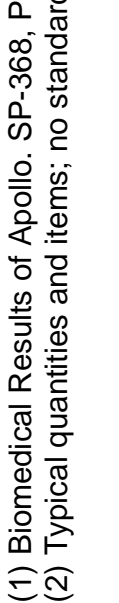 \\
\hline
\end{tabular}




\section{APPENDIX E \\ CORRESPONDENCE}


National Aeronautics and

Space Administration

Lyndon B. Johnson Space Center

2101 NASA Road 1

Houșton, Texas 77058-3696

Reply to Attn. of: SD-06-029

May 9,2006

Dear

The Space Medicine Division at NASA/Johnson Space Center is currently developing the medical requirements for the Crew Exploration Vehicle (CEV), Lunar Surface Ascent Module (LSAM), Lunar Habitat, and Advanced EVA suits.

In order for Medical Operations to write requirements for the new systems and hardware, a thorough review of the Apollo mission documents was conducted. This review identified areas that need further clarification before beginning development of future crew health and safety systems.

We request your attendance at a face-to-face meeting on June 7:9, 2006 in Houston. Our main goal is to elucidate any insight you may have into opportunities for improvement and to provide your ideas for future missions emphasizing the steps necessary to ensure crew health and safety based on your experience. The results of your efforts will be evident in the creation or modification of requirements for the exploration vehicles, suits, and mission activities, as well as flight surgeon support of exploration crews.

The first two days of this meeting will be private and limited to current flight surgeons, Apollo crewmembers, and administrative support personnel. The third day will be open to other parties interested in participating in the discussions. Please feel free to suggest additional invitees (e.g. members of the research community, current astronauts, Apollo flight surgeons, flight directors or engineering staff) that you feel would contribute to the third day.

Please confirm your desire to attend this meeting by May 26, 2006. Point of contact for the event and travel funding information is Dr. Rick Scheuring, (281) 743-1510, richard.a.scheuring@nasa.gov.

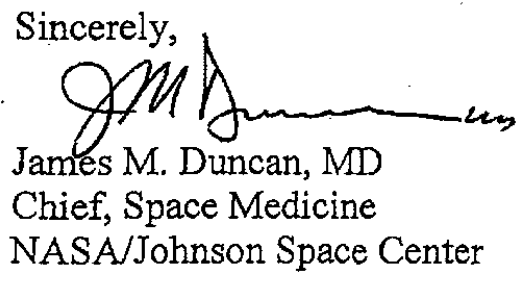




\section{wylde}

May 5, 2006

Dear Mr.

I certainly hope you accept our invitation to this June meeting as it will be very exciting to hear from you as to how we can create the best program for crew health and safety.

To best facilitate the meeting and maximize your time with us, we will have pertinent issues from the Apollo documentation researched and ready for discussion. For example, a couple of issues from the Apollo16 documents include:

1) Crew comment - Urine volume measurements were difficult at best and quite time consuming for the crew to perform. The procedures for the urine dump system were not well thought out.

Our questions - A portion of body fluid is lost through insensible means (respiration, perspiration, etc.) not easily measured. Obtaining daily fluid input/output is an important indicator of hydration status, but not perfect.

What system of maintaining accurate records of input/output would the crew recommend, given all the trouble they had with the water and waste management systems?

2) Crew comments - During the three lunar EVA's, the crew often worked harder during "rest" periods (as evidenced by heart rate data) than during work periods. However, the crew did not feel this level of physical activity pushed them to their exercise capacity limits.

Our questions - The three lunar EVA's totaled 20 hours and 17 minutes. Although you did not feel physically challenged during your lunar EVA's, can you offer any insights how you might have felt carrying out this surface activity timeline over the course of 7-14 days? How do you feel the pre-flight EVA training program prepared you for lunar EVA? What would you do differently in your training for these longer surface sorties?

These are a few examples of the many questions that only the Apollo crew members can answer which is why this meeting is very important to future missions. We've discussed this project with LG Stafford, Dr. Schmitt, and Capt. Cernan, who are in agreement with our primary objectives: to make sure those issues encountered during the Apollo missions are brought forth and discussed to optimize crew health and performance and prevent "reinventing the wheel."

During your visit, we are including a tour of several mock-ups of the exploration vehicles including the CEV and lunar habitat. Also, if you prefer, we can coordinate your visit with the 
Longitudinal Study group and the Flight Medicine Clinic to complete your annual physical exam during the same trip.

Please call me at 281-461-2774, e-mail at Richard.a.scheuring@nasa.gov with your intentions or if you have any questions. Thank you for considering this invitation and we look forward to working with you.

Sincerely,

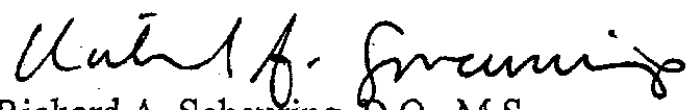

Richard A. Scheuring, D.O., M.S.

Apollo Summit-Project Manager

Advanced Projects/Flight Surgeon 


\section{APPENDIX F \\ MEETING AGENDA}




\section{Apollo Constellation Medical Operations Summit \\ June 7-8, 2006 \\ Space Center Houston-Club Conference Room}

Wednesday Morning, 7 June 2006

\begin{tabular}{|l|l|}
\hline $7: 30$ & Continental Breakfast \\
\hline $8: 00$ & Opening Remarks - Mr. Mike Coats \\
\hline $8: 15$ & $\begin{array}{l}\text { Welcome and Introductions - JD Polk, DO } \\
-\quad \text { Safety procedures } \\
-\quad \text { Review Agenda } \\
\end{array}$ \\
\hline $8: 45$ & $\begin{array}{l}\text { Apoles of Engagement } \\
\text { Impacts on Crew Health \& Performance - Rick Scheuring, DO } \\
\text { Review of Apollo data sources }\end{array}$ \\
\hline $9: 30$ & Break \\
\hline $\mathbf{9 : 4 5}$ & Constellation mission design and architecture - Jeff Jones, MD \\
\hline $11: 15$ & Exploration Medical Operations CONOPS - JD Polk, DO \\
\hline $12: 00$ & Lunch \\
\hline
\end{tabular}

Wednesday Afternoon, 7 June 2006

\begin{tabular}{|c|c|c|c|}
\hline $13: 00$ & \multicolumn{3}{|l|}{ Breakout session introduction - Joe Kerwin, MD } \\
\hline TIME & SESSION & GROUP A & GROUP B \\
\hline $13: 10$ & 1 & Crew Medical \& Safety Issues \\
\hline $14: 30$ & Break & Lunar Surface Ops \\
\hline $14: 45$ & 2 & \\
\hline $16: 30$ & \multicolumn{2}{|l}{} \\
\hline $17: 00$ & \multicolumn{2}{|l}{ End of Day 1 } \\
\hline
\end{tabular}




\section{Apollo Constellation Medical Operations Summit \\ June 7-8, 2006 \\ Space Center Houston-Club Conference Room}

Thursday Morning, 8 June 2006

\begin{tabular}{|c|c|l|l|}
\hline $\mathbf{7 : 3 0}$ & \multicolumn{2}{|l|}{ Continental Breakfast } \\
\hline $\mathbf{8 : 0 0}$ & Overview of Day 2 - JD Polk, DO & \multicolumn{1}{c|}{ GROUP B } \\
\hline TIME & SESSION & \multicolumn{1}{|c|}{ GROUP A } & \multicolumn{1}{|l|}{$\begin{array}{l}\text { GRess, Med Kits, } \\
\text { Bioinstrumentation }\end{array}$} \\
\hline $\mathbf{8 : 1 5}$ & $3 a$ & Environmental Impacts & Environmental Impacts \\
\hline $\mathbf{9 : 1 0}$ & $3 \mathrm{~b}$ & $\begin{array}{l}\text { Illness, Med Kits, } \\
\text { Bioinstrumentation }\end{array}$ & \\
\hline $\mathbf{1 0 : 0 0}$ & Break & & Crew Schedule \\
\hline $\mathbf{1 0 : 1 0}$ & $4 \mathrm{a}$ & Exercise/Food/Nutrition & Exercise/Food/Nutrition \\
\hline $\mathbf{1 1 : 0 0}$ & $4 \mathrm{~b}$ & Crew Schedule & \\
\hline $\mathbf{1 1 : 4 5}$ & Lunch & & \\
\hline
\end{tabular}

Thursday Afternoon, 8 June 2006

\begin{tabular}{|c|c|l|l|}
\hline TIME & SESSION & \multicolumn{1}{|c|}{ GROUP A } & \multicolumn{1}{c|}{ GROUP B } \\
\hline $12: 30$ & $5 a$ & Launch/Recovery Ops & Performance \\
\hline $13: 25$ & $5 b$ & Performance & Launch/Recovery Ops \\
\hline $14: 15$ & Break & & Free Association \\
\hline $14: 25$ & $4 a$ & $\begin{array}{l}\text { Flight Surgeon/Crew } \\
\text { Interaction }\end{array}$ & Flight Surgeon/Crew Interaction \\
\hline $15: 00$ & $4 b$ & Free Association & \\
\hline $15: 30$ & Summary of Day 2 - JD Polk & EVA Walk-back Tour at B9 \\
\hline $16: 00$ & BLDG 9 & CEV/POGO \\
\hline $17: 00$ & End of day 2
\end{tabular}




\section{Apollo Constellation Medical Operations Summit \\ June 7-8, 2006 \\ Space Center Houston-Club Conference Room}

Friday, 9 June 2006

\begin{tabular}{|c|c|}
\hline $7: 30$ & Continental Breakfast \\
\hline 8:00 & Opening Remarks - Drs. Rich Williams, Joseph Kerwin, Harrison Schmitt \\
\hline 8:30 & $\begin{array}{l}\text { Welcome and Introductions - JD Polk, DO } \\
\text { - } \quad \text { Safety procedures } \\
\text { - } \quad \text { Review Agenda } \\
\text { - } \quad \text { Rules of Engagement }\end{array}$ \\
\hline $8: 45$ & $\begin{array}{l}\text { Flight surgeon view on medical issues and support from Apollo - JD Polk, DO } \\
\text { - Summarize knowledge gaps for open sessions }\end{array}$ \\
\hline 9:30 & Break \\
\hline 9:45 & Constellation mission design and architecture - Jeff Jones, MD \\
\hline 10:30 & $\begin{array}{l}\text { Open sessions - JD Polk, DO } \\
\text { - Summary of Day } 1 \text { \& } 2 \text { Recommendations - Rick Scheuring, DO } \\
\text { Session } 1 \\
\text { - Apollo crewmembers address invited guest questions } \\
1 \text { EVA Suit Crew Medical \& Safety Issues } \\
2 \text { Lunar surface operations } \\
3 \text { Crew work/rest schedules }\end{array}$ \\
\hline 12:00 & Lunch \\
\hline 13:00 & $\begin{array}{ll}\text { Session } 2 \\
\quad \\
4 & \text { Environmental Impacts } \\
5 & \text { Bioinstrumentation/Medical Kits } \\
6 & \text { Food/nutrition }\end{array}$ \\
\hline 14:45 & Break \\
\hline 15:00 & $\begin{array}{ll}\text { Session } 3 \\
\quad 7 & \text { Exercise } \\
8 & \text { Launch/Recovery operations }\end{array}$ \\
\hline
\end{tabular}




\section{APPENDIX G PERSONAL COMMUNICATIONS}


Richard,

Nothing is based on my input since I don't recall ever making one on the CEV. I was supporting Northrop Grumman on their proposal effort and felt it might be a conflict of interest. You also sent me one for inputs on the Landing craft crew accommodations, relative lunar surface stay. I did not respond on that one either as I did not land and have the experience to relate.

Now that the competition is over and the CEV overweight, I will look at your email and provide my thoughts.

Regards, Fred Haise 
From: tkmattingly

Subject: Comments on your Apollo Medical Briefing charts

Rick,

Thanks for sharing your results. A couple of thoughts from reading the presenation follow.

1. Lots of good ideas but we have to remember that spaceflight will always be constrained by mass, volume and power. Suggest that while you have everyone's attention you might try to prioritize these desires. Recommend use of the pair-wise comparison technique to help eliminate unrecognized internal pressure. If you're not familiar with the technique, it involves making a list of all options and then having each evaluator compare the importance of each possible pair. This requires establishing a single objective, such as, "if I was returning to the moon and could have only one improvement, which of each pair would I prefer having?" Then, start with number one on the list and test it against each other suggestion, one at a time. Then you rank order the ideas according to the number of these pair-wise votes. That is \#1 vs. \#2, \#1 vs \#3, etc. then \#2 vs. \#3 ...... You and your evaluators may be surprised at the results. Armed with this info, you can make better choices when the cost and schedule crunch time arrives.

2. I think I mention that the taste of food in Apollo was lousy but some of the same foods tasted good in shuttle. I attributed this to the lack of a diluent gas but may be due to some other aspect of the cabin environment such as total pressure.

3. The only discomfort (nuisance) I encountered in space flight was the periodic episodes of nasal congestion. During Apollo, it would come and go. During shuttle, I noticed that 30 seconds on the treadmill would clear the sinuses for hours. I tried it on others and they had the same reaction. I believe this is due to the redistribution of fluid within the body during micro-g. Seems consistent with the observed swelling of our faces. Also wonder if this might be applicable to headaches. Can't tell from experience because I was one of those fortunate enough to have avoided such episodes.

4. Lots of comment on impotence of Exer-genie. I didn't find it particularly satisfying or useful but found the Shuttle treadmill to be a magic device. I think the body as a whole responds far more to the large mass muscles in the legs than to the arms.

5. You observed that while many of the lunar crews experienced trauma to parts of the hands during lunar surface EVA, this had not been an issue in training. It occurs to me that we all had our custom flight suits made as small as possible to maximize mobility. What we didn't account for was the fact that our bodies stretch when gravity is removed. Some folks had a hard time zipping up on orbit. We made some measurements during early STS flights that showed how much our height extended on rbit. Don't think we ever thought about measuring changes in arm length but it would seem logical. If we had tight suits and our bodies extended, even in $1 / 6$ th $\mathrm{g}$, this could account for your observation. 
6. I think I mentioned that the biggest contributor to glove forces was the thermal insulation layers. If you're thinking of augmenting the gloves with mechanical aids, you might consider using a pressure sensitive sensor on the interior of the glove and sending this signal back to a mechanical aid on the back of the hand. It should be sized to offset only the glove (finger) bending loads, not create a bionic hand. It should work in both directions and have the ability to be disabled without adding additional loads.

Good show. The time is right to start think about these things again.

TK 
From: Harrison Schmitt

To: Scheuring, Richard A. (JSC-SD)

Subject: Sleep in apollo

See CAPS embedded below. Just remember that operations will start out conservative and then get more realistic as experience is gained.

Harrison

-----Original Message-----

From: Scheuring, Richard A. (JSC-SD)

Harrison H. Schmitt

Dr. Schmitt-

The Apollo recommendations are getting a lot of attention on the Constellation side of things these days. That being said, a question has come up regarding sleep (below), the procedure for a cabin depress on return from the moon, and the land vs. water landing issue. The sleep issue is primarily concerned with sleep on the lunar surface. I remember the lunar crews stating that lack of sleep was multifactorial, but environmental issues, such as inability to adequately block sunlight from the windows, laud background noise, and a cold floor were some of the more pressing issues. The hammock seemed to work okay from what I remember for the short stays, but how well would they work for longer duration missions?

FROM MY PERSPECTIVE, APOLLO 17 BENEFITED FROM ALL THE EXPERIENCE AND MISTAKES OF PREVIOUS MISSIONS, AT LEAST I WENT TO A LOT OF EFFORT TO MAKE THIS THE CASE. SUNLIGHT (WE PUT SHADES ON THE WINDOWS), NOISE (IT WAS COMFORTING TO HEAR THINGS DOING WHAT THEY SHOULD DO AND IF THEY HAD NOT, IT WOULD HAVE BEEN "A WAKE-UP CALL"), HAMMOCKS (VERY COMFORTABLE IN ONE-SIXTH G) WERE NOT PROBLEMS AND CERTAINLY WOULD BE OKAY FOR A WEEK. I AM NOT SURE CERNAN SLEPT AS WELL AS I DID (I WOKE BRIEFLY EVERY TWO HOURS OR SO, I THINK), BUT YOU SHOULD ASK HIM IF NOT COVERED IN HIS BOOK. I THINK WE ALL SLEPT WELL IN THE CM - RON CERTAINLY DID! THEY COULD NOT WAKE HIM ONE MORNING WHEN HE WAS ON WATCH.

\section{CAN ONLY SPEAK FOR MYSELF, BUT I DID NOT FEEL SLEEP DEPRIVED BEFORE ANY LUNAR EVA. I LITERALLY FELT AS READY AFTER EACH SLEEP PERIOD AS I DID BEFORE THE FIRST EVA.}

Currently, we are working out a 144 hour depress scenario where the cabin has vented to space over time and the leak cannot be found. Consequently the crews are in their suits for the ride home. Did you have any such procedures during Apollo? Lots of issues 
associated with this scenario and I would like some guidance on how you might have handled it.

I DON'T REMEMBER HOW APOLLO RULES STARTED OUT BUT APOLLO 17 AND MOST OTHER MISSIONS IF NOT ALL WERE OUT OF THE SUITS FOR THE RETURN, BUT DID HAVE PROCEDURES FOR EMERGENCIES. WE DID NOT WEAR THEM EVEN FOR ENTRY. I WOULD NOT LET THE ENGINEERS ASSUME THAT THE CREW WILL STAY IN THE SUITS FOR 144 HOURS! THE ORION MUST BE BETTER THAN THAT.

The recommendation from the summit was that the Apollo crews preferred a water landing over land. This is a hot topic because Constellation is opting for land at this point in time.

THIS IS A DESIGN ISSUE AND A DESIGN CONFIDENCE ISSUE. I WOULD PLAN A MISSION FOR WATER LANDING TO BUILD CONFIDENCE, MAYBE THAT "APOLLO 8" STYLE MISSION YOU ARE CONSIDERING.

The Apollo concern was off-nominal re-entry putting the spacecraft in downtown LA or some other populated area. Water landings allowed a much greater margin of error.

However, the vehicle cannot be re-used and this seems to be one of the drivers for a land landing. Were there other concerns that made water preferable? Also, the outward opening hatch in the CM has raised a number of questions, but I think this recommendation came from the Apollo 204 experience.

\section{YES. WHAT ARE THE QUESTIONS?}

The draft of the completed paper is almost ready to send out. I am breifing the Constellation control board (CxCB) on Wednesday and fully expect to field questions related to these and other issues. Your time is greatly appreciated. Please call me (281.743.1510) if you would rather discuss this on the phone than email.

Thanks again,

Rick

Richard A. Scheuring, DO, MS

Constellation Medical Operations Specialist NASA-Johnson Space Center 
From: N. Armstrong

To: Scheuring, Richard A.

Sleep in apollo

Dear Dr. Scheuring,

I found your e-mail awaiting my return from a little time in Washington.

With regard to sleep issues, my Apollo procedures documents are in storage so I must depend on memory, which is not very good.

We did not have any sleeping facilities in the LM, which was marginally acceptable for the 3 day period. For anything longer than that, reasonable sleeping accommodations should be provided to assure that productive time could be assured during the working day. The problems we had: (1) light in the cockpit (2) pump noise (3) cold temperatures, and (4) inadequate sleeping facilities -- all seem to readily solvable.

I cannot comment on the hammock. We had only a improvised leg sling in the A-11 LM. The Command Module sleeping sacks seemed to work reasonably well.

We kept our pressure suits available for whenever they might be needed. I'm sure we had some kinds of procedures, but I can't remember any details without the check lists. Operating in pressurized suits is difficult and brings with it a substantial amount of risk: inadvertent switch or control operations, inability to reach controls, substantial difficulty in moving about the cabin, etc. For that reason, Gemini and Apollo crews pressed for a 'shirt-sleeve environment'. The pressure suit is mandatory for situations such as the one you postulate, but when not absolutely required it is genuinely disadvantageous.

The Mercury, Gemini, and Apollo launch trajectories were all over water. So the ability to safely land in water was required for any launch abort. The Soviet launch trajectories were principally over land. So the ability to land safely on the land was required for their launch aborts. Once providing the ability for the launch case, it made sense (with our extreme weight limitations) to use the same system for both.

I suspect Orion/Ares will also need to provide a launch abort ability for water landings. Whether there will be a substantial weight penalty for adding land landing ability, I do not know. I certainly understand the reluctance to accept the costs of water landings as a routine matter, so I could support a land landing if I were convinced that there was a very high probability of landing close to the intended destination.

These are just some random thoughts, so I provide them with some reluctance, but I am confident that you will consider them in the light of their incompleteness.

Sincerely,

Neil Armstrong 
From: lovell13

To: Scheuring, Richard A.

Subject: Sleep in Apollo

Dear Mr. Scheuring:

In regards to your e-mail of April 9th -- in zero gravity sleep is not a problem. The body can be lightly restrained within a body bag. Body heat will form a blanket within the bag. If the noise level is low and once the person gets use to sleeping in a strange environment, there should be no problem.

In a gravity environment such as the lunar surface consideration has to be given to adequate space, cold surfaces, body pressure points and the noise level. From what I heard, these factors were marginal in the lunar module.

Water landings were preferred in Apollo for the following reasons:

1. The availability of large bodies of water to accommodate long landing foot pads dictated by high reentry velocity.

2. The consistency of the landing surface and the absence of uneven terrain and large obstacles.

3. The elimination of wings and therefore weight.

4. The ease to position the recovery force.

5. The necessity to plan to land in water in emergency since Apollo launched east from Cape Canaveral.

I hope this can be of help.

Captain Lovell 



\section{REPORT DOCUMENTATION PAGE}

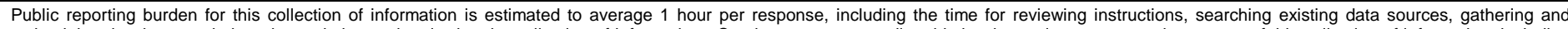

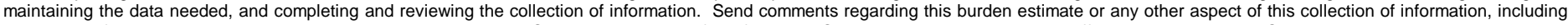

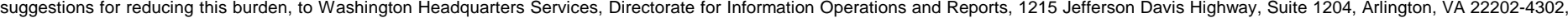
and to the Office of Management and Budget, Paperwork Reduction Project (0704-0188), Washington, DC 20503.
1. AGENCY USE ONLY (Leave Blank)
2. REPORT DATE
August 2007
3. REPORT TYPE AND DATES COVERED
NASA Technical Memorandum

4. TITLE AND SUBTITLE

The Apollo Medical Operations Project: Recommendations to Improve Crew Health and

Performance for Future Exploration Missions and Lunar Surface Operations

6. $\operatorname{AUTHOR}(\mathrm{S})$

R. A. Scheuring, J. A. Jones, . D. Polk, D. B. Gillis, J. Schmid, J. M. Duncan, J. R. Davis and J. D. Novak,

\section{PERFORMING ORGANIZATION NAME(S) AND ADDRESS(ES)}

Lyndon B. Johnson Space Center

8. PERFORMING ORGANIZATION REPORT NUMBERS

Houston, Texas 77058

S-1005

9. SPONSORING/MONITORING AGENCY NAME(S) AND ADDRESS(ES)

National Aeronautics and Space Administration

10. SPONSORING/MONITORING

AGENCY REPORT NUMBER

Washington, DC 20546-0001

TM-2007-214755

11. SUPPLEMENTARY NOTES

\section{2a. DISTRIBUTION/AVAILABILITY STATEMENT}

Available from the NASA Center for AeroSpace Information (CASI)

7121 Standard

Hanover, MD 21076-1320

Category: 52

12b. DISTRIBUTION CODE

\section{ABSTRACT (Maximum 200 words)}

Medical requirements for the future Crew Exploration Vehicle (CEV), Lunar Surface Access Module (LSAM), advanced

Extravehicular Activity (EVA) suits and Lunar habitat are currently being developed. Crews returning to the lunar surface will construct the lunar habitat and conduct scientific research. Inherent in aggressive surface activities is the potential risk of injury to crewmembers. Physiological responses to and the operational environment of short forays during the Apollo lunar missions were studied and documented. Little is known about the operational environment in which crews will live and work and the hardware that will be used for long-duration lunar surface operations.Additional informantion is needed regarding productivity and the events that affect crew function such as a compressed timeline. The Space Medicine Division at the NASA Johnson Space Center (JSC) requested a study in December 2005 to identify Apollo mission issues relevant to medical operations that had impact to crew health and/or performance. The operationally oriented goals of this project were to develop or modify medical requirements for new exploration vehicles and habitats, create a centralized database for future access, and share relevant Apollo information with the multiple entities at NASA and abroad participating in the exploration effort.

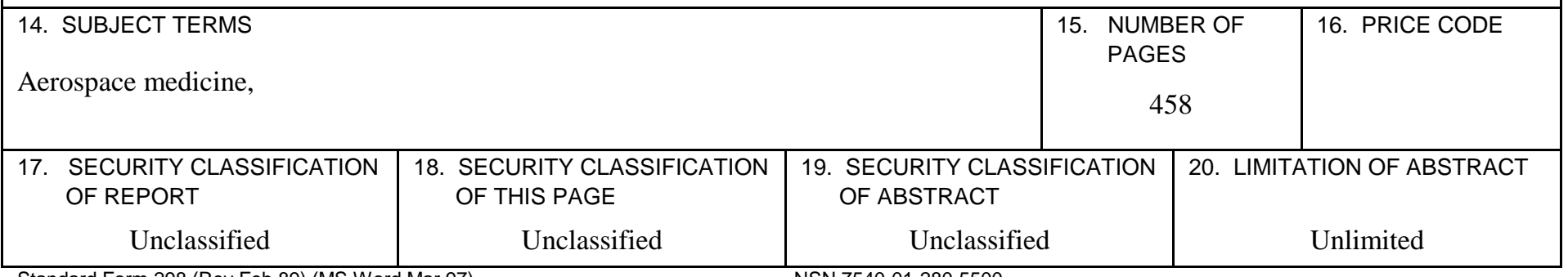

Standard Form 298 (Rev Feb 89) (MS Word Mar 97)

Prescribed by ANSI Std. 239-18

298-102 



\footnotetext{
-
} 